Tesis doctoral

\title{
Estado, escuela e inmigración boliviana en la Argentina contemporánea
}

\author{
Eduardo E. Domenech
}

Director de tesis:

Dr. Mariano Fernández Enguita

Tutor:

Dr. Pedro Iriso Napal

Doctorado en Sociología

Departamento de Sociología y Comunicación

Universidad de Salamanca

Febrero 2012 

Índice

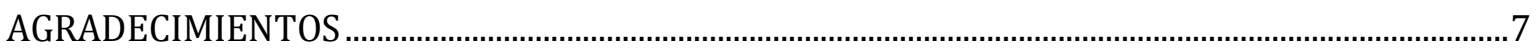

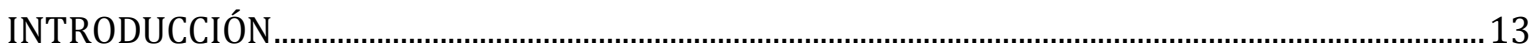

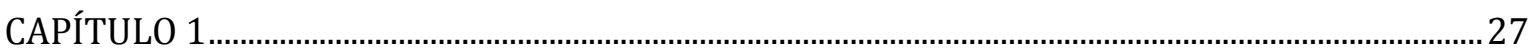

COMPRENDER LA DIMENSIÓN SOCIOPOLÍTICA DE LA MIGRACIÓN............................................ 27

La sociología, los estudios migratorios y la dimensión sociopolítica de la migración

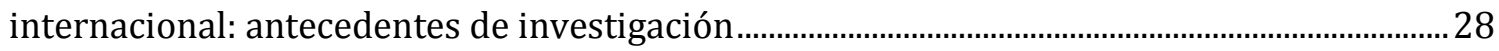

Estado, escuela y migración: encuadre y aproximación teórico-metodológica .......................... 47

El Estado y la escuela desde adentro: el trabajo de campo ................................................................. 78

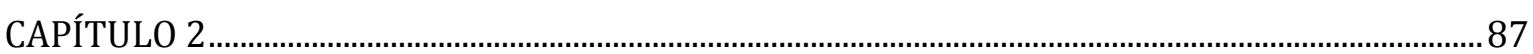

LOS BOLIVIANOS COMO EMIGRANTES: LA VISIÓN DEL ESTADO DE ORIGEN ............................... 87

El Estado boliviano y las migraciones durante el siglo veinte ..................................................... 88

Las migraciones internacionales en la Bolivia actual ………………………………............... 109

Las migraciones internacionales y el nuevo gobierno nacional ............................................ 113

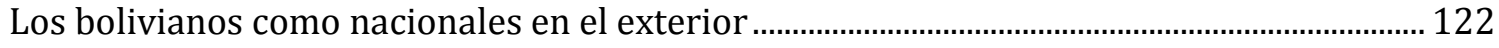

El voto en el exterior: los emigrantes como ciudadanos .............................................................. 129

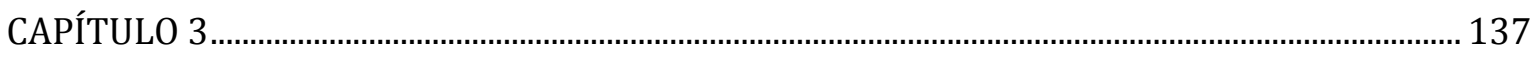

ESTADO, INMIGRACIÓN E “ILEGALIDAD”: LA “INMIGRACIÓN LIMÍTROFE” COMO

PROBLEMA SOCIAL EN LA ARGENTINA CONTEMPORÁNEA ........................................................... 137

El Estado argentino y las restricciones a la inmigración: los extranjeros "indeseables” y

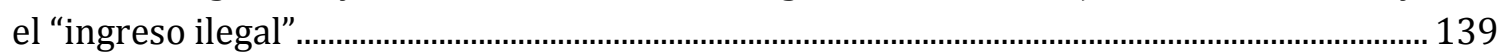

Ni turistas, ni pasajeros en tránsito: los “indeseables" y la "permanencia ilegal” ................. 147

La inmigración de países limítrofes como problema: los nuevos indeseables y el control

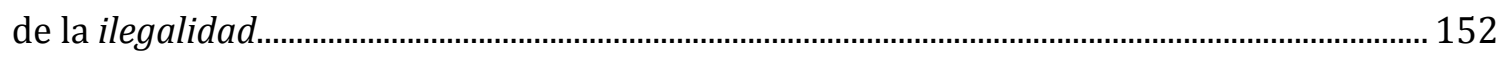

La doctrina de la seguridad nacional hecha norma: la instauración de la Ley Videla .......... 165

Migración y Estado en la Argentina de los noventa: crónica de una amenaza anunciada.. 172

La construcción de la "inmigración limítrofe" como problema bajo el auge neoliberal. 175

La última embestida oficial de los noventa contra la inmigración limítrofe ........................ 190

La legalización migratoria como solución: seis amnistías en medio siglo ................................. 197

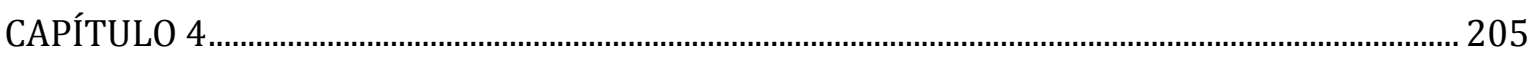

INMIGRACIÓN Y ESTADO EN LA ARGENTINA RECIENTE: LA “NUEVA POLÍTICA

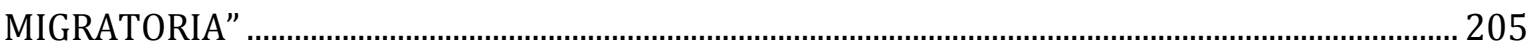

Hacia una "nueva política migratoria": la transición entre los años 2000 y 2003 .................. 207

La "nueva política migratoria" y los derechos humanos: el "cambio de paradigma" ........... 222

La ley Giustiniani: una ley para el "nuevo siglo" ............................................................................. 231

Empezando de nuevo: nueva ley migratoria, nueva política migratoria .............................. 236 
Una política "realista, amplia y de regularización": el diagnóstico oficial

"El Estado ha confiado en cada uno de nosotros...": los agentes del control (o los guardianes de la nación)

CAPÍTULO 5

EL ESTADO Y LA “IRREGULARIDAD MIGRATORIA” EN LA ARGENTINA ACTUAL: REGIONALIZACIÓN, LEGALIZACIÓN E INTEGRACIÓN

La migración ordenada como misión: hacia un régimen global de control de las

migraciones internacionales

Entre la integración regional de los países y la integración social de los extranjeros.

El Programa Nacional de Normalización Documentaria y el "Patria Grande": un plan para "la gente que está debajo de la alfombra"

De la ilegalidad como problema y la regularización como solución 291

La delgada línea de la (i)legalidad 299

Trabajando en Migraciones: la visión de un funcionario de planta permanente. 308

El país como cuartel militar: la "doctrina del control". 311

Una doctrina por otra: la gobernabilidad migratoria 314

La 25871 (o la veinticinco ocho setenta y uno): imperfecta, pero indefectible 324

Resolver el tema migratorio: la regularización migratoria como prioridad 326

CAPÍTULO 6.

EDUCACIÓN, ESCUELA E INMIGRACIÓN: LA PRESENCIA DE LOS BOLIVIANOS EN EL ESPACIO ESCOLAR

Córdoba como destino: los inmigrantes bolivianos en Villa El Libertador. 336

La Forestieri, una escuela en la periferia 341

La "escuela del fondo" 352

Acceso restringido: los "indocumentados" y la ley Videla en las escuelas. 358

Los "indocumentados" en el espacio escolar. 363

Los "bolivianos" en la escuela argentina: ¿una presencia problemática?................................... 368

Ser "boliviano" en la escuela argentina .................................................................................... 378

Los "alumnos bolivianos": estereotipos y prejuicios............................................................. 393

CAPÍTULO 7

INMIGRACIÓN BOLIVIANA, NACIONALIZACIÓN Y RECONOCIMIENTO: NACIONALES Y EXTRANJEROS EN LA ESCUELA HOY

La construcción del Estado argentino y la presencia de los extranjeros: la nacionalización como mandato estatal

Nuevas leyes educativas, viejos mandatos políticos: la ley Federal de Educación y la ley de Educación Nacional. 418

Reglamentando la rutina escolar: las efemérides y los actos escolares. 426 
Integrar a los extranjeros cien años después: los actos escolares patrióticos (o la construcción de la argentinidad en la escuela) .......................................................................... 435

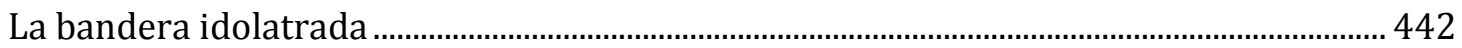

Llevar la bandera: el proyecto de abanderados ………........................................................... 445

Honrar la bandera: la "promesa de lealtad a la bandera" ............................................................ 454

Integrar bolivianos y argentinos: los actos escolares "interculturales" (o la construcción de hermandad latinoamericana y bolivianidad en la escuela)..................................................... 459

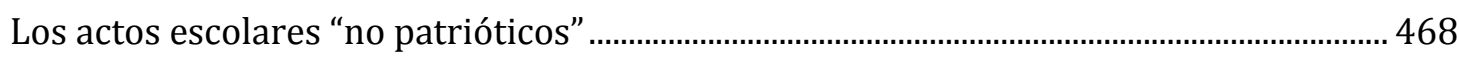

Los actos escolares "bolivianos": la celebración del día de la independencia de Bolivia474 CONCLUSIONES: PRESENCIA INMIGRANTE Y VISIÓN DE ESTADO …............................................. 488

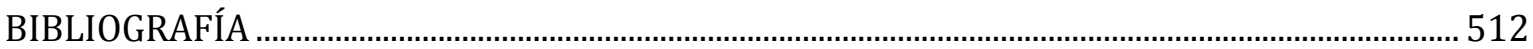

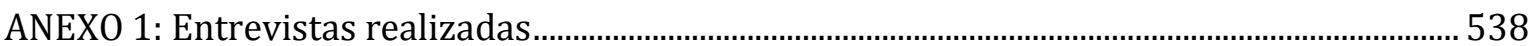

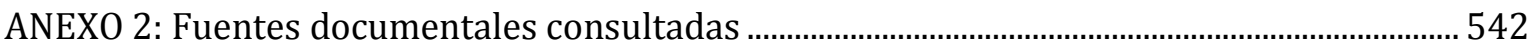





\section{AGRADECIMIENTOS}

Esta tesis ha llevado casi una década de trabajo. Con ella, después de mis estudios de licenciatura y maestría, transité una etapa de mi vida académica en la cual empecé a formarme como investigador y profesor universitario. Fueron muchas personas las que de uno u otro modo intervinieron a lo largo del trayecto recorrido. Sin todas ellas esta tesis hubiera sido seguramente muy diferente. Como contrapartida a esta generosidad humana, la realización de esta tesis contó con escasa ayuda económica. Fue gracias a una beca de la Secretaría de Ciencia y Tecnología de la Universidad Nacional de Córdoba que pude dedicarme dos años a trabajar exclusivamente en ella, los cuales fueron fundamentales para recoger y sistematizar buena parte del material empírico que obtuve. El financiamiento obtenido a través de los subsidios de investigación de esta institución también resultó importante para solventar económicamente algunas de las tareas de investigación realizadas.

Mi agradecimiento a todos aquellos que me permitieron ingresar a sus espacios de trabajo, los cuales a pesar de ser nominalmente públicos, son espacios cerrados que no todos están dispuestos a abrir. Agradezco a todas las maestras, directivos, alumnos, madres y padres con los cuales compartí innumerables y memorables momentos en las escuelas que visité de manera prolongada. Estoy especialmente agradecido con Yolanda ("Yoly") Ripoll, Chabela Elías y Sandra Zotar por su invalorable ayuda para llevar adelante el trabajo de campo en la escuela Vicente Forestieri y brindarme allí todo aquello que estuvo a su alcance, entre otras cosas, su escaso tiempo disponible. A Yoly, asimismo, por las largas conversaciones en su casa y hacerme parte de sus búsquedas personales. Agradezco también enormemente a Janet Velasco Herbas, quien fue fundamental no sólo para identificar ciertos nudos problemáticos acerca de la "bolivianidad" en la escuela, sino también para acercarme a diversos espacios de la "colectividad boliviana" y conocer desde adentro su heterogeneidad y sus singularidades. Agradezco también a todos aquellos funcionarios que accedieron a mantener una o varias entrevistas. A diferencia de quienes evadieron de distinto modo un encuentro, ellos siempre mostraron la mejor predisposición para colaborar con la investigación. Mi particular reconocimiento a Alberto Rubio, ex jefe de la delegación Córdoba de la Dirección Nacional de Migraciones, por su apertura al diálogo. A través de él aprendí muchas cuestiones que me sirvieron para comprender el punto de vista que asumen aquellos que hablan en nombre del Estado. 
A Mariano Fernández Enguita, mi director de tesis, por confiar en esta investigación cuando aún era un proyecto y por su inspiración para no transitar lugares cómodos desde los cuales pensar ciertos hechos y relaciones sociales analizados en esta tesis. Su mirada rigurosa fue decisiva al momento de empezar a interpretar lo que observaba en el espacio escolar y a elaborar un argumento sostenido empíricamente. También deseo agradecer muy especialmente a Pedro Iriso por su apoyo como tutor de esta tesis.

A Sandra Gil Araujo por sus sugerencias bibliográficas, la lectura minuciosa, sus valiosos comentarios sobre un primer manuscrito de la tesis y el aliento para finalizarla. También por estar siempre pendiente de lo que uno anda buscando.

A quienes me facilitaron o ayudaron a acceder a algunos documentos oficiales $\mathrm{o}$ intervenciones públicas de funcionarios de gobierno que resultaron de enorme utilidad para el desarrollo de la tesis: Alfonso Hinojosa Gordonava, Silvana Begala, Claudia Ortiz, Silvina Romano, Silvana Santi, Víctor Vélez y Lucila Nejamkis. También a Alejandra Martínez por proveerme del programa informático que me facilitó la ardua tarea de desgrabación de entrevistas y transcripción de registros.

A Pedro Enriquez por su motivación para no que deseche lo que en aquellos primeros años me proponía estudiar con esta tesis cuando aún en el medio académico argentino el tema de la migración y su relación con la escuela no formaba parte de las agendas de investigación. Más aún: cuando diversos investigadores del ámbito académico argentino me lo desaconsejaban. Y por los inolvidables momentos viviendo "afuera", junto a Silvia Baldivieso, Irene Castilla Sánchez, Samuel Carvajal y René Houle, que hicieron posible una duradera amistad. A Pedro le debo, además, muchos de mis primeros aprendizajes sobre metodología cualitativa y las lecturas iniciales sobre la sociología crítica de la educación.

A aquellas personas sin las cuales mis comienzos en el campo de la investigación y la docencia hubieran sido más difíciles. A Dora Celton por las incontables posibilidades que me brindó, por estar siempre presente. A Roberto Benencia por su total apoyo, por las extensas conversaciones sobre la migración boliviana, por los poemas inéditos compartidos. A Lidia Wagner de Williams por la oportunidad de empezar a enseñar en el posgrado cuando recién me iniciaba en la docencia.

A Alfonso Hinojosa Gordonava por las andanzas compartidas, por su generosidad aún en la escasez, por los brindis ocasionales, pero sentidos. A Leonardo de la Torre Ávila y Germán Guaygua por todo lo compartido en Cochabamba y La Paz y por ser de esos anfitriones que 
siempre te hacen volver. A Jacques Ramírez por ese entusiasmo contagioso, por hacerme parte, junto a los amigos bolivianos, de las aventuras de lo que él irónicamente llama el "cartel andino".

A los integrantes del programa Multiculturalismo, Migraciones y Desigualdad en América Latina del CEA-UNC, especialmente a quienes se sumaron cuando aún era un espacio incipiente e inestable: Claudia Ortiz, Silvina Romano, Silvana Begala, María José Magliano, Sofía Soria, Fernanda Stang, Janneth Clavijo y Silvana Santi. A quienes ya no forman parte, pero sin los cuales el programa no hubiera sido lo mismo: Carlos Mora-Ninci, Claudia Abichain, Zoraida Ahumada, Laura Misetich, Renata Rufino y Javier Alba. Este espacio fue un importante lugar de lectura y discusión sobre la temática de las migraciones, la identidad y la política cuando en Córdoba escaseaban lugares propicios para ello. Fue en este espacio que discutí (apasionadamente) algunas de las ideas y argumentos sostenidos en esta tesis. A todos los demás estudiantes y tesistas que, formal o informalmente, se incorporaron después y lo hicieron crecer por todos lados y en muchos sentidos: Paula Sciolla, Andrés Pereira, Katherine Salamanca, Luciana Ingaramo, Rosa Quiroga, Javier Páez, María Victoria Perissinotti, Denise Zenklusen, Melisa Luc, Ignacio Clément, Ana Beltramone, María José Calderón, Karem Rivero, Luciana Rodrigues Alves Ribeiro, Truyitraleu Tappa, Emiliano Horn, Iván Zgaib, Ayelén Sánchez, Rita Herrera, Milva Valor, Evangelina Pérez y Mariana Ferreiro. Un especial agradecimiento a Renata Rufino, quien hacia el año 2005, cuando todavía formaba parte del programa MMDAL, me acercó una copia de la traducción al portugués del libro L'immigration, ou, les paradoxes de l'altérité de Abdelmalek Sayad y me dijo algo así: "Esto te va a encantar". Efectivamente. Encontré allí un acercamiento a la migración y a la experiencia de los migrantes que dialogaba muy estrechamente con mis búsquedas, preocupaciones e intuiciones.

A los miembros del Grupo de Trabajo "Migración, Cultura y Políticas" de CLACSO: Roberto Benencia, Sergio Caggiano, Bela Feldman-Bianco, Alfonso Hinojosa Gordonava, Gioconda Herrera, Susana Novick, Liliana Rivera Sánchez, Miriam Rodríguez, Carolina Stefoni, Alicia Torres, Marta Villa y Guillermo Acuña. Allí encontré un espacio de discusión amable y creativo e interlocutores que fueron muy importantes para mi producción académica. Cada reunión del GT supuso un encuentro de trabajo, diversión y amistad.

A todos aquellos amigos y colegas que en diversas oportunidades me han convocado o me han hecho partícipe de alguna de sus iniciativas: Rossana Baeninger, Roberto Benencia, Hugo Biagini, Xavier Bonal, Sergio Caggiano, Dora Celton, Gustavo Emmerich, Milka Castro Lucic, Bela Feldman-Bianco, Sandra Gil Araujo, Luin Goldring, Lourdes Gouveia, Alejandro 
Grimson, Ana Inés Heras, Dave Hill, Alfonso Hinojosa Gordonava, Denise Jardim, Ravi Kumar, Jean-Michel Lafleur, Françoise Lestage, Fernando Lozano Ascencio, Pepe Luque, Susana Novick, Claudia Pedone, Cynthia Pizarro, Liliana Rivera Sánchez, Cecilia Salazar, Sylvain Souchaud, Marta Villa y Eduardo Vior. Un especial agradecimiento a Gioconda Herrera, quien ha sido siempre sumamente generosa conmigo. Gracias a ellos tuve distintas posibilidades de presentar, intercambiar, discutir y publicar diversos avances de la tesis en varios lugares. Una vez finalizada la escritura de la tesis, las presentaciones hechas en el seminario del departamento de Sociología VI de la Facultad de Educación y del departamento de Antropología Social de la Facultad de Ciencia Política y Sociología de la Universidad Complutense de Madrid fueron de gran utilidad para recibir otras miradas sobre esta investigación. Agradezco a Mariano Fernández Enguita y a Adela Franzé, respectivamente, por dichas invitaciones. A Adela también por hacer de la estancia realizada una experiencia espléndida. Deseo agradecer también a Roberto Luis do Carmo por su incansable amabilidad durante las visitas al NEPO de la Universidad Estadual de Campinas (UNICAMP), Brasil.

Estoy agradecido, asimismo, con los directivos del CEA-UNC y el CIECS-CONICET por el apoyo institucional que he recibido cada vez que lo he solicitado durante todos estos años. También a las secretarias de ambas instituciones, Celeste Ceballos y Mercedes Sappia, por su buena predisposición y gran ayuda en las más variadas circunstancias. A los compañeros de trabajo devenidos en amigos en el transcurso de esta tesis: a Adrián Carbonetti, Vanina Papalini y Juanjo Vagni por querer que la terminara tanto o más que yo. A Claudia Ortiz por su incondicionalidad.

A los distintos grupos de estudiantes de la Escuela de Trabajo Social de la Facultad de Derecho y Ciencias Sociales de la UNC que han participado del seminario sobre "Migración, Cultura y Sociedad" por haber contribuido a crear un espacio que me ha permitido sostener mi entusiasmo por la docencia. También a quienes me acompañaron con sumo interés, dedicación y compromiso en esta propuesta docente: Paula Sciolla, Luciana Ingaramo, Florencia Molina, Azul Lozano y Sabrina Goi.

Mi reciente vinculación con proyectos de cine y teatro relacionados con las migraciones me han permitido explorar nuevos lenguajes para hablar sobre la "condición migrante". A Ivana Altamirano y María Laura Romero por hacerme parte de sus proyectos de teatro comunitario, donde encontré un lugar especial para mirar desde otro ángulo mi actividad académica cotidiana y pensar las idas y vueltas de la intervención social con población inmigrante. Agradezco especialmente a Pablo Spollanksy y Diego Mina por todo lo 
compartido durante la realización de Un día, todos los días: migrantes peruanos en Córdoba y los momentos vividos alrededor de la elaboración de nuevos proyectos audiovisuales que forjaron una alegre amistad. Mi agradecimiento a Franco Morán y Franco Rizzi por convocarme para esta película documental que me permitió conectarme con viejas inquietudes que tenía olvidadas.

A los amigos de distintos momentos de la vida con quienes el presente tiene mucho de un pasado inolvidable. En orden cronológico: Lucas Gesumaría, Marcos Badie, Conrado Chiappero, Damián Mansilla, Pablo Castagno, Christian Gebauer, Marcelo Maciá y Javier Aguirre.

A mis padres, gracias a quienes viví en carne propia las experiencias escolares "multiculturales" de las cuales habla la literatura científica, por proveerme aquellas herramientas para explorar nuevos territorios que fueron mucho más que un cambio de residencia. Y a mi hermana, con quien de chicos tuvimos que aprender a movernos juntos en el terreno movedizo de ser "extranjeros", por estar de una forma u otra en todo momento y lugar. Y a mis primos que son como hermanos.

A Paola y Salvador, a quienes les tocó vivir muy de cerca las vicisitudes de una tesis. A Paola por su incondicional y eterno apoyo durante todo este largo período de tiempo. Salvador creció junto a esta tesis y ya más grande tuvo que aprender a convivir con ella. No alcanzan las palabras para agradecerles. Sin ellos la vida diaria se parecería mucho a algunas experiencias de la migración: ni acá, ni allá. A ellos dedico esta tesis. También a Herbert Hörstensmeyer, in memoriam. 



\section{INTRODUCCIÓN}

El estudio de los procesos migratorios internacionales constituye una de las principales preocupaciones de la sociología contemporánea. Dicha manifestación ha dado lugar a una especialidad como la sociología de las migraciones y ha colaborado, junto a otras disciplinas científicas, en la formación de un campo de indagación específico conocido como estudios migratorios. Esta tesis, inscripta en el terreno de la reflexión sociológica con vocación de diálogo interdisciplinar, se interesa particularmente por la dimensión sociopolítica de la migración. Su propósito principal es comprender desde una perspectiva crítica la relación entre el Estado nacional y la inmigración en la Argentina contemporánea en el marco de las transformaciones acontecidas en el pensamiento estatal sobre las migraciones internacionales. De algún modo, constituye una respuesta a la invitación teórica que hiciera Sayad (1999) al postular que pensar la inmigración implica pensar el Estado y que es el Estado el que se piensa a sí mismo pensando la inmigración. Se trata de un estudio acerca de la visión de Estado que se construye en relación a la inmigración y los inmigrantes de acuerdo a determinadas coyunturas históricas y en contextos sociales específicos, como la escuela pública, marcados especialmente por la presencia del Estado nacional, aunque con una autonomía relativa que habilita variadas apropiaciones y resignificaciones. Dicha relación es analizada es espacios tanto macro como microsociales a través de las representaciones, prácticas y políticas que producen aquellas instituciones del Estado argentino que mantienen un vínculo histórico con aquellos sujetos nombrados e identificados como inmigrantes: por un lado, el organismo estatal especializado que históricamente se ha encargado de la regulación y el control de los movimientos migratorios internacionales, la Dirección Nacional de Migraciones, y por otro, la institución estatal que desde sus inicios tuviera como mandato la formación del ciudadano y la nacionalización de los inmigrantes, la escuela pública. Esquemáticamente, a través del análisis de estas dos instituciones, se pretende comprender el modo en que el Estado, como espacio de disputa, utiliza -según la metáfora de Bourdieu- su mano derecha e izquierda en relación a la llamada inmigración limítrofe a la luz de aquella presencia inmigrante construida como ilegal e ilegítima en la Argentina contemporánea: la inmigración boliviana.

Para llevar adelante esta propuesta de investigación, la tesis plantea en términos metodológicos un estudio cualitativo que combina diversas estrategias y técnicas de recolección e interpretación de la información como la indagación documental, la 
observación participante y la entrevista en profundidad para analizar los procesos, instrumentos, representaciones y prácticas a través de los cuales el Estado, sus agentes e instituciones construyen su relación con la inmigración y producen la figura social del inmigrante. En esta tarea, considerando la influencia decisiva que ejercen las nominaciones y clasificaciones sociales en las experiencias de vida de quienes son interpelados o se asumen como migrantes, el estudio muestra un particular interés en la formación sociohistórica de las categorías de la visión de Estado como parte de la búsqueda por develar los modos en que se sustancializa a los sujetos migrantes (o quienes son identificados como tales, directamente o por añadidura, como los hijos de inmigrantes) y en que se legitiman tales categorías en la legislación o las políticas públicas (Feldman-Bianco et al., 2011), así como la manera en que son impuestas o inculcadas en espacios institucionales determinados por la presencia estatal. Igualmente, considerando el poder que tiene el pensamiento de Estado para penetrar nuestros esquemas y categorías de análisis, o las dificultades para escapar a los condicionamientos de lo que se ha denominado nacionalismo metodológico, quienes asumimos la tarea de analizar la relación entre Estado y migración no estamos exentos de "ser pensados por un Estado que creemos pensar" (Bourdieu, 1997: 91).

Las preguntas de investigación que emergieron durante el extenso recorrido realizado y guiaron el proceso de construcción del objeto de estudio fueron las siguientes: ¿Qué visión construye el Estado argentino acerca de la inmigración y los inmigrantes de países limítrofes? ¿Cuál es la visión del Estado de origen de estos inmigrantes? ¿Qué representaciones, prácticas y políticas sustentan estas visiones de Estado? ¿Cuáles son las respuestas estatales desarrolladas históricamente frente a la inmigración de países limítrofes? ¿De qué modo el Estado argentino interpela a los inmigrantes latinoamericanos en el contexto actual de reformas migratorias? ¿Qué categorías y clasificaciones se producen para regular la inmigración y la presencia de los inmigrantes? ¿Qué procesos, prácticas e instrumentos están detrás del surgimiento y la transformación de las categorías con las cuales se nombra e identifica a los sujetos migrantes? ¿Qué motiva la elaboración y quiénes participan de la elaboración y negociación de estas construcciones categoriales? ¿Cuándo y cómo se define desde el Estado la inmigración como problema? ¿A través de qué procesos y mecanismos sociales se legitima o se pretende legitimar la presencia de los inmigrantes? ¿Qué contenido y forma adquieren los discursos y políticas nacionales y las prácticas sociales y escolares bajo la representación de la Argentina como país de inmigración? ¿Cuál es la visión que se construye en la escuela acerca de los hijos de inmigrantes? ¿Cómo responde la escuela y qué estrategias se ponen en juego frente a la presencia de hijos de inmigrantes en la escuela? ¿Cuándo y bajo qué condiciones sociales 
aparece la inmigración como problema o como una presencia problemática en la escuela? ¿Quiénes y en qué situaciones sociales son identificados como bolivianos en la escuela? ¿Qué significa ser boliviano en la escuela argentina? ¿Qué representaciones, prácticas y categorías se producen y circulan en el espacio escolar acerca de los alumnos identificados como bolivianos? ¿Qué representaciones y prácticas se desarrollan en torno a los hijos de inmigrantes bolivianos en un contexto escolar atravesado por la marginalidad social y la pobreza?

Estos interrogantes fueron configurándose a medida que avanzaba con el trabajo de campo y la sistematización, análisis e interpretación de la información que recogía. Pero todo se inició bajo otras inquietudes, motivaciones e intereses relacionados tanto con la vida personal como con la académica. Mi experiencia escolar de niño viviendo como extranjero durante varios años en Alemania, el auge que cobró la temática de la inmigración extracomunitaria mientras viví y estudié en España durante finales de los años noventa y la visibilidad social y política que cobró la llamada inmigración limítrofe en la Argentina y las respuestas xenófobas del Estado nacional durante esos años influyeron para que me decidiera por un tema de estudio vinculado a la migración. En particular, hay tres hechos relacionados con mi residencia en Alemania que de algún modo han estado presentes en los diversos momentos del trabajo de campo y la escritura de la tesis. Primero, recién de adulto comprendí que mis amigos y compañeros de clase en la escuela la primaria, Luis y Michael, hijos de Gastarbeiter provenientes de España y Yugoslavia respectivamente, eran producto del reclutamiento laboral que el Estado alemán había promovido en los años sesenta y setenta. Segundo, el intenso sentimiento de provisoriedad con el cual viví la permanencia de mi familia en Alemania, a pesar de que laboral y económicamente la vida familiar era estable. Tercero, el regreso a la Argentina y las implicancias subjetivas y burocráticas que tuvo la reincorporación mía y la de mi hermana a la escuela, desde las dificultades para tramitar las equivalencias de las asignaturas hasta los exámenes de patriotismo a los que fue sometida mi hermana para poder cursar el último año de su primaria como cantar el himno nacional argentino a cappella frente a una maestra evaluadora en una sala vacía.

Por el lado académico, mis nuevos intereses de investigación se derivaban de un estudio cualitativo anterior (con modalidad de estudio de casos) sobre la formación de la cultura escolar y su relación con la desigualdad social (Domenech, 2000) en el cual la visión que construían los docentes sobre el contexto sociocultural de los alumnos resultaba un elemento central en tanto conllevaba una redefinición o reelaboración de distintas dimensiones de la vida escolar, contribuyendo a la distribución diferencial de uno u otro 
tipo de educación. Las representaciones sobre los alumnos provenientes de sectores urbanos pobres mostraban una fuerte asociación entre deficiencias materiales (reales) y carencias de tipo cultural, moral y afectivo (atribuidas). Ya interesado en la cuestión multicultural y la problemática inmigrante, fue esta construcción del Otro a partir de cualidades atribuidas, fundadas en diversos prejuicios y preconceptos de clase, lo que me llevó a interesarme en el proceso de construcción de la diferencia cultural y su relación con los procesos de inclusión/exclusión de los hijos de inmigrantes en el espacio escolar.

En los inicios, seducido por la temática de la diversidad cultural en el campo de la educación, mis intereses apuntaban a comprender el proceso de construcción de la otredad/alteridad en espacios caracterizados como multiculturales o, en otras palabras, la producción de la diferencia cultural. Más específicamente, mi intención era conocer el modo en que el Estado-nación se relaciona con grupos étnicos vinculados al fenómeno migratorio a través de sus instituciones, especialmente la escuela, entendida ésta como un agente fundamental en la producción y reproducción de la hegemonía estatal o, en términos de Balibar (1991), de la forma nación. Para analizar dicha relación con el Estado, asumía la distinción que realiza Kymlicka (1996) entre minorías nacionales y grupos étnicos. Las minorías nacionales serían producto de un proceso de conquista o incorporación, cuya demanda es la autonomía política y administrativa o la autodeterminación, y los grupos étnicos resultantes de un proceso de inmigración, cuya demanda se basa en el reconocimiento cultural e identitario. Me preguntaba si en los tiempos actuales y de qué manera el Estado nacional argentino aún participaba activamente de proyectos políticos de asimilación de la población extranjera con el interés de crear y modelar a las minorías étnicas, como sugiere Bauman (2001), a su propia imagen. Así, en los inicios, bajo la influencia de la noción de etnicidad, seleccioné dos agrupamientos sociales que en aquél momento identificaba como grupos étnicos: bolivianos y gitanos. Pensaba en la relevancia que pudiera tener para el estudio que estos grupos respondieran a distinto tipo de movilidad espacial, se articularan de forma diferente con las categorías de etnicidad y nacionalidad y se diferenciaran por su grado de organización e institucionalización. Por dificultades materiales y prácticas como también por decisiones teóricas y empíricas relacionadas con la construcción del objeto de estudio, después de dos años de trabajo de campo abandoné la escuela frecuentada por los niños gitanos y decidí concentrar mis esfuerzos en la escuela visitada por hijos o nietos de 
inmigrantes bolivianos. ${ }^{1}$ Igualmente, las numerosas observaciones y entrevistas realizadas allí me permitieron visualizar por contraste varios aspectos y connotaciones de la presencia de los hijos de inmigrantes bolivianos en la escuela.

Influenciado por la literatura del momento, el trabajo de campo, cuyo desarrollo detallaré en el próximo capítulo, lo inicié mediante preguntas que giraban en torno a la diferencia/desigualdad para indagar la construcción del Otro en la escuela. Posteriormente, mi indagación empezó a centrarse en cuestiones más específicas sobre la construcción de la diferencia cultural en contextos multiculturales marcados por la desigualdad social. Mis primeras interpretaciones de aquello que sucedía en el espacio escolar estuvieron muy condicionadas por la literatura consultada y no hacían más que ratificar lo que con el tiempo se volvería una especie de premisa de investigación o algo así como una verdad autoevidente para quienes se introducen en el tema: en la escuela, la construcción de la diferencia cultural operaba como forma de legitimación de las desigualdades socioculturales que se constituyen en su interior. Entendía que las discontinuidades existentes entre el medio escolar y el entorno sociocultural de alumnos hijos de inmigrantes pretendían ser salvadas por medio de estrategias de homogeneización o diferenciación cultural para asegurar la continuidad entre ambos universos. En aquellos momentos consideré que la noción de ilusión de la unidad podía sintetizar aquellos procesos que observaba. Conectado con mis observaciones en otros espacios sociales de marcada presencia inmigrante, la ilusión de la unidad adquiriría en la relación entre bolivianos y argentinos una connotación distinta, resignificándose como ilusión de la hermandad.

Con el transcurso del tiempo en el escenario escolar, aquellas primeras observaciones realizadas en ambas instituciones escolares permitían pensar en dos modos de integración, ${ }^{2}$ diferenciables sólo en términos analíticos (es sabido que la realidad se encarga de desmentir las formas puras). En las primeras observaciones realizadas, sólo encontraba indicios de que las escuelas en estudio, frecuentadas por alumnos gitanos y bolivianos, continuaban actuando como agentes de uniformización cultural. Prevalecía con arrolladora fuerza el modelo asimilacionista o de integración monocultural que había

\footnotetext{
1 Tomar esta decisión fue extremadamente difícil, debido a que durante los dos años de trabajo de campo en la escuela que contaba con la presencia de chicos gitanos ya había reunido más de un centenar de registros de observaciones y había realizado doce entrevistas a docentes y directivos.

2 Si bien hay cierto acuerdo en el ámbito académico sobre el uso de la categoría "integración”, entendida en muchas ocasiones como opuesta a la categoría "asimilación”, en este trabajo, en vez de oponer una a la otra, se concibe la asimilación como una forma de integración, en un intento por superar la dicotomía establecida.
} 
propuesto históricamente el Estado argentino. Algunos meses más adelante, comencé a observar diferentes estrategias adoptadas, nombradas como integración, por la institución escolar visitada por los hijos o nietos de inmigrantes bolivianos. La llamada integración parecía estar adquiriendo nuevas formas y contenidos, ya que determinadas manifestaciones socioculturales y símbolos políticos que históricamente no habían tenido cabida en las instituciones escolares, ahora pretendían ser reconocidas. Y no sólo se trataba de un reconocimiento promovido en la escuela, sino que también había un relato oficial que señalaba la pertinencia o la conveniencia de atender la llamada diversidad cultural. Es decir, ahora se visualizaba una manera de pensar la integración bajo una modalidad desconocida hasta el momento en la escuela, que hablaba de la importancia del reconocimiento de la diferencia cultural y que en la vida cotidiana escolar adquiría visibilidad a través de expresiones multiculturales esencialistas.

Bajo esta modalidad, la diferencia cultural quedaba establecida y era utilizada como algo exótico o extraño que esencializa la cotidianeidad de aquellos sujetos identificados como diferentes, destacando los componentes expresivos antes que los instrumentales de la cultura. En otras palabras, había determinadas diferencias que eran atendidas antes que otras. Algunas observaciones también me llevaron a pensar que no se presentaba como una alternativa de cambio a la integración monocultural o asimilacionista debido a la forma de multiculturalismo esencialista que adquiría. Consideraba que, más allá de las buenas intenciones de los involucrados con la búsqueda de reconocimiento de la otredad, el llamado multiculturalismo esencialista, quizás por definición, no era adoptado para problematizar la realidad social y cultural de la escuela, sino para mostrarse abierto a la diversidad, sirviendo de pantalla para cubrir directa o indirectamente los mecanismos reales de marginación o exclusión. En estas circunstancias también me preguntaba si esta especie de reconocimiento apuntalado en un multiculturalismo esencialista no era verdaderamente un falso reconocimiento, tal como lo entiende Taylor (1993). ${ }^{3}$ Empecé a darme cuenta que en la escuela, la presencia admitida de los alumnos hijos de inmigrantes bolivianos, pensados como bolivianos, ocurría justamente en situaciones sociales pretendidamente interculturales (recreadas según algunas pautas del multiculturalismo esencialista), las cuales solían alcanzar gran visibilidad en los actos escolares, adquiriendo allí su máxima expresión. Ahora podía ver más claramente que la presencia de los hijos de inmigrantes era experimentada de una manera mucho más ambigua de lo que imaginaba

3 Charles Taylor sostiene la tesis de que "nuestra identidad se moldea en parte por el reconocimiento o por la falta de éste; a menudo, también, por el falso reconocimiento de otros". Entiende que "el falso reconocimiento o la falta de reconocimiento puede causar daño, puede ser una forma de opresión que aprisione a alguien en un modo de ser falso, deformado y reducido" (Taylor, 1993:43-44). 
al comienzo. Su presencia cobraba sentidos y significados diversos de acuerdo a las coyunturas de la vida escolar cotidiana y de la historia de la institución.

Aunque en buena medida me alejé, descarté y reinterpreté muchos de estos elementos emergentes, a partir de estos primeros hallazgos obtuve mayor claridad acerca de la búsqueda que estaba realizando y la investigación empezó a transitar, con unas pocas certezas y diversas incertidumbres, un nuevo recorrido que me llevaría a problematizar la relación entre el Estado, la escuela y la inmigración bajo una mirada más atenta a las tensiones, negociaciones, acuerdos y contradicciones sobre lo que provocaba la presencia de los bolivianos en la escuela, indagando la producción de la bolivianidad y la argentinidad más que buscando identificar lo que suscitaba la diversidad cultural o la diferencia cultural. En este proceso comprendí que para entender la construcción de la bolivianidad debía prestar atención al mismo tiempo a la producción de la argentinidad. A la vez, al elevar y colocar la mirada en la influencia del Estado en las relaciones sociales que estaba estudiando en la escuela, enmarcadas en las transformaciones que venían teniendo lugar en las políticas educativas desde los años noventa con el ingreso del discurso de la diversidad cultural y la llamada educación intercultural, empezaba a advertir con mayor claridad el modo en que aquella legislación escolar, sedimentada históricamente, orientada a asegurar la presencia material y simbólica del Estado en la escuela, así como reproducir su existencia, a través de disposiciones relativas a la construcción de la nación argentina y a regular la formación de sujetos nacionales como las fiestas patrias a través de las efemérides establecidas por el Ministerio de Educación, participaba también de la configuración de determinadas representaciones y prácticas en el espacio escolar destinadas al reconocimiento de la presencia de los alumnos identificados como bolivianos.

Luego, teniendo en cuenta que, como señala Sayad (1989), para la sociedad de recepción, cuya posición hegemónica asume naturalmente una visión etnocéntrica del hecho migratorio, la migración sólo existe en términos de inmigración o como hecho que se reduce a la inmigración, ignora -desconoce a la vez que se desentiende- de todo aquello relacionado con la sociedad de emigración, tanto de las condiciones que la producen como los efectos que provoca la emigración, me pareció conveniente atender, primeramente (en un sentido cronológico como epistemológico), la relación entre el Estado y sociedad de origen y los emigrantes. Aunque el foco de interés estaba puesto en los emigrantes, es decir, en aquellos sujetos que posteriormente se convierten en objeto de las políticas de los Estados de destino en tanto inmigrantes, consideré que también era necesario reconstruir históricamente, en un entramado más complejo de emigración/inmigración, la 
visión del Estado boliviano respecto al hecho migratorio en general, a través del discurso jurídico que mantuvo a lo largo del siglo veinte hasta la primera década del veintiuno, para mostrar la emergencia de la figura del emigrante como nacional en el exterior bajo un Estado que en el pasado se había proyectado como país de inmigración a pesar de que su realidad migratoria expresaba lo contario. Suponía, asimismo, que dicho análisis me ayudaría a comprender más cabalmente, por contraste, las particularidades o especificidades que tuviera un Estado nacional como el argentino que se imaginó y se constituyó históricamente como país de inmigración frente a una inmigración de ultramar que efectivamente adquirió hacia finales del siglo diecinueve y principios del veinte tal dimensión que hizo que fuera identificada como masiva o de masas.

Al mismo tiempo, me dediqué a explorar la normativa migratoria nacional que se había aprobado recientemente en la Argentina, contrastándola con la que había estado vigente hasta ese momento. La nueva ley de migraciones mostraba algunos indicios de cambio importantes: frente al enfoque de seguridad nacional que dominaba la antigua ley, la nueva incorporaba en su articulado el reconocimiento de determinados derechos a los inmigrantes que la anterior negaba y desconocía completamente. Esto llevó a diversos investigadores a señalar una radical ruptura entre las políticas migratorias desarrolladas bajo la vigencia de una y otra ley migratoria. En aquél momento, yo mismo, demasiado apresuradamente, consideré que las diferencias entre una y otra ley permitían interpretar los cambios en la política migratoria en términos de ruptura. Pero mi interés por la relación entre el Estado y los inmigrantes me llevó a analizar la visión de Estado que proponía en conjunto la llamada nueva política migratoria. Para ello, como detallaré en el próximo capítulo, no sólo analicé en profundidad la normativa recientemente aprobada, sino que también empecé a explorar el origen y la formación de la nueva política migratoria a través de las distintas iniciativas de reforma o derogación de la ley migratoria de la dictadura militar y los nuevos proyectos de ley, las intervenciones públicas de los distintos directores de la Dirección Nacional de Migraciones y otros funcionarios de jerarquía durante el proceso anterior y posterior a la aprobación de la nueva ley en diversos espacios y eventos institucionales, el diseño y la implementación de programas nacionales de gobierno destinados a la población inmigrante o extranjera inspirados en la nueva ley y los acontecimientos que se desarrollaban en el orden regional e internacional en materia de migraciones internacionales. Todo ello me hizo revisar mi propia mirada sobre el alcance de los cambios en materia de migraciones internacionales en la Argentina y profundizar la crítica que había empezado a esbozar. Además, este análisis ofrecía la posibilidad de discutir aquellos trabajos que adjudicaban los cambios en materia de política de migraciones al giro ideológico del nuevo gobierno nacional arribado a la 
presidencia y descuidaban tanto las continuidades con el régimen de control de las migraciones instaurado a lo largo del siglo veinte en la Argentina como el proceso de internacionalización de la política migratoria en América del Sur y la adscripción a un enfoque técnico-político de alcance global, la gobernabilidad migratoria, promovido por agencias internacionales, como la Organización Internacional para las Migraciones (OIM), que forman parte de las estructuras hegemónicas del orden mundial. Igualmente, también había elementos que permitían y obligaban a prestar atención a la renovada visión de Estado que se vislumbraba en materia de política de migraciones internacionales bajo una retórica de la inclusión afirmada en los derechos humanos, la integración regional y el pluralismo cultural frente a la retórica de la exclusión de los noventa que confinaba a los inmigrantes a ser representados como amenaza social.

Diversas representaciones, prácticas y políticas desplegadas en el presente en el ámbito de gobierno de las migraciones como en el espacio escolar sugerían la importancia de mirar hacia el pasado y analizar su origen y constitución bajo fórmulas oficialmente avaladas y validadas. Algunos de los indicios de cambio se evidenciaban en los desplazamientos que sufrían las formas estatales de nombrar a los inmigrantes. Quizás el más significativo y que para mí condensaba algunas de las singularidades de la visión de Estado que se estaba configurando, era el reemplazo del inmigrante ilegal por el inmigrante irregular. Esto me hizo indagar más a fondo la construcción de la figura social del inmigrante limítrofe como problema, corporeizado como inmigrante ilegal, tanto en el pasado inmediato (los años noventa) como mediato, realizando un pormenorizado análisis del discurso jurídico, que vehiculiza el pensamiento de Estado, destinado a controlar el ingreso y la permanencia de los extranjeros en el territorio nacional, y documentando y reconstruyendo diversos momentos y hechos de especial significación para comprender la visión de Estado que emergía bajo la nueva política migratoria. Por otra parte, la centralidad que adquirió la acción estatal de regularización de los inmigrantes como solución política a los problemas migratorios en el marco de la nueva política migratoria ponía de relieve la histórica preocupación del Estado en torno a la ilegalidad migratoria. Esto indicaba también la necesidad de explorar la formación sociohistórica de la categoría de inmigrante ilegal de la mano de las políticas de control consolidadas a lo largo del siglo veinte en la Argentina para comprender de qué manera el Estado argentino a través de las disposiciones legales y sus clasificaciones había contribuido a producir una visión de la inmigración, actualizada de manera permanente, como problema social e, inclusive, como amenaza (por ejemplo, a la seguridad nacional) en determinadas coyunturas históricas. En otro orden, la reconstrucción histórica de ciertas prácticas rituales desarrolladas en el ámbito escolar en relación a la construcción de la nación argentina y la nacionalización de los inmigrantes de 
ultramar revelaba otra dimensión de la constitución de la inmigración como problema o amenaza, ligado fundamentalmente a la identidad nacional, con importantes implicancias para las experiencias escolares de los alumnos hijos inmigrantes de países limítrofes en la actualidad.

La organización de la tesis no sigue necesariamente el recorrido empírico realizado, sino que más bien está estructurada de acuerdo a un orden lógico acorde al propósito perseguido en la investigación. El primer capítulo realiza una breve aproximación al estudio de la dimensión política de la migración internacional en el campo de las ciencias sociales y en particular de la sociología y de los denominados estudios migratorios, expone la perspectiva teórica-metodológica desde la cual comprendo e interrogo a lo largo de la tesis la relación entre el Estado, la escuela y la migración y, por último, presenta los diferentes momentos del trabajo de campo realizado. El segundo capítulo analiza la visión del Estado boliviano sobre las migraciones internacionales, en especial la emigración, durante el siglo veinte hasta la primera década del siglo veintiuno, marcada por la llegada del Movimiento al Socialismo (MAS) a la presidencia. Interesa su visión en tanto Estado de origen de la población inmigrante constitutiva de las políticas desarrolladas por el Estado argentino, en particular desde mediados del siglo veinte. El tercer capítulo historiza la producción estatal de la inmigración como problema en la Argentina contemporánea, en particular la figura del inmigrante limítrofe como ilegal, mediante un análisis de la legislación y las políticas desarrolladas por el Estado argentino a lo largo del siglo veinte. Dado que la nueva política migratoria se desarrolló en buena medida frente a la experiencia política de la década anterior, el capítulo le dedica especial atención a los años noventa. El cuarto capítulo examina la visión de Estado que se configuró alrededor de la inmigración en el contexto de las reformas impulsadas en materia de política migratoria alrededor de la aprobación de una nueva ley de migraciones, indagando especialmente la perspectiva del organismo estatal que históricamente ha monopolizado el control de la inmigración en la Argentina, la Dirección Nacional de Migraciones. El quinto capítulo analiza la visión que desarrolla el Estado argentino en relación a la inmigración ilegal en el marco de los desplazamientos de la nueva política migratoria acontecidos en un período histórico determinado por un novedoso proceso de regionalización e internacionalización de ciertas ideas y prácticas sobre la regulación de las migraciones internacionales, cuyo análisis ayuda a explicar la adopción de determinadas medidas políticas nacionales destinadas a los inmigrantes. Le dedica especial atención al programa nacional de regularización migratoria, conocido como "Patria Grande", que se destacó como la medida política más trascendental del período. El sexto capítulo problematiza la presencia inmigrante y/o extranjera en un espacio social específico definido nacionalmente como la 
escuela, en tanto institución histórica del Estado encargada de la formación del ciudadano y la nacionalización del extranjero, a partir de la aparición de hijos de inmigrantes bolivianos en una escuela periurbana de la ciudad de Córdoba. El séptimo capítulo, después de revisar las respuestas políticas del Estado argentino a la inmigración en el terreno de la educación y el papel de la escuela en el proceso histórico de construcción de la identidad nacional y nacionalización de los extranjeros, analiza las formas actuales que adquieren en el espacio escolar las estrategias de inclusión y reconocimiento que propone la escuela al ser interpelada por la presencia de dichos hijos de inmigrantes bolivianos. Finalmente, retomando algunas de las ideas centrales planteadas y realizando una lectura transversal de los capítulos, se exponen las conclusiones de la tesis.

Algunas de las ideas, planteos y argumentos contenidos en esta tesis han aparecido publicados en distintos libros y revistas especializadas. El capítulo referido a la visión estatal sobre las migraciones internacionales en Bolivia retoma los artículos "Migraciones internacionales y política en Bolivia: pasado y presente" (con M.J. Magliano), en Estudios Migratorios Latinoamericanos, año 21, núm. 62, pp. 3-41, 2007 (reproducido bajo el mismo título como capítulo de libro en E. Domenech, comp., Migración y política: el Estado interrogado. Procesos actuales en Argentina y Sudamérica, UNC, Córdoba, pp. 201-256, 2009), y "Avatares de la política migratoria en Bolivia: el Estado y los emigrantes como nacionales en el exterior", publicado en AA.VV., Migraciones contemporáneas. Contribución al debate, CIDES-UMSA / CAF / Plural, La Paz, 2009, pp. 259-288. Estos textos sirvieron de base para la elaboración de otras dos publicaciones: "Emigración, Estado y sociedad en Bolivia: la reivindicación del 'voto en el exterior'” (con A. Hinojosa Gordonava), en M. Roosta (coord.) Población y Desarrollo. Bolivia y los fenómenos de la migración internacional, Colección 25 Aniversario, CIDES-UMSA/OMS, La Paz, pp. 83-108, 2009 (reproducido posteriormente en C. Amescua y J. Luque, coords., Política en Movimiento: Estado, ciudadanía, exilio y migración en América, CRIM-UNAM, México D.F., en prensa). Parte del capítulo referido a la producción de la ilegalidad en la Argentina contemporánea ha aparecido publicado en 'Crónica de una 'amenaza' anunciada. Inmigración e ‘ilegalidad': visiones de Estado en la Argentina contemporánea”, en el libro organizado por B. Feldman-Bianco, M. Villa, L. Rivera y C. Stefoni, comps., La construcción social del sujeto migrante en América Latina: prácticas, representaciones y categorías, CLACSO / FLACSOEcuador / UAH, Quito, 2011. Los dos capítulos que analizan la configuración de la "nueva política migratoria" en la Argentina reciente se nutren de diversos artículos: "La agenda política sobre migraciones en América del Sur: el caso de la Argentina", en Revue 
Européenne des Migrations Internationales (REMi), vol. 23, núm. 1, pp. 71-94, 2007 (una versión revisada de este artículo también fue publicada en castellano bajo el mismo título en C. Pizarro, comp., Migraciones internacionales contemporáneas: Estudios para el debate, Ediciones CICCUS, Buenos Aires, 2011); “La ciudadanización de la política migratoria en la región sudamericana: vicisitudes de la agenda global", en S. Novick, comp., Las migraciones en América Latina. Políticas, culturas y estrategias, CLACSO / Catálogos, Buenos Aires, pp. 53-72, 2008; "La visión estatal sobre las migraciones en la Argentina reciente. De la retórica de la exclusión a la retórica de la inclusión", en E. Domenech, comp., Migración y política: el Estado interrogado. Procesos actuales en Argentina y Sudamérica, UNC, Córdoba, pp. 21-69, 2009; "La 'nouvelle politique migratoire' en Argentine: les paradoxes du programme ‘Patria Grande'”, en Problèmes d'Amérique Latine, núm. 75, pp. 37-59, invierno 2009. Finalmente, algunas de las intuiciones iniciales que aparecen en los dos últimos capítulos sobre el espacio escolar y la presencia de hijos de inmigrantes bolivianos fueron publicadas en los artículos "Etnicidad e inmigración: ¿Hacia nuevos modos de 'integración” en el espacio escolar?", en Astrolabio: revista virtual del CEA-UNC, año 1, núm. 1, 2004; "Migraciones contemporáneas y pluralismo cultural en la Argentina: el discurso oficial y las prácticas escolares", en D. Jardim, org., Cartografias da Imigração: Interculturalidade e Políticas Públicas, Universidade Federal do Rio Grande do Sul (UFRGS), Porto Alegre, 2007, pp. 19-45.

Ciertos avances de investigación también fueron presentados y discutidos en reuniones científicas de diversa índole, a saber: Seminario Internacional "Pobreza, exclusión social y discriminación étnico-racial en América Latina y el Caribe" (Cali, Colombia, 23-25 de noviembre de 2005); Seminario-Taller "Perspectivas sobre Migración Transnacional desde la Región Andina y el Cono Sur” y I Reunión del Grupo de Trabajo “Migración y Cultura” del Consejo Latinoamericano de Ciencias Sociales (CLACSO) (Lima, Perú, 30 de noviembre y 12 de diciembre de 2005); Congreso Argentino de Estudios sobre Migraciones Internacionales y Políticas Migratorias y de Asilo (Buenos Aires, Argentina, 25-27 de abril de 2006); 52ํㅡㄹ Congreso Internacional de Americanistas, Simposio "Migraciones, Identidad y Nacionalismo en América Latina" (Sevilla, España, 17-21 de julio de 2006); Seminario Permanente de Migraciones del Instituto de Investigaciones Gino Germani de la Universidad de Buenos Aires (Buenos Aires, Argentina, 28 de septiembre de 2006); Jornadas Preparatorias del XXVI Congreso ALAS: "Sociología y Ciencias Sociales: conflictos y desafíos transdisciplinarios en América Latina y el Caribe" (Buenos Aires, Argentina, 2324 de mayo de 2007); Workshop Internacional: "Dinâmica e Diversidade da Migração SulSul: perspectivas teórico-metodológicas a partir das migrações bolivianas" (Campinas, San Pablo, Brasil, 4-5 de junio de 2007); II Reunión del Grupo de Trabajo "Migración y 
Cultura": "Migraciones en América Latina y el Caribe: una perspectiva crítica desde el Sur" (Quito, Ecuador, 27-28 de octubre de 2007); II Taller sobre Migración y Desarrollo: "Agendas de desarrollo, movilidad humana y sociedad civil transnacional en Suramérica" (Caracas, Venezuela, 24 y 25 de abril de 2008); Seminario internacional "Las nuevas dimensiones del conflicto internacional: diversidad cultural, migraciones y recursos naturales" (Córdoba, Argentina, 26 de agosto de 2008); Coloquio Internacional: "Migrantes regionales en las Américas. Casos de Argentina, Brasil, Chile y Estados Unidos" (Buenos Aires, Argentina, 8 y 9 de septiembre de 2008); Seminario Internacional sobre Migración (La Paz, Bolivia, 2 y 3 de octubre de 2008); III Reunión del Grupo de Trabajo Migración, Cultura y Políticas del Consejo Latinoamericano de Ciencias Sociales (CLACSO): "Las migraciones en América Latina: debate abierto de un proceso contradictorio" (Buenos Aires, Argentina, 22-24 de octubre de 2008); IV Reunión del Grupo de Trabajo Migración, Cultura y Políticas del Consejo Latinoamericano de Ciencias Sociales (CLACSO): "La construcción social del migrante. Reflexiones desde América Latina y el Caribe" (Guatemala C.A., Guatemala, 14-16 de octubre de 2009); Seminario internacional: "Migraciones internacionales contemporáneas: estudios para el debate" (Buenos Aires, 4, 5 y 6 de enero de 2010); IV Congreso de la Red Internacional de Migración y Desarrollo: "Crisis global y estrategias migratorias: hacia la redefinición de las políticas de movilidad" (Quito, Ecuador, 18-20 de mayo 2011). 



\section{CAPÍTULO 1}

COMPRENDER LA DIMENSIÓN SOCIOPOLÍTICA DE LA MIGRACIÓN

La relevancia que posee en la actualidad el estudio de la migración internacional y, en particular, la problematización de la relación entre el Estado y los inmigrantes es un hecho relativamente reciente que deriva de su mutua (pero no necesariamente simultánea) constitución como problema social y como problemática sociológica. La migración, aunque devenida en objeto de gobierno y de estudio con los movimientos migratorios masivos de fines del siglo diecinueve y comienzos del veinte, tardó décadas en ser asumida en la investigación social como un objeto con estatuto científico propio así como un asunto determinado políticamente. La ausencia formal de la figura del Estado, así como su naturalización, en la producción de conocimiento sobre la migración atraviesa la historia del estudio de la movilidad humana, ligado al devenir histórico de las ciencias sociales, y forma parte del proceso de institucionalización en el campo de la investigación social en los distintos contextos nacionales. Asimismo, los marcos analíticos y las explicaciones acerca del fenómeno migratorio, producidos mayormente en instituciones académicas de países del Norte, así como las revisiones teóricas acerca del desarrollo de las llamadas teorías migratorias, estuvieron centrados de manera predominante en la experiencia nacional de sociedades con una larga tradición en la recepción de inmigrantes de ultramar (en particular, la estadounidense) y, hasta finales de la década del ochenta, a excepción de algunas investigaciones históricas o sociológicas, se ignoraron casi por completo las sociedades y Estados de origen de las corrientes migratorias o colectividades de inmigrantes estudiadas (además de la producción académica producida allí).

Este capítulo tiene como propósito situar el objeto de estudio de la presente investigación en el marco del desarrollo que ha tenido la mirada sociológica sobre las migraciones internacionales en relación a los antecedentes de investigación existentes sobre el tema de estudio y ofrecer las claves de lectura de la presente tesis, además de dar a conocer los detalles del trabajo de campo desarrollado. Para ello, se presentan los antecedentes de investigación considerados en la literatura especializada como más relevantes o que han tenido mayor difusión y accesibilidad, mediante una breve historización del desarrollo de la perspectiva sociológica y de los estudios migratorios sobre la dimensión política de la migración internacional. Luego se exponen algunas proposiciones y conceptualizaciones teórico-metodológicas que sirvieron para interrogar, problematizar e interpretar la 
relación entre el Estado, la escuela y la migración a lo largo de la tesis. Al final, se presenta el trabajo de campo realizado para llevar a cabo el estudio propuesto.

\section{La sociología, los estudios migratorios y la dimensión sociopolítica de la migración internacional: antecedentes de investigación}

Los representantes de la sociología clásica no se dedicaron al estudio pormenorizado del hecho social que hoy llamamos "migraciones" o de las relaciones sociales que involucran sujetos que nombramos "inmigrantes". Sin embargo, bajo distintos contextos sociohistóricos y coyunturas sociales, sus preocupaciones y reflexiones comprendieron diversas cuestiones relacionadas con los movimientos poblacionales y los extranjeros. En la obra de Karl Marx y Friedrich Engels, las migraciones aparecen contenidas, principalmente, en sus explicaciones acerca de la relación entre la población, en particular la sobrepoblación relativa, y el modo de producción capitalista. Es en La condición de la clase obrera en Inglaterra, El Capital y las Teorías de la plusvalía que se encuentra lo más significativo de su pensamiento sobre el tema poblacional, apoyado en buena medida en el trabajo sociológico sobre la Inglaterra de mediados del siglo diecinueve (Charbit, 2006). Con la publicación de obras como Los trabajadores inmigrantes y la estructura de clases en la Europa occidental (1973) de Castles y Kosack y la posterior producción académica de los sociólogos Alejandro Portes y Saskia Sassen en los años ochenta sobre la migración laboral en el orden internacional ${ }^{4}$, el pensamiento marxista mostró una particular acogida y disfrutó de una notable vitalidad en el campo de los estudios migratorios contemporáneos. Las reflexiones de Max Weber sobre las migraciones se enmarcan en los estudios que realizó por encargo del Verein für Sozialpolitik, publicados entre 1892 y 1894, sobre la cuestión agraria en las provincias prusianas al este del río Elba y su análisis de la participación de los trabajadores temporales de nacionalidad no prusiana que ingresaron a partir de la reapertura parcial de las fronteras cerradas en 1887 por orden del gobierno prusiano. En estas investigaciones, la atención a las migraciones se vincula con los motivos que llevaron a miles de campesinos alemanes a abandonar sus territorios de origen, migrando hacia el Oeste, y con las consecuencias sociales y políticas de la entrada masiva de trabajadores agrícolas foráneos como respuesta a la escasez de mano de obra (Mezzadra, 2005). Para Émile Durkheim, la cuestión de los inmigrantes, en particular polacos, italianos o ucranianos, y de las minorías religiosas, entre otros grupos sociales minoritarios, necesitaban ser comprendidas en relación a la formación del Estado-nación y

4 Entre otras publicaciones de la época de estos autores, véanse Portes y Walton (1981) y Sassen-Koob (1988). 
de la sociedad nacional: el derecho, en tanto mediador o conciencia de la acción del Estado, es asumido como el principal mecanismo de cohesión social, acompañado de otros medios de socialización política como el sistema fiscal, el ejército y la escuela nacional, a la cual le otorga un papel fundamental en la transmisión cultural; por medio de ella, la historia y la cultura de un país alcanzaría a toda la sociedad y no sólo a los nacionales "de origen" (Santamaría, 2002). De las obras clásicas, Digresión sobre el extranjero de Georg Simmel constituye una de las piezas sociológicas célebres donde se tematiza la figura del extranjero a partir de su lugar ambiguo y singular en el espacio social definido como condición social antes que estatuto jurídico. En su aproximación espacializada de las relaciones sociales, las nociones de proximidad y alejamiento determinan la posición del extranjero como parte de un grupo social al cual se integra mediante su exclusión, constituyendo una categoría que abarca otros sujetos sociales habitualmente excluidos como los locos, los pobres o los desviados (Penchaszadeh, 2008). Así, para Simmel, el extranjero es un "tipo social" que no se caracteriza únicamente por su exterioridad, sino que es definido por la instalación de esta exterioridad en un espacio geográfico y social concreto (Santamaría, 1994).

Los primeros estudios sistemáticos destinados específicamente a comprender los desplazamientos humanos tuvieron lugar entre finales del siglo diecinueve y comienzos del veinte. La literatura especializada reconoce generalmente dos importantes antecedentes de investigación empírica, cuyas aproximaciones teórico-metodológicas abrieron distintas vías y modalidades de indagación sociológica. El primero se sitúa en el contexto de la revolución industrial de Inglaterra: es muy probable que el geógrafo Ernst Georg Ravenstein, quien trabajaba en la Royal Geographical Society en Londres, nunca haya imaginado que su artículo "The Laws of Migration", publicado en el Journal of the Statistical Society en 1885 y ampliado en 1889, originaría la llamada teoría moderna de la migración que sentó las bases del modelo explicativo dominante de la primera mitad del siglo veinte: el enfoque push-pull. Sus trabajos, elaborados en el marco del capitalismo en expansión, estuvieron influidos por una terminología e imágenes que remitían al mundo industrial, igualados a componentes mecánicos, y por marcos conceptuales que consideraban a la migración en términos positivos como una contribución a la modernización, la movilidad del trabajo y el crecimiento económico (Simmons, 1991). Posteriormente, las apreciaciones teóricas y las investigaciones empíricas de Ravenstein serían retomadas por algunos representantes de la teoría económica neoclásica en el campo de las migraciones como Michael Todaro y George Borjas. ${ }^{5}$ El segundo antecedente 
se enmarca en la inmigración masiva a los Estados Unidos y se desprende de los aportes de la Escuela de Chicago de principios del siglo veinte: entre 1918 y 1920, el sociólogo norteamericano William Thomas y su colega polaco Florian Znaniecki publicaron un libro que con el tiempo se convirtió en uno de los textos fundadores de la sociología de las migraciones: El campesino polaco en Europa y América. Esta obra pionera sobre la experiencia migratoria, tanto por sus contribuciones teóricas como metodológicas, es resultado de un extenso estudio cualitativo realizado en origen y destino, a través del análisis de correspondencia privada, archivos de la Oficina de Inmigración, diarios de los emigrantes y una historia de vida. ${ }^{6}$

Hacia mediados del siglo veinte, después que las migraciones masivas de ultramar (ya en declinación) empezaron a atraer mayormente la atención de los investigadores sociales, el proceso de institucionalización de los estudios migratorios iniciado en distintas regiones del mundo, en particular en países caracterizados por la llegada masiva de inmigrantes, comenzó lentamente a consolidarse, adquiriendo un claro predominio las teorías económicas de la escuela neoclásica. El discurso académico sobre la migración que se forjó con la constitución de un campo de saber especializado, que diera lugar a las llamadas teorías migratorias o teorías de la migración, nunca contempló al Estado como un actor significativo o sólo lo consideró secundariamente entre los factores políticos estructurales que favorecían o desalentaban las migraciones internacionales. Especialmente aquellas teorías que buscaban explicar las causas y el mantenimiento de los movimientos poblacionales principal o exclusivamente a partir de la intervención de factores de naturaleza económica ${ }^{7}$ desatendieron en buena medida el papel del Estado en la constitución de los movimientos migratorios internacionales. De acuerdo a algunas revisiones de los marcos analíticos empleados para el estudio de las migraciones (Durand y Massey, 2003), las principales teorías explicativas de raigambre económica como la economía neoclásica, la nueva economía de la migración laboral o la de los mercados laborales segmentados, otras teorías sociales como la teoría de los sistemas mundiales y aquellas originadas específicamente para explicar el desarrollo de los flujos migratorios como la teoría de las redes migratorias (también llamada teoría del capital social por algunos estudiosos de la migración próximos a las formulaciones de Coleman y Putnam) y la teoría de la causación acumulativa no consideran al Estado en sus desarrollos o le

6 Para un análisis de esta obra (la versión publicada en castellano) y sus vicisitudes, véase Camas Baena (2001).

7 Es necesario diferenciar aquí entre aquellas teorías que explican los movimientos migratorios en base a motivaciones económicas individuales o colectivas y aquellas que consideran la naturaleza económica de las migraciones en el marco de la historia económica y social de la realidad nacional y mundial. 
otorgan distinto peso según el rol que le asignen en sus interpretaciones acerca de las relaciones sociales y el cambio social.

Durante el largo predominio de las teorías económicas, en particular de la teoría neoclásica (tanto micro como macro), en la explicación de los movimientos migratorios internacionales, Aristide Zolberg advirtió hacia finales de los años setenta la omisión de las fronteras políticas y sus efectos, imprescindibles para el mantenimiento de la desigualdad global, en el estudio de las migraciones internacionales. Indicó que dicha ausencia ya se encontraba en el nacimiento de la teoría moderna de las migraciones, originada a finales del siglo diecinueve con E.G. Ravenstein, uno de sus fundadores, cuando estableció sus famosas "leyes" para explicar los movimientos poblacionales: al no distinguir entre unas y otras terminó equiparando las migraciones internas a las internacionales. Transcurridas varias décadas hasta que se empezara a indagar el papel del Estado y las fronteras en relación a los movimientos migratorios, sostuvo que uno de los más importantes aportes teóricos que tuvo lugar después de mediados del siglo veinte ha sido el reconocimiento de que es precisamente "el control que ejercen los Estados sobre las fronteras lo que define a la migración internacional como un proceso social distintivo" (Zolberg, 1989: 405).

Este olvido histórico-un "olvido que está lleno de memoria", como dice el escritor Mario Benedetti-que durante décadas primó en el estudio de los movimientos migratorios se explica, en parte, debido a que la existencia del Estado fue tomada como algo dado o natural. No sólo las investigaciones sobre las migraciones internacionales, sino también aquellas dirigidas a escudriñar específicamente las políticas migratorias. Como señala Torpey, habiendo dado por hecho la presencia de los Estados, no se prestó suficiente atención a la necesidad territorial de los Estados de distinguir entre diferentes poblaciones ni a las formas a través de las cuales las actividades de los Estados participan de la producción de los movimientos de población. De esta manera, los estudios de las políticas migratorias, al dar por sentado el papel del Estado más que ignorarlo, pasaron por alto el modo en que la regulación de los movimientos de población contribuye a la formación de la estatalidad (Torpey, 2000). Ahora bien, que estos trabajos académicos no hayan contemplado la presencia estatal en sus análisis, no significa que el Estado y su accionar hayan estado ausentes. Por el contrario, el isomorfismo entre las categorías del pensamiento de Estado y las categorías analíticas construidas o asumidas, implícita o explícitamente, en estas investigaciones es una muestra concreta de su efectiva -en su doble sentido, tanto "real" como "con efecto"- existencia. 
Fueron las corrientes poblacionales de la llamada nueva inmigración en los países capitalistas centrales, cuyo comienzo suele relacionarse con la crisis del petróleo de 1973, las que motivaron una nueva fase de estudios sobre las migraciones internacionales. ${ }^{8}$ En Estados Unidos, bajo la duradera influencia de la Escuela de Sociología de Chicago, la perspectiva de la asimilación fue el paradigma sociológico dominante hasta que entró en crisis con el resurgimiento de la cuestión étnica en los años sesenta y fuera cuestionada con el auge que tuvo el estudio de la migración a comienzos de la década del ochenta (Schmitter Heisler, 2008[2000]). ${ }^{9}$ En Europa, la migración internacional comenzó a ser estudiada, primeramente, en aquellos países que recibieron inmigrantes por los procesos de descolonización y reclutamiento laboral. En Francia se originaron algunas investigaciones aisladas sobre la migración internacional en la década del cincuenta y a partir de los setenta, después que estuviera casi completamente ausente durante los debates sobre la cuestión social en los sesenta (Rea y Tripier, 2003), comenzó a ser tratada más sistemáticamente por una generación de jóvenes investigadores, entre los cuales se destacó el franco-argelino Abdelmalek Sayad. Su trabajo es considerado actualmente uno de los más influyentes en la formación de la sociología de la inmigración (como se la denomina en Francia). ${ }^{10}$ En Gran Bretaña, la literatura científica sobre migraciones estuvo centrada en las relaciones raciales y básicamente se constituyó alrededor de tres perspectivas: la economía política del racismo, la sociología de las relaciones étnicas y un cuerpo ecléctico de bibliografía que podría ser definido como una sociología de la migración, dominada por el enfoque estructuralista (Phizacklea, 1984). En aquellos países que, como España, históricamente fueron expulsores de población antes de que comenzaran a recibir inmigrantes de países del Sur con su incorporación a la Unión

\footnotetext{
8 Algunos autores atribuyen el resurgimiento del estudio de la migración internacional al creciente número de movimientos migratorios y a su diversificación a escala mundial, a la trascendencia que aquélla ha adquirido en un mundo de economía globalizada, caracterizado por el desplazamiento de los factores de producción, incluido el traslado de personas (Martiné et al., 2001). Este argumento es discutido por quienes sostienen que actualmente la migración internacional está excluida del nuevo proceso de globalización (Tapinos y Delaunay, 2001).

9 Véase Schmitter Heisler (2008 [2000]) para una revisión del desarrollo de la sociología de las migraciones en Estados Unidos. Entre los primeros escritos que buscaban sistematizar las distintas aproximaciones sociológicas a las migraciones internacionales en Estados Unidos se encuentra el artículo de Andrew M. Greeley (1964) titulado "American Sociology and the Study of Ethnic Immigrant Groups" (publicado y escrito especialmente para el segundo número del primer año de la revista conocida hoy en día como International Migration Review (en aquél entonces se llamaba International Migration Digest). Pocos años más tarde, J.J. Mangalam y Harry K. Schwarzweller publican "General Theory in the Study of Migration: Current Needs and Difficulties" (1968) y "Some Theoretical Guidelines Toward a Sociology of Migration" (1970). Véase García Borrego (2006) para una revisión bibliografía sobre la "segunda generación" de inmigrantes en Estados Unidos donde trata diversos aspectos de la perspectiva de la asimilación.

10 Véase Sayad (1984) para un análisis del desarrollo de la investigación sobre migraciones en Francia después de los años sesenta.
} 
Europea, los estudios sobre los movimientos migratorios internacionales se desarrollaron de manera creciente alrededor de la llamada inmigración extracomunitaria o inmigración no comunitaria, especialmente a partir de los años noventa. ${ }^{11}$

El interés por las políticas migratorias entre los teóricos norteamericanos y europeos, como señala López Sala (2005a), cobró mayor notoriedad en la segunda mitad de los años noventa. A lo largo de esta década, las discusiones de orientación sociológica se centraron en el análisis del control de flujos, los vínculos entre migraciones, política exterior y política doméstica, y la influencia de las migraciones en la cohesión social, la identidad política y la ciudadanía. ${ }^{12}$ La explicación de las diversas políticas regulatorias y su vinculación con factores económicos, políticos y sociales resultó de particular interés para los estudiosos de las migraciones. Hacia finales de los noventa, el rol del Estado y el sistema interestatal se consagraron entre los tópicos con mayor potencial teórico en el

11 La convergencia entre la tendencia a la especialización en las ciencias sociales y la creciente legitimidad que irá obteniendo la migración como objeto de estudio favorecerá la conformación de instituciones especializadas en la materia, posibilitando la emergencia de un nuevo campo de investigación constituido mediante aportes disciplinares diversos como la demografía, la economía, la historia, la geografía, la sociología, la antropología y la ciencia política: los estudios migratorios. Es preciso señalar que el peso de cada disciplina en la conformación de este campo de estudio varía de acuerdo a cada contexto nacional. En los años sesenta se formaron en Estados Unidos los primeros centros e institutos de investigación especializados en las migraciones internacionales, como el Center for Migration Studies de Nueva York, y varios años más tarde, acompañando el cambio en la composición de la migración internacional, se generalizaron en el ámbito universitario estadunidense. En Europa, en cambio, la creación de unidades académicas especializadas tuvo su auge hacia finales de los ochenta y comienzos de los noventa, cuando se consolida la migración Sur-Norte en esta región. Con la formación de estas instituciones aparecen las primeras revistas científicas especializadas en el tema de las migraciones internacionales. En los años sesenta se comienzan a publicar la revista europea International Migration editada por el Research Group for European Migration Problems (como continuación de Migration (ICEM) y REMP-Bulletin) y la norteamericana International Migration Digest, que cuatro años más tarde pasará a llamarse International Migration Review, publicada por el Center for Migration Studies de Nueva York. En la década del ochenta surgen en Europa otras publicaciones especializadas: en Gran Bretaña, el Journal of Ethnic and Migration Studies (antes New Community) y el Journal of Ethnic and Racial Studies y en Francia (1985) la Revue Européenne des Migrations Internationales (REMI) publicada por el MIGRINTER. También las distintas asociaciones de profesionales de carácter nacional, regional o internacional comienzan a dedicar a la temática migratoria su propio espacio. Así, por ejemplo, se establece en 1972 el comité de investigación sobre Sociología de las Migraciones (Sociology of Migration) de la International Sociological Association (ISA). También durante los años noventa (1991-1997) se constituyó el Commitee on South-North Migration de la International Union for the Scientific Study of Population (IUSSP), presidido por Douglas S. Massey e integrado por Joaquín Arango, Graeme Hugo, Ali Kouaouci, Adela Pellegrino y J. Edward Taylor.

12 Véase Meyers (2000) para una discusión acerca de los distintos enfoques teóricos y su influencia sobre las pespectivas que asume la política migratoria: marxismo, realismo, liberalismo, identidad nacional, políticas domésticas e institucionalismo. Hollifield (1992), por su parte, analiza la visión de las migraciones internacionales que ofrecen cuatro teorías de las relaciones internacionales: el realismo, el marxismo-leninismo, el liberalismo y la estabilidad hegemónica. 
campo de los estudios migratorios (Portes, 1997). En conjunto, frente a la ausencia del Estado en un amplio abanico de investigaciones sobre la temática migratoria, distintas revisiones teóricas realizadas durante esta década y en años posteriores (Portes, 1997, 2004; Arango, 2000; Durand y Massey, 2003; Hollifield, 2004; Calderón Chelius, 2006) enfatizaron la necesidad de considerar la dimensión política en los estudios de las migraciones internacionales y de analizar el papel del Estado (algunos de ellos también han señalado más recientemente a los organismos supraestatales ${ }^{13}$ ) para una adecuada comprensión de los fenómenos migratorios y los procesos sociales adyacentes a ellos. En pocas palabras, hoy en día el Estado es un actor ineludible en el análisis de las migraciones, cuya presencia debiera evitar ser sobredimensionada o subestimada (Grimson y GodoyAnativia, 2003). ${ }^{14}$

En estos años, la teoría transnacional aplicada al campo de los estudios migratorios -el transnacionalismo político en particular- contribuyó a destacar, por definición, la trascendencia del Estado-nación en la conformación de los movimientos y contextos migratorios en general y en la constitución de las comunidades transnacionales en particular, así como su transformación a partir de las actividades transnacionales de los migrantes (Glick-Schiller, Basch y Szanton-Blanc, 1992; Basch, Glick-Schiller y SzantonBlanc, 1994; Levitt y Glick-Schiller, 2006).15 En particular, el modo en que las políticas internacionales de los Estados nacionales afectan la forma y el alcance de las iniciativas transnacionales de los inmigrantes se convirtió en una cuestión analítica de importancia en el campo de los estudios migratorios (Portes, 2001). En muchas de estas investigaciones, el Estado aparece como objeto de estudio cuando se trata de indagar la organización y definición de los modos de incorporación de los migrantes en la sociedad de destino/recepción, ${ }^{16}$ aunque sin perder de vista que el transnacionalismo como

13 En el año 2003, una conferencia internacional realizada en los Estados Unidos, patrocinada por el Centro de Migraciones y Desarrollo de la Universidad de Princeton y el Consejo de Ciencias Sociales de EEUU, incluía al Estado y las entidades supraestatales entre las principales preocupaciones académicas sobre la temática migratoria (Portes y De Wind, 2006).

14 Así lo expresan Grimson y Godoy-Anativia (2003:514): "Si el papel del Estado se exagera, se corre el riesgo de perder de vista el campo de interrelaciones en el cual está inserto. Pero si el papel del Estado se menosprecia, el resultado es, generalmente, un tipo de culturalismo extremo que imagina los mundos como si los poderes y las instituciones no tuvieran que ver con ellos".

15 Para un relato intimista sobre los orígenes de la reflexión transnacional en el terreno de las migraciones, , narrado por algunas de sus protagonistas, véase Feldman-Bianco y Glick-Schiller (2011).

16 Una las significaciones más importantes que se le atribuye al transnacionalismo es su capacidad para modificar el proceso de incorporación de los migrantes de la llamada "primera generación” y su descendencia en la sociedad receptora (Portes, 2001:478). 
fenómeno político-ideológico asociado a la globalización (Ribeiro, 1996) también está vinculado con otros actores que desarrollan actividades políticas de carácter transfronterizo como las organizaciones no gubernamentales internacionales, entre ellos las organizaciones de movimientos sociales transnacionales (la mayoría de ellas dedicadas a temas de derechos humanos), y las llamadas diásporas étnicas (Vertovec, 1999).

Incorporado el papel del Estado y las fronteras en las explicaciones sobre las migraciones, buena parte de los esfuerzos de la sociología han estado dirigidos a describir e interpretar, desde una perspectiva comparada, distintos modelos de respuesta estatal ante la inmigración y a analizar sus efectos en la ciudadanía y en los derechos de corte liberal (López Sala, 2005a). En el contexto europeo, las intervenciones estatales destinadas a los trabajadores inmigrantes, que pasaron a ser conceptualizadas en términos de integración a partir de los años ochenta (Favell, 2001a; Gil Araujo, 2010), motivaron un vasto conjunto de estudios de caso e investigaciones comparadas sobre las llamadas políticas de integración. En los Estados Unidos, por su parte, existe una extensa literatura sobre las narrativas de incorporación de los inmigrantes, entre los cuales se destacan los estudios históricos de Aristide Zolberg. ${ }^{17}$ Por otro lado, a excepción de ciertas investigaciones provenientes del campo de la historia, el análisis de las políticas de migraciones internacionales, en particular el sociológico, realizado en instituciones y centros académicos de los países centrales se ha focalizado en general en las experiencias nacionales de países tradicionalmente receptores de población del Norte (en su sentido político-económico, no sólo geográfico) como los Estados Unidos, Canadá y Australia, omitiendo países del Sur que registraron los más altos niveles de inmigración a nivel mundial como la Argentina, y en aquellos países europeos que recibieron diversas corrientes migratorias como producto de los procesos de descolonización y reclutamiento laboral. ${ }^{18}$ Más recientemente, ya en el marco de la Unión Europea, las políticas de migración de algunos países europeos como España, que hacia finales del siglo veinte comenzaron a recibir inmigración proveniente de África y América Latina, han motivado una significativa cantidad de investigaciones. En contraste, como señalé anteriormente, las

\footnotetext{
17 Para revisión histórica de la literatura sociológica relacionada con la incorporación de los hijos de inmigrantes en los Estados Unidos, véase García Borrego (2006).

18 Aquí también cabe señalar que, en diversas ocasiones, la literatura producida en los países centrales sobre las migraciones en contextos regionales periféricos suele omitir o tergiversar de manera significativa la realidad migratoria que presentan, además de desconocer la producción académica que allí tiene lugar. Éste es el caso, por ejemplo, del trabajo de Castles y Miller (2004) en relación a la región latinoamericana. Su conocido libro La era de la migración adolece de importantes imprecisiones y las referencias bibliográficas consideradas no son completas ni pertinentes (Martínez Pizarro, 2005).
} 
políticas de los Estados de origen sólo recientemente han empezado a ser mayormente atendidas.

En América Latina, por su parte, la fuerte crítica de los años sesenta a los enfoques teóricos y metodológicos dominantes en ciencias sociales como la teoría de la modernización y el funcionalismo, articulada desde visiones alternativas como la teoría de la dependencia y el enfoque histórico estructural, también alcanzó a los estudios especializados en la migración. Además de la teoría de la modernización y el enfoque histórico-estructural, que monopolizaron la discusión académica durante los sesenta y setenta, otras aproximaciones al fenómeno migratorio que más adelante adquirieron trascendencia en los países latinoamericanos fueron la perspectiva de la unidad doméstica, la sociología económica y la teoría de redes (cuyo desarrollo en el campo de la historia estuvo vinculado con el enfoque de las cadenas migratorias). ${ }^{19} \mathrm{El}$ interés académico por las migraciones se originó ligado a las indagaciones en el campo de las ciencias sociales sobre el desarrollo y la discusión estuvo vertebrada por la teoría de la modernización de raigambre funcionalista y el enfoque histórico-estructural de inspiración marxista. ${ }^{20}$ Particularmente durante los sesenta y setenta, en un contexto de significativas transformaciones económicas que provocaron importantes procesos de industrialización y urbanización, el estudio de los movimientos poblacionales en la región estuvo centrado en la migración interna ${ }^{21}$, especialmente en los aspectos demográficos,

19 Para una revisión de estas perspectivas teóricas, véanse Ariza (2000) y Herrera Carassou (2006). Por su parte, Kearney (1986) discute la perspectiva de la modernización, de la dependencia y de la articulación a partir de una lectura de la relación entre migración y desarrollo en la literatura antropológica.

20 Algunos organismos regionales como la CEPAL y otras instituciones como CLACSO y PISPAL tuvieron un rol protagónico en el desarrollo e impulso de la investigación social en general y aquella dedicada a las migraciones en particular. Diversos autores destacan el papel relevante que tuvo la CEPAL, creada en 1948, en el impulso y desarrollo de las ciencias sociales en la región latinoamericana (Devés Valdés, 2003; Blanco, 2004). En un primer momento, las migraciones fueron contempladas en el marco de las discusiones sobre el desarrollo económico; posteriormente, a partir de la fundación del Centro Latinoamericano de Demografía (CELADE) en 1957, se iniciaron las primeras investigaciones cuantitativas de alcance regional sobre migraciones internacionales. Desde finales de los años noventa, la CEPAL/CELADE produce una serie de documentos referidos a las políticas sobre migraciones internacionales que tienen lugar en la región.

21 En el marco de las actividades que impulsaba CLACSO, un año después de su creación, comenzó a funcionar en 1968 la Comisión de Población y Desarrollo. Uno de los tres grupos de trabajo que se formaron en el seno de esta comisión fue el de Migraciones Internas. Fue creado en 1971 y estuvo integrado por Raúl Benítez Zenteno, Susana Lerner, Humberto Muñoz, Orlandina de Oliveira, Paul Singer y Claudio Stern. Este grupo de trabajo, bajo un enfoque histórico-estructural, se ocupó primordialmente de los aspectos sociológicos de las migraciones internas y mantuvo sus discusiones alrededor de temas como los siguientes: consideraciones teórico-metodológicas en el estudio de las migraciones; estudios histórico-comparativos acerca del proceso de desarrollo y sus relaciones con las migraciones internas; estudios sobre la situación agraria y su vinculación con los desplazamientos de las poblaciones; estudios 
económicos y sociológicos de la migración rural-urbana. ${ }^{22}$ Algunas de las revisiones críticas de la época sobre la literatura relacionada con las migraciones internas sostenían que en aquél momento todavía no se habían desarrollado planteamientos teóricos integrados, sino más bien esquemas teórico-analíticos sectoriales y que en su mayoría atendían los aspectos individuales antes que los estructurales (Muñoz y Oliveira, 1972). En aquellos tiempos, el análisis de las migraciones internas estaba fundamentalmente orientado a conocer sus causas o determinantes (factores individuales y estructurales), sus características (tipos de migración, volumen y distancia, selectividad y contexto social de la migración) y sus consecuencias o efectos (en el lugar de origen y de destino). Algunas investigaciones también establecieron comparaciones entre los migrantes y los nativos en el lugar de destino (diferencias socioeconómicas, movilidad social y marginalidad). En este contexto comenzó a desarrollarse, además del historiográfico y el antropológico, uno de los enfoques disciplinares que durante décadas fue dominante en la región, el sociodemográfico (Herrera Lima, 2000). ${ }^{23}$ La década del ochenta en general representó, como indica Canales (2006), un retroceso para los estudios sobre migración y para las ciencias sociales en su conjunto debido a la interrupción y el estancamiento que sufrió el debate de las décadas anteriores y la desarticulación que se produjo entre las redes y grupos de trabajo que sustentaban el pensamiento crítico en la región. A pesar de ello, sobrevivieron diversos espacios de discusión. En esta década, los flujos de población entre algunos países de la región empezaron a ser considerados en el marco de las llamadas "migraciones temporales". ${ }^{24}$

Entre las principales líneas de investigación que identifica Calderón Chelius (2006) relacionadas con la dimensión política de las migraciones internacionales, en América

referidos al desarrollo urbano-regional y movimientos geográficos de la población; estudios que vinculan las políticas de redistribución de la población y las políticas de desarrollo (Muñoz y Oliveira, 1972).

22 Según Muñoz y Oliveira (1972), los estudios sobre la migración interna en la región latinoamericana se generalizaron durante la década de los sesenta.

23 Véase Herrera Lima (2000) para una visión general sobre los enfoques disciplinares dominantes en los "estudios sobre migración en América Latina".

24 En el año 1984 se realizó en Quito el Seminario sobre migraciones temporales en América Latina, organizado por el Programa de Investigaciones Sociales sobre Población en América Latina (PISPAL), el Centro de Estudios de Población (CENEP) y el Centro de Investigaciones CIUDAD con la colaboración de la Unión Geográfica Internacional y la Comisión de Población y Desarrollo de CLACSO y el apoyo financiero del propio PISPAL, de la Fundación Interamericana de los Estados Unidos y del Centro Internacional de Investigaciones para el Desarrollo de Canadá. Durante estos años también aparecen en la región las primeras publicaciones periódicas especializadas en el tema de las migraciones: la Revista del CIM sobre Migraciones en América Latina en 1982 (Herrera Lima, 2000) y la revista Estudios Migratorios Latinoamericanos, editada por el Centro de Estudios Migratorios Latinoamericanos (CEMLA), en 1985. 
Latina se ha priorizado el estudio de las políticas migratorias o de la participación política de los migrantes (la mayoría de estas investigaciones indagan las prácticas políticas de los emigrantes en los lugares de destino y/u origen) y el transnacionalismo político. ${ }^{25}$ En los últimos años han surgido en América del Sur diversos trabajos referidos a las políticas de los Estados de la región andina destinadas a regular las migraciones internacionales, en particular los casos ecuatoriano (Eguiguren, 2011; Herrera, 2011; Margheritis, 2011) y colombiano (Guarnizo, 2006; Ardila, 2006; Clavijo, 2011). En el caso boliviano, el estudio de las políticas estatales en materia de migraciones internacionales no ha tenido mayor desarrollo. ${ }^{26}$ El importante crecimiento y la notable visibilidad social que obtuvieron los procesos de emigración en estos países, junto a las nacientes preocupaciones gubernamentales respecto a ella, pareciera haber contribuido a que la mayoría de estos estudios recientes, situados en el campo de la sociología, se haya centrado preferentemente en las respuestas de los Estados de origen ante los ciudadanos en el exterior. Este particular interés se ha plasmado en algunos artículos sobre el voto en o desde el exterior (Eguiguren y Araujo, 2009; Domenech e Hinojosa Gordonava, 2009; Canelo et al., 2010; Emmerich y Pries, 2011). El aspecto novedoso de todos estos trabajos, como sugiere Eguiguren (2011), radica en que contemplan la perspectiva de los Estados de origen, a diferencia de los numerosos análisis de prácticas estatales que únicamente consideran al Estado receptor. Las investigaciones llevadas adelante sobre los demás casos nacionales de la región sudamericana, en particular Brasil, contemplan la relación entre el Estado y la migración desde distintos ángulos, destacándose aquellos estudios, mayormente históricos y/o etnográficos, que privilegian el análisis de las prácticas y discursos estatales desarrollados en virtud de las diferentes corrientes de inmigración y

25 Calderón Chelius (2006) identifica como líneas de investigación sobre la dimensión política de la migración las siguientes: la participación laboral y organización sindical; el activismo de grupos étnicos o lobby étnico; el ejercicio electoral y la naturalización; las políticas migratorias; la socialización política; la organización comunitaria; y el transnacionalismo político.

26 Cierto interés existente en el ámbito de las ciencias sociales y de las organizaciones de la sociedad civil acerca del tema no ha logrado plasmarse en investigaciones sistemáticas. Sólo aparecen tratados algunos aspectos de la política migratoria boliviana en informes regionales de la OIT y de la Federación Iberoamericana de Ombudsman (FIO). El informe de la OIT (Torales et al., 2003) describe el panorama general de las migraciones laborales en la Comunidad Andina y las medidas políticas adoptadas por los países miembros en materia migratoria, mientras que el informe de la FIO, documento base para el Informe de Derechos Humanos en Bolivia, compendia las principales disposiciones legales que se encuentran vigentes en materia migratoria y de derechos humanos. Más recientemente, un informe preparado por De la Torre (2011) para la OIM da cuenta de la etapa actual de diseño y elaboración de nuevos lineamientos en materia de política migratoria en Bolivia. 
emigración, así como la vinculación con la llamada "diáspora" (Vainer, 1995; FeldmanBianco, 2001, 2007, 2011; Machado, 2004; Etcheverry, 2007).27

En el caso argentino, en particular, el análisis de la dimensión sociopolítica de las migraciones se ha centrado fundamentalmente en las políticas migratorias y el asociacionismo inmigrante. El estudio referido al Estado argentino y su relación con la inmigración, desarrollado casi exclusivamente en el propio país, ha privilegiado como objeto de análisis las políticas migratorias, en especial la legislación nacional. ${ }^{28}$ Es factible que dicha tendencia se haya desarrollado en el campo académico argentino debido a la temprana experiencia y larga trayectoria del Estado nacional en materia migratoria. Por otra parte, la participación política de los inmigrantes en ámbitos no gubernamentales como las asociaciones de inmigrantes o los sindicatos durante la inmigración de masas fue uno de los temas que más interés suscitó entre los historiadores, luego retomado por sociólogos, antropólogos y politólogos con la formación de innumerables asociaciones de inmigrantes de países limítrofes durante los años noventa hasta la actualidad. ${ }^{29}$

En la Argentina, la inmigración como objeto de reflexión se remonta a los orígenes de las ciencias sociales en el país, cuyo ingreso y adopción tuvo lugar a finales del siglo diecinueve. ${ }^{30}$ Sin embargo, las indagaciones más sistemáticas se iniciaron hacia finales de la década del cincuenta. En un período histórico marcado por la inmigración europea, apareció entre las primeras preocupaciones de los intelectuales que conformaban la élite ilustrada de la década de 1880 como de aquellos que tuvieron a su cargo la enseñanza de

\footnotetext{
27 De manera reciente, también aparecido algunos trabajos sobre la política migratoria en Chile (Jensen Solivellas, 2009; Stefoni, 2011) y en Uruguay (Taks, 2006, 2010).

28 Excepcionalmente, algunos estudios han sido desarrollados por investigadores radicados en los Estados Unidos (Cook-Martin, 2006, 2008; Albarracín, 2004).

29 Es conocida la importancia de la formación y desarrollo de las asociaciones de inmigrantes en los procesos de inserción de los inmigrantes en la sociedad receptora. Actualmente es frecuente encontrar entre los principales objetivos de las asociaciones de inmigrantes de países limítrofes aspectos tendientes a la "integración" en la sociedad de destino/recepción. Entre las poblaciones de migrantes en la Argentina se destaca la colectividad boliviana por el grado de institucionalización social y la permanencia y estabilidad que han adquirido los vínculos entre los residentes y la relación con los lugares de origen (Benencia y Karasik, 1995). Como han mostrado algunos estudios realizados en diferentes ciudades de la Argentina, las iniciativas y acciones de las asociaciones bolivianas muestran una preeminencia de la dimensión "cultural" sobre la "social", lo cual limitaría la atención de determinadas necesidades e intereses de la colectividad (Caggiano, 2005; Ortiz, 2005).

30 Según Altamirano, “(e)n la Argentina, como en el conjunto de América Latina, los modos de descripción e interpretación del mundo social que llamamos sociológicos no fueron el producto de una reflexión endógena, y no podría hablarse del surgimiento, sino mas bien del ingreso, la adopción y, eventualmente, la adaptación de esas formas todavía nuevas del discurso sobre la vida social" (Altamirano, 2004:31).
} 
las ciencias sociales y la sociología en las tres instituciones universitarias ya existentes a comienzos del siglo veinte (Córdoba, Buenos Aires y La Plata). También en otros espacios de la incipiente vida académica de estos años se constata el interés que despertaban las migraciones internacionales, siempre pensadas en términos de "inmigración". ${ }^{31}$ Aquellas primeras incursiones alrededor de la migración europea recién se cristalizarían en un programa sistemático de investigación hacia finales de la década del cincuenta cuando el sociólogo italiano Gino Germani y el historiador argentino José Luis Romero impulsaron un proyecto sobre los efectos de la inmigración masiva en la Argentina, asentado en la Facultad de Filosofía y Letras de la Universidad de Buenos Aires (Devoto, 1992b). ${ }^{32}$ Este hecho coincide con la institucionalización de la sociología como disciplina científica en la Argentina o al menos con la ruptura que se produce respecto a la etapa anterior, dividiendo el campo entre la sociología de cátedra y la sociología científica, a partir de la creación en 1957 del Departamento y la Carrera de Sociología en la Facultad de Filosofía y Letras de la Universidad de Buenos Aires (Blanco, 2004). ${ }^{33}$ Según Devoto, el escaso interés que suscitó el estudio de las migraciones hasta mediados del siglo veinte, al menos entre los historiadores, tanto dentro como fuera del país, se debe a que los movimientos migratorios no resultaban de utilidad explicativa, ya que, acostumbrados a análisis restringidos al ámbito del Estado-nación, se trataba de un fenómeno desarrollado en ámbitos espaciales supranacionales y de un colectivo -los migrantes- demasiado heterogéneo para atribuirle un rol específico en la historia. ${ }^{34} \mathrm{~A}$ ello se sumaba la dispersión geográfica de las fuentes y sus límites para estudiar grupos sociales en movimiento y la interdisciplinariedad requerida para su argumentación (Devoto, 1992b). Durante esta década y los años subsiguientes, el estudio de las migraciones se desarrolló en el marco de una historia social circunscripta al ámbito nacional (Marquiegui, 2005). La reflexión sociológica de esta época en torno al hecho migratorio no llevó a conformar en el ámbito académico argentino una especialidad disciplinar como la sociología de las migraciones. Más bien, resultó el antecedente más importante para la conformación de un

\footnotetext{
31 Altamirano (2004) señala que, hacia finales del siglo diecinueve, el hecho inmigratorio estaba incluido dentro de los tres temas propuestos por la Facultad de Filosofía y Letras de la Universidad de Buenos Aires para la realización de las tesis de doctorado en el área de sociología. Asimismo, en el Congreso Americano de Ciencias Sociales, celebrado en la Argentina en 1916, la sección de sociología contenía aspectos relativos a la inmigración y la raza, ligados mayormente al medio físico y social.

32 Véase Blanco (2009) sobre las trayectorias intelectuales y los proyectos académicos de Gino Germani y José Luis Romero acerca de la inmigración masiva en la Argentina moderna.

33 Para un minucioso análisis sobre la institucionalización de la sociología en la Argentina y el protagonismo que tuvo Gino Germani en este proceso, véase Blanco (2004; 2006).

34 Sobre los estudios dedicados a la inmigración en la historiografía argentina, véanse Armus (1986), Sábato (1991), Devoto (1992) y Devoto y Otero (2003).
} 
campo científico multidisciplinar que más adelante, con la creación de instituciones especializadas en el tema a partir de los años ochenta, quedará instituido con el calificativo de "estudios migratorios". Específicamente, sentará las bases de lo que llegará a conformarse más adelante como la primera generación de estudios migratorios en la Argentina: un conjunto de estudios sociodemográficos o económicos que comparten el propósito de describir, generalmente en términos cuantitativos, el volumen, el desarrollo y las características de los flujos migratorios o explicar sus causas y consecuencias (generalmente en el plano económico).

Hasta la década del ochenta, a excepción de algunos trabajos aislados, el estudio de los movimientos migratorios internacionales estuvo centrado en las corrientes ultramarinas en general y algunas europeas en particular (italiana y española especialmente). Es recién con la visibilidad social y política que adquirió la nueva configuración de la inmigración internacional en la Argentina, a partir de la llegada y presencia de los trabajadores inmigrantes de países limítrofes en los grandes conglomerados urbanos, que la migración regional sudamericana (o intrarregional) comenzó a ocupar un lugar más preponderante en las agendas de investigación. Fueron principalmente las corrientes migratorias desde Paraguay, Chile y Bolivia las que motivaron su estudio. En la década de los noventa se inició una fase de consolidación del campo de los estudios migratorios con la introducción de nuevos enfoques disciplinares y aproximaciones teórico-metodológicas junto al desarrollo de nuevas temáticas de investigación sobre el fenómeno migratorio en diversas áreas geográficas del país. La emergencia de investigaciones sobre el tema migratorio en distintas regiones del interior de la Argentina, cuya mayor concentración se localiza en Buenos Aires, contribuyó a que paulatinamente se consolidara esta nueva etapa. Durante este decenio, bajo un contexto marcado por el auge de la ideología neoliberal y una mayor visibilidad social y política de la inmigración de países limítrofes, se conforma una segunda generación de estudios migratorios, cuyos antecedentes se retrotraen inmediatamente a la década anterior. Los trabajos que podrían reunirse bajo esta categoría, guiados por nuevas preocupaciones teóricas y enfoques metodológicos, se han ocupado de los procesos migratorios contemporáneos en el país, las estrategias de los migrantes recientes y las relaciones y representaciones sociales que se producen y modifican con su presencia, considerando consecuentemente el punto de vista de los actores sociales involucrados. Aunque la mayor parte de los trabajos que conforman esta generación de estudios se originaron en el ámbito de disciplinas que tradicionalmente se han ocupado de las relaciones sociales y culturales en contextos urbanos o rurales como la sociología y la antropología, también se vio robustecida, en correspondencia con el carácter 
multidisciplinar de este campo de estudio, por los aportes de trabajos provenientes de algunas de sus especializaciones como la sociología o la antropología de la educación y de otras áreas de las ciencias sociales y humanidades como comunicación social, ciencia política e historia.

Como en otros países de la región, entre las cuestiones que mayores investigaciones suscitaron, especialmente a partir de mediados de los noventa, prevaleció el tema de la identidad e identificaciones sociales, ligadas particularmente a las estrategias socioculturales de los migrantes. La tensión entre la diversidad cultural y la desigualdad social fue uno de los ejes analíticos que priorizaron muchos de los estudios emprendidos. Las nuevas preocupaciones temáticas motivaron estudios específicos, generalmente sociológicos o antropológicos de carácter cualitativo, en los cuales las migraciones fueron problematizadas en relación a la etnicidad, las fronteras, la nación, las organizaciones de inmigrantes, los medios de comunicación, el racismo, el género, la discriminación, el mercado de trabajo, las políticas públicas y la ciudadanía. ${ }^{35}$ Entre la última década del siglo veinte y comienzos del presente decenio, fue notable el crecimiento que experimentó la producción académica dedicada a la inmigración boliviana. Fue en este período que se desarrollaron diversas investigaciones sobre los aspectos identitarios y culturales de la inmigración boliviana en contextos urbanos de la Argentina como Buenos Aires (Grimson, 1999) y Córdoba (Giorgis, 1998, 2000) y se retomó el análisis de los mecanismos y procesos de discriminación y exclusión social referidos en esta oportunidad a los migrantes latinoamericanos en el país (Oteiza y Aruj, 1997; Casaravilla, 1999; Margulis et al. 1999; Neufeld y Thisted, 1999). Asimismo, una gran parte de las investigaciones desarrolladas continuaron siendo de carácter sociodemográfico, ofreciendo una descripción cuantitativa de los flujos migratorios limítrofes (incluida la corriente desde Bolivia) a la Argentina o a alguna región o localidad específica y una caracterización de los migrantes (Rey Balmaceda, De Marco y Sassone, 1994; INDEC, 1996, 1997; Cacopardo y López, 1997; Almandoz, 1997; Domenach y Celton, 1998; Meichtry y Beck, 1999; Lattes, Comelatto y Levit, 2003; Bologna, 2007). En ciertos casos, estos análisis han abordado alguna dimensión en particular de este fenómeno social como la participación de los "migrantes limítrofes" en el mercado de trabajo (Maguid, 1995, 1997; Lattes y Bertoncello, 1997; Sala, 2000; Cerrutti y Parrado, 2002). Entre los estudios sociológicos cualitativos de

\footnotetext{
35 Hacia finales de los noventa, Benencia (1999) identificaba cinco áreas temáticas de interés en el campo de los estudios migratorios de la Argentina: a) el acceso de los inmigrantes a distintos espacios geográficos; b) las nuevas formas de inserción de los migrantes limítrofes en los mercados de trabajo; c) la existencia de procesos de movilidad social de los migrantes; d) el fenómeno de la diversidad cultural y la discriminación; y e) las estrategias migratorias (Benencia, 1999:431).
} 
esta etapa se destacan los trabajos de Roberto Benencia orientados a comprender el proceso de inserción y movilidad social de las familias bolivianas en el mercado de trabajo y en particular en la horticultura de la periferia bonaerense (Benencia, 1992; Benencia y Karasik, 1994, 1995; Benencia y Gazzotti, 1995). Posteriormente abordó esta problemática junto a otras preocupaciones temáticas y aproximaciones teóricas en diversas regiones del país (Karasik y Benencia, 1999; Benencia, 2000, 2004, 2006; Benencia y Geymonat, 2005). Mientras tanto, en Bolivia, Alfonso Hinojosa Gordonava, Liz Pérez y Guido Cortéz realizaron una investigación sobre las estrategias migratorias de campesinos del valle central tarijeño en el norte argentino (Hinojosa Gordonava et al., 1999, 2000); Geneviève Cortes, por su parte, desarrolló un extenso trabajo sobre las prácticas migratorias de los campesinos de los valles interandinos de Cochabamba al interior y exterior de Bolivia (Cortes, 2004a, 2004b) y Eróstegui (1997) analizó las implicancias de "ser boliviano en Jujuy". ${ }^{36}$ Desde una perspectiva antropológica, Silva (1996) estudió en Brasil la llegada e inserción de los inmigrantes bolivianos en San Pablo.

36 El estudio de las migraciones internacionales en Bolivia y Argentina tiene un desarrollo comparativamente diferente: mientras que en Bolivia las investigaciones se originaron y ampararon en los procesos de emigración hacia los países vecinos, en la Argentina las indagaciones empíricas se iniciaron relacionadas con las corrientes de inmigración de Europa y se consolidaron con las de los países limítrofes. Más aún: la investigación sobre las migraciones internacionales en Bolivia se erige sobre la emigración hacia la Argentina, cuando en la Argentina se robustece con la inmigración boliviana, entre otros movimientos migratorios transfronterizos de importancia (como Paraguay y Chile). Estas diferencias, a su vez, se traducen en un desarrollo desigual: la mayor producción académica referida a la migración boliviana tiene lugar en la Argentina, el país constituido históricamente como principal destino. En este sentido, la división intelectual existente en este campo de estudio reproduce la división emigración/inmigración a la cual se somete el objeto, expresando y participando de la relación de dominación y las asimetrías en las relaciones de fuerza que originan y constituyen el fenómeno migratorio (Sayad, 1998). Farah (2005) ofrece una primera sistematización de las investigaciones realizadas en Bolivia acerca de las migraciones. Divide el desarrollo de los estudios migratorios en dos fases: una centrada en las migraciones internas y otra focalizada en la migración internacional. La primera fase, cuyo inicio ubica a finales de la década de los setenta, abarca aquellos estudios realizados sobre las migraciones internas rural-urbanas y rural-rurales en el marco de las transformaciones acontecidas en el período 1952-1982. En esta etapa, como lo indica Blanes (1986), los estudios sobre migraciones, originados básicamente en reparticiones estatales o agencias externas como el BID y el USAID, estuvieron guiados por una preocupación en torno a "la posibilidad y necesidad de que se produzca una mejor distribución en el espacio" y, más concretamente, a "la planificación de los esfuerzos por repoblar el territorio, redistribuir los recursos humanos y garantizar las inversiones en las áreas de frontera" (Blanes, 1986:140). De ahí que el principal interés del Estado y de las agencias internacionales fuera estudiar las migraciones definitivas antes que las temporales. La segunda fase, cuyo comienzo lo establece Farah (2005) a principios de los ochenta, concentra aquellas investigaciones interesadas en los movimientos migratorios internacionales o transnacionales hacia la Argentina en general y en las estrategias desplegadas por los migrantes en particular, sobre todo por aquellos emigrantes de las comunidades campesinas del alto valle cochabambino (Blanes, 1986; Dandler y Medeiros, 1991; Cortes, 2004a; Cortes, 2004b) y de los valles tarijeños (Hinojosa Gordonava et al., 1999, 2000). A esta segunda fase habría que añadir los estudios empíricos sobre los vínculos transnacionales de la migración entre Bolivia y Estados Unidos (De la Torre Ávila, 2006; De la Torre Ávila y Alfaro Aramayo, 2007) o España (Hinojosa Gordonava, 2006, 
Más tarde, las investigaciones de corte antropológico y sociológico sobre las implicancias culturales, sociales y políticas de la migración de países vecinos, en particular la boliviana (Gavazzo, 2004; Caggiano, 2005; Vargas, 2005; Ortiz, 2006; Baeza, 2006; Bompadre, 2007; Pizarro, 2009; Mallimaci, 2010), junto al estudio de algunas corrientes contemporáneas de inmigración extracontinental (como aquellas provenientes de Corea del Sur: Mera, 1998; Courtis 2000; Bialogorski, 2002; Mera, Palacios de Cosiansi y González, 2005 y de Europa del Este: Masseroni y Ponisio, 2005), experimentaron un inusitado auge. A partir de la crisis que estalló en diciembre de 2001, la emigración de argentinos se convirtió en otra de las preocupaciones de investigadores especializados en la temática migratoria (Aruj, 2004; Novick, 2007). En otros contextos académicos nacionales también surgieron distintos estudios sobre la emigración boliviana hacia Brasil (Silva, 2005; 2006), Estados Unidos (De la Torre Ávila, 2006; De la Torre Ávila y Alfaro Aramayo, 2007) y España (Hinojosa Gordonava, 2006; 2008; 2009; Guaygua, 2008; Guaygua et al. 2010).37

2008, 2009; Guaygua et al., 2010) y algunos ensayos teóricos dedicados a diversos aspectos socioculturales e identitarios de la emigración boliviana (Mansilla, 1997; Paz Soldán, 2000; Zalles Cueto, 2002).

37 A pesar de que la presencia de migrantes bolivianos en países vecinos como la Argentina tiene más de cien años de antigüedad, los primeros esfuerzos de investigación aparecen recién en la década de los setenta. En estos años se realizaron distintos estudios sobre el fenómeno migratorio limítrofe en la Argentina, promovidos desde instituciones académicas, agencias del Estado argentino y organismos internacionales. Aquellos dedicados a la inmigración boliviana se concentraron tanto en los antiguos como en los nuevos destinos de esta corriente migratoria. Entre los primeros estudios sistemáticos de carácter académico dedicados a la migración boliviana en la Argentina se encuentra una tesis de licenciatura en sociología (Villar, 1972), una tesis doctoral realizada en el noroeste argentino (Salta y Jujuy) por un antropólogo norteamericano (Whiteford, 1975), un trabajo sobre inmigrantes bolivianos en un barrio de la ciudad de Buenos Aires (Mugarza, 1975), una tesis de maestría dedicada a la inserción de los inmigrantes bolivianos en el mercado de trabajo argentino (Ardaya, 1978) y dos trabajos destinados a analizar los desplazamientos temporales y el asentamiento de los migrantes bolivianos en la provincia de Mendoza (Guibourdenche de Cabezas, 1976; Heras, Guillot y Galvez, 1978). A inicios de la década del ochenta aparecen publicados los trabajos de Adriana Marshall y Dora Orlansky sobre la migración paraguaya, chilena y boliviana vista desde los lugares de origen (Marshall y Orlansky, 1981) y destino (Marshall y Orlansky, 1983) mediante un análisis de las condiciones de expulsión y atracción del proceso migratorio limítrofe entre los años cuarenta y ochenta aproximadamente. Durante esta década se realizan diversos trabajos sobre la migración desde Bolivia hacia la Argentina que contemplan también el lugar de origen y de destino, aunque desde una perspectiva centrada en la unidad doméstica: Blanes (1986), Balán (1990) y Dandler y Medeiros (1991) analizan especialmente la migración temporaria de mujeres y hombres cochabambinos a la Argentina, en particular a Buenos Aires, entre los años setenta hasta mediados de los ochenta. Por otra parte, Susana Mugarza (1985) ofrece una de las primeras descripciones relativas a la inserción de los inmigrantes bolivianos en la ciudad de Buenos Aires. A mediados de los ochenta surgen, asimismo, los primeros trabajos de Graciela De Marco y Susana Sassone sobre la inmigración limítrofe en la Argentina. De Marco (1986) realiza un análisis cuantitativo de los flujos de inmigración limítrofe en la Argentina entre inicios de los setenta y mediados de los ochenta. En esta misma línea, Sassone (1987), por su parte, analiza la migración "indocumentada" a partir de fuentes inéditas. Al año siguiente de esta publicación, aparecerá un trabajo de 
Fue en esta época que la presencia de hijos de familias inmigrantes de países limítrofes en escuelas públicas de la Argentina empezó a ser indagada, especialmente en el área de la investigación educativa. ${ }^{38}$ Aunque en los últimos años ha habido un creciente interés, lo cual suscitó diversos proyectos individuales y colectivos, aún sigue siendo escasa la producción existente sobre el tema en comparación con la de otros contextos nacionales donde la inmigración también forma parte de las agendas de investigación (Neufeld y Thisted, 1999; Sinisi, 1999; Cohen, 1998/1999; Novaro, 2005; Novaro et al. 2008; Trpin, 2004; Beherán, 2007). En contraste, ha habido una mayor proliferación de estudios que analizan la relación entre la escuela o el sistema educativo y la población indígena, provenientes en su mayoría del campo de la antropología de la educación. Ello ha dado lugar a una vasta producción teórica y empírica sobre la interculturalidad o la diversidad cultural en los contextos escolares (entre otros, Achilli, 1996; Sagastizábal, 2000; Novaro, 1999, 2002; Díaz, 2001; Díaz y Alonso, 2004; Batallán y Campanini, 2007; Heras y Holstein, 2003; Heras, 2002, 2005; Montesinos, 2005; Ameigeiras y Jure, 2006; Hecht, 2007; Soria, 2011). ${ }^{39}$ Por otra parte, también cabe señalar, que las numerosas investigaciones sobre los procesos de construcción de la identidad nacional y de la idea de nación en la escuela pública argentina (Díaz, 1995; Blázquez, 1996; Amuchástegui, 2000; Romero, 2004; Carretero, 2007; Guillén, 2008) no han incluido como unidades de análisis u observación instituciones que cuenten con una significativa presencia de hijos de inmigrantes de países

esta investigadora (Sassone, 1988) sobre la inmigración boliviana a la Argentina, donde se examina particularmente la zona de El Ramal jujeño. Asimismo, en esta década, Gabriela Karasik comienza a investigar desde una perspectiva antropológica la presencia de inmigrantes bolivianos en la provincia de Jujuy, cuyos resultados serán publicados en años posteriores. Un párrafo aparte merecen las iniciativas del Estado argentino en materia de producción de conocimiento sobre las migraciones internacionales. Entre los años 1945 y 1955, como parte de la estructura ministerial, el Instituto Étnico Nacional, que tuvo entre su personal directivo a antropólogos, se erigió como un espacio de "antropología aplicada" y de "gobierno científico de la población"; entre otras dependencias estatales prestó asesoramiento a la DNM (véase Lazzari, 2004). Hacia finales de los sesenta, se crea el Instituto Nacional de Estadística y Censos (INDEC): análisis del desarrollo los flujos migratorios internacionales: actualmente produce y suministra la mayor información cuantitativa sobre las migraciones internacionales. En los años setenta, el Ministerio del Interior desarrolló a través de la Oficina Sectorial de Desarrollo de Recursos Humanos una serie de estudios una serie de estudios sobre distintas corrientes migratorias limítrofes (boliviana entre ellas) en la Argentina: describen aspectos de su historia migratoria, su inserción social y laboral en la agricultura y su situación legal-administrativa en las provincias de Salta y Jujuy (Villar, 1975) y Mendoza (Bellati, 1973). En la actualidad, la Dirección Nacional de Población también tiene previsto diversos estudios cuantitativos y cualitativos referidos a los inmigrantes de países vecinos.

38 El proyecto de investigación, dirigido por María Rosa Neufeld, llevado adelante en escuelas de la ciudad de Buenos Aires durante los años noventa dio lugar a una serie de trabajos pioneros en la Argentina (Neufeld y Thisted, 1999). 39 Véase Pallma y Sinisi (2004) para una reflexión sobre la propia experiencia de investigación y el itinerario recorrido para llegar a problematizar la relación diversidad/desigualdad en la escuela. 
vecinos o se sitúen en contextos sociales caracterizados por la afluencia de familias inmigrantes.

Por otra parte, a partir de los años ochenta, con el regreso de la democracia en el país, las políticas estatales en materia de migraciones internacionales empezaron a ocupar un lugar cada vez más destacado entre los intereses de investigación. ${ }^{40}$ Gran parte de las primeras investigaciones provinieron del campo de la historia. En su conjunto, estos estudios han abarcado el período que se extiende desde mediados del siglo diecinueve hasta mediados del siglo veinte (Halperín Donghi, 1987; Devoto, 1989). Varios de ellos se han ocupado de algunas etapas históricas concretas como el período de entreguerras y/o la inmediata posguerra, con especial atención de los gobiernos peronistas (fundamentalmente el primero) (Senkman, 1985; Devoto, 2001; Biernat, 2007; Quinteros, 2008), o de estudios comparativos (Devoto, 2004; Sánchez Alonso, 2004). Básicamente se han referido a la migración de ultramar proveniente de Europa y sólo recientemente han empezado a surgir en el ámbito de la historia algunos trabajos que abordan la migración limítrofe (Ceva, 2006; Magliano, 2009). Entre el reducido número de estudios históricos dedicados a la relación entre el Estado argentino y la inmigración de países limítrofes, el trabajo de Quinteros (2008) constituye un aporte imprescindible para comprender el vínculo entre los extranjeros provenientes de países limítrofes (sean europeos o nativos) y el Estado argentino durante las décadas del treinta y cuarenta.

\footnotetext{
40 El creciente interés por el tema de las migraciones internacionales contemporáneas en el ámbito académico argentino también se constata, desde mediados de los años ochenta, en el desarrollo de reuniones específicas sobre el tema. En 1985 se realizan en Buenos Aires las Jornadas Internacionales sobre "Integración e identidad cultural de los inmigrantes en la Argentina", organizadas por el CEMLA y la Universidad Nacional de Luján. Más tarde, en 1987, se desarrollan las Jornadas sobre Colectividades, organizadas por el Centro de Estudios Migratorios Latinoamericanos (CEMLA), el Instituto de Desarrollo Económico y Social (IDES), el Museo Roca y el Instituto de Investigaciones Gino Germani de la UBA, cuyos encuentros serán renovados en los años 1989, 1991, 1993, 1995 y 1998. Entre otras reuniones científicas organizadas en la década de los noventa, se destacan las Jornadas de Reflexión sobre Bolivianos en la Argentina auspiciadas por el Instituto de Investigaciones Gino Germani de la Universidad de Buenos Aires, el IDES y el CEMLA en 1996; el Seminario Permanente de Migraciones, desarrollado mensualmente desde el año 1994 hasta la fecha en el marco de las actividades del Grupo de Estudios "Población, Migración y Desarrollo" del Instituto de Investigaciones Gino Germani de la Universidad de Buenos Aires; y el Seminario Internacional "Procesos Socioculturales en los bloques regionales: fronteras, naciones e identidades", organizado en Buenos Aires por el Instituto de Desarrollo Económico y Social (IDES) en 1999. El renovado interés en el ámbito académico por temas vinculados a las migraciones contemporáneas en la Argentina también empezó a reflejarse, especialmente a partir de finales de los años noventa, en la creciente producción bibliográfica, el significativo aumento del número de proyectos de investigación y la nueva creación de programas de investigación sobre la temática.
} 
Otro conjunto de trabajos, más próximos a la sociología, la antropología o la ciencia política, se ha dirigido a estudiar la política migratoria argentina, especialmente a través de la legislación migratoria, contemplando tanto el período concerniente a las migraciones de ultramar o históricas como a las migraciones de países limítrofes o contemporáneas (Novick, 1986, 1992, 1997; Pérez Vichich, 1988; CELS, 1999; Pacecca, 2000; Courtis y Pacecca, 2007; Pacecca y Courtis, 2008). En algunos casos estos análisis han estado enmarcados en diversos procesos regionales, tanto económicos como políticos (Mármora, 1988, 1994, 1996, 2003; Novick, 2005; Novick, Hener y Dalle, 2005; Stuhldreher, 2006; Romano, 2009; Stang, 2009). Entre los primeros estudios, centrados específicamente en la migración limítrofe y la legislación migratoria argentina en el transcurso de la segunda mitad del siglo veinte, se destacan los trabajos de Pacecca $(2000,2001)$. El discurso del Estado argentino sobre los inmigrantes limítrofes durante la década de los noventa también recibió la atención de diversos investigadores atraídos por las manifestaciones discriminatorias y xenófobas de la época, cuyos análisis se basaron fundamentalmente en fuentes provenientes de la prensa escrita (Oteiza y Aruj, 1997; Villalón, 1999; Grimson, 2000; Albarracín, 2005). Respecto a la llamada inmigración ilegal, Sassone (2002) y Casaravilla (1999) se encuentran entre las únicas investigaciones dedicadas a estudiar específicamente el tema en la Argentina. ${ }^{41}$ A comienzos del presente siglo, los cambios en la política migratoria argentina, especialmente a partir de la discusión y aprobación de la nueva ley de migraciones, motivaron una serie de trabajos sobre la antigua y nueva legislación migratoria y las transformaciones del discurso estatal argentino relacionadas con la ciudadanía y los derechos humanos (Ceriani Cernadas, 2004; Mármora, 2004; Novick, 2004; Oteiza, 2004; Pérez Vichich, 2004; CELS, 2005, 2007; Courtis, 2006; Badaró, 2006; Caggiano, 2006; Courtis, 2006; Courtis y Pacecca, 2007; Vior, 2008; Nicolao, 2010).

\section{Estado, escuela y migración: encuadre y aproximación teórico-metodológica}

Las definiciones convencionales describen la migración como un hecho básicamente demográfico o geográfico, asumiendo el traslado o cambio de residencia como uno de los criterios determinantes para su conceptualización. De acuerdo a ello, supone un tipo de desplazamiento caracterizado por un particular comportamiento en el espacio y a través

\footnotetext{
41 En éstos como en tantos otros artículos de investigación aparece naturalizada la categoría de ilegal, aspecto que los propios autores pusieron de relieve en posteriores publicaciones o modificando las categorías utilizadas. Una cuestión central que habría que considerar al momento de trabajar estos temas es la que identifica De Genova (2002): es preciso diferenciar entre estudiar indocumentados y estudiar la ilegalidad.
} 
del tiempo. En este sentido, la migración se diferenciaría de otros desplazamientos humanos por el cruce de un límite administrativo (local, regional o internacional) y la duración de la estadía. Esta caracterización como simple traslado de un grupo de individuos o de una población en el espacio geográfico, vinculado a la residencia, desconoce como oculta el significado político de la migración. Precisamente, lo que pasan por alto estas definiciones es que constituye un hecho eminentemente político de base económica: se trata fundamentalmente del traslado de trabajadores extranjeros (en su sentido jurídico, pero también social) que son ciudadanos, miembros de una comunidad política distinta al Estado receptor. Una caracterización de la migración exclusivamente como traslado de mano de obra (extranjera y provisoria) ocultaría su significación política, las implicancias políticas, los dilemas políticos del hecho migratorio (Sayad, 2008). En una palabra, lo que se suele descuidar u omitir es la politicidad inherente a la migración. Como supieron advertir tempranamente tanto Zolberg como Sayad, el desplazamiento físico de los migrantes supone la transferencia de ciudadanos de la jurisdicción de un Estado a la de otro, con importantes consecuencias e implicancias políticas para ambas sociedades nacionales y para los propios inmigrantes (Sayad, 1979, 1984, 1989; Zolberg, 1978, 1981, 1989). Desde esta perspectiva, el orden de la inmigración/emigración y el orden nacional están intrincadamente relacionados. De ahí que Sayad (2008) defina la emigración como la ausencia de los nacionales del orden nacional que les otorga existencia jurídica y la inmigración como la presencia de los no-nacionales en un orden nacional para el cual son extranjeros o (identificados como) nacionales de otra nación y de otra nacionalidad. Esto explica que la inmigración haya sido históricamente un asunto político, procesado de distinta manera según cada sociedad nacional, aunque siempre regulado conflictivamente.

Uno de los grandes quiebres en la historia de la movilidad humana a partir del cual la migración adquiere una significación particular sucede con la creación de los Estados nacionales. En una economía-mundo, como propone Wallerstein, desarrollada en la forma de un mercado universal, son precisamente las fronteras, las cuales organizan una división basada en una pluralidad de unidades políticas, las que permiten la concentración del poder económico y la defensa de posiciones de renta o monopolio a través de medios extraeconómicos como los instrumentos de coacción políticos (o jurídicos) en manos de los Estados nacionales (Balibar, 2008). En el largo plazo, más allá de la notable diversidad de situaciones que involucran a la migración y las variaciones que despliega en el tiempo y el espacio, el fenómeno migratorio (tanto de la emigración como de la inmigración) también exhibe ciertas constantes (en tanto características sociales, económicas, jurídicas y políticas que reaparecen a lo largo de la historia), constituidas como una especie de base 
común e irreductible, las cuales son producto y objetivación del pensamiento de Estado (Sayad, 1999). Entre las constantes políticas podríamos considerar las características o los modos de regulación estatal a los cuales estuvieron condicionados los movimientos internacionales de población en el mundo occidental según determinadas etapas o ciclos históricos. ${ }^{42}$ Como ha señalado Torpey (2000), el paso desde el control privado al control estatal de los movimientos de población fue un aspecto esencial de la transición del feudalismo al capitalismo. La monopolización de los medios legítimos de movimiento, que supuso la monopolización de la autoridad para regular el movimiento de personas, fue intrínseco a la construcción de los Estados desde el advenimiento del absolutismo en la temprana Europa moderna. Recién hacia finales del siglo diecinueve, mediante la creación de una infraestructura burocrática y tecnologías más sofisticadas, los Estados nacionales estuvieron en mayores condiciones y tuvieron las capacidades necesarias para llevar adelante y hacer efectiva la monopolización de la autoridad estatal de los medios legítimos de movimiento. En su estudio sobre la invención del pasaporte, Torpey sostiene que en esta transición los Estados modernos expropiaron a los individuos y a las organizaciones privadas como las entidades económicas y religiosas de los medios legítimos de movimiento, privando la libertad de desplazamiento entre territorios nacionales y condicionando los cruces de las fronteras internacionales a una autorización estatal. Gradualmente, en detrimento del interés por el movimiento entre espacios locales de los diversos dominios territoriales, el control de las fronteras externas de los Estados nacionales en formación fue adquiriendo mayor relevancia conforme la administración de la beneficencia fue quedando bajo la órbita estatal. Al mismo tiempo, la monopolización estatal de los medios legítimos de movimiento no habría sido posible sin la monopolización estatal de los medios legítimos de violencia. ${ }^{43}$ La introducción de los instrumentos de control trajo consigo una forma específica de pensar la migración: sólo cuando los Estados emitieron una legislación que declaró la inmigración no deseada como ilegal y la hicieron punible y se introdujeron tecnologías (fotografías, pasaportes, visados), administraciones (autoridades de inmigración) y procedimientos de vigilancia (la deportación), la migración se convirtió en migración clandestina (Düvell, 2008).

\footnotetext{
42 Para una periodización de las etapas históricas en las cuales se suelen dividir las migraciones internacionales, véase Massey (1990), entre otros. Allí repasa la historia moderna de la migración internacional (dividida en cuatro grandes periodos) y discute los fundamentos económicos y sociales atribuidos generalmente a este fenómeno. 43 Dice Elias: “El monopolio de la violencia física es una de esas invenciones sociales no planeadas. Se ha conformado bajo la forma de un largo proceso, muy gradual, a lo largo de los siglos, hasta alcanzar el estadio actual" (Elias, 2009[1989]:187).
} 
En América Latina, la regulación estatal de los movimientos poblacionales empezó a delinearse con la formación de los Estados-nación en el período independentista, pero recién adquirió un carácter más sistemático a partir de su consolidación como Estados nacionales hacia finales del siglo diecinueve y su inserción en el mercado capitalista mundial junto a la llegada de contingentes de inmigrantes de ultramar, que en determinadas sociedades nacionales trastocó ciertas estructuras y nociones del orden social establecido. Fue en este período que pudieron visualizarse algunos de los aspectos interrelacionados que Torpey identifica como decisivos para alcanzar la monopolización de los medios legítimos de movimiento: la gradual definición de los Estados como nacionales; la codificación de leyes que establecen qué tipo de personas pueden moverse dentro y a través de sus fronteras y determinan cómo, cuándo y dónde pueden hacerlo; la estimulación del desarrollo internacional de las técnicas para la identificación ${ }^{44}$ individualizada de la población mundial, desde el nacimiento hasta su muerte, de forma única e inequívoca; la construcción de burocracias diseñadas para llevar a cabo este régimen de identificación y para vigilar a personas y documentos con el fin de verificar las identidades; y la creación de un cuerpo legal de normas diseñadas para juzgar las peticiones de los individuos para entrar a determinados espacios y territorios (Torpey, 2000). Mármora (1988; 1994) identifica el predominio de diversos argumentos que sirvieron de fundamento a las medidas estatales adoptadas desde el período colonial hasta la actualidad en materia de regulación de los movimientos internacionales de población en la región latinoamericana: el aprovisionamiento de mano de obra, la ocupación territorial; la protección laboral, social, política y cultural; y el desarrollo y la integración regional. ${ }^{45}$ En términos cronológicos, hacia comienzos del siglo diecinueve se optó por la fuerza de

\footnotetext{
44 Torpey acuerda con Gérard Noirel acerca de la importancia de la codificación e institucionalización de las identidades para que sean significativas socialmente. Considera que los procedimientos y mecanismos de identificación son esenciales para que el Estado consiga la monopolización de los medios legítimos de movimiento. A través de documentos tales como los pasaportes y los documentos de identidad los Estados nacionales tienen la posibilidad de identificar de forma inequívoca a unos y otros en el control de los desplazamientos y hacer que las distinciones establecidas sean inteligibles y que ciertas disposiciones sean cumplidas (Torpey, 2000). Entre los instrumentos creados para controlar los desplazamientos humanos y otorgar su autorización se impuso la posesión o acreditación de una nacionalidad. Es frecuente que en algunos textos se confunda la identidad nacional con la nacionalidad. Ocurre, por ejemplo, cuando se hace referencia a la "acreditación de la identidad": lo que se acredita, en realidad, es la nacionalidad. Véase Etcheverry (2007) para una exploración antropológica acerca del valor de los documentos para el “inmigrante” y el “extranjero” como experiencia de negociación de la identidad.

45 Si bien recupero el análisis de Mármora (1988; 1994) para referirme a los patrones identificables en materia de política migratoria en la región latinoamericana, sólo me remito al período posterior a la fundación de los Estados nacionales, debido a que discrepo con utilizar y aplicar la noción de política de migraciones internacionales para describir los modos de regulación de los movimientos internacionales de población en el período colonial. Considero también que es inexacto hablar de "migraciones internacionales" para designar los desplazamientos y traslados de individuos y grupos humanos en la etapa histórica anterior a la creación de los Estados nacionales.
} 
trabajo in situ y se promovió el reemplazo de mano de obra a través del aumento de la población económicamente activa y la llegada de inmigrantes de ultramar. Hasta la crisis de los años treinta del siglo veinte, la mayoría de los países latinoamericanos consideraron a la población como un aporte al desarrollo, sirviendo de fundamento de sus políticas de fomento de la inmigración: se asignaba a los inmigrantes la capacidad de aumento de la producción económica. La relación entre población y desarrollo económico era vista a partir de los beneficios o perjuicios que determinada cantidad/calidad de población representaba para las posibilidades de desarrollo o bienestar. Asimismo, a partir de la segunda mitad del siglo diecinueve, las políticas orientadas a la ocupación territorial mediante el asentamiento de inmigrantes se generalizaron en América Latina. La inmigración fue asumida por los Estados nacionales como un factor fundamental de transformación de las sociedades: la inmigración fue vista como un aporte fundamental al "progreso". A partir de principios del siglo veinte, especialmente a partir de la década de 1930 con la crisis en los mercados laborales y la llegada de refugiados provenientes de Europa (entre otros grupos sociales considerados indeseables) las políticas desarrolladas se orientaron a la protección de la mano de obra nacional y a fortalecer la construcción de la identidad nacional, apareciendo por primera vez en el continente diversas medidas restrictivas según criterios étnicos, políticos y laborales. En los años sesenta, la sobreoferta de trabajo, la desaceleración relativa del proceso de industrialización y la disminución de la generación de empleo volvieron a hacer emerger el interés estatal por la protección de la mano de obra local. Durante los años setenta, con las dictaduras militares establecidas en la región, se extendió la doctrina de la seguridad nacional y se consolidó el aparato administrativo migratorio como un órgano de control policial. En la década de los noventa, en el marco de los procesos de integración económica retomados o iniciados en pleno auge neoliberal, se actualizó la visión positiva sobre la relación entre población y desarrollo y se impulsaron políticas orientadas a fortalecer los procesos y mecanismos de integración regional. A lo largo de estas décadas, la Argentina se constituyó en la región en el centro gravitacional de un sistema de migraciones internacionales en el Cono Sur (Balán, 1988), que asumió características particulares en tanto Estado receptor de una inmigración que en la literatura se ha difundido como migraciones Sur-Sur.

Por otro lado, así como la inmigración obedece a la existencia del Estado nacional, el Estado se constituye y define a sí mismo al establecer categorías y modos de intervención para regular la emigración o la inmigración. Es decir, cuando habla e interviene sobre la inmigración, ofreciendo su visión a través de sus discursos y políticas, también está hablando y produciéndose a sí mismo, constituyéndose como Estado, tanto en el orden 
material como simbólico. La inmigración y el Estado nacional deben su existencia uno a otro, ya que -como sostiene Sayad- para que haya inmigración, es necesaria la existencia de los Estados nacionales, esto es, de las fronteras y los territorios nacionales. A la vez, el Estado existe en la medida en que es soberano sobre un territorio que, definido nacionalmente, produce la figura del extranjero: por extensión, el ejercicio de dicha soberanía territorial lo habilita a disponer sobre la existencia de los extranjeros. Esta mutua imbricación ha llevado a Sayad (1999) a equiparar la sociología de la inmigración a una de las mejores introducciones a la sociología del Estado. Es en este sentido que diversos autores contemporáneos han destacado la importancia de estudiar las implicancias políticas de las migraciones. Para Torpey, estudiar el proceso de monopolización de los medios legítimos de movimiento resulta imprescindible para "una adecuada comprensión del funcionamiento real de los Estados modernos" (Torpey, 2000: 61). Asimismo, como señala Doty, las visiones que ofrecen las prácticas estatales respecto a la llamada inmigración ilegal permiten comprender al Estado y las fuerzas que motivan dichas prácticas como la necesidad de reproducir las fronteras espaciales, sociales, culturales, económicas y políticas como naturales (Doty, 1996).

Hay dos expresiones del Estado que propone Gramsci, entendido como sociedad política y sociedad civil, que ilustran bien aquellas funciones que desempeña el aparato estatal, bajo la articulación coerción-consenso, a través de aquellas instituciones y agentes que históricamente han estado involucrados y encargados de la regulación de la presencia de los inmigrantes en las sociedades capitalistas contemporáneas: el Estado gendarme y el Estado educador. En el caso argentino, tanto el organismo estatal creado para controlar los movimientos migratorios como la institución educativa destinada a promover la asimilación de los extranjeros son representativos de estas figuras del Estado. La expresión Stato-carabiniere o Estado gendarme que utiliza Gramsci (relacionada con la noción de guardián de noche o veilleur de nuit perteneciente a Lassalle) en oposición al Estado ético, otorga una imagen del Estado, en tanto aparato de coerción estatal, que sintetiza bien la función coactiva y represiva que ejerce un Estado limitado a "la tutela del orden público y del respeto de las leyes" (Gramsci, 1984: 157) (o como "el guardián de la 'lealtad del juego' y de sus leyes", Gramsci, 1984: 159), no sólo mediante la imposición de la fuerza física, sino también a través del disciplinamiento social obtenido por medio de la regulación legal, para la conservación del orden establecido. En este sentido, como señala De Genova (2002), las leyes de inmigración sirven como instrumentos para suministrar y refinar los parámetros de la disciplina y la coacción. Ahora bien, este carácter táctico de la ley no puede hacer soslayar que las prácticas encaminadas a lograr que un objeto disciplinado y manejable de cualquier grupo social sean coyunturales y que nunca habrá 
completa certeza acerca de su efectiva realización. En palabras de Gramsci, "el derecho es el aspecto represivo y negativo de toda la actividad positiva de civilización -o de formación civil, según la traducción- llevada a cabo por el Estado" (Gramsci, 1985: 112). Esta actividad considerada positiva alude al Estado educador.

El Estado concebido como educador, en cuanto "tiende a crear un nuevo tipo o nivel de civilización" (Gramsci, 1985: 112), orienta sus actividades a la producción de hegemonía ejerciendo un liderazgo intelectual y moral conseguido mediante el consentimiento de las clases subalternas. Devenido el Estado en "educador", ahora ejerce "la fuerza moral, intelectual y cultural: ejerce poder presentándose como el poder ético-político, representando valores universales, independientes de valores estrechos, económicos, sociales o de clase" (Fontana, 2001). Dice Gramsci: "Si todo Estado tiende a crear y a mantener un cierto tipo de civilización y de ciudadano (y por consiguiente de convivencia y de relaciones individuales), tiende a hacer desaparecer ciertas costumbres y actitudes y a difundir otras: el derecho será el instrumento para este fin (al lado de la escuela y de otras actividades) y debe elaborarse de modo que sea conforme al fin, así como de la máxima eficacia y productividad en resultados positivos" (Gramsci, 1985: 111-112). En suma, la escuela como función educativa positiva y los tribunales como función educativa represiva y negativa, siendo las actividades estatales convergentes más importantes, cumplen un papel clave, junto a otras iniciativas y actividades, en la producción de la hegemonía política y cultural.

Mi aproximación comprehensiva a los relatos y políticas, así como a las representaciones y prácticas sociales que se construyen en torno a la inmigración y los inmigrantes, está conducida por el concepto de visión de Estado: un conjunto de representaciones y prácticas instituidas como visión dominante o hegemónica en la construcción de la figura social de la inmigración y los inmigrantes. Utilizo esta noción, advertida durante el trabajo de campo y en momentos analíticos posteriores ${ }^{46}$, siguiendo los planteos teóricos de Bourdieu y Sayad acerca del Estado y el pensamiento de Estado (Bourdieu, 1997; Sayad, 1999), aunque desprendido del esquema o modelo de análisis bourdiano. De acuerdo a sus

\footnotetext{
46 En los diversos documentos, intervenciones públicas y entrevistas a funcionarios estatales se habla de visión. En algunas circunstancias en particular dicha noción se impuso de manera contundente. A modo de ilustración: en una de las entrevistas con un funcionario estatal, mientras conversábamos acerca de los cambios en la política migratoria argentina, él señaló que “en las acciones concretas se manifiesta una visión...” (Entrevista con Jefe de la Delegación Córdoba de la DNM, 2007).
} 
postulados, entiendo el pensamiento de Estado como una forma de pensamiento (que involucra acción) producida por el Estado de manera relacional con otros actores sociales y políticos e interiorizada como visión dominante o hegemónica, a través de la cual se establecen determinados principios de visión y división del mundo social como legítimos ${ }^{47}$ Sayad establece una relación inseparable entre pensamiento de Estado y pensamiento del Estado ya que, según entiende, "es el pensamiento de Estado el que haría el pensamiento de Estado todo lo que es y en todos los ámbitos en que se aplica, igual que el pensamiento del Estado, por efecto de su constancia, de sus repeticiones, de su fuerza misma, de su poder de imposición, podría haber acabado por engendrar la manera durable de pensar típica del pensamiento de Estado" (Sayad, 1999: 399). En el terreno de las migraciones, como señala Sayad (2000), este modo de pensamiento, nunca estático y siempre sujeto a cambios, reflejado en las categorías nacionales -también nacionalistas- a través de las cuales se piensa la inmigración, está plenamente inscripto en la línea de demarcación que divide de manera taxativa los nacionales de los no-nacionales. Balibar (2008), por su parte, asumiendo que el punto de vista nacional penetra nuestras categorías de pensamiento y acción, plantea si no somos, además de un ser sociable (animal sociale) o sujeto económico (homo oeconomicus), un ser nacional (homo nationalis). En otro lugar también ha señalado que “(u)na formación social sólo se reproduce como nación en la medida en que se instituye al individuo como homo nationalis, desde su nacimiento hasta su muerte, a través de una red de mecanismos y de prácticas cotidianas, al mismo tiempo que como homo economicus, politicus, religiosus..." (Balibar, 1991:144-145). Esta formación de sujetos nacionales sería el resultado de una construcción cultural colectiva que Elias (2009[1989]) ha denominado habitus nacional.

La visión de Estado condensa las cosas dichas y hechas, pero también las cosas que se han de hacer como lo expresa el sentido etimológico de la noción de agenda y el carácter prospectivo que se le atribuye en su uso habitual en el ámbito de las políticas públicas cuando se indican las acciones de un programa de gobierno. En este sentido, relacionada con el significado de envision en inglés, la visión de Estado no sólo remitiría a las intervenciones discursivas o prácticas ya desarrolladas en el pasado o en el presente, sino también a aquellas intervenciones a ser consideradas en el futuro, que pretenden ser

\footnotetext{
47 Partiendo de la conocida definición de Max Weber, Bourdieu propone incluir en el concepto de Estado la dimensión simbólica del uso legítimo de la violencia que monopoliza y reclama para sí exclusivamente. Dice Bourdieu: "el Estado es una X (por determinar) que reivindica con éxito el monopolio del empleo legítimo de la violencia física y simbólica en un territorio determinado y sobre el conjunto de la población correspondiente" (Bourdieu, 1997:97).
} 
realizadas o que son enunciadas como si se las fuera a realizar en el futuro. ${ }^{48}$ En este sentido, resulta productiva la noción de teoría pública oficial, acuñada por Favell (2001b), para examinar la visión de Estado. Favell sostiene que muchas de las ideas y justificaciones otorgadas para sustentar determinadas políticas o dirigirlas hacia nuevas direcciones se refieren a principios abstractos, conceptualizaciones inventadas o complejas afirmaciones cuasi-científicas sobre el funcionamiento del orden social. Cuando estas argumentaciones políticas, las cuales son consideradas un prerrequisito cognitivo para cualquier actor que pretenda comprender una situación y formular una acción a partir de ella, obtienen cierta aceptación generalizada y se instauran como la teoría total dominante estaríamos en presencia de una teoría pública oficial: primero, describe y conceptualiza hechos y realidades básicas de la situación social a la que se aplica (afirmaciones epistemológicas); segundo, teoriza el sentido y la aplicación de las intervenciones políticas y establece causalidades entre procesos políticos y sociales (afirmaciones explicativas); y, por último, da cuerpo a alguna clase de núcleo de valor o valores que manifiesta el objetivo último de las políticas y que resulta su justificación filosófica subyacente (afirmaciones normativas). A diferencia de una teoría política o filosófica, no es el producto de una reflexión a priori, sino el resultado de un proceso político que ha forjado una teoría dominante y públicamente reconocida para tratar con los problemas públicos en cuestión, bajo una serie de restricciones o condicionamientos. El diagnóstico y las explicaciones oficiales que suelen brindar los funcionarios públicos encargados de elaborar, definir y divulgar las políticas implementadas o a implementar acerca de las migraciones internacionales contienen ideas y argumentaciones que sirven a los fines de legitimar determinadas medidas políticas. Es decir, los enunciados sobre la inmigración, como otros objetos sociales, no son meramente explicativos, sino que también cumplen una función de legitimación: una argumentación que justifique una presencia que de otra manera sería impensable y, posiblemente, hasta escandalosa, desde cualquier punto de vista (intelectual, político, cultural, ético, etc.) (Sayad, 1998). En el presente estudio, tanto en la descripción analítica de los procesos y relatos históricos y políticos de alcance nacional como de los procesos y mecanismos sociales cotidianos en el espacio escolar hay un

\footnotetext{
48 A propósito de la presentación de su nuevo libro, Erik Olin Wright explicaba durante una conferencia dictada en la Universidad de Buenos Aires en el año 2007: "Mientras me preparaba para esta conferencia, me enfrenté con un problema de traducción. De traducción del título de mi libro, que es `Envisioning Real Utopias'. Y tuve una discusión muy interesante con Rodolfo [¿Elbert?] y otros estudiantes en Madison, no encontraba la palabra correcta para la traducción de la palabra envisioning. [...] no tenemos un equivalente exacto para la palabra envisioning. 'Imaginan do' no es exactamente lo mismo, porque implica algo que está demasiado en la cabeza y que es arbitrario con respecto al mundo. 'Prediciendo' y 'pensando' tampoco son correctos, envision en inglés sugiere imaginar una alternativa que uno quiere que sea realidad a través de la acción, es decir, tiene la implicancia de una intervención futura, es decir, es un sentir muy activo, a diferencia de 'imaginación' que es una posibilidad”.
} 
esfuerzo orientado a la comprensión de esta función de legitimación, que pretende alejarse de miradas prescriptivas o evaluativas tendientes a explicar los avances o los fracasos de determinadas políticas o medidas, tan habituales en los discursos institucionales de organismos gubernamentales y organizaciones internacionales, e incluso en el discurso académico.

Esta investigación se interesa y presta especial atención y cuidado a los procesos de clasificación y a la construcción de categorías que produce el Estado, definido como forjador de alteridades y desigualdades en tanto interlocutor con un enorme poder de interpelación (Segato, 1999). Aunque sean diversos actores los que participan del proceso de producción de la figura social de la inmigración, el Estado en tanto "contribuye en una parte determinante a la producción y a la reproducción de los instrumentos de construcción de la realidad social" (Bourdieu, 1997: 117), cumple un papel clave en la formación y circulación de imágenes, ideas y prácticas acerca de los inmigrantes. A través de la producción de clasificaciones y categorías, plasmadas en documentos oficiales, procedimientos administrativos y prácticas políticas, entre otros posibles soportes de la vida burocrática, el Estado participa de la construcción de una determinada visión como legítima y natural que posee efectos materiales concretos. En el terreno de las migraciones, la figura del inmigrante ilegal es una de las construcciones políticas más reveladoras del poder estatal para crear o participar de la creación de determinados objetos o sujetos sociales como preexistentes al Estado. Como afirma González Cámara (2010) al considerar el trabajo de Joseph Nevins sobre la producción de la frontera entre México y Estados Unidos, la supuesta "ilegalidad" del migrante no se basa en sus características sociales, económicas, políticas o raciales, sino que dicha construcción parte de la apropiación social de la lógica estatocéntrica. Según Nevins, es la capacidad del Estado para modelar las representaciones sobre la realidad social de acuerdo a sus propios límites lo que posibilita la identificación del migrante como culpable de una transgresión, codificada como crimen o delito, por el hecho de estar presente en un espacio determinado sin autorización del Estado.

Siendo el Estado el lugar donde la inmigración se instituye como objeto de gobierno (Gil Araujo, 2004), es en el terreno de la política de migraciones internacionales donde, en gran medida, se expresan o se evidencian los dilemas políticos de las migraciones internacionales. Es allí donde se regula de manera unilateral el ingreso y permanencia, la concesión de derechos y la pertenencia a la comunidad política de los extranjeros, 
limitando o ampliando determinados preceptos a través de la ejecución de políticas públicas y medidas administrativas concretas (López Sala, 2005a). ${ }^{49}$ Para los inmigrantes extranjeros, una de las consecuencias de estos sistemas de clasificación y categorización que suele señalarse es la posibilidad de acceder a los derechos que gozan los nacionales (al menos formalmente, porque no siempre los pueden ejercer) (Pacecca, 2000; Bauböck, 2004). Este interés por conocer cuáles son los sujetos sociales autorizados a ingresar y permanecer en el territorio nacional, así como las condiciones impuestas para ello, y cuáles son los derechos y obligaciones que conlleva su estadía y las sanciones a la inobservancia de ley, es una de las posibilidades que ofrece la sociología para interrogar críticamente al Estado. Así, dado que es a través de su aparato sociojurídico que el Estado determina quiénes son (y qué no son) sus miembros, sus nacionales, sus ciudadanos (Santamaría, 1994), este estudio recurre, en parte, al discurso jurídico, examinándolo a través de leyes, reglamentos, convenios, decretos y resoluciones, pero sin asumir una perspectiva jurídica, sino adoptando lo jurídico, en tanto componente constitutivo y expresivo del pensamiento de Estado, como una vía factible de indagación o "posibilidad metodológica de aproximación al proceso político dentro de la migración" (Calderón Chelius, 2006: 46).

\footnotetext{
49 López Sala (2005a) define la política migratoria como "una esfera de intervención pública en continuo cambio, en donde confluyen intereses diversos y contrapuestos entre distintos redes de actores y donde se destilan determinados entendimientos sobre la comunidad nacional". Conceptualiza la política de inmigración a partir de tres esferas: a) política de regulación y control de los flujos migratorios: acceso y permanencia en el territorio; b) política de integración: acceso a derechos; y c) política de nacionalidad: acceso a la comunidad política. A partir de ello, ofrece dos definiciones. Una primera la considera como conjunto de normas, leyes, prácticas e instrumentos estatales destinados a regular el acceso secuencial de los extranjeros a diferentes esferas de la sociedad de recepción: a) territorio; b) derechos; c) comunidad política (López Sala, 2005a). Luego, en una versión ampliada, incorpora a la definición las instituciones supranacionales: "conjunto de mecanismos legales y administrativos articulados por lo general desde el Estado, pero también desde otras instituciones supranacionales, que regulan el acceso al territorio, la estancia y el establecimiento, la integración socioeconómica y cívica de los inmigrantes y el disfrute de derechos ciudadanos, así como la incorporación a la comunidad política” (López Sala, 2005b:28). Esferas específicas: la regulación de la entrada al mercado de trabajo en destino y la implantación de iniciativas económicas en las cuencas migratorias orientadas a contener los flujos de salida. Estas esferas -control de flujos y control interno, integración, cooperación al desarrollo y política de naturalización- han servido de referencia a la hora de establecer pautas y de construir modelos (López Sala, 2005a). También especifica que "el peso de cada una ellas en el conjunto de la política ha sido muy variado. En la actualidad las acciones de regulación y de integración comparten protagonismo y concentran una buena parte de los recursos, en especial las medidas dirigidas al control fronterizo y a la lucha contra la inmigración irregular." (López Sala, 2005b:28).
} 
Para el análisis de las políticas estatales, este trabajo de investigación también recoge y se nutre de distintos aportes teóricos y analíticos de la etnografía del Estado ${ }^{50}$ y lo que algunos autores han denominado antropología de las políticas (Shore y Wright, 1997). Por su parte, Shore y Wright (1997) sugieren que las políticas públicas pueden ser indagadas de diferentes maneras: como textos culturales, sistemas clasificatorios con diversos significados, narrativas que sirven para justificar o condenar el presente o formaciones discursivas que operan para otorgar poder a algunos grupos sociales y silenciar a otros. Desde su perspectiva, las políticas no sólo codifican valores y normas sociales y articulan los principios fundamentales de organización social, sino que también contienen implícitamente modelos de sociedad. A través de las políticas se clasifican personas y se definen problemáticas, con importantes consecuencias materiales, al mismo tiempo que moldean el modo en que los individuos se construyen como sujetos: son categorizados, clasificados, nombrados, se les atribuye determinados roles y estatus (por ejemplo, "ciudadano", "nacional", “criminal" o "desviado"). Como sugiere Favell, a su vez, las construcciones categoriales forman parte de un marco institucional dominante que impone un lenguaje, un esquema epistemológico, teórico e ideológico para el tratamiento y el debate de la inmigración como problema público, se refleja en los consensos sobre los términos y el lenguaje de las políticas dentro de los cuales se discuten y deciden las diferentes opciones prácticas en un contexto sociohistórico concreto. En pocas palabras, mediante las políticas "se elaboran e imponen explicaciones y se ofrecen soluciones" (Gil Araujo, 2010). Si bien el lenguaje de las políticas, generalmente prescriptivo antes que descriptivo, como señalan Shore y Wright, aparenta respaldar cierto realismo al presentar los problemas como solucionables mediante información nueva y objetiva, no deja de contener determinados valores morales y preconcepciones: el discurso dominante opera creando los términos de referencia y desautorizando o marginando las alternativas. Al mismo tiempo, las políticas establecen una agenda pública y otorgan autoridad institucional a uno o varios de los discursos superpuestos, siendo habitual que en el proceso de formulación de un nuevo discurso, ciertas palabras clave sufran cambios en el uso y el significado (Shore y Wright, 1997). Esto no quiere decir que no haya diferentes posiciones o disputas y contradicciones entre las esferas del Estado nacional y entre sus distintas jurisdicciones (nacionales, provinciales, municipales). En materia de políticas públicas en general y de migraciones en particular, los intereses y visiones de aquellos organismos encargados de la política interna y de las relaciones exteriores o los dependientes de los poderes ejecutivo, legislativo y judicial o en los cuales se delegan las

50 Para una interesante colección de trabajos publicados en América Latina, véanse los números correspondientes de las revistas Cuadernos de Antropología Social (№ 27, Buenos Aires, 2008) e Íconos (№ 34, Quito, 2009). 
diferentes áreas de las políticas públicas suelen ser divergentes y, en algunos casos, hasta resultar antagónicos. De todas maneras, en determinados momentos sociohistóricos, la convergencia entre algunos sectores del Estado o la preponderancia de alguno frente a los demás, sumado a los esfuerzos gubernamentales por presentar un relato coherente y sin fisuras, puede otorgarle al relato oficial un carácter distintivo, en apariencia unívoco o uniforme (en palabras de Gramsci: "el Estado como tal no tiene una concepción unitaria, coherente y homogénea" [Gramsci, 1985:123]), que permite identificar determinados patrones de sentido. Como señala Favell (2001b), los consensos que se obtienen pueden ser vinculados con la tradición, pero a la vez pueden ser el resultado institucional de un proceso político contemporáneo contingente, con una específica configuración de fuerzas y tiempo detrás de sí.

Además de analizar el relato oficial que se construye sobre las migraciones en las altas esferas de gobierno a través de una importante diversidad de documentos públicos e intervenciones de funcionarios estatales, los cuales expresan mayormente el punto de vista de quienes elaboran y definen las políticas, es decir, de quienes participan de instancias gubernamentales relativas a la toma de decisiones, en distintos momentos procuro contrastar el marco institucional dominante con el punto de vista de quienes están involucrados en la ejecución de las políticas y ocupan una posición subordinada en la estructura gubernamental, sea como gendarme en la frontera, funcionario de planta permanente en una delegación regional del organismo central especializado en los asuntos migratorios o docente de una escuela primaria en la periferia urbana. Contemplar la mirada de estos agentes pretende un acercamiento a aquella experiencia de la posición ocupada en el macrocosmos social que es determinada, sino modificada, por el efecto que se experimenta de manera directa en las interacciones sociales dentro del microcosmos social (Bourdieu, 1999a: 10). Es decir, la especificidad de su punto de vista se configura en torno a su posición subordinada en la estructura jerárquica del Estado y su posición privilegiada como agente del Estado en la estructura social. Por otra parte, dicha posición también pone de manifiesto, a mi juicio, la in/inteligibilidad de las prácticas y políticas gubernamentales por los propios empleados o funcionarios de gobierno, expresada en la incertidumbre con que estos agentes experimentan el relato oficial al mismo tiempo que participan de su construcción. En este estudio hay una búsqueda orientada a, como propone Rockwell para el campo de la educación, integrar el análisis documental con la mirada etnográfica, estudiando el presente como el pasado, para "describir ambientes y narrar procesos que no se encuentran explícitos en ningún discurso oficial, pero que explican gran parte de lo que está en juego" (Rockwell, 2009: 14). 
En la medida que a través de los sistemas de enclasamiento o clasificación inscriptos en el derecho y los procedimientos burocráticos, así como en las estructuras escolares y los rituales sociales, el Estado modela estructuras mentales e impone principios de visión y de división comunes o formas de pensamiento que participan de la construcción de la identidad nacional (Bourdieu, 1997), manifestada habitualmente en las creencias, en los relatos, en los sentimientos, en las prácticas institucionales (Balibar, 2008), esta investigación asume la institución escolar como un lugar privilegiado de observación de la visión de Estado en acto (es decir, el modo en que opera el pensamiento de Estado y la manera en que es reproducido, apropiado o resignificado por diversos actores sociales). En estos espacios sociales históricamente monopolizados por el Estado, esto es, producidos como extensiones o parcelas materiales y simbólicas del territorio de la nación, a través de los rituales, en tanto manifestación del carácter material de la ideología (Althusser, 2003[1969]) ${ }^{51}$, es posible conocer más de cerca la apropiación y resignificación de determinadas visiones y divisiones que propone el Estado como naturales y dadas. Los actos escolares como los rituales patrióticos desarrollados en la escuela pueden ser considerados como "un acto político para crear, formatear y mantener lo común (lo nacional) siempre amenazado por las diferencias" (Díaz y Valdez, 2009). En el espacio escolar, como señala Amuchástegui, el análisis de los rituales permite aprehender los sentidos atribuidos a estas prácticas como expresión de normas vinculadas al orden social y político enseñado allí. De acuerdo con el lugar que se ocupe en ese orden escolar, las prescripciones acerca del comportamiento correcto, que involucra los cuerpos y las mentes, dan cuenta del lugar que asumen y se les asigna a los sujetos en el orden social y político expresado en las acciones educativas. En este sentido, los actos escolares pueden ser analizados a partir de su capacidad para representar sentidos del orden social, del lugar de los sujetos y del vínculo entre ambos (Amuchástegui, 2005). El análisis histórico y etnográfico de estos contenidos educativos propende a diferenciar, por un lado, contenidos coyunturales y de larga duración dispuestos para mantener o transformar las relaciones de poder $\mathrm{y}$, por el otro, contenidos establecidos a través de mecanismos de mediación y coerción estatal y aquellos derivados de apropiaciones hechas por los sujetos

\footnotetext{
51 Althusser identifica la escuela como el aparato ideológico de Estado (AIE) dominante en las formaciones sociales capitalistas (Althusser, 2003 [1969]). Según la interpretación de Balibar (1991), la expresión aparatos ideológicos de Estado (AEI) no designa el funcionamiento de una institución que por sí misma constituye un AIE, sino el funcionamiento combinado de varias instituciones dominantes que conforman un AIE. Es decir, no habría más que “un `aparato ideológico de Estado' que domina en las formaciones sociales burguesas, que utiliza para sus propios fines las instituciones escolar y familiar y, en forma accesoria, otras instituciones incorporadas a la escuela y a la familia, cuya existencia está en la base de la hegemonía del nacionalismo" (Balibar, 1991:159).
} 
de la vida escolar y que producen la transformación, la diversificación y la historicidad de la escuela (Rockwell, 2009).

En el análisis de la vida escolar considero, en particular, un tipo de conocimiento local objetivado en el quehacer cotidiano de los maestros y marcado por la historia de cada escuela: el saber docente. Este saber, construido en el proceso del trabajo docente, en la relación entre las biografías particulares de los maestros y la historia social e institucional experimentada, se vincula con la práctica docente y con los demás conocimientos que requiere el trabajo de maestro. Se trata de saberes que son utilizados por los maestros en su práctica diaria, adquieren sentido dentro del contexto de cada aula y conforman una matriz que reelabora los conocimientos pedagógicos transmitidos durante su formación y las disposiciones oficiales que reciben las escuelas (Rockwell, 2009). Para su indagación, me detengo especialmente en las categorizaciones que se producen en la vida cotidiana de la escuela, ya que éstas "crean entre los profesionales un marco común de comprensión que prefigura lo que ha de ser visto y cómo proceder para resolver los problemas así identificados", al mismo tiempo que "la aceptación institucional de la validez de las categorías desarrolla la tendencia a encontrar sujetos que encajen en ellas" (Franzé et al. 2011: 281).

Aunque las migraciones son un fenómeno universal, la manera en que son pensadas y tratadas presenta importantes variaciones según los contextos históricos y geográficos particulares (Gil Araujo, 2007). Como señalan Feldman-Bianco y demás colegas, reflexionar acerca de la construcción social y política del sujeto migrante contemporáneo, tratándose de una actividad performativa siempre contingente, implica "una comprehensión de los procesos históricos, las continuidades y discontinuidades sociales, las políticas situadas en las que pueden leerse las interconexiones entre lo local y lo global, las negociaciones, las tensiones e interacciones entre múltiples actores, así como el reconocimiento de las similitudes $\mathrm{y}$, al mismo tiempo, de la heterogeneidad entre los migrantes de nuestra región, sus contradicciones y ambigüedades" (Feldman-Bianco et al., 2011: 17). Para comprender la configuración particular que adquiere la visión de Estado sobre la inmigración y los inmigrantes en determinados momentos sociohistóricos y contextos sociales específicos de la Argentina contemporánea, inicialmente me centro en las representaciones y prácticas estatales relacionados con la cuestión migratoria en el escenario nacional, entendiendo que la visión resultante es producto de múltiples tensiones, préstamos, intercambios, disputas y acuerdos que trascienden el ámbito nacional e involucran escenas, espacios y actores que interactúan a diversas escalas. Es 
decir, el estudio toma en cuenta la existencia de redes y relaciones transnacionales (Mato, 2004), otorgándole especial atención a la creciente participación de los organismos internacionales, en particular aquellas con alcance global o vocación globalista, en la elaboración y difusión de determinadas representaciones y prácticas sociales que intervienen en la configuración del orden estatal. ${ }^{52}$ Así, esta mirada contempla el fenómeno de la transnacionalización de determinadas áreas de política pública como los asuntos migratorios y educativos. En otras palabras, entiendo que la visión de Estado, aunque siempre definida nacionalmente, no es un producto exclusivo de la actuación del Estado nacional, sino también de espacios y actores supranacionales que colaboran en su conformación, validación y consolidación.

La aparición de las migraciones internacionales, en especial las denominadas ilegales, como asunto político-económico de envergadura en la escena mundial ha dado lugar a una perspectiva divulgada como migration management o, más recientemente, migration governance, cuya traducción más frecuente al castellano es gobernabilidad migratoria, que propone un régimen global de control de los flujos migratorios internacionales, denominado por uno de sus mayores ideólogos como nuevo régimen internacional para el movimiento ordenado de las personas (Ghosh, 2008), resignificando algunas de las clasificaciones convencionales en torno a las migraciones internacionales. Bajo este enfoque se postula una nueva manera de organizar, clasificar y controlar los movimientos internacionales de población, basada fundamentalmente en las nociones de equilibrio y eficacia. Los migrantes son categorizados en base a una supuesta (in)utilidad, estableciendo una serie de ventajas o beneficios y desventajas o perjuicios (no sólo económicos) de la migración: serán deseables o indeseables de acuerdo a su carácter ordenado/desordenado, voluntario/forzoso y reducido/masivo. De ello se deriva un excedente de movilidad (Mezzadra, 2012) que, bajo la perspectiva de la gobernabilidad migratoria, es identificado como objeto de control y vigilancia.

Entiendo que la perspectiva de la gobernabilidad migratoria, identificada en esta investigación para el caso argentino, es una forma ideológica concreta que asume la visión

\footnotetext{
52 Según la tipología propuesta por Portes (2003), las actividades transfronterizas de diferentes actores sociales pueden ser internacionales, multinacionales o transnacionales. Establece una distinción entre las actividades internacionales de los gobiernos y otras instituciones que se identifican con un Estado-nación particular, las iniciativas multinacionales de instituciones globales (como diversas agencias de Naciones Unidas y la Iglesia Católica) y las actividades transnacionales de las ONG y actores no corporativos provenientes de la sociedad civil, entre los cuales considera las asociaciones de migrantes transnacionales.
} 
de Estado en materia de migraciones internacionales. En una de las tantas acepciones de la noción de ideología, la gobernabilidad migratoria constituye, a mi modo de ver, una "resolución imaginaria de contradicciones reales" (Eagleton, 1997: 24). Surgida en los años setenta con los informes de la Trilateral Commission, difundida en los ochenta por el Banco Mundial y retomada en los noventa por las Naciones Unidas a instancias del gobierno sueco, la noción de gobernabilidad comenzó a aparecer en el terreno de las migraciones promovida, principalmente, por la OIM en un contexto de profundas transformaciones en el orden internacional y el ingreso de las migraciones internacionales entre los asuntos políticos de mayor relevancia mundial.53 También en esta década, la inmigración ilegal se incorporó a la agenda de la Unión Europea, la OCDE, la OIM y muchas otras agencias y se colocó a la cabeza de las preocupaciones de política internacional junto al comercio de armas, el tráfico de drogas y el crimen organizado, al mismo tiempo que el combate a la inmigración ilegal se extendió a otros terrenos de políticas como la ayuda al desarrollo, el comercio y las relaciones internacionales en general (Düvell, 2008). Los diagnósticos realizados por instituciones supranacionales, consultores internacionales y académicos asociados a reconocidos centros de investigación y think tanks (en muchos casos, actuando como voceros de diversas agencias globales) convinieron en que se trataba de un estado de desgobernabilidad o crisis migratoria. En América Latina, esta desgobernabilidad migratoria (Mármora, 2002) se habría producido por los cambios en los patrones migratorios internacionales durante la década de los noventa y las dificultades de los Estados para darles respuesta, motivando distintas acciones bi y multilaterales a través de espacios de integración subregional y la formación de procesos consultivos especializados en la temática migratoria (Mármora, 2003). Entre los aspectos que compondrían esta crisis, Mármora apunta "el aumento de la irregularidad migratoria, el incremento de las situaciones de xenofobia y discriminación, el aumento del negocio de las migraciones, la incongruencia entre políticas migratorias y los espacios regionales de integración económica, los problemas de relaciones bilaterales entre países con flujos migratorios fronterizos, y la ruptura de la funcionalidad de las políticas migratorias en relación con los requerimientos de mano de obra y de recambio poblacional" (Mármora, 2004: 3). En otra parte, ha señalado específicamente el "incremento de migrantes en situación irregular" y los "mecanismos de tráfico e introducción clandestina de personas asociados a este fenómeno" como ejemplos ilustrativos de los "problemas de gobernabilidad existentes" (Mármora, 2002: 46). Descartada la posibilidad de utilizar medidas unilaterales, la superación de esta crisis requeriría de modalidades bi y

53 Acerca del concepto de gobernabilidad y su aplicación a la regulación de las migraciones internacionales, véanse también Badie et al. (2008) y Betts (2011). 
multilaterales que permitan alcanzar los acuerdos regionales necesarios en materia de políticas migratorias que favorezcan la gobernabilidad de los flujos migratorios internacionales. Actores institucionales como la OIM y la CEPAL, como se reconoce en los propios documentos de políticas de estos organismos, "colaboran estrechamente en la consolidación de estas iniciativas orientadas a la gobernabilidad de la migración internacional" en la región (Martínez Pizarro, 2001: 16).

Entre las definiciones elaboradas por quienes han propiciado este enfoque en la región y que circulan por ámbitos de gobierno, donde disfrutan además de amplia aceptación, algunas resultan esclarecedoras para dilucidar la visión de Estado que se construye en la Argentina reciente en materia migratoria. Para Calcagno y Mármora, la llamada gobernabilidad migratoria, enarbolada como el principal desafío de las actuales políticas migratorias (Mármora, 1996), consiste en "el ajuste entre las características, causas y efectos del fenómeno migratorio, las expectativas y demandas sociales sobre el mismo, y las posibilidades reales de los Estados para darles respuesta" (Mármora, 2002: 390). Según su planteo, un esquema de gobernabilidad migratoria, como cualquiera otra "forma de gobernabilidad" (Mármora, 2002), debe incluir dos elementos básicos: la legitimidad y la eficacia. Entre los componentes principales del primero, la legitimidad, identifica a) la equidad con que los Estados respondan a las demandas que se generan alrededor de las migraciones, cuyo mecanismo básico sería el consenso de intereses entre los países involucrados y los diferentes sectores de la sociedad receptora; b) el cumplimiento de los acuerdos y principios de alcance nacional e internacional, así como su coherencia con los principios y valores aceptados universalmente; y c) la transparencia en el manejo del proceso migratorio. El segundo elemento, la eficacia con que se consigan los objetivos establecidos de las políticas y programas migratorios, reconoce entre sus componentes a) el conocimiento objetivo del hecho migratorio (que comprende, a su vez, cuatro aspectos centrales: la elaboración de la información migratoria, el diagnóstico de los procesos migratorios, las fuentes de datos y la difusión e intercambio de la información), b) el realismo en los objetivos (entendido como la concordancia entre las metas establecidas, tanto de las estrategias, acciones o normas que se adopten frente al fenómeno migratorio, como de los medios disponibles para poder cumplirlas) y c) la eficiencia administrativa, compuesta por la articulación interinstitucional y la gestión migratoria (Mármora, 1996; 2002). ${ }^{54}$

54 En uno de los primeros artículos dedicado a la gobernabilidad migratoria (Mármora, 1996), la eficiencia administrativa, además de contemplar lo que llama la articulación interinstitucional y la gestión migratoria, también 
Tradicionalmente, la sociología, como señalara Elias (1990) a comienzos de los años ochenta, ha privilegiado el estudio de problemas de un único plano social, esto es, restringido a los límites del Estado, relegando los problemas interestatales a otros campos disciplinares (como la ciencia política o las relaciones internacionales) por no considerarlos problemas sociológicos. Él, por el contrario, se pronuncia a favor de una mirada sociológica que contemple la interrelación entre los asuntos internos del Estado y los interestatales. ${ }^{55}$ En este sentido, considera que los eventos que tienen lugar dentro del Estado nunca han estado tan inextricablemente ligados a los acontecimientos internacionales, en particular las relaciones de poder interestatales, como en el siglo veinte. ${ }^{56}$ La inmigración, por su parte, en tanto conecta por definición dos o más Estados nacionales, difícilmente pueda pensarse por fuera de esta interrelación, ya sea que encuentre expresión a través de acuerdos bi o multilaterales, convenios enmarcados en políticas de integración regional o tratados internacionales. La misma autoridad estatal para regular la movilidad humana, como producto de un consenso entre Estados nacionales interesados en controlar los movimientos poblacionales que suceden a través de sus territorios y fronteras, es fundamentalmente una derivación de las atribuciones del sistema internacional, organizado como sistema interestatal (Torpey, 2000). Es decir, la reflexión sobre la inmigración supone pensar el Estado en relación al orden internacional en su conjunto. Las migraciones internacionales, expresan las relaciones de poder y dominación existentes a nivel mundial entre Estados, sean clasificados como centrales o periféricos, desarrollados o subdesarrollados, ricos o pobres: dicha asimetría o desigualdad estructural está en la base de la determinación y perpetuación de los movimientos migratorios contemporáneos orientados desde el Sur hacia el Norte y detrás de las posiciones sociales diferenciales que se les confiere y asumen los inmigrantes en las sociedades de destino o recepción de acuerdo a su origen nacional y social (Sayad, 1989).57

incluía un punto referido a la legislación migratoria donde aboga por una normativa actualizada que considere tanto sus fuentes (acuerdos internacionales y legislación interna) como su contenido.

55 En relación a ello, vale la pena recordar que en Notas sobre Maquiavelo, sobre la política y sobre el Estado moderno, cuando Gramsci invita a examinar "las relaciones orgánicas entre la política y exterior de un Estado", también se pregunta bajo una mirada relacional: “¿Es la política interior determinante de la exterior o viceversa?”. También sugiere la conveniencia de diferenciar "las grandes potencias con relativa autonomía internacional, y las demás potencias”, además de analizar las diversas formas de gobierno (Gramsci, 1984:160).

56 Para un sugerente análisis de la obra de Norbert Elias y su aproximación a las relaciones internacionales, véase Devin (2005).

57 Como señala Balibar, “la línea de demarcación entre `Norte’ y `Sur', entre zonas de properidad y de poder y zonas 'de desarrollo y de subdesarrollo' no está trazada de forma estable. El 'Norte’ mismo está lleno de 'Sur', y el `Sur’ no renuncia a formar parte del 'Norte'” (Balibar, 2008:39). 
Por lo tanto, además del origen social, entra en juego el origen nacional de los extranjeros: no se trata sólo de extranjeros, sino de extranjeros clasificados de acuerdo a la posición que ocupan los Estados de los cuales son ciudadanos o nacionales (o con la nacionalidad que se los identifica socialmente más allá de su pertenencia jurídica) en la jerarquía del orden interestatal. Estas clasificaciones, que ponen en relación lo macro con lo microsocial, participan de las relaciones sociales que se desenvuelven cotidianamente en diversos espacios sociales como el escolar donde la división entre nacionales y nonacionales, origen de las más diversas desigualdades, cobra una particular relevancia.

Precisamente, las definiciones clásicas (y no tanto) acerca de la migración no permiten advertir que la relevancia que ha adquirido en escenarios locales como globales no deriva tanto de las características demográficas de los flujos migratorios como de los atributos político-ideológicos que se le asignan a la emigración o la inmigración según el momento histórico y contexto social en que tenga lugar. Parafraseando a Balibar (2008), podríamos decir que ningún inmigrante es un hombre o mujer sin cualidades, sino siempre un individuo con sus propiedades sociales y morales: de acuerdo a los atributos que le asignen, es un buen inmigrante o un mal inmigrante, un inmigrante deseable o indeseable, un inmigrante útil o improductivo. Que los migrantes, según las coyunturas históricas y sociales, sean concebidos como deseables o indeseables, o que algunos flujos migratorios sean leídos en términos positivos o negativos, destacando sus ventajas o desventajas, sus cargas o contribuciones, revela la dimensión político-ideológica de la migración. Y es, precisamente, la interpretación política de estos desplazamientos humanos en el espacio y en el tiempo lo que la ha colocado en el centro de los debates públicos. La relevancia que fue adquiriendo paulatinamente, tanto en ámbitos nacionales como internacionales, hasta convertirse en uno de los grandes temas o preocupaciones de la llamada comunidad internacional, se corresponde con la lectura política que se ha hecho sobre los efectos o las consecuencias de la movilidad humana a escala mundial, en particular a partir del modo en que afectan a los países centrales. Son especialmente los flujos migratorios Sur-Norte los que han provocado, a esta altura, infinidades de reuniones y documentos internacionales sobre este fenómeno global. No hay ninguna duda que si las migraciones internacionales se produjeran exclusivamente a través del eje Sur-Sur, otra sería la atención que recibirían. Las preocupaciones de la comunidad internacional relacionadas con la migración se circunscriben fundamentalmente a la proporción que representa la migración Sur-Norte sobre el total de los desplazamientos internacionales. 
A pesar de la antigüedad que posee la inmigración como hecho social, el problema social que constituye para la sociedad de recepción (incluido el Estado) es independiente de esa realidad fenoménica y posee determinadas condiciones sociales de posibilidad (Sayad, 1999). El dominio del Estado, como indica Bourdieu, se puede apreciar especialmente en el ámbito de la producción simbólica: "las administraciones públicas y sus representantes son grandes productores de 'problemas sociales' que la ciencia social con frecuencia se limita a ratificar, asumiéndolos como propios en tanto que problemas sociológicos" (Bourdieu, 1997: 95). ${ }^{58}$ El Estado, como plantea Sayad, es el principal lugar donde la inmigración es construida como problema. Es a través del trabajo de creación del Estado y de sus diversos agentes e instituciones que el inmigrante/inmigrado pasa a existir socialmente. Uno de los modos en que se define su existencia y adquiere entidad se produce a partir de su configuración como problema y los problemas que aparecen asociados a la inmigración, un problema medular que revela otros problemas, un problema en relación al cual los otros problemas no son más que asuntos secundarios. ${ }^{59} \mathrm{Se}$ erige como problema debido a los intereses que afecta en la sociedad de acogida, al orden -el orden social, económico, político, jurídico, moral, policial o estético- que trastoca y pretende ser restablecido (es en este sentido que muchas de las respuestas políticas a la inmigración pueden ser interpretadas). Pero se trata de un orden social, económico, político, jurídico, moral, policial o estético definido en términos nacionales. En última instancia, la inmigración, a través de la figura del inmigrante, en tanto extranjero, el orden que altera, que desafía, es el orden nacional: con su presencia, real o imaginaria, el extranjero cuestiona ciertos parámetros establecidos como naturales para la convivencia cotidiana y revela la arbitrariedad con que operan las clasificaciones estatales en distintos espacios para regular la vida social (Sayad, 1996, 1998, 1999). La denominada inmigración ilegal, en particular, es disruptiva en tanto desestabiliza la autoridad del Estado soberano (Doty, 1996).

\footnotetext{
58 Sayad (1998) se refiere a la inmigración como problemática impuesta. Esta imposición se pronuncia de manera elocuente cuando el inmigrante es percibido, definido, pensado o enunciado, en breve interpelado, como problema social, sea de manera explícita o implícita. La percepción colectiva en torno a la inmigración de la cual participa tanto el discurso político como académico contenida en la definición que se asume naturalmente y se actualiza a través de intervenciones discursivas y prácticas cotidianas está estrechamente ligada con la visión del orden social y político y las categorías de nuestro entendimiento político (y no sólo político) que en buena medida están definidas estatalmente o en términos nacionales.

59 Según Sayad (1998:15), el discurso sobre el inmigrante y la inmigración establece una relación indefectible con otros objetos o problemas para poder hablar de su objeto: sólo a través de los diferentes problemas a los cuales son asociados es que los inmigrantes son "nominados, captados y tratados". Aquí los "problemas" son entendidos tanto como "dificultades", “disturbios" o "daños" y como "problemática constituida de forma crítica en relación a un objeto que crea necesariamente un problema" y que debe su existencia a los problemas que representa para la sociedad.
} 
La sociología constructivista ha aportado de manera sustantiva a la comprensión de la producción material y simbólica de los problemas sociales o públicos que se tratan en esta tesis en relación a la migración y los inmigrantes. ${ }^{60}$ Frente a las aproximaciones objetivistas, Blumer (1971) señaló hace varias décadas la necesidad de desarrollar una "nueva perspectiva y enfoque en el estudio sociológico de los problemas sociales". En este sentido, postuló que los problemas sociales son producto de un proceso de definición colectiva que determina su emergencia, el modo en que son vistos, la manera en que son abordados y tratados y el tipo de plan oficial que se elabora y se aplica como solución. Con ello tomaba distancia de aquellos enfoques que interpretaban los problemas sociales en el marco de una sociedad socialmente sana afectada por hechos sociales de naturaleza intrínsecamente buena o mala, asumiéndolos como parte de un estado de disfunción, patología, desorganización o desvío. La mirada sociológica que se construyó a partir de estas premisas pretendía identificar las condiciones que causaban el problema y formular propuestas acerca de la manera en que los problemas debían ser manejados. Para ello, los hallazgos resultantes de los estudios proveerían elementos sólidos y efectivos para el tratamiento del problema. Los trabajos inspirados en los postulados de Blumer, por el contrario, parten de la asunción de que existen hechos sociales que, bajo ciertas condiciones y en diferentes situaciones (sin que necesariamente se verifique un cambio objetivo en el ámbito de la vida social), pueden convertirse en problemas públicos, cuya aparición supone siempre la emergencia de una visión particular del problema que resulta de las luchas entre diferentes actores sociales por la definición de la realidad y el intento de imponer un punto de vista específico (Valcarce, 2005). Una cuestión crucial de las proposiciones de Blumer (1971) es la importancia que le atribuye a las acciones oficiales en la producción de los problemas sociales. Tanto la elaboración de los programas oficiales como su implementación son aspectos constitutivos del proceso de construcción colectiva: "El plan oficial que es aprobado constituye en sí mismo la definición oficial del problema; representa cómo la sociedad a través de su aparato oficial percibe el problema e intenta actuar frente al problema (...) La implementación del plan desemboca en un nuevo proceso de definición colectiva. Crea el marco para la formación de nuevas líneas de acción para aquellos envueltos en el problema social y aquellos afectados por el plan." (Blumer, 1971: 304-305). En otras palabras, como sugiere Valcarce (2005:5), "los planes oficiales contribuyen a darle existencia al problema que dicen atacar".

60 Véase Valcarce (2005) sobre algunas consideraciones fundamentales para una sociología crítica de los problemas públicos. 
En su estudio comparativo sobre las políticas públicas desarrolladas en Francia y Gran Bretaña en materia de migraciones, Favell (2001b) muestra que la inmigración no surge espontáneamente como problema de interés estatal, sino que es producida como tal bajo determinadas circunstancias sociohistóricas. La inmigración derivada de los lazos coloniales y el reclutamiento laboral no se convirtió en una cuestión política destacada en Europa hasta la crisis del petróleo a comienzos de los setenta. Durante el período de posguerra, la inmigración fue vista, en general, como una fuente de mano de obra temporal que resultaba beneficiosa para las economías nacionales. Los conflictos sociales que podían involucrar a los inmigrantes, en tanto eran considerados como nuevos miembros de la clase trabajadora, quedaban subsumidos en la problemática más general del conflicto de clases y la desigualdad social. Recién con la conjunción de diversos factores económicos y políticos fue que la inmigración se convirtió en un asunto de importancia para los Estados: una crisis económica acompañada de un conjunto de transformaciones de las sociedades postindustriales como el retiro del Estado, la disolución de una cultura política unificada y la emergencia de fuerzas que transcendieron el ámbito nacional. La nueva configuración que ha adoptado el discurso sobre la llamada inmigración extracomunitaria en Europa ha llevado a algunos autores como Stolcke (1999) a hablar de la constitución de una nueva retórica de la exclusión. Düvell (2008), por su parte, señala que el miedo a las clases peligrosas y los inmigrantes clandestinos coincide con períodos de cambio radical y de transición en Europa (industrialización y democratización primero, desindustrialización y globalización después). Es decir, la criminalización de ciertas corrientes migratorias y figuras sociales de la migración está invariablemente relacionada con consideraciones acerca del orden social y político y procesos de transformación social más amplios.

La constitución de la inmigración como problema advierte acerca de la necesidad de analizar la visión de Estado con una mirada de largo plazo. Resulta difícil explicar la existencia de una serie de prácticas estatales desarrolladas en el presente sin mirar hacia el pasado donde fueron prefiguradas y se constituyeron como opciones lícitas y legítimas. Como dice Norbert Elias acerca de la escritura de la biografía de una sociedad estatal, "las experiencias de otras épocas continúan actuando en el presente y en el desarrollo de una nación" (Elias, 2009[1989]:191). Así sucede tanto con las acciones de ilegalización y su contraparte, la legalización o regularización, como con los actos escolares en general y los ligados a la construcción de la idea de nación en particular. El presente trabajo de investigación considera, asumiendo que la administración de la migración posee una 
autonomía relativa respecto a otras esferas estatales, que es en el largo plazo que se puede apreciar la constitución de una visión o visiones de Estado sobre la inmigración contemporánea (entre otros objetos sociales cuya construcción está significativamente marcada por el Estado), independientemente del carácter de facto o constitucional o del signo político del gobierno. Aunque por momentos no sean puestas en práctica, distintas disposiciones estatales pueden revelarse como el núcleo duro de una visión de Estado que perdura o trasciende ciertas coyunturas sociales. Aunque determinadas leyes o decretos pierdan vigencia al ser derogados, igualmente pueden contribuir a consolidar a lo largo del tiempo una visión de Estado sobre las migraciones o la identidad nacional y un modo de regularlas muy próximos a parámetros establecidos en épocas anteriores. Lo mismo puede ocurrir con ciertas representaciones y prácticas instituidas en el ámbito escolar inspiradas en antiguos reglamentos o resoluciones ya caducadas. Situado en el presente, este estudio adopta una mirada diacrónica sobre algunas de las prácticas estatales asumidas socialmente como si fueran naturales, fijas o eternas, y tratadas habitualmente como si tuvieran un presente sin pasado. De acuerdo a ello, en esta investigación se historizan las normas y acciones de (i)legalización de los inmigrantes de países limítrofes o los rituales patrióticos desplegados en las escuelas, indagando sus orígenes en tanto prácticas estatales, bajo el entendimiento de que, como dice Bourdieu, “(e)l análisis de la génesis del Estado como fundamento de los principios de visión y de división en vigor en la extensión de su jurisdicción, permite comprender, a la vez, la adhesión dóxica ${ }^{61}$ al orden establecido por el Estado y también los fundamentos propiamente políticos de esta adhesión en apariencia natural” (Bourdieu, 1997:120-121). La historización del presente como opción analítica emparentada con la perspectiva genealógica, retomada en el terreno de las migraciones por Gil Araujo (2007) en su estudio sobre las políticas de integración de inmigrantes en el contexto español, contribuye a desnaturalizar la vida social en la medida que ayuda a desenmascarar el carácter histórico y contingente que poseen las prácticas sociales y la arbitrariedad de las reglas que rigen el orden social.

Una de las fuerzas que subyace a las prácticas de gobierno es la necesidad de reproducir las fronteras (espacial, social, cultural, económica y política) como algo natural, es decir, como dadas y sin necesidad de explicación (Doty, 1996). En este sentido, los diferentes atributos que se asignan a los inmigrantes y que sirven para legitimar las distintas retóricas y prácticas de exclusión (también de inclusión), se apoyan habitualmente en la

61 Bourdieu define la doxa como "un punto de vista particular, el punto de vista de los dominantes, que se presenta y se impone como punto de vista universal; el punto de vista de los que dominan dominando al Estado y que han constituido su punto de vista como punto de vista universal al hacer al Estado" (Bourdieu, 1997:121). 
división entre nacionales y extranjeros, una división que asume la exterioridad a la sociedad nacional que lo recibe como un criterio fundante de la visión que se instituye acerca de la inmigración. Esta exterioridad procede de la institución del vínculo entre el Estado y sus ciudadanos (o nacionales) como natural. Así, como sugiere Pacecca (2000) en su análisis de la política migratoria argentina desarrollada en el siglo veinte, los dispositivos de control sobre los inmigrantes extranjeros, se fundamentan en el presupuesto de la no naturalidad de su vínculo con la comunidad en la que son extranjeros por oposición a la naturalidad del vínculo que con ella tienen los nacionales. En nuestra época, como sostiene Balibar, lo nacional supone de antemano un estatuto privilegiado en tanto para determinados individuos, que son nacionales, la nacionalidad posee un significado efectivo, mientras que para otros no tiene más que un significado ficticio, que no les confiere ningún reconocimiento en particular (Balibar, 2008:37). Aunque la figura más extrema o paradigmática de esta exclusión se halla en los refugiados y los apátridas, un amplio conjunto de inmigrantes como los llamados denizens (Hammar, 1990), que podrían ser reunidos bajo la categoría de no-nacionales que utiliza Sayad, se encuentran en la práctica en la misma o equivalente situación.

Las especificaciones que hacen a la definición e identificación de la figura del inmigrante obedecen a su estatuto político: no es un alienígena más, sino un no-nacional que como tal es excluido del campo político. La producción social del inmigrante como un elemento nonacional "justifica la economía de las exigencias que se tiene con él en materia de igualdad de trato frente a la ley y en la práctica" (Sayad, 1998:58). Los inmigrantes, en tanto nonacionales, no son necesariamente extranjeros en términos jurídicos, sino también en términos sociales. En el país de destino o residencia, son trabajadores no-nacionales, esto es, excluidos de lo político a pesar de su condición de sujetos políticos. Ahora bien, debido a que las fronteras no son inmutables, resulta decisivo comprender el modo en que "los Estados-nación y su población (o algunos de sus elementos) deciden un desplazamiento de las fronteras en unas circunstancias en las que la regla de exclusión se hace históricamente inoperante o en la que resulta imposible mantenerla o adaptarla" (Balibar, 2008:52). Como sostiene Balibar, la ideología o institución nacional se basa en una regla de exclusión con fronteras visibles o invisibles, pero siempre materializadas en unas leyes y unas prácticas. Postula, asimismo, que la exclusión es la "esencia misma de la forma nación": exclusión o, en todo caso, acceso desigual o preferencial a determinados bienes y a determinados derechos, dependiendo de que uno sea nacional o extranjero, es decir, perteneciente o no a una determinada comunidad política. La forma nación, en cuanto estructura, produce una diferenciación y la perpetúa, a la vez que obliga a defenderla. 
Como tal se resiste a la supresión de las fronteras o a su ampliación indefinida y constituye un medio institucional para preservar la regla de la exclusión o para no renunciar a su necesidad. Aunque también hay importantes diferencias históricas, políticas y morales en el modo en que las instituciones practican la regla de la exclusión: puede ser de manera rígida o flexible, de manera restrictiva o expansiva, de manera universalista o discriminatoria, de acuerdo a que si se la asume como un hecho natural o una convención negociable (Balibar, 2008).

La división entre nacionales y no-nacionales encuentra en la escuela, la escuela del Estado en tanto territorio privilegiado de construcción de la nación perteneciente al Estado como esfera política y como modo de producción burocrático ${ }^{62}$ (Enguita, 1988), una de las instituciones estatales que mayormente colabora de manera eficaz en su producción y reproducción. Es que, como dice Thomas Bernhard en su obra "Maestros antiguos", recuperada por Bourdieu (1997), "(l)a escuela es la escuela del Estado, donde se hace de los jóvenes criaturas del Estado, es decir, ni más ni menos que agentes del Estado". ${ }^{3}$ Como sabemos, la educación masiva se produjo históricamente como una función inseparable del Estado: "Los sistemas y las prácticas educativas son patrocinadas, están bajo el mando, son organizadas y certificadas por el Estado" (Torres, 1996:61)". El sistema escolar, definido nacionalmente (es decir, el sistema escolar nacional), al imponer e infundir universalmente, en los límites de su jurisdicción, una cultura dominante constituida en cultura nacional legítima, inculca los fundamentos de una religión cívica -o religión de Estado, según Balibar (1991)- y, en particular, los presupuestos fundamentales de la imagen (nacional) de sí (Bourdieu, 1997). De acuerdo a Balibar, esta analogía entre el

62 De acuerdo a Enguita, la escuela, en tanto esfera política, refiere a una "esfera de la vida social en la cual los individuos que forman una sociedad se relacionan entre sí como iguales, con independencia de su lugar en las esferas económica o familiar" (Enguita, 1988:160); en tanto modo de producción burocrático, la institución escolar produce un sevicio que "satisface como valor de uso unas necesidades que son casi enteramente determinadas por el Estado, tanto si son sentidas como tales por sus consumidores como si no y con independencia de la forma precisa que, eventualmente, pudieran querer darle éstos" (Enguita, 1988:162).

63 Y prosigue diciendo Thomas Bernhard: “Cuando entraba en la escuela, entraba en el Estado, y como el Estado destruye a los seres, entraba en el establecimiento de destrucción de seres. [...] El Estado me ha hecho entrar en él por la fuerza, como por otra parte a todos los demás, y me ha vuelto dócil a él, el Estado, y ha hecho de mí un hombre estatizado, un hombre reglamentado y registrado y dirigido y diplomado, y pervertido y deprimido, como todos los demás. Cuando vemos a los hombres, no vemos más que hombres estatizados, servidores del Estado, quienes, durante toda su vida sirven al Estado y, por lo tanto, durante toda su vida sirven a la contra-natura". Este extracto no ha sido tomado de la traducción al castellano del libro Razones prácticas de Bourdieu, publicado por la editorial Anagrama, que utilizo generalmente aquí, sino de la versión obtenida en http://www.cholonautas.edu.pe/modulo/upload/bourd.pdf por considerarla más exacta. 
nacionalismo y el patriotismo con la religión es factible, en parte, debido a que el discurso teleológico no sólo prescribe una moral social, sino que también ha proporcionado sus modelos a la idealización de la nación, a la sacralización del Estado, las cuales permiten instaurar entre los individuos el vínculo del sacrificio y conferir a las normas jurídicas la marca de la verdad y de la ley. Esta analogía supone una transferencia entre una y otra comunidad, la religiosa y la nacional, sólo posible porque se trata de un tipo distinto de comunidad: la ideología nacional encierra ideales a los que se transfieren sentimientos relacionados con lo sagrado o con el amor, respeto, sacrificio o temor que han cimentado las comunidades religiosas (Balibar, 1991).

Según Balibar, las instituciones fundamentales de la forma nación -como la escuela- crean pertenencias dobles, identidades primarias y secundarias. La identidad nacional sería "una identidad secundaria que presupone unas identidades primarias, de forma que se puede distinguir de ellas, establecerse por encima de ellas y legitimarlas para sus propios fines" (Balibar, 2008:58-59). Debido a que las identidades primarias (identidades de clase, regionales, lingüísticas, religiosas, familiares y sexuales) no se pueden transformar inmediatamente en identidades secundarias (nacionales, cívicas), es preciso que sean trabajadas, es decir, sometidas a un proceso de destrucción y reconstrucción que supone el ejercicio de la violencia estructural (o violencia simbólica). ${ }^{64}$ Para Balibar, un primer tipo de violencia, de carácter permanente aunque difuso, atañe intrínsecamente al proceso de formación o Bildungsprozess y, de forma más general, al proceso de identificación controlado por la hegemonía nacional o religiosa. Un segundo tipo de violencia, que remite a la cuestión multicultural, proviene de que determinada identidad lingüística, religiosa, geográfica o histórica no sea oficialmente considerada o excluida como una de las mediaciones legítimas de la identidad nacional en tanto identidad secundaria. Para Balibar se trata de exclusión debido a que la lógica de la hegemonía, por el contrario, sería poder recurrir a todas las identidades primarias para integrarlas en la comunidad nacional o construir una etnicidad ficticia. ${ }^{65}$ El tercer tipo de violencia, señalado por Balibar, se

\footnotetext{
64 De acuerdo a Bourdieu, la violencia simbólica que ejerce el Estado resulta posible debido a que se encarna tanto en la objetividad bajo la forma de estructuras y mecanismos específicos como también en la subjetividad bajo la forma de estructuras mentales, de categorías de percepción y de pensamiento. Así, dice Bourdieu, “la institución instituida hace olvidar que es la resultante de una larga serie de actos de institución y se presenta con todas las apariencias de lo natural." (Bourdieu, 1997:98).

65 Balibar denomina etnicidad ficticia a "la comunidad formada por el Estado nacional". Aclara que la noción de ficción no debe ser entendida como "pura y simple ilusión sin efectos históricos", sino en su sentido de "efecto institucional”, es decir, como "fabricación”. Afirma Balibar: "Ninguna nación posee naturalmente una base étnica, pero a medida que las formaciones sociales se nacionalizan, las poblaciones que incluyen, que se reparten o dominan
} 
desarrolla cuando las instituciones clave de la forma nación dejan de complementarse y de operar en un mismo sentido, es decir, el de la integración ideológica (Balibar, 2008).

Junto a ello, las figuras de la presencia ausente y de la ausencia presente combinadas con su provisoriedad, de hecho o de derecho, o de su durabilidad que propone Abdelmalek Sayad en relación a la inmigración/emigración también tienen una importante utilidad interpretativa y explicativa para pensar la relación entre el Estado, la escuela y la migración y los modos en que la presencia inmigrante en tanto presencia no-nacional es construida como (i)legal o (i)legítima. Sayad (1998) señala que a medida que la inmigración se distancia de la definición ortodoxa y de la representación ideal se ponen al descubierto las paradojas que la constituyen y se desenmascaran las ilusiones que configuran la propia condición de llegada y de perpetuación de la emigración y la inmigración. Estas ilusiones son colectivamente mantenidas por una especie de complicidad objetiva, compartida por la sociedad de emigración, la sociedad de inmigración y los propios emigrantes/inmigrantes. Esto se produce debido a que las ilusiones que les son comunes proceden de las mismas categorías de pensamiento, que también son categorías sociales, económicas, culturales, políticas, y del Estado (nacional o nacionalista). En la medida que la presencia del inmigrante es una presencia extranjera o que es percibida como tal, las ilusiones asociadas a ella y que al mismo tiempo la constituyen ponen al descubierto las certezas y sospechas que la rodean: la ilusión de una presencia/ausencia necesariamente provisoria (de hecho o de derecho) o una presencia/ausencia durable, cuando no definitiva, acompañada de la ilusión de una neutralidad política, que no sólo es exigida al inmigrante, sino también se impone al propio fenómeno de la inmigración o emigración, cuya naturaleza intrínsecamente política es enmascarada, cuando no negada, en provecho únicamente de su función económica.

De acuerdo a Sayad, una de las características fundamentales del fenómeno de la inmigración, es que, más allá de algunas situaciones excepcionales, contribuye a ocultar su propia verdad. Dado que no consigue hacer compatible una situación de derecho y de hecho, la inmigración estaría condenada a engendrar una situación que pareciera estar destinada a una doble contradicción. En este sentido, Sayad señala que todo acontece como si para poder perpetuarse y reproducirse la inmigración necesitase ignorarse (o

quedan 'etnificadas', es decir, quedan representadas en el pasado o en el futuro como si formaran una comunidad natural, que posee por sí misma una identidad de origen, de cultura, de intereses, que trasciende a los individuos y las condiciones sociales" (Balibar, 1991:149). 
hacer que se ignora) y ser ignorada en cuanto provisoria y, al mismo tiempo, no admitirse ni admitirla como trasplante definitivo. Esta contradicción fundamental, que a su modo de ver sería constitutiva de la propia condición del inmigrante, impondría a todos el mantenimiento de la ilusión colectiva de un estado que no es ni provisorio ni permanente o de un estado que sólo es admitido como provisorio (de derecho) con la condición de que ese provisorio pueda durar indefinidamente, o como definitivo (de hecho) con la condición de que ese definitivo jamás sea enunciado como tal (Sayad, 1998).

Así como, según Sayad, la inmigración permite tanto como exige reflexionar sobre las relaciones entre lo nacional y lo no-nacional, tratándose de una división que pertenece totalmente al orden de lo arbitrario en el sentido estrictamente lógico del término (es decir, que lo contrario puede ser igualmente verdadero) (Sayad, 1996), esta investigación también contempla la inmigración como un lugar que habilita y obliga a indagar la demarcación arbitraria entre lo legal y lo ilegal. En el terreno de las migraciones y su regulación política, las categorías que se desprenden de estos principios de exclusión y diferenciación (por ejemplo, legales/ilegales o regulares/irregulares), que afectan amplios sectores sociales, pueden funcionar en determinados contextos y coyunturas sociohistóricas y espacios sociales como una categoría subsidiaria de la división nacionales/extranjeros. Entre los modos estatales de nombrar a los inmigrantes, aquellas etiquetas que apelan ya sea a la ilegalidad o a la irregularidad para calificar a los inmigrantes o las migraciones, resultan un poderoso instrumento de clasificación de la población inmigrante. La discusión alrededor de la terminología adecuada para nombrar a los inmigrantes de acuerdo a su estatus legal pone de manifiesto de que se trata de un problema epistemológico y conceptual central con ramificaciones metodológicas, implicaciones éticas y repercusiones políticas significativas (De Genova, 2002). Como señala Düvell (2008), la terminología a utilizar, así como el cuidado que requiere por parte de los investigadores sociales, importa en tanto invoca determinados entendimientos y desencadena procesos cognitivos específicos (Goffman) a la vez que confirma la semántica de las estructuras de poder (Luhman) que, en última instancia, refuerza la exclusión del grupo social involucrado.

Algunas etnografías comparadas del Estado en regiones afectadas duramente por reformas políticas y económicas (África, América Latina y sur de Asia), distanciándose de la idea de que estas reformas habrían producido un debilitamiento o achicamiento de las formas de regulación y pertenencia que supuestamente constituyen el Estado-nación 
moderno, examinan los márgenes del Estado, tanto territoriales como sociales, para profundizar su comprensión: asumen que dichos márgenes son supuestos necesarios del Estado de la misma manera que la excepción es a la regla. De ahí su inquietante pregunta: ¿acaso no son las formas de ilegalidad, pertenencia parcial y desorden que parecen habitar los márgenes estatales las que constituyen las condiciones necesarias para el Estado en tanto objeto teórico y político? (Das y Poole, 2008). ${ }^{66}$ Los márgenes son comprendidos aquí como lugares no meramente territoriales, sino también (o especialmente) como "sitios de práctica en los que la ley y otras prácticas estatales son colonizadas mediante otras formas de regulación que emanan de las necesidades apremiantes de las poblaciones, con el fin de asegurar la supervivencia política y económica" (Das y Poole, 2008:24). Como señala Doty (1996), la inmigración ilegal es uno de esos espacios ambiguos localizados en los márgenes del Estado-nación.

En este estudio se entiende la ilegalidad migratoria como una construcción social y política sujeta a determinadas estructuras, contextos y coyunturas sociohistóricas. La migración ilegal no es un fenómeno social dado, fijo o independiente, sino que existe porque es construido social, política y legalmente (De Genova, 2002; Düvell, 2008; González Cámara, 2010).67 En este sentido, es preciso considerar que las distintas configuraciones de "ilegalidad" tienen una especificidad histórica y se constituyen mutuamente por corrientes migratorias particulares dentro de regímenes de inmigración de Estados-nación específicos (De Genova, 2002). Dicho punto de partida permite escapar a la esencialización, naturalización o reificación de la cual es objeto la migración ilegal, tanto en el discurso social, político y académico, cuando es pensada como "un hecho dado, inmutable e independiente del contexto social, político y legal en el que se ha generado" (González Cámara, 2010:673). Erigida como una construcción específica del siglo veinte (Düvell, 2008) resultante de la monopolización estatal de los medios legítimos de movimiento (Torpey, 2000), la migración ilegal, aunque siempre sujeta al orden nacional, ha pasado a ser edificada y colocada en el nuevo orden global entre los principales cuestiones que atañen a la "comunidad internacional", colaborando en su fabricación como una entidad social con existencia propia.

\footnotetext{
66 Véase Eguiguren (2011) para un análisis que considera la noción de márgenes del Estado en el terreno de la política migratoria a partir del caso ecuatoriano.

67 Como observa De Genova (2002), no hay comunidades herméticamente cerradas de migrantes indocumentados. En la vida cotidiana, los migrantes indocumentados están siempre envueltos en relaciones sociales con migrantes "legales" y en proximidad muy íntima a diversas categorías de personas "documentadas", sea como miembros de la familia (a menudo compartiendo el mismo hogar), vecinos o compañeros de trabajo, entre otros.
} 
De Genova habla de la producción legal de la ilegalidad para referirse a la "ilegalidad" como "un factor determinante (o real) de abstracción producida como efecto de la materialidad práctica de la ley" (De Genova, 2002:424). La ley define los parámetros de sus propias operaciones, generando las condiciones de posibilidad para la conformación de lo legal así como de lo ilegal.68 Así, las "ilegalidades" son constituidas y reglamentadas por la ley, directa o explícitamente, de modo que presume ser más o menos definitiva, con múltiples ambigüedades e indeterminaciones siempre manipulables en la práctica y, además, con un considerable grado de deliberación calculado. Esto no significa que la "ilegalidad" migratoria se produzca sólo como un efecto de la ley o de intervenciones legales deliberadas: su producción es también un efecto ideológico de una formación discursiva que comprende el debate público más amplio (De Genova, 2002; 2003). Por otro lado, De Genova considera que la "ilegalidad" es producto de la legislación migratoria no sólo en el sentido abstracto de que sin la ley nada podría ser interpretado como fuera de la ley, ni en el sentido genérico de que la ley de inmigración construye, diferencia y clasifica las distintas categorías de "extranjeros", sino en un sentido más profundo: la historia de las intervenciones deliberadas que han revisado y reformulado la ley ha implicado un proceso activo de inclusión a través de la "ilegalización". Las migraciones no se constituirían como indocumentadas con el fin de excluir físicamente, sino que las incluiría bajo condiciones impuestas de vulnerabilidad forzada y prolongada. De esta manera, la duración de muchos años de "ilegalidad" serviría como un aprendizaje disciplinario de subordinación laboral, tras lo cual ya no sería necesario prolongar la condición de indocumentados.

Este estudio presta atención, asimismo, a aquellos procesos administrativos con una fuerte carga política que son presentados como la contracara de las "ilegalizaciones", conocidos como "legalizaciones", "regularizaciones" o "amnistías". Como plantea De Genova, mientras que las "legalizaciones" instituyen una corrección oficial del estatus jurídico para los indocumentados, las "ilegalizaciones" suministran las condiciones de posibilidad de estos programas: "Cada ilegalización implica la posibilidad de su propia rectificación" (De Genova, 2002:429). Además, el carácter invariablemente parcial de los procesos de "legalización" o "regularización" nunca elimina el campo de la "ilegalidad",

68 En su conceptualización del derecho, Gramsci define, casi al paso, el modo en que son concebidos aquellos sujetos cuyo comportamiento transgrede la ley: "los violadores del derecho serían seres antisociales por naturaleza o disminuidos psíquicos" (Gramsci, 1984:162). 
sino que más bien refina y reconstituye ese campo para los que no resultan elegibles y permanecen indocumentados a la par de todas las posteriores llegadas "ilegales".

En suma, la denominada migración ilegal no es simplemente la consecuencia de ingresar o permanecer sin autorización en el territorio nacional de un Estado infringiendo las leyes establecidas allí. No se trata, como sugiere Düvell (2008), sólo de una violación o transgresión a la ley. La ilegalidad migratoria, además de designar un status jurídico, que implica una (determinada) relación social con el Estado, señala una particular condición sociopolítica espacializada (De Genova, 2002; 2003). Por ello no se la puede entender, como señala González Cámara (2010), única y exclusivamente en términos jurídicos o restringirla a su definición formal (que es la que otorga habitualmente el Estado). La representación de determinados grupos nacionales como ilícita o ilegal es independiente de su situación administrativa. La inmigración requiere de mucho más que un cruce de fronteras sin autorización estatal o una permanencia más allá del plazo permitido para constituirse en ilegal o irregular. Designa una condición social más que una condición jurídica mediada por una falta administrativa que en ciertas circunstancias es tipificada como delito. Más allá de este hecho legal concreto, lo que en definitiva hace la migración ilegal, es vulnerar el principio de soberanía del Estado. En otras palabras, como dice De Genova, la ilegalidad migratoria no es más que "una transgresión a la autoridad soberana del Estado-nación" (De Genova, 2003:541). ${ }^{69}$ De ahí que poner la aparente naturalidad de la "ilegalidad" migratoria en tela de juicio requiera de una crítica al modo en que los presupuestos y conceptos socioespaciales del nacionalismo han moldeado significativamente la propia conceptualización de la migración en sí (De Genova, 2002).

\section{El Estado y la escuela desde adentro: el trabajo de campo}

El trabajo de campo se desarrolló entre los años 2002 y 2008, esquemáticamente, a través de dos momentos diferentes, mediante la combinación de distintas técnicas de investigación como la observación participante, la entrevista en profundidad y la

69 “El ejercicio absolutista del poder estatal descansa decisivamente sobre la noción de un consentimiento 'democrático' por el que el Estado se inviste con la ficción política del 'contrato social' para autorizarse a actuar en nombre de los ciudadanos soberanos, o por lo menos de 'la mayoría'" (De Genova, 2003:541). 
indagación documental. ${ }^{70}$ Uno dedicado a la esfera escolar, en particular a una institución educativa periurbana de nivel primario, desplegado alrededor de los primeros tres años con un breve regreso al terreno tres años más tarde, y otro destinado, a partir de mediados del año 2004, a la esfera estatal, en especial al ámbito de gobierno de las migraciones. ${ }^{71}$ En estos años, buena parte de la tarea dirigida a escudriñar y analizar estos espacios disímiles ha consistido en documentar lo no-documentado (Rockwell, 2009): lo familiar, lo cotidiano, lo oculto, lo inconsciente. Lo no-documentado como aquél "entramado real de los intereses y poderes de quienes dominan" y "aquella parte de su propia realidad que nunca ponen por escrito" (Rockwell, 2009:21).

En la escuela, el trabajo de campo lo llevé a cabo fundamentalmente entre los años 2002 y 2004. Allí contemplé tanto las relaciones simbólicas como las relaciones sociales materiales dentro y fuera de la escuela (Enguita, 1986), o relaciones sociales del proceso educativo, y los procesos informales de interacción (Enguita, 1995). Durante este período realicé principalmente observaciones periódicas y prolongadas en distintos ámbitos del centro educativo y en situaciones de la vida cotidiana de la escuela (más de un centenar de registros de observaciones): sala de maestros, aula, patio de juegos, entrada y salida de la escuela, actos escolares, eventos sociales organizados por la escuela, movilizaciones de protesta como las "tomas" de la institución llevadas a cabo por un grupo de madres, entre otros. Si bien en estos años desarrollé algunas entrevistas individuales y grupales con docentes, alumnos de quinto grado y madres de alumnos identificados como bolivianos, la mayor parte de las entrevistas en profundidad tuvieron lugar en los años posteriores, especialmente hacia mediados de 2007 y 2008 con las docentes y directivos que permanecían en la institución desde mi ingreso al terreno. ${ }^{72}$ Durante aquellos primeros años también realicé observaciones en distintos eventos públicos organizados por representantes de la colectividad boliviana en Córdoba, tanto en la zona de la escuela

70 En el anexo 1 se presenta un listado completo, en orden cronológico, de las entrevistas realizadas y en el anexo 2 las fuentes documentales utilizadas.

71 Para la realización del trabajo de campo en la escuela resultaron de enorme utilidad diversos textos sobre metodología cualitativa y etnografía: Hammersley y Atkinson (1983), Woods (1987), Goetz y LeCompte (1988), Bertely Busquets (2000) y Guber (2001, 2004). También los diversos artículos de Elsie Rockwell de los años ochenta sobre la etnografía escolar, recientemente reunidos en Rockwell (2009). El texto de Bourdieu (1999b) fue muy importante para comprender todo aquello que entra en juego en la entrevista en tanto relación social. Las reflexiones sobre el proceso de investigación en el terreno de las migraciones contenidas en la obra colectiva de Rivera Sánchez y Lozano Ascencio (2009) también fueron un aporte significativo al momento de volver a revisar algunas cuestiones metodológicas del estudio.

72 Para asegurar el anonimato de aquellas personas que estuvieron involucradas en el desarrollo del trabajo de campo, el nombre de docentes, directivos, madres y alumnos entrevistados ha sido reemplazado por nombres ficticios. 
como en otros puntos de la ciudad: la celebración de los carnavales (febrero), el festejo del día de la "madre boliviana" (mayo), el día de la Independencia de Bolivia (agosto) y la fiesta de la Virgen de Urkupiña y de Copacabana (agosto). Toda la información recogida en la escuela y en los contextos extraescolares fue registrada mediante notas de campo, grabaciones (de audio, principalmente) y fotografías. Una de las maestras, nacida en Bolivia y que se autoadscribía como "boliviana", se convirtió paulatinamente en una de las informantes clave que me facilitó el acceso a información, personas y lugares que de otra manera difícilmente hubiera podido conseguir. También el estrecho vínculo personal establecido con una de las directoras de la institución fue trascendental para comprender las distintas miradas depositadas en la escuela.

Tomé contacto con la institución escolar que había seleccionado de acuerdo a los registros de matrícula escolar obtenidos en el Ministerio de Educación de la provincia y negocié el ingreso a ella a comienzos del año 2002. Según los registros estadísticos, en esta escuela se concentraba un significativo porcentaje de alumnos extranjeros (en términos jurídicos) que, conociendo la población del barrio, debían ser de nacionalidad boliviana. El contacto con la escuela, una vez identificada, lo realicé a través de la vía informal, es decir, utilizando redes de relaciones personales o simplemente "tocando la puerta". Elegí esta opción ya que, en general, el contacto informal y directo suele ser más eficaz y las personas tienden a responder de modo más favorable a una petición directa e interpersonal que a un pedido formal, a través de canales oficiales (Goetz y LeCompte, 1988). El acceso fue a través de la directora, lo cual es importante tener presente, ya que en las organizaciones formales segmentadas jerárquicamente como es el caso de las escuelas, el investigador se puede acercar por una o varias vías y a través de uno o más niveles de jerarquía. Lograr el acceso a través de los responsables de más alto nivel en las instituciones escolares puede tener la ventaja de garantizar la aprobación para el estudio, pero también puede presentar la desventaja de ser rechazado de inmediato o, en caso de ser aceptado, de quedar identificado excesivamente con los niveles superiores de la organización ante los demás miembros (Goetz y LeCompte, 1988). A razón de ello, también busqué contar con la aprobación de mi presencia en el centro por parte de los docentes, dando a conocer primeramente el tema, los propósitos generales y la metodología de la investigación. En esta reunión acordamos, asimismo, la devolución de las conclusiones del estudio, así como algunos adelantos durante la estadía en la escuela. Fueron necesarias varias visitas y contactos (vía teléfono y correo electrónico) para lograr ingresar a la escuela. El ingreso efectivo se demoró más de lo esperado, debido por un lado a los tiempos propios de la 
institución escolar y por el otro a un episodio que llegó a tomar estado público y que detallaré en el capítulo 6.

A partir de mediados de año comencé a frecuentar la escuela de manera regular. Generalmente visité la escuela de manera espontánea (es decir, sin previo aviso) y la estadía diaria en el centro podía ajustarse a la observación específica de una situación concreta, a veces prevista con anticipación (en ocasiones, comunicada previamente por la directora), o a la espera de que sucediera algo de interés para la investigación, lo cual significó permanecer largas horas en el centro educativo. Entre los meses de junio y noviembre me concentré principalmente en realizar observaciones que me permitieran obtener un conocimiento aproximado acerca de lo que era la vida cotidiana en la institución. Para ello intenté cubrir aquello que se vivía en distintos momentos y espacios escolares, especialmente durante el turno de la mañana. Presté atención a las ceremonias de entrada y salida de la escuela y del aula, los recreos, las carteleras (o esteras) colgadas de las paredes, las interacciones entre alumnos y maestras, las conversaciones mantenidas entre docentes en la sala de maestros, determinadas clases en las aulas (en tercer y quinto grado del turno mañana), reuniones del personal docente, encuentros entre miembros de la comunidad educativa y funcionarios del Ministerio de Educación (motivados puntualmente por algún conflicto) y algunas fechas significativas para la escuela (como el aniversario de la institución, el día del maestro, el final de clases o la entrega de diplomas a los alumnos egresados) o celebraciones escolares que hacían alusión o pretendían señalar la presencia de la "comunidad boliviana". Al mismo tiempo mantuve distintas conversaciones informales con la directora (muchas de ellas al finalizar la jornada escolar), la mayoría de las docentes (especialmente del turno mañana), algunas madres de alumnos y la mujer dueña del kiosco (ambulante) de la escuela, quien era nacida en Cochabamba (Bolivia). La sala de maestros resultó un lugar propicio para tomar mis notas de campo y establecer los lazos de confianza con las maestras. Durante este año también realicé unas pocas entrevistas con maestras que en los años anteriores habían protagonizado la organización de algún evento relacionado con la "comunidad boliviana", algunas mujeres bolivianas cuyos hijos asistían a la escuela y dos grupos de alumnos/as de una de las dos secciones de quinto grado del turno de la mañana. También empecé a recoger y seleccionar documentos de la escuela que me permitieran conocer algunos aspectos organizacionales y guiarme en la reconstrucción de la historia de la institución que luego haría. Hacia finales de año entrevisté a dos técnicos del Ministerio de Educación para conocer los detalles de un programa provincial de "atención a la diversidad" que recientemente se había reformulado y renombrado. 
$\mathrm{Al}$ año siguiente, en el 2003, si bien las notas de campo no dejaron de contemplar distintos eventos cotidianos que pudieran ser o no significativos en el momento, las observaciones se focalizaron en ciertos actos organizados para las fechas centrales de las efemérides escolares como el 25 de mayo (Revolución de Mayo o "día de la Patria”), el 9 de Julio (día de la Independencia), el 17 de agosto (aniversario de la muerte San Martín), el 12 de Octubre (el "día de la Raza") y otras celebraciones de menor despliegue escénico como el día de la independencia de Bolivia, el día de las Américas o el día del inmigrante. También tuve la oportunidad de participar de las actividades áulicas que se realizaron en el marco de un proyecto que llevó adelante la profesora de música (acompañada por una profesora de teatro como voluntaria) en ambas secciones del tercer grado del turno mañana dirigido a tematizar la "interculturalidad". Este año también presencié también el multitudinario y rimbombante festejo oficial organizado en ocasión del día del Himno Nacional por el gobierno de la Provincia de Córdoba a través del Ministerio de Educación en el estadio de fútbol más grande de la ciudad. En el 2004 asistí a la escuela para realizar algunas observaciones puntuales relacionadas con celebraciones escolares ligadas a fechas nacionales argentinas y bolivianas como el 25 de mayo y el 6 de agosto respectivamente y el desarrollo de un proyecto áulico denominado "La virgen que nos une" en referencia a la Virgen de Urkupiña oriunda de la región de Cochabamba, Bolivia.

Durante estos años, al mismo tiempo, asistí a diversos eventos sociales organizados por asociaciones de la colectividad boliviana en Córdoba. En el 2002 presencié el festejo del "día de la madre boliviana" en el centro municipal Obispo Mercadillo, la celebración oficial del día de la independencia de Bolivia a cargo del consulado en la plaza central de la ciudad (la Plaza San Martín) y las fiestas desarrolladas en zonas periurbanas de la ciudad como la Virgen de Urkupiña en Villa El Libertador y la Virgen de Copacabana en Villa Esquiú y la celebración de la Navidad en una pequeña capilla del barrio periférico Nuestro Hogar III. En el 2003 registré los festejos del carnaval (durante tres domingos), del día de la madre boliviana en el CPC de Villa El Libertador y en el centro municipal Obispo Mercadillo, las vísperas del día de la independencia de Bolivia a lo largo de avenidas principales de la ciudad (realizado por primera vez) y de la Virgen de Urkupiña en Villa El Libertador. En el año 2004, además de las visitas puntuales a la escuela, comencé con las tareas de recolección, selección y sistematización de documentos oficiales, las cuales continué durante los años subsiguientes. 
En los años 2007 y 2008, luego de sistematizar, ampliar y analizar el material de campo recogido en la escuela, regresé en dos ocasiones al terreno para entrevistar a varias de las maestras y directivos que había conocido durante los primeros años del trabajo de campo. Después de numerosas conversaciones informales durante los años anteriores, finalmente acordé una entrevista con la mujer cochabambina que atendía el kiosco de la escuela debido al lugar preponderante que le confirió la en relación a la "comunidad boliviana". En estos años también entrevisté a algunos referentes políticos con un marcado protagonismo público como el presidente del Centro de Residentes Bolivianos en Córdoba y la vicecónsul de Bolivia. La aprobación de la ley de Educación Nacional a finales del año 2006 implicó una nueva revisión de documentos oficiales centrada en aspectos que pudieran tener alguna consecuencia para los alumnos extranjeros o hijos de inmigrantes, sea directa o indirectamente (desde cuestiones relacionadas con la identidad nacional o la diversidad cultural hasta disposiciones legales que los afectara por su condición de alumnos extranjeros y su situación administrativa o la de sus padres). También la realización de entrevistas con técnicos de la planta permanente del Ministerio de Educación o con profesionales contratados para algún proyecto en particular como los talleres de formación docente en materia de "interculturalidad". Los intentos hechos para entrevistar a funcionarios provinciales del Ministerio de Educación fueron infructuosos. Algunas de las entrevistas que pretendí hacer no pude concretarlas debido a los obstáculos que colocaron y las excusas que otorgaron en cada oportunidad. El caso más patente fue la Directora General de Proyectos y Políticas Educativas: en el año 2007 realicé varios llamados telefónicos y tres visitas al Ministerio de Educación para concertar la entrevista. Durante la última visita me comunicó a través de su secretario que no podría recibirme debido a que dentro de pocos días dejaba su cargo (lo cual era un secreto a voces).

Por otra parte, a partir de mediados del año 2004 comencé a indagar la esfera estatalgubernamental. Para ello, me serví, en primer lugar, de una vasta cantidad de fuentes documentales: normativa jurídica nacional e internacional, documentos de políticas, informes gubernamentales, programas institucionales, declaraciones finales de reuniones internacionales, comunicados oficiales de prensa, páginas de internet y textos hemerográficos. Por otro lado, en lugar de entrevistar a funcionarios nacionales, privilegié trabajar con sus intervenciones públicas, tanto en ámbitos como la Cámara de Diputados de la Nación como en eventos nacionales e internacionales dedicados al tema migratorio, cubriendo el período 2000-2010. Algunas de estas intervenciones estaban disponibles en soporte electrónico y otras fueron obtenidas (grabadas en directo) mediante la asistencia 
a dichos acontecimientos. Si bien el interés mayor estaba centrado en la gestión que, con la aprobación de la "nueva ley de migraciones", dio nacimiento a la "nueva política migratoria", este recurso me permitió acceder tanto al testimonio público de los funcionarios que estuvieron en aquél momento en funciones como al de los antecesores. Para la comprensión de este período también resultó trascendental el vínculo establecido con el Jefe de la Delegación Córdoba de la DNM entre los años 2002 y 2009.

En la Argentina, la sanción de una nueva ley de migraciones y, dos años más adelante, la implementación de un programa de legalización migratoria ofrecieron una cantidad importante de documentos y eventos oficiales para el análisis de la visión de Estado sobre la migración y los inmigrantes. Además de los nuevos documentos resultantes de los cambios en materia de legislación migratoria, las intervenciones de los directores de la DNM, disponibles en versión taquigráfica, en la Cámara de Diputados de la Nación entre los años 2000 y 2003 fueron muy esclarecedores al momento de interpretar lo que oficialmente se llamó la "nueva política migratoria". Durante los años 2005 y 2006 registré $\mathrm{u}$ obtuve las intervenciones públicas de funcionarios gubernamentales en encuentros nacionales (en Córdoba, Rosario y Buenos Aires) organizados por la Dirección Nacional de Migraciones (DNM) del Ministerio del Interior o en los cuales el organismo estuvo presente. La observación directa en un taller desarrollado en el marco de un seminario titulado "Migración y ciudadanía”, organizado por la DNM en el año 2006 y destinado a agentes de la Policía Migratoria Auxiliar, me permitió resituar y redimensionar las declaraciones oficiales relativas a los cambios en la política migratoria argentina. El acceso a las presentaciones hechas en eventos internacionales fue posible gracias a su publicación en los documentos resultantes. De manera complementaria, en los años 2005 y 2007, mantuve dos extensas conversaciones estructuradas como entrevista con el Jefe de la delegación regional de la Dirección Nacional de Migraciones localizada en Córdoba. Cierta confianza con dicho funcionario, obtenida a través de distintos acercamientos y la participación en espacios institucionales compartidos desde que me inicié en el tema migratorio, posibilitó la realización de una entrevista en profundidad diferente a las habituales entrevistas con agentes de gobierno. También entrevisté en Córdoba a algunos funcionarios del ámbito provincial relacionados (coyunturalmente) con la temática migratoria. Mi participación en la Mesa de Diálogo Permanente por los Derechos de las/los Inmigrantes en Córdoba, promovida por la Defensoría del Pueblo provincial, desde mediados del 2007 a comienzos del 2008 y en algunas de las acciones que se desprendieron de dicho espacio como el proyecto InmigrArte, me ofreció la posibilidad de conocer más desde adentro algunas de las dinámicas, tensiones, preocupaciones e 
intereses que toman forma en el ámbito estatal en torno a la migración y los inmigrantes. Me incorporé a este espacio a mediados del 2007 y permanecí hasta su disolución en el 2008. A partir de esta actividad institucional entrevisté a funcionarios provinciales y al presidente de la asociación de inmigrantes bolivianos más antigua de la ciudad. Como ocurriera con la vasta información reunida en lugares extraescolares muchas veces no utilizada, la participación directa en estos espacios -lo cual no formaba parte de esta investigación doctoral- fue de gran ayuda al momento de la interpretación de ciertas representaciones y prácticas, sean gubernamentales o escolares, generadas en torno a la inmigración. En Bolivia, además de reunir documentación sobre la legislación boliviana en materia de migraciones internacionales, durante el mes de octubre del 2006 realicé en la ciudad de La Paz diversas entrevistas con funcionarios de gobierno, principalmente del Ministerio de Relaciones Exteriores y Cultos (Cancillería), y representantes de organizaciones civiles involucradas con la temática migratoria. 



\section{CAPÍTULO 2}

\section{LOS BOLIVIANOS COMO EMIGRANTES: LA VISIÓN DEL ESTADO DE ORIGEN733}

Los movimientos migratorios en el contexto andino ya formaban parte de las estrategias habituales de reproducción de las sociedades del altiplano y de los valles interandinos mucho antes de la formación del Estado-nación moderno en la región sudamericana. A partir de la fundación del Estado boliviano, a excepción de algunas corrientes de población que tuvieron a Bolivia como destino, la historia de las migraciones internacionales del país se caracteriza por un importante proceso de emigración, profundizado en los últimos decenios del siglo veinte. La migración se ha convertido en Bolivia en una realidad estructural y constitutiva, especialmente en las áreas rurales, volviéndose la emigración hacia otros países una práctica cotidiana, arraigada económica y culturalmente (Cortes, 2004a:168, énfasis en el original). Sin embargo, aunque las transformaciones sociales, políticas y económicas en Bolivia repercutieron sustantivamente en las características, composición, volumen y orientación que adoptaron los flujos migratorios, muchos de estos cambios no llegaron a reflejarse en las disposiciones jurídicas del Estado sobre las migraciones internacionales durante el siglo veinte.

Este capítulo analiza primero, a través de un examen minucioso de la legislación migratoria, la visión de Estado que se conforma en Bolivia a lo largo del siglo pasado en relación a las migraciones internacionales y, luego, mediante la exploración de diversas fuentes documentales y algunas entrevistas a agentes del Estado, revisa la visión política que insinuaban las primeras reformulaciones de la política migratoria y el itinerario de la emergencia de la figura de los nacionales en el exterior a partir de los cambios políticos acontecidos en el país con la llegada a la presidencia del Movimiento al Socialismo (MAS) bajo la fórmula compuesta por Evo Morales y Álvaro García Linera. El reconocimiento de la plurinacionalidad llevada adelante significó una reformulación del Estado de carácter inédito en América Latina. En términos de Boaventura de Sousa Santos (2010), dicha experiencia, como parte de un entramado más complejo y abarcativo de cambios de todo

73 Este capítulo, como especifiqué en la introducción, es una versión revisada y corregida de diversos artículos publicados con anterioridad. Dos de ellos son en coautoría. La revisión y reescritura de estos textos fue realizada de acuerdo al propósito del capítulo y los objetivos de la tesis. Para ello se recuperaron las fuentes documentales utilizadas y se realizó un nuevo análisis. 
orden, contribuiría a caracterizarlo como un Estado de las venas cerradas que desafía tanto el capitalismo como el colonialismo.

El análisis muestra aspectos recurrentes en el discurso estatal desplegado a lo largo del siglo pasado: el fomento de la inmigración europea para suplir las necesidades demográficas y económicas del país; la preocupación por la emigración de trabajadores hacia el exterior; y la restricción y la selectividad como principios centrales para la regulación de las corrientes migratorias. A pesar de la escasa repercusión de la inmigración de ultramar, el Estado boliviano se posicionó frente al fenómeno migratorio como país de inmigración, preocupado de manera particular por la regulación de los flujos migratorios hacia y desde el exterior y el control de la presencia de los extranjeros al interior de sus fronteras. Si bien bajo esta visión el Estado no le prestó demasiada atención al proceso emigratorio y a los emigrantes establecidos en los países vecinos, desde épocas tempranas expresó su afán por frenar y controlar la salida de trabajadores migrantes a través de diferentes medidas políticas, reflejadas en la legislación migratoria. A partir de la llegada del MAS al gobierno en el año 2006 empiezan a vislumbrarse nuevas preocupaciones políticas en torno a las migraciones internacionales $\mathrm{y}$, en particular, en relación a los emigrantes bolivianos que pasarán a ser concebidos como ciudadanos en el exterior.

\section{El Estado boliviano y las migraciones durante el siglo veinte}

La cuestión migratoria aparece en Bolivia entre los asuntos de gobierno poco tiempo después de proclamada su independencia en 1825. En 1826 se firmó un decreto que concebía al crecimiento de la población como una fuente de riqueza y prosperidad para el país, promoviendo la inmigración de hombres de "todos los pueblos y naciones". La concesión de franquicias, el transporte de equipaje libre de derechos arancelarios, la ocupación de un terreno de cincuenta hectáreas y el goce de facilidades para el pago de estas tierras fueron algunas de las facilidades otorgadas por esta disposición a los inmigrantes, sobre todo europeos, que eligieran Bolivia como destino (Seeghers y Téllez Flores, 2007:87). De todas maneras, a diferencia de lo que ocurriera en otros países de la región, estos primeros intentos estatales de fomentar la inmigración durante el siglo diecinueve y la posterior búsqueda de intensificar las corrientes inmigratorias 
transatlánticas -en particular europeas- desarrollado a lo largo del siglo veinte no se tradujeron en una llegada significativa de inmigrantes.

Durante el siglo diecinueve hasta bien entrado el veinte, los movimientos poblacionales tematizados como inmigración eran los que provenían de ultramar. En la legislación migratoria decimonónica que perduró durante las primeras décadas del siglo veinte se definía como inmigrante a "todo extranjero, obrero, agricultor o industrial que teniendo menos de sesenta años y comprobada su moralidad y aptitudes, quiera establecerse en el territorio de la República". ${ }^{74}$ En el marco una política de fomento de la inmigración, la radicación en el país era promocionada a través del otorgamiento de diversas facilidades y franquicias a los extranjeros. Por otra parte, aún cuando las fronteras políticas entre países limítrofes ya habían sido trazadas en su mayoría (aunque no completamente definidas), los intercambios poblacionales transfronterizos no fueron conceptualizados ni atendidos en términos de emigración o inmigración por un Estado que se encontraba en pleno proceso de formación e inmerso en sucesivas crisis políticas. La legislación migratoria no contemplaba aquellos movimientos de tipo estacional entre Bolivia y Argentina que, a partir de mediados de la década de 1870, como señala Hinojosa Gordonava et al. (2000), asumieron un carácter laboral y estaban compuestos por mano de obra indígena reclutada por enganchadores y dirigida hacia el norte argentino. ${ }^{75}$ Siendo tenue la presencia de los Estados boliviano y argentino en estas regiones fronterizas (Hirsch, 2000; Karasik, 1992) y adoptada en parte también la migración como una alternativa a las duras condiciones de vida y de trabajo a las cuales estaban sometidos en las haciendas de Bolivia, numerosas familias guaraníes frecuentaban la Argentina, entre ellos, los guaraníes del sudoeste boliviano que se trasladaban a las provincias de Salta y Jujuy para trabajar en los ingenios azucareros, fincas y aserraderos y que en ocasiones formaban nuevas comunidades o barrios (Hirsch, 1999; 2000).

Luego de la Guerra del Pacífico (1879-1883), la cual significó para Bolivia la pérdida de su salida al mar, se inició un proceso de reorganización política y económica con importantes repercusiones sociales. A comienzos del siglo veinte, como señala Mayorga (1999:334), la modernización del país y la construcción del Estado nacional fueron concebidas como un proyecto indisolublemente ligado a la "raza blanca y señorial", cuya premisa central era la

74 Ley de 27 de diciembre de 1926.

75 Estas migraciones laborales de carácter estacional se intensificaron entre 1920 y 1950. 
homogeneidad racial. Además, durante estos tiempos, Bolivia combinaba una estrategia económica liberal dependiente de los mercados externos con formas de acción política basadas en la represión y la violencia, siendo una etapa teñida por la manipulación de las elecciones, la supresión de las libertades políticas y el destierro de los opositores (Mayorga, 1999:331). En esta época conservadora-liberal, las medidas destinadas a regular el ingreso de mano de obra extranjera, ya no sólo contemplaban criterios y mecanismos de selección basados en la capacidad para el trabajo, sino también prohibiciones derivadas del activismo político de los extranjeros. Nueve años después de que se dictara en la Argentina, en el año 1911 se decretó en Bolivia la ley de Residencia, la cual fijaba en materia de migraciones importantes restricciones al ingreso y disponía acerca de la expulsión de los extranjeros. Permitía al Poder Ejecutivo "ordenar la salida del territorio de la Nación" e "impedir la entrada al territorio de la República" a todo extranjero que hubiera sido condenado o perseguido por tribunales extranjeros debido a crímenes o delitos comunes o que comprometiera la "seguridad nacional" o perturbara el "orden público". ${ }^{76}$ Asimismo, como medida de "seguridad pública", autorizaba al Poder Ejecutivo a detenerlo hasta que hiciera abandono del país. Esta ley es una fiel copia de la dictada en 1902 en la Argentina. ${ }^{77}$

Artículo 1.- El Poder Ejecutivo podrá ordenar la salida del territorio de la Nación a todo extranjero que haya sido condenado o sea perseguido por los tribunales extranjeros por crímenes o delitos comunes.

Artículo 2.- El Poder Ejecutivo podrá ordenar la salida de todo extranjero, cuya conducta comprometa la seguridad nacional o perturbe el orden público.

Artículo 3.- El Poder Ejecutivo podrá impedir la entrada al territorio de la República, de todo extranjero cuyos antecedentes autoricen a incluirlos entre aquellos a que se refieren los dos artículos anteriores.

Artículo 4.- El extranjero contra quien se haya decretado la expulsión tendrá tres días para salir del país, pudiendo el Poder Ejecutivo, como medida de

\footnotetext{
76 Ley de Residencia del 18 de enero de 1911.

77 La única diferencia aparece en el artículo 4. Dado que los ingresos y salidas del territorio nacional sólo se producían por la vía terrestre, en lugar de decir como en la ley argentina "hasta el momento de su embarco", en la norma boliviana se especifica que el Poder Ejecutivo podrá ordenar la detención del extranjero "hasta el momento de su salida del país".
} 
seguridad pública, ordenar su detención hasta el momento de su salida del país.

La legislación migratoria de las primeras décadas del siglo veinte expresaba, por un lado, el interés gubernamental por evitar o limitar el arribo de determinados extranjeros a partir de sus características individuales. En 1924, una norma nacional -basada en las corrientes higienistas de la época- prohibía el ingreso a aquellas personas que, "sin domicilio legal en la República", padecieran enfermedades o discapacidades físicas o mentales y lo supeditaba a la presentación de un pasaporte sanitario, cuyo otorgamiento se basaba en el respectivo certificado médico, quedando el extranjero sujeto a la expulsión en caso de que entrara al país sin él. ${ }^{78}$

Artículo 1.- Prohíbase el ingreso al territorio nacional de las personas afectadas de enfermedades infectocontagiosas, de los idiotas, dementes, enajenados mentales, epilépticos, alcohólicos crónicos, paralíticos, polineuríticos, mutilados de los miembros, ciegos, sordomudos y lesionados graves que sean una carga pública. La disposición anterior se refiere únicamente a los extranjeros sin domicilio legal en la República.

Artículo 3.- Todo inmigrante está obligado a presentar ante la primera autoridad policiaria de la frontera boliviana el pasaporte sanitario expedido por un cónsul boliviano, en vista de certificado médico.

Artículo 4.- El individuo que ingrese a territorio nacional sin pasaporte sanitario y que estuviese comprendido en la prohibición del Artículo $1^{\circ}$ será obligado a abandonar el país en el término de 24 horas.

Por otra parte, el fomento de la inmigración se realizaba privilegiando determinados grupos nacionales o étnicos mediante criterios de selección instituidos desde las primeras décadas del siglo veinte. Si bien en la normativa no figuraban referencias explícitas a la pertenencia nacional de los inmigrantes, la sola mención de los lugares de asentamiento de las oficinas de inmigración en el exterior manifestaba las preferencias respecto al origen de los flujos migratorios que el Estado impulsaba. Una ley de 1926, por ejemplo, 
que elevaba a rango de ley un decreto supremo de 1907, establecía que los consulados y especialmente las oficinas consulares de Hamburgo, Viena, Amberes, Barcelona, París, Burdeos, Havre, Marsella, Lyon, Londres, Liverpool, Génova, Nápoles, Roma, Turín, Milán, Lisboa, Estocolmo, Berna y Ginebra actuarían como "oficinas de información para inmigrantes" y como "agentes directos del gobierno".

La Guerra del Chaco ${ }^{79}$ entre Bolivia y Paraguay (1932-1935) tuvo importantes efectos en la vida política y económica del país, acarreando el derrumbe del gobierno civil y de los partidos políticos tradicionales, instalando nuevos temas en el debate nacional como la cuestión india, la cuestión obrera y la cuestión agraria, creándose nuevos partidos y movimientos revolucionarios, emergiendo prominentes organizaciones sindicales y deteniéndose la expansión de la industria minera y de la gran hacienda (Klein, 2002[1982]). En materia migratoria, apenas terminado el conflicto bélico, en el año 1936 se creó el Despacho (también denominado Ministerio) de Inmigración, bajo la jurisdicción del Ministerio de Agricultura y Colonización. Al año siguiente, se reglamentó la concesión de permisos de ingreso a Bolivia con el explícito propósito de controlar la inmigración, de tal manera que ella fuera "provechosa para el mejoramiento étnico del país", como establecía en los considerandos. ${ }^{80} \mathrm{El}$ decreto establecía que los documentos requeridos para el ingreso eran el pasaporte (con fotografía y huellas digitales), los respectivos certificados de bautismo, buena salud y buena conducta, además de una constancia que mostrara que el solicitante había ejercido "profesión u oficio lícito" durante los últimos cinco años y, según su categoría de ingreso, un monto determinado de capital. ${ }^{81}$ Aparte de quedar obligado a presentar su pasaporte y documentos de identificación cuando estuviera en tránsito y comparecer ante la policía y el Ministerio de Inmigración cuando llegara a destino, durante su permanencia en el país debía "observar conducta intachable

79 Con la Guerra del Chaco entre Bolivia y Paraguay (1932-1935) se produjo un nuevo desplazamiento de poblaciones indígenas al trasladarse familias enteras hacia el noroeste argentino para evitar ser utilizados por el ejército como medio de transporte de vituallas y provisiones. Sin embargo, cientos de guaraníes fueron reclutados por el ejército boliviano, mientras que otros trabajaron como zapadores, y un gran contingente fue llevado a Paraguay en calidad de prisioneros (Hirsch, 2000). Después de la guerra, una pequeña proporción de campesinos mestizos del valle tarijeño -su número era reducido en comparación con el de aquellos provenientes de la región andina- se dirigieron temporalmente a los ingenios azucareros y a las unidades productivas agrícolas donde trabajaron como peones bajo condiciones laborales deplorables (Hinojosa Gordonava et al. 2000).

80 Decreto Supremo del 28 de enero de 1937.

81 Este requisito valía para los extranjeros que ingresaran para "radicarse definitivamente". Quedaban exceptuados, "los obreros contratados legalmente, colonos, agricultores, etc.". El pasaporte, el certificado médico y el de buena conducta eran obligatorios para cualquier extranjero que quisiera ingresar a Bolivia, incluido quien lo hiciera como turista. 
con absoluta prescindencia en cuestiones políticas de orden interno". Asimismo, prohibía directamente el ingreso a diversos individuos y grupos sociales habitualmente excluidos por las normativas migratorias nacionales de la época, ampliando su alcance:82

a) Las personas afectadas de enfermedades infectocontagiosas, los idiotas, dementes, enajenados mentales que carezcan de bienes suficientes para mantenerse, los epilépticos, alcohólicos crónicos, toxicómanos o que se dediquen al comercio de drogas enervantes, polineuríticos, paralíticos, mutilados de los miembros, ciegos, sordomudos y en general los que teniendo lesiones graves que disminuyan su capacidad para el trabajo sean considerados como una carga pública; b) Los que tienen más de sesenta años de edad. Exceptúase a las personas que encontrándose en esta condición tienen en Bolivia una persona que los sostenga, o vienen acompañados de inmigrantes con capacidad de trabajo; c) Los gitanos o nómadas; d) Los que no demostrando tener una profesión lícita se dediquen a la prostitución o se caractericen por costumbres de notoria inmoralidad, los sospechosos de conducta nociva al orden público o que puedan atentar la seguridad de la República o sus autoridades; e) Los perseguidos por los tribunales de justicia extranjeros, por la comisión de delitos comunes que puedan determinar su extradición, de acuerdo a tratados vigentes; f) Los expulsados de Bolivia, mientras subsistan las causas que la motivaron y las personas sospechosas de espionaje contra la República.

\footnotetext{
$82 \mathrm{El}$ articulado del decreto también preveía la negación del ingreso a aquellos individuos considerados como "personas peligrosas" por el Convenio de la Policía Internacional, suscripto en Buenos Aires el 29 de febrero de 1920 y aprobado en Bolivia por ley del 16 de octubre de 1924: a) Todo individuo respecto del cual se compruebe que ha intervenido como autor, cómplice y encubridor, más de una vez, en delitos contra la propiedad o que tengan conexión con éstos; y todo aquel que, careciendo de medios lícitos de subsistencia, hace vida común con delincuentes habituales, o usa instrumentos u objetos conocidamente destinados para cometer delitos contra la propiedad; b) El que haya intervenido alguna vez, como autor, cómplice o encubridor en el delito de falsificación de moneda o de título o valores mobiliarios; c) El responsable más de una vez como autor de delitos graves contra las personas; d) El extranjero o nacional que haya estado ausente del país, que intervenga en cualquier delito contra la propiedad o contra las personas, si la forma de ejecutarlo, el carácter impulsivo u otras circunstancias, hacen presumir que tenga antecedentes desfavorables en el país de procedencia; e) Los individuos que habitualmente y con fines de lucro ejercen la trata de blancas; f) Los incitadores habituales a subvertir el orden social por medio de delitos contra la propiedad, las personas o las autoridades; g) Los agitadores o incitadores para perturbar con actos de coacción, de violencia o de fuerza, la libertad del trabajo, o para atacar las propiedades o las instituciones (Artículo 13).
} 
El decreto, que según una disposición posterior del Poder Ejecutivo guardaba "armonía con el espíritu y el texto" de la ley de Residencia de 1911, también instruía la expulsión de aquellos extranjeros que estuvieran comprendidos en las siguientes categorías:

a) Los que violando los reglamentos de admisión hayan ingresado al país, sin solicitar permiso, contraviniendo a la negativa de ingreso, o haciéndolo por lugares diferentes a los señalados para tal objeto; b) Los que habiendo ingresado con los requisitos correspondientes, comprometan su conducta posterior, atentando contra la seguridad del Estado o del orden público; c) Los que turben las relaciones internacionales de Bolivia con cualquier otro país del mundo; d) Los que falten a la neutralidad que deben observar en asuntos de política interna; e) Los condenados por tribunales extranjeros como consecuencia de la comisión de delitos comunes y cumplidos como sean con carácter previo, los trámites de extradición de acuerdo a los tratados vigentes.

Todos estos extranjeros pasibles de expulsión figuran agrupados y nombrados como “extranjeros indeseables" en la normativa coetánea. En 1939, basándose en la ley de Residencia de 1911 y el decreto supremo anterior (de enero de 1937), se estableció el procedimiento para hacer efectiva la expulsión de estos "extranjeros indeseables", argumentando que "esta atribución ha sido invariablemente ejercitada por el Ministerio de Gobierno", organismo estatal que tenía a su disposición "organizaciones completas para controlar la conducta que observan en el país los inmigrantes". ${ }^{83}$

Entre los extranjeros que fueron considerados de esta manera, en tiempos de la Segunda Guerra Mundial, estaban los judíos. En 1942 se dictó un decreto supremo orientado a regular el ingreso a Bolivia de familiares de los extranjeros residentes. La norma establecía que la solicitud hecha por "elementos extranjeros en general" e "inmigrantes semitas en particular", debía estar acompañada por certificados policiales y municipales relativos a los antecedentes personales, la situación económica y el tipo de actividad que desarrollaban. Esta medida estaba fundada en la necesidad de establecer "el grado de solvencia moral y capacidad económica de los impetrantes", asumiéndola como parte de un "proceso de selección tendiente a encauzar provechosas corrientes inmigratorias". 84

83 Decreto Supremo del 15 de febrero de 1939.

84 Decreto Supremo del 17 de abril de 1942. 
Durante estos años, frente a la existencia de una demanda de mano de obra no satisfecha, fundamentalmente para actividades agrícolas y mineras, el Estado boliviano tomó algunas medidas para evitar la "emigración de braceros nacionales al exterior" o "el éxodo de trabajadores bolivianos al exterior". Entre ellas, a nivel normativo, aprobó dos decretos supremos, uno en octubre de 1937 y otro en julio de 1938. El primero establecía una serie de exigencias para los patrones, empresas mineras, agrícolas e industriales que constituyeran reenganchadores de empleados $\mathrm{u}$ obreros que se dirigieran hacia los centros agrícolas e industriales de otros países, bajo el argumento de que "la despoblación de determinados centros urbanos y de las regiones fronterizas perjudica[ba] las labores mineras y agrícolas, obstaculizando el desarrollo de otras actividades relacionadas con la economía nacional". En el segundo decreto, declarando la necesidad de dictar "una reglamentación definitiva sobre emigración en la República, que sancione radicalmente la fuga de braceros nacionales", el Estado fue más lejos en su intento por reducir el "alarmante éxodo de trabajadores bolivianos al exterior". Además de especificar las obligaciones que le correspondían a los reenganchadores, indicaba que, a manera de sanción, "todo boliviano que fuese sorprendido abandonando clandestinamente el país será obligado, bajo apremio, a concurrir a trabajos de obras públicas en la jurisdicción del departamento de su último domicilio", negándoles cualquier ayuda a "los bolivianos que hayan salido al extranjero, sin su respectivo pasaporte internacional".

El reclutamiento de trabajadores temporarios produjo un conjunto de denuncias y reclamos del gobierno boliviano al argentino durante el primer quinquenio de la década del cuarenta que, como muestra Quinteros (2008), tuvieron diversos resultados. En 1940, a raíz de las condiciones de trabajo y de vivienda prometidas e incumplidas de los "indígenas nativos del territorio boliviano" reclutados por reenganchadores, la embajada de Bolivia en la Argentina solicitó al MREC firmar un convenio bilateral de protección de los trabajadores. El embajador boliviano pretendía que el acuerdo contemplara el control la propaganda y contratación de mano de obra extranjera de manera que se garantizaran, entre otros aspectos, contratos de trabajo con igualdad jurídica y el reconocimiento de los cónsules como representantes de sus conciudadanos. El gobierno argentino, por un lado, se negó a reconocer las condiciones de explotación de trabajadores indígenas bolivianos y, por el otro, se mostraba interesado en un convenio interestatal que impidiera las migraciones no autorizadas entre ambos países, lo cual, como veremos en el próximo capítulo, trascendía a los nativos bolivianos, cuya entrada no autorizada era tolerada, 
implicando más bien a europeos residentes en Bolivia considerados por el Estado argentino como "indeseables". Antes de finalizar el año, las autoridades bolivianas volvieron a insistir con los reclamos, denunciando que trabajadores indígenas eran empleados masivamente en las minas e ingenios azucareros de Salta y que los salarios que recibían no eran iguales a los de los trabajadores de nacionalidad argentina. La respuesta del Estado argentino consistió en negar la realidad denunciada por la contraparte boliviana: en las provincias del norte argentino no existían ni reclutadores, ni bolivianos explotados.

Durante los años siguientes, las demandas del Estado boliviano encontraron mayor recepción entre algunos funcionarios argentinos, aunque finalmente fueron desestimadas por el gobierno nacional. Quinteros (2008) señala las idas y vueltas que tuvo el tema: en 1942, frente al pedido de considerar el desamparo jurídico y económico en que quedaban las familias de los trabajadores bolivianos en casos de accidentes de trabajo seguidos de muerte y la imposibilidad de cobrar pensiones e indemnizaciones, un asesor letrado del MREC atendió la solicitud y confirmó que debido a la inexistencia de convenios de trabajo entre ambos países a los familiares de trabajadores extranjeros que no residieran en la Argentina no les correspondía el derecho a la indemnización, al mismo tiempo que sugería la firma de dicho acuerdo bilateral, previa aprobación del Congreso Nacional; el mismo año, a pesar que el cónsul argentino en La Paz había reconocido la explotación de indígenas bolivianos en los ingenios azucareros del noroeste argentino, declarando que en la Argentina eran "explotados con salarios miserables" y que no contaban "con la protección de leyes sociales que puedan ampararlos", la DGM se pronunció diciendo que el reclamo del gobierno boliviano era producto de la emigración voluntaria de sus trabajadores atraídos por los mejores salarios obtenidos en la Argentina que provocaba la falta de mano de obra en sus minas; en 1943, las notas aparecidas en la prensa boliviana, informadas por el cónsul argentino en La Paz, sobre la emigración de braceros bolivianos hacia la Argentina, eran para el gobierno argentino la constatación de que la movilidad transfronteriza se originaba en la preferencia por las condiciones de trabajo en los ingenios azucareros del noroeste argentino ante las existentes en las minas del sur de Bolivia, validando la idea de que las condiciones laborales en la Argentina eran buenas, aceptables y superiores a las bolivianas; con la construcción de vías ferroviarias, en 1944, aunque el gobierno argentino no desconocía que los peones reclutados eran indígenas bolivianos que no contaban (o sólo parcialmente) con la documentación exigida (por ejemplo, pasaportes sin visado) y el gobierno boliviano insistía con que se les reconocieran sus cartas de ciudadanía y cédulas de identidad, el MREC estipuló que dichos 
trabajadores debían presentar toda la documentación en regla para poder cobrar sus salarios (en dinero efectivo y no en bonos), justificando las irregularidades que cometían en base a dicha carencia las empresas contratantes.

Hacia mediados del siglo veinte, el Estado boliviano mantenía una visión de las migraciones asociada al desarrollo económico y demográfico del país. El propósito era incrementar la población en las zonas menos pobladas de Bolivia como una manera de ejercer la soberanía sobre esos territorios. En este sentido, en 1950 se sancionó una ley de concesión de tierras a colonizadores que otorgaba parcelas en el departamento de Santa Cruz, prácticamente despoblado en aquella época, a "las familias de colonizadores nacionales y extranjeros" que se establecieran para realizar trabajos agrícolas o industriales. ${ }^{85}$ Esta iniciativa determinaba que los inmigrantes agricultores, ganaderos o industriales que ingresaran a Bolivia para establecerse en el departamento de Santa Cruz, quedarían exentos del pago de impuestos fiscales por el término de cuatro años desde la fecha de su radicación y se beneficiarían de franquicias en los trámites y visas consulares, siempre que pudieran acreditar su condición de agricultores, profesionales, peritos o técnicos en cualquiera de los rubros mencionados.

A comienzos de 1951 se creó, mediante decreto supremo, el Consejo Nacional de Inmigración y Colonización. ${ }^{86}$ La legislación migratoria de esta época muestra también que el impulso a la inmigración, vista siempre como contribución al desarrollo de la producción económica, y la organización de la radicación de los extranjeros en el país constituían los ejes vertebradores de la política migratoria que se perseguía. A pocos días de la creación del Consejo Nacional de Inmigración y Colonización, un decreto supremo ponía de manifiesto la relación entre estas dos dimensiones. En sus fundamentos, se consideraba la necesidad de "reglamentar en forma definitiva" el procedimiento a seguir por parte de los inmigrantes interesados en radicarse en Bolivia, debido a que las normas legales vigentes al ser confusas y no corresponderse con los objetivos de la política migratoria establecida, entorpecían el arribo de contingentes migratorios. En consecuencia, el gobierno nacional pretendía "otorgar las mayores facilidades a la inmigración, simplificando los trámites, formalidades y requisitos" exigidos. Entre las medidas dispuestas por el decreto se señalaba la concentración en manos del Ministerio

85 Ley de 4 de enero de 1950.

86 Decreto Supremo del 1 de febrero de 1951. 
de Inmigración de los asuntos de política migratoria. En principio, dicha conducción debía ser realizada "en forma amplia y sin discriminaciones de orden racial, político o religioso". ${ }^{87}$ Los alcances de este enunciado general quedaban sujetos en la práctica a los antecedentes del extranjero solicitante y la actividad específica a desarrollar, a partir de los cuales el Ministerio de Inmigración autorizaba el otorgamiento de los visados consulares.

Con la llegada del MNR a la presidencia en 1952, se inició un proceso de migración interna desde las zonas rurales hacia las ciudades y desde la región occidental hacia la región oriental del país, favorecido por la reforma agraria iniciada en 1953, las mejoras en las comunicaciones y al significativo acercamiento que se produjo entre la zona del Altiplano (la más poblada en aquél momento) y el Oriente boliviano, prácticamente despoblado por entonces pero que progresivamente adquirirá mayor relevancia dentro de la economía del país. Con la implementación de la Reforma Agraria en 1953 se movilizó un gran número de campesinos, ya que se produjo la liberación de las obligaciones laborales y económicas impuestas por el patrón latifundista, convirtiéndose la migración estacional o temporal en una estrategia de sobrevivencia: trabajaban en la Argentina durante algunos años y regresaban periódicamente a las comunidades de origen, volviendo a partir para generar ahorros complementarios que les permitieran sostener la economía familiar (Hinojosa Gordonava et al. 2000).

Durante estos años, uno de los aspectos que se pretendió regular en materia de migraciones internacionales fue el movimiento de turistas, estableciendo las condiciones relativas a su ingreso y permanencia y organizando la Dirección Nacional de Turismo, que en el año 1957 pasó a depender del Ministerio de Inmigración. A través de distintos decretos supremos, se fijaron prohibiciones y sanciones, tanto para aquellas empresas y demás establecimientos que contrataran extranjeros que hubieran ingresado $y$ permanecieran en el país en calidad de turistas, como para aquellos extranjeros que infringieran el reglamento de turismo. 88

87 Decreto Supremo del 13 de febrero de 1951.

88 Decreto Supremo del 25 de marzo de 1954 y de 28 de septiembre de 1957, entre otros. 
Al mismo tiempo, los extranjeros nacionalizados o naturalizados fueron objeto de medidas de carácter restrictivo, bajo el argumento de que "numerosos extranjeros adquieren la nacionalidad boliviana con el fin de conseguir fácil ingreso a otros países”, en particular al territorio nacional de Estados vecinos. Para controlar dicho movimiento transfronterizo, se dispuso un plazo mínimo de cinco años de permanencia obligada en el país a partir de su "naturalización", además de limitar los usos del pasaporte y la estadía en el extranjero. ${ }^{89}$

Con el derrocamiento en 1964 de Víctor Paz Estenssoro se iniciaron en Bolivia una serie de sucesivos gobiernos militares que llegaron al poder mediante golpes de Estado. En 1971, se inició la dictadura militar conducida por Hugo Banzer, caracterizada por la represión ejercida durante su gobierno. Entre las medidas de restructuración administrativa, se determinó que el Ministerio del Interior, Migración y Justicia tuviera "a su cargo la formulación, dirección y coordinación de la Policía Interna del Gobierno, la regulación de las migraciones y la representación del Poder Ejecutivo ante el Poder Judicial", encargándole como funciones "el mantenimiento del orden público y la organización, dirección y coordinación de las unidades competentes, estudiando las causas de la delincuencia y de los actos anti-sociales, procurando prevenir el delito en sus diferentes manifestaciones como la subversión y el terrorismo, en defensa de la seguridad del Estado, la preservación de la salud y de la paz social" .90

Años más tarde, se instauró la ley de Inmigración ${ }^{91}$ de 1976 mediante la cual se pretendió organizar y sistematizar distintos aspectos concernientes a los movimientos internacionales de población y, fundamentalmente, regular la inmigración. ${ }^{92}$ Resulta llamativo que, bajo una dictadura militar, la visión preventiva y represiva presente en las facultades conferidas a los organismos del Estado que tenían a su cargo los asuntos migratorios no se haya traducido a esta ley migratoria. Pareciera que al momento de su elaboración se tuvieron sólo en mente las antiguas ideas promotoras de la inmigración europea. En términos generales, esta norma asume la inmigración como una variable poblacional que, visualizada como contribución, serviría como motor de desarrollo,

89 Decreto Supremo del 12 de junio de 1958.

90 Decreto-ley № 10.460 de 12 de septiembre de 1972.

91 La noción de "ley de Inmigración" se puede prestar a equívocos. En realidad, se trata de un decreto-ley, dado que bajo un gobierno de facto queda suspendido el Poder Legislativo.

92 Decreto-ley № 13.344 de 30 de enero de 1976. 
inscribiéndose en la línea de las políticas de promoción de la inmigración que el Estado boliviano habría alentado desde su formación. ${ }^{93}$ En este sentido, en sus considerandos, se diagnosticaba que el bajo índice demográfico de Bolivia constituía "uno de los mayores problemas para el logro del desarrollo económico, social y político del país", advirtiendo que dicha situación podía agravarse si no se adoptaban "medidas oportunas" como "el fomento de corrientes inmigratorias que dinamicen la actividad nacional". Asimismo, se subraya en diversas ocasiones la necesidad de incrementar la "población activa" o el "capital humano" mediante "corrientes migratorias que contribuyan al desarrollo nacional" o a través del "más decidido apoyo a planes y programas de inmigración", considerando que dicha política "redundará en beneficio del país". También se deja constancia que para favorecer "la llegada al país del mayor número de inmigrantes", es necesario ofrecerles "las máximas facilidades para su asentamiento". Si bien se explicita en los considerandos que "el asentamiento de profesionales, técnicos medios y mano de obra calificada" resulta indispensable para el desarrollo de Bolivia, en los dos primeros artículos se subraya el papel de la inmigración en los planes de colonización y el incentivo que tendría la producción agropecuaria a través de ella en tanto "instrumento de política demográfica" y "medio de desarrollo socio-económico".

Para obtener los objetivos planteados, la ley (o decreto-ley) de Inmigración también señalaba la necesidad de crear un organismo especializado que "dirija y planifique una política integral, canalizando en forma sistemática programas de inmigración y de defensa de los recursos humanos del país". De este modo, se constituía el Consejo Nacional de Inmigración (CONAIN) como organismo especializado dependiente del Ministerio del Interior, Migración y Justicia, siendo una de sus finalidades "estudiar, preparar planes y programas de inmigración, en coordinación directa con los organismos especializados nacionales, internacionales y privados. No obstante, a pesar de los incentivos y las negociaciones, no fue significativo el número de inmigrantes europeos que llegaron a Bolivia, siendo los países latinoamericanos, sobre todo limítrofes, los principales orígenes de la población extranjera en Bolivia. ${ }^{94}$

93 No es casual que en los fundamentos, este decreto-ley se apoye en la ley del 24 de mayo de 1826 en la cual se expresó que "los hombres de todos los pueblos y naciones son invitados a venir a Bolivia, donde su libertad civil tiene todas las garantías que dan las leyes bolivianas".

94 Véase CEPAL (2006). 
Según lo establecido por la norma, otro de los propósitos del CONAIN era "promover el retorno de bolivianos radicados en el exterior". En el año 1976, este objetivo -que en este caso reflejaba también la importancia geopolítica que le atribuyen generalmente los gobiernos militares a la población- se concretó cuando el dictador boliviano Hugo Banzer y su par argentino Jorge Videla acordaron un programa de repatriación destinado a las familias bolivianas que vivían en villas de emergencia en Buenos Aires. ${ }^{95}$ El plan de erradicación de estos asentamientos, iniciado en 1968, tomó impulso en 1976 cuando el gobierno militar argentino determinó compulsivamente el regreso a los países y provincias de origen. ${ }^{96}$ Para hacer efectiva esta medida se contó con la participación de la Dirección Nacional de Migraciones y Ferrocarriles Argentinos (Mugarza, 1985:101). En el acuerdo establecido entre ambos gobiernos militares cada parte asumía determinadas responsabilidades: mientras el gobierno boliviano permitiría importaciones sin impuestos y prometía terrenos para edificar casas en Cochabamba, créditos para la construcción y la obtención de empleo, el gobierno argentino se comprometía a solventar el transporte a cambio de que los emigrantes entregaran sus documentos de residencia. En el marco de este programa regresaron aproximadamente mil familias, pero el gobierno boliviano no cumplió con la totalidad de los compromisos asumidos (Dandler y Medeiros, 1991:50).97

Por otro lado, la definición de inmigrante otorgada por esta norma hacía referencia a aquél extranjero cuyo establecimiento en el país fuera definitivo y mostrara voluntad de integración a la sociedad nacional boliviana, sirviendo así como "elemento productivo permanente". Esta definición al mismo tiempo que expresa sin ambigüedades aquellos requisitos y condiciones que debe reunir un extranjero para que sea considerado como inmigrante, precisa aquello que el Estado nacional espera de él: que trabaje, que se establezca, que se integre.

Artículo 3.- Se considera inmigrante al extranjero que ingrese al país, para asentarse definitivamente en el territorio nacional y con ánimo de integrarse a

\footnotetext{
95 Es importante destacar que durante los gobiernos militares de Banzer en Bolivia y Videla en Argentina se instrumentaron políticas migratorias que reemplazaron a las anteriores normativas vigentes en ambos países.

96 Si bien no se puede dar una cifra exacta de la cantidad de bolivianos que habitaban las "villas de emergencia" antes de la erradicación, debido a que las mismas fueron censadas en distintos meses y años, se calcula que alrededor del 20 por ciento de la población total era de origen boliviano (Mugarza, 1985:100).

97 Por ejemplo, sólo unas 200 familias consiguieron terrenos y los créditos nunca fueron otorgados a quienes regresaron (Dandler y Medeiros, 1991:50).
} 
la sociedad boliviana, constituyéndose en un elemento productivo permanente.

Aunque en su articulado aparecía diferenciada de la asimilación, la noción de integración asumida en este texto legal -y quizás una de las primeras veces utilizada en la legislación migratoria boliviana- remitía necesariamente a una concepción asimilacionista de la incorporación de los inmigrantes, la cual gozaba por entonces de una amplia aceptación en la formulación de políticas. En este sentido, establecía como una de las "obligaciones" de los inmigrantes "asimilarse e integrarse a la sociedad boliviana". Para tal efecto, según la norma, el Estado a través del Consejo Nacional de Inmigración y organismos especializados, promovería dicha integración a través de disposiciones reglamentarias y medidas administrativas que aseguraran, entre otros objetivos, la enseñanza del idioma oficial de la República, la enseñanza necesaria para el conocimiento del medio físico, cultural, social y económico del país, y la enseñanza cívica de los derechos, beneficios, deberes y obligaciones que dispusieran las leyes de la República. A su vez, aunque la definición de inmigrante no revelaba el origen preferible de las corrientes migratorias esperadas, su carácter europeo estaba implícito en las medidas que pretendía impulsar el Estado para atraer inmigrantes. La ley disponía que el CONAIN negociaría con organismos internacionales, especialmente con el Comité Intergubernamental para las Migraciones Europeas (CIME), y los gobiernos de los países interesados en la emigración, "las bases sobre las cuales puedan llevarse a cabo los planes de inmigración en Bolivia".

A partir del Decreto Supremo $N^{\circ} 21.060$ de agosto de 1985, que supuso la puesta en práctica de las medidas neoliberales en Bolivia, se modificó radicalmente el modelo socioeconómico del país, repercutiendo en los movimientos poblacionales dentro y fuera del territorio nacional. En este sentido, varios estudios coinciden en señalar que esa fecha marca un antes y un después en la realidad migratoria boliviana (Vacaflores, 2003; Farah, 2005). Sin embargo, pese a estas transformaciones, el posicionamiento del Estado frente a la cuestión migratoria no sufrió importantes cambios, preservando los lineamientos principales de las políticas de migración adoptadas durante todo el siglo veinte.

La ola de reformas neoliberales en Bolivia se caracterizó por la instrumentación de una serie de medidas de carácter estructural tendientes a la apertura externa y la disminución 
de la influencia del Estado. ${ }^{98}$ Una de las medidas más relevantes en este nuevo escenario fue la privatización de las minas, con profundas consecuencias para vastos sectores de la sociedad. El despido masivo de trabajadores de las minas de Oruro y Potosí y la crisis del sector agrario, no sólo generó un aumento de la desocupación sino también el quiebre de las economías rurales que abastecían la "vida minera". El deterioro de los mercados de trabajo y el incremento de los índices de pobreza y desempleo en las zonas mineras y agrícolas provocaron un gran movimiento de población interna desde estas zonas hacia los principales centros urbanos del país, especialmente Santa Cruz, Cochabamba y El Alto. 99

Asimismo, las sucesivas crisis de los sectores agrario y minero sirvieron de base para la continuidad e intensificación de la emigración de bolivianos hacia países vecinos como la Argentina (Marshall y Orlansky, 1981). Si la aplicación del recetario neoliberal en Bolivia causó un gran movimiento de población interno que modificó la distribución poblacional del país, la pobreza estructural y el desempleo, tanto en las zonas rurales como urbanas, originó un incremento del número de migrantes hacia el exterior. Además, durante este período se produjo una mayor diversificación de los destinos de los migrantes: constituida la Argentina durante el siglo veinte como el destino emblemático (Hinojosa Gordonava, 2009), a partir de los años ochenta Brasil y Estados Unidos y, más recientemente, España empezaron a sobresalir como nuevos destinos de la migración boliviana contemporánea. ${ }^{100}$

En 1996, durante el penúltimo año de la primera presidencia de Gonzalo Sánchez de Lozada -quien ha quedado en la memoria histórica como fiel exponente del neoliberalismo en Bolivia- se aprobó el decreto supremo $\mathrm{N}^{\circ} 24.423$ de noviembre de 1996 mediante el cual se pretendía reunir en un mismo instrumento legal aquellas disposiciones relativas al ingreso y salida de individuos del territorio nacional, incluidos

98 Véase Fernández Terán (2004) para un sugerente análisis de los mecanismos y procesos de aplicación de las medidas neoliberales en Bolivia.

99 Este fenómeno, que el Estado denominara eufemísticamente "relocalización”, suponía que estos trabajadores desempleados encontrarían nuevas oportunidades laborales en otras actividades del mercado de trabajo boliviano. Estos cambios aceleraron el proceso de urbanización que se había iniciado con posterioridad a la Revolución de 1952 y por primera vez en la década del noventa las personas que vivían en las ciudades superaron a aquellas que residían en el campo.

100 Según algunas estimaciones oficiales alrededor del 15 por ciento de la población nacida en Bolivia se encuentra actualmente en el exterior. 
los nacionales, como también las condiciones de permanencia de los extranjeros, asumiendo que dicha regulación era una "obligación del Estado". En vistas a ello, la norma determinaba los organismos y medios que permitían "controlar el movimiento migratorio y turístico" así como el funcionamiento y competencia de la autoridad de migración, asumiendo una visión restrictiva, selectiva y punitiva sobre las migraciones y los inmigrantes. Básicamente establecía que serían dos los organismos encargados de tratar todas las cuestiones relacionadas con la migración, ahora dependientes del Ministerio de Gobierno: el Consejo Nacional de Inmigración y la Subsecretaría de Migración.

Asimismo, si bien desde mediados de la década del ochenta la salida de bolivianos al exterior se intensificó, la emigración y la situación de los nacionales en el extranjero no adquirieron un lugar preponderante en la normativa migratoria. En un contexto de profundización del fenómeno, el decreto supremo de 1996 prácticamente omite la cuestión de la emigración. A pesar que define como uno de los roles del Consejo Nacional de Inmigración "estudiar, elaborar y proponer al Gobierno Nacional, planes y programas que tiendan a frenar la emigración de personas al extranjero", y estipula que la Unidad de Planificación, Seguimiento y Evaluación se encargará de "elaborar programas que permitan detener los flujos emigratorios y hagan posible el retorno de los ciudadanos bolivianos residentes en el extranjero", es relativa la importancia que recibe el proceso emigratorio en una legislación monopolizada por el interés de regular la inmigración.

Entre los enunciados generales, el decreto declara el valor estratégico atribuido a la inmigración y a la emigración como variable de población y desarrollo. En este sentido, precisa que "(e)l Estado boliviano reconoce que la migración representa un factor importante para el país" y que "la migración favorece el crecimiento demográfico y debe constituirse un elemento coadyuvante del desarrollo social y económico, a través de la inversión real y del trabajo efectivo, siendo además necesario evitar la emigración de nacionales". Asimismo, acude a la tradición aperturista y a los principios constitucionales de Bolivia para proclamar la igualdad entre los nacionales y los extranjeros, aunque pareciera que dicho beneficio sólo valiera para aquellos que signifiquen una contribución al "desarrollo nacional". Como suele ocurrir con estas declaraciones de principios, se invoca la "tradición" para destacar la actitud generosa de las naciones hacia los inmigrantes, sobreactuando las aperturas y silenciando las restricciones contenidas en legislación nacional sobre migración. 
Artículo 4.- La Nación boliviana, consecuente con su tradición y con los principios que sustenta la Constitución Política del Estado, otorga a los extranjeros que provengan de cualquier parte del mundo e ingresen a su territorio con el objeto de radicarse definitivamente en él y contribuir con sus capitales o con su dedicación y trabajo al desarrollo nacional, los beneficios de los derechos, libertades y garantías que reconoce a sus propios nacionales.

Define como inmigrante al "extranjero industrial, agricultor, inversionista en empresas de producción o comercio de exportación, profesor de artes, ciencias y oficios o que realice cualquier actividad de utilidad social", que no sea mayor a 45 años, que no esté afectado por enfermedades infecto-contagiosas y que tenga como propósito "asentarse definitivamente en el territorio nacional, integrarse a la sociedad boliviana y trabajar en labores productivas". En esta línea, también precisa que "toda inmigración deberá tomar en cuenta los requerimientos demográficos de la Nación y propenderá a una integración económica, social y cultural".

Bajo la misma concepción asimilacionista de la normativa de 1976, en esta nueva disposición la "integración" aparece como uno de los "requisitos" establecidos por el Estado para definir la condición de inmigrante y para obtener la radicación. Al mismo tiempo, esta requerida integración es acotada a ciertos espacios de la sociedad boliviana, imposibilitando la participación en "cualquier forma de política interna o de dirección sindical” y reduciéndola al ámbito estrictamente económico y para determinadas categorías de extranjeros (empresario, industrial, poseedor de bienes inmuebles). En relación a ello, un informe de la Federación Iberoamericana de Ombudsman (FIO, 2003) manifiesta que "el Estado no adopta, en forma global y sistemática, medidas destinadas a favorecer la integración social" y que son "las sociedades de la sociedad civil las que han tomado la iniciativa en este tema".101

101 También se afirma en este documento que tanto ACNUR como la Pastoral para la Movilidad Humana han celebrado convenios con algunas escuelas para realizar talleres y otras actividades de promoción de los derechos de los migrantes y refugiados y contra la discriminación, a la vez que la organización no gubernamental "Instituto de Terapia e Investigación" brinda apoyo psicológico a los migrantes (FIO, 2003:92). 
Los principios y definiciones generales quedan aún más acotados cuando se detallan las disposiciones relativas al ingreso, permanencia y salida del territorio nacional y el consecuente sistema de clasificación que constituye el núcleo duro del pensamiento de Estado en materia migratoria. Es aquí donde se pone de manifiesto la visión restrictiva, selectiva y punitiva que estructura y sustenta -también ostenta en términos de demostración del poder estatal- el llamado Régimen Legal de Migración de 1996. Así, el control de las fronteras y de los extranjeros y de las actividades que realicen "desde su ingreso hasta su salida del territorio nacional" se erige como el principal objetivo de la política migratoria.

La misma definición de inmigrante que ofrece este decreto supremo muestra el alcance de la visión restrictiva y punitiva en las clasificaciones estatales. Para ser considerado como inmigrante, además de los requisitos ya mencionados, el extranjero no puede estar comprendido entre aquellos individuos o grupos sociales que tienen prohibido el ingreso. Entre ellos, se encuentran clasificados todos aquellos extranjeros que infringieran las reglas de admisión o permanencia, estuvieran asociados a determinados problemas sociales o padecieran determinadas enfermedades físicas o mentales, pudieran resultar una amenaza a la seguridad nacional y al orden público, no desarrollaren actividades laborales o fueran una carga pública para el Estado:

a) Los que presenten documentos falsos o adulterados,

b) Los que hubieran sido condenados o se hallen perseguidos por delitos comunes de orden público, los sindicados de terroristas, tratantes de blancas, falsificadores de moneda o narcotraficantes y aquellos cuya conducta anterior haga prever situaciones que sean contrarias a la seguridad nacional, al orden público o a las autoridades constituidas,

c) Los que hubieran sido expulsados por cualquier motivo de Bolivia [...],

d) Los que no cuenten con la respectiva visa, salvo convenios internacionales que lo liberen de la misma,

e) Los que padezcan enfermedades infecto-contagiosas; los psicópatas, alcohólicos, maníaco peligrosos o drogadictos, 
f) Los menores de 21 años que no estén acompañados de sus padres o representante legal o no tengan autorización escrita, refrendada por autoridad competente y legalizada por un Consulado boliviano,

g) Los notoriamente vagos y que no acrediten contar con los recursos suficientes para solventar sus gastos de permanencia en el país,

h) Los mayores de setenta años y que no cuenten con alguna persona que lo sostenga en Bolivia, que no vengan acompañados de inmigrantes con capacidad de trabajo o no demuestren capacidad económica que les posibilite su manutención durante su permanencia en el territorio nacional.

También la reglamentación de la permanencia en el territorio nacional, al constituir una de las expresiones más acabadas acerca de la división entre nacionales y extranjeros como al interior de aquellos considerados inmigrantes, muestra las limitaciones y condiciones que les impone el Estado a partir de la regulación de su estancia en el país como modo de ejercer el control sobre su vida social y política: los inmigrantes quedan inhabilitados para participar en la política, sea a través de los partidos o de los sindicatos, condicionados a no ofender las ambiguas y cambiantes normas morales y sociales, limitados a una existencia ordenada legal y administrativamente y amarrados al trabajo remunerado en particular y a la utilidad social que puedan tener en general. La permanencia autorizada queda así sujeta a una serie de condiciones, cuya inobservancia o transgresión habilita su cancelación y consecuentemente su expulsión. ${ }^{102}$ El decreto especifica que la residencia puede ser cancelada

a) Cuando el extranjero se inmiscuya en asuntos de política interna o de dirección sindical.

b) Cuando realice actividades contrarias a la moral pública o que afecten la salud física o mental de la comunidad.

102 El decreto dispone que "la cancelación o anulación de la permanencia o de la radicatoria conlleva la expulsión del extranjero del territorio nacional" (artículo 45). 
c) Cuando incurra en delitos, contravenga leyes migratorias ${ }^{103} \mathrm{o}$ esté comprendido en las determinaciones de los Arts. 46 o $48^{104}$.

d) Cuando sin contar con ingresos probados, se dedique a la vagancia o se convierta en menesteroso.

En relación a las expulsiones, el decreto retoma, adecua y amplía las prescripciones establecidas en la normativa migratoria nacional desde la aprobación de la ley de Residencia de 1911. Al margen de que las expulsiones se concreten o no, los motivos otorgados para decretar la expulsión revelan quienes no son considerados como merecedores o apropiados para integrar la comunidad nacional (entre los cuales se destacan los inmigrantes ilegales) a partir de su identificación con actividades que serían legalmente sancionables o moralmente repudiables debido a que suponen una alteración del orden social y político, reuniendo bajo un mismo epígrafe ilícitos o delitos de distinta índole y magnitud que no se corresponden con la condición inmigrante, y equiparando a la vez transgresiones a determinadas normas sociales o infracciones de orden administrativo hechas por inmigrantes en su intento por asegurar su sobrevivencia con delitos penales perpetrados por sujetos individuales o colectivos relacionados con redes de comercio u organizaciones políticas internacionales. ${ }^{105} \mathrm{Si}$ bien el inmigrante nace al cruzar una

103 En la misma línea, en otro apartado, se establece que es factible que la permanencia o la radicatoria sea anulada "cuando se compruebe por las autoridades de Migración, que para la obtención de las mismas se han falsificado o adulterado documentos o se haya incurrido en irregularidades".

104 Estos artículos se refieren a los causales de rechazo en el ingreso y de expulsión respectivamente.

105 Según la letra del decreto, quedan expuestos a la expulsión aquellos que a) Que porten o presenten en cualquier tiempo pasaporte, cédula de identidad u otros documentos falsos o adulterados; b) Que hubieran ingresado ilegalmente al país, infringiendo normas establecidas en el presente Decreto Supremo que formulen declaraciones falsas o presenten documentos o contratos simulados antes las autoridades de Migración o las de Trabajo; c) Que fueran sorprendidos permaneciendo en el país, sin causa justificada, mayor tiempo que el que tuvieran autorizado por su respectiva visa o permanencia; d) Que les hubiera sido cancelada o anulada su permanencia o su radicatoria; e) Que estuvieran dedicados a comercio ilícito o hubieran ejecutado actos contrarios a la moral pública o a la salud social o dedicados a la vagancia; f) Que intervengan directa o indirectamente en actividades relacionadas con trata de blancas, narcotráfico, terrorismo, comercio o tenencia de armas, falsificación de moneda o aquellos que encubran o protejan a quienes estuvieran dedicados a ellas, aún cuando las sentencias condenatorias no determinen su expulsión; g) Que hubieran defraudado en cualquier forma al Tesoro General de la Nación o a Instituciones del Estado; h) Que hubieran cometido delitos que merezcan pena privativa de libertad mayor a seis meses o condenados por quiebra fraudulenta, aún cuando las sentencias respectivas no determinen su expulsión; i) Que intervengan en cualquier forma en política interna o de dirección sindical o inciten por cualquier medio a la alteración del orden social, político o de las organizaciones sindicales. Que se incorporen a asociaciones que tengan directa o indirectamente fines políticos. Que intervengan en la organización o dirección de desfiles, asambleas o cualquier clase de manifestaciones públicas de carácter político o contrarias a las decisiones del Supremo Gobierno o que 
frontera internacional, como dice Sayad, no todo cruce de frontera constituye a un extranjero en inmigrante: si fuera así, el tráfico de armas y personas, el terrorismo o cualquier otro acto considerado como delito internacional, cometido por un extranjero, sería imputable a los inmigrantes. Esto es lo que la normativa migratoria siempre confunde y a lo cual nunca renuncia.

En el año 1998, elegido Hugo Banzer como presidente, se aprobó el Decreto Supremo $\mathrm{N}^{\circ}$ 25.150 mediante el cual se organizó el Servicio Nacional de Migración (SENAMIG) como órgano dependiente del Ministerio de Gobierno, reemplazando al antiguo CONAIN. Entre sus funciones principales se especifican: regular, registrar y controlar el ingreso y salida de personas del territorio nacional; administrar el régimen de extranjería y naturalización, regulando y procesando el ingreso, residencia y permanencia de los ciudadanos extranjeros; administrar la emisión y control de pasaportes; y estudiar la política migratoria. La implementación de planes de inmigración y la competencia para la expulsión de extranjeros en base a lo previsto en la legislación de 1996 son algunas de sus atribuciones, revelando la persistencia de una mirada restrictiva y punitiva de la migración. Aunque en el año 1999 el Servicio Nacional de Migración elevó una propuesta de modificación del Decreto Supremo firmado en 1996, ésta no llegó a instrumentarse. Vacaflores (2003) sostiene que si bien este proyecto estaba en la "línea moderna del rol socioeconómico de las migraciones" no lograba escapar a la mentalidad punitiva y policíaca, siendo el control de las fronteras como mecanismo de protección contra el narcotráfico y el terrorismo algunos de sus objetivos fundamentales.

\section{Las migraciones internacionales en la Bolivia actual}

A excepción de algunas corrientes de población que tuvieron a Bolivia como destino, la historia de las migraciones internacionales del país se caracteriza por un marcado proceso

\footnotetext{
efectúen declaraciones o publicaciones en el mismo sentido u ofensivas a las instituciones y/o autoridades nacionales. Que inciten de alguna manera al desobedecimiento a las leyes de la República o a las autoridades legalmente constituidas; j) Que entorpezcan en cualquier forma las buenas relaciones internacionales de Bolivia o desarrollen actividades de agitación o propaganda contra los gobiernos con los cuales mantenemos relaciones; k) Que incumplan la residencia que en su caso les hubiera sido impuesta (Artículo 48).
} 
de emigración, tendencia que se profundizó en los últimos decenios. ${ }^{106}$ Ahora bien, como he sugerido junto a Hinojosa Gordonava en otra oportunidad (Domenech e Hinojosa Gordonava, 2009), más allá del paulatino incremento de la emigración y la diversificación de los destinos, la visibilidad que adquirieron las migraciones internacionales a inicios del presente siglo en el escenario nacional boliviano se relaciona con ciertas transformaciones en los contextos de origen y destino, el papel que desempeñaron diversos actores sociales y las representaciones dominantes acerca de la emigración que se cristalizaron en los medios de comunicación.

En el marco de las consecuencias sociales de la implementación del modelo neoliberal en la Argentina, cuyos efectos se evidenciaron de manera drástica con la crisis económica y política de diciembre de 2001, en Buenos Aires tuvo lugar una serie de hechos de violencia y xenofobia contra bolivianos y bolivianas que alcanzaron una importante repercusión en Bolivia a través de los medios de comunicación. Mediante imágenes y contenidos dramáticos e impactantes, los titulares de periódicos bolivianos resaltaban, entre otros, acontecimientos como: "Bolivianos en Argentina reciben amenazas de muerte" (La Prensa, 3/5/2000); "Xenófobos argentinos echaron a boliviana y su bebé desde el tren" (Opinión, 19/6/2001); “Asesinaron a golpes a dos bolivianos en Buenos Aires" (La Prensa,

106 No hay demasiadas cifras confiables respecto a la cantidad de emigrantes bolivianos. Según diversas estimaciones, la población nacida en Bolivia que reside en el exterior oscila entre el 20 y 30 por ciento. Un documento de la Mesa Técnica de Bolivia del año 2007 ofrece algunas precisiones: “De acuerdo a censos oficiales, en 1976 vivían 250.000 bolivianos fuera del país y, en 1992, la cantidad de 380.000. Un informe del Servicio Nacional de Migración de finales de agosto de 2004 elevó la cuenta oficial de bolivianos fuera de Bolivia a 1.366.821. El último Censo Nacional de Población y Vivienda de 2001, contabiliza 8.274.325 habitantes, según el cual, un 14,18\% de los bolivianos no viviría en Bolivia. Estimaciones moderadas de la Organización Internacional de las Migraciones (OIM) establece que en el extranjero viven entre un millón y medio y dos millones de bolivianos, cifras que indicarían que el 19,4 por ciento de los nacidos en Bolivia no radica en el país. Datos más actuales del Capítulo Boliviano de Derechos Humanos Democracia y Desarrollo en su Informe sobre `La situación de Migrantes en Bolivia’ (2006) estima que más de dos millones y medio de bolivianos y bolivianas residen fuera del país, es decir, un porcentaje que se acerca al 30 por ciento. En la misma línea, un documento de trabajo preparado por la Defensoría del Pueblo de Bolivia en ocasión de la 8 ${ }^{a}$ Conferencia de Instituciones Nacionales de DD.HH. en el 2006, tomando datos parciales del SENAMIG, establece que aproximadamente existen dos millones 600 mil bolivianos y bolivianas viviendo en el exterior del país. Una última estimación realizada por la Cancillería boliviana, vía las embajadas, dan el resultado de 1.676 .177 bolivianas/os que viven en distintos países donde se cuenta con representaciones diplomáticas." Por otra parte, los censos nacionales de los países de destino ilustran el crecimiento cuantitativo que tuvo la emigración en términos absolutos durante las últimas tres décadas. Según datos del proyecto IMILA del CELADE, la población nacida en Bolivia ha tenido el siguiente desarrollo: en Argentina, se registraron 101.000 nacidos en Bolivia en 1970 y 233.464 en el 2001; en Brasil, 10.712 en 1970 y 20.588 en el 2000; en Estados Unidos, 6.878 y 53.280 respectivamente; en España, el censo registra 6.619 en el 2000 y 97.947 en el 2005. 
23/6/2001). La notoriedad que cobraron muchos de estos sucesos en la opinión pública boliviana presionó a distintos sectores gubernamentales a manifestarse de manera puntual sobre el tema mediante acuerdos y convenios bilaterales tendientes a facilitar la regularización de su situación migratoria en ciertos países de destino como la aprobación por ley del "Protocolo Adicional al Convenio de Migración entre la República Argentina y la República de Bolivia" en el mes de julio de 2001.

Por otra parte, la creciente crisis de Estado (García Linera, 2005) que atravesaba Bolivia a principios de la presente década, junto a la crisis argentina, favoreció el inicio de una corriente migratoria de bolivianos y bolivianas hacia Europa, particularmente España, cuyo significativo crecimiento se producirá en un período relativamente corto de tiempo.107 Las particulares características que asumió la emigración a España puso de relieve un conjunto de representaciones, reflejadas y producidas por los medios de comunicación, con un fuerte arraigo en la opinión pública nacional que paulatinamente interpelará al Estado. Estas representaciones acerca de la emigración se construyeron en torno a acontecimientos que le dieron gran visibilidad: la abrumadora demanda de pasaportes a las oficinas del Servicio Nacional de Migración, las continuas deportaciones desde España, la promoción de pasajes de las agencias de viajes y las remesas familiares, entre otras. Relacionado con la feminización de los flujos migratorios hacia España, un hecho que sensibilizó especialmente a la opinión pública fueron las consecuencias familiares atribuidas a la partida de mujeres -muchas de ellas madres- cuyos hijos quedaron en Bolivia al cuidado de terceros. ${ }^{108}$

Igualmente, tal como lo explicita la Federación de Asociaciones Civiles Bolivianas (FACBOL) al reconocerse en su conformación como "el resultado de un largo proceso donde no ha estado ajena la realidad, política y social de la República Argentina y de la República de Bolivia”, las realidades y situaciones que en Bolivia se vivían producto de su crisis de Estado (García Linera, 2005) repercutieron en el seno de determinadas organizaciones de bolivianos residentes en la Argentina, donde empezó a generarse un fenómeno particular de politización, dando pie a niveles organizativos ya no sólo de tipo laboral y/o cultural, sino básicamente político como el Comité de Defensa del Proceso de Cambio por la Soberanía Popular Originaria en Bolivia o la Juventud Boliviana en Acción. De

107 Datos recientes del Instituto Nacional de Estadística del Estado español, obtenidos a través del Padrón Municipal correspondiente al año 2008, señalan que son 236.048 las personas nacidas en Bolivia que residen en España. 108 Véanse Ferrufino Quiroga et al. (2007); Peñaloza Chej et al. (2008); Román Arnez (2008). 
manera concreta, durante el mes de octubre del 2003, cuando en El Alto (La Paz) se desarrollaba la denominada guerra del gas, en Buenos Aires se llevaban adelante también manifestaciones de apoyo a los movimientos sociales (marchas multitudinarias, piquetes de huelgas de hambre, manifestaciones de apoyo) en demanda de la nacionalización de los hidrocarburos y la expulsión de Sánchez de Lozada del gobierno, expresando un nivel de politización de los bolivianos en la Argentina que habilitará el surgimiento de un nuevo actor social en el escenario político nacional: los bolivianos residentes en el exterior. Después de este primer atisbo de acción política, ciertos sectores de la colectividad boliviana en la Argentina ya no sólo van a denunciar o solidarizarse con las luchas que transcurren en su país, sino que también se involucrarán con asuntos políticos de la sociedad receptora como la aprobación de la nueva ley de migraciones en la Argentina (finalmente sancionada en diciembre de 2003) y definirán una posición política propia a la hora de realizar demandas dirigidas a la sociedad de origen como el "voto en el exterior", como veremos más adelante.

Finalmente, con la llegada del MAS al poder a principios del año 2006 la cuestión migratoria -en particular, la emigración- obtuvo una inusitada receptividad por parte del Poder Ejecutivo, especialmente en el área de gobierno de las relaciones internacionales, incluyéndolas en el programa de gobierno propuesto para los próximos años, el Plan Nacional de Desarrollo109 (PND), asumiendo medidas concretas frente a hechos que involucraban a ciudadanos bolivianos en otros países y definiendo una posición específica frente a la temática migratoria en el debate público nacional como en la arena política internacional. La trascendencia política que empezó a adquirir la migración como asunto de gobierno por estos años se corresponde con decisiones originadas en ámbitos de la Presidencia y el Ministerio de Relaciones Exteriores y Cultos (MREyC) antes que en organismos del Ministerio de Gobierno históricamente consagrados al control migratorio como el Servicio Nacional de Migraciones (SENAMIG). Si bien entre los funcionarios de gobierno se suele manifestar que, idealmente, la Cancillería y el SENAMIG "deben ir de la mano, [ya que] si falla uno, falla el otro", en la práctica estos organismos estatales, como ocurre en las más diversas experiencias nacionales, están envueltos en una disputa

109 El Plan Nacional de Desarrollo fue publicado a mediados de 2006. Según este Plan, las propuestas y orientaciones que contiene "son la base de la transición que iniciará el desmontaje del colonialismo y neoliberalismo, y servirán para construir un Estado multinacional y comunitario que permita el empoderamiento de los movimientos sociales y pueblos indígenas emergentes. Su principal aspiración es que los bolivianos y bolivianas vivamos bien." (Plan Nacional de Desarrollo, 2006). Cabe destacar que este plan nacional, a diferencia de otras instancias gubernamentales latinoamericanas, no contempla las remesas de los migrantes como parte de una estrategia de desarrollo económico. 
respecto al manejo de los asuntos migratorios ${ }^{110} \mathrm{y}$, en consecuencia, de la definición de la política migratoria, que mantienen separados los asuntos concernientes a la inmigración y a la emigración, habilitando distintas miradas y prácticas sobre el fenómeno migratorio y sus implicancias, como si fueran dos dimensiones mutuamente excluyentes de un mismo hecho social. Al momento de las definiciones políticas a escala nacional, el modo en que el resto de los organismos del Estado y las organizaciones de la sociedad civil interpelan y se relacionan con uno y otro, sugiere que -parafraseando una expresión popular- todos los caminos conducen a Cancillería.

\section{Las migraciones internacionales y el nuevo gobierno nacional}

Diversos actores sociales y políticos relacionados con las migraciones internacionales coinciden en señalar que desde la llegada del MAS al poder a principios del año 2006 las migraciones internacionales han adquirido una relevancia sin precedentes en la agenda política. En ciertos organismos estatales, especialmente en Cancillería, no sólo se destaca la importancia que habría obtenido el "tema migratorio"; algunos funcionarios consideran que se trata de una "prioridad" para el gobierno nacional. En este sentido, algunas acciones llevadas adelante por el Poder Ejecutivo, bajo el sello de la figura presidencial, avalarían esta creencia común. Un primer indicador lo constituye el hecho de que las migraciones internacionales hayan sido contempladas y se haya fijado una posición respecto a ellas en el programa de gobierno propuesto para los próximos años, el Plan Nacional de Desarrollo111 (PND), especialmente en los apartados referidos a las relaciones exteriores e internacionales. ${ }^{112}$ Asimismo, frente a determinados hechos sociales como la muerte de seis migrantes de la colectividad boliviana -cuatro de ellos eran niños- en un

110 Estas disputas entre organismos gubernamentales también está atravesada por los fondos económicos en juego, especialmente a partir de la supresión de los "gastos reservados" del Ministerio de Gobierno debido al uso y abuso que se hizo de ellos durante gobiernos anteriores.

111 El Plan Nacional de Desarrollo fue publicado a mediados de 2006. Según este Plan, las propuestas y orientaciones que contiene "son la base de la transición que iniciará el desmontaje del colonialismo y neoliberalismo, y servirán para construir un Estado multinacional y comunitario que permita el empoderamiento de los movimientos sociales y pueblos indígenas emergentes. Su principal aspiración es que los bolivianos y bolivianas vivamos bien." (Plan Nacional de Desarrollo, 2006).

112 Como contracara, es llamativa la ausencia de la "cuestión migratoria" en el texto de la Nueva Constitución Política del Estado, aprobada por el Congreso Nacional en el mes de octubre de 2008. Los emigrantes, en tanto "bolivianas y bolivianos residentes en el exterior", sólo son mencionados en la segunda sección, referida a los derechos políticos. 
taller textil clandestino de un barrio de la ciudad de Buenos Aires, donde trabajaban numerosas familias bajo condiciones de explotación, se tomaron inmediatamente medidas al respecto. ${ }^{113}$ También se ha hecho presente el gobierno en eventos nacionales o internacionales dedicados a las migraciones internacionales. Por ejemplo, el propio presidente Evo Morales participó de la apertura de la Octava Conferencia Internacional de las Instituciones Nacionales para la Promoción y Protección de los Derechos Humanos, organizada por el Defensor del Pueblo de Bolivia en Santa Cruz de la Sierra en el mes de octubre de 2006, cuyo tema central fueron los derechos de los migrantes. Más recientemente, Evo Morales ha sido uno de los líderes sudamericanos que con mayor firmeza se ha pronunciado en contra de la llamada Directiva de Retorno -votada por el Parlamento Europeo en junio de 2008- que pretendía establecer "procedimientos y normas comunes en los Estados miembros para el retorno de los nacionales de terceros países que se encuentren ilegalmente en su territorio". En la Carta abierta que firmó en rechazo a esta medida de la Unión Europea sostuvo:

Los problemas de cohesión social que sufre Europa no son culpa de los migrantes, sino el resultado del modelo de desarrollo impuesto por el Norte, que destruye el planeta y desmiembra las sociedades de los hombres. (Carta abierta del presidente Evo Morales Ayma a propósito de la "Directiva Retorno" de la Unión Europea, La Paz, 2008)

En distintas ocasiones, Evo Morales ha recurrido también a su experiencia en el extranjero, ya sea como hijo de migrantes, dirigente sindical o jefe de Estado, para ilustrar las vivencias e injusticias que padecen los emigrantes que pretenden ingresar o se encuentran en los principales destinos de la migración boliviana: "Por eso comprendo el dolor de los bolivianos que, por buscar fuentes de trabajo, por mejorar su situación, migran a la Argentina, a España o a Estados Unidos. Y, al no tener papeles, la vida se vuelve

113 Por ejemplo, a la semana de ocurridos los hechos se envió una comisión del gobierno boliviano integrada por el Viceministro de Relaciones Exteriores y Cultos, el Viceministro de Coordinación Gubernamental y el Viceministro de Trabajo, entre otros. Esta comisión propuso la conformación de equipos de trabajo para enfrentar los distintos problemas que afectan a la comunidad boliviana en la Argentina así como la reducción de los plazos en la atención y los costos de los documentos. También se habría acordado la creación de un observatorio de derechos humanos para hacer un seguimiento de las condiciones a las que están expuestos los inmigrantes bolivianos en la Argentina. Frente a una relación bilateral monopolizada por la venta y compra de gas, Evo Morales declara en una entrevista periodística publicada en la revista argentina Veintitrés Internacional: "Y no sólo gas o hidrocarburos, también estamos avanzando en el tema de los inmigrantes". 
dramática para muchos de ellos" (Página 12, 16/04/06). En la Argentina estuvo de niño con su padre que trabajó como zafrero a comienzos de los años sesenta en los cañaverales de azúcar de la provincia de Jujuy. Sus recuerdos se remontan a las dificultades que tuvo como aymara en la escuela (que hicieron que la abandonara) y la extrema pobreza en la que vivía su familia. Ya como adulto su relato se refiere a las limitaciones que tuvo en el otorgamiento de la visa, aún como presidente, para ingresar a los Estados Unidos. Tampoco su entrada a España, habiendo sido invitado a participar de un foro internacional como dirigente sindical, estuvo exenta de dificultades. Frente a la situación que se planteó con los agentes españoles de Migraciones, Evo Morales acudió al mismo argumento que sostendrá años más tarde como presidente en sus intervenciones públicas:

Yo me acuerdo hace 10 años, teníamos la invitación del Ayuntamiento de Bilbao para participar en un foro internacional. Me pagaron mis billetes para que pueda participar ahí, me mandaron los billetes correspondientes, llegué al aeropuerto de Barajas en Madrid, y algunos policías o militares no me dejaron salir, me pedían 500 dólares, y yo no tenía 500 dólares, estaba detenido ahí, querían devolverme hacia Bolivia. Les dije, estoy invitado, aquí está la carta de invitación, me mandan los pasajes, tengo el pasaje de retorno, no me entendían, eran los uniformados de Barajas. Yo me enojé finalmente, les dije, si por 500 años saquearon, robaron oro, plata en Bolivia pues no hay 500 dólares, qué voy a hacer yo si no hay 500 dólares. (Discurso de apertura del presidente Evo Morales Ayma en la Octava Conferencia Internacional de las Instituciones Nacionales para la Promoción y Protección de los Derechos Humanos, Santa Cruz, 2006)

Este relato personal del actual presidente refleja la visión que posee el gobierno actual sobre las causas y consecuencias de los movimientos migratorios internacionales. En general, éstos son interpretados en el marco de la relación de dominación colonial entre países centrales y periféricos: uno de los asesores del Canciller expresa que la migración "es resultado de un proceso mucho más largo" y que se trata de "quinientos años de transferencia de recursos del sur al norte". Cuando la mirada se vuelve sobre la realidad migratoria actual en Bolivia, los flujos de población -en particular, la emigración- son atribuidos a los efectos estructurales causados por el neoliberalismo. Consecuentemente, la emigración es vista como un hecho social que afecta a las mayorías, tanto en un sentido sociológico como demográfico. Así lo enuncia el Viceministro de Relaciones Exteriores y 
Cultos de Bolivia en la VI Conferencia Sudamericana sobre Migraciones realizada en el mes de mayo de 2006 en Asunción, a unos pocos meses de que el MAS ocupara el gobierno nacional: "el actual gobierno ha priorizado los objetivos de los sectores mayoritarios de la población boliviana, como es el caso de la atención a la temática migratoria, particularmente por la situación que atraviesan miles de bolivianos que emigraron". Como se precisa en diversos pasajes, estas condiciones objetivas son las que motivarían la emigración "en busca de mejores condiciones de vida", entre otras estrategias individuales y colectivas. Esta relación también queda claramente expresada en el Plan Nacional de Desarrollo: "(l)as administraciones neoliberales ocasionaron significativos daños económicos al Estado, que repercutieron negativamente en los sectores productivos y en la generación de empleo, incrementando también una masiva corriente migratoria de bolivianos a países del exterior en busca de mejores oportunidades de vida". Y así se pronuncia Evo Morales en los eventos sobre migraciones internacionales de los cuales participó hacia fines de 2006:

Cuando la migración es de norte a norte no hay problema en esas migraciones, esas migraciones más bien son una gran solución para esos países de norte a norte. Cuando la migración es de norte hacia el sur, eso es bienvenido, no hay exclusión, no hay marginación, aunque nos dejan mucha diferencia económica y social en nuestro continente, en nuestros países, especialmente si hablamos de Bolivia y otros países de la región. [...] (D)e la migración del sur al norte, eso es lo que nos preocupa, y esa migración es satanizada, criminalizada, en algunos casos expulsada [...] En esta migración del sur al norte está el problema [...] (H)ay migración porque hay problemas económicos, porque hay problemas sociales, y si hay problemas sociales y económicos es porque hay profundas asimetrías de un país a otro país, de una nación a otra nación. Si no resolvemos esas asimetrías de un país a otro país, o de un continente a otro continente jamás vamos a resolver el tema de la migración... (Discurso de apertura del presidente Evo Morales Ayma en la Octava Conferencia Internacional de las Instituciones Nacionales para la Promoción y Protección de los Derechos Humanos, Santa Cruz, 2006)

Cuando la migración es de norte a sur hay saqueo de los recursos naturales y acaparamiento de miles de hectáreas de tierra de nuestros pueblos, cuando es de sur a norte, se criminaliza, hay muros y deportaciones, esa es la violencia 
que estamos soportando en estos momentos [...] (M)ientras no haya políticas que permitan achicar las diferencias económicas de un Estado a otro, las asimetrías seguirán existiendo (Intervención del presidente Evo Morales Ayma en la primera plenaria de XVI Cumbre Iberoamericana de Jefes de Estado y de Gobierno, Montevideo, 2006)

Sin embargo, al mismo tiempo que se sostiene una visión amparada en las desigualdades entre el Norte y el Sur, la perspectiva que asumen los representantes del Estado boliviano en ámbitos internacionales especializados en materia de migraciones no escapa a los efectos que ha tenido y tiene el proceso de internacionalización de la política migratoria, desarrollado a nivel mundial a partir de foros regionales intergubernamentales de carácter no vinculante como la Conferencia Sudamericana sobre Migraciones, asistidos técnica y financieramente por organismos internacionales como la OIM, alejándose de la visión, fundada en la noción de conflicto, que se suele explicitar en relación a las causas y consecuencias de los procesos migratorios. La intervención del Viceministro de Relaciones Exteriores y Cultos de Bolivia en la VI Conferencia Sudamericana sobre Migraciones da muestras al respecto. Reconociendo la importancia de los programas de regularización migratoria, a la vez que relativiza su alcance, suscribe aquella máxima de la perspectiva de la gobernabilidad migratoria que, en palabras de la OIM, entiende a la migración como un fenómeno positivo: "la migración humana ordenada para beneficio de todos".

Pero es importante atender el fenómeno migratorio no sólo desde una óptica de la regularización documentaria, sino como un hecho social y económico que beneficia y da oportunidades para todos. (...) La concepción actual y cada vez más generalizada, es ver la migración como un fenómeno positivo para los individuos como para las sociedades, que deben ser encauzadas correctamente para alentar al máximo sus beneficios, no sólo en lo económico, sino también en lo social y cultural. (Intervención y reporte de la República de Bolivia en su carácter de Presidencia Pro-Témpore saliente en la VI Conferencia Sudamericana de Migraciones, Asunción, 2006)

Según la versión oficial, las medidas que puedan desarrollarse para enfrentar la "temática de migración" no se agotarían en las modificaciones necesarias a nivel de política 
migratoria o en el campo de las relaciones exteriores o internacionales. ${ }^{114}$ Uno de los asesores del Canciller señala que lo que se pretende es modificar -mediante el Plan Nacional de Desarrollo propuesto- la estructura productiva del país. Como dice otro funcionario de Cancillería, se trata de impulsar "políticas de Estado que creen condiciones de oportunidades". La transformación de las políticas económicas y la producción de nuevas condiciones sociales permitirían el (¿esperado?) retorno de los exiliados del neoliberalismo. ${ }^{115}$ Afirma Evo Morales a pocos meses de asumir la presidencia:

Parte de nuestro proyecto de refundación de Bolivia es crear las condiciones para que los compatriotas que migraron puedan retornar a su país. Quienes se fueron lo hicieron porque parecía que no cabían en este país destruido por el neoliberalismo, que generó un masivo exilio económico y social; queremos que se incorporen a este proyecto de construcción de una nueva Bolivia que pueda contener a todos sus habitantes. Aspiramos a que, con el Plan Nacional de Desarrollo que estamos elaborando, que incluye la mecanización del agro y el apoyo a las comunidades, nuestros hermanos encuentren en Bolivia lo que buscaban y no encontraron en el extranjero. (...) Hay que cambiar las políticas económicas y recuperar e industrializar nuestros recursos naturales. Para mí los recursos naturales siguen siendo la esperanza para el pueblo boliviano. (Entrevista al presidente Evo Morales Ayma, Página 12, 16/04/06)

Junto a la idea que el desarrollo productivo del país y la creación de fuentes de trabajo garantizarán un lugar para quienes permanezcan en o retornen a Bolivia, también suele aparecer la noción de "resolver el tema de migración", concebida de dos maneras. Mientras que por un lado puede expresar la convicción de que los cambios estructurales

\footnotetext{
114 En algunas oportunidades, la "política migratoria" aparece, especialmente en el discurso de los funcionarios de Cancillería, equiparada a "política exterior": "la política migratoria es una política exterior".

115 Es necesario subrayar que si bien la implementación del modelo neoliberal en Bolivia tuvo importantes efectos sobre la dimensión y la visibilidad que adquirieron los flujos migratorios hacia países limítrofes, especialmente Argentina, y hacia otros destinos extracontinentales, la emigración de ciudadanos de nacionalidad boliviana no se produce exclusivamente en este período. En la Argentina, por ejemplo, la presencia de inmigrantes bolivianos es recogida desde el primero hasta el último censo nacional de población. La reciente migración a España, en cambio, surge claramente como una consecuencia de las medidas neoliberales aplicadas en Bolivia. En tal sentido, puede hablarse sin lugar a dudas de "exiliados/as del neoliberalismo". Bajo el título "Las exiliadas del neoliberalismo" (2004), María Galindo dirigió un documental que retrata las crudas condiciones de vida de cinco mujeres emigrantes bolivianas en España.
} 
internos y externos en el plano económico y político atenuarán la magnitud de los movimientos de emigración y servirán para proteger los derechos de los emigrantes en la sociedad de destino/recepción, por el otro puede remitir a una representación ilusoria de la dinámica de las migraciones internacionales, el fin de las migraciones. Esta ficción no adquiere aquí el contenido de aquellos diagnósticos demográficos que pronostican una drástica reducción de la propensión a migrar, sino, más bien, frente a la perplejidad que puede producir el fenómeno migratorio, emerge como una expresión del resultado esperado de las políticas migratorias que aspiran a detener los movimientos migratorios hacia el interior/exterior y asegurar el regreso de los in/emigrados.

Entendida la emigración, a diferencia de períodos anteriores, en el marco de una relación de dominación entre países centrales y periféricos y como una consecuencia de factores económicos estructurales, no se trataría únicamente -según declaraciones públicas del presidente Evo Morales y también de funcionarios de Cancillería- de cumplir con los compromisos asumidos en el ámbito internacional (desde la firma de convenios regionales hasta la ratificación de convenciones internacionales), sino de enfrentar las marcadas desigualdades existentes entre los países vecinos y entre los llamados países desarrollados y los países en vías de desarrollo a partir de cambios en la estructura de la economía mundial que posibiliten la incorporación de productos provenientes de Bolivia en los mercados internacionales. De esta manera, al favorecer la creación de nuevas fuentes de trabajo, se evitaría o acabaría con el "tema de migración”.

Al margen de ratificar un acuerdo de las Naciones Unidas por medios internacionales, creo que todos saben eso, creo que hay dos o tres propuestas. Si no se termina con las asimetrías de un país a otro país, de una nación a otra nación, sería seriamente pensar cómo al migrar mejora el derecho de la ciudadanía planetaria. Segundo tema, yo apostaría cómo achicar esas asimetrías, y eso es dando mercados con precios justos a los países subdesarrollados, los llamados países en vías de desarrollo, [...] (E)n vez de que bolivianas y bolivianos cada día entren a Europa, quisiera que nuestros productos entren a Europa, sería la mejor forma de generar fuentes de trabajo y evitar el tema de migración, acabar con el tema de migración (Discurso de apertura del presidente Evo Morales Ayma en la Octava Conferencia Internacional de las Instituciones Nacionales para la Promoción y Protección de los Derechos Humanos, Santa Cruz, 2006) 
Ahora bien, con todo ello, distintas voces del gobierno nacional asumen -a manera de autocrítica- que el "tema migratorio" todavía no se ha plasmado en una política pública, ni tampoco ha alcanzado el rango de política de Estado. También suelen subrayar el carácter incipiente que tendría el tratamiento de los asuntos migratorios: algunos funcionarios afirman que en materia de políticas migratorias Bolivia "está en pañales" o que el tema se encuentra "en pleno proceso de germen". Otros van más allá: "en Bolivia no hay política migratoria... lo que existe son normas jurídicas relativas a la migración solamente". ${ }^{116}$ En el año 2006 la Cancillería promovió la conformación de un Consejo Nacional para las Migraciones, compuesto por organismos gubernamentales y organizaciones de la sociedad civil, con el propósito de discutir y elaborar políticas públicas en la materia y acordar las bases para el diseño de una nueva ley migratoria (en realidad, la primera ley de migraciones ${ }^{117}$ ), pero los avances fueron muy escasos (entre otras razones por las disputas que mantienen los diferentes organismos de gobierno con competencia en el tema y las diferencias existentes entre las organizaciones de la sociedad civil).

En aquél año, en Cancillería todavía se consideraba que había una coyuntura política propicia para la revisión y discusión de la política migratoria nacional, en particular para la elaboración de una ley de migraciones. ${ }^{118}$ Para un alto funcionario consular se trataba de "una excelente ocasión para que en los próximos meses se pueda consensuar una nueva ley de migraciones". Asimismo, señalaba que "la idea de las nuevas autoridades es crear una nueva ley". En la actualidad hay mayor escepticismo en Cancillería: durante la VIII Conferencia Sudamericana sobre Migraciones, celebrada en la ciudad de Montevideo en el mes de septiembre de 2008, la representación del Estado boliviano se refirió a las "dificultades internas" en el Congreso Nacional, debido a la fuerte oposición que tiene el MAS en el Senado, para aprobar en el corto plazo una ley migratoria.

\footnotetext{
116 Esto lo lleva a considerar que "la migración es espontánea, no obedece a ninguna política migratoria" implementada en el país.

117 Es necesario destacar que durante todo el siglo veinte la formulación de las principales directrices en materia de política migratoria estuvo sujeta a las decisiones del Poder Ejecutivo: las disposiciones jurídicas sobre migraciones adoptaron generalmente la forma de decretos.

118 En esta dirección, uno de los representantes de la organización civil que se ocupó de organizar el Encuentro Alternativo de Migraciones en el año 2004, el Capítulo Boliviano sobre Derechos Humanos, Democracia y Desarrollo, también sostenía en aquél momento que en Bolivia había una coyuntura particular para el tratamiento de las migraciones. Afirmaba que "hay otra mirada, aunque no ha logrado materializarse en una propuesta" y que "hay otra sensibilidad" frente a las migraciones, que "hay voluntad política de proteger a los bolivianos en el exterior".
} 
En diferentes ámbitos de gobierno, pero especialmente en Cancillería, la legislación migratoria vigente en Bolivia -fundamentalmente la norma principal, el decreto supremo de 1996 analizado en apartados anteriores- es cuestionada desde distintos ángulos. ${ }^{119}$ Ya durante el primer año de gobierno del MAS, un funcionario del MREyC señalaba que "las normas que existen están desactualizadas" y que "el régimen legal migratorio está en desuso".120 Más recientemente, en el marco de la VIII Conferencia Sudamericana de Migraciones, la Directora General de Asuntos Consulares hizo referencia a la "caducidad" de la norma migratoria. Otro de los aspectos que se señala desde Cancillería es que la actual legislación migratoria no se ajusta a las transformaciones que la región sudamericana experimenta en el tratamiento de los asuntos migratorios. En palabras de uno de los funcionarios de Cancillería entrevistados: "[el Decreto Supremo de 1996] no va con la dinámica política migratoria regional". Esta incompatibilidad entre la norma nacional y los lineamientos regionales en materia migratoria radicaría en la distancia que el decreto supremo de 1996 tiene respecto a los consensos obtenidos en el marco de foros consultivos como la Conferencia Sudamericana de Migraciones ${ }^{121}$, donde el tema de los derechos humanos de los migrantes aparece como una de las principales preocupaciones declaradas. Otra de las cuestiones relevantes incorporada en la agenda de trabajo de la CSM desde sus inicios y que se destaca dentro de los consensos alcanzados entre los Estados sudamericanos, otorgándole cierta especificidad frente al resto de los foros regionales esparcidos por el mundo, es la vinculación de los Estados de origen con los

119 Si bien los distintos funcionarios de gobierno consultados tienen importantes observaciones a la norma migratoria vigente, es posible encontrar diferencias significativas según el ámbito de gobierno que se trate: mientras que en Cancillería se la considera "desactualizada" o "caduca", en el SENAMIG es vista como "incompleta". La directora del Servicio Nacional de Migraciones, entrevistada en octubre de 2006, opinaba que el Decreto Supremo de 1996 es "sumamente incompleto" y que había "muchas más cosas que normar".

120 Cabe recordar que la normativa migratoria vigente en Bolivia -como la de otros tantos países latinoamericanosestá inspirada en los principios de la llamada Doctrina de Seguridad Nacional, cuyo arraigo tuvo lugar en América Latina mediante el accionar del gobierno de los Estados Unidos y la instalación de las dictaduras militares durante los años setenta. El Régimen Legal de Migración de 1996 (Decreto Supremo № 24.423), aprobado durante el gobierno de Sánchez de Lozada, sostiene una visión restrictiva y represiva de las migraciones. Como vimos anteriormente, el control de los ciudadanos extranjeros, de los puestos fronterizos y de las actividades que realicen los extranjeros "desde su ingreso hasta su salida del territorio nacional" (Art. 20) se presentan como objetivos centrales.

121 La Conferencia Sudamericana sobre Migraciones se ha desarrollado hasta ahora en Buenos Aires (2000), Santiago de Chile (2001), Quito (2002), Montevideo (2003), La Paz (2004), Asunción (2006), Caracas (2007), Montevideo (2008) y Quito (2009). Los Estados participantes son Argentina, Bolivia, Brasil, Colombia, Chile, Ecuador, Paraguay, Perú, Uruguay y Venezuela. En la II Conferencia participó también Guyana y en la VI Suriname. 
ciudadanos emigrados y residentes en terceros países, tanto a nivel intrarregional como extraregional. 122

\section{Los bolivianos como nacionales en el exterior}

A pesar de la existencia de organismos, agentes, normas y prácticas estatales destinados a regular, clasificar y controlar los flujos migratorios, el relato de diversos representantes gubernamentales y no gubernamentales entrevistados sugiere que el Estado boliviano ha estado ausente o pasivo frente a las migraciones internacionales y se ha desentendido sistemáticamente de los bolivianos en el exterior. ${ }^{123}$ En palabras de un dirigente de una organización de derechos humanos, en Bolivia "hubo una despreocupación total del Estado". En esta misma línea, una de las personas encargadas del tema migratorio en la oficina central del Defensor del Pueblo, expresa que el Estado se ha mantenido en "silencio" y que de esta manera ha sido "cómplice". También otro de los funcionarios consulares considera que siempre se ha pretendido "sacarse el tema de encima" y que "no se toca la raíz del problema", agregando que "el fenómeno migratorio no quiere ser visto por el Estado".

Esta "ausencia" o "pasividad" que ha caracterizado -según la visión de diversos actores políticos, entre ellos los estatales- al Estado boliviano frente a las migraciones internacionales, puede comprenderse -en términos de Sayad (1998)- como parte de

\footnotetext{
122 En este espacio político de carácter no vinculante, además de la promoción de los derechos humanos de los migrantes y sus familias y la vinculación entre los nacionales en el exterior y sus países de origen, entre los temas transversales que se suelen destacar se encuentran la inserción de los migrantes en los países de destino, la regularización migratoria, la gobernabilidad de los flujos migratorios, la generación de información y conocimiento acerca de los procesos migratorios intraregionales y extraregionales, la modernización de las administraciones nacionales migratorias y la actualización de las legislaciones migratorias nacionales. La estrecha relación existente entre las prioridades fijadas en la Conferencia Sudamericana sobre Migraciones y las directrices de organismos regionales e internacionales como algunas agencias de las Naciones Unidas o la OIM (véanse, por ejemplo, las conclusiones del Seminario sobre Migración Internacional en las Américas o del documento "Migración internacional, derechos humanos y desarrollo en América Latina y el Caribe", publicado a comienzos de 2006) pone en cuestión la supuesta independencia de los Estados a la hora de definir la agenda política regional. De todas maneras, en relación a la política nacional, los Estados poseen un margen amplio de libertad para definirla y ponerla en práctica.

123 La categoría "bolivianos en el exterior" es relativamente reciente. Su uso es producto de la visibilidad social que adquirió en los últimos años la emigración en Bolivia.
} 
aquella complicidad objetiva, compartida por la sociedad de emigración, la sociedad de inmigración y los propios emigrantes/inmigrantes a través de categorías de pensamiento y de Estado, que permite el mantenimiento de la ilusión de una presencia/ausencia necesariamente provisoria o una presencia/ausencia durable, cuando no definitiva, de los migrantes. Sayad (1998:45-46) sugiere que "(t)odo acontece como si la inmigración necesitase, para poder perpetuarse y reproducirse, ignorarse (o hacer que se ignora) y ser ignorada en cuanto provisoria y, al mismo tiempo, no admitirse ni admitirla como trasplante definitivo". En el caso de la sociedad de emigración, ésta haría de cuenta que los emigrantes son simples ausentes, una ausencia provisoria. Así, aquél "silencio" a través del cual el Estado boliviano se vuelve "cómplice" o aquella actitud de "despreocupación" frente al fenómeno migratorio que perciben diversos actores políticos -no sólo estatalespodría ser interpretada como una muestra de la doble negación que ha mantenido el Estado ante el fenómeno de la emigración, más que de las migraciones en general: por un lado, se imagina a sí mismo básicamente como país de inmigración y, por el otro, niega la condición durable o definitiva que puede adquirir la emigración de sus ciudadanos, cuya aparente provisoriedad le autorizaría a desentenderse de ellos, atribuyendo la migración a una decisión individual ajena a su responsabilidad. De esta manera, el Estado boliviano habría convertido a los nacionales residentes fuera del territorio nacional en nonacionales, excluidos de lo político.

En la actualidad, en cambio, el eje principal del discurso estatal en el ámbito de las migraciones gira alrededor del interés nacional que representan las comunidades de emigrantes establecidas fuera del país -definidas por De la Torre Ávila (2006) como "Bolivia exterior"- bajo la forma de "protección y atención al ciudadano boliviano en el exterior". ${ }^{224}$ Según consta en el Plan Nacional de Desarrollo, esto supone objetivos como "documentar, facilitar la regularización migratoria, defender sus derechos, asegurar su participación en el voto electoral”. Se busca (re)incorporar a los emigrantes a la

\footnotetext{
124 Un antecedente importante en materia de normativa migratoria lo constituye el Decreto Supremo $\mathrm{N}^{\circ} 27.698$ del 24 de agosto de 2004 mediante el cual se reglamenta "la doble nacionalidad y la recuperación de la nacionalidad boliviana". Por otra parte, las disposiciones establecidas por el Ejecutivo en materia de migraciones durante el año 2006 se refieren fundamentalmente a los ciudadanos bolivianos residentes en el exterior, ya sea en Argentina o España. En el año 2007, entre las medidas de protección dirigidas a los ciudadanos residentes en el exterior, el informe anual de gestión del Ministerio de Relaciones Exteriores y Cultos destaca el trabajo realizado con los "menores de edad": "Como parte de las actividades de protección de los intereses y de respeto a los derechos de los ciudadanos bolivianos y de sus familias en el exterior, en coordinación con autoridades fronterizas de Argentina y Chile en especial, se realizaron acciones en defensa de bolivianos menores de edad. Así, se lograron repatriar 182 niños de Argentina, Brasil, Chile, Paraguay y Perú, precautelando de este modo sus derechos."
} 
comunidad política reconociéndolos como ciudadanos del Estado boliviano e interpelándolos como miembros de la nación boliviana, disolviendo -en términos simbólicos- aquella división entre nacionales y no-nacionales establecida anteriormente de acuerdo a criterios de territorialidad más que de nacionalidad. Para el $182^{\circ}$ aniversario de la Independencia de Bolivia el presidente Evo Morales se dirigió expresamente -lo cual subraya la importancia que se les atribuye- a las "hermanas y hermanos" residentes en el "exterior" de esta manera:

\begin{abstract}
Aunque estén lejos, nosotros los sentimos cerca, porque Bolivia somos todos, los que vivimos acá y los que, como ustedes, fueron al exterior en busca de mejores condiciones de vida. [...] No duden de nuestro esfuerzo. Desde Bolivia seguiremos trabajando y luchando para que sus derechos se reconozcan en todo el mundo. (Mensaje del presidente Evo Morales, 182ํㅡㄹ Aniversario de la Independencia de Bolivia, La Paz, 2007) ${ }^{125}$
\end{abstract}

Según la visión oficial, la nueva relación entre el Estado -redefinido como plurinacional126 de acuerdo al nuevo texto constitucional- y los emigrantes implicaría una reformulación del vínculo entre el servicio diplomático y los ciudadanos en el exterior, históricamente marcado por una relación de subordinación de carácter étnico y de clase, a partir del establecimiento de lineamientos políticos en el ámbito de las relaciones internacionales que configuren una "diplomacia de doble vía". De esta manera lo explica Evo Morales:

Como hemos dicho, vamos a implementar una diplomacia de doble vía, con los gobiernos y con las comunidades. Se incluirá en las agendas bilaterales con los países receptores programas de promoción de los derechos de los migrantes, pero los cónsules y embajadores bolivianos deben entender que la mayoría de los migrantes son indígenas, pobres, que tienen derecho a ser tratados de

\footnotetext{
125 Esta expresión es ilustrada de manera elocuente por una funcionaria de la Defensoría del Pueblo de La Paz al referirse al modo en que el Estado y los emigrantes deberían establecer su relación: "Esta propuesta, de acuerdo a lo que nosotros pensamos, va en la corriente de protección, aprovechar que el receptor garantice la protección de derechos y nosotros como emisor, acompañar la migración, que el migrante no se vaya sin Estado, si no que el migrante sienta la presencia de su Estado donde vaya (...) El intento es que el migrante que se va sepa que tiene un Estado que lo respalda".

126 Véase García Linera (2007) para un análisis del Estado boliviano y sus posibilidades de transformación pluralista.
} 
igual a igual. No vamos a tolerar expresiones de racismo contra sus propios compatriotas de parte de funcionarios que viven de espaldas a las comunidades. (Entrevista al presidente Evo Morales Ayma, Página 12, 16/04/06).

En este sentido, uno de los funcionarios del Ministerio de Relaciones Exteriores y Cultos (MREyC) indica que Cancillería debería prestar un "servicio público en el exterior" y que debería trabajar de manera conjunta con las asociaciones de inmigrantes, los cuales son considerados como los "principales sujetos y actores". Así lo cree también otro de los funcionarios entrevistados al señalar que los consulados trabajan como si fueran "una cosa extraña a ellos" cuando en realidad deberían ser "servidores de las comunidades bolivianas". Afirma que la política consular implica "atención al boliviano en el exterior" y que "no se trata sólo de proteger, sino de darles los elementos necesarios... que los consulados sean representativos de ellos, siempre hubo un divorcio en esto".

En este marco, la obtención de la documentación, contemplada en este caso como un instrumento para hacer efectivos determinados derechos, resulta una tarea prioritaria para Cancillería. De esta manera lo expresa uno de los agentes de Cancillería: "La obligación consular es documentar gente [...] La documentación es la base fundamental para que esta gente pueda acceder a cosas que en su vida jamás hubiera imaginado". La aprobación del Decreto Supremo N²8.709 de mayo del 2006 avala la importancia que adquiere esta medida política: según esta norma se pretende “(e)stablecer y promover acciones para que los ciudadanos bolivianos en situación irregular migratoria que radican en la República Argentina, puedan contar con documentos personales, a fin de acogerse al Programa Nacional de Normalización Documentaria Migratoria de la República Argentina". ${ }^{127}$ A tal punto es considerada una acción relevante que en el informe de gestión del año 2007 presentado por el MREyC la política migratoria es equiparada al otorgamiento de documentación: allí se indica que "Bolivia adoptó como política migratoria la de documentar a los ciudadanos bolivianos residentes en el exterior".

127 Posteriormente, a inicios del año 2007, se aprobó el Decreto Supremo № 28.995 que "amplía el proceso de documentación de inmigrantes bolivianos en la República Argentina, destinado a facilitar su regularización migratoria". Asimismo, se firmó el Decreto Supremo № 28.996, a través del cual "se autoriza la otorgación de la tarjeta inteligente de matrícula consular en favor de los residentes bolivianos en los Estados Unidos". 
Las acciones dirigidas a favorecer el acceso a la documentación no sólo servirían a los fines de proteger a los ciudadanos bolivianos en el exterior, sino también para habilitar el voto en el exterior. Este doble sentido ya está presente desde el comienzo de la gestión de Evo Morales:

Estamos muy preocupados, por eso ha viajado una comisión compuesta por cuatro viceministros y el director del Registro Civil que ya ha comenzado a trabajar para reducir los costos y los tiempos de provisión de partidas de nacimientos y certificados de antecedentes, que se requieren para el trámite de residencia y servirán también para implementar el voto de los ciudadanos bolivianos en el exterior. (Entrevista al presidente Evo Morales Ayma, Página $12,16 / 04 / 06)$.

En nombre de nociones como democracia, unidad nacional, participación, justicia e igualdad, el gobierno nacional -a través de la figura presidencial- exhorta a aquellos ciudadanos que se encuentran fuera del territorio nacional boliviano a apoyar la construcción del proyecto político que se lleva adelante en Bolivia mediante su contribución en las urnas, el voto en el exterior.

Queridos hermanos y hermanas, ustedes tienen que ayudarme a construir una Bolivia con mayor democracia, con mayor participación de todos nosotros. El compromiso de nuestro gobierno es permitir que ustedes decidan el destino del país, votando, sufragando donde se encuentren. No sólo se trata de cumplir un mandato constitucional, sino se trata de profundizar la democracia con la participación de los distintos sectores y sobre todo de los hermanos que viven en el exterior. [...] Ustedes en el exterior son la garantía de la unidad nacional. Por eso quiero compartir con ustedes, estén donde estén, juntos celebrar un nuevo aniversario de la patria, pidiéndoles que nos acompañen en esta transformación histórica, en busca de la igualdad y la justicia en nuestro país. (Mensaje del presidente Evo Morales Ayma, 182ํㅜ Aniversario de la Independencia de Bolivia, La Paz, 2007) 
En este sentido, la implementación del voto en el exterior funcionaría a manera de lo que el origen etimológico de la noción de sufragio evoca (esto es, ayuda o apoyo), generando una particular relación de intercambio. ${ }^{128} \mathrm{El}$ gobierno nacional, al ocuparse de la protección y defensa de los ciudadanos en el exterior, también espera ser retribuido mediante la ayuda o apoyo que puedan brindarle mediante el voto en instancias de consulta popular o en momentos electorales. Es decir, de algún modo, el Estado nacional también estaría protegiendo sus propios intereses al proteger los derechos de los ciudadanos en el exterior. El voto en el exterior pasaría a formar parte de la estrategia política del gobierno nacional en tanto confía en que los/as ciudadanos/as bolivianos/as radicados fuera de Bolivia están dispuestos a apoyar al gobierno nacional en las urnas al identificarse con el proyecto político del MAS o, al menos, con aquello que representa la figura de Evo Morales. Así lo expresaba uno de los asesores del MREyC mucho antes de que el voto en el exterior comenzara a tratarse en espacios formales de negociación política como la Cámara de Diputados:

\begin{abstract}
Esta población migrante tiene peso e importancia para el nuevo gobierno por su afinidad política, es decir de alguna manera es una población que se siente identificada con este proyecto político. [...] Yo me animaría a decir que es realmente importante ese voto del exterior en las próximas urnas, tanto en el referéndum como en las elecciones, que es una prioridad.
\end{abstract}

En el año 2009, en ocasión del 184º aniversario de la declaración de la Independencia, el presidente Evo Morales envió un nuevo mensaje vía internet "a los compatriotas en el extranjero". Era la primera vez que los ciudadanos bolivianos en el exterior participarían de las elecciones generales previstas para el 6 de diciembre para elegir al primer mandatario del ahora denominado Estado Plurinacional de Bolivia. Evo Morales, después de someter y quedar ratificado en el cargo por medio de un referéndum popular, se presentaba por la reelección acompañado por el vicepresidente Álvaro García Linera. En aquél mensaje se ratificaba la importancia que habían adquirido los bolivianos en el exterior. Los convoca a participar de estas elecciones nacionales, a ejercer el derecho ciudadano al voto y decidir con él "el futuro y la esperanza de nuestra querida Bolivia", una Bolivia que se la pretende democrática, justa, igualitaria, digna y soberana. Los interpela

128 Otro de los factores de peso que podría explicar la importancia que se le otorga en la posición oficial a las comunidades migrantes en el exterior son las remesas. Sin embargo, no he reunido suficientes elementos que permitan sistematizar y apoyar dicha afirmación. 
como parte de la patria, es decir, como "hijos" que "llevan a Bolivia en el corazón" y no solamente en los papeles. Son parte de "una gran familia", cuyo jefe -jefe de familia, jefe de gobierno- como padre, los espera "con los brazos abiertos", haciéndoles saber que "los necesita", al mismo tiempo que valora el esfuerzo mediante el cual "contribuyen a la economía de nuestra querida patria", manifestando su admiración personal "por su trabajo, por su valentía y por su honestidad", un reconocimiento nunca antes hecho.

Queridas hermanas y hermanos. Bolivia festeja 184 años de vida independiente. Estoy seguro que, estén donde estén, ustedes son parte de esta celebración. Por eso, en este día de la Patria les mando un abrazo de hermandad. Por muy lejos que estén estoy convencido que ustedes llevan a Bolivia en el corazón, porque es orgullo ser hijos de esta tierra hermosa y diversa.

Quiero expresarles mi profunda admiración por su trabajo, por su valentía y por su honestidad, y porque con su esfuerzo contribuyen a la economía de nuestra querida patria, todo ese esfuerzo hoy tiene ese reconocimiento.

Por primera vez, en 184 años de historia, los bolivianos que viven fuera del país podrán votar, podrán ejercer sus derechos en democracia, para decidir con su voto, el futuro y la esperanza de nuestra querida Bolivia, para que su voz y sus demandas sean escuchadas. Esto es posible gracias a la nueva Constitución y a un pueblo con fe en el cambio.

Hemos cumplido lo que prometimos, ahora les toca a ustedes participar, participar en el sueño de una Bolivia digna, soberana y con justicia social, sin analfabetismo y de lucha contra la pobreza.

Un pueblo unido por la esperanza y el progreso y esta Bolivia con democracia, igualdad y justicia; un país con trabajo digno que crece y se desarrolla; una patria les espera con los brazos abiertos, una patria que les necesita, porque los bolivianos somos una gran familia. Un abrazo y felicidades en el día de la Patria. (Mensaje del presidente Evo Morales Ayma, 184ํㅡ Aniversario de la Independencia de Bolivia, La Paz, 2009) ${ }^{129}$

129 El video dirigido a "los compatriotas en el extranjero" está disponible en YouTube: http://www.youtube.com/watch?v=wc2T0FMJ1Vk\&feature=player_embedded 
Uno de los antecedentes más significativos referido al voto en el exterior se remonta al año 2005. En el mes de septiembre, la Sala Penal Segunda de la Corte Superior de Justicia de La Paz declaró procedente el recurso de amparo constitucional que interpusieron los representantes legales de los ciudadanos bolivianos residentes en la Argentina para que pudieran votar en las elecciones generales del 4 de diciembre. ${ }^{130}$ El fallo emitido por el Tribunal de Amparo se apoyó en el artículo 97º del Código Electoral (1991). Este artículo, titulado "Voto de residentes en el exterior", establece que "(l)os ciudadanos bolivianos en ejercicio, residentes en el extranjero, podrán votar para elegir a Presidente y Vicepresidente en las elecciones generales. Una ley expresa regulará este derecho”. En su fallo, los vocales ordenaron que el Congreso Nacional sancione una ley con urgencia para que pueda ejercerse este derecho. Pero, bajo el argumento de la falta de capacidad técnica -se interpusieron dificultades legales, administrativas, económicas y logísticas- para implementar el voto en el exterior, la elaboración y discusión del proyecto de ley se fue postergando hasta que finalmente el MAS -interpelado de manera constante por la demanda de ciudadanos bolivianos radicados en diversos países como Argentinaconsiguió que ingresara en la Cámara de Diputados.

El 21 de mayo de 2008 la Cámara de Diputados, donde el MAS tiene mayoría, aprobó en primera instancia la "Ley de voto de ciudadanos bolivianos residentes en el extranjero"131 y dos días más tarde (23 de mayo) la remitió para su sanción a la Cámara de Senadores. El artículo $1^{\circ}$ de dicha ley dispone que "los ciudadanos bolivianos mayores de 18 años, en ejercicio de sus derechos, domiciliados en el exterior de la República, cumpliendo los requisitos exigidos, ejercerán su derecho a voto para la elección del Presidente y Vicepresidente únicamente, elecciones generales y Referéndum de carácter nacional". Esta ley fue congelada en su aprobación en la Cámara Alta por el partido opositor PODEMOS (Poder Democrático Social) hasta abril del 2009. Así como el oficialismo sabe que puede contar con el apoyo que le brindan los bolivianos en el exterior, la oposición teme el peso decisorio que puedan tener -especialmente a partir del apoyo explícito y masivo que

130 Los reclamos por el "voto en el exterior" han tenido lugar también en otros países, aunque con diferentes resultados. En el año 2002, durante la visita de Sánchez de Lozada a los Estados Unidos, diversas organizaciones de residentes bolivianos tuvieron un encuentro en la ciudad de Washington D.C. con el presidente donde le manifestaron una serie de demandas, entre las cuales estaba incluido el derecho al voto desde el exterior.

131 El proyecto de Ley № 443/08 contiene 19 artículos y siete capítulos e incorpora un anexo de disposiciones finales que fueron considerados en la 35aㅗ sesión ordinaria. 
recibió el MAS durante la jornada del voto simbólico realizada en diversos países en ocasión del Referéndum Revocatorio- en próximas contiendas electorales. Uno de los senadores por PODEMOS lo expresa claramente en una de sus intervenciones públicas ${ }^{132}$ :

\begin{abstract}
De implementarse el voto boliviano en el exterior, significaría que los que se fueron decidirían las elecciones nacionales. (...) Siendo Bolivia un país de emigrantes, de llegarse a implementar el voto boliviano en el exterior, significaría que aquellos que se fueron decidirían las elecciones nacionales y referendos, pero sin sufrir o beneficiarse de sus resultados. Es decir, los de afuera deciden quienes nos gobiernan a los de adentro. ¿Cómo se puede justificar que los electores que habitan sólo en Argentina, cuyo número se estima en 500.000, tengan más peso electoral que los departamentos de Tarija, Beni o Pando, que juntos suman 372.000 votos? (Carlos D'Arlach, Senador por PODEMOS)
\end{abstract}

En el Ampliado ${ }^{133}$ Nacional realizado el 23 de agosto de 2008, a casi dos semanas de transcurrido el Referéndum Revocatorio, la Coordinadora Nacional para el Cambio (CONALCAM), compuesta por diferentes organizaciones sociales del país, resolvió instar a que se convoque, por decreto supremo, a un referéndum nacional para aprobar la Nueva Constitución Política del Estado (NCPE) y llamar a elecciones de subprefectos, consejeros departamentales y los prefectos revocados en las elecciones del 10 de agosto. Bajo este contexto, el presidente Evo Morales instruyó a los senadores del MAS que se declaren en huelga de hambre para conseguir la aprobación de la llamada "ley de voto en el exterior" en la Cámara de Senadores, ya aprobada en la Cámara de Diputados:

Hay que apostar a que nuestros hermanos que viven en el extranjero participen para aprobar la nueva Constitución y pedimos desde este Ampliado, desde esta reunión para que el Senado apruebe lo más antes posible. Quiero pedirles a nuestros senadores, que el próximo 25 de agosto entren en huelga

\footnotetext{
132 Extraído de http://noticiasdeboliviabolivar.blogspot.com/2008/09/el-voto-boliviano-en-el-exterior.html, acceso 11 de noviembre de 2008.

133 Un Ampliado, como estrategia de consenso, trasciende la noción de asamblea. De este proceso resulta una decisión dependiente de la participación de todos los sectores involucrados y prácticamente es considerada inapelable.
} 
de hambre en el Senado hasta que se apruebe esa ley para que los bolivianos que viven en el exterior voten por la nueva Constitución.

En posteriores Ampliados, se definieron distintas medidas de presión al Congreso Nacional para que se apruebe el nuevo texto constitucional: la más efectiva fue la masiva marcha que se organizó -respaldada por el gobierno nacional y con la presencia de Evo Morales en particular- el 21 de octubre hacia La Paz. Similar medida fue también llevada adelante en la capital argentina el mismo día. En el mismo sentido también se desarrollaron distintas acciones y manifestaciones de presión de organizaciones de "residentes bolivianos en el exterior" (fundamentalmente desde Argentina) que van desde la recolección de firmas y marchas de protesta contra el Senado y/o apoyo a Evo Morales y el "proceso de cambio en Bolivia", pasando por un recurso de amparo, hasta la realización de varias huelgas de hambre para exigir el voto en el exterior. Así se logró que hacia fines de octubre del 2008 el MAS y el principal partido opositor PODEMOS llegaran al acuerdo que permitió fijar las fechas para el Referéndum Constitucional (enero de 2009), indispensable para la aprobación de la Nueva Constitución Política del Estado, y para las elecciones generales anticipadas (diciembre de 2009). La NCPE -elaborada y negociada en la Asamblea Constituyente ${ }^{134}$ hasta diciembre de 2007 y discutida y modificada entre septiembre y octubre de 2008 en el Congreso Nacional- reconoce el derecho al voto de los ciudadanos residentes en el extranjero: "Las bolivianas y los bolivianos residentes en el exterior tienen derecho a participar en las elecciones a la Presidencia y Vicepresidencia del Estado, y en las demás señaladas por la ley. El derecho se ejercerá a través del registro y empadronamiento realizado por el Órgano Electoral." (Artículo 27, inciso I).135

Bajo este panorama, es evidente que en Bolivia el rumbo de la política migratoria también está supeditado a los discursos y prácticas de aquellos actores sociales y políticos locales sin desconocer la influencia que en la actualidad también tienen otros actores como los organismos internacionales- que intervienen y disputan la definición política de los asuntos migratorios. Esto se relaciona con el proceso de ciudadanización de la política migratoria en dos sentidos: por un lado, la creciente intervención de movimientos y

134 Véase la edición especial de la revista T'inkazos del PIEB (número 23/24, marzo de 2008, coordinado por Xavier Albó y Carmen Beatriz Ruiz) para una mirada desde y por dentro del proceso de la Asamblea Constituyente.

135 En relación a "las extranjeras y los extranjeros residentes en Bolivia” se establece que "tienen derecho a sufragar en las elecciones municipales, conforme a la ley, aplicando principios de reciprocidad internacional." (artículo 27, inciso II). El artículo 27 no aparece modificado en la versión revisada del texto constitucional (octubre 2008). 
organizaciones de la sociedad civil en la determinación de los asuntos migratorios y, por el otro, el reconocimiento o extensión formal de derechos civiles, sociales, económicos, políticos y culturales a los migrantes, tanto a los emigrantes como a los inmigrantes (Domenech, 2008). Se trata en general de organizaciones o instituciones que interpelan de forma permanente al Estado y que desarrollan sus acciones, tanto en el ámbito nacional como supranacional, a través de redes internacionales o transnacionales. La cada vez más extendida participación de las organizaciones de la sociedad civil en el tema, protagonismo que no es ajeno a los organismos políticos nacionales e internacionales en el proceso de legitimación para la elaboración e instrumentación de sus políticas, es reconocida y alentada por el gobierno actual:

No basta con la voluntad política de los gobiernos y sus gobernantes, y tampoco es suficiente contar con los instrumentos internacionales de derechos humanos universales y regionales. [...] Finalmente, deseo proponer a ustedes, señores delegados, podamos realizar una reflexión conjunta para que nuestros esfuerzos puedan trascender el enfoque intergubernamental, necesitamos conocer el sentir y la posición de nuestros pueblos sobre el tema de las migraciones. (Intervención y reporte de la República de Bolivia en su carácter de Presidencia Pro-Témpore saliente en la VI Conferencia Sudamericana de Migraciones, Asunción, 2006)

En este sentido, como dan cuenta diversas experiencias (trans)nacionales, es cada vez más notable la manera en que los y las emigrantes y sus descendientes -en ocasiones a través de sus organizaciones (formadas o en formación, formales o informales) de distinto tipo (sociales, culturales, políticas, económicas, etc.)- han comenzado a involucrarse en la vida política de las sociedades de emigración e inmigración a través de actividades transnacionales. En relación a ello, un ejemplo lo constituye la creación de la "Comisión Internacional del Voto Boliviano en el Exterior", una organización nacida en Buenos Aires, que articula con otras instancias similares en España, Brasil y Chile, creada fundamentalmente para exigir al Congreso Nacional de Bolivia la inmediata sanción de la ley reglamentaria del voto en el exterior, pero que también canalizó otras demandas sociales como las referidas a la "nacionalización de los hidrocarburos" luego del año 2003. Algunos/as de ellos/as podrían ser considerados verdaderos heréticos del orden de la inmigración (y de la emigración) y del orden nacional, como denomina Sayad (1998:281282) a aquellos/as que rechazan conformarse con el conjunto de normas que los definen y 
que definen la inmigración (o emigración), que rechazan someterse al imperativo de lo provisorio, de la subordinación en el trabajo y de la exclusión política, que rechazan ser expulsados o expulsables, excluidos o excluibles de lo político de acuerdo a la división entre nacionales y no-nacionales. Este discurso (en acto) herético se forja en diversas protestas públicas que desafían el orden nacional -tanto de la sociedad de emigración como de inmigración ${ }^{136}$ - a través de marchas, huelgas de hambre, conferencias de prensa, votaciones simbólicas, etc. Algunas escenas ocurridas reciente y paralelamente en Argentina y Bolivia dan cuenta de ello.

Simultáneamente a la realización del referéndum revocatorio del mandato popular del Presidente, Vicepresidente y Prefectos de Departamento realizado en Bolivia el 10 de agosto de 2008, diversas organizaciones de migrantes, pueblos indígenas y derechos humanos (entre otras instituciones sociales, culturales y políticas) llevaron a cabo una jornada de voto simbólico en algunos centros urbanos de la Argentina como un modo de hacerse presente en estas elecciones y reclamar el derecho al voto, cuyo ejercicio formal hasta ese momento parecía depender de la sanción de la "Ley del voto de ciudadanos bolivianos residentes en el extranjero" en el Senado Nacional.137 Es que se trata de estar presente (desde el exterior) para poder existir -esto es, existir políticamente- (hacia el interior): como declaró a la prensa uno de los huelguistas, Mario Flores, que reclamaba la aprobación de dicha ley: "Vamos a exigir que se apruebe, incluso con nuestras vidas, porque afuera somos muertos civiles" ${ }^{138}$

\footnotetext{
136 Como dice Sayad, “la emigración/inmigración involucra en realidad dos órdenes políticos, dos naciones y dos nacionalidades y no solamente dos países, dos sociedades, dos economías” (Sayad, 1998:280).

137 Estas votaciones simbólicas también se desarrollaron en algunas ciudades de países europeos como España, Suecia y Bélgica. En general, el gobierno nacional obtuvo un fuerte respaldo en las distintas localidades donde se realizó el "voto simbólico". Según las cifras que se dieron a conocer, en Argentina el apoyo que recibió fue abrumador: por ejemplo, en Buenos Aires el 90,3\% votó por el Sí. En esta ciudad el acto electoral fue organizado por el Comité de Defensa del Proceso de Cambio y la Soberanía Popular Originaria en Bolivia y contó con presidentes, fiscales y veedores en cada mesa.

138 Estas reivindicaciones dirigidas al Estado de origen no están separadas de los reclamos que se llevan a adelante para la obtención de derechos políticos en la sociedad de destino/recepción. Sin embargo, algunas voces llegan a justificar la "exclusión política" o relativizan la negación de determinados derechos políticos como el voto en el país de residencia. Por otra parte, diversos reclamos de sectores organizados de la sociedad civil referidos al voto se restringen a las elecciones municipales. Por ejemplo, en la Segunda Declaración de Rivas, resultante del III Foro Social Mundial de las Migraciones, se exige: "el derecho al voto en el ámbito municipal y la participación activa en la definición de los planes locales de desarrollo y el respeto a la autonomía de las organizaciones y movimientos sociales, de tal manera que el ejercicio pleno de la ciudadanía de las personas migrantes sea efectivo; la participación política del migrante para incidir, tanto en la política interna como en la política externa, de un país de llegada, a
} 
Poco tiempo más tarde, como medida de presión al Senado Nacional para la aprobación de la "ley del voto en el exterior", el 27 de octubre de 2008, algunos ciudadanos bolivianos residentes en Argentina y en Chile iniciaron -frente al Consulado General de Bolivia en las localidades de Buenos Aires y Arica- una huelga de hambre para apoyar aquella comenzada casi un mes atrás en la ciudad de La Paz por el grupo de residentes bolivianos en Argentina que integra Mario Flores. Días después, otras manifestaciones públicas de la misma índole comenzaron a desplegarse frente a las embajadas de Bolivia en Brasil, España y Alemania junto a diversas declaraciones de apoyo solidario -tanto individuales como institucionales- provenientes de países como Suecia y Estados Unidos.

En medio de este proceso, el 18 de diciembre del 2008, día internacional del migrante, la Cancillería boliviana hace público el Acuerdo Nacional por el Boliviano en el Exterior, donde diversos Ministerios del Estado, representantes del poder Legislativo y Judicial, así como la Corte Electoral, la Defensoría del Pueblo y diversas instituciones de la sociedad civil reconocen y ratifican los convenios internacionales que protegen y garantizan los derechos humanos de los migrantes y sus familias y se comprometen entre otras cosas a consolidar un "mecanismo de diálogo permanente en materia migratoria" como un paso más en la construcción de políticas públicas para este sector a la par de intervenir en otros aspectos puntuales.

En el mes de febrero del 2009, dos semanas después del referéndum sobre la nueva Constitución de Bolivia, y ante una nueva negativa del Senado Nacional para aprobar la ley del voto en el exterior, el presidente Evo Morales emite un Decreto Supremo donde conmina a la Corte Nacional Electoral al registro y empadronamiento de las bolivianas y bolivianos residentes en el exterior, para garantizar su derecho al sufragio en futuros procesos electorales, disponiendo para ello recursos económicos y apoyos institucionales (Ministerio de Relaciones Exteriores y Cultos, Ministerio de Gobierno y Ministerio de Economía y Finanzas). Ante la inminencia de la aprobación de una "ley electoral transitoria" por un lado y la cerrada postura de la oposición, en particular, a la temática del voto en el exterior y la representación indígena parlamentaria por el otro, en el mes de abril, el presidente Evo Morales Ayma decide iniciar una huelga de hambre, que 
rápidamente se masifica no sólo en el país, sino también en la Argentina, España y Chile, con el propósito de presionar a los Senadores opositores para que aprueben esta normativa que faculta la realización de los comicios de diciembre del 2009. Producto de esta fuerte presión de diversos sectores sociales y estatales se logran determinados acuerdos en el Congreso que posibilitan a la Corte Nacional Electoral un nuevo proceso de empadronamiento de tipo biométrico, garantizando la realización de las primeras elecciones presidenciales en la historia de Bolivia con participación de los residentes en el exterior, en un máximo de un seis por ciento del padrón electoral (alrededor de unos 230 mil electores) en cuatro países: Argentina, Brasil, Estados Unidos y España. Finalmente, en una jornada histórica, el 6 de diciembre de 2009 se llevaron a cabo las elecciones nacionales en las cuales la fórmula compuesta por Evo Morales y Álvaro García Linera triunfó con un amplio margen y con el apoyo contundente de los ciudadanos bolivianos residentes en el exterior. En la Argentina, alrededor del 94\% de los votantes ratificó a los candidatos del MAS en la presidencia y el proyecto político que se insinuaba a comienzos de la década así como el "proceso de cambio" que se comenzó desplegar una vez asumido el gobierno nacional. ${ }^{139}$

En suma, mientras que la política migratoria boliviana, como otras tantas experiencias nacionales en la región, se basó históricamente en la regulación y control de las migraciones internacionales bajo la idea de país de inmigración, en la actualidad se busca otro tipo de respuestas, sustentadas en un proyecto político que aspira a atender los sectores sociales tradicionalmente marginados y excluidos, entre ellos los emigrantes, considerados migrantes pobres. También la magnitud y la significación política que habría adquirido la emigración ha hecho que los bolivianos en el exterior se vuelvan -como lo pone de manifiesto el voto en el exterior- sujetos de derecho en tanto objetos de política exterior. En este sentido, el propósito de "documentar gente" evidencia este doble interés: no sólo apunta a otorgarle a los residentes en el exterior una herramienta para hacer efectivos sus derechos, sino también a obtener un registro confiable de potenciales electores que sirvan de apoyo al proyecto político nacional en curso. Además, a diferencia de otros momentos históricos en los cuales el Estado se interesaba por los trabajadores migrantes en tanto mano de obra necesaria para el desarrollo poblacional y económico del país, en la actual coyuntura política los emigrantes son interpelados en calidad de ciudadanos en el exterior. Por otra parte, si bien es sabido que la historia migratoria del

139 Véase Gallinati et al. (2010) para una descripción etnográfica de las jornadas electorales realizadas en la Argentina, especialmente en Buenos Aires. 
país se caracteriza por un éxodo persistente, que el propio Estado -según manifiesta la normativa migratoria examinada- buscó controlar en varias oportunidades, el discurso estatal actual se apodera del fenómeno migratorio más reciente -la emigración de hombres y mujeres a partir de las reformas neoliberales implementadas en Bolivia desde la década del ochenta- para posicionarse frente a esta problemática, otorgándole un lugar de peso en su lógica argumentativa. 


\section{CAPÍTULO 3}

\section{ESTADO, INMIGRACIÓN E “ILEGALIDAD”: LA “INMIGRACIÓN LIMÍTROFE” COMO}

PROBLEMA SOCIAL EN LA ARGENTINA CONTEMPORÁNEA

Aunque en sus comienzos la inmigración -cuando hablar de inmigración equivalía a hablar de inmigración de ultramar o europea ${ }^{140}$ - fuera concebida como solución a los distintos hechos sociales de la época identificados como problemas, pronto empezaría también a ser concebida como problema o asociada a problemas al afectar o trastocar las nociones de orden y estabilidad social establecidas. A partir de allí, durante las primeras décadas del siglo veinte, la presencia de extranjeros europeos considerados de acuerdo a los parámetros estatales como "indeseables" empezó a ser regulada a través de un conjunto de disposiciones relativas a su ingreso y permanencia, codificadas en términos de ilegalidad, al mismo tiempo que se instituía la figura de la expulsión, la cual estaba ausente en la ley de Inmigración y Colonización aprobada en el año 1876 y conocida como Ley Avellaneda. La ilegalidad se constituyó, especialmente desde mediados del siglo veinte, como una dimensión central de la definición de la migración como problema y, consecuentemente, de la política migratoria argentina, en tiempos en que la inmigración laboral de países limítrofes alcanzaba una más amplia difusión en el territorio y adquiría mayor visibilidad social. Fue precisamente a través de la construcción como ilegales, que estos inmigrantes de países limítrofes pasaron a ser representados como amenaza, heredando el cuerpo de disposiciones estatales creadas y destinadas a aquellos extranjeros europeos considerados durante las primeras décadas del siglo veinte como "indeseables".

En este capítulo se analiza la visión del Estado argentino acerca de la inmigración y la aparición de la inmigración limítrofe enunciada como problema mediante el examen de las medidas de control que progresivamente se fueron diseñando e implementando para regular la presencia de las diversas corrientes y grupos migratorios. Muestra que la construcción de la migración como problema estuvo estrechamente ligada a una visión estatal que, independientemente del carácter de facto o constitucional o del signo político del gobierno nacional en el poder, estuvo irremediablemente sustentada en la división 
legal/ilegal como forma subsidiaria de la división nacional/extranjero. Un conjunto de mecanismos y medidas referidos a la admisión, la permanencia y la expulsión de los extranjeros favorecieron la instauración y consolidación a lo largo del siglo veinte -de manera progresiva y acumulativa así como selectiva y fragmentada- de un régimen de control de la inmigración que se conformó alrededor de ideas y prácticas de prevención y represión de sujetos migrantes o extranjeros concebidos como ilegales. A partir del análisis de un vasto conjunto de fuentes documentales de carácter jurídico, complementadas con algunas provenientes de la prensa escrita, se examinan los procesos, los instrumentos y las categorías a través de los cuales se fue produciendo la ilegalidad en el terreno de las migraciones a lo largo del siglo veinte, primero ligada a aquellos indeseables de la inmigración de ultramar y luego vinculada con los inmigrantes de países limítrofes, así como las respuestas técnico-políticas que ofrecieron distintos gobiernos, cristalizadas en diversas normas jurídicas y programas de regularización migratoria. ${ }^{141}$ Como veremos a continuación, la división legal/ilegal, entre otras divisiones posibles, como principio constitutivo de la visión que dominó sobre la inmigración en la Argentina contemporánea, fue adoptada primero para ejercer el control de aquella fracción de inmigrantes europeos de ultramar considerados indeseables y luego trasladada a los inmigrantes de países limítrofes, quienes bajo una mayor visibilidad social y política pasaron a ser los nuevos indeseables. ${ }^{142}$

Dada la importancia que posee la década de los noventa para comprender la visión del Estado argentino en el marco de la "nueva política migratoria", el capítulo le dedica una sección especial. Allí se plantea que mientras la inmigración de países limítrofes fue asumida en general como un problema social, la figura del inmigrante como amenaza

\footnotetext{
141 Véase De Genova (2002) para una aguda reflexión sobre los aspectos epistemológicos, teóricos, metodológicos y políticos del estudio de la "ilegalidad".

142 En algunos artículos he contrapuesto, creo que desacertadamente, dos modos de concebir la inmigración: uno fundado en la migración como problema o amenaza y otro en la migración como oportunidad o necesidad. Actualmente, adhiero más bien a la idea de que la inmigración como hecho y relación social es construida como problema o ligada a problemas, con diversas acepciones, más allá de que se pongan de relieve los aportes o contribuciones que la migración realizaría. Como señala Sayad (1998), el discurso sobre el inmigrante y la inmigración establece una relación indefectible con otros objetos o problemas para poder hablar de su objeto: sólo a través de los diferentes problemas a los cuales son asociados es que los inmigrantes pueden ser "nominados, captados y tratados". Aquí los problemas son entendidos como dificultades, disturbios o daños y como "problemática constituida de forma crítica en relación a un objeto que crea necesariamente un problema" y que debe su existencia a los problemas que representa para la sociedad. En otros lugares (por ejemplo, Domenech 2007a, 2009) he argumentado en contra de la dualidad problema-oportunidad mediante la cual se ataca o se defiende la inmigración y los inmigrantes al responder a la misma lógica de legitimación.
} 
estuvo representada por el inmigrante ilegal que condensó diversas características que no son atribuibles a ningún grupo migratorio en particular, sino a un conjunto social imaginario que se lo considera o pretende ser excluido y a la vez criminalizado (o excluido mediante criminalización). En este decenio se pone de manifiesto que, al igual que sucediera con algunos matices en tiempos pasados, la ilegalidad, en tanto construcción social y política, no comprende sólo a quienes habrían cometido una infracción administrativa o un delito, sino a un sector de los inmigrantes mucho más vasto que es considerado ajeno a las reglas sociales necesarias para la convivencia y la pertenencia a la comunidad nacional. En este sentido, la visibilidad social y política que adquirieron los llamados inmigrantes limítrofes en la década de los noventa, siendo el Estado un actor central en dicho proceso de visibilización, se produjo a partir de la presencia de inmigrantes de determinados países vecinos como Paraguay, Bolivia y Perú, enmarcada en un contexto de cambios en el régimen de visibilidad étnica (Grimson, 2003; 2006) y un modelo político-económico de acumulación como el neoliberalismo sustentado en premisas como competencia, eficiencia y eficacia, cuyos efectos sociales devastadores no podían ser asumidos como tales, sino buscando causas externas que lo explicaran o justificaran.

\section{El Estado argentino y las restricciones a la inmigración: los extranjeros "indeseables" y el "ingreso ilegal"}

Aunque las primeras medidas restrictivas tuvieron lugar en la década de 1910, especialmente durante la posguerra (Devoto, 2001), fueron los años treinta los que marcaron el final de la llamada política de puertas abiertas. ${ }^{143}$ Allí comenzó una nueva etapa caracterizada por importantes restricciones bajo la cual se consolidó la figura del inmigrante como una amenaza al orden y cohesión sociales, instituida durante las décadas anteriores. Entre finales del siglo diecinueve y comienzos del veinte, el activismo político de los extranjeros despertaba serios temores y preocupaciones entre sectores de la élite

\footnotetext{
143 Durante este período considerado de "puertas abiertas" sostenido mediante una explícita política de fomento de la inmigración europea, la selección de los "inmigrantes" se realizaba de acuerdo a lo establecido en la ley Avellaneda. En los años de la primera posguerra, frente a los acontecimientos conocidos como la "Semana Trágica" y la “Patagonia rebelde", el gobierno de Yrigoyen recurrió a dos decretos de 1916 que reglamentaban el artículo 32 de la ley de 1876, los cuales establecían como requisito para ingresar al país, además del pasaporte con foto, la presentación de documentación que acreditara falta de antecedentes penales, no mendicidad y buena salud (Devoto, 2001) y a la ley de Residencia de 1902 (Quinteros, 2008).
} 
dirigente. La imagen del inmigrante comenzó a transformarse con la participación de españoles e italianos en la formación de asociaciones obreras y movimientos políticos anarquistas y socialistas. En este contexto, a su vez, las nociones de orden público y defensa social cobraban importancia entre los grupos gobernantes (Zimmermann, 1995), generalizándose el discurso criminológico positivista en distintos niveles de la sociedad y el Estado (Ruibal, 1993), y una fracción de los inmigrantes pasó a estar asociada al delito y a la marginalidad y a ser vista como parte de las clases peligrosas. ${ }^{144}$

En las dos primeras décadas se dictaron algunas leyes que fueron fundantes de la visión restrictiva y represiva que mantuvo el Estado argentino a lo largo de todo el siglo, al margen de su derogación formal: la ley de Residencia de 1902, la ley de Defensa Social de 1910 y el decreto-ley de 1923 que reglamentó la ley Avellaneda. ${ }^{145}$ La ley de Residencia facultaba al Poder Ejecutivo a "ordenar la salida del territorio de la nación" e "impedir la entrada en el territorio de la República" al extranjero que "haya sido condenado o sea perseguido por tribunales extranjeros, por crímenes o delitos de derecho común", o de aquél "cuya conducta comprometa la seguridad nacional o perturbe el orden público".146 También disponía sobre su expulsión y su previa detención hasta que se hiciera efectiva su salida. ${ }^{147}$ La ley de Defensa Social, por su parte, reforzaba y extendía la prohibición de ingreso a "los que hayan sufrido condenas o estén condenados por delitos comunes que según leyes argentinas merezcan pena corporal”, a "los anarquistas y demás personas que profesan o preconizan el ataque por medio de fuerza o violencia contra los funcionarios públicos o los gobiernos en general o contra las instituciones de la sociedad" y a "los que hayan sido expulsados de la República", sancionando mediante multa o arresto a quienes introdujeran o intentaren introducirlos en el territorio nacional. La prohibición de asociación o reunión de personas que tuvieran por objeto "la propagación de doctrinas anarquistas o la preparación e instigación a cometer hechos reprimidos por las leyes de la

\footnotetext{
144 Sobre el proceso y mecanismos de criminalización de los inmigrantes como parte de las "clases peligrosas" en el período 1880-1920, véase Ruibal (1993).

145 La ley № 817 fue la principal norma nacional por medio de la cual se sustentó la política de fomento que se desarrolló en la Argentina durante el período considerado de migración masiva o de masas.

146 Esta ley fue derogada recién en el año 1958 durante el gobierno de Arturo Frondizi mediante la ley № 14.445, la cual dejaba sin efecto los decretos de expulsión dictados y posibilitaba el regreso al país de los extranjeros beneficiados (Novick, 1997).

147 Véase Pacecca (2003) para un análisis del debate parlamentario de la ley de Residencia, donde una de las principales discusiones que tuvo lugar fue el derecho de expulsión que dispone el Estado.
} 
Nación" fue otra de las arbitrariedades estipuladas en esta ley. ${ }^{148}$ El reglamento migratorio de 1923 indicaba entre los motivos que permitían impedir el ingreso de pasajeros al país, además de carecer de las aptitudes físicas y mentales idóneas para el trabajo y la documentación exigida, el hecho de "ser clandestino" o, habiendo obtenido el permiso oficial para desembarcar en otros países, "traer como destino real la República Argentina". 149

A lo largo de la década del treinta se afianzaron y extendieron los criterios y mecanismos de control que se habían empezado a delinear en las décadas anteriores y que utilizará, en adelante, el Estado argentino para impedir o restringir la entrada de extranjeros al territorio nacional, adquiriendo la Dirección General de Migraciones (DGM) mayores competencias para regular los movimientos migratorios, tanto los de ultramar como los transfronterizos, y participando los consulados argentinos en el exterior del proceso de selección en los países de origen. Como muestra Quinteros (2008) en su estudio, durante la llamada Década Infame (1930-1943), iniciada con el golpe militar de José Félix Uriburu en 1930, se estableció un conjunto de disposiciones mediante las cuales se permitía a la DGM ejercer el poder de policía, ampliando las atribuciones que le confería el reglamento de 1923. Además, mediante estas disposiciones, al mismo tiempo que se promovía la

148 Véase Zimmermann (1995) para un análisis de la criminalización del anarquismo y la cuestión obrera a principios del siglo veinte y su relación con las leyes de Residencia y Defensa Social.

149 Además de los requisitos condensados en la definición de "inmigrante" en la Ley Avellaneda, el artículo 10 del reglamento de 1923 establecía específicamente como impedimentos para la entrada al país: a) Presentar síntomas de hallarse afectado de tuberculosis, lepra, tracoma, o cualquier enfermedad crónica que disminuya su capacidad para el trabajo; b) Padecer de demencia o enajenación mental, en cualquiera de sus formas de manifestación, idiotez, imbecilidad, epilepsia, etc.; c) Tener un vicio orgánico, congénito o adquirido, total o parcial, que los haga inútiles o disminuya en cualquier forma su incapacidad para el trabajo, como ser ciegos, sordos, mudos, paralíticos, raquíticos, enanos, mancos o inválidos de una pierna o cualquier otro vicio o defecto que impida ser considerado del todo apto para el trabajo; d) Estar comprendido en el concepto de inmigración viciosa o inútil; e) Ser persona que se presuma que pueda caer a cargo de la beneficiencia (sic) pública; f) Ser mujer sola con hijos menores de 15 años, salvo que posea un permiso especial de desembarco expedido por la Dirección general de inmigración; g) Ser menor de 15 años, que viaje sin los padres, a no ser que posea permiso de libre desembarco otorgado por la Dirección general de inmigración. Todos los menores de 15 años que viajen en compañía de sus padres deberán poseer la partida de nacimiento; h) Tener más de 60 años, aunque haya sido residente anterior en el país, a no ser que posea un permiso de libre desembarco expedido por la Dirección general de inmigración; i) Carecer de pasaporte, con fotografía, visado por un cónsul argentino en la nación que lo ha expedido y a la que pertenezca el extranjero; j) Carecer de un certificado judicial o policial que acredite que no ha estado bajo la acción de la justicia por delitos comunes o contra el orden social, durante los últimos cinco años. Este certificado debe ser expedido por las autoridades policiales o judiciales de la nación a que pertenezca el extranjero, visado por un Cónsul Argentino acreditado en la misma; k) Ser clandestino; l) Traer como destino real la República Argentina y haber obtenido visación en consulados de otra nacionalidad, en la suposición que se dirigen a puertos de naciones limítrofes. 
entrada de colonos que tuviesen un destino rural efectivo, se buscaba instrumentar medidas que disminuyeran la llegada de extranjeros "indeseables", desde el aumento de los requisitos de documentación y las tasas consulares hasta el impedimento del desembarco.

A finales de 1930, con el propósito de desalentar la inmigración, se dispuso a través de un decreto el pago obligatorio de un arancel consular más costoso que hasta entonces por cada certificado requerido, por el cual los inmigrantes debían acreditar la falta de antecedentes penales y de enfermedades físicas y mentales y su "no mendicidad" (Biernat, 2007; Quinteros, 2008). Al año siguiente, fueron eximidos de dicha obligación aquellos inmigrantes que llegaran como colonos agrícolas (Devoto, 2001). El decreto titulado explícitamente "Detención de indeseables que entran al país", autorizaba a la Dirección de Inmigración, apoyándose en el reglamento migratorio de 1923, a detener a los extranjeros con carta de ciudadanía argentina que pretendieran reingresar a la Argentina "invocando el hecho de la naturalización" en caso que llegaran a figurar en el prontuario policial como "tratantes de blancas" o estuvieran relacionados con "cualesquiera de las otras tachas morales previstas por la ley 817 y sus reglamentaciones". 150 En 1932, mediante decreto, primero se extendieron los requisitos habituales para acreditar el estado de salud ${ }^{151} \mathrm{y}$ luego se condicionó la entrada al país a la presentación de un contrato o convenio de trabajo a los efectos de acreditar "un destino, empleo u ocupación que les asegure su subsistencia", limitando la visación consular y la expedición de permisos de desembarco a dicha documentación, además de "la certificación sanitaria, la de no haber sufrido condena criminal o haber ejercido la mendicidad". También permitía el ingreso de familiares de extranjeros radicados en el país mientras pudieran acreditar "solvencia y buena conducta" y a su vez se comprometieran "a costear su subsistencia en caso necesario".152 Un decreto del año 1934, por su parte, establecía que "(t)odo pasajero que viaje a la República en segunda o tercera clase" debía contar con el pasaporte y los certificados de "buena conducta", "no mendicidad" y "buena salud", legalizados en el correspondiente consulado argentino. ${ }^{153}$ Entre los individuos y grupos sociales que quedaban exentos del pago de la visación se mencionaba a los "nacionales de países limítrofes y antiguos residentes en esos

150 Decreto del 8 de noviembre de 1932.

151 Por ejemplo, un certificado donde constara no haber padecido tracoma, una de las enfermedades que figuraba junto a la tuberculosis entre las principales causas de rechazo en el ingreso (Quinteros, 2008). Sobre los mecanismos de selección de inmigrantes fundados en el tracoma, véase Di Liscia y Fernandez Marrón (2009).

152 Decreto del 26 de noviembre de 1932 (con las modificaciones del decreto del 14 de diciembre).

153 Decreto del 19 de enero de 1934. 
países", quienes tendrían que demostrar tal condición, haciéndola constar en su documentación personal: "En tránsito para país limítrofe, comprobó su antigua residencia en él”. También estaban exentos de este arancel los "trabajadores rurales" y sus familiares que pudieran probar un "destino rural" en el país mediante la presentación del contrato de arrendamiento o compra de tierra (reemplazable por la declaración de "una entidad colonizadora o industrial de reconocida responsabilidad") o, en su defecto, la acreditación de un capital propio.

En la segunda mitad de la década, se extendieron las medidas de control, mediante la incorporación de mayores requisitos o reforzando el cumplimiento de los ya existentes, y se crearon nuevos organismos de inspección (Devoto, 2001). En el año 1936, un decreto sostenía que la coyuntura del momento exigía "extremar las medidas de control y vigilancia del movimiento de pasajeros con destino al país, tendientes a evitar infiltraciones en el mismo de elementos que puedan constituir un peligro para la salud física o moral de nuestra población o conspiren contra la estabilidad de las instituciones creadas por la Constitución Nacional". ${ }^{154}$ Según se establecía en su articulado, se trataba de prevenir la entrada de toda persona que pudiera corporeizar dicho peligro, encargándole a la Dirección de Inmigración, con la asistencia de la Prefectura Nacional Marítima, la Policía de la Capital y la Dirección de Aeronáutica Civil, que efectuara un control "en forma general y rigurosa”, "cualquiera sea el medio usado para llegar a la República y la clase o categoría del pasaje utilizado". Además, según se indicaba en los considerandos, se pretendía que este control pudiera hacerse efectivo "en forma permanente, aun después del ingreso al país", implicando a la Policía de la Capital, de los Territorios Nacionales y Provincias, a las oficinas consulares en el exterior y a los capitanes de barcos en la verificación de la documentación exigida. Más tarde, en 1938, se realizó el intento más importante por reducir la inmigración a través de mecanismos administrativos, estableciendo -además del resto de la documentación solicitada- la exigencia de un permiso de desembarco (Devoto, 2001) y predicando, al mismo tiempo, la conveniencia de estimular la inmigración con destino rural (Quinteros, 2008). ${ }^{155}$ El objetivo principal era reprimir el ingreso de los extranjeros con estatuto de refugiados que llegaran a la Argentina desde países limítrofes, como Uruguay o Brasil, por alguna vía no autorizada (Biernat, 2007). 
Precisamente, en esta década el intercambio poblacional entre la Argentina y los países limítrofes empezó a recibir una atención específica por parte del Estado argentino a raíz del ingreso y tránsito no autorizado (calificado por los funcionarios de gobierno como "clandestino" o "ilegal") de aquellos extranjeros considerados "indeseables" en los años de la Segunda Guerra Mundial, como los republicanos españoles o los judíos centroeuropeos expulsados de Europa. Esta preocupación estatal en torno al ingreso y al tránsito ilegales o clandestinos empezó a evidenciarse en el fortalecimiento de las diferentes medidas de control y vigilancia implementadas en las fronteras terrestres o marítimas. Quinteros muestra que durante estos años se establecieron condiciones de embarque de pasajeros en dirección a los países limítrofes que debían atravesar la Argentina para llegar a destino, se crearon nuevos puestos migratorios en la frontera ${ }^{156} \mathrm{y}$ un registro de extranjeros y se firmaron convenios de tránsito entre los Estados que compartían la frontera, como el Acuerdo de Inmigración de 1939 entre los ministros de Hacienda de Brasil, Paraguay, Uruguay y Argentina, cuya finalidad era fiscalizar y mantener informados a los países signatarios sobre la entrada de los extranjeros considerados indeseables (como los refugiados europeos) o el convenio firmado con Paraguay en el mismo año. Más adelante, la Argentina participó también de algunas conferencias regionales, en las comisiones referidas al tránsito de extranjeros, en particular, de los "clandestinos". ${ }^{157}$ Mientras tanto, como veremos enseguida, hacia finales de la década, se dictaban algunas medidas que facilitan la entrada temporaria de jornaleros de países limítrofes, favoreciendo el inicio de un proceso de contratación de mano de obra temporaria para las haciendas y latifundios del norte del país que se profundizaría durante los años subsiguientes, disponiendo el Estado argentino una serie de medidas tanto para posibilitar su entrada como para garantizar su salida después de concluidas las cosechas y tareas agrícolas para las cuales habían sido contratados (Quinteros, 2008).

Durante los primeros años de la década del cuarenta, como señala Quinteros, el control migratorio continuó siendo una preocupación fundamental de la DGM. Ya no sólo se trataba de vigilar la frontera, sino también de resolver las diferentes situaciones que se creaban una vez que el extranjero ya había ingresado al territorio nacional. El modo de nombrar y el interés por diferenciar a los extranjeros que habían entrado al país eludiendo el control migratorio de aquellos que lo habían conseguido burlándolo (a través de

156 Si bien Buenos Aires era la principal vía de ingreso al país, durante las décadas de 1910 y 1920 ya se podía constatar que muchos extranjeros entraban por otros lugares, lo cual motivó la creación de diversos puestos migratorios fronterizos (Quinteros, 2008).

157 Quinteros (2008) se refiere concretamente a la conferencia realizada en septiembre de 1942 en Rivera, Uruguay. 
documentación falsificada, por ejemplo) o residían violando alguna norma migratoria es una muestra de la relevancia y especificidad que estaba adquiriendo en esta época el criterio legal para calificar el ingreso y la residencia. Para la DGM, de acuerdo a lo que aconsejaba su director, los primeros tenían que ser denominados "clandestinos", mientras que los segundos debían ser llamados "residentes ilegales" (Quinteros, 2008).

Quinteros afirma que durante este período surgieron diversas normas que aspiraban a fortalecer el control migratorio: en 1940, se implementaron algunas medidas, las cuales no tuvieron demasiado éxito de acuerdo al objetivo explicitado, como prohibir el desembarco de las personas en tránsito, exigir el pasaje hasta el lugar de destino, requerir los impuestos consulares pagos y hacer constar en la documentación que eran "pasajeros en tránsito"; en 1941 el Congreso nacional aprobó el proyecto de creación de nuevos puestos fronterizos y de un registro de extranjeros propuesto por la DGM, apoyándose el control en la exigencia de documentación (permiso de desembarco y visa consular) y la inspección sanitaria, para lo cual cada puesto contaba con un médico. Por otra parte, hacia mediados de la década, las disposiciones de gobierno también alertaban sobre la amenaza que podía suponer la presencia de un extranjero para la seguridad nacional, previendo determinadas sanciones para aquél que la pusiera en riesgo: un decreto del año 1945 estipulaba penas para aquellos que atentaran contra la "seguridad del Estado", determinando para los extranjeros castigos que consistían en prisión, pérdida de ciudadanía y/o expulsión del país. Esta norma preveía como actos ilícitos la entrada ilegal del extranjero al territorio argentino, la falsa declaración de la dirección de residencia y la realización de acciones a favor de otros países, contra el Estado argentino o contra países aliados (Quinteros, 2008).158 Asimismo, de uno u otro modo, diversos autores (Devoto, 2001; Biernat, 2007; Quinteros 2008) coinciden en señalar que el traslado ${ }^{159}$ de la DGM desde el Ministerio de Agricultura al Ministerio del Interior en 1943, bajo la conducción de un militar, el Cnel. Eduardo Larronde, fue resultado de la mirada restrictiva sobre las migraciones que el Estado argentino, bajo diversos gobiernos militares y conservadores, había comenzado a desplegar, y que se había visto reforzada a su vez por el avance de la Segunda Guerra Mundial. 160

158 Decreto № $536 / 45$.

159 Decreto № 1.070 del 8/10/43.

160 Hacia finales del segundo gobierno peronista, la DNM fue nuevamente trasladada: en el año 1954 pasó del Ministerio de Asuntos Técnicos al de Relaciones Exteriores. Quinteros (2008) indica que probablemente esta medida 
Por otra parte, la escasez de mano de obra en el sector económico primario de las zonas fronterizas dio lugar a un proceso de reclutamiento y contratación de trabajadores rurales temporarios. ${ }^{161}$ Estos trabajadores nativos de países vecinos, cuya presencia ya había sido registrada oficialmente por el primer Censo Nacional de Población de 1869162, no estaban comprendidos en la definición de inmigrante otorgada por la ley de Inmigración y Colonización, en tanto no provenían de ultramar ni tampoco se establecían de manera permanente. ${ }^{163}$ Pero no sólo no respondían a los criterios consignados en la ley ni a las pautas más generales con que pudiera manejarse el Estado argentino, sino que tampoco se encuadraban en las definiciones de la época referidas a las migraciones internacionales. Según la Conferencia Internacional de Emigración de Roma, realizada en 1924, la emigración suponía la voluntad de residencia permanente y que el traslado en busca de trabajo no fuera temporario, en cuyo caso sería considerado trabajador y no emigrante. Luego, en 1932, la OIT propuso denominar emigrante a todo aquél que cambiara de residencia y se asentara en otro país durante un año como mínimo (Devoto, 2003: 35-36).

La movilidad transfronteriza de nacionales de países limítrofes, cuyos protagonistas no fueron considerados como inmigrantes hasta la segunda mitad del siglo veinte, no resultaba una preocupación particular para el Estado argentino. Sus movimientos se regulaban por normas distintas a las que se aplicaban a los extranjeros europeos que ingresaban desde países limítrofes. Durante estos años las acciones del Estado argentino se limitaban a contabilizar los ingresos y egresos de extranjeros (Villar, 1984), así como a posibilitar su entrada y garantizar su salida después de concluidas las cosechas y tareas

haya respondido a la voluntad de complementar "la resolución que obligaba a ambos ministerios a una mayor colaboración para impedir la entrada ilegal de extranjeros".

161 En la década del treinta, con el auge y la expansión de las economías regionales y la creciente demanda de mano de obra para las tareas de cosecha, la inmigración boliviana, por ejemplo, comenzó a adquirir mayor relevancia al sustituir la fuerza de trabajo nativa existente en las plantaciones de caña de azúcar en El Ramal y de hojas de tabaco en Salta y Jujuy (Balán, 1990).

162 Según los datos censales disponibles, a fines del siglo diecinueve y comienzos del veinte la población boliviana en la Argentina tenía el menor peso relativo entre la inmigración de carácter limítrofe. En 1869 se contabilizaron 6.194 personas nacidas en Bolivia, 7.361 en 1895 y 18.256 en 1914 (INDEC, 1996), representando alrededor del 15\%, 6\% y 9\% de la población total de países limítrofes respectivamente.

163 La ley Avellaneda definía al inmigrante como “todo extranjero jornalero, artesano, industrial, agricultor o profesor, que siendo menor de sesenta años y acreditando su moralidad y sus aptitudes, llegase a la República para establecerse en ella, en buques a vapor o a vela, pagando pasaje de segunda o tercera clase, o teniendo el viaje pagado por cuenta de la Nación, de las Provincias, o de las empresas particulares protectoras de la inmigración y la colonización”. 
agrícolas para las cuales habían sido contratados (Quinteros, 2008). Hacia finales de la década del cuarenta, se dictaron algunas medidas que facilitaron la entrada de jornaleros de países limítrofes, lo cual contribuyó a que se iniciara un proceso de contratación de mano de obra temporaria para las haciendas y latifundios del norte del país, que se profundizaría durante los años siguientes. Las medidas dirigidas a los trabajadores temporarios de los países limítrofes, dispuestas mediante decretos de carácter general como a través de resoluciones para cada situación regional específica, continuaron autorizando su entrada temporal debido a la necesidad de mano de obra en los ingenios azucareros y las plantaciones de tabaco y yerba mate del norte argentino, favoreciendo su reclutamiento.

\section{Ni turistas, ni pasajeros en tránsito: los “indeseables" y la "permanencia ilegal”}

En general, la llegada del peronismo al poder no supuso modificaciones importantes en materia de política migratoria, manifestando marcadas continuidades con el control migratorio iniciado en los gobiernos anteriores (Devoto 2001; Biernat, 2007; Quinteros, 2008). Si bien fueron presentadas y justificadas de otro modo, las medidas impulsadas mostraban una constante preocupación por ejercer el control sobre los extranjeros, en particular sobre aquellos que pretendían ingresar como "turistas" o trasladarse como "pasajeros en tránsito" hacia algún país limítrofe, buscando diversos medios para hacerlo más efectivo (Quinteros, 2008). Se pretendía evitar que bajo estas categorías ingresaran aquellos extranjeros que ya habían sido definidos en los años anteriores como indeseables: refugiados, comunistas, judíos y otros grupos étnico-nacionales y religiosos minoritarios. Considerados en conjunto, la aplicación de las disposiciones legales emanadas de períodos anteriores y los mecanismos de control instituidos durante el peronismo destinados a regular estos grupos sociales como al resto de individuos identificados como indeseables, contribuirán decisivamente a la conformación de la visión punitiva y represiva que, como veremos más adelante, se afianzó en el seno del Estado argentino a partir de los años sesenta, a través de diversas medidas destinadas fundamentalmente a los trabajadores inmigrantes originarios de Estados vecinos, llamados genéricamente inmigrantes limítrofes o extranjeros de países limítrofes. 
Que durante el peronismo no haya habido grandes innovaciones en materia de política migratoria, no significa que no haya tenido sus particularidades. En 1949, bajo la primera presidencia de Juan Domingo Perón, además de crearse la Dirección Nacional de Migraciones (DNM) y otros organismos gubernamentales involucrados con los asuntos migratorios ${ }^{164}$, una serie de decretos estuvieron destinados a regular diversos aspectos relativos al ingreso y permanencia de los extranjeros europeos "indeseables" que cruzaban la frontera proviniendo de países limítrofes. Uno de estos decretos fue el $\mathrm{N}^{\circ}$ 1.162: establecido a inicios del año y dirigido a implementar múltiples medidas para controlar específicamente la inmigración de carácter temporal o transitorio, constituye una de las expresiones del Estado argentino que coadyuvó a instaurar la figura de la ilegalidad en el ámbito de las migraciones a través de la categoría de "permanencia ilegal". En uno de sus artículos estipulaba que "el extranjero" que violara alguna de las disposiciones relacionadas con el ingreso al territorio nacional, lo cual produciría "la caducidad del término legal respectivo concedido por el Estado", o que "sin autorización especial excediese el plazo de permanencia acordado, será considerado como de 'permanencia ilegal', sin perjuicio de las sanciones policiales que se estipulen para cada caso [...]". Precisaba, asimismo, que "el infractor" debía abandonar el territorio nacional en el plazo que fuera establecido y ser conducido "al lugar de origen, de procedencia o a otro país que lo admitiere". Para ejercer dicho control, el "documento identificatorio" debía ser acompañado de una "tarjeta de contralor" donde se especificaba la correspondiente categoría de ingreso y permanencia, que podía ser turista, beneficiario de convenio, tránsito o permanencia temporaria, así como "los términos de estada legal de cada categoría de viajeros" y “el texto de la notificación de la fecha de vencimiento". ${ }^{165}$

El decreto también disponía sanciones para aquellos que "directa o indirectamente, facilitaren de cualquier modo el ingreso al país de extranjeros en infracción a las leyes inmigratorias, reglamentaciones dictadas por el Poder Ejecutivo nacional o a los convenios y tratados internacionales vigentes en la materia". También eran objeto de sanción aquellos propietarios, administradores, gerentes o encargados de hoteles y hoteles-

\footnotetext{
164 Entre estos organismos especializados se encuentra el Instituto Étnico Nacional (IEN), cuya existencia tuvo lugar entre 1946 y 1955. Una de las principales agencias estatales que recibió los servicios de asesoramiento del IEN fue la DNM. Véase Lazzari (2004) para conocer la trayectoria del IEN y la de sus directores en el marco de un análisis de la construcción de la antropología como saber de Estado y como disciplina académica.

165 Además de esta información, la autoridad policial debía consignar los datos personales del “viajero” (nombre y apellido, documento de identidad exhibido, localidad, calle y número “donde fijare su permanencia”) y una “constancia de la notificación al viajero de su obligación contraída con el Estado de abandonar el país cumplido el término de estada legal y de no ejercer actividades comerciales o asalariadas bajo ningún concepto".
} 
alojamiento como también propietarios, locadores o sublocadores de casas-habitación, entre otros, que aceptaren como pasajeros, pensionistas, inquilinos o huéspedes a extranjeros que "no poseyeren perfectamente al día la documentación exigida en las presentes disposiciones o documento extranjero con las constancias de su permiso de radicación definitiva en el país". Junto a ello, en el decreto se comprometía a un conjunto de agentes públicos y privados a ejercer el control de la documentación que acreditara la "permanencia legal" en el país. ${ }^{166}$

De manera inédita, la división legal/ilegal también llegó a plasmarse en el articulado de la Constitución Nacional reformada en 1949.167 Mientras que el texto original de 1853 establecía en su articulado que "(l)os extranjeros gozan en el territorio de la Confederación de todos los derechos civiles del ciudadano", la reforma constitucional introducía cambios que limitaban dichos derechos a aquellos que "entren en el país sin violar las leyes", pronunciándose también sobre la adquisición y pérdida de la nacionalidad así como sobre su expulsión. Según el artículo 31,
Los extranjeros que entren en el país sin violar las leyes gozan de todos los derechos civiles de los argentinos como también de los derechos políticos después de cinco años de haber obtenido la nacionalidad. A su pedido podrán naturalizarse si han residido dos años continuos en el territorio de la Nación y adquirirán automáticamente la nacionalidad transcurridos cinco años continuados de residencia, salvo expresa manifestación en contrario. La ley establecerá las causas, formalidades y condiciones para el otorgamiento de la nacionalidad y para su privación, así como para expulsar del país a los extranjeros.

En general, las medidas de control dispuestas se mantuvieron principalmente para regular el ingreso y la permanencia de los europeos "indeseables", entre los que se contaban en

\footnotetext{
166 Si bien se encomendaba a la Dirección General de Migraciones (DGM) “la función de contralor de aplicación de las disposiciones contenidas en el presente decreto", cuyo cumplimiento también debía ser cuidado por la Policía Federal, Gendarmería Nacional, Prefectura General Marítima y policías de los territorios nacionales y los gobiernos provinciales a través de acuerdos con el Poder Ejecutivo nacional con el propósito de "desplegar una acción directa de contralor, vigilancia y represión" o "informar a la autoridad migratoria más próxima de la existencia de cualquier infracción prevista en la presente reglamentación", también se obligaba a empleadores, reparticiones públicas, instituciones privadas que prestasen servicios públicos y empresas de transporte marítimo, fluvial, aéreo y terrestre, exigir y verificar aquellos certificados y constancias que dieran cuenta de una estadía autorizada en el país. 167 Agradezco este señalamiento a Silvana Begala.
} 
esta época los refugiados, pero evitaron ser aplicadas a los trabajadores temporarios provenientes de países limítrofes como Bolivia, Paraguay y Chile debido a la creciente demanda de trabajadores temporarios ${ }^{168}$ en las economías regionales, cuyo ingreso fue favorecido y promocionado por el Estado a través de diversos organismos nacionales. Hasta aquél momento, como señala Karasik $(1992,2000)$ para el caso de la frontera argentino-boliviana, la presencia de los Estados estaba representada por los puestos aduaneros, concentrándose el control en los bienes antes que en las personas. La pertenencia a una u otra comunidad política no formaba parte de la división de la vida social local y no había obstáculos institucionales que dificultaran la residencia y la circulación entre ambos lados del límite estatal. Fue a partir de la década de 1940 que el límite entre Bolivia y Argentina comenzó a operar, tanto en términos materiales como simbólicos, como frontera política para los habitantes de la zona, adquiriendo visibilidad institucional y consecuencias político-sociales. En estos años, como destaca Quinteros (2008), los extranjeros nativos de países limítrofes, nombrados como braceros, no eran considerados inmigrantes según las definiciones estatales de la época, a diferencia de los trabajadores rurales europeos. A la vez, en tanto braceros, eran vistos y tratados como una mano de obra temporal alejada de la noción de trabajadores. Evidencia de ello sería, por ejemplo, la inexistencia de acuerdos bilaterales de trabajo entre la Argentina y los países latinoamericanos y la consecuente falta de protección jurídica. Con los países europeos, en cambio, se firmaron diversos convenios bilaterales que contemplaban, al menos formalmente, apoyo y amparo de los Estados de origen.

Como vimos anteriormente, hasta 1950 el flujo migratorio boliviano hacia la Argentina respondió a la escasez de mano de obra necesaria para las tareas rurales, trabajos zafrales y temporales en las zonas fronterizas. ${ }^{169}$ La inmigración boliviana, en particular, se volvió relevante cuando las plantaciones azucareras de las provincias del Noroeste (Salta y Jujuy) comenzaron a sustituir a los trabajadores locales por los trabajadores migrantes (Balán, 1990:271-272). Ya hacia la década del cincuenta, el área metropolitana de Buenos Aires,

\footnotetext{
168 En general, el tiempo de residencia y trabajo no superaba el año, oscilando el promedio entre tres y seis meses (Galante, 2008b).

169 Karasik (1992) indica que hacia fines del siglo diecinueve, pero especialmente en las primeras décadas del XX, el flujo de migrantes bolivianos que había llegado a la Argentina desde mediados del siglo anterior a diferentes zonas de la Quebrada de Humahuaca -entre ellas Tilcara- con recursos económicos suficientes para una privilegiada inserción en la estructura socioeconómica local, comenzó a ser sustituida por otro compuesto por migrantes empobrecidos de origen campesino que se asentaron en la zona cañera del Río San Francisco, la Puna y la Quebrada de Humahuaca, dedicándose en su mayoría a la producción agropecuaria (Karasik, 1992:44-45). Al menos desde las primeras décadas del siglo XX, la población reclutada entre campesinos y jornaleros de Tilcara como mano de obra estacional para los ingenios azucareros de la zona del río San Francisco fue qolla (Karasik, 1992:43).
} 
donde la remuneración de los empleos en los sectores de la construcción, la industria manufacturera y los servicios era mayor que en los países de origen o en las provincias limítrofes, empezaba a surgir como uno de los principales destinos, constituyéndose a partir de los años ochenta en el más importante (Balán, 1990). Durante esta década, bajo un marcado proceso de migración interna hacia el área metropolitana, los trabajadores inmigrantes reemplazaron a los nativos, alcanzando en 1960 una participación muy alta en la población económicamente activa en las provincias de destino tradicionales (Marshall y Orlansky, 1983).

Marshall y Orlansky (1983) muestran que el primer gran incremento de la inmigración boliviana, paraguaya y chilena ocurrió a mediados del siglo veinte durante dos períodos comparativamente expansivos en la economía argentina: primero entre 1946 y 1950 y después entre 1956 y 1960. Si bien no descartan la influencia de acontecimientos que tuvieron lugar en el país de origen, como la crisis de las economías campesinas luego de la reforma agraria en el caso de Bolivia (Marshall y Orlansky, 1981), este crecimiento lo atribuyen fundamentalmente a los aumentos en la demanda de mano de obra en la Argentina. Según las autoras, durante la segunda mitad de la década del cuarenta los inmigrantes bolivianos, paraguayos y chilenos, además de satisfacer nuevas necesidades de mano de obra, ocuparon los puestos que abandonaban los trabajadores nativos en las producciones regionales, al trasladarse masivamente hacia el área metropolitana argentina. Durante el segundo quinquenio de la década siguiente, la inmigración fue particularmente estimulada por el enorme desarrollo que tuvieron las producciones provinciales y, como en el período anterior, por la demanda de mano de obra que generaba la continua migración interna hacia otras regiones urbanas que proporcionaban mejores oportunidades laborales.

Dado el interés en la mano de obra estacional, el cruce de frontera de trabajadores de países limítrofes fue facilitado por el Estado argentino. La sustitución de la "tarjeta de contralor" por la "cédula de bracero"170 como documento de acreditación del ingreso y la

170 Galante (2008b) comenta que la "cédula de bracero" surgió en respuesta a una demanda puntual de trabajadores paraguayos ejercida por empresarios algodoneros y avalada por los gobernadores de las provincias implicadas (Chaco y Formosa). La resolución № 206 de la DNM del 24/03/1950, partiendo de la premisa que "la mayoría de los braceros extranjeros disponibles" carecían de la documentación requerida, reclamaba una modalidad de control que no impidiera disponer libremente de la mano de obra estacional. Esta respuesta gubernamental, concebida originalmente como una medida de emergencia, se transformará luego, a través de sucesivas resoluciones de la DNM, 
permanencia legales y la simplificación de los trámites administrativos para la entrada ilustra bien el modo diferencial en que operaba la frontera para los extranjeros provenientes de países limítrofes en tanto fueran europeos indeseables o trabajadores temporarios. Mediante la cédula de bracero -otorgada en principio por tres meses pero que podía extenderse en ocasiones hasta un año- el bracero podía permanecer en el país durante el tiempo que había sido empleado para la zafra y a su término debía regresar a su país (Quinteros, 2008). ${ }^{171}$ En 1951, frente a la falta de documentación de los jornaleros contratados y a partir de reclamos patronales se autorizó por medio de una resolución de la DNM, la entrada de trabajadores bolivianos conducidos a ingenios azucareros sin exigirles la documentación identificatoria, asumiendo como válida la declaración del contratante, trasladándose Gendarmería hasta los lugares de trabajo para extender las cédulas (Galante, 2008b; Quinteros, 2008). Ese mismo año se dispuso mediante decreto ${ }^{172}$ que aquellos obreros hacheros de países vecinos que pudieran acreditar "buena conducta" y hubieren trabajado "en el mismo obraje por un lapso no inferior a un año", serían considerados "radicados de hecho", creándose al mismo tiempo una comisión para que estudie "los problemas emergentes por la falta de braceros en el interior de la República", presumiblemente debido al ya iniciado proceso de migración interna hacia las ciudades (Pacecca, 2000).

\section{La inmigración de países limítrofes como problema: los nuevos indeseables y el control de la ilegalidad}

Hacia mediados del siglo veinte se empezaron a evidenciar ciertos cambios en la composición de los flujos migratorios internacionales, fundamentalmente como consecuencia de la declinación de la inmigración de ultramar: aunque la migración de

\footnotetext{
en una "política de promoción del ingreso de braceros de origen limítrofe para una importante variedad de desarrollos regionales con frontera internacional" como Salta, Jujuy, Misiones, Chaco, Formosa y Santa Cruz. Estas resoluciones, originadas a partir de la solicitud de compañías privadas (ingenios azucareros del NOA, empresas algodoneras y yerbateras y cooperativas agrarias tabacaleras del NEA y construcciones ferroviarias o explotaciones mineras estatales en el Sur), organismos estatales como el Ministerio de Industria y Comercio de la Nación o la Gendarmería Nacional, pretendían agilizar el control fronterizo ante el numeroso ingreso de trabajadores de países limítrofes (Bolivia, Paraguay y Chile, principalmente).

171 Con el objetivo de sistematizar el otorgamiento de las "cédulas de bracero", la DNM elaboró un proyecto de decreto sobre el ingreso de braceros, que suponía la derogación los decretos № 1.162 y 24.104 dictados en 1949 y alentaba la "radicación automática", pero finalmente no consiguió que fuera aprobado. Con ello, la DNM continuó manejándose con resoluciones, mediante decisiones propias de su competencia (Galante, 2008b).

172 Decreto $N^{\circ} 13.721 / 51$.
} 
países limítrofes no variara de manera significativa (en términos relativos) durante todo el siglo, manteniéndose entre el dos y el tres por ciento sobre el total de la población, su presencia entre el conjunto de extranjeros residentes en el país se elevó considerablemente a partir de la década del sesenta (INDEC, 1997). La inmigración boliviana, en particular, se convirtió en una de las tres corrientes migratorias de los países limítrofes con mayor aporte cuantitativo. En la segunda mitad del siglo, la participación de la población boliviana en el total de la población de países limítrofes osciló entre el quince y diecinueve por ciento, siempre menor a la migración paraguaya y chilena. La caída de los precios de los productos regionales y la creciente mecanización de la producción agrícola, mayormente en la cosecha de caña de azúcar y en menor medida en el cultivo del tabaco (Marshall y Orlansky, 1983), produjo una reducción de la demanda de mano de obra estacional en el noroeste argentino, que motivó la adopción de nuevos destinos para la inmigración boliviana donde las oportunidades laborales eran mayores como el sector de la construcción y la horticultura, principalmente en la ciudad y la provincia de Buenos Aires, pero también en las regiones de Mendoza, Santa Fe y Córdoba. ${ }^{173} \mathrm{~A}$ mediados de los años setenta, los migrantes bolivianos ya participaban de amplios circuitos estacionales de trabajo que conectaban diversas zonas rurales de la Argentina (Hinojosa Gordonava et al., 2000).174

Al revertirse el proceso de reemplazo de mano de obra, como indican Marshall y Orlansky, la fuerza laboral proveniente de países limítrofes adquirió un carácter residual. Ya no era tan requerida como en los períodos anteriores y su inserción estaba prácticamente subordinada a la migración interna, dirigiéndose a las provincias relativamente más deprimidas de cada contexto regional, generalmente expulsoras de población y poco atractivas para los migrantes internos. En las distintas provincias, los trabajadores inmigrantes mostraron una alta concentración en los sectores productivos y una gran selectividad en comparación con los trabajadores, fueran o no locales de la provincia. Los trabajadores provenientes de países limítrofes se ubicaban generalmente en los sectores más desfavorecidos, caracterizados por la precariedad de la relación laboral, condiciones contractuales más adversas y condiciones de trabajo más duras, peligrosas o menos saludables. En el caso de los hombres, estaban sobrerrepresentados en la agricultura, la minería, la industria o la construcción, mientras que las mujeres en los servicios

173 Existe una amplia literatura que da cuenta de este desplazamiento y difusión de la migración boliviana en la Argentina. Véanse, entre otros, Sassone (1988); Balán (1990); Dandler y Medeiros (1991); Benencia (1992, 1997, 2003); Benencia y Karasik (1995).

174 A finales de la década se inició un desplazamiento hacia localidades de la costa atlántica como Villa Gessel y Pinamar, Puerto Madryn, Río Gallegos y Comodoro Rivadavia (Mugarza, 1985). 
personales y en el comercio (generalmente por cuenta propia). A diferencia de lo que sucedía en las economías regionales, en el Gran Buenos Aires la participación de los trabajadores migrantes en la fuerza laboral de esta zona se incrementó progresivamente, básicamente por la intensificación de la inmigración de hombres y mujeres paraguayos y hombres bolivianos. La significativa inserción de trabajadores migrantes en el sector de la construcción respondía al aprovechamiento que se hacía de la mano de obra disponible en desmedro de un mayor dinamismo tecnológico mediante la utilización de nuevas técnicas productivas (Marshall y Orlansky, 1983).

Con el advenimiento de nuevos gobiernos militares, el cuerpo de disposiciones jurídicas y demás mecanismos institucionales de control creados en las décadas anteriores para regular el ingreso y la permanencia de los europeos indeseables inspiró las medidas que serían aplicadas a los trabajadores de países limítrofes. Éstos, a medida que fueron percibidos como parte de una inmigración más permanente, se convirtieron en los nuevos indeseables, adquiriendo la ilegalidad una especial relevancia en la normativa producida. Asimismo, como sugiere Pacecca (2000), a medida que el ingreso por tierra desde los países limítrofes se fue afianzando, la normativa migratoria se desplazó desde el control del ingreso hacia el control de la permanencia, administrado mediante importantes restricciones en las condiciones de residencia y trabajo formalizadas legalmente.

A poco más de un año del golpe militar de 1962, el gobierno presidido por José María Guido estableció nuevas medidas para regular la población inmigrante mediante el decreto-ley titulado "Extranjeros: régimen de admisión, permanencia y expulsión del territorio de la República", asociando explícitamente el "problema migratorio" a la ilegalidad. ${ }^{175}$ Según esta nueva disposición, era "imprescindible adecuar las normas de la Ley de Inmigración, dictada hace más de ochenta años, a las reales necesidades del problema migratorio en nuestro país". Pacecca (2000) indica que esta es la primera pieza jurídica que explícitamente propone una actualización de la Ley Avellaneda de 1876 a la vez que constituye el antecedente inmediato del Reglamento de Migración de 1965.176

Bajo la finalidad de "reglamentar la admisión, permanencia y expulsión de extranjeros", uno de sus artículos ofrece una definición de ilegal que recuerda lo establecido en el

175 Decreto-ley № 4.805/63.

$176 \mathrm{El}$ decreto señala en los considerandos que "la legislación existente sobre la materia está constituida por un conjunto asistemático y, en ciertos casos contradictorio, de normas reglamentarias que han desvirtuado los lineamientos esenciales de la ley de Inmigración 817". 
decreto dictado en enero de 1949 en el cual se introduce y especifica la categoría de "permanencia ilegal":

La Dirección Nacional de Migraciones considerará ilegal el ingreso o permanencia en el país de todo extranjero que hubiere ingresado sin someterse a contralor migratorio o por lugar no habilitado al efecto, no cumpliere con los requisitos legales que condicionan el ingreso y permanencia de extranjeros o permaneciere en territorio de la República vencido el plazo de permanencia autorizado.

Como se desprende de los considerandos del decreto-ley, la política de control que se pretendía llevar adelante, bajo un recorte de derechos para los extranjeros cuyo ingreso o permanencia fuera considerado ilegal, buscaba ampararse en la Constitución Nacional, recurriendo a fallos de la Corte Suprema de Justicia de la Nación en los cuales se declaraba que "el derecho de la Nación a regular y condicionar la admisión de extranjeros no es incompatible con los derechos individuales consagrados por la Constitución Nacional”. Según los fundamentos de la norma, el texto constitucional, en su artículo 14, no protegería al extranjero que lograra entrar al territorio nacional "eludiendo el cumplimiento de los requisitos exigidos por la ley de inmigración y su reglamentación y la autoridad competente para exigir y verificar el cumplimiento de dichos requisitos". ${ }^{177} \mathrm{El}$ decreto también imponía limitaciones a quienes fuesen admitidos y estuvieran viviendo en el país aún bajo la categoría de "extranjeros residentes permanentes", condicionándola a una permanencia continua en el territorio nacional. Asimismo, la DNM pasó a tener mayores competencias sobre la regulación de los movimientos migratorios, incrementando sus funciones de control, apoyadas por la Policía Migratoria Auxiliar conformada por la Policía Federal, Prefectura Nacional Marítima y Gendarmería Nacional.

También son significativas las limitaciones que se le imponían a quienes habían sido admitidos y vivían en el país bajo la categoría de "extranjeros residentes permanentes". Según lo dispuesto en el decreto, perdían tal condición en caso de que se ausentaran del "territorio de la República" por un lapso de tiempo mayor a dos años de manera continuada. Su posible reingreso, previa solicitud de permiso, sería resuelto por la "autoridad migratoria" -esto es, la DNM- según la valoración que hiciera de "su situación familiar en el país, su domicilio, la sede de sus negocios, profesión y antecedentes

177 Véase Begala (2007) para un análisis del artículo 14 y la noción de "habitante” en el marco de la discusión sobre ciudadanía. 
personales". Además de las excepciones que podían otorgar, discrecionalmente, los ministerios del Interior y de Relaciones Exteriores y Culto, estaban exceptuados aquellos cuya ausencia mayor a dos años se produjera por "razones de salud, de estudio, familiares, profesionales o de negocios".

Iniciado ya el gobierno constitucional de Arturo Illia, en 1965 se aprobó el Reglamento de Migración, el cual se mantuvo vigente hasta mediados de los años ochenta, bajo el argumento de que era necesario "modernizar, sistematizar y facilitar los regímenes de admisión, ingreso, permanencia y salida de extranjeros, y disponer de un cuerpo normativo simple y coherente en beneficio de administrados y administradores". ${ }^{178}$ Entre las numerosas funciones de la DNM relacionadas con la regulación de la población inmigrante figuraban algunas ideas que vertebran el pensamiento de Estado en materia migratoria: la importancia de gestionar -utilizando una noción extemporánea para aquellos tiempos- los flujos migratorios mediante una adecuada selección y distribución en el espacio, que reparara en la incorporación a la sociedad de destino/recepción, sin descuidar sus efectos sociales, además de contemplar severas sanciones a los empleadores y a los extranjeros infractores de la ley como un modo de prevenir la "inmigración clandestina".

[...] 2o Seleccionar y encauzar las corrientes migratorias, salvaguardando la salud moral y económica de la República, de acuerdo a la política migratoria fijada por el Poder Ejecutivo; 3o Orientar la inmigración hacia las áreas que se destinen a colonización; [...] 5o Proveer lo conducente a la recepción, radicación y establecimiento de los inmigrantes en la República, en las zonas que resulten aptas para tales fines; 6ํㅜ Fomentar y facilitar la internación de inmigrantes; 7ํ Proveer al embarco y transporte de los inmigrantes que manifiesten el deseo de radicarse en el país; 8º Promover la represión de la explotación del inmigrante; 9o Proveer lo necesario para la prevención y represión de la inmigración clandestina.

El criterio para establecer las categorías bajo las cuales los extranjeros podían ser admitidos se basaban en la noción de permanencia: los dividía entre extranjeros "con 
residencia permanente" y "con residencia no permanente" y proponía una clasificación en la cual, a la vez que introducía categorías concernientes a la inmigración de países limítrofes, diferenciaba entre los "inmigrantes", clasificados como "espontáneos", "llamados" y "asistidos", y aquella mano de obra comprendida bajo rótulos como "temporarios" o "trabajadores de temporada" y los habitantes "de tránsito vecinal fronterizo". Aunque todo extranjero, con o sin permanencia estaba expuesto a la expulsión, las diferentes disposiciones relativas a cada categoría permitían que esta distinción administrativa se tradujera en mayores o menores posibilidades de ser declarado ilegal.

A su vez, el reglamento disponía de un conjunto de criterios que condicionaban el ingreso y la permanencia en el país con residencia permanente y distinguía entre extranjeros "absolutamente inhabilitados" y "relativamente inhabilitados". Entre los primeros se encontraba una serie de motivos que, reunidos bajo un mismo rubro, hacen a la amplia categoría de marginales o excluidos: enfermos, vagabundos, prostitutas, adictos, traficantes, delincuentes, rebeldes, agitadores y un largo etcétera. ${ }^{179}$ Todas las restricciones dispuestas para acceder a la residencia permanente estaban supeditadas a una sola condición: ser extranjero. Las excepciones que se establecían para quienes se encontrasen "residiendo de hecho" denotan la importancia que revestía tal condición, entendida en términos jurídicos: existía la posibilidad de concederles, excepcionalmente, la radicación definitiva a quienes pudieran comprobar que tenían una residencia en forma continua durante los cinco años anteriores a la solicitud o un cónyuge argentino, e hijos argentinos, o ser hijo de argentino. La residencia continua en el territorio nacional, como muestra de voluntad de permanencia, y la relación contractual o de sangre con un nacional argentino absolvían a los extranjeros de su pecado original: ser precisamente no nacionales o nacionales de otro Estado.

\footnotetext{
179 Las definiciones dadas son mucho más abarcativas que alguna de estas figuras sociales: a) Estar afectado por enfermedad infecto-contagiosa o transmisible, de modo que pueda presumirse un riesgo para la salud pública; b) Estar afectado de alienación mental o de semialienación mental, sean dementes, psicóticos, oligofrénicos, insuficientes mentales, neuróticos y personalidades psicopáticas, en grado tal de alteración de sus estados de conciencia y conducta como para provocar graves dificultades familiares y sociales; c) Cuando pueda presumirse que se trata de elementos viciosos o inútiles, por carecer de profesión, industria, arte, oficio u otro medio de vida lícito, o por cualquier otra circunstancia; d) Ejercer la prostitución; haber lucrado o sea presumible el propósito de venir a lucrar con la prostitución de personas; e) Ser adicto a los estupefacientes o traficar o haber traficado con ellos; f) Registrar condena o estar proceso por delitos comunes que merezcan por las leyes argentinas penas privativas de libertad. (...); g) Registrar antecedentes que hagan presumir comprometerán la seguridad nacional o el orden público.
} 
Por otra parte, entre los "relativamente inhabilitados" estaban comprendidos los extranjeros que fueran mayores de 60 años, o tuvieran "defecto físico, congénito o adquirido, o una enfermedad crónica que disminuya su capacidad general para el trabajo o para el ejercicio del arte, profesión, industria u oficio" que poseyeran, o aquellos, según las leyes argentinas, cuya pena o acción penal hubiese extinguido o no registraren una pena máxima que excediera los dos años, o hubieran sido objeto de expulsión. Las excepciones a la norma se fundamentaban en la correspondencia que tuvieran sus actividades y capacidades, principalmente económicas, con los intereses nacionales, además de la relación ya definida con un/a nacional argentino en calidad de cónyuge, padre o madre, e hijo. ${ }^{180}$ Asimismo, a la hora de ponderar la radicación de los extranjeros "con residencia no permanente" que hubieren ingresado como temporarios, trabajadores de temporada, turistas, pasajeros en tránsito o asilados políticos (también aquellos "extranjeros en virtud de visaciones diplomáticas, oficiales o de cortesía"), se consideraba su "conducta (...), lugar de residencia, condiciones personales, profesionales, de aptitud física y sanitaria, de trabajo y de familia y los demás elementos de valoración que estime oportunos [la autoridad migratoria], en directa concordancia con el interés social, económico y demográfico del país". Aquellos que ingresaban bajo el régimen de "tránsito vecinal fronterizo" o "en prosecución de viaje" no podían obtener la radicación definitiva, salvo que su "actividad, profesión, conocimiento o especialidad resultaren de interés para el país". También podían obtener la radicación definitiva aquellos extranjeros que se encontrasen "residiendo de hecho" en el país durante un lapso de tiempo no inferior a los tres años. Igualmente, aquí había excepciones basadas las características que poseyera el individuo: en caso de que no cumpliesen con este requisito, también se les concedía la radicación definitiva a aquellos cuya residencia resultase "de interés para el país, considerando sus condiciones personales, familiares, profesionales, aptitud física, etc.".

Como ya se venía proponiendo desde las primeras décadas del siglo en la normativa migratoria, el reglamento preveía un sistema de control indirecto de la ilegalidad en el ingreso como en la permanencia que alcanzaba a todos aquellos que se vincularan o trataran con inmigrantes. Los empleadores que proporcionasen trabajo u ocupación o contratasen extranjeros estaban obligados a comprobar que contaban con la categoría de

\footnotetext{
180 Entre las excepciones el artículo correspondiente mencionaba: a) Grado de interés que tengan para la República las actividades que habrán de desarrollar; b) Las posibilidades de trabajo, o de subsistencia o de amparo cuando se trate de incapaces; c) Las condiciones físicas, morales y económicas y la capacidad laborativa, apreciada en conjunto, del núcleo familiar del que forma parte; d) Tener cónyuge argentino, o hijo argentino o ser hijo de argentino, y e) Toda otra consideración que en forma objetiva pueda servir de elemento de juicio para fundar la excepción.
} 
ingreso o permanencia o tenían el permiso correspondiente para "desempeñar actividades asalariadas o remuneradas en el país". Asimismo, un amplio rango de individuos relacionados con el alojamiento (propietarios, administradores, gerentes, encargados o responsables de hoteles y demás sitios de hospedaje, como también los propietarios, locadores o sublocadores de casas habitación) así como todos aquellos que tratasen como pasajeros, inquilinos o huéspedes con extranjeros debían exigirles la documentación que acreditase que estaban "residiendo legalmente en el país, debiendo comunicar toda irregularidad de inmediato a la autoridad migratoria o policial más próxima". En caso de que se declarara ilegal ${ }^{181}$ el ingreso o la permanencia de un extranjero, en virtud del valor que tuviera "su situación personal y familiar, su profesión, condiciones personales y la utilidad del mismo para el país", la DNM podía concederle la regularización solicitada, intimarlo a regularizar su situación o conminarlo a abandonar el país, "bajo apercibimiento de decretar su expulsión”, o decretar directamente su expulsión, pudiendo proceder a su detención.

Ese mismo año, al mes siguiente, se creó por decreto una Comisión Interministerial en el ámbito del Ministerio del Interior encargada de estudiar "los problemas emergentes definidos en los considerandos como "complejos"- de la afluencia al país y permanencia en él de personas provenientes de países limítrofes". Su misión consistía en analizar "los aspectos legales y administrativos, políticos, sociales, económicos, laborales, sanitarios, educacionales, etc. del problema" con el fin de proponerle al Poder Ejecutivo "un plan de soluciones". ${ }^{182}$ Uno de los elementos que podría haber contribuido a percibir a la migración en términos de problema, como sugiere Pacecca (2000), es la radicación de inmigrantes limítrofes en respuesta al plan de regularización migratoria de 1964, que trataremos más adelante. Por estos años, a la vez que aumentaba la concentración de inmigrantes limítrofes en el Área Metropolitana de Buenos Aires (AMBA) también su presencia comenzaba a adquirir mayor visibilidad social. 183

181 Esta norma recoge la definición de "ilegal” otorgada en el decreto-ley № 4.805/63. Según el reglamento, bajo el capítulo titulado "De la declaración de ilegalidad del ingreso y la permanencia”, la DNM “deberá declarar ilegal el ingreso y/o la permanencia en el territorio de la República a todo extranjero que: a) hubiere ingresado sin someterse a contralor migratorio; b) hubiere ingresado por lugar no habilitado a tales efectos, c) no cumpliere con los requisitos legales que condicionan el ingreso yo la permanencia de los extranjeros en sus distintas categorías; d) permaneciere en la República una vez vencido el plazo de permanencia autorizada" (artículo 151).

182 Decreto № 5.144/65.

183 A comienzos de la década del setenta, el AMBA concentraba alrededor de la tercera parte de los migrantes bolivianos (INDEC, 1970) y en los ochenta ya superaba la población existente en las provincias fronterizas. Según 
Esta comisión interinstitucional involucraba una amplia variedad de organismos de gobierno, que según lo expresado en los considerandos, estarían afectados por los movimientos migratorios de países limítrofes. Estaría presidida por el Misterio del Interior e integrada por representantes de los Ministerios del Interior, Relaciones Exteriores y Culto, Defensa Nacional, Trabajo y Seguridad Social, Asistencia Social y Salud Pública y Educación y Justicia como también por el Secretario General de la Presidencia de la Nación, el Secretario de Informaciones de Estado y los Directores Nacionales de Migraciones, Gendarmería, Prefectura Marítima y Registro Nacional de las Personas, el Director General de Provincias, el Jefe de la Policía Federal y el Presidente de la Comisión Nacional de Zonas de Seguridad. Las áreas de gobierno involucradas suponían de por sí una definición acerca de los ámbitos en los cuales se pensaba que estos problemas emergerían (Pacecca, 2000).

Con el gobierno de facto de Juan Carlos Onganía (1966-1970) se reforzó el carácter restrictivo y represivo de las medidas estatales dirigidas a la población inmigrante, guiadas centralmente por el objetivo de "impedir la inmigración clandestina". ${ }^{184}$ Con esta finalidad, mediante un decreto-ley, se prohibía a "los extranjeros que se encuentren ilegalmente en el país" y a los "residentes temporarios" llevar a cabo "tareas o actividades remuneradas en todo el territorio de la República, ya sea por cuenta propia o en relación de dependencia" (a los residentes temporarios se les permitía trabajar en caso de que "estuviesen habilitados por la autoridad migratoria"), obligando a "las reparticiones oficiales, empresas estatales y todo empleador o dador de trabajo", así como a "los propietarios, administradores, gerentes, encargados o responsables de hoteles o casas de hospedaje" que les exigieran los comprobantes o constancias que acreditaran su "residencia legal en el país", además de denunciar a las autoridades migratoria o policial

\footnotetext{
Mugarza (1985), mientras que en los años cuarenta y cincuenta era frecuente que llegaran a Buenos Aires por etapas, siguiendo la ruta noroeste hasta Mendoza o la ruta central a través de Córdoba, a partir de la década del sesenta aumentan y se acentúan los traslados directos. A su llegada a Buenos Aires, los inmigrantes bolivianos se radicaban en asentamientos espontáneos (villas miseria), construyendo viviendas precarias en terrenos fiscales, o se instalaban en pensiones o casas de inquilinato en la zona céntrica de la ciudad, cercanas a las terminales de ferrocarril y ómnibus. Años más tarde, hacia fines de los setenta, se produjo una importante retirada hacia diversas zonas del Gran Buenos Aires, estableciéndose en lotes propios o en terrenos fiscales, generalmente escasos de servicios básicos, alejados de las escuelas y del transporte urbano.

184 Así se declara en la nota que acompaña el proyecto de ley: "Entre los objetivos fijados en el punto 4o -Potencial Humano- del Programa de Ordenamiento y Transformación del Gobierno de la Revolución Argentina, figura el de impedir la inmigración clandestina".
} 
"las situaciones irregulares que pudieren comprobar". ${ }^{185}$ Acorde a los rasgos autoritarios de la norma en general, en caso de incumplimiento de estas obligaciones, la DNM, facultada a ejercer "el poder de policía migratoria en todo el territorio de la República" con la asistencia de la Policía Migratoria Auxiliar, podía aplicar un amplio abanico de sanciones. ${ }^{186}$

Los argumentos mediante los cuales se pretendía avalar dicha norma, expresados en la nota adjuntada al proyecto de ley, ofrecen algunos elementos que permiten comprender más cabalmente el modo en que se pretendía explicar en este período la existencia de la ilegalidad como problema necesario de solución y las consecuencias que se le imputaban. En primer lugar, se apoyaba en la "insuficiencia" que habían tenido las acciones de control ejercidas en el ingreso al territorio nacional, la aplicación de las medidas concernientes a la expulsión de los "extranjeros indeseables ingresados o establecidos ilegalmente" y los procesos de regularización migratoria o "regímenes de excepción" -como se las denomina en la norma- para obtener "una solución integral del problema de la inmigración clandestina que subsiste vigorosamente" o, como también afirmaba, para "mitigar los males que nacen de esa situación anómala". En segundo lugar, la existencia de "una considerable inmigración ilegal" era atribuida principalmente a "una insuficiencia normativa" que permitía que el inmigrante ilegal tuviera los mismos derechos, libertades y garantías que el "habitante de derecho", la cual produciría "una irritante desigualdad a favor del ilegal", desincentivándolo a que acuda a los procesos de "regularización". Junto a ello, "la existencia de una dilatada frontera de difícil vigilancia" y "la vigencia de liberales regímenes para la admisión de turistas, pasajeros en tránsito, trabajadores de temporada y para el denominado tránsito vecinal fronterizo" contribuirían a explicar la presencia de la inmigración ilegal en la Argentina. La "solución integral", por tanto, radicaría en la modificación de "las condiciones de atractividad que el país ofrece hoy al residente ilegal", lo cual suponía, en los términos del decreto-ley, el establecimiento de un instrumento jurídico que evitara su acceso al trabajo remunerado y que sancionara y reprimiera las "infracciones" cometidas en torno a él. A su vez, la norma, en busca de legitimidad, pretendía respaldarse en la Constitución Nacional, argumentando que las restricciones que imponía a los "residentes ilegales" no contradecían sino que armonizaban con su finalidad: el reconocimiento de los derechos civiles a los extranjeros sería en función de su condición de "habitantes de la Nación". Dicha condición sólo sería alcanzable mientras

185 Decreto-ley № 17.294/67.

186 Además, los despidos eran considerados como "justificados" y los empleadores eran absueltos de la (correspondiente) indemnización. 
hubiera un "previo acatamiento de las normas que regulan el ingreso de los inmigrantes". Esta afirmación suponía una definición concreta acerca de los criterios de pertenencia a la nación, que si bien emerge explícitamente en esta oportunidad, está contenida en los supuestos básicos de la normativa migratoria en general: los ilegales nunca podrán formar parte de la nación; en la nación sólo tienen lugar los legales. Ser un nacional implica estar legal como condición sine qua non.

Cabe destacar, que tal limitación no contradice sino que armoniza con los fines de la Constitución nacional, que reconoce a los extranjeros que han adquirido la condición de habitantes de la Nación los mismos derechos civiles de los ciudadanos, lo cual presupone para los primeros el previo acatamiento de las normas que regulan el ingreso de los inmigrantes.

Unos meses más tarde, el gobierno de Onganía dictó un nuevo decreto-ley que actualizaba el monto de las multas para las infracciones relacionadas con el "transporte ilegal de extranjeros", esgrimiendo que el monto máximo establecido en el año 1963 carecía de "suficiente eficacia punitiva", y por tanto, habría favorecido "un marcado aumento de las infracciones por parte de las empresas transportadoras". ${ }^{187}$ Esta "anomalía", como se la denomina en el documento, que pretendía ser corregida mediante una sanción a los transportistas, funcionaba como un mecanismo (indirecto) que tenía como objeto el control de la inmigración ilegal. La legitimidad de tal medida pretendía apoyarse en "(l)os perjuicios e inconvenientes que derivan de la llegada al país de extranjeros carentes de la documentación necesaria”.188

Este mismo año, otro decreto-ley otorgaba una cédula de identidad a los extranjeros que acreditaran ser residentes permanentes y una resolución de la DNM creaba el documento oficial -documento que perdurará hasta la actualidad bajo la denominación informal de "la precaria"- que colocaba al migrante en una situación inestable en la cual estaba "indocumentado" pero no se lo consideraba ilegal (Pacecca, 2000): un "certificado de autorización de residencia precaria y para ejercer actividades remuneradas para quienes

187 Decreto-ley № $17.489 / 67$.

188 Nota al Poder Ejecutivo acompañando el proyecto de ley № 17.489/67. 
estén regularizando la permanencia, por 180 días renovables". 189 De aquí en adelante, esta "residencia precaria" -denominación que pretende evocar una corta duración, pero que también funciona como reconocimiento del estado de provisoriedad en la que coloca al inmigrante que la posee- se institucionalizará, incorporándola a los distintos instrumentos legales, y se adoptará como una categoría administrativa que le permite al Estado distinguir entre aquellos inmigrantes que han mostrado su voluntad de resolver su situación de ilegalidad, sometiéndose a los procesos de regularización, y los que persisten manteniéndose más allá de la legalidad, fuera o contra de la ley, según la interpretación que predomine.

En 1969, en un contexto marcado por la protesta social como el Cordobazo, la dictadura militar conducida por Onganía establecía, mediante un decreto-ley inspirado en la ley de Residencia de $1902^{190}$, la facultad del Poder Ejecutivo a ordenar y decretar de manera "irrecurrible" -tal como se expresa en su articulado- la expulsión de los extranjeros denominados por esta norma como "indeseables"191, incluido el "extranjero residente permanente", en los casos que "registrare condena en el extranjero y lo hubiere ocultado o no fuere conocido por la autoridad al producirse la admisión", o "fueren condenados por los tribunales argentinos por delitos dolosos" o, finalmente, "realizare en la República actividades que afecten la paz social, la seguridad nacional o el orden público". ${ }^{192}$ Alegaba que por "razones de seguridad" el Poder Ejecutivo podía "ordenar su detención hasta el momento que se haga efectiva la medida [de expulsión]”. Así, en nombre del orden público y la seguridad nacional, como se desprendía de los fundamentos del decreto, al mismo tiempo que se destacaba la generosidad de la Constitución Nacional para recibir "a todos los hombres del mundo que quieran habitar el suelo argentino", así como la hospitalidad de su pueblo, se advertía que quienes no se atuvieren a las normas fijadas podían ser "segregados de nuestra comunidad" -que tratándose de la voz del Estado podría ser interpretada como comunidad nacional o directamente como nación- mediante los mecanismos que posee el Estado para desterrar a quienes considera "indeseables": la expulsión.

189 Resolución de la DNM № 2016.

190 Así lo reconoce el decreto-ley № 18.235 en la nota dirigida al Poder Ejecutivo que acompaña el proyecto de ley. Dice textualmente: “El proyecto cuya aprobación someto a la consideración de V.E. se inspira en la ley № 4.144 que estuvo vigente más de medio siglo, y en disposiciones análogas de la legislación comparada."

191 Este decreto-ley se titula explícitamente “Extranjeros - Expulsión de indeseables”.

192 Decreto-ley № 18.235/69. 
La Constitución Nacional abre generosamente la entrada al país a todos los hombres del mundo que quieran habitar el suelo argentino. Pero quienes se acogen a nuestra hospitalidad deben observar una conducta digna y no perturbar las instituciones y el orden público. Si así no lo hicieren, se hacen pasibles de ser segregados de nuestra comunidad. Los graves acontecimientos ocurridos en el país durante los últimos días demuestran la urgencia de dotar al Poder Ejecutivo de un instrumento eficaz y ágil que permita expulsar a los extranjeros indeseables. ${ }^{193}$

A mitad de 1970, a pocos días de ser destituido Onganía y reemplazado por Levingston, se establecieron las "políticas nacionales", entre las cuales se proponía un "programa de crecimiento demográfico" que proporcione "una población más numerosa, estable y regionalmente equilibrada, prestando particular atención a la áreas rezagadas y fronterizas”. ${ }^{194}$ Con tales fines se hacía alusión, entre otras variables demográficas, a la “inmigración y su radicación” y el "afincamiento de núcleos de población” en zonas específicas. Uno de los puntos del decreto sugería promover la inmigración de manera selectiva en base a ciertas ideas que remiten al eugenismo y postulados recurrentes en la fundamentación de las políticas migratorias como "el desarrollo" y "la seguridad": "Impulsar la inmigración con carácter selectivo, procurando mantener la actual composición étnica de la población y teniendo en cuenta los requerimientos del desarrollo y la seguridad". También la protección de la frontera -como parte de la protección de la nación- aparecía de manera implícita al declararse la necesidad de "(p)romover la radicación de población nativa en la zona de frontera" (énfasis propio).

Al año siguiente, durante el cual -siguiendo con la alternancia de gobiernos militares- se produjo el reemplazo de Roberto Levingston por Alejandro Lanusse, se dictaron tres decretos que tuvieron como objeto el control de los extranjeros con residencia no autorizada en el país a través de su regularización administrativa: uno los eximía o reducía el pago de la tasa de radicación cuando exista justificativo ${ }^{195}$; otro les permitía a aquellos que tuvieran menos de tres años de residencia solicitar la radicación temporaria por un

193 Nota dirigida al Poder Ejecutivo que acompaña el proyecto de ley $\mathrm{N}^{\circ} 18.235$ de 1969.

194 Decreto № 46/70.

195 Decreto № 4.419/71. 
año196; y el último los habilitaba a iniciar el trámite de regularización y al mismo tiempo les otorgaba permiso para trabajar y alojarse ${ }^{197}$ (Pacecca, 2000; Giustiniani, 2004).

\section{La doctrina de la seguridad nacional hecha norma: la instauración de la Ley Videla}

A mediados de los años setenta, los militares volvieron a tomar el gobierno nacional por la fuerza. Durante la última dictadura iniciada con el golpe de Estado del 24 de marzo de 1976, autodenominada "Proceso de Reorganización Nacional", la normativa migratoria mantuvo y sistematizó la visión restrictiva y represiva sobre los inmigrantes de países limítrofes que, bajo los principios de la llamada doctrina de seguridad nacional ${ }^{198}$, se había ido ratificando en la década anterior, y que tuvo como corolario la Ley General de Migraciones y Fomento de la Inmigración, más conocida como la ley Videla. Por medio de dicha ideología, de marcado arraigo en las diversas experiencias de política migratoria en América Latina, se confeccionó una maquinaria estatal dirigida a identificar enemigos internos y externos identificados con la ilegalidad, entre los cuales estaban incluidos tanto los subversivos como los ilegales o clandestinos.

Asimismo, las normas dictadas a lo largo de este período, revelan la importancia otorgada a la ilegalidad y las distintas acepciones que podía adoptar esta categoría según la corriente migratoria o el grupo social que se tratara. Uno de los primeros decretos referidos a la inmigración apuntaba a obligar a que todos los extranjeros mayores de 16 años, que se encontraban "ilegalmente en el territorio nacional" y no podían "regresar a su país de origen o de residencia habitual o procedencia por razones políticas, sociales, raciales o religiosas", se presentasen ante la DNM para regularizar su "situación

\footnotetext{
196 Decreto № 3.206/71. Esta norma también aclara que se les podrá conceder, de manera excepcional, la "radicación definitiva" cuando ésta "resulte de interés para el país, considerando sus condiciones personales, familiares, profesionales, aptitud física, etcétera".

197 Decreto № 682/71.

198 Para profundizar sobre la doctrina de seguridad nacional en la Argentina y el Cono Sur, véanse Nina (1979), Tapia Valdés (1980), Cherñavsky (1993), Velásquez Rivera (2002), Leal Buitrago (2003), Izaguirre (2004, 2006) y Franco (2009), entre otros.
} 
migratoria”. ${ }^{199}$ Aquí cabe recordar, como bien observa Pacecca (2000), que en este período la represión ilegal del Estado se apoyaba en los "grupos de tareas" de las Fuerzas Armadas y de seguridad, que en ocasiones operaban conjuntamente con los de otros países vecinos. En este contexto, un extranjero que se presentara ante un organismo del Estado como la DNM para declararse como "residente ilegal" y aducir que no podía retornar a su país por razones políticas o sociales se exponía a convertirse en desaparecido.

Si bien el alcance de este decreto es puntual, no dejan de resultar sugerentes los fundamentos que se ofrecen para la implementación de tal medida, en tanto permiten visualizar los parámetros desde los cuales se evaluaba una política dirigida a regular la inmigración. En los considerandos se apelaba a la necesidad de "efectuar un adecuado relevamiento y estudio de la situación migratoria de los extranjeros que se encuentran irregularmente en el país" y de "conocer la cantidad de aquellos extranjeros que residiendo ilegalmente en la República, no pueden regresar a sus países de origen o residencia anterior por razones de índole política, social, racial o religiosa" bajo el argumento de que "el desarrollo de una eficiente política de población en la República requiere regular, controlar, seleccionar y encauzar debidamente los flujos migratorios". 200

$\mathrm{Al}$ año siguiente, mediante otro decreto, se pretendía favorecer "el regreso de argentinos residentes en el exterior" y "el ingreso y afincamiento en el país, de núcleos humanos extranjeros especialmente capacitados en tareas rurales, industriales, mineras y pesqueras, entre otras" a través de programas especiales que respondieran "al interés social, demográfico y económico de la República". Para ello se consideraba que era "menester otorgar facilidades para el ingreso al país de bienes y capitales pertenecientes a los posibles inmigrantes". ${ }^{201}$

Ese mismo año, un decreto agilizaba la radicación definitiva para aquellos "residentes extranjeros arribados al país con anterioridad al año 1910" y que no pudieran "acreditar fehacientemente su ingreso a la República", pero que consiguieran demostrar 30 años

199 Decreto № 1.483/76. Para ello, según el decreto, deben reunir los siguientes requisitos: “1. Que no se hayan presentado a la autoridad migratoria dando razón de su ingreso a la República, o 2. Que se encuentren vencidos los términos por los cuales se autorizó su ingreso o permanencia en el país".

200 Decreto № $1.483 / 76$.

201 Decreto № $464 / 77$. 
continuos o discontinuos de "residencia efectiva" y, además de "acreditar identidad", pudieran probar una edad igual o mayor a 66 años. ${ }^{202}$ Es muy probable que la fecha de ingreso fijada se corresponda con el interés de formalizar en términos administrativos la residencia de aquellos inmigrantes europeos que formaron parte de la llamada inmigración de masas o masiva. Por ello, visto retrospectivamente y en comparación a las exigencias establecidas históricamente para los inmigrantes de países limítrofes, no dejan de ser sugerentes las consideraciones que se formularon a propósito de la falta de documentación. El decreto señalaba que "tal circunstancia en manera alguna resulta imputable a los extranjeros que peticionan su certificación de ingreso", a la vez que se daba por hecho que dichas peticiones se realizaban "en gran mayoría, para iniciar la tramitación de beneficios previsionales". En orden a justificar esta medida, los extranjeros afectados por la norma eran contemplados como parte de la nación argentina y se aludía a la "incorporación de hecho" e incluso "de derecho" de estos extranjeros a "la vida del país" por efecto del tiempo en el territorio nacional, la cual contribuiría a cumplir con el fin último de "lograr su definitiva consolidación en la República". Asimismo, en otro decreto 203 , mediante el cual se ampliaba el plazo para que los "extranjeros residentes ilegales" se presentasen ante las autoridades migratorias, se hacía valer la constancia que éstas extendieran como "instrumento hábil suficiente para que los residentes ilegales (...) puedan inscribirse y cursar estudios temporalmente, en las escuelas del nivel primario y secundario". También disponía que en ningún caso servía para acreditar "residencia legal de los extranjeros en el territorio nacional".

Acorde con el valor estratégico que posee la población para la visión geopolítica militar, a fines del año 1977 se dictó un decreto por el cual se aprobaron los "Objetivos y Políticas Nacionales de Población".204 Entre los objetivos se proponía aumentar el "crecimiento cuantitativo y cualitativo de la población" para que "la Argentina pueda desarrollarse como comunidad nacional y cumplir un papel relevante en América Latina y en el mundo", cuyo cumplimiento junto a las "razones fundamentales de seguridad nacional" se consideraba necesario para una "mejor relación entre población y territorio". Bajo el capítulo referido a las "políticas requeridas para alcanzar estos objetivos", se pretendía "incrementar sensiblemente la inmigración extranjera, con un mínimo de selección que aseguren condiciones de salud y características culturales que permitan su integración en la sociedad argentina", además de determinar "áreas territoriales estratégicas" que 
permitieran "la más conveniente distribución y radicación de la población inmigrante, facilitando su integración con grupos nativos y evitando la formación de colectividades cerradas". Asimismo, explicitaba algunas medidas relacionadas con el trabajo y la migración: la creación de fuentes laborales que tuvieran en cuenta "la incorporación de la mano de obra inmigrante", la atracción de "la inmigración de contingentes calificados", la facilitación de la entrada de "inmigrantes con capital" y finalmente la "organización de un régimen de ingreso que permita la adecuada selección y encauzamiento de los inmigrantes de países limítrofes".

En 1981, durante el régimen militar encabezado por Rafael Videla, se instauró la ley $\mathrm{N}^{\circ}$ 22.439, titulada "Ley General de Migraciones y Fomento de la Inmigración", que se mantuvo vigente a lo largo de los dos últimos gobiernos democráticos de distinto signo político, posteriores a la dictadura militar (1976-1983), hasta su derogación con la nueva ley de migraciones a finales del 2003 (Ley 25.871). Bajo esta ley la DNM, dependiente de la Secretaría de Población del Ministerio del Interior, tenía amplias facultades para "controlar el ingreso, egreso y permanencia y ejercer el poder de policía de extranjeros en todo el territorio de la República". También estaba autorizado a allanar aquellos lugares donde se sospechara la presencia de inmigrantes irregulares, detenerlos sin orden judicial y expulsarlos (CELS, 1999). A su vez, en el marco de una (declarada) "política de fomento de la inmigración", como su propio título lo indica, la ley Videla especificaba -retomando la definición que diera en el decreto anterior- en uno de sus primeros artículos que "(e)l Poder Ejecutivo, de acuerdo con las necesidades poblacionales de la República, promoverá la inmigración de extranjeros cuyas características culturales permitan su adecuada integración en la sociedad argentina". Este principio de selectividad basado en criterios étnicos y nacionales -dejando en claro que los inmigrantes deseables eran los europeos- se combinaba con un articulado basado en una concepción represiva de la migración dirigida a los nuevos indeseables, los llamados inmigrantes limítrofes.

Como señala un informe del Centro de Estudios Legales y Sociales, esta normativa era violatoria de diversas normas de la Constitución Nacional. Desconocía los derechos de las personas migrantes, omitiendo dos principios fundantes del sistema jurídico argentino: el derecho a la igualdad y a la no discriminación. La ley también le otorgaba facultades excesivas a la DNM, dependiente de la Secretaría de Población del Ministerio del Interior: la autorizaba a "controlar el ingreso, egreso y permanencia y ejercer el poder de policía de extranjeros en todo el territorio de la República". Según se disponía en su articulado, este organismo del Poder Ejecutivo estaba facultado a allanar aquellos lugares donde se sospechara la presencia de inmigrantes sin autorización de ingreso o permanencia, 
detenerlos $\sin$ orden judicial y expulsarlos. Entre otras violaciones a los derechos humanos contenidas en esta ley, se destacaba la obligación legal de denunciar la existencia de una persona extranjera sin permiso de residencia ante la autoridad migratoria, las restricciones o prohibiciones respecto a la educación, al trabajo y a la libre circulación en el territorio nacional y la ausencia de garantías procesales (inexistencia de debido proceso y recurso judicial efectivo, allanamiento y detención sin orden judicial) (CELS, 2000).205

Al igual que en la legislación migratoria de las décadas anteriores, la ley establecía una serie de restricciones, totales o parciales, de acuerdo a las categorías que utilizaba para clasificar a los extranjeros: residentes permanentes, residentes temporarios y residentes transitorios. A los "residentes permanentes" se les permitía "desarrollar toda tarea o actividad remunerada o lucrativa, por cuenta propia o en relación de dependencia, gozando de la protección de las leyes que rijan la materia". Para los "residentes temporarios", el desarrollo de "tareas o actividades remuneradas o lucrativas, por cuenta propia o en relación de dependencia" estaba limitado al período de permanencia autorizado por la autoridad migratoria. A los "residentes transitorios", en cambio, se les prohibía desarrollarlas, excepto que tuvieran autorización para ello. La ley también contemplaba la categoría de la "residencia precaria" -siempre revocable- para aquellos extranjeros que gestionasen "la regularización de su permanencia en la República", los cuales podían "excepcionalmente ser habilitados para trabajar, por el plazo, en los lugares, y con las modalidades que establezca la autoridad de migración". Los "extranjeros que residan ilegalmente en la República" no estaban autorizados para trabajar o realizar tareas remuneradas o lucrativas y se prohibía proporcionales "trabajo u ocupación remunerada, con o sin relación de dependencia", contratarlos, convenir u obtener sus servicios (también vale para aquellos que residan "legalmente" pero que no estén habilitados por la autoridad migratoria) ni otorgarles "alojamiento a título oneroso"; en caso de que se proporcionara de manera gratuita o a modo benéfico, debía "comunicarse fehacientemente a la autoridad migratoria".

La ley disponía también sanciones, de menor o mayor severidad de acuerdo a la "naturaleza de la infracción", para aquellos "empleadores, dadores de trabajo y alojadores" que quebrantaran las disposiciones relacionadas con el control del trabajo y del alojamiento de los "extranjeros que residan ilegalmente", habilitando a la autoridad migratoria, asistida por la Policía Migratoria Auxiliar, "la inspección de contralor

205 Existe una gran cantidad de trabajos dedicados a analizar la ley Videla. Véase Giustiniani (2004) para conocer una de las publicaciones, aparecida después de su derogación, que reúne diversos artículos sobre el tema. 
migratorio en los lugares de trabajo, o alojamiento u hospedaje". Como medida complementaria, la no eximición de la obligación del empleador o dador de trabajo a cumplir con la legislación laboral, quedaba suspendida para el extranjero en "los casos en que al inicio de la relación laboral, éste residiera legalmente en el país y luego se transformare en ilegal o caducare la habilitación para trabajar".

Todas aquellas personas o entidades públicas o privadas, fueran de carácter nacional, provincial o municipal ${ }^{206}$ que tuvieran "conocimiento de la existencia de un residente ilegal en el país" estaban obligados a constatar su "permanencia legal en la República" y en caso de que pudiesen "comprobar" la ilegalidad estaban obligadas a denunciarlo, o como dice la ley, a "comunicarlo fehacientemente a la autoridad de migración". Esta obligación también alcanzaba a quienes contrataran o acordaren con "extranjeros que residan ilegalmente en la República la adquisición o venta, o constitución de gravamen sobre bienes inmuebles, derechos o muebles registrables, o la constitución o integración de sociedades civiles o comerciales".

En la ley Videla buena parte de sus artículos estaban dirigidos a especificar las condiciones bajo las cuales se podía hacer efectiva la expulsión. Los residentes permanentes gozarían "en su territorio de los derechos civiles de los argentinos, sujetos a iguales obligaciones y deberes", pero su residencia podía ser cancelada por la autoridad migratoria dentro de los dos primeros años cuando el extranjero no cumpliese con las disposiciones fijadas para promover el poblamiento ${ }^{207}$ del país (en el marco de la "política de fomento de la inmigración") o en el caso de que se ausentara del territorio nacional por un período mayor a dos años, a excepción de que lo hiciere de manera autorizada por el Ministerio del Interior, ejerciere una "función pública argentina" o tuviera que realizar "actividades, estudios o investigaciones que puedan resultar de beneficio posterior, o interés para la República". En el caso que la residencia fuera cancelada, tenía que "abandonar el territorio nacional en el plazo que fije la autoridad de migración". Los residentes temporarios o transitorios, por su parte, estaban autorizados a permanecer en el territorio nacional mientras durara el plazo otorgado, teniendo que abandonarlo al finalizar, pero su residencia podía ser cancelada en el caso de que se "desnaturalizaren los motivos que se

206 La ley menciona autoridades competentes, instituciones hospitalarias o asistenciales, organismos administrativos, centralizados o descentralizados, así como los autárquicos, empresas y sociedades del Estado y funcionarios públicos en general, escribanos, autoridades de la Inspección General de Justicia y de los Registros Públicos de Comercio, de la Propiedad Inmueble, de la Propiedad del Automotor y de la Comisión Nacional de Valores.

207 En los artículos 6 y 7 (inc. h), más específicamente, se habla de "programa de asentamiento de inmigrantes" y "programas para el encausamiento y orientación de inmigrantes" respectivamente. 
tuvieron en cuenta para otorgarla". Asimismo, la ley determinaba que a los extranjeros que no cumplieran o violaran sus disposiciones y las reglamentarias se les cancelaría su residencia temporaria, transitoria o precaria, se los obligaría a abandonar el territorio nacional en un plazo determinado o directamente se lo expulsaría. Si el ingreso o la permanencia fuera declarada como ilegal ${ }^{208}$, la ley habilitaba a la autoridad migratoria a "conminarlo a hacer abandono del país o disponer su expulsión del territorio de la República [...] con destino a su país de origen, nacionalidad, procedencia, o a otro que lo admitiera" como también expulsarlos "inmediatamente después de su entrada, ante la sola constatación del hecho", previa detención por parte de la Policía Migratoria Auxiliar.

También podía ser expulsado aquél extranjero, "cualquiera sea su situación de residencia”, que resultara "condenado por juez o tribunal argentino, por delito doloso a pena privativa de libertad mayor de cinco años" o "realizare en el país o en el exterior actividades que afecten la paz social, la seguridad nacional o el orden público de la República, quedando inhabilitado para reingresar "sin expresa autorización del Ministerio del Interior". La medida de expulsión podía ser absuelta en los casos que "se tuviere hijos o padres argentinos, o cónyuge argentino siempre que su matrimonio fuere anterior al delito por el cual resulte condenado" o que el extranjero "tuviere una residencia inmediata anterior en el país superior a los diez años". La expulsión podía conllevar también la prohibición de reingreso al país, el cual "sólo podrá producirse cuando sea expresamente autorizado". La sanción prevista para el caso de que se transgrediera esta disposición contemplaba una pena con prisión, cuya duración se extendía en el caso que el reingreso "se produjere por lugar no habilitado o eludiendo el contralor migratorio". Además, se establecía que "(l)a pena llevará como accesoria la expulsión del país".

Agotada la dictadura militar, fue también la ley Videla la que rigió durante los sucesivos gobiernos democráticos. En el año 1987, bajo el gobierno de Raúl Alfonsín, se la reglamentó, derogando el establecido en 1965.209 Las disposiciones relacionadas con la admisión y permanencia, las expulsiones y el reingreso, y el control de la ilegalidad no diferían sustancialmente de lo establecido en la legislación anterior. Entre las pocas modificaciones existentes, el reglamento especificaba quiénes serían los extranjeros

208 Retomando lo establecido en las normas migratorias de la década de los sesenta, la ley Videla define como "legal” el ingreso o la permanencia de aquellos extranjeros que cumplan con los requisitos fijados para la admisión y, habiendo sido admitidos, ingresen al país por "lugar habilitado al efecto sometiéndose a contralor migratorio" y no permanezcan más allá del plazo concedido (artículo 33). Por el contrario, “ilegal” será aquél ingreso o permanencia que se efectúe en contraposición a lo establecido para la admisión “legal” (artículo 34). 
deseables, limitando la concesión de la residencia en el país a extranjeros que representaran una mano de obra calificada, contaran con un capital que les permitiera desarrollar actividades económicas generalmente valoradas por los gobiernos para sus planes de desarrollo o revistieran un particular interés para el Estado argentino, entre los cuales -como ya lo advirtiera Pacecca (2000)- no estaban contemplados los trabajadores de países limítrofes. ${ }^{210}$

\section{Migración y Estado en la Argentina de los noventa: crónica de una amenaza anunciada}

En los años noventa, la particular relevancia que adquirió la visibilidad de los inmigrantes de países limítrofes, como han sugerido diversos autores, no se relaciona ni única ni principalmente con los cambios poblacionales 211 ligados al crecimiento o a la composición de los flujos migratorios y la distribución espacial, sino más bien con las transformaciones materiales y simbólicas que tuvieron lugar en el plano económico, político y cultural. Para Sabarots, los cambios ocurridos durante estos años en la percepción en algunos sectores sociales sobre la inmigración de países limítrofes se deben fundamentalmente a "los modos de procesar ideológicamente, en las luchas entre sectores hegemónicos y subalternos, las tensiones sociales producto de la aplicación de los modelos neoliberales vigentes" (Sabarots, 2002:103). Grimson, por su parte, sin desestimar el alcance que han tenido los cambios sociodemográficos -el aumento de la proporción de inmigrantes

210 Según lo dispuesto en el decreto, a partir de la puesta en vigencia del reglamento la DNM sólo iba a poder conceder la residencia en el país a los extranjeros que se encontraran comprendidos entre los siguientes grupos: a) Profesionales, o técnicos o personal especializado requeridos por empresas o personas establecidas en el país; b) Empresarios, hombres de negocios, artistas, deportistas (...); c) Científicos, profesores, escritores o en general personas de especial relevancia en el orden cultural, social, político, etc.; d) migrantes con capital propio suficiente para el desarrollo de su actividad comercial, industrial, comercial, agropecuaria, minera o pesquera, circunstancia que se deberá acreditar debidamente a juicio de la autoridad de aplicación; e) Religiosos pertenecientes a cultos oficialmente reconocidos; f) Extranjeros que, por sus especiales condiciones o circunstancias personales, revistan un especial interés para el país; g) Padres, hijos o cónyuges de argentinos o de residentes permanentes o temporarios o de las personas mencionadas en los incisos precedentes.

211 Desde los primeros registros censales hasta los últimos, la inmigración limítrofe nunca superó el 3\% del total de población. Si se adopta, como propone Giusti, una perspectiva apoyada en el hogar como unidad de análisis, esto es, hogares con integrantes de países limítrofes, la cifra se duplicaría. Siguiendo este procedimiento, se estima que en el año 2001 casi el 6\% de los hogares de Argentina contaban con algún integrante nacido en un país limítrofe y prácticamente el 7\% de la población establecida en la Argentina residía en hogares con al menos un "inmigrante limítrofe" (Giusti, 2005). 
limítrofes sobre la población total de extranjeros, su desplazamiento desde zonas fronterizas hacia los centros urbanos, especialmente Buenos Aires ${ }^{212}$ (ciudad y provincia), y su distribución por nacionalidad- en el proceso de visibilización de la inmigración de países vecinos, se concentra en las profundas transformaciones socioculturales que experimentó la Argentina en este período para explicarlo. Según su argumento, en la década de los noventa se evidencia el surgimiento de un cambio en el régimen de visibilidad de la etnicidad en Argentina: se pasa de una situación de invisibilización a una de hipervisibilización de las diferencias, lo cual implicaría un desplazamiento de las identificaciones de clase por las étnicas (Grimson, 2003; 2006). En este sentido, sugiere que "los inmigrantes de países limítrofes tuvieron un lugar específico en los imaginarios sociales de la década de 1990 y que ese lugar fue modificado al producirse cambios profundos acerca de cómo la Argentina se imagina a sí misma” (Grimson, 2006:92).

En este proceso de visibilización de la llamada inmigración limítrofe del cual participaron distintos actores sociales y políticos, el Estado argentino -en su articulación con los medios de comunicación de alcance nacional 213 - jugó un papel trascendental, (re)instalando la figura del inmigrante como problema social. La presencia de inmigrantes de países limítrofes, en particular a través de su representación como ilegal, sirvió de pretexto para explicar las distintas situaciones sociales por las que atravesaba el país durante los años noventa y justificar una serie de medidas económicas enmarcadas en las políticas de ajuste estructural del programa neoliberal que se pretendía consolidar. Fue principalmente desde determinados organismos y agentes del Estado nacional (como el Ministerio del Interior) que se asociaron los problemas sociales y económicos a la inmigración, encontrando en los inmigrantes limítrofes los responsables de aquellos

212 En este sentido, es importante tener en cuenta que es precisamente la ciudad de Buenos Aires una de los zonas urbanas donde mayor visibilidad adquirió la inmigración de países vecinos y donde "se definen las políticas nacionales, se genera el discurso oficial de alcance nacional y se plasman y difunden la mayor parte de las visiones e interpretaciones de los procesos sociales y políticos que ocurren en el país" (Oteiza, 2004:101).

213 Con marcado arraigo en el imaginario social de la década de los noventa, también los medios de comunicación jugaron un papel decisivo en la construcción de una imagen negativa y estereotipada de estos inmigrantes, mediante estrategias discursivas de criminalización, racialización y etnización, entre otras, que privilegiaron noticias relacionadas con la ilegalidad, la delincuencia o la competencia con los "locales” por los puestos de trabajo. Una muestra elocuente de la estrecha relación entre Estado y medios de comunicación es, indirectamente, la proliferación de estudios sobre el discurso gubernamental a través de la prensa. En los últimos quince años, la presencia del inmigrante en los medios de comunicación, especialmente en la prensa escrita, ha sido objeto de múltiples estudios en Argentina, dando cuenta de las estrategias discursivas que fueron desarrolladas en relación con la cuestión migratoria, principalmente de origen limítrofe, asumiendo un rol central en la construcción de la imagen del inmigrante en la sociedad. Véanse Oteiza y Aruj (1997), Orlog y Vives (1999), Courtis y Santillán (1999), Casaravilla (1999), Halpern (2005), Grimson (2006) y Castiglione y Cura (2007), entre otros. 
efectos provenientes de las reformas económicas implementadas en la Argentina bajo el neoliberalismo. Durante esta década, mientras las causas estructurales de los problemas económicos y sociales fueron desestimadas en gran parte del debate público (hasta hacerse finalmente evidentes), los inmigrantes de países vecinos -especialmente bolivianos, paraguayos y peruanos- fueron interpelados básicamente como un problema social, configurado en términos de amenaza: en sus declaraciones, (re)producidas por distintos medios de comunicación, altos funcionarios públicos adjudicaron a los inmigrantes provenientes de países limítrofes aquellos hechos sociales que se materializaron a lo largo de la década como los máximos exponentes de la desigualdad social, exacerbada por las medidas implementadas por el menemismo: la proliferación de enfermedades como el cólera, el aumento del desempleo y los bajos salarios, la ocupación de viviendas, la delincuencia y la inseguridad. ${ }^{214}$

En otras palabras, los inmigrantes de países colindantes reunían aquella exterioridad, como característica inherente a la inmigración, que permitía depositar en ellos las dificultades que atravesaban los sectores sociales más perjudicados por los efectos del programa neoliberal. Esta exterioridad, fuente de ilegitimidad, fue reforzada mediante su adjudicación a un universo social más amplio crecientemente criminalizado, cuya ilegitimidad no puede ser puesta en duda porque menoscaba las bases sociales de una sociedad organizada jurídicamente: los ilegales. Así, el Estado y sus agentes intervinieron en la construcción de un inmigrante peligroso encarnado en el inmigrante ilegal, en contraposición a la imagen del inmigrante como buen trabajador que contribuye a la economía nacional. Es decir, el paroxismo estatal que llevó a construir la inmigración limítrofe como una amenaza social o como una causa de los problemas sociales del país estuvo centrada en la categoría más abarcativa de "ilegal", la cual condensaba diversas nacionalidades representadas como inferiores en la jerarquía de las naciones y relacionaba a los inmigrantes con las clases peligrosas. Si bien es posible identificar momentos álgidos en los cuales este paroxismo estatal tuvo su mayor despliegue,215 amplificado fundamentalmente por los medios de comunicación, la década de los noventa como totalidad supuso una embestida contra la inmigración que se conformó

\footnotetext{
214 Véanse Oteiza y Aruj, 1997; Grimson, 1999; Casaravilla, 1999.

215 Por ejemplo, Caggiano (2005) identifica tres momentos durante la década de los noventa en los cuales "los 'inmigrantes limítrofes' fueron visibilizados como responsables o culpables de los problemas”, intensificándose en cada uno de ellos los actos y manifestaciones discriminatorios: el primero en 1992, con la crisis del sistema de salud y de potabilización del agua y la detección de casos de cólera; el segundo en 1994, con el crecimiento de la desocupación; el tercero en 1999, con las "explosiones" delictivas en Buenos Aires y los discursos sobre la “inseguridad urbana” (Caggiano, 2005:17).
} 
paulatinamente y se consolidó a partir de mediados de la década ${ }^{216}$, configurando una política de la exclusión ${ }^{217}$ que, bajo el neoliberalismo, alcanzó amplios sectores sociales, proceso que habilitó categorías como los nuevos pobres.

Los ataques de los cuales fueron objeto los inmigrantes limítrofes de parte del Estado estuvieron dirigidos o apuntaron la mayoría de las veces, como decíamos, a su condición (imaginaria) de ilegales. De hecho, los inmigrantes de países limítrofes, caracterizados -en tanto amenaza- como portadores o propagadores de enfermedades, invasores del territorio nacional, usurpadores de trabajo y viviendas, competidores desleales en el mercado laboral, delincuentes peligrosos, abusadores (o beneficiarios no legítimos) de los servicios públicos encontraron su justificación para ser perseguidos por ser considerados ilegales. La década de los noventa vuelve a mostrar que es bajo esta condición que son excluidos de la nación: para los inmigrantes de países vecinos la imposibilidad de formar parte de la nación vendría dada por la ilegalidad que se les atribuye. A la vez, de esta ilegalidad, que asociada a la inmigración habilita a construir la inmigración como una presencia ilegítima, pretende servirse el Estado para legitimar su propio accionar frente a la inmigración.

A comienzos de los noventa, el primer brote epidémico de cólera del siglo veinte resurgía en Sudamérica. Identificado primeramente en Perú, se extendió rápidamente entre los países de Ecuador, Colombia, Brasil, Bolivia, Chile y Venezuela. ${ }^{218}$ En la Argentina, después de casi cien años sin que se notificara algún caso, reapareció en el mes de febrero de

\footnotetext{
216 Según Mármora, la Ley Videla "tuvo su reflejo más nítido en la conjunción de la mayor política restrictiva aplicada desde la recuperación de la democracia” durante la segunda presidencia de Carlos Menem (Mármora, 2004:61).

217 En trabajos anteriores he utilizado la noción de "retórica de la exclusión" para caracterizar las representaciones y prácticas que se desarrollaron durante la década de los noventa frente a la inmigración. Dada la falta de materialidad que se le suele atribuir o relacionar con la idea de "retórica" y las confusiones a las cuales se suele prestar, he preferido denominarla como "política de la exclusión".

218 Según los datos de la Organización Panamericana de la Salud (OPS), obtenidos a partir de las estadísticas oficiales de los ministerios de salud de los respectivos gobiernos nacionales, los países donde mayor cantidad de casos de cólera se registraron en el año 1991 fueron Perú (322.564), Ecuador (46.284), Colombia (16.800) y Brasil (2.103). En el resto de los países mencionados, la cantidad de casos no era demasiado alta: Bolivia (206), Chile (41) y Venezuela (13). Datos extraídos de http://www.paho.org/Spanish/AD/DPC/CD/cholera-1990-2006.pdf.
} 
$1992^{219}$, registrado en dos provincias del norte argentino, Jujuy y Salta, que limitan con Bolivia, hasta extinguirse en el año $1999 .{ }^{220}$ Los funcionarios del gobierno nacional no tardaron en culpar a los inmigrantes bolivianos: este episodio inaugura la serie de problemas sociales que serían atribuidos a la presencia inmigrante, a través de los cuales se viabilizó la construcción del inmigrante como amenaza durante la década de los noventa. ${ }^{221}$

En este contexto se produjo, en palabras de Benencia y Karasik, una externalización de la causalidad social de la enfermedad a través de la culpabilización de las poblaciones afectadas (Benencia y Karasik, 1995). Se adjudicó el cólera a los inmigrantes bolivianos, en tanto enfermos y portadores de la enfermedad, atribuyendo las causas a sus costumbres en

219 Esta fecha es arbitraria, ya que en realidad se trata del momento en que el cólera tomó estado público a través de los medios de comunicación. La información oficial correspondiente a los casos de cólera en la Argentina para el año 1991 no existe. Según los cuadros estadísticos que ofrece la OPS, esta falta de información se evidencia bajo el rótulo "casos no reportados".

220 Durante el período que duró la epidemia de cólera, el registro de los casos anuales se desarrolló de la siguiente manera, según los datos de la OPS: 553 en 1992; 2.080 en 1993; 889 en 1994; 188 en 1995; 474 en 1996; 637 en 1997; 12 en 1998; y 1 en 1999 y en el 2000. Datos extraídos de http://www.paho.org/Spanish/AD/DPC/CD/cholera1990-2006.pdf.

221 En esta ocasión, me limito a la relación entre la aparición del cólera y la inmigración proveniente de Bolivia. De todas maneras, no se puede desconocer que el contexto en el cual apareció el cólera y el escenario que se construyó en torno a esta enfermedad trasciende dicha relación, abriendo un debate público con múltiples implicaciones. Petracci, Quevedo y Vacchieri (1998) afirman que durante el período 1991-1993 la aparición del cólera produjo un escenario complejo: 1) movilizó a los gobiernos provinciales para lograr recursos del gobierno central (y replanteó el tema de la coparticipación federal); 2) puso en marcha la necesidad de construir obras públicas de agua potable y cloacas y demostró que aquellos gobiernos no vigilaban las condiciones sanitarias de la población; 3) dejó al descubierto que los productores rurales de tabaco de Jujuy y Salta no cumplían con la ley en cuanto a las condiciones mínimas de salud, vivienda y trabajo del personal contratado e influyó, de alguna manera, en la cotización del deprimido precio del tabaco que dichos productores venden a los lobbies, movilizando a los sindicatos de trabajadores rurales y a las ligas y federaciones agrarias; 4) demostró la carencia de hospitales y salas de asistencia en las zonas rurales; 5) puso en marcha varios entredichos internacionales: por las condiciones sanitarias de la frontera argentino-boliviana que hizo aparecer a la enfermedad, ante la opinión pública, como proveniente de Bolivia o por el problema que se suscitó con los Estados Unidos por la comida contaminada del catering de una compañía aérea que, además, acababa de ser privatizada; 6) provocó un debate público acerca de la posibilidad de aparición del cólera en la Capital Federal si es que se daban más casos en el conurbano bonaerense; 7) exhibió la pobreza en el Gran Buenos Aires; 8) causó problemas de comercio exterior para determinar qué alimentos se exportaban y cuáles se importaban; 9) puso en duda la calidad y seguridad del filtrado de agua potable; 10) provocó cambios de Ministros de Salud en los gobiernos provinciales y, fundamentalmente, 11) evidenció un conflicto entre actores políticos y sociales: el tema de la "pobreza" de la mano de las declaraciones de la Iglesia; la respuesta del presidente Menem: "no es un problema de pobreza sino de higiene" (Clarín, 6/2/93) y la pugna (minimización/maximización) por las cifras de casos entre el gobierno y los medios. 
lugar de reconocerlas en sus precarias condiciones laborales y sanitarias (Benencia y Karasik, 1995; Sala, 2002). También se responsabilizó a los propietarios agrícolas de las viviendas e infraestructura sanitaria deficiente provista a sus trabajadores residentes (Sala, 2002). Según Caggiano (2009), en esta circunstancia, los inmigrantes bolivianos se constituyeron, por un lado, en el chivo expiatorio de la crisis estructural que atravesaba el sistema sanitario por las políticas neoliberales llevadas adelante en materia de salud y, por el otro, sirvieron de sustento para la producción de "la figura de un extranjero contagioso, portador de eventuales males que podrían infiltrarse en el cuerpo nacional" (Caggiano, 2009). Al mismo tiempo, al culpabilizar a los propios enfermos por su enfermedad -como a los pobres por su pobreza- los procesos de desigualdad social son relegados al plano individual (por tanto, según esta visión, superables mediante esfuerzo y voluntad personales), ocultando su carácter estructural y colectivo, y se diluye la responsabilidad social que el Estado neoliberal de los noventa (tanto en la órbita nacional como provincial) pretende asumir sólo parcialmente.

La epidemia de cólera, al ser considerada en términos de importación de enfermedades (Abel y Caggiano, 2006), llevó a que el Estado nacional desplegara a través de la Gendarmería Nacional ${ }^{222}$ una serie de medidas dirigidas a controlar las vías de entrada y

222 La Gendarmería Nacional fue creada el 28 de julio del año 1938 durante la presidencia de Roberto M. Ortiz por la ley № 12.367 que establecía como mandato "contribuir decididamente a mantener la identidad nacional en áreas limítrofes, a preservar el territorio nacional y la intangibilidad del límite internacional”. De acuerdo a la Ley Orgánica № 19.349 de 1971, la Gendarmería Nacional es definida como "una fuerza de seguridad militarizada, dependiente del Comando en Jefe del Ejército, estructurada para cumplir las misiones que precisa esta ley, en la Zona de Seguridad de Fronteras y demás lugares que se determinen al efecto" (artículo 1). Entre sus funciones se enumeran: a) Policía de seguridad y judicial en el fuero federal; b) Policía auxiliar aduanera, de migraciones y sanitaria, donde haya autoridad establecida por las respectivas administraciones y dentro de las horas habilitadas por ellas; c) Policía de prevención y represión del contrabando, migraciones clandestinas e infracciones sanitarias en los lugares no comprendidos en el inciso anterior, como así también en éstos, fuera del horario habilitado por las respectivas administraciones; d) Ejercer por delegación, mediante acuerdo, funciones inherentes a los organismos aduaneros, de migración y sanitarios en los lugares que en cada caso se establezca; e) Policía de prevención y represión de infracciones que le determinen leyes y decretos especiales; f) Policía en materia forestal de conformidad con lo que determinen leyes, reglamentaciones y convenios pertinentes; g) Policía de prevención y de represión de infracciones a normas especiales que determine el Comando Militar establecido, cuando se la afecte a la vigilancia de fronteras, protección de objetivos y otras actividades afines con sus capacidades; h) Policía de seguridad de la navegación en los lagos, ríos y demás cursos de agua, cuando dicha función sea delegada por el Comando en Jefe de la Armada al Comandante en Jefe del Ejército. El ejercicio de esa delegación no incluirá lo relativo a habilitación de personal y material; i) Intervenir para reprimir la alteración del orden público, o cuando éste se vea subvertido, o cuya magnitud sobrepase las posibilidades de control de las fuerzas policiales, o cuando adquiera las características de guerrilla, en cualesquiera de sus formas. Esta función será ejercida por disposición del Poder Ejecutivo Nacional; j) Toda otra función que se le asigne conforme a su misión y capacidades. 
de circulación y a perseguir a los inmigrantes ilegales, reforzando la vigilancia de la frontera argentino-boliviana y creando "fronteras internas" que evitaran la circulación de personas hacia las provincias (Benencia y Karasik, 1995). El cólera, como parte de las enfermedades importadas, sería una enfermedad surgida y traída desde fuera del territorio nacional o provincial por inmigrantes, en tanto trabajadores golondrinas o indocumentados, provenientes de Bolivia. Transcurrido este episodio, la figura de la importación de enfermedades mantuvo una marcada adhesión entre los prestadores de salud y la sociedad en general con importantes consecuencias en la atención médica y en la promulgación de leyes y programas de gobierno (Abel y Caggiano, 2006). Asimismo, Sala (2002) sostiene que la mayoría de las acciones del programa para la prevención y control del cólera, el programa ARBOL II, contemplaron la problemática de la salud en la región fronteriza bajo la idea del peligro extranjero, desatendiendo tanto en sus explicaciones como sus estrategias aquellos aspectos ligados a las condiciones de vida y a la falta de acceso geográfico, económico y cultural a los servicios de salud de los inmigrantes. En suma, esta negación de la dimensión social, económica y política del proceso de saludenfermedad permite que las condiciones que producen la enfermedad se borren, o al menos, se disimulen (Benencia y Karasik, 1995; Benencia, 2004).

Durante los años que duró la epidemia del cólera en la Argentina también se instaló en el debate público y en los ámbitos de gobierno otro de los argumentos políticos del llamado discurso antiinmigración: los inmigrantes como usurpadores (es decir, beneficiarios no legítimos) de los servicios públicos, en este caso de la salud, y como costo económico adicional para el Estado (nacional y provincial), negando una serie de derechos a los inmigrantes por su condición jurídica de extranjeros o su condición social de ilegales. En su análisis referido al sistema público de salud y la atención médica de inmigrantes en la provincia de Jujuy, Sala (2002) señala que en el contexto de ajuste neoliberal de los años noventa, frente a la creciente demanda recibida en los establecimientos públicos debido a la crisis presupuestaria de las obras sociales y del sistema de previsión social y a la pérdida de cobertura de muchos afiliados y sus familias a raíz de la desocupación o precarización de sus condiciones laborales, el principio de universalidad y gratuidad de la atención médica fue cuestionado, en particular cuando los beneficiarios no podían acreditar la condición de ciudadanos plenos por ser extranjeros, en algunos casos indocumentados, negándoles su derecho a recibir atención sanitaria gratuita y atribuyéndoles la responsabilidad en el aumento del gasto en salud. ${ }^{223}$

223 En un estudio más reciente, cuyo trabajo de campo fue desarrollado en Buenos Aires, Jelin, Grimson y Zamberlin (2006) muestran que los profesionales y administrativos del sistema de salud pública se basan en el "estatus 
Una muestra elocuente de esta visión es la ley provincial $\mathrm{N}^{\circ} 5.043$, sancionada por la legislatura de Jujuy en 1998, que disponía la realización de un "censo migratorio" en las distintas áreas dependientes del Estado provincial que ofrezcan servicios públicos, cuyo objeto declarado era "conocer a situación legal, laboral, habitacional, educacional y de salubridad de los inmigrantes que ingresen al territorio de la Provincia de Jujuy". En realidad, la finalidad última de este relevamiento no estaba orientada a conocer dicho escenario, sino a "evaluar el impacto económico que le representa al Estado provincial la prestación a los inmigrantes que ingresan al territorio de la Provincia" de los servicios de salud, educación, asistencia social, vivienda, justicia y demás servicios públicos básicos, utilizando los resultados para "solicitar al Poder Ejecutivo Nacional un resarcimiento económico que compense las erogaciones que le ocasionan al presupuesto provincial” el uso de los servicios públicos a los inmigrantes.

Durante ese mismo año, en el contexto de la estrategia de apertura y liberalización de la economía, el gobierno nacional se manifestó predispuesto -ante el Parlamento Europeo- a atraer 300.000 ciudadanos de Europa Central y Oriental mediante un programa que aspiraba a conseguir financiamiento para facilitar a los inmigrantes cursos de idioma, alojamiento temporario y créditos para vivienda. En este contexto, algunos funcionarios públicos de alto rango como el presidente Menem y el canciller DiTella se mostraban proclives a solucionar los problemas que generaría en Europa el desplazamiento de personas resultante de las transformaciones sociales, económicas y políticas de los países europeos del Este (Albarracín, 2005).224 Más adelante, mediante dos resoluciones del

migratorio" y el tipo de prestación requerida para diferenciar las personas que serían usuarios legítimos de los servicios públicos. A partir de dichos criterios se dificultaría o facilitaría el uso de determinadas prestaciones. Señalan que en el caso de las emergencias médicas o partos el acceso de los inmigrantes es irrestricto generalmente, mientras que el acceso a intervenciones programadas, tratamientos de enfermedades crónicas, entrega de medicamentos o admisión a programas del Ministerio de Salud de la Nación es obstaculizado. Uno de los mecanismos instituidos para ello es la solicitud del documento nacional de identidad, sin constituir un requisito formal, por parte del personal administrativo. Detrás de esta práctica, como también de otras, se trasluce la idea de que los extranjeros son usurpadores de las recursos públicos de carácter gratuito que ofrece el Estado argentino, que al ser escasos imposibilitarían o desplazarían de su acceso a un ciudadano argentino o, llevado más allá, a un inmigrante "legal". Estos autores señalan que si bien la distinción entre nacionalidad y residencia queda en muchos casos desdibujada, no deja de erigir la legalidad de la residencia como criterio de diferenciación.

224 La prensa, por su parte, destaca los beneficios asociados con la inmigración de europeos centrales y orientales promovida por el Estado argentino y la relaciona con las posibilidades de crecimiento económico. Los beneficios atribuidos a la inmigración limítrofe, en cambio, son mucho más modestos y son desvinculados del crecimiento económico. En general, la prensa se limita a reconocer que los limítrofes trabajan e, indirectamente, producen un aporte al país (Albarracín, 2005). 
Ministerio del Interior 225 , se formalizó el "tratamiento especial migratorio" que les otorgaba a los inmigrantes procedentes de Europa Central y Oriental una serie de "facilidades administrativas, de carácter excepcional". ${ }^{226}$ Aunque la llegada de extranjeros de países europeos del Este era vista con buenos ojos, antes que se concretara ya se advertía que esta inmigración podía entrañar una serie de dificultades para la sociedad receptora. De todas maneras, dado el interés estatal en atraer a europeos del Este, la medida promotora llegó a ser invocada como un "test a la tolerancia de los argentinos".227

En el año 1993 comenzaron a visualizarse las primeras consecuencias sociales de la implementación de las medidas neoliberales en el campo económico, al comprobarse un aumento del desempleo que alcanzó tasas históricas superiores al 17\% en los años 1995 y 1996. En este contexto, las dificultades económicas que empezaban a emerger en el país eran atribuidas, en parte, a la inmigración limítrofe. Los inmigrantes de países limítrofes, pero especialmente los ilegales, fueron acusados de aumentar el desempleo, constituir una "competencia desleal" para la mano de obra nativa, provocar una baja salarial y quitar

225 Resoluciones del Ministerio del Interior № 4.632/94 y № 1.931/95.

226 Un estudio de CAREF y IOM, llevado a cabo entre los años 1999 y 2002, señala que según datos de la Dirección Nacional de Migraciones, desde 1994 hasta junio del 2001 ingresaron a la Argentina 12.596 ciudadanos de Europa del Este. Del total el 71,8\% era de nacionalidad ucraniana, el $21,75 \%$ de nacionalidad rusa y el resto estaba compuesto por búlgaros, rumanos, armenios y de otras nacionalidades del Este Europeo. El informe precisa que estos datos corresponden a aquellos extranjeros ingresados al país a través de los decretos de Tratamiento Especial y no incluyen a quienes habiendo ingresado como turistas, permanecieron en el país sin poder luego regularizar su situación migratoria.

227 En un seminario realizado en Buenos Aires en el mes de marzo de 1992, el canciller Di Tella, después de diferenciar la corriente migratoria de Europa del Este -denominada por el funcionario como "la tercera ola"- de la inmigración de ultramar y de la limítrofe en términos cuantitativos y al mismo tiempo destacar su importancia desde "el punto de vista cualitativo", expresaba: "Nosotros, como ustedes saben, hemos abierto el camino de una política de inmigración de los países del Este de Europa. No creemos que esto tenga la importancia que tuvo ni la primera migración de principios de siglo, ni la segunda migración de los países vecinos, sino que esta tercera ola va a ser mucho más pequeña, pero desde el punto de vista cualitativo nos parece muy importante, y además es un test a la tolerancia de los argentinos. Por el momento, nadie ha protestado demasiado, pero cuando lleguen a aparecer personas de culturas distintas, que hablan el idioma con dificultad y que van a tener los problemas que tienen los nuevos inmigrantes, vamos a ver si todo lo que decimos nosotros que la Argentina es un país tolerante, lo es de verdad. A mí me parece que esta actitud no racista, abierta, ha sido interpretada como lo que es, como un acto que un país maduro puede hacer en un momento en que países que creíamos eran muy maduros en muchos temas con respecto al tema inmigratorio se han vuelto ciegos de una manera realmente impresionante." (Palabras de cierre del canciller Guido Di Tella, Buenos Aires, 1992). Extraído de http://www.argentina-rree.com/15/15-090.htm. Discurso publicado originalmente en Roberto Russell (ed.), La política exterior argentina en el nuevo orden mundial, Buenos Aires, FLACSO/GEL, 1992. 
puestos laborales a los "trabajadores argentinos". ${ }^{228}$ Esta imputación a los inmigrantes de países limítrofes, en tanto ilegales, fue enunciada en diversas ocasiones a lo largo de toda la década.

Albarracín (2005) sostiene que durante estos años, a partir de la interacción entre funcionarios de gobierno, periodistas y dirigentes sindicales, se construyó una crisis inmigratoria. El primer evento que habría disparado esta crisis fue la contratación de 350 trabajadores brasileros para una planta hidroeléctrica de Buenos Aires en julio de 1993. Durante los meses siguientes, representantes del gobierno nacional y de una organización del sindicalismo ortodoxo se expresaron en contra de los trabajadores inmigrantes. A los pocos días de la contratación, el secretario general de la Unión Obrera de la Construcción de la República Argentina (UOCRA), Gerardo Martínez, salió a pedir al gobierno el establecimiento de cuotas de inmigración. Al otro día, el Ministro del Interior, Gustavo Beliz, acusaba a los inmigrantes de tener más derechos que los trabajadores nativos. En el mes de agosto, la UOCRA también se manifestó a través de volantes y afiches en contra de los trabajadores inmigrantes, contraponiendo "mano de obra clandestina" y "trabajadores argentinos". Junto a ello, el secretario general de la UOCRA hacía declaraciones que responsabilizaban a los propios trabajadores por la precarización laboral. En las declaraciones que hizo a la prensa durante el mes de noviembre asociaba la inmigración con el aumento de la desocupación, advirtiendo sobre el peligro que conllevaba, asimilado a una catástrofe (en tanto se trata de un riesgo que amerita estar en "estado de alerta roja"), para los "trabajadores argentinos". ${ }^{229} \mathrm{Al}$ año siguiente, en mayo de 1994, la Confederación General del Trabajo (CGT) expresaba su posición en la prensa, acusando indirectamente a los inmigrantes de constituir una "competencia desleal", una amenaza que justificaba la necesidad de brindarle protección al "trabajador argentino".

Hacia finales del año 1993, entre las voces del gobierno nacional que se pronunciaron en materia de migraciones estuvo la del Ministro del Interior, Carlos Ruckauf (1993-1995). En sus declaraciones advertía sobre las "migraciones ilegales", identificadas como un

228 Algunos estudios publicados durante la década de los noventa (Maguid, 1995; Benencia y Gazzotti, 1995) mostraron que la participación de trabajadores inmigrantes provenientes de países limítrofes en el nivel de desocupación registrado en el Área Metropolitana de Buenos Aires era insignificante, desmintiendo las declaraciones públicas de los funcionarios acerca de la estrecha relación que establecían entre inmigración limítrofe y desocupación.

229 En aquella oportunidad sostuvo que los trabajadores brasileños contratados en aquella oportunidad eran parte de "un plan que proyecta traer a la Argentina 500.000 obreros desde el Brasil. Esto aumentaría la desocupación local en un $4 \%$. Si se tiene en cuenta que ya llegó al 10\%, lo menos que podemos decir es que los trabajadores argentinos estamos en estado de alerta roja" (citado en Clarín, 5/11/93). 
"tema de alta política", y las consecuencias que traerían aparejadas: la inmigración como problema para la salud pública y la seguridad y como competencia desleal para la mano de obra nacional. ${ }^{230}$ Asumía la ilegalidad como un problema necesario de solución para la sociedad receptora antes que para los inmigrantes. Los trabajadores ilegales como sinónimo de trabajadores inmigrantes eran quienes amenazan las fuentes de trabajo de los ciudadanos argentinos y es en su defensa (o a su favor) que el gobierno se declaraba. En diversas oportunidades, como indica Albarracín (2005), el Ministro del Interior se expresó a favor del incremento de los controles migratorios para evitar que los "turistas se conviertan en trabajadores ilegales" o se mezclen en actos criminales. En otras circunstancias también hizo declaraciones sobre la necesidad de adoptar medidas tendientes a regular el ingreso de trabajadores inmigrantes que prioricen la ocupación laboral de los ciudadanos argentinos y de terminar con "el problema de los trabajadores ilegales".

Asimismo, en 1993, junto a la enorme repercusión pública que empezaba a adquirir la ocupación de predios, edificios y viviendas, representada en la figura de las casas tomadas, los inmigrantes de países limítrofes fueron conceptualizados desde las instancias gubernamentales como intrusos o usurpadores, responsables del déficit habitacional de la ciudad e infractores de las leyes que protegen la propiedad privada, estableciendo sentidos y usos diferenciales de la legislación y los derechos (Montesinos y Pallma, 1999). Por entonces, el Subsecretario General de la Presidencia, Luis Prol, asumiendo la inmigración como un problema, sugería la convergencia entre usurpación, extranjeros y ocupación de casas y se pronunciaba a favor de la defensa de la seguridad, los derechos de los ciudadanos y de la propiedad privada. Según su visión, los inmigrantes de países limítrofes pondrían en riesgo el "nivel de vida" de "los argentinos". En defensa del derecho a la propiedad privada y "la seguridad y los derechos de los ciudadanos", establecía una diferencia entre un nosotros, "los ciudadanos" como sujetos de derechos (equiparados a "los argentinos") y los otros, enunciados pero sin ser nombrados como no-ciudadanos, esto es, sujetos sin el derecho legítimo a reclamar por sus derechos: los inmigrantes, los

230 En este mismo mes, el diario Ámbito Financiero publicó una nota en la cual se advertía acerca del riesgo que contenía la inmigración de países limítrofes para los trabajadores nacionales: "La sensación térmica es que hay muchos inmigrantes limítrofes que están radicados en el territorio nacional, fundamentalmente en Capital Federal y Gran Buenos Aires y que hace suponer que se han convertido en una fuerte competencia para la mano de obra [local]" (Ámbito Financiero, 28/12/93). A ello se agregaba una declaración del titular de la Subsecretaría de Población, Mario Oporto, que revela el modo en que se llevan adelante determinadas iniciativas estatales y la determinación que tiene la coyuntura social en la toma de decisiones políticas: "Es precisamente esa sensación térmica la que pesa en el momento de tomar decisiones". Extraído de http://www.paralelo35.com/revista/sociedad/universitarios/migra/inmigracion.htm 
ilegales, los inmigrantes ilegales. Además, circunstancias como éstas, en las cuales la inmigración era presentada como una amenaza al bienestar de la sociedad en general o de un sector social en particular (en este caso de un grupo específico como "los sin techo"), se volvían propicias para responsabilizar a los inmigrantes limítrofes por "los problemas sociales del país". ${ }^{231}$ También el gobernador de la provincia de Buenos Aires, Eduardo Duhalde, interpeló a los inmigrantes ilegales como los causantes de la falta de empleo. Grimson (2000) recuerda que en el mes de junio de 1995 lanzó un plan laboral, cuyos ejes eran el asfalto de las calles y la persecución de trabajadores ilegales, destinado a "los argentinos" o, en su defecto, a los "extranjeros radicados legalmente". Este plan se basaba en la inspección de lugares donde se contrataba mano de obra extranjera y en la sanción a los ilegales con el regreso a sus países de origen.

Durante este año, al igual que en 1992, el Poder Ejecutivo, a través de la Gendarmería Nacional, efectuó centenares de expulsiones de inmigrantes invocando infracciones o delitos de distinto tipo en el marco de distintos operativos de control: ingreso al territorio nacional por pasos fronterizos no habilitados, vencimiento de las visas, ocupación de tierras y viviendas, violación de leyes de orden público. Las explicaciones oficiales pretendían justificar estas acciones bajo el argumento de la efectiva "integración" de los inmigrantes. Acorde con su condición de integrado o no integrado, división absolutamente arbitraria dada la imposibilidad práctica de separar unos de otros, los inmigrantes serían pasibles de ser llamados a regularizar su situación administrativa o a abandonar el territorio nacional, decretando su expulsión. ${ }^{232}$

Bajo este contexto, como corolario, en diciembre de 1993 se dictó un decreto ${ }^{233}$ que preanunciaría la nueva política restrictiva (Oteiza y Novick, 2000), la cual se iría afianzando a partir del año siguiente, acompañada por una inocultable criminalización de

\footnotetext{
231 Así lo manifestó el mismo funcionario en otras declaraciones a la prensa: "Los problemas sociales del país, y en especial el de los sin techo, se originan en las migraciones desde los países limítrofes" (Página 12, 13/8/93, citado en Oteiza y Aruj, 1997).

232 En este contexto, el director de admisión y control de la Dirección de Población y Migraciones, Sergio Arturo Rodríguez Oneto, sostuvo en la prensa: "Si es un individuo que se ha integrado bien en la sociedad, se lo intima a regularizar la situación, si no estuviera integrado, se lo conmina a abandonar el país, se le fija un plazo y se lo acompaña al puesto de frontera para que salgan" (El Cronista Comercial, 17/8/93, citado en Novick, 1997).

233 Decreto № 2.771/93.
} 
la inmigración. ${ }^{234}$ De acuerdo a Albarracín (2005), este decreto fue la respuesta del gobierno nacional a la crisis que se había edificado en torno al tema migratorio. ${ }^{235}$ Mediante este decreto el gobierno oficializaba las acciones policíacas y represivas dirigidas a los inmigrantes de países limítrofes, llevadas adelante por el Estado mediante la intervención articulada de dependencias del Ministerio del Interior y las fuerzas de seguridad. Como si se tratara de una acción inédita, en el decreto se adelantaba que se iban a coordinar y ejecutar operativos y procedimientos de control de la situación legal de los inmigrantes en todo el ámbito del territorio nacional y que la DNM, en tanto autoridad de aplicación, dispondría de la inmediata expulsión de "los extranjeros que, habiendo ingresado ilegalmente a la República, fueren sorprendidos `in fraganti' en la comisión de delitos de acción pública" y de aquellos que no pudieren justificar "fehacientemente el título que les otorgue derecho para la posesión o tenencia de los inmuebles que ocupan". El objetivo político explicitado, según el contenido del decreto, era "encarar el grave problema provocado por las ocupaciones ilegales de viviendas y otros delitos que alteren la paz social". Esta norma establecía también que para hacer operativa la política migratoria instrumentada era imperante que el Poder Ejecutivo Nacional "adoptara las medidas necesarias para afrontar este grave problema, empleando una metodología ágil y efectiva, que permita la inmediata expulsión de los inmigrantes ilegales”.236

El discurso estatal se volvía amenazante, haciendo uso de la condición de deportabilidad o expulsabilidad del inmigrante ilegal y llevando adelante, mediante el aval de diversas normas jurídicas, acciones puntuales (no masivas) de inspección, detención y expulsión, que remiten a lo que De Genova llama el "espectáculo de la frontera", recreado en diversos espacios sociales de la vida cotidiana (De Genova, 2003). A principios del año 1994, el vicecanciller Fernando Petrella anunciaba en la prensa -otorgando una definición contundente acerca del pretendido accionar estatal en materia de migraciones- que las deportaciones respondían a lo que calificaba como "nueva política migratoria". Durante el

\footnotetext{
234 Según Albarracín (2005) en el año 1994 el discurso de la prensa denota una "creciente criminalización de los inmigrantes", haciendo un uso generalizado de los términos "ilegal' y "clandestino": el crimen pasa a ser el principal problema asociado a la inmigración. Hay una creciente conmoción en esta época por irregularidades cometidas en las tramitaciones de las residencias, muchas de ellas vinculadas con la participación de gestores. En enero de 1994, al momento del vencimiento del plazo para la radicación por la amnistía aprobada por el Decreto № 1.033/92, numerosos artículos de diario se dedicaron a describir la situación de los inmigrantes y de la Dirección Nacional de Migraciones.

235 Por entonces, el Director Nacional de Migraciones, Jorge Gurrieri, habría manifestado que el gobierno "sintió que debía hacer algo" (citado en Albarracín, 2005).

236 Decreto № 2.771/93.
} 
mismo mes, el Ministro del Interior Carlos Ruckauf advertía, utilizando el eufemismo de la repatriación, acerca de la expulsión del "extranjero ilegal" que infringiera la ley, al mismo tiempo que anunciaba un aumento de los controles en frontera y un llamado a concurso para la informatización de dichos controles (Albarracín, 2005). Luego de la deportación de treinta ciudadanos peruanos, acusados de ser "residentes ilegales", las declaraciones oficiales revelaban la intencionalidad disciplinadora que estaba detrás de estas acciones. ${ }^{237}$

Frente al creciente malestar social que, según algunos medios de comunicación, se estaba generando en torno a los inmigrantes limítrofes (Betrisey Nadali, 2005), surgieron algunas declaraciones oficiales que pretendían mitigar el discurso xenófobo que el propio Estado producía. Una vez más, el Ministro del Interior fue uno de funcionarios que salió a explicar la situación y a recomendar de qué manera se podía impedir la proliferación de la xenofobia. La fórmula era simple (por no decir, rústica): se trataba de separar a los malos inmigrantes, los "extranjeros ilegales", de los buenos, los "inmigrantes normales", autorizados a trabajar y vivir en la Argentina. Dos meses más tarde, una declaración del Ministro de Trabajo en contra de las actitudes xenófobas ratificaba la importancia que tiene el trabajo como condición de permanencia para los inmigrantes o, como diría Sayad, en tanto razón última para justificar su existencia como no-nacional: los inmigrantes de países limítrofes que el gobierno nacional estaba dispuesto a aceptar eran aquellos que trabajan en la Argentina.

Hacia mitad del año 1994, antes de la aprobación del nuevo Reglamento de Migración que impulsaba el gobierno nacional, las declaraciones de los funcionarios volvían a instalar el tema de la "inmigración ilegal", destacando la prioridad que deberían tener "nuestros obreros" a la hora de ocupar los puestos de trabajo o, a la inversa, la amenaza que podría suponer para los trabajadores locales o nativos. Junto a ello, se empezaba a anunciar la intención de enfrentar el tráfico de personas, que luego tomará forma con el nuevo reglamento. Más tarde, adelantando las sanciones que según las nuevas disposiciones tendrían aquellos empleadores que contraten "ilegales", el Ministro del Interior explicitaba cuál era la finalidad que se perseguía con las medidas de control previstas: "Esta modificación forma parte de una política tendiente a establecer un estricto control interno

237 En palabras del Ministro del Interior, el gobierno esperaba que "estos primeros casos de residentes peruanos sean aleccionadores" (La Nación, 11/1/94, citado en Albarracín, 2005). 
para desalentar la inmigración ilegal, focalizando en la inspección a los empleadores" (Clarín, 26/6/94, énfasis propio).

A fines de junio de 1994 se aprobó finalmente por decreto el nuevo reglamento de migraciones. ${ }^{238}$ Entre los considerandos se puntualizaba que las modificaciones al reglamento de 1987 eran hechas "adaptando los procedimientos migratorios a las actuales circunstancias". Esta medida respondería a una "etapa de transición" signada por la reformulación de los objetivos de la política de población y, en particular, de la migratoria en el marco del proceso de integración regional que se llevaba adelante. Asumiendo implícitamente el carácter restrictivo del reglamento, declaraba su voluntad de "retornar al carácter de país de esperanza para todos los inmigrantes del mundo acorde con la irrenunciable vocación de libertad que anima al pueblo argentino". Todo ello, se aclaraba, no suponía "desconocer la facultad que asiste al Estado Nacional de autorizar la admisión y permanencia de extranjeros en la República”.

Junto a ello, se consideraba la "ilegalidad" y los flujos migratorios regionales como asuntos a atender en la determinación de los criterios de admisión y permanencia. Bajo la noción de una "correcta política migratoria" se expresaba la disposición a "fortalecer aquellas acciones e instrumentos que tiendan a evitar la existencia de situaciones de ilegalidad" $239 \mathrm{y}$ se apelaba a la necesidad de "efectuar un estudio previo de las corrientes migratorias que inciden en nuestro país, a fin de resguardar los intereses nacionales". Se declaraba, asimismo, que era necesario que los criterios y procedimientos a fijar se adecuaran a "la diversidad de situaciones que caracterizan a los fenómenos poblacionales y migratorios", fueran compatibles con "la actual política de gobierno, los principios y derechos que consagra la Constitución Nacional y el contenido de los instrumentos internacionales ratificados por nuestro país" y se correspondieran "con la política de población que impulsa el Poder Ejecutivo Nacional", bajo la finalidad de "brindar seguridad jurídica a los extranjeros que quieran residir en la República". Entre los nuevos criterios de admisión y permanencia, el decreto establecía que la DNM le concedía residencia permanente o

\footnotetext{
238 Decreto № 1.023/94.
}

239 Ya aprobado el nuevo reglamento de migración, la noción de "expulsabilidad" se tradujo en acciones estatales concretas, aumentando de manera importante el número de potenciales y efectivas expulsiones de "extranjeros ilegales", la gran mayoría procedentes de países vecinos. Según fuentes periodísticas, en 1995, sólo entre el 1 de enero y el 17 de febrero, 1.289 personas fueron conminadas a abandonar el territorio nacional y 841 fueron expulsadas (La Nación, 18/2/95). 
temporaria a aquellos trabajadores extranjeros, bajo la figura de "trabajadores contratados", que cumplieran con el requisito de celebrar la contratación por escrito. El decreto determinaba también que, bajo la aprobación del Ministerio del Interior, la DNM quedaba facultada para disponer sobre las normas aclaratorias e interpretativas necesarias para su aplicación y que el Ministerio del Interior estaba habilitado para "modificar los lineamientos de políticas de inmigración" establecidos en el nuevo reglamento.

Mientras el carácter restrictivo de la política migratoria que llevaba adelante el gobierno nacional se reforzaba, representantes del Estado argentino pretendían mostrar en los foros internacionales los logros de su gestión en materia de migraciones internacionales bajo un envoltorio discursivo que destacaba el valor de la inmigración y el respeto que le confería el gobierno a los inmigrantes. En la Conferencia Internacional sobre la Población y el Desarrollo, celebrada en septiembre de 1994 en El Cairo, Egipto, el Ministro de Relaciones Exteriores (1991-1999), Guido Di Tella, en su intervención, define a la Argentina como un país conformado por inmigrantes, que había beneficiado primero de la inmigración originaria de Europa y luego de aquella procedente de los países limítrofes. Destacó tanto la "pluralidad étnica", la "diversidad cultural" y -como si en el país el componente religioso tuviera un rol protagónico en la conflictividad social- la "pacífica convivencia religiosa" y calificó de "generosa" la política llevada adelante en materia migratoria. Evocó también la llamada "política de puertas abiertas", coyuntura histórica que siempre es referenciada en el discurso estatal para proclamar la disposición receptora de la Argentina, pero le antepuso "el derecho de nuestro gobierno" -es decir, la soberanía estatal- a regular las migraciones internacionales según "las circunstancias de cada época". El reconocimiento institucional referido al rol de la inmigración limítrofe como contribución y, por añadidura, como contribución a la pluralidad étnica y la diversidad cultural del país, estaba lejos de ser una expresión que la descubra como inmigración deseable. ${ }^{240}$ Como parte de los logros en materia de migraciones internacionales, resaltó, en un primer momento, la cantidad de regularizaciones de "migrantes ilegales" realizadas

240 Grimson (2000), retomando las declaraciones del canciller Guido DiTella (extraídas del periódico Página 12, 11/06/95) en las cuales pronostica que "en el 2020 el 20\% de la población [en la Argentina] será boliviana o paraguaya" y afirma que "[w]e want to be near the rich and the beautiful” y "[w]e don't want to be with the horrible people", sugiere que la política de identidad condensada en estas afirmaciones revela que "la migración limítrofe tropieza y hace entrar en crisis el imaginario secular de las élites argentinas de constituir el reducto europeizado en América Latina". 
y la creación de instituciones especializadas en materia de población. ${ }^{241}$ Los nuevos criterios de admisión establecidos en el reglamento de migración de 1994 de marcado carácter restrictivo fueron presentados como parte de la "modernización" de la normativa migratoria. Al final de su intervención, el canciller DiTella depositó en la comunidad internacional en su conjunto el reconocimiento y ejercicio de derechos universalmente aceptados como los de migrar y no migrar, entre otros, colocando la cuestión migratoria en el orden de las relaciones bilaterales y la "integración de los pueblos", aduciendo la necesidad de desplazarla desde el ámbito de los "conflictos interiores" al de la cooperación internacional. ${ }^{242}$

Hacia fines de los noventa, el Ministerio de Relaciones Exteriores, Comercio Internacional y Culto, a través de su Secretaría de Asuntos Consulares y Generales, recupera el protagonismo que tuvo antaño en la toma de decisiones en materia de política migratoria cuando disputaba con la DNM la jurisdicción sobre las migraciones. Durante estos años, se implementaron otros mecanismos de regulación de la inmigración, que distaban de los modos represivos de ejercer el control migratorio, orientados a organizar los flujos de población provenientes de algunos países limítrofes identificados como prioritarios

241 En su exposición, el canciller DiTella menciona la creación de la Secretaria de Población y Relaciones con la Comunidad en la órbita del Ministerio del Interior y del Consejo Federal de Población (COFEPO). El COFEPO, creado en diciembre de 1993, fue uno de los ámbitos estatales en los cuales se trataron y discutieron principalmente cuestiones relativas a las migraciones internacionales. A tono con las preocupaciones políticas que expresaba públicamente el gobierno nacional, el control de la inmigración ilegal fue uno de los temas más recurrentes. Oteiza y Novick (2000) comentan que, según el material elaborado por el Ministerio del Interior, la primera reunión ordinaria de este organismo, realizada en Buenos Aires en marzo de 1995, en la cual el tema migratorio fue prácticamente el único y exclusivo eje de debate, tuvo como objetivo "unificar criterios sobre el control de migraciones ilegales". Así aparece incluida entre los temas del día: a) migración ilegal y control; b) migración y mano de obra; c) migración, turismo y falso turista; d) interés en la recepción de migración extranjera; e) impacto social de las migraciones; f) participación del municipio en las políticas de población; g) temas a propuesta e iniciativas de las provincias. Por otra parte, también señalan que, en términos del informe presentado en esta ocasión por la Dirección de Europa Central y Oriental del Ministerio de Relaciones Exteriores, el principio general desarrollado por el gobierno nacional era que "la migración constituye, en principio, una iniciativa privada cuyo costo debe ser asumido por el propio migrante, quien es su beneficiario inmediato". Al año siguiente, se forma el Instituto Nacional contra la Discriminación, la Xenofobia y el Racismo (INADI). Esta institución se crea en julio de 1995 como una entidad descentralizada, mediante la ley № 24.515, en el seno del Ministerio del Interior, con el objeto de "elaborar políticas nacionales y medidas concretas para combatir la discriminación, la xenofobia y el racismo". Según la interpretación de Betrisey Nadali (2005), la creación de este organismo estatal fue parte de una respuesta a la efervescencia que había cobrado el tema de la "intolerancia" social hacia los extranjeros en los medios de comunicación. En este sentido, el INADI sería un medio para controlar a la prensa, actuando el director de la institución como interlocutor oficial encargado de lidiar con los medios de comunicación y expresar el punto de vista del Estado.

242 Véase Clavijo y Santi (2009) para un análisis sobre la noción de “cooperación internacional” y la posición del Estado argentino en materia migratoria. 
debido a los niveles de ilegalidad/irregularidad migratoria e informalidad laboral que presumía el gobierno nacional. En 1998, el Estado argentino firmó convenios migratorios con Bolivia y Perú (aprobados en la Argentina en el año 1999 por las leyes N² 25.098 y 25.099), complementados a través de protocolos adicionales. ${ }^{243}$ Con estos convenios se proponía obtener la "regularización" de aquellos inmigrantes que se encontraban en una "situación migratoria irregular" para que desarrollen sus actividades económicas de modo "formal" (es decir, legal), ya sea en relación de dependencia o autónomas, buscando evitar la evasión y pérdida fiscales. ${ }^{244}$ Este objetivo quedaba inscripto en la propia noción de inmigrante empleada en el convenio. Definía como inmigrantes a "los nacionales de las Partes que deseen establecerse en el territorio de la otra para desarrollar una actividad formal en relación de dependencia o que se encuentren en el territorio de la otra para desarrollar una actividad formal en relación de dependencia o una actividad formal autónoma". También precisaba que la expresión "irregular" utilizada en el marco de la noción de "situación migratoria irregular" indicaba "la permanencia de nacionales de una Parte en el territorio de la otra, que no cumplen los requisitos vigentes en las respectivas legislaciones migratorias internas" y que el convenio no era aplicable a nacionales que tuvieran una "residencia transitoria", se encuadren en la categoría de "tránsito vecinal fronterizo", residan en el país para cursar estudios de nivel terciario o universitario o hayan sido "expulsados del territorio" de alguna de las partes. Finalmente, este mismo año se aprobó un decreto 245 modificatorio del Reglamento de Migraciones mediante el cual se exigía un contrato de trabajo por escrito como requisito para poder ejercer formalmente actividades económicas, se impedía el cambio de categoría de residencia (de categoría transitoria a temporaria estudiante o temporaria trabajador contratado) y se ampliaban las facultades del Poder Ejecutivo (en particular, de la DNM), afianzando las políticas restrictivas (Novick, 2001).

\footnotetext{
243 Estos convenios se focalizaron casi con exclusividad en la regulación de la actividad laboral de los migrantes. Respecto al convenio argentino-boliviano, a pesar que eliminó ciertos elementos restrictivos de la ley migratoria vigente en aquel momento, permitiendo por ejemplo el acceso a la educación pública para los hijos de los migrantes en condición irregular (Artículo 13), se concentró fundamentalmente en la inserción económica del migrante boliviano en relación formal de dependencia o autónomo (Artículo 1).

244 A pesar de la preocupación formal de los países firmantes de estos convenios de proporcionar los medios para que miles de inmigrantes "regularizaran" o "normalizaran" su situación, los excesivos requerimientos de esta legislación, en especial la obtención de determinados documentos y el pago de una tasa retributiva de servicios, así como la falta de acceso por parte de los inmigrantes a la información necesaria, demostraron que estos convenios no dejaron de ser soluciones coyunturales, que no lograron alcanzar el objetivo propuesto.

245 Decreto № 1.117/98
} 
Durante los últimos años de la década, el oficialismo impulsó en el Congreso Nacional tres proyectos de modificación de la Ley Videla que aspiraban a aumentar las restricciones, fortaleciendo fundamentalmente el control de la inmigración ilegal, como modo de organizar y ordenar aquella exterioridad -una exterioridad asumida como ilegítima e ilegal y pensada en términos de flujos migratorios en lugar de personas migrantes- que pudiera irrumpir o estuviera presente en la sociedad mayoritaria. ${ }^{246}$ Los dos proyectos de ley presentados por los diputados nacionales oficialistas declaraban en sus fundamentos que la finalidad era "completar el sistema migratorio impuesto por las disposiciones vigentes, incorporando normas que armonicen el ejercicio del poder de policía de extranjeros con la política poblacional, a fin de asegurar una adecuada incorporación de los flujos migratorios al seno de la sociedad argentina" (énfasis propio), introduciendo principios establecidos en la "legislación extranjera más avanzada" y otros que "sólo han sido impuestos por normas administrativas, a pesar de su indudable importancia y vinculación con cuestiones de raigambre constitucional". También se expresa la necesidad de "modificar el régimen que actualmente reprime los ilícitos migratorios", incorporando, "la primera disposición que tipifica el tráfico de personas como delito autónomo" con el objetivo de "poner coto a las maniobras que se realizan con relación al ingreso irregular de personas al territorio nacional y la obtención posterior de documentación argentina", entre otros "ilícitos" que se pretende que sean determinados como "infracciones administrativas". ${ }^{247}$ El proyecto de ley impulsado por el Poder Ejecutivo fundamentaba el pedido de modificación de la ley Videla, alegando el imperativo de hacer más riguroso, aclarar, ampliar y/o simplificar sus disposiciones para conseguir un "mejor cumplimento". Como una muestra de la necesidad que tiene el Estado de legitimar sus medidas a partir del reconocimiento de derechos universalmente validados, en los fundamentos se expresaba también que con este medida "se procura consolidar la defensa de la dignidad personal y el respeto a la persona humana", además de "evitar que en la práctica se reduzca a los individuos carentes de recursos a situaciones que implican reducción a la servidumbre", afirmando que ello "no

\footnotetext{
246 Hasta 1994 las propuestas de modificación de la Ley Videla sólo contemplaban cambios menores relativos a la actualización de tasas y multas y algunas competencias. A partir de esa fecha, se incrementa la labor parlamentaria dedicada a la elaboración de proyectos en materia migratoria (Courtis, 2006). Véanse CELS (1997), Oteiza y Novick (2000); Novick (2001) y Courtis (2006) para una revisión de los proyectos de ley ingresados a la Comisión de Población y Recursos Humanos de la Cámara de Diputados que pretendían modificar parcialmente o reemplazar y derogar a la Ley Videla. También Cozzani de Palmada (2000) para un análisis de los proyectos de ley impulsados a finales de los noventa.
}

247 Expedientes № 6490-D-96 y № 7952-D-98. 
es compatible con los principios que inspiran la legislación nacional, la acción de los poderes públicos y las exigencias de la comunidad internacional”. ${ }^{248}$

En general, estas iniciativas de reforma apuntaban a endurecer aquellos elementos que constituyen el núcleo duro de la visión de Estado sobre las migraciones: las condiciones de entrada, permanencia y expulsión. Aquella expresa voluntad de armonización entre el poder de policía y la política poblacional no suponía otra cosa que el establecimiento de mayores restricciones a las ya contempladas en la Ley Videla. El primer proyecto de ley fue presentado en 1996 y discutido en la Comisión de Población y Recursos Humanos de la Cámara de Diputados de la Nación en junio de 1997.249 Fue respaldado públicamente por el secretario de Población, Aldo Carreras, y el director nacional de Migraciones, Hugo Franco. ${ }^{250}$ Este proyecto buscaba reformar las categorías de admisión, impidiendo el cambio de categoría para aquellos que ingresaran como "residentes transitorios" 251 (por ejemplo, en calidad de "turistas"), así como requerir que las personas que soliciten ingresar o residir en la Argentina por razones laborales o parentesco lo hagan mediante escritura pública. Entre las modificaciones propuestas, se contemplaba la posibilidad de otorgarle residencia permanente a aquellos "extranjeros que hubieren adquirido bienes inmuebles o de capital" o "hubieren realizado depósitos en dinero efectivo", de carácter intransferible, en el territorio nacional al mismo tiempo que ampliaba los casos en los cuales la autoridad migratoria podía disponer la cancelación de la residencia, sea precaria, permanente o transitoria. Además de lo dispuesto en la ley Videla, este proyecto incluía entre los motivos para cancelar la residencia el procesamiento por delitos que supongan una pena superior a los tres años y la realización, dentro o fuera del país, de "actividades que afecten la paz social, la seguridad nacional o el orden público de la República”. Asimismo, extendía las posibilidades de expulsión, cualquiera sea la categoría de residencia, involucrando al extranjero que "resulte procesado por delito que tenga

\footnotetext{
248 Expediente 87-PE-98.

249 El proyecto fue firmado por los diputados oficialistas Carlos Dellepiane, Sergio Acevedo, Pascual Rampi, Miguel Robles, Alberto Herrera y Lidia Mondelo.

250 Según Cozzani de Palmada (2000), algunos medios de prensa del interior del país, frente a la inminente presentación de la propuesta, afirmaban la idea de que la inmigración proveniente de países vecinos es negativa, responsabilizándola de la excesiva presión a que se ven sometidos los sistemas educativos y de salud estatales.

251 La figura del "falso turista", como antesala de la "ilegalidad", siempre ha resultado una preocupación para quienes elaboran o ejecutan medidas de control migratorio. En los fundamentos del proyecto de ley se especifica que el sistema adoptado es "singularmente pernicioso porque permite una violación sistemática del control migratorio, ya que alienta el fraude configurado por la declaración falsa del extranjero ante el consulado o en la frontera que, pretextando una finalidad de turismo o esparcimiento, realmente encubre la intención de permanecer en el país" (Expediente 6490-D-96).
} 
prevista una pena máxima superior a tres años" o "se le conceda libertad condicional en una causa en la que resulte condenado por juez o tribunal argentino, por delito doloso a pena privativa de libertad mayor de tres años", además que -en ambos casos- "su presencia en el territorio nacional no resulte de interés para las autoridades judiciales argentinas". ${ }^{252}$

El proyecto de ley también preveía una serie de sanciones para aquellos que se implicaran con la inmigración ilegal. En efecto, el proyecto introducía altas multas y severas penas aumentadas en esta ocasión- aplicables a dadores de trabajo o alojamiento a "ilegales" como a toda aquella persona que cometiera alguno de los delitos o infracciones contempladas en la ley. ${ }^{253}$ Este sistema de sanciones, cuya finalidad radica en controlar de modo indirecto la ilegalidad, fueron presentadas por el gobierno nacional como una medida de protección al inmigrante. En esos días, el secretario de Población declaró a la prensa en defensa del proyecto: "Esta propuesta defiende al inmigrante ilegal, porque sanciona a los generadores de ilegalidad. Y además, indirectamente, combate la marginalidad y la xenofobia que surgen en torno a la ilegalidad" (citado en Clarín, 3/7/97). Uno de los legisladores justicialistas y co-autor del proyecto, Pascual Rampi, manifestó que la finalidad que se persigue con las modificaciones introducidas a la ley en aquél momento vigente era "perseguir, por la vía legal, a los mafiosos y a los inescrupulosos que explotan a los inmigrantes ilegales" (citado en Clarín, 3/7/97). Agregó que "estamos hartos de ver situaciones de explotación y creemos que lo importante es avanzar en la protección de estas pobres personas que vienen al país buscando un destino mejor" (citado en Clarín, 3/7/97).

Uno de los aspectos más polémicos del proyecto de ley fue la introducción de la figura de la delación: el 15\% de la recaudación de las multas sería destinado a aquellos funcionarios que intervengan en las inspecciones tendientes a detectar la existencia de infracciones o a quienes -persona física o ideal- hicieran la denuncia que permita la constatación de la infracción (CELS, 1997; Cozzani de Palmada, 2000). En medio de la polémica suscitada, la

252 Entre los motivos para decretar la expulsión, siguiendo lo dispuesto en relación a la cancelación de la residencia, el proyecto de ley también contemplaba las "actividades que afecten la paz social, la seguridad nacional o el orden público de la República". La ley Videla, en cambio, incorpora esta posibilidad para los casos de expulsión, pero no lo hace para la cancelación de la residencia.

253 Las restricciones contenidas en el proyecto en relación a las condiciones de admisión al territorio nacional ya estaban definidas por el reglamento de migración de 1994 (decreto № 1.023) y las sanciones destinadas a empleadores y dadores de alojamiento ya estaban contempladas en la Ley Videla (Cozzani de Palmada, 2000). 
Cancillería se opuso al proyecto y lo calificó como "violatorio de los derechos humanos" (citado en Clarín, 3/7/97). La coordinadora de la Unidad de Migraciones Internacionales del Ministerio de Relaciones Exteriores, Susana Larregui, fue uno de los funcionarios de este organismo que se pronunció públicamente en contra del proyecto. Declaró a la prensa que "ni en las peores épocas de la dictadura militar existió una iniciativa como ésta" (citado en Clarín, 3/7/97). El proyecto, en particular la figura de la delación, no sólo fue cuestionado por Cancillería, sino también recibió duras críticas por parte de actores sociales y políticos como la Iglesia Católica y otras iglesias cristianas, partidos políticos opuestos al gobierno nacional y la OIM (CELS, 1997), además de representantes consulares de Estados vecinos y académicos. A partir de ello, tanto el presidente como el Ministro del Interior salieron a tomar distancia del proyecto, desvinculándolo del Poder Ejecutivo y desautorizando a los funcionarios que habían apoyado explícitamente la iniciativa, lo que los obligó a matizar las declaraciones hechas previamente. Cuestionada y retirada la propuesta oficial, el subsecretario de Población, Aldo Carreras, al momento de pronunciarse en contra de la figura de la delación, sostuvo que "tenemos que convertir al ilegal en inmigrante" (citado en La Nación, 5/7/97).254

Aunque el proyecto de ley fue retirado, los legisladores oficialistas no tardaron en intentarlo una vez más. En 1998, los diputados del bloque justicialista Pascual Rampi y Miguel Ángel Pichetto volvieron a presentar un proyecto de ley que, al igual que su antecesor, pretendía sustituir aquellos artículos de la Ley Videla relacionados con las categorías de admisión y el otorgamiento de la residencia, las sanciones y las expulsiones, eliminando sus aspectos más discutidos como la figura de la delación. ${ }^{255}$ El nuevo proyecto de ley mantenía los mismos fundamentos que el anterior y no contenía cambios sustanciales. Finalmente, este proyecto tampoco logró ser aprobado, pero las expulsiones siguieron su curso, incrementándose su número en relación a años anteriores. En 1998, según datos de la Gendarmería Nacional y Prefectura Naval publicados en la prensa, casi 5.000 extranjeros fueron expulsados del país (La Nación, 19/1/1999).256 Más adelante, el

254 De acuerdo a Cozzani de Palmada (2000), las notas de la mayoría de los medios de prensa referidas a la propuesta de ley de 1997 se manifestaron en contra de ella. En un artículo se señalaba que la Argentina carecía de "políticas nacionales destinadas a la integración, respetuosas de todos los derechos de los hombres y mujeres de buena voluntad que eligen este suelo para volver a empezar" (No se cita la fuente en el original).

255 Los artículos a sustituir son exactamente los mismos contemplados en el proyecto anterior firmado por Dellepiane y otros. Se trata de los artículos № 12, 15, 16, 17, 18, 21, 48, 49, 52, 53, 54, 62, 82, 95 y 102. En esta nueva versión se elimina la polémica figura de la "delación” contenida en el artículo № 48 .

256 En los últimos años este índice habría aumentado: sólo la Prefectura Naval deportó a 286 ciudadanos de países limítrofes en 1995 y tres años después a 1700 (La Nación, 19/1/1999). Un detalle significativo: en esta misma nota, el diario conservador La Nación descubre que, según lo expresa en el título, "La nacionalidad tiene poco que ver con 
Poder Ejecutivo someterá a consideración del Congreso un nuevo proyecto ley con disposiciones más duras que las de la Ley Videla.

Las críticas al gobierno debido al aumento de los niveles de pobreza también fueron enfrentadas acudiendo a las consecuencias imputadas a la presencia de la inmigración de países limítrofes. En sus explicaciones, los funcionarios no sólo atribuían el crecimiento del número de pobres a la afluencia de inmigrantes de países limítrofes, sino que también se los acusaba de inhabilitar u obstaculizar las oportunidades de ascenso social y la mejora de los ingresos que el crecimiento económico posibilitaría a los "sectores más pobres" de la sociedad. El "inmigrante" le quitaría esa posibilidad al "argentino". En el mes de junio de 1998, el viceministro de Economía, Carlos Rodríguez, lo manifestaba de esta manera en una entrevista otorgada al diario Clarín: “El argentino que está en la franja más pobre sube un escalón más cuando crece la economía. Y el inmigrante ocupa ese lugar. Por eso no quiero que se eche la culpa al modelo económico de que los sectores más pobres no mejoran sus ingresos si se demuestra que el factor determinante es la inmigración" (citado en La Nación, 16/8/98). En una economía neoliberal, que enfrentaba la pobreza a través de políticas focalizadas sin la menor intención de cuestionar la distribución de la riqueza, era necesario encontrar causas y causalidades externas, antes que reconocer el fracaso del modelo económico implementado.

El 27 de enero de 1999 el Poder Ejecutivo presentó un nuevo proyecto firmado por el presidente Carlos Menem, el jefe de Gabinete Jorge Rodríguez y el ministro del Interior, Carlos Corach, con la intención de modificar, sustituir, derogar e incorporar diversos artículos de la ley Videla. ${ }^{257}$ Ya desde comienzos del mes se habían intensificado los operativos de control en la frontera como las inspecciones en aquellos espacios de la ciudad de Buenos Aires con una importante concentración de inmigrantes, además de ejecutar numerosas expulsiones de extranjeros. ${ }^{258}$ Días antes que el proyecto de ley fuera enviado al Congreso Nacional, altos funcionarios de gobierno arremetieron una vez más contra los inmigrantes ilegales, adjudicándoles el incremento de los índices de delincuencia y de los niveles de inseguridad que se habría alcanzado. Casaravilla

el crimen". Esta afirmación que pretende relativizar la atribución generalizada que recae sobre los inmigrantes como responsables de la delincuencia, en realidad, termina confirmando que "algo tiene que ver".

257 Este proyecto buscaba sustituir los incisos b y c del artículo 7 y los artículos 12, 13, 48, 49, 62, 95; derogaba los artículos 14 y 90; e incorporaba cuatro artículos $(115,116,117$ y 118) bajo el título XV “De los delitos”.

258 Según una nota publicada en el diario Clarín, sólo en una comisaría del barrio de Once detuvieron a 1.103 extranjeros en 19 días por no tener los documentos requeridos (Clarín, 21-1-99). 
interpreta este momento como "los preludios de uno de los más asombrosos simulacros construidos políticamente en el último de los diez años en que Menem gobernara la Argentina" (Casaravilla, 2000:6).259 Para Mármora, a su vez, la ofensiva dirigida contra los inmigrantes ilegales durante estos años finales del menemismo fue parte de una campaña mediática orquestada por el gobierno para desviar la atención y reducir la repercusión pública que había empezado a suscitar un episodio de corrupción (uno más) relacionado con la confección de los DNI y los pasaportes que con el paso del tiempo se confirmaría. ${ }^{260}$

Las declaraciones del director nacional de Migraciones fueron las que más polémica despertaron: expresó, según se consignó en la prensa, que "en la Capital Federal se extranjerizó el delito", ofreciendo una explicación de causalidad lineal sobre la producción de la delincuencia originada en la falta de la documentación requerida para tener una estadía autorizada: la indocumentación genera marginalidad y esta marginalidad produce delito. Acusó también a los extranjeros de cometer más del 60\% de los delitos menores de la ciudad de Buenos Aires. El Ministro del Interior, por su parte, sin dejar de asociar inmigración a delincuencia e inseguridad, pretendió defender el proyecto de ley

259 En su análisis, Casaravilla (2000) señala que durante la primera quincena de enero de 1999, salvo un pequeño recuadro dedicado a la detención de una mujer boliviana relacionada con el comercio informal (en el diario Crónica), no apareció ninguna otra referencia a la temática en la prensa escrita. En cambio, durante la segunda quincena, las noticias sobre la "inmigración ilegal" inundaron los diarios nacionales. Al mes siguiente, aunque los medios comunitarios continuaban registrando denuncias de persecuciones, el tema ya había desaparecido de la prensa nacional. También Cozzani de Palmada (2000) señala la especial cobertura que recibió la temática migratoria, en particular la "inmigración ilegal”, en la prensa escrita de distribución nacional (producida en Buenos Aires) durante el tratamiento del proyecto de ley presentado por el gobierno.

260 Comentario personal de Lelio Mármora a la ponencia que presenté bajo el título "Migraciones internacionales y Estado nacional en la Argentina reciente. De la retórica de la exclusión a la retórica de la inclusión" en el III Congreso Latinoamericano de Población en el mes de septiembre de 2008. Durante este período se preparó y ejecutó un controvertido contrato referido al control migratorio y documentación de los migrantes entre el gobierno argentino y una compañía multinacional (Mármora, 2004:61), la empresa Siemens. En 1998, la empresa alemana gana la licitación. Ese mismo año la justicia federal comienza una investigación que será archivada en mayo de 1999 (luego reabierta en el 2004 por iniciativa de la Oficina Anticorrupción). El contrato, que fue rescindido en el año 2001 debido a las sospechas de sobreprecio e irregularidades en el proceso de licitación señaladas en un informe de la Sindicatura General de la Nación, preveía la informatización de los procedimientos migratorios, el desarrollo de un nuevo documento de identidad (que incluía su digitalización) y la actualización de los padrones electorales (Mármora, 2004:62). Hacia finales de 2008, la multinacional Siemens admitió ante una Corte Federal de los EE.UU. el pago de sobornos por 105 millones de dólares entre 1997 y 2007 en la Argentina, de los cuales 26 millones habrían sido destinados al presidente Carlos Menem, el Ministro del Interior Carlos Corach y el Director de Migraciones Hugo Franco para poder cerrar el arreglo millonario (u\$s 1.260 millones) con el gobierno argentino en 1998. Según diversas fuentes periodísticas, el pago de coimas (sobornos) también involucraría a empresarios del Grupo Macri y a representantes de las administraciones de Fernando de la Rúa (1999-2001) y Eduardo Duhalde (2002-2003). Si bien la empresa multinacional habría pagado sobornos hasta enero de 2007, la declaración de Siemens busca no involucrar directamente a funcionarios del gobierno de Kirchner. 
sosteniendo que dicho instrumento legal pretendía castigar a quienes se involucraban con el tráfico de inmigrantes indocumentados. Por otro lado, el gobernador oficialista Eduardo Duhalde de la provincia de Buenos Aires brindó su respaldo al proyecto, ofreciendo un conocido argumento para justificar el carácter restrictivo de las medidas políticas en materia migratoria: "A raíz de que cada día hay menos trabajo, es necesario repartirlo entre los argentinos" (Clarín, 21/1/99).

Durante esa semana, el 20 de enero 1999, el presidente Carlos Menem anunció en una reunión con gremialistas durante la inauguración de la nueva sede de una obra social que "aquellos que no estén documentados como corresponde tendrán que abandonar el país" (Clarín, 21/1/99). En esa misma ocasión, dijo que "la Argentina no cerró las puertas a nadie. A los únicos a quienes les cerramos las puertas es a aquellos que vienen a delinquir en nuestra patria", asumiendo que "muchas veces llegan indocumentados de distintas partes del continente, y se organizan en bandas" (Clarín, 21/1/99). Aquí, la amenaza de expulsión recae sobre los "indocumentados", quienes al ser vistos como proclives a cometer delitos o identificados como delincuentes se pretende impedirles el ingreso al país como su incorporación a la "patria". Por tanto, en este contexto, la pretensión de cerrar las puertas a "aquellos que vienen a delinquir en nuestra patria" puede interpretarse como la exclusión de aquellos inmigrantes que en su condición de "indocumentados" infringirían la ley al cometer cualquier tipo de delito que se les pueda atribuir -cruce de la frontera por lugar no autorizado, permanencia en situación administrativa irregular, utilización de documentos falsos, hurtos menores, entre otros-, pero también cuando no cumplieran con el requisito de estar legales para integrar la nación.

En su intervención también discute el alcance de los derechos humanos, estableciendo una asociación directa entre "los indocumentados" y "los delincuentes", cuestionando la protección que el Estado debería asegurar tanto a unos y a otros como un modo de justificar el recorte de sus derechos que se impondría a partir de las modificaciones propuestas en el proyecto de ley:

No podemos someter a los rigores del delito y la inseguridad a nuestra gente y a nuestras fuerzas de seguridad. ¿O es que los policías no tienen derechos humanos como los delincuentes? Estos son los aspectos que debemos controlar. Tenemos la obligación de hacerlo, para evitar situaciones dramáticas. Si uno les pide a los indocumentados que se documenten, inmediatamente salta el tema de los derechos humanos. Derechos humanos sí, 
pero para todos, y no para proteger a los delincuentes, que se encuentran protegidos a partir de las leyes, que serán modificadas. (Presidente de la Nación, Carlos Menem, 20 de enero de 1999)

El proyecto de ley, aunque con algunas modificaciones, mantenía el carácter restrictivo y represivo de los anteriores. Las reformas introducidas tenían como objeto el control de la inmigración ilegal, a través del endurecimiento de las medidas de vigilancia y persecución ejercidas directa o indirectamente sobre los extranjeros sin residencia autorizada y el aumento del poder de policía a los organismos estatales especializados en migraciones como la DNM. A raíz de ello, como señalan diversos autores, la ley encontró una amplia resistencia en organismos de derechos humanos, agrupaciones políticas opositoras y un sector de la iglesia católica, cuyos reclamos y denuncias contribuyó a que la reforma no fuera aprobada (Casaravilla, 2000; Cozzani de Palmada, 2000). Este proyecto mantenía las mismas categorías de ingreso (permanentes, temporarios y transitorios) que la normativa vigente, prohibía el cambio de categoría para aquellos que hubieran ingresado como "residentes transitorios" y buscaba acelerar los procesos administrativos de expulsión, además de facilitarlos (Oteiza y Novick, 2000). Al igual que la Ley Videla, este proyecto estipulaba la detención y expulsión para aquellos extranjeros que permanecieran en el país vencido el permiso de estadía autorizado; en cuanto a los extranjeros que cometieran actos delictivos, cualquiera fuese su situación de residencia, establecía la expulsión para la pena de prisión mayor de dos años -antes eran cinco- e introducía también la pena de prisión de uno a seis años para quienes utilicen documentación migratoria falsa. El proyecto también preveía severas sanciones -multas y prisión, según el caso- para todos aquellos individuos $\mathrm{u}$ organizaciones $\mathrm{y}$ entidades que se involucraran con ilegales: empleadores, propietarios de hoteles y pensiones, individuos y toda persona o entidad que favorezca o colabore con el ingreso y/o permanencia no autorizada y comercialice documentos falsificados (Cozzani de Palmada, 2000).

\section{La legalización migratoria como solución: seis amnistías en medio siglo}

A lo largo de la última mitad de siglo, convertida la ilegalidad migratoria en uno de los asuntos que ponen en cuestión tanto la capacidad administrativa como la legitimidad del

Estado, diversas administraciones buscaron en los llamados programas de 
regularización ${ }^{261}$ migratoria el instrumento con el cual regular la acumulación de extranjeros o inmigrantes, tipificados como ilegales, recibida de gobiernos anteriores, en particular de las dictaduras militares. En este sentido, aunque sea considerada una medida de excepción, la regularización migratoria no corre por fuera, sino que forma parte del régimen de control instituido paulatinamente por el Estado para regular el ingreso, la permanencia y la expulsión de la población extranjera. Por más que la regularización migratoria se aleje de las convencionales medidas represivas, es importante que sea entendida como un mecanismo de control y vigilancia estatales para regular la inmigración en general y la construida como ilegal en particular, una medida que pone a prueba el poder del Estado.

La Argentina, como uno de los principales países receptores de inmigración, fue también uno de los primeros países del mundo en adoptar un proceso de regularización migratoria, cuya implementación recién comenzó a generalizarse en la década del ochenta. Durante el siglo XX, estos procedimientos fueron llevados adelante de manera periódica, únicamente por gobiernos constitucionales, en los años 1949, 1958, 1964, 1974, 1984 y 1994. Los dos primeros fueron de carácter general y los restantes estuvieron dirigidos particularmente a los extranjeros de países limítrofes. Más allá de las diferencias en los fundamentos ofrecidos en estas ocasiones, todos perseguían la misma finalidad: dar una solución definitiva a un hecho social, político y económico que se renueva constantemente, asumido por el Estado como un problema regulable en términos administrativos y legales. Aunque pareciera paradójico, a través de una regularización migratoria el Estado pretende solucionar un problema que él mismo ha creado -como diría De Genova (2002), se trata de la producción legal de la ilegalidad. En este sentido, y sólo en este sentido, podría decirse que la ilegalidad no es un problema en sí, sino un problema para el Estado.

El primer llamado de regularización migratoria tuvo lugar a mediados del siglo veinte. Desde entonces, como vimos en los apartados anteriores, la migración se fue constituyendo progresivamente en un asunto de ilegalidad. Es decir, hubo un momento histórico en que la migración se movía en el terreno de la alegalidad: el Estado regulaba los movimientos de entrada y salida sin que fueran concebidos en términos de legal/ilegal.

\footnotetext{
261 La misma noción de regularización es significativa: el significado de "regularización" (como de normalización", como también suelen ser denominados estos programas), remite a un orden que ha sido alterado y que busca ser restablecido, adaptado a las normas y reglas de las cuales se ha apartado. En esta ocasión, se trata de la restitución del orden establecido a través de la vía jurídica, entendiendo el orden jurídico como el orden natural de las cosas. La noción de "legalización", también utilizada para denominar estos programas, manifiesta abiertamente la idea de colocar dentro de la ley algo que estaba al margen de o contra (según algunas interpretaciones oficiales) ella.
} 
Por lo tanto, sin una declaración oficial de ilegalidad, tampoco hubiera podido haber una respuesta política dirigida especialmente a una población extranjera cuyo ingreso fuera calificado en base a esa clave interpretativa.

En el año 1949 se estableció la primera medida de regularización migratoria en el país denominada "indulto general"- dirigida a "los extranjeros que hubieren penetrado al país ilegalmente"262. El decreto obligaba a todos los extranjeros que se encontraran en el país y que no poseyeran "documentos de identidad argentinos" o "permiso de residencia definitiva" a presentarse ante la DNM para "regularizar su situación". ${ }^{263}$ Esta medida, más allá de este objetivo explícito, también fue expresión de las deficiencias e irregularidades administrativas en el manejo de los asuntos migratorios durante el peronismo (Devoto 2001). El plazo estipulado para el trámite de regularización fue prorrogado a través de sucesivos decretos ${ }^{264}$, ampliando su vigencia por algo más de dos años. En una de estas normas aparecía uno de los argumentos que será retomado en la década siguiente: la regularización migratoria formaliza en términos legales una radicación de hecho de antigua data. Entre los considerandos de uno de los decretos, se alegaba que "la inmensa mayoría de los interesados, por el largo tiempo que lleva en el país, se encuentra incorporada de hecho a su vida y actividades por múltiples vínculos de todo orden", afirmando que "es de sabia política gubernamental contribuir a consolidar" dicho proceso. ${ }^{265}$ Determinaba que quienes estuvieran en condiciones de probar su ingreso, además de su "residencia y arraigo" (antes del 8 de julio de 1949), serían considerados "radicados de hecho". ${ }^{266}$

262 Decreto № 15.972/49. Un dato de curiosidad histórica: en una entrevista otorgada al diario Página 12, el diputado nacional por la provincia de Buenos Aires del Frente para la Victoria, Héctor Recalde, cuenta lo que habría respondido Perón frente a la pregunta que le hicieron en relación a los "inmigrantes ilegales": "Una vez le preguntaron al general Perón qué se podía hacer con los inmigrantes ilegales. Él dijo: La respuesta es muy sencilla, hay que legalizarlos" (Página 12, 2/7/06).

263 Galante (2008a) señala que si bien la regularización comenzó a partir del decreto № 1.162 (20/01/49; art. 16) con algunos requisitos (como la realización de trámites ante autoridad judicial) que podían ofrecer alguna dificultad para su acceso, las sucesivas normas (decretos № 15.972/49, 24.666/49, 12.369/50 y 29.950/50) la convirtieron en un "efectivo indulto general".

264 Se trata de los decretos № $15.972 / 49,24.666 / 49,12.369 / 50$ y 29.950/50.

265 Decreto № 24.666/49.

266 El artículo 2 estipula que: “A tal objeto los interesados deberán presentar antes del 31 de marzo de 1950 la documentación que compruebe la época, actividades y condiciones de ingreso; las tareas desempeñadas en territorio argentino; estudios cursados, celebración de matrimonio o nacimiento de hijos argentinos, y cualquier otro elemento que demuestre la residencia y arraigo invocados. La falta de dichos testimonios podrá ser suplida por la prueba de dos testigos por lo menos que depongan acerca de las condiciones y circunstancias de su ingreso, así como las de su residencia y arraigo." (Decreto № 24.666/49). 
Casi una década más tarde, en 1958, el gobierno del presidente Frondizi impulsó la segunda iniciativa de regularización migratoria, denominada en sus considerandos como "una medida generosa de carácter excepcional", con el objetivo de que obtuvieran "su radicación legal", exigiéndoles los "requisitos mínimos indispensables en cuanto a identidad y residencia". La justificación de la medida se apoyaba en dos hechos: por un lado, en la existencia de "una apreciable cantidad de extranjeros [que] no formularon la presentación pertinente" bajo la regularización migratoria de 1949 y, por el otro, en la posterior incorporación al país de "nuevos núcleos de extranjeros que a pesar de encontrarse en la misma situación, han ligado su vida y actividades a nuestro propio desarrollo". Los potenciales beneficiarios de la medida, a quienes nombraba como "extranjeros establecidos de hecho en el país" (antes del 1o de mayo de 1958) que no podían "justificar su ingreso o estada legal”, no eran responsabilizados por dicha situación, indicando que "la mayoría de dichas personas no pueden satisfacer los requisitos usuales para radicarse legalmente en el país, no obstante su efectiva vinculación al mismo; hallándose además imposibilitados para obtener documentos de identidad”.267

A principios de 1964, durante el gobierno de Illia, se estableció la tercera medida de regularización migratoria para "todo extranjero nativo de país limítrofe que se encuentre establecido de hecho en el territorio de la República" (antes del 12 de octubre de 1963), sin importar "la forma y condición de su ingreso", y que no poseyera "documentación personal argentina". ${ }^{268}$ De todas maneras, los requisitos y exigencias para obtener la "radicación definitiva" se incrementaron en esta oportunidad. Ya no sólo era necesario "acreditar su residencia" y "probar su identidad": la radicación pasaba a estar supeditada también, al menos formalmente, a la "carencia de antecedentes penales" y "buena salud".

En 1974, el tercer gobierno de Perón llevó adelante el cuarto proceso de regularización migratoria dirigido a los "ciudadanos provenientes de países limítrofes en situaciones legales irregulares". ${ }^{269}$ Dicha medida, vista como parte de la necesidad de "traducir en hechos concretos las aspiraciones expresadas en el plano de las ideas, principios y propósitos", se fundamentaba, por un lado, en las consecuencias que tendría la falta de "documentación adecuada" para los trabajadores inmigrantes, considerados "pasibles de abusos por parte de sus empleadores", permitiendo con ello la formación de "un verdadero mercado negro de mano de obra" que deprimía los salarios establecidos por leyes y convenios laborales y obstaculizaba "el desenvolvimiento de sus vidas con las

267 Decreto № 3364/58.

268 Según datos oficiales, en 1964 se radicaron con esta medida 216.677 extranjeros de países limítrofes.

269 Con esta medida de regularización se radicaron 147.383 extranjeros de países limítrofes. 
seguridades que la Nación está obligada a ofrecerles". ${ }^{270}$ Por el otro, la medida de regularización se apoyaba en la posición oficial del gobierno nacional en materia de migraciones y relaciones exteriores, declarando su adhesión a "los altos principios de hermandad e integración latinoamericana" y a una "política generosa, consecuente con su tradición en materia de inmigración". Entre los requisitos que se les exigía para obtener la "radicación definitiva" figuraban la acreditación del ingreso al país y de identidad, un estado de salud que careciera de las "inhabilidades" establecidas en la normativa migratoria y la inexistencia de antecedentes penales.

Diez años después, a pocos meses de la asunción de Raúl Alfonsín como presidente, en marzo de 1984 se dictó un nuevo decreto de regularización migratoria destinado a "extranjeros de diversas nacionalidades con situación migratoria irregular" para la obtención de la radicación definitiva. ${ }^{271}$ Declaraba la necesidad de "plasmar con hechos concretos los principios consagrados en nuestra Constitución Nacional” y, en particular, "aquél que convoca a todos los hombres del mundo que quieran habitar el suelo argentino". ${ }^{272} \mathrm{En}$ los considerandos explicaba que la "situación de irregularidad" era producto de la implementación de "una política migratoria escindida de la realidad socioeconómica del país y de los habitantes que la conforman" y declaraba que después de "sanearla" se seguiría una "política migratoria firme, racional, que sepa conciliar las necesidades poblacionales de la República con el legítimo derecho de sus habitantes o de quienes deseen habitarlo, de modo tal que no sea justificable en lo sucesivo, la permanencia en el país de grupos ilegales extranjeros". Asimismo, afirmaba que dicha "situación de irregularidad" concernía a "todo el contingente extranjero que durante años ha aportado su trabajo fecundo en beneficio de la comunidad argentina, aún en los peores momentos que a la República le ha tocado vivir". Suponía, asimismo, que las medidas de regularización harían "frustrar los espúreos (sic) intereses de aquellos empleadores que, aprovechándose de la situación de ilegalidad de estos extranjeros, los contratan proporcionándoles indignas condiciones de trabajo" y, simultánemente, afirmaba que esta "mano de obra clandestina compite con la mano de obra local", la cual sería "rechazada y reemplazada" al exigir una contratación acorde a lo establecido por ley.

Hacia mediados de 1992, pocos meses después del atentado a la embajada de Israel, se dispuso desde el Poder Ejecutivo, a través de un decreto273, "extremar los controles para el

270 Decreto № $87 / 74$.

271 Decreto № $780 / 84$.

272 Mediante esta medida de excepción regularizaron su residencia 136.902 extranjeros de países limítrofes. 273 Decreto № $1.013 / 92$. 
otorgamiento de las radicaciones ante las nuevas modalidades adoptadas por la delincuencia internacional" (Oteiza y Novick, 2000). Al mismo tiempo, el gobierno de Menem implementó la sexta medida de regularización migratoria ${ }^{274}$ dirigida a inmigrantes nombrados como "extranjeros nativos de países limítrofes residentes en el territorio nacional" o "ciudadanos nativos de países limítrofes" en el marco del proceso de integración regional iniciado en 1991, el Mercosur. ${ }^{275}$ Albarracín (2005) indica que si bien el MERCOSUR no estuvo ausente como motivación para convocar a la regularización migratoria, ésta no fue planteada como producto del acuerdo regional. Según su análisis, los funcionarios sostenían que la regularización podía o debía, más bien, coadyuvar a la integración de la región. ${ }^{276}$

Esta iniciativa de regularización, según los considerandos expuestos en el decreto, era justificada apelando a las ventajas que traería consigo la presencia de inmigrantes, afirmando que "tales personas, aún sin la documentación legal necesaria, en su mayoría desarrollan actividades útiles para el país". Además, se fundamentaba en los beneficios que tendría "adoptar medidas tendientes a normalizar" la situación producida por la falta de "documentación legal", tanto para los inmigrantes como para el Estado. Se consideraba que la medida era necesaria debido a "las implicancias sociales y económicas que tiene para las personas y familias que residen en tal condición" y "al innegable perjuicio que ocasiona al fisco nacional, el hecho de que, tanto los empleadores como los extranjeros, puedan evadir todo tipo de contribución y aporte obligatorio que deba efectuarse en razón de su relación de empleo en el país". Apropiándose de la letra del decreto de regularización migratoria de 1958, afirmaba que se trataba de una "medida de carácter excepcional", orientada a "dar solución a las situaciones planteadas", destacando las dificultades de la mayoría de los inmigrantes para "satisfacer los requisitos usuales para radicarse legalmente" y su "efectiva vinculación" con el país.

\footnotetext{
274 En 1992, con la implementación de esta medida de regularización migratoria se radicaron, según datos oficiales, 224.471 extranjeros de países limítrofes.

275 Decreto № 1.033/92.

276 El ministro del Interior (entre 1991 y 1992) José Luis Manzano expresó en una de sus declaraciones que la "amnistía" era "un primer paso para la profundización del proceso de integración entre las naciones sudamericanas" (Página 12, 1/4/92, citado en Albarracín, 2005). Durante los años noventa las medidas de regularización migratoria, convencionalmente así llamadas, fueron nombradas generalmente como "amnistías" en el debate público, tanto por los funcionarios de gobierno como por los representantes de la Iglesia católica y de organizaciones de derechos humanos y de inmigrantes. Albarracín (2005) sugiere que en este período inicial de la década, a pesar que los inmigrantes eran comúnmente nombrados como "ilegal" o "ilegales", aún no existían en la prensa discursos estructurados que excluyeran a los inmigrantes como potenciales miembros de la comunidad nacional.
} 
Finalmente, la medida buscó ser encuadrada como parte de "la reformulación de objetivos de la política de población y en particular de la migratoria vigente" -desmarcándose de los objetivos y políticas nacionales establecidos en el año 1977, "atento la importancia y significación que adquiere esta problemática en relación con el desarrollo de nuestro país"- a la vez que de "políticas que contemplen la diversidad de situaciones que caracterizan a estos fenómenos" y que fueran "compatibles con el actual período democrático, los principios y derechos que consagra la Constitución Nacional, y el contenido de los instrumentos internacionales ratificados por nuestro país". Asimismo, en vistas a los "altos principios de hermandad e integración latinoamericana, que persigue como objetivo prioritario el Gobierno Nacional en la etapa actual" y el "desarrollo de actividades conjuntas con los países limítrofes en materia de integración migratoria y poblacional", el decreto declaraba que el Poder Ejecutivo consideraba "necesario suspender los criterios migratorios hoy vigentes, para los nativos de estos países limítrofes y facilitar su radicación legal en nuestro territorio". Por otro lado, a través de la prensa, el gobierno expresó su interés en los efectos que podía tener la "amnistía" en ámbitos sociales como el mercado de trabajo.277

277 En una de sus declaraciones, el Secretario de Población, Germán Moldes, manifestó a la prensa que la regularización migratoria lograría "la transparencia del mercado de trabajo" (Página 12, 6/6/92, citado en Albarracín, 2005). 



\section{CAPÍTULO 4}

\section{INMIGRACIÓN Y ESTADO EN LA ARGENTINA RECIENTE: LA “NUEVA POLÍTICA MIGRATORIA"}

El creciente malestar y descontento popular con que experimentaron amplios sectores sociales los efectos del neoliberalismo en la Argentina de fines siglo hizo eclosión en el mes de diciembre del año 2001, encarnado en una profunda crisis con importantes implicancias económicas, políticas y culturales. A partir de allí, después de un relativamente corto pero tumultuoso período de sucesiones presidenciales, la Argentina empieza a transitar una época (ambiguamente) desmarcada de la retórica neoliberal.278 Con el acceso al gobierno de partidos, coaliciones y movimientos políticos autodesignados o afiliados a la izquierda, la centro-izquierda o al progresismo, las distintas reformas estatales experimentadas bajo el heterogéneo panorama de la política latinoamericana fueron interpretadas en el marco de lo que se ha conocido como "giro a la izquierda". 279 En este contexto, entre las dos vertientes de transformación del Estado en América Latina que advierte Boaventura de Sousa Santos, la experiencia estatal argentina posterior a la crisis del 2001 podría inscribirse en lo que él llama el Estado-comunidad-ilusoria: un "conjunto de reformas recientes que buscan devolver alguna centralidad al Estado en la economía y en las políticas sociales", que no compromete la lealtad a la ortodoxia neoliberal internacional, pero que utiliza todo el campo de maniobra que, en el plano interno, tal ortodoxia concede coyunturalmente. Posee una vocación política nacional-popular y transclasista, residiendo la "comunidad" en "la capacidad del Estado para incorporar algunas demandas populares por vía de inversiones financieras y simbólico-ideológicas" (Santos, 2010:72-73).

En materia de políticas de migraciones internacionales se pronuncian algunos indicios de cambio que fueron bien recibidos por diversos actores sociales y políticos, en especial aquellos comprometidos con la defensa de los derechos humanos de los inmigrantes. Después de varios años de discusión de diversos proyectos de ley que pretendían reformar o reemplazar la Ley Videla, a fines del año 2003 el Congreso Nacional sanciona una nueva norma migratoria nacional, la ley $\mathrm{N}^{\circ} 25.871$, la cual derogó la normativa establecida por la

278 Véase Slipak (2011) para un análisis de las articulaciones y desplazamientos del discurso político en el contexto de pos-crisis en la Argentina durante el período 2002-2004.

279 Para una revisión introductoria de la reciente experiencia política latinoamericana, véase Pousadela (2011). 
última dictadura militar en 1981. Al año siguiente, se creó mediante decreto presidencial el Programa de Normalización Documentaria Migratoria, difundido por el gobierno nacional como Patria Grande. Este programa de gobierno fue presentado a finales de 2005 en el Salón Blanco de la Casa Rosada por el presidente Kirchner y puesto en marcha a principios del año 2006. Ambos instrumentos fueron centrales en la conformación de la llamada "nueva política migratoria".

Este capítulo analiza la visión de Estado que se constituye en la Argentina reciente sobre la inmigración de países limítrofes en un contexto de significativas transformaciones en materia de política de migraciones internacionales, inaugurado formalmente a partir de la aprobación de la nueva ley de migraciones. Dicho análisis comprende el período 20002010 y se realiza mediante el examen de diversos documentos oficiales de política y legislación migratorias, las intervenciones públicas de funcionarios de gobierno que participan del diseño, elaboración y toma de decisión sobre los asuntos migratorios (los llamados policy-makers), especialmente agentes de la DNM, y los registros de observación directa en espacios destinados a explicar y difundir la llamada nueva política migratoria. Sugiere que hacia comienzos de la presente década, frente a la política de exclusión desarrollada durante los años noventa, la visión estatal sobre las migraciones internacionales empezó a experimentar determinadas reconfiguraciones, a partir de la internalización y articulación de categorías como derechos humanos, integración regional e integración de los extranjeros, conformándose una retórica de la inclusión que encontrará su sustento ideológico en la perspectiva de la llamada gobernabilidad migratoria adoptada paulatinamente en el seno del Estado argentino y resignificada según las particularidades del contexto político nacional y regional. ${ }^{280}$ Estos desplazamientos, si bien se volvieron evidentes a partir de la aprobación de la nueva ley de migraciones, cuya difusión se apoyó en el reconocimiento de los derechos humanos a los inmigrantes, ya se pueden percibir en las intervenciones públicas de algunos representantes de los organismos del Estado como la Dirección Nacional de Migraciones- inmediatamente después de la finalización del segundo mandato de Menem.

\footnotetext{
280 En algunos trabajos anteriores (Domenech, 2007a, 2007b, 2008) sugerí que estas reconfiguraciones se concretaban en una retórica de la inclusión compuesta básicamente por tres elementos: los derechos humanos, la ciudadanía comunitaria y el pluralismo cultural. Visto en perspectiva, esta proposición estuvo demasiado atada a las primeras formulaciones de la política migratoria argentina, marcada especialmente por la nueva ley de migraciones. Luego, revisada la gestión de Ricardo Rodríguez al frente de la DNM (2004-2007) en su integralidad y con mayor distancia, decidí adoptar como categorías centrales los derechos humanos, la integración regional y la integración de los extranjeros, quedando las nociones de ciudadanía comunitaria y pluralismo cultural utilizadas anteriormente subsumidas en ellas.
} 
Entre la última iniciativa política del gobierno de Carlos Menem, hacia finales de su mandato presidencial, para impulsar una reforma de ley dirigida a fortalecer el carácter restrictivo y represivo de la ley Videla hasta la aprobación de la Ley $\mathrm{N}^{\circ} 25.871$, sancionada en el Congreso Nacional durante el primer año de la presidencia de Néstor Kirchner, se produjo un intenso debate acerca del rumbo que debía tomar la política migratoria del país y, en particular, las modificaciones que debía asumir la nueva legislación. Esta discusión pública, marcada por la experiencia neoliberal de la década de los noventa y luego también por el contexto de crisis social y política que estalló en diciembre del 2001, involucró a diversos actores sociales y políticos que desde algunos años venían reclamando una amnistía "amplia y generosa” y luchando por la derogación de la Ley Videla. Aunque hubo algunos episodios aislados de la prensa gráfica con alto impacto mediático 281 , en general la cuestión migratoria no tuvo las grandes repercusiones de años anteriores y los medios masivos de comunicación adoptaron un discurso moderado respecto al tema, sin otorgarle una cobertura especial. ${ }^{282}$ Gran parte del debate transcurrió en la Comisión de Población y Recursos Humanos de la Cámara de Diputados de la Nación a raíz de la elaboración de una nueva ley migratoria: en el año 2000 se organizó el seminario "Política y Normativa Migratoria en la Argentina" y en el 2002 la audiencia pública "Legislación Migratoria en la República Argentina", además de los diversos encuentros desarrollados hasta la sanción de la nueva ley de migraciones y otros organizados por la DNM después de su puesta en vigencia.

Los años previos a la aprobación de la nueva ley de migraciones, en particular el período transcurrido entre el 2000 y el 2003, fueron decisivos en la gestación de la llamada "nueva política migratoria", cuyos lineamientos se manifestarán más abiertamente hacia mediados de la década. Como sabemos, estos años fueron de una intensa labor legislativa, concentrada particularmente en la elaboración y discusión de la nueva ley migratoria. Pero no sólo fue importante el proceso de negociación que se dio al interior del Poder

281 Uno de los hechos con mayor repercusión pública fue la tapa y la nota de uno de los números de la revista sensacionalista La Primera, publicada en abril del 2000, que llevó como título "La invasión silenciosa". Allí se reproduce fielmente el discurso xenófobo característico de los noventa, indicando una serie de problemas que los inmigrantes, en particular los "ilegales", causarían al país. Es una muestra paradigmática de la construcción discursiva sobre los inmigrantes como problema o amenaza social.

282 Véase Castiglione y Cura (2007) para un análisis de las migraciones en los medios de comunicación escrita durante el período 2000-2005. 
Legislativo, sino también la posición que asumieron los distintos organismos del Poder Ejecutivo -en particular, el Ministerio del Interior a través de la DNM- frente a la cuestión migratoria en medio de diferentes administraciones gubernamentales. A partir de comienzos de la presente década, finalizada la presidencia de Carlos Menem, vencido el partido justicialista en las elecciones nacionales de 1999 y arribada la Alianza (la Alianza por el Trabajo, la Justicia y la Educación) -frente político formado por la Unión Cívica Radical y el FREPASO, constituido por los partidos políticos Frente Grande, la Unidad Socialista, el Demócrata Cristiano y PAIS- al gobierno nacional, comienza a delinearse una visión sobre las migraciones internacionales que más adelante se verá cristalizada en las directrices de la "nueva política migratoria" y en los argumentos oficiales ofrecidos, especialmente desde la sanción de la "nueva ley de migraciones".

Durante este período, al compás de los continuos cambios de mandatarios nacionales ${ }^{283}$, se sucedieron distintos funcionarios encargados de conducir la Dirección Nacional de Migraciones. Durante la presidencia de Fernando de la Rúa, al frente de esta dependencia estuvo Ángel Roig, quien fuera intendente municipal de Mar del Plata entre 1983 y 1989, hasta que debido a internas partidarias fue reemplazado por otro dirigente bonaerense de la Unión Cívica Radical, Manuel "Titi” Martínez, cuyo paso por este organismo duró hasta la renuncia anticipada de Fernando De la Rúa a la presidencia. Posteriormente, con Eduardo Duhalde como presidente, el cargo lo ocupó Juan Manuel Llavar, un militar retirado en el año 1999 como comandante del III Cuerpo de Ejército. Asumida la presidencia por Néstor Kirchner, el primer director de la DNM fue Jorge Rampoldi, un abogado laboralista con una extensa militancia política en el justicialismo que tuvo que renunciar al cargo por denuncias de violación de derechos humanos durante la última dictadura militar, lo cual no es un dato menor en el marco de la política de derechos humanos que se empezara a desarrollar en el orden nacional. En su reemplazo, en septiembre de 2003 asumió como director el abogado Ricardo Rodríguez, quién se desempeñó anteriormente como Secretario de Política Ambiental del Ministerio de Desarrollo Social y Medio Ambiente de la Provincia de Buenos Aires, gobernada en aquél momento por Carlos Ruckauf, ex Ministro del Interior entre los años 1993 y 1995 y ex vicepresidente en el período 1995-1999 durante la gestión de Carlos Menem como presidente (1989-1999). La conducción de la DNM llevada adelante por Ricardo Rodríguez

283 Entre la renuncia de Fernando de la Rúa el 21 de diciembre de 2001 y la asunción de Eduardo Duhalde el 2 de enero de 2002, el cargo de presidente fue ocupado por Ramón Puerta, Adolfo Rodríguez Saa y Eduardo Camaño. 
bajo la gestión de Aníbal Fernández como Ministro del Interior ${ }^{284}$ finalizó con la presidencia de Néstor Kirchner, la cual llegó a su término en diciembre de 2007. Ya como presidente Cristina Fernández de Kirchner, lo sucedió en el cargo el abogado Martín Arias Duval, quien llegó a la DNM avalado por el Ministro del Interior Florencio Randazzo, ex Jefe de Gabinete y ex Ministro de Gobierno de la provincia de Buenos Aires durante el mandato de Felipe Solá como gobernador. Antes de ocupar el cargo de director de la DNM fue viceministro de Seguridad de la Provincia de Buenos Aires durante la gestión del ministro León Arslanián, bajo la gobernación de Felipe Solá, quien antes de alinearse con el gobierno de Néstor Kirchner y distanciarse del de Cristina Fernández de Kirchner, fue Secretario de Agricultura, Ganadería y Pesca de la Nación durante el primer gobierno de Menem, vicegobernador de la Provincia de Buenos Aires durante la gestión de Carlos Ruckauf y finalmente gobernador con el apoyo de Eduardo Duhalde.

A excepción del sucesor de Roig, todos los funcionarios que estuvieron al frente DNM durante el proceso de discusión, elaboración y aprobación de la nueva ley de migraciones, participaron de los encuentros que realizó la Comisión de Población y Recursos Humanos de la Cámara de Diputados de la Nación durante estos años. Durante la presidencia de esta comisión parlamentaria a cargo de los diputados Rubén Giustiniani y María Elena Barbagelata se convocó a los directores de la DNM a exponer sobre las acciones que llevaba adelante el organismo. Durante este período asistieron: Roig en diciembre del 2000, Llavar en abril del 2002, Rampoldi en julio del 2003 y Rodríguez en mayo del 2004 y del 2005. Los distintos directores de la DNM, salvo Rampoldi, concurrieron a la Cámara de Diputados acompañados por la asesora y, posteriormente, jefa en Temas Internacionales de la DNM, Adriana Alfonso. Su participación en los distintos encuentros es sólo una muestra de la relevancia que tiene su trabajo cotidiano en la constitución del discurso oficial. Las ideas que lograrán imponerse en el ámbito de la DNM en particular y en el

\footnotetext{
284 Como se podrá apreciar, los altos funcionarios del gobierno de Kirchner (como también él mismo), quienes en la actualidad pretenden desvincularse, discursivamente, de la década neoliberal de los noventa, fueron protagonistas o socios de ambos períodos presidenciales de Carlos Menem. Este es el caso también del Ministro del Interior de la presidencia de Kirchner. Aníbal Fernández fue Secretario de Gobierno de la Provincia de Buenos Aires cuando se desempeñaba como gobernador Eduardo Duhalde (quien fuera vicepresidente durante el primer mandato de Menem). También se desempeñó como Ministro de Trabajo de Provincia de Buenos Aires durante la gobernación de Ruckauf (quien fuera vicepresidente durante el segundo mandato de Menem) y Secretario General de la Presidencia y, posteriormente, Ministro de la Producción durante el gobierno de la provincia de Buenos Aires de Eduardo Duhalde.
} 
ámbito de gobierno de las migraciones en general una vez finalizada la presidencia de Menem son atribuibles a su autoría. ${ }^{285}$

Ya en el año 2000, luego de la embestida oficial contra los inmigrantes limítrofes -en particular la inmigración ilegal y los inmigrantes ilegales- durante el último año de gobierno de Menem y el rechazo generalizado que provocó en diversos sectores de la sociedad civil (asociaciones de inmigrantes, organizaciones de derechos humanos, instituciones de la iglesia católica y académicos fundamentalmente), altos funcionarios de organismos del Estado, aunque contradichos por la persistencia de prácticas restrictivas y arbitrarias en el seno de organismos de la administración pública como el Ministerio del Interior ${ }^{286}$, procuraban mostrar una posición aperturista frente a los inmigrantes de países limítrofes. Apelando a la metáfora teológica del cielo y el infierno, el funcionario encargado en aquél momento de la Dirección Nacional de Investigación, Política y Desarrollo Demográfico del Ministerio del Interior, Noel Breard, sugería durante su intervención en la Cámara de Diputados que de acuerdo a las críticas que recibían de distintos sectores sociales -por un lado, la prensa que defiende los intereses de determinadas corporaciones económicas asociada al "infierno" y, por el otro, la iglesia representada como utopía, vinculada al "cielo"- el gobierno estaría en la senda correcta -estaría "haciendo bien las cosas"- en materia de política migratoria, colocándolo en una posición intermedia, el "purgatorio", por tanto, con posibilidades de alcanzar el estadío superior, el “cielo".

285 Según lo que se trasluce del análisis diacrónico de los distintos documentos y de las diferentes intervenciones públicas, esta funcionaria ha tenido un rol protagónico en la definición de la nueva política migratoria y ciertos indicios hacen suponer que se habría encargado de escribir el "guión" del discurso oficial de la DNM en el período en cuestión (2000-2007).

286 Uno de los informes anuales del CELS sobre la situación de los derechos humanos en la Argentina (CELS, 2001) denuncia que en el año 2000 la DNM rechazó solicitudes de radicación de personas con discapacidad y decidió, arbitrariamente, no renovar las radicaciones precarias de 3.000 inmigrantes de nacionalidad boliviana, declarando "ilegal" su permanencia y disponiendo su expulsión en algunos casos. También denuncia la violación del principio de gratuidad del régimen administrativo en detrimento de los inmigrantes en relación a la igualdad ante la ley. Por otra parte, cabe señalar que durante este período se realizaron expulsiones de manera permanente. Entre los años 2000 y 2002 hubo aproximadamente 11.685 expulsiones. Según cifras de la Dirección de Migraciones y del CELS, los informes de la Gendarmería Nacional señalaban 1.600 expulsiones en 2000, 3.300 en 2001 y 1700 hasta octubre de 2002 (estos datos no incluyen las deportaciones de personas con antecedentes penales). La Prefectura Naval, por su parte, registra 1.505 expulsiones en 2000, 2.098 en 2001 y 1.482 hasta octubre de 2002. La colectividad paraguaya fue la más afectada por estas medidas: el número de deportaciones oscilaba entre 80 y 200 ciudadanos por mes. 
Yo veía hoy Ámbito Financiero, casi nos explica lo que está pasando, nos acusa paradójicamente a Roig, a mí, al Ministerio del Interior, que somos flexibles, que abrimos las tranqueras, que tiramos las murallas, que nos van a invadir los pobres, que estamos queriendo llenarnos de bolivianos, peruanos, y en buena hora, porque somos latinoamericanos, pero en definitiva nos acusan de flexibles. Y por el otro lado la Iglesia Católica nos pide amnistía, nos trata como si estuviéramos restrictivos, es decir parece que estuviéramos haciendo bien las cosas porque estamos en el camino del medio, nos acusan los de la patria de la concentración [económica] y también va por más la Iglesia, que siempre es la utopía. Entonces nosotros decimos metafóricamente que el Ámbito Financiero nos lleva al infierno, la Iglesia nos pide que estemos en el cielo, estamos en el purgatorio en términos de política migratoria, es decir podemos llegar al cielo. (Noel Breard, Cámara de Diputados de la Nación, Buenos Aires, 2000)

El debate en torno a una nueva ley de migraciones parecía constituir el escenario propicio para que el Poder Ejecutivo, a través de los organismos tradicionalmente encargados de las migraciones internacionales, pudiera dejar sentada su posición. Las dos intervenciones de Ángel Roig -una en representación del Ministro del Interior y otra como director de la DNM- apuntaban a presentar una serie de reflexiones acerca de la política migratoria argentina, sentando algunas bases para su discusión, pero sobre todo ofreciendo una propuesta programática. En este sentido, el contenido de su presentación tiene un carácter inaugural, ya que los lineamientos políticos que proponía se corresponderán con el núcleo duro de ideas que sostuvieron los sucesivos funcionarios a cargo de la DNM, particularmente durante la gestión de Rodríguez entre los años 2004 y 2007 y su continuación con Arias Duval a partir del año 2008.

En su primera exposición establece la necesidad de definir una "nueva política" guiada por "el conocimiento de la realidad", incluida la "realidad migratoria", y fundamentada en una concepción que la considere como "parte de las relaciones internacionales" 287 entre

\footnotetext{
287 Sobre la concepción de relaciones internacionales que asume esta gestión se pronuncia extensamente el Director Nacional de Investigación, Política y Desarrollo Demográfico del Ministerio del Interior, Noel Breard: “Nosotros que no somos ni marxistas ni liberales, sino que creemos en una visión socialdemócrata algunos, otros con la visión socialcristiana, creemos en definitiva el Estado tiene mucho por hacer, aún a pesar de las mutilaciones y los condicionamientos que tiene a futuro. Y es por eso que es fundamental pensar que cuando hacemos políticas
} 
Estados, se inserte en los "objetivos de integración” que llevan adelante los países de la región como el Mercosur y se encuadre en la "dimensión ética del respeto por los derechos humanos". Para este funcionario, la aproximación a la "realidad migratoria" debe suponer un análisis fundado en la "objetividad", que reconozca a las migraciones como un fenómeno social complejo. Esta "objetividad en el conocimiento" es reclamada como uno de los requisitos indispensables para poder llevar adelante medidas y políticas que cumplan con sus objetivos.

Este desafío implica el conocimiento de la realidad, su aceptación, y la utilización de los antecedentes preexistentes sobre la materia, sin ellos se corre el riesgo de fundamentar las políticas migratorias a partir de preconceptos muy generales, prejuiciosos y carentes de objetividad, o de implementar medidas que no aportan soluciones duraderas. El desconocimiento de la realidad migratoria suele desembocar en el estereotipo de la política "voluntarista" que no apreciando el problema en su verdadera complejidad, tiende al planteo de diagnóstico simplista, y consecuentemente a la aplicación de medidas poco eficaces que no consiguen los fines perseguidos o, lo que es peor, terminan generando mayor irregularidad migratoria. (Ángel Roig, Cámara de Diputados de la Nación, Buenos Aires, 2000)

migratorias, aún de la Argentina, tenemos que pensar que no las podemos hacer con el paradigma del aislacionismo o el concepto de las relaciones internacionales que implicaban el realismo político, que era encerrase en sí mismo, negar la cooperación, el de al lado era enemigo, y lo que se llamaba la mala fe inherente: como el otro era malo y se armaba para atacarme, yo me tengo que armar para atacar, y generábamos el círculo de lo que se llamaba la paz armada, y la posibilidad de guerra. En definitiva, cambiando los conceptos en estos términos de relaciones internacionales que significa tener otra visión de país, creer en la cooperación, pero en la cooperación inteligente, creer en un proceso de integración, como una faz más profunda que la cooperación, porque la cooperación implica simples contactos que no son vinculantes ni obligatorios, no así la integración, que empieza a tener compromisos bilaterales, compromisos multilaterales, compromisos regionales, que implican empezar a tener una visión de corresponsabilidad. Y ahí aparece también en el tema migratorio toda una visión diferente, si tenemos este concepto, porque ya no somos nosotros en términos de aislacionismo que vamos a hacer un proceso de política migratoria, de una norma migratoria, sino con una visión regional, teniendo una visión como bien dijo Roig, tenemos que definir la política del Mercosur y asociados en la visión de regionalismo abierto que tenemos, y una política extraMercosur, extracontinental, y aún una respuesta que tenemos que dar al ALCA, que nos aprieta y que nos obliga a definirnos políticamente, porque se está construyendo el ALCA y tenemos que dar una respuesta, tenemos que saber para dónde vamos. Nosotros definimos tener un proceso sudamericano diferente a este proceso, esto es una definición política que hemos establecido." 
En este sentido, se identifican dos aspectos relevantes a tener en cuenta para la elaboración de la nueva política migratoria: la transformación de los patrones migratorios en el ámbito latinoamericano así como los que conforman la inmigración hacia la Argentina y el proceso de integración regional Mercosur. Estos mismos elementos serán considerados por la gestión de la DNM, que asumirá poco tiempo antes de la aprobación de la nueva ley de migraciones, en su fundamentación de la nueva política migratoria. Asimismo, además de señalar la necesidad de superar las limitaciones del esquema estatocéntrico para el manejo de las migraciones, aquí ya se evidencia una clara preocupación, inspirada en la perspectiva de la gobernabilidad migratoria, por la necesidad de canalizar los flujos migratorios provenientes de los países limítrofes y las limitaciones que posee la normativa migratoria para detenerlos.

La creciente libre movilidad de personas, en los espacios de integración que se van construyendo mundialmente, en nuestro caso el MERCOSUR, debe necesariamente influir en las políticas migratorias que se adopten en el futuro. [...] Por su parte, específicamente en el ámbito latinoamericano, los últimos años se han caracterizado por una clara transformación de los patrones migratorios internacionales generada a partir de la crisis que afecta en forma generalizada a los países de la región. Ambos procesos se encuentran ligados en una doble lógica donde la integración aparece incompleta si no se considera el intercambio de personas manifiesto a través de las migraciones; y [las] políticas migratorias resultan ineficaces si no contemplan el marco de integración en el que están comprometidos los países. Lo dicho encuentra su fundamento en la constatación de la irrealidad con que se han manejado las políticas migratorias y en la necesidad de canalizar estos flujos migratorios de la manera más conveniente posible en los procesos conjuntos de integración para el desarrollo de los países. En nuestro caso conocer y aceptar la realidad implica reconocer que los flujos migratorios provenientes de países limítrofes no pueden ser frenados por disposiciones normativas; así como también desechar la falsa perspectiva de análisis del fenómeno migratorio como un problema interno, entendiendo que su verdadera esencia se inserta en las relaciones bilaterales e incluso multilaterales de los países involucrados. Aproximadamente el $85 \%$ de los flujos migratorios que recibe Argentina provienen de países limítrofes y de Perú. Conociendo esa circunstancia y frente a la existencia del MERCOSUR, deberíamos implementar una política 
migratoria que contemple ambas situaciones. (Ángel Roig, Cámara de Diputados de la Nación, Buenos Aires, 2000)

También destaca la importancia que tiene la integración del migrante en la formulación de la política estatal referida a las migraciones internacionales, diferenciando integración de asimilación. ${ }^{288}$ En esta oportunidad ya se esboza uno de los argumentos centrales esgrimidos para fundamentar las medidas de regularización migratoria que varios años más tarde implementará el gobierno nacional: la "plena integración" (o "inserción plena") del inmigrante se encuentra supeditada a la legalidad. Para ello, era necesario que la nueva ley, en respuesta a "la realidad", creara "mecanismos de fácil acceso a la legalidad".

Finalmente quiero señalar que la plena integración del migrante al medio nacional debe constituir un aspecto esencial de la política del Estado en el enfoque y modo de tratar el fenómeno migratorio. El concepto es el de integración y no el de asimilación, toda vez que la aspiración no es convertir a los inmigrantes en individuos idénticos a nuestros ciudadanos nativos, la intención es respetar las diferencias e individualidades e incentivar la inserción plena del inmigrante a la sociedad, circunstancia esta última solo alcanzable mediante la legalidad. De allí la importancia de que la ley, como herramienta de la política, responda a la realidad y cree mecanismos de fácil acceso a la legalidad. (Ángel Roig, Cámara de Diputados de la Nación, Buenos Aires, 2000)

La intervención de la asesora del DNM, Adriana Alfonso, recupera las nociones centrales de la propuesta que realizara Roig en nombre de esta dependencia estatal. Ella hace nuevamente hincapié en "la necesidad de que la legislación migratoria se ajuste a la

\footnotetext{
$288 \mathrm{Si}$ bien las declaraciones de los funcionarios pueden diferir de la posición oficial que pretenden sostener las instituciones, ellas no dejan de ser un buen reflejo de las representaciones hegemónicas del Estado sobre los inmigrantes y los procesos de inserción social que subyacen a ellas. Es elocuente la siguiente expresión del encargado de la Dirección Nacional de Investigación, Política y Desarrollo Demográfico del Ministerio del Interior: “Nosotros queremos encontrar lo que llamamos una política migratoria, usando un concepto cristiano, la paternidad responsable. Este es el concepto de filosofía que nosotros tenemos como política migratoria para adelante, porque tenemos que integrar a la gente, tenemos que dar trabajo, y fundamentalmente, tenemos un drama" (cursivas nuestras). Este "drama” estaría constituido por la tensión entre el imperativo moral de atender a los inmigrantes en tanto "país receptor" y de solucionar los "grandes problemas económicos" que atraviesa el país.
} 
realidad", lo cual implicaría contemplar la situación geográfica e histórica de la Argentina y el proceso de integración regional del cual participa el país como miembro. En su exposición también adelanta el mecanismo que terminará adoptando el Estado en el marco de la regularización migratoria impulsada durante la gestión de Ricardo Rodríguez: allí dice que "la nueva legislación deberá contemplar de alguna manera algún criterio diferenciado respecto de aquellos que formamos parte de una región y de aquellos países que vendrían a ser terceros dentro del proceso de regionalización". Efectivamente, como veremos más adelante, el proceso de regularización migratoria finalmente se llevó a cabo en base a la división entre ciudadanos de Estados miembros del Mercosur ampliado (básicamente todos los países sudamericanos) y ciudadanos de Estados que no pertenecen a este espacio regional. Por otra parte, en esta oportunidad plantea "los tres grandes interrogantes" que utilizan -y utilizarán en el futuro próximo- en la adopción e instrumentación de una medida política: ¿qué tenemos?, ¿qué queremos? y ¿qué podemos lograr?

En principio, las respuestas a estas preguntas orientarán las acciones gubernamentales. Pero lo que interesa aquí es la visión que subyace al planteo general y el razonamiento que se sigue: se tiene un condicionante que está dado por la realidad geográfica e histórica del país, la cual entre otras cosas implica la aceptación de la migración limítrofe como un dato fehaciente de la realidad, y se pretende "una migración ordenada" y su "integración" a través de la "legalidad". Para lograr este propósito, se necesitan "medidas que se ajusten a la realidad", una realidad que debe ser identificada para ser "normada". Esta visión conduce necesariamente a un programa de regularización migratoria, ya que, en definitiva, lo que se pretende regular, regularizar, reglamentar, es decir, normalizar, es aquella migración que no reúne condiciones de legalidad, o más concretamente, una fracción específica de los extranjeros, los llamados inmigrantes ilegales y, posteriormente, irregulares.

Respecto del qué tenemos, tenemos una realidad geográfica histórica que nos condiciona respecto de la normativa que podemos llegar a implementar. Respecto del qué queremos, coincidiremos que queremos una migración ordenada y con posibilidades ciertas de integración total a la sociedad, esta integración deberá darse a través de la legalidad. Y ahora sí, viene la conjunción de ambos puntos: qué podemos. Para poder lograr la integración plena a la sociedad a través de la legalidad deberemos implementar medidas 
que se ajusten a la realidad, debemos tener en cuenta cuál es la realidad que queremos normar. (Adriana Alfonso, Cámara de Diputados de la Nación, Buenos Aires, 2000)

En su segunda presentación, Roig se centra en las prioridades que la nueva legislación debería atender. Siguiendo las consideraciones hechas durante su primera exposición referidas al "conocimiento de la realidad", plantea que "(e)l diagnóstico de la situación de la migración en la Argentina nos lleva a la conclusión de que nuestra normativa migratoria no se ajusta a la realidad y que resulta necesaria su modificación". ${ }^{289}$ Dentro de los distintos temas salientes que enumera y que llegarán a plasmarse en la nueva ley de migraciones, los dos últimos anuncian las preocupaciones que mantendrán en vilo al Estado: la búsqueda de una "solución viable y duradera al problema de la ilegalidad" y el desplazamiento del control del ingreso al control de la permanencia. ${ }^{290}$

Como corolario de lo dicho esta mañana y lo recientemente manifestado, cabe señalar que desde la Dirección Nacional de Migraciones entendemos que una nueva ley migratoria debería contener, como prioridades: el reconocimiento y aceptación de la realidad migratoria que nos condiciona, y la necesaria adecuación de la normativa a la misma; la creación de un mecanismo de consulta a las provincias como forma de conocer las diferentes realidades regionales; la legalidad como única forma de integración plena a la sociedad; el respeto a los derechos y libertades del extranjero y su equiparación con los nacionales, fundamentalmente en lo referente a educación y salud; la intervención judicial en la revisión de las resoluciones que conllevan la expulsión o que implican la privación de la libertad del extranjero; la penalización de la figura del traficante de personas y de quienes se aprovechan de la migración irregular; la necesaria influencia del Mercosur en la política migratoria, la reciprocidad y el diálogo multilateral que sobre el

\footnotetext{
289 Algunos años más tarde la funcionaria Adriana Alfonso sostendrá en un seminario organizado por la DNM: “Toda esta realidad nos hizo llegar a la conclusión de que era necesario cambiar la óptica con que se estaba manejando la estrategia migratoria” (Adriana Alfonso, Seminario “Migraciones y Derechos Humanos”, Rosario, 2005).

290 Mediante un análisis de la legislación migratoria argentina, Pacecca (2000) muestra que la preocupación estatal por el control del ingreso es desplazada por el control de la permanencia a partir del cambio que se produce en la composición de las corrientes migratorias (esto es, mayor participación de la inmigración limítrofe sobre el total de la población extranjera) hacia mediados del siglo XX y la visibilidad que adquiere este proceso.
} 
fenómeno migratorio en la región conlleva la existencia del mismo; los convenios bilaterales como solución viable y duradera al problema de la ilegalidad; la previsión sobre el paulatino aumento que deberá registrar el control de permanencia a medida que los controles de ingreso se hagan más laxos como producto del avance de la integración. (Ángel Roig, Cámara de Diputados de la Nación, Buenos Aires, 2000)

Finalmente, entre otros aspectos, el director de la DNM expresa la intención de revertir la imagen que tiene la DNM como institución representativa del aparato represivo del Estado. Como veremos más adelante, esta preocupación emergerá nuevamente con la implementación del programa de regularización migratoria que se llevará a cabo bajo la gestión de Ricardo Rodríguez: dado que dicha imagen es considerada como un impedimento para alcanzar una cantidad importante de trámites de regularización, el Estado se asociará con distintas organizaciones civiles para llevar adelante el programa. En esta ocasión, en nombre de la justicia y la protección de los inmigrantes, en particular de aquellos que están "en forma irregular", apela a la sociedad civil para que se involucre y coopere con las medidas de control, el control de la permanencia más precisamente, como si la explotación laboral fuera una situación coyuntural o una emergencia o se tratara de casos aislados, bajo la promesa de no sancionar a los inmigrantes, pero sin nombrar a los responsables que pretenden castigar. Como pudimos observar en el capítulo anterior, no es la primera vez que se pretende involucrar a la sociedad civil en el control de la inmigración.

Yo quiero aprovechar este auditorio para decirles que nosotros hemos intentado, y realmente venimos haciendo una recorrida por distintos lugares del país, poniendo en funciones a los nuevos delegados de migraciones, e insistimos en todos los auditorios de tener una participación activa. De que tenemos el propósito, pero el propósito fundado en la convicción de que la Dirección Nacional de Migraciones tiene que dejar de ser un organismo que sea visto como un organismo autoritario, de carácter casi persecutorio. La intención nuestra no solamente es cordializar el trato, sino que se encuentre en la Dirección Nacional de Migraciones el lugar de la consulta, el lugar en donde realmente se pueda llegar en un diálogo fecundo a buscar la forma y las soluciones de los problemas. Cuando nosotros hablamos de un control de permanencia, no es que hablamos de un Estado policial, para que esté en la 
calle Migraciones, sino al revés, estamos queriendo decir con esto que el que esté en forma irregular -y venimos diciendo e insistiendo nosotros todos acá en estos paneles que el que está en forma irregular es producto de la explotación- lo queremos identificar, pero no para sancionarlo a él, para darle una posibilidad a la mujer o al hombre que se encuentre en esa condición. Queremos por otra parte, queremos, deseamos y lo estamos dando como instrucción, que realmente el que sea sancionado sea el que se aproveche de la condición de ilegalidad o de la situación irregular. Pero para eso también necesitamos colaboración. La Dirección Nacional de Migraciones, por intermedio de ustedes, tiene que recibir incluso la denuncia de dónde debemos actuar. Si actuamos a tiempo es muy probable que ese trabajador no sea explotado en la forma en que es explotado con el sistema de camas calientes, con rebajas de salarios, con aumentos de horarios de trabajo, con situaciones incluso infrahumanas de vivienda. Y esto lo podemos hacer en la medida en que tengamos una colaboración cierta de todos. Lo hacemos con la gente de Ministerio de Trabajo, lo hacemos con la AFIP, lo hacemos con los gobiernos provinciales y de la ciudad de Buenos Aires, pero necesitamos también una sociedad que esté convencida de que la Dirección Nacional de Migraciones no va a perseguir, sino que trata de poner justicia. (Ángel Roig, Cámara de Diputados de la Nación, Buenos Aires, 2000)

La exposición del militar retirado Juan Manuel Llavar en abril de 2002, a tres meses de haber asumido el cargo de director, se inicia con distintos aspectos relacionados a la capacidad operativa de la DNM, ofreciendo al auditorio una gran cantidad de cifras. Luego, su intervención se centra -como buen militar- en la relación entre migraciones y seguridad: "Cuando se habla de migraciones hay que pensar en migraciones y en seguridad, buscando el justo medio". Entre las cuestiones que identifica como prioritarias aparecen el "tráfico de personas" y los "inmigrantes ilegales" junto al negocio de las "mafias" en el contexto internacional. Al final, señala como "otra falencia grave" la carencia de una política migratoria y subraya la necesidad de modificar la ley de migraciones con el objetivo de conseguir "la legalidad en el ingreso y permanencia de los extranjeros". La ilegalidad de los migrantes es atribuida a la incompetencia de los organismos del Estado encargados de administrar el ingreso y la permanencia de los inmigrantes. La solución, una vez más, consistiría en la facilitación de los trámites migratorios, aunque sin descuidar el tema de la seguridad. 
El objetivo que queremos lograr con ese cambio es la legalidad en el ingreso y permanencia de los extranjeros, facilitándoles las cosas sin dejar de lado la seguridad. El hecho de que se deban hacer trámites tan engorrosos, sea por impericia o por inoperatividad de las delegaciones, lleva muchas veces a que los extranjeros se transformen en ilegales. Para evitarlo, estamos intentando facilitar los trámites pero sin descuidar el tema de la seguridad. (Juan Manuel Llavar, Cámara de Diputados de la Nación, Buenos Aires, 2002)

El intercambio con los diputados también discurre mayormente sobre la capacidad operativa del organismo, la seguridad nacional y los inmigrantes nombrados como ilegales o irregulares. ${ }^{291}$ Nuevamente, una de las preocupaciones centrales que emerge desde la dirección de la DNM es la regularización de la situación administrativa de los inmigrantes. Es significativo el modo en que se expresa: "poner en la legalidad a todos los inmigrantes que en estos momentos se encuentran dando vueltas" (énfasis propio).

Por ejemplo, sería conveniente reforzar el cuerpo de inspectores; ello nos daría la posibilidad de poner en la legalidad a todos los inmigrantes que en estos momentos se encuentran dando vueltas. Con un cuerpo de inspectores podríamos asistir mejor a los inmigrantes, porque tampoco es cuestión de meterlos presos o perseguirlos. Hay gente que viene al país con toda la buena voluntad de trabajar, y creemos que debemos darle una oportunidad. (Juan Manuel Llavar, Cámara de Diputados de la Nación, Buenos Aires, 2002)

En su intervención también hace referencia a la necesidad de definir la política migratoria a partir de la "aceptación de la realidad". Vuelve a aparecer, asimismo, la idea de que la ilegalidad es producto de los obstáculos administrativos que establece el propio Estado y la voluntad de facilitar el trámite para la obtención de la documentación requerida para no tener "tantos ilegales".

291 El director de la DNM afirma que "tenemos 350.000 ilegales en todo el país". 
Creo que esto lo podemos hacer muy bien en el tiempo, y no estoy hablando de mucho tiempo. Simplemente hay que fijar políticas sobre qué queremos nosotros con respecto a las migraciones, por ejemplo las de los bolivianos, de los chilenos, etcétera. Necesitamos una política de migraciones, partiendo de la aceptación de la realidad que vivimos. Si el Ejecutivo y el Legislativo fijan una política, esto lo podremos sanear rápidamente. Estamos trabajando para facilitar -sin dejar de lado la seguridad del país- al inmigrante la obtención de la documentación necesaria. Creo que tenemos tantos ilegales porque nosotros a veces ponemos demasiadas trabas en los trámites que tienen que hacer, y en eso estamos trabajando. [...] Entonces, lo que acá hay que ajustar son los procedimientos, y decir cómo se hacen las cosas. De esta manera, y sacando algunos pasos del viejo procedimiento, yo creo que esto lo podremos arreglar muy rápido. (Juan Manuel Llavar, Cámara de Diputados de la Nación, Buenos Aires, 2002)

En la misma línea, la asesora de la DNM, refuerza la sugerencia de desarrollar una política migratoria que "se ajuste a nuestra realidad y que no genere ilegalidad", para lo cual debe ser "lo suficientemente amplia y flexible". Ello implica tomar en cuenta los movimientos intrarregionales de población y el Mercosur como proceso de integración regional. Esta decisión política es enunciada como contrapunto a los escasos resultados que tuvieron las llamadas amnistías, implementadas con gobiernos anteriores, para enfrentar la ilegalidad.

Con respecto a la experiencia que hemos tenido con anteriores amnistías generales -la última data de 1992- cabe decir que ésta no ha sido buena. Hemos advertido que en realidad se trata de un parche muy coyuntural, que cuando termina la amnistía empezamos a generar ilegales nuevamente. La idea pasa entonces por plasmar una política que se ajuste a nuestra realidad y que no genere ilegalidad, que sea lo suficientemente amplia y flexible como para poder abarcar esta realidad nuestra. En este momento tenemos que tener en cuenta por supuesto lo que es el movimiento regional y el MERCOSUR. Es muy posible que nuestra próxima política migratoria deba tener algún criterio diferenciado respecto de nativos nacionales de los países MERCOSUR, sin que ello implique llegar a pensar en una libre circulación. (Adriana Alfonso, Cámara de Diputados de la Nación, Buenos Aires, 2002) 
La breve exposición del director de la DNM, Jorge Rampoldi, en el seno de la Comisión de Población y Recursos Humanos de la Cámara de Diputados de la Nación durante el mes de julio de 2003, estuvo dirigida a expresar tres "niveles de preocupación" de la DNM que define como "lo urgente, lo estratégico y lo importante". En relación a "lo urgente" señala la intención de resolver asuntos pendientes de la DNM que hacen a las características de una administración ordenada, eficiente y transparente. "Lo estratégico" es relacionado con el modo en que el "tema migratorio", en tanto elemento constitutivo de las políticas de población, se articula con el "proyecto de país" asociado a la noción de desarrollo: entiende que este asunto "consiste concretamente en diseñar una matriz poblacional". En cuanto a "lo importante", según el funcionario de la DNM, "se trata de reconstruir nuestro pasado histórico migratorio inmediato [...] para que este pasado histórico que tiene la inmigración -que fue de nuestros abuelos y nuestros padres- sirva también para enorgullecernos de este proyecto de país y de base para el proyecto de país que pretendemos". La DNM sería la "herramienta idónea" para concretar esta misión en el marco de un "proyecto mayor".

La idea es que Migraciones sea la herramienta idónea para un proyecto de país en el tema poblacional. Hoy Migraciones tiene muy precisos sus objetivos desde el punto de vista funcional pero creo que hay que integrarlo dentro de un proyecto mayor. (Jorge Rampoldi, Cámara de Diputados de la Nación, Buenos Aires, 2003)

En una de sus respuestas a los diputados, destaca -junto a los costos que implica para el Estado un proceso de regularización migratoria, que asocia particularmente con los "ciudadanos bolivianos"- el lugar central que debe ocupar el "ser humano" en "los desvelos del Estado". Esta noción del "ser humano" como eje de las políticas también aparecerá más adelante en las distintas intervenciones públicas de los funcionarios de la DNM y en la intervención del propio presidente Kirchner durante el acto de lanzamiento del programa nacional de regularización migratoria Patria Grande a finales del año 2005.

También observamos que, por ejemplo, han sido muy magros los que han utilizado este protocolo [se refiere a los convenios bilaterales firmados por la Argentina], y para nosotros esto significa un costo importante en dinero y en distracción de personal, pues hemos abierto una oficina puntual para la regularización de ciudadanos bolivianos. Por eso digo que hay que ver las reciprocidades y las consecuencias. En principio, creo que hay que asumir esta realidad y darle forma, a fin de que tenga al ser humano como eje de todos los 
desvelos del Estado. (Jorge Rampoldi, Cámara de Diputados de la Nación, Buenos Aires, 2003)

\section{La "nueva política migratoria" y los derechos humanos: el "cambio de paradigma"}

En busca de legitimidad, con la asunción de Ricardo Rodríguez como nuevo director de la DNM y ya aprobada la ley de migraciones $\mathrm{N}^{\circ} 25.871$ por el Congreso Nacional, diversos funcionarios de alto rango de la institución y, en menor medida, de otros organismos del Poder Ejecutivo, comenzaron a difundir y explicar las medidas que estaban llevando adelante en materia de política de migraciones en distintos eventos nacionales e internacionales. Estas medidas inspiradas en la "nueva ley de migraciones" y reunidas bajo la denominación de "nueva política migratoria", responderían a una nueva perspectiva ${ }^{292}$ sobre los asuntos migratorios, que en algunas intervenciones y documentos oficiales es caracterizada como un "nuevo paradigma"293, inscripta ya en algunos espacios del orden internacional y regional en los cuales la noción de gobernabilidad migratoria tuvo una importante acogida: el enfoque de los derechos humanos. ${ }^{294}$

Lo expresado precedentemente, da cuenta de que tanto en el ámbito universal como en el plano regional se ha ido plasmando paulatinamente un nuevo paradigma en el tratamiento de la cuestión migratoria, que es el de su enfoque desde una perspectiva de los derechos humanos y la no discriminación. (MRECIyC, Encuentro Iberoamericano sobre Migraciones y Desarrollo, Madrid, 2006)

Según la visión de los funcionarios estatales, el actual escenario de las migraciones internacionales intra y extrarregionales requiere del Estado un "cambio de paradigma", concebido como un desplazamiento desde el enfoque estatocéntrico de la seguridad y

\footnotetext{
292 En los diversos documentos también se utilizan nociones como "mirada", "enfoque” o “abordaje”.

293 MRECIyC, Encuentro Iberoamericano sobre Migraciones y Desarrollo, Madrid, 2006.

294 En este contexto, si bien el ámbito estatal ha sido históricamente el espacio reservado para el tratamiento de esta materia, en los últimos tiempos, según Sassen, asistimos a una "transnacionalización de facto" en el manejo de los asuntos migratorios, lo cual implica que el Estado no define exclusivamente las políticas migratorias en el marco de sus fronteras nacionales, sino mediante la actuación de diversos actores sociales y políticos, sean de carácter nacional o transnacional, en espacios locales o supranacionales. En este sentido, la internacionalización del régimen de derechos humanos estaría afectando cada vez más la política migratoria (Sassen, 2003).
} 
control de fronteras hacia una perspectiva integral de derechos humanos, en la cual el migrante y su familia sean el objeto principal de las intervenciones de gobierno.

La República Argentina entiende que el Siglo XXI nos obliga a responder a la complejidad de los flujos migratorios en Iberoamérica con un cambio de paradigma en el tratamiento de las migraciones internacionales: debemos pasar de un enfoque de seguridad y control de fronteras -basado exclusivamente en el concepto de Estado-Nación- a una perspectiva integral de derechos humanos, donde el migrante y su familia deben ser el eje de las políticas gubernamentales en la materia. (MRECIyC, Encuentro Iberoamericano sobre Migraciones y Desarrollo, Madrid, 2006)

Este "nuevo paradigma" o "cambio de paradigma" relativo a las migraciones internacionales habría sido adoptado con la "nueva política migratoria" del Estado argentino -plasmado en el "espíritu de su política migratoria"- y se habría materializado en dos instrumentos centrales, que analizaremos en detalle más adelante: la ley de migraciones y el programa nacional de regularización migratoria.

La República Argentina ha procurado plasmar este nuevo paradigma en el espíritu de su política migratoria y, en consecuencia, en las disposiciones de la nueva Ley Nacional de Migraciones, vigente en nuestro país desde el mes de enero de 2004. (MRECIyC, Encuentro Iberoamericano sobre Migraciones y Desarrollo, Madrid, 2006)

Muestra de ello [del cambio de paradigma] es el Programa Nacional de Normalización Documentaria Migratoria (denominado "Patria Grande"), que, congruente con esa visión estratégica de país, refleja una perspectiva humana y social en la materia, beneficiando a todos los extranjeros nativos de los estados Parte y Asociados del MERCOSUR, siendo el criterio de regularización la nacionalidad del solicitante. (MRECIyC, Encuentro Iberoamericano sobre Migraciones y Desarrollo, Madrid, 2006) 
Según el planteo subyacente a los diversos documentos oficiales e intervenciones públicas de los funcionarios, la "nueva política migratoria" sería la concreción del paso de un enfoque basado en los principios de seguridad y control a otro fundado en el precepto de los derechos humanos, presentados como perspectivas antagónicas y mutuamente excluyentes. En este proceso, la perspectiva del control y la seguridad, colocada en el pasado, habría sido reemplazada por la perspectiva de los derechos humanos, en plena vigencia, acentuando de este modo, la idea de ruptura entre ambos sistemas de pensamiento y acción, en particular cuando se considera el cambio en términos de paradigma. Así, siguiendo el argumento oficial, lo nuevo de la "nueva política migratoria" sería el cambio de enfoque adoptado, sustentado en los derechos humanos. De acuerdo a ello se postula un "giro diametral" en materia de política migratoria y se presenta la postura del Estado argentino como una "posición de avanzada" en relación a la protección de los derechos de los migrantes.

En términos de medidas políticas, las distintas perspectivas son caracterizadas de acuerdo a los criterios de admisión y permanencia que una y otra supondrían, contraponiendo un modelo basado en una noción restrictiva y punitiva de la migración frente a otro fundado en las ideas de integración e inserción asentadas en los derechos humanos. Ya a pocos meses de aprobada la nueva ley de migraciones, en algunas disposiciones jurídicas se afirmaba, por ejemplo, que a la fecha se habían ejecutado "diferentes acciones para remediar la situación encontrada, como participar activamente en la modificación de la legislación cambiando un régimen expulsivo por un sistema de integración e inserción basado en los Derechos Humanos". 295

Para dar cuenta de este cambio de paradigma o enfoque, los documentos oficiales de política migratoria, especialmente cuando se trata de documentos presentados en el ámbito internacional, suelen enunciar las distintas convenciones internacionales referidas a la protección de los derechos humanos en general y de los derechos de los inmigrantes en particular, especialmente la Convención Internacional sobre la Protección de los Derechos de Todos los Trabajadores Migratorios y de sus Familiares de Naciones Unidas.

295 Decreto № 836/04. No mucho antes, en el mes de abril, la DNM había establecido que "los extranjeros que ingresen al país deberán denunciar el domicilio o el nombre y domicilio del hotel en el que se alojarán en la República” (Disposición de la DNM № 17.628/04). 
Visto en perspectiva histórica, la adopción del discurso de los derechos humanos en materia de política migratoria constituye una discontinuidad o disrupción ${ }^{296}$ significativa con la visión restrictiva y represiva que mantuvo el Estado argentino frente a los inmigrantes y las migraciones internacionales durante las últimas décadas del siglo veinte. En la Argentina, a diferencia de otros contextos nacionales, la defensa de los derechos de los migrantes se inscribe, en parte, en la propia experiencia política del país. Como señala Jelin, en la transición política posterior a la dictadura militar, si bien la cuestión migratoria no ocupaba el centro de la agenda estatal, "el marco interpretativo dominante ponía el énfasis en defender los 'derechos humanos' que habían sido violados durante la dictadura y en ampliar la noción de derechos humanos para convertirla en la piedra fundacional del nuevo orden constitucional", lo cual posibilitó -junto a la apertura de mecanismos de expresión directa de demandas ciudadanas- que el tema migratorio ingresara en los ámbitos del Estado (Jelin, 2006: 59). Pero tuvieron que transcurrir muchos años para que, en el marco del Estado, se adoptaran medidas políticas nacionales que recogieran los preceptos de los derechos humanos en materia de migraciones. Como se ha señalado en reiteradas ocasiones, la Ley Videla estuvo vigente durante más de dos décadas de sucesivos gobiernos democráticos. ${ }^{297}$

Sin que formara parte de la agenda de gobierno, es a partir de la sanción de la nueva ley de migraciones -como expresión de distintos intereses y diversas fuerzas sociales y políticasque el Estado nacional incorporó como un aspecto constitutivo de su discurso la temática de los derechos humanos de los inmigrantes. El hecho de que encontrara resonancia en el Estado y resultara viable su desarrollo en el tiempo se explica, en alguna medida, por el contexto inmediato en el cual se inauguró y llevó adelante la "nueva política migratoria". Con el gobierno de Kirchner, como sostiene Svampa, la condena de las violaciones de los derechos humanos realizadas durante la última dictadura militar (1976-1983) se asumió como política de Estado, cuestionando la teoría de los dos demonios y promoviendo una política de la memoria, lo cual estableció una importante diferencia con las administraciones anteriores. En el marco de esta política de derechos humanos, el gobierno llegó "al punto de solicitar perdón a la sociedad en nombre del Estado argentino,

\footnotetext{
296 Más allá de que en este trabajo no adopte una mirada analítica centrada en identificar continuidades y rupturas, en esta oportunidad, explícitamente, evito hablar de ruptura para calificar algunos de los cambios que pueden advertirse en materia migratoria en esta coyuntura o, al menos, la idea de cambio que se pretende sugerir con la categoría nativa de "nueva política migratoria". En este sentido, a lo largo del trabajo he pretendido no asumir como algo dado la idea de cambio que los actores gubernamentales y no gubernamentales enuncian y anuncian en sus intervenciones públicas o entrevistas.

297 Hoy en día es un lugar común hacer esta observación. En su momento, cuando la política migratoria argentina empezaba a ser indagada, una de las autoras que lo señaló por primera vez fue Novick (1997).
} 
por la situación de impunidad registrada a lo largo de dos décadas de gobierno democrático respecto de las violaciones de derechos humanos durante aquella trágica época" (Svampa, 2007:42).

Por otro lado, el proceso de internacionalización de la política migratoria ha jugado un papel fundamental en la constitución de la "nueva política migratoria" y la emergencia del consecuente "cambio de paradigma" o la renovada visión que empieza a arraigarse en los organismos del Estado argentino especializados en la temática poblacional y migratoria. En este sentido, a mi juicio, la aparición del tema de los derechos humanos en el terreno de las migraciones en el contexto argentino se relaciona principalmente con la penetración de la gobernabilidad migratoria en los ámbitos de gobierno de las migraciones, como veremos en los próximos apartados. Como observan Geiger y Pécoud (2010), los derechos humanos tienen un rol central, aunque ambivalente, en el despliegue del migration management, posibilitando la construcción de entendimientos comunes. De allí el habitual énfasis en la necesidad de respetar los derechos humanos de los migrantes y las constantes referencias a las convenciones internacionales que servirían para dicho propósito. Precisamente, una de las tesis centrales de uno de los ideólogos del llamado nuevo régimen internacional para el movimiento ordenado de personas, Bimal Ghosh, es que la protección de los derechos humanos de los migrantes y la administración efectiva de la migración -asegurar que la migración sea ordenada y predecible $\mathrm{y}$, en consecuencia, más manejable- están estrechamente interrelacionados; dicho nexo sería el "eslabón perdido" (Ghosh, 2008). Mármora (2002), uno de los mayores propulsores de la gobernabilidad migratoria en América Latina, buscando operacionalizar dicha perspectiva, señala la importancia que posee el cumplimiento de los acuerdos y normas nacionales e internacionales, así como su coherencia y consecuencia con los principios y valores aceptados universalmente, para que la gobernabilidad migratoria obtenga la legitimidad necesaria.

En el marco de la "nueva política migratoria", guiada por el "nuevo paradigma", distintas dependencias del Poder Ejecutivo, tanto la DNM como el MRECIyC, buscan distanciarse de la visión economicista de las migraciones, pretendiendo mostrar una preocupación orientada por el "ser humano" o "la condición de persona" en la definición y formulación de la política migratoria y que vaya más allá de comprender a los migrantes como actores económicos. ${ }^{298}$

298 Esta visión también la expresa el sucesor de Ricardo Rodríguez al año siguiente que dejara la dirección del organismo: "Es que nuestra mirada sobre el bienestar no se reduce al buen pasar económico o financiero; se relaciona íntimamente con aquello que constituye la esencia del ser humano, con el reconocimiento de un status 
Argentina ha decidido mantener un "enfoque centrado en el ser humano" a la hora de establecer políticas públicas migratorias (MRECIyC, Encuentro Iberoamericano sobre Migraciones y Desarrollo, Madrid, 2006).

Este proceso regional, que nace con una visión arancelaria, hoy ha superado esa expectativa comercial y busca un objetivo mayor, aspira a lograr el bienestar de los pueblos y toma al hombre en su dimensión de "ser humano" de forma integral y no exclusivamente como actores de procesos económicos. (Ricardo Rodríguez, Encuentro Iberoamericano sobre Migraciones y Desarrollo, Madrid, 2006)

También bajo esta renovada concepción acerca de las migraciones internacionales, después que la inmigración de carácter limítrofe estuviera asociada en el discurso dominante de los años noventa a los problemas sociales y económicos del país bajo la figura de la amenaza, el discurso oficial toma distancia de esta caracterización y se manifiesta una visión fundada en las nociones de contribución o aporte de la inmigración, tanto la de ultramar como la de los países vecinos, reconociéndola a su vez -en algunas circunstancias- como necesidad u oportunidad para la Argentina. Se destaca básicamente, a pesar del distanciamiento que se pretende tomar de la visión economicista de las migraciones, la participación de la inmigración en el desarrollo poblacional y económico.

Argentina le debe mucho a las migraciones, a las migraciones europeas, a las limítrofes, a las asiáticas a las latinoamericanas, cada una con su idiosincrasia y cada una con su aporte. Cuando allá por el 1900 los migrantes europeos llegaron, llegaban a la Argentina, se encontraban con el Hotel de Inmigrantes, un enorme edificio que el gobierno argentino había construido especialmente para darles alojamiento y orientación e introducirlos a lo que era la sociedad argentina. Ellos venían perseguidos por la guerra y el hambre, necesitaban un lugar para vivir, para trabajar y Argentina los necesitaba, necesitaba mayor población, gente que trabajara nuestras tierras. El tiempo fue pasando, las 
migraciones europeas descendieron, las limítrofes se mantenían de manera constante, vientos raros comenzaron a correr por la Argentina y se llegó a sostener que no necesitábamos migrantes, y no sólo que no los necesitábamos, sino que muchas veces eran los causales de problemas como la desocupación y la inseguridad. (Adriana Alfonso, Seminario Migraciones y Derechos Humanos, Rosario, 2005)

Lo cierto es que muchos de los avances intelectuales en el arte, en las ciencias y en el derecho fueron generados por los recién llegados. Las organizaciones gremiales, la legislación previsional y laboral abrevó en las fuentes intelectuales y las experiencias de los recién llegados. [...] El país creció de forma notable gracias al aporte de la inmigración, en 1869, año del primer censo poblacional, la Argentina contaba con 1.737.676 habitantes, y para 1914 ya tenía una población cercana a los 8.000.000, es decir en 45 años había multiplicado por 4,5 su cantidad de habitantes. [...] Los migrantes, ya sea bajados de los barcos o cruzando fronteras terrestres contribuyeron, en ese entonces, al salto inicial de Argentina hacia su crecimiento demográfico y su despegue económico. [...] La inmensa mayoría de los migrantes que recibíamos llegaban a nuestra tierra con una honesta intención de arraigo, sin embargo el autoritarismo y la necedad de algunos sectores internos llevaron a sostener que Argentina no necesitaba de los migrantes y que estos eran la causal de algunos de los males que nos aquejaban como el desempleo y la inseguridad. (Ricardo Rodríguez, Encuentro Iberoamericano sobre Migraciones y Desarrollo, Madrid, 2006)

Además, frente a las distintos perjuicios que se le adjudicaron a la "inmigración limítrofe" durante la década de los noventa, responsabilizándola principalmente por el desempleo y la delincuencia, diversos representantes del gobierno nacional buscan refutar o desmentir -generalmente apelando a estadísticas oficiales o a investigaciones científicas apoyadas en las mismas fuentes de datos- los efectos negativos que su presencia habría tenido. Es importante el contexto en el cual se desarrollan estas explicaciones: precisamente se trata del momento en que se pretendía iniciar la implementación del programa nacional de regularización migratoria. Para ello era necesario (de)mostrar que la estrategia elaborada no perjudicaría el crecimiento económico ni el empleo. 
Cuando desde la nueva política migratoria argentina se comenzó con el objetivo de regularizar a los indocumentados, muchas voces se alzaron advirtiendo que ese tipo de medidas acrecentaría el ya preocupante desempleo. La tasa de desempleo en el tercer trimestre de 2003 era del 16,3\%. Entre 1992 y 2003 habían obtenido residencia legal en Argentina 156.000 extranjeros, es decir aproximadamente 13.000 por año. Desde que el desempleo había estallado como problema a mediados de la década del '90, la culpable natural era la falta de restricciones adecuadas en la política migratoria. La ecuación 'inmigrante igual a culpable de desempleo' era sostenida pese a estudios que mostraban que los cómputos relacionados con los extranjeros tenían una incidencia menor de medio punto en la tasa de desocupación. (Ricardo Rodríguez, Encuentro Iberoamericano sobre Migraciones y Desarrollo, Madrid, 2006)

Llegado este punto es conveniente señalar que Argentina comienza a proyectar su nueva política migratoria en momentos en que se encontraba inmersa en una profunda crisis económica y con una tasa de desocupación cercana al 19\%. Hoy cuatro años más tarde, con 800.000 que han regularizado su situación la mejora económica es notable y la tasa de desocupación ha descendido a un dígito. Ello no implica que las mejoras se deban a la política migratoria, pero sí nos habilita a afirmar que una política migratoria, realista, amplia y de regularización no incide negativamente ni en el crecimiento económico ni en la tasa de desocupación. (Adriana Alfonso, Organización de los Estados Americanos, Washington D.C., 2008)

Por otra parte, la construcción de una visión sobre la migración articulada con los derechos humanos también supuso algunas modificaciones en el lenguaje empleado para referirse a los procesos migratorios y, entre ellas, las formas de nombrar a quienes los protagonizan. En diversos documentos oficiales e intervenciones públicas son denominados como "extranjeros", "migrantes" o "inmigrantes", evitando marcas atributivas relacionadas con su condición o situación administrativa. En los casos que se vuelve imprescindible hacer alguna referencia, los migrantes son definidos generalmente como "inmigrantes irregulares", "en situación irregular" o "en situación migratoria irregular" $299 \mathrm{y}$, ocasionalmente, como "indocumentados" o "clandestinos", desplazando

299 Es necesario señalar que estos modos de nombrar a los inmigrantes es especialmente notorio entre funcionarios de organismos gubernamentales directamente involucrados con la temática migratoria como la DNM y algunos 
progresivamente la noción de "inmigrante ilegal” (o "ilegales" directamente), naturalizada por los agentes estatales, entre otros. Durante muchos años, especialmente desde finales de la década de los noventa, el uso del término "ilegal" fue duramente cuestionado impugnado- por diversos representantes de organizaciones de la sociedad civil (ciertas asociaciones de inmigrantes, algunos sectores de la iglesia católica y determinados organismos de derechos humanos fundamentalmente).

Esta adecuación o corrección en el lenguaje sucede junto a la entrada en vigencia de la nueva ley, manifestándose con mayor nitidez durante la gestión de Ricardo Rodríguez al frente de la DNM. En sus dos intervenciones en la Cámara de Diputados -una en el 2004 y otra en el 2005- establece su preferencia -aunque con distinto tono- por el uso de "indocumentados" en lugar de "ilegales".

Realmente no me gusta usar la palabra "ilegales", prefiero decir "indocumentados". [...] Reitero que no me gusta la palabra "ilegal", serían "indocumentados". Lo ilegal está en contra de la ley, y aquí en realidad la persona no está contra la ley sino que lo que hace es un seguimiento de los capitales para tratar de sobrevivir. (Ricardo Rodríguez, Cámara de Diputados de la Nación, Buenos Aires, 2004)

El mayor problema que tenemos respecto a las migraciones es el que hemos atacado primeramente porque creemos que es el más importante: los inmigrantes llamados, entre comillas, ilegales, que nosotros denominamos indocumentados. (Ricardo Rodríguez, Cámara de Diputados de la Nación, Buenos Aires, 2005)

\footnotetext{
departamentos del Ministerio de Relaciones Exteriores. Esto no ocurre en otras dependencias del gobierno nacional. En las pocas intervenciones públicas del Ministro del Interior Aníbal Fernández sobre el tema nunca se hace uso del término "inmigrante", más bien se hace referencia a "extranjeros". Durante el discurso presidencial pronunciado en ocasión del lanzamiento del programa Patria Grande, mediante referencias elípticas, se elude toda mención explícita a los "extranjeros" o "inmigrantes" (en una sola ocasión se habla de "mano de obra extranjera") o se enfatiza el fenómeno social ("el problema migratorio").
} 
Asimismo, el término ilegalidad es sustituido por irregularidad para designar la situación administrativa del inmigrante. ${ }^{300}$ Es significativo este desplazamiento en las intervenciones públicas de los funcionarios de la DNM: antes de la aprobación de la ley la noción de ilegalidad era utilizada sin ningún tipo de reparo; después, prácticamente desaparece de los documentos, exposiciones y declaraciones oficiales. La noción de legalidad, sin embargo, es frecuentemente utilizada para señalar la condición necesaria (o el requisito indispensable) para asegurar su "plena integración". Como podremos constatar a lo largo de los próximos apartados, el progresivo abandono de los términos ilegalidad e ilegales y su reemplazo por legalidad o regularidad, por un lado, e irregulares por el otro, en el discurso oficial no significó que durante la gestión de Ricardo Rodríguez en la DNM la condición o estatus legal del inmigrante perdiera centralidad. ${ }^{301}$ Por el contrario, como mostraré más adelante, paulatinamente definirá la principal medida de intervención estatal en los asuntos migratorios.

\section{La ley Giustiniani: una ley para el "nuevo siglo"}

Después de varios años de discusión de diversos proyectos de ley, finalmente en el mes diciembre del año 2003 el Congreso Nacional sancionó una nueva norma migratoria nacional, la ley $\mathrm{N}^{\circ} 25.871$, derogando la normativa establecida por la última dictadura militar en 1981.302 De acuerdo a los fundamentos otorgados, la aprobación de la nueva ley de migraciones se fundaba no sólo "en la necesidad de poner fin a la vigencia de la Ley Videla", sino también en la preocupación por "definir las bases fundamentales para una política migratoria y poblacional para la República Argentina de cara al nuevo siglo y a las nuevas realidades del contexto regional e internacional" (Giustiniani, 2004:19).

300 Como se pudo advertir en el capítulo anterior, la noción de "irregularidad” también se empleó en los decretos de regularización migratoria de 1974 y 1984.

301 Este relativo consenso existente sobre el modo de nombrar a los inmigrantes o su situación administrativa, que pone de relieve las disputas en torno a la definición de la realidad sobre la cual se pretende actuar, no supone que haya un total acuerdo sobre el uso de uno u otro término.

302 La nueva Ley de migraciones fue sancionada por la Cámara de Diputados de la Nación el 4 de diciembre y la Cámara de Senadores de la Nación el 17 de diciembre. Fue promulgada de hecho el 20 de enero de 2004. La Ley № 25.871 posee 126 artículos agrupados en capítulos contenidos en 11 títulos: Título Preliminar: Política migratoria argentina; Título I: De los derechos y obligaciones de los extranjeros; Título II: De la admisión de extranjeros a la República Argentina y sus excepciones; Título III: Del ingreso y egreso de personas; Título IV: De la permanencia de los extranjeros; Título V: De la legalidad e ilegalidad de la permanencia; Título VI: Del régimen de los recursos; Título VII. Competencia; Título VIII: De las tasas; Título IX: De los argentinos en el exterior; Título X: De la autoridad de aplicación; Título XI: Disposiciones complementarias y transitorias. 
El autor del proyecto de ley fue el diputado del Partido Socialista (PS) Rubén Giustiniani, quien para su redacción se basó en el proyecto unificado que había tenido dictamen en la Comisión de Población y Recursos Humanos de la Cámara de Diputados de la Nación en 1999, pero que perdió estado parlamentario. En diciembre del 2001 presentó el proyecto de ley, que fue sometido a discusión y reelaborado, obteniendo el dictamen por unanimidad de la Comisión de Población y Recursos Humanos a fines del 2002. Dado que el proyecto caducó, se volvió a presentar en marzo de 2003.303

La ley resultante es de carácter "híbrido" (Courtis, 2006) debido a las divergencias existentes entre los proyectos que sirvieran de base para su elaboración: iniciativas de carácter restrictivo y represivo como los proyectos presentados por los diputados oficialistas Rampi y Pichetto y por el Poder Ejecutivo, firmado por Menem, Rodríguez y Corach, y otras de características contrarias que recogen la perspectiva de los derechos humanos como el proyecto de regularización migratoria de 1999 encabezado por el diputado Juan Pablo Cafiero. Al mismo tiempo, muchos de los artículos de ley, en particular aquellos referidos a los derechos de los inmigrantes, estuvieron influidos por la normativa internacional en materia migratoria. Como lo manifiesta el autor del proyecto de ley (Giustiniani, 2004), las normas y principios contenidos en la Convención Internacional sobre la Protección de los Derechos de Todos los Trabajadores Migratorios y de sus Familiares, la cual recoge anteriores convenios de la OIT relacionados con los derechos de los trabajadores migrantes, fueron adaptados y orientaron el proceso de redacción del proyecto de ley que después tuviera diversas modificaciones. En aquél momento esta Convención, aprobada por la Asamblea General de Naciones Unidas el 18 de diciembre 304 de 1990 y entrada en vigor en el mes de julio del año 2003, si bien había sido firmada por el Estado argentino, aún no había sido ratificada. 305

Así, la ley finalmente aprobada por unanimidad en el Congreso Nacional es resultado de la participación y de la relación de fuerzas entre diferentes actores sociales y políticos que intervinieron directamente en su elaboración y discusión como distintos órganos y organismos del Estado nacional y organizaciones de la sociedad civil (algunos organismos

303 Para una descripción del proceso de elaboración y aprobación de la nueva ley de migraciones, véanse Giustiniani, 2004; Novick, 2005; 2008.

304 Basándose en la fecha de aprobación de la Convención Internacional sobre la Protección de los Derechos de Todos los Trabajadores Migratorios y de sus Familiares, en el año 2000 la Asamblea General de Naciones Unidas proclamó el 18 de diciembre como el Día Internacional del Migrante.

305 Dicha convención fue ratificada por el Estado argentino el 23 de febrero del 2007. 
de derechos humanos, sectores de la Iglesia Católica, representantes de organizaciones de inmigrantes y especialistas de organismos internacionales así como del ámbito académico a título individual) e indirectamente a través de la incorporación de normas internacionales sobre migraciones del sistema de Naciones Unidas. De ahí que en la nueva ley hayan tenido cabida y hayan quedado resguardados intereses convergentes y divergentes como el derecho a migrar, la extensión y protección de derechos ciudadanos a los extranjeros, la libre circulación de mano de obra, la securitización de las fronteras y el derecho del Estado a admitir y rechazar el ingreso de extranjeros y a disponer su expulsión. Como veremos enseguida, la nueva ley de migraciones no sólo amplía y protege los derechos de los inmigrantes, como pretenden mostrar los funcionarios de gobierno en sus intervenciones públicas, sino que también recoge un conjunto de componentes de carácter restrictivo y represivo del régimen de control instituido a lo largo del siglo en la Argentina.

La reglamentación de la nueva ley, reclamada por diversos organismos de derechos humanos y asociaciones de inmigrantes, llegó varios años más tarde. La demora para su aprobación ha sido adjudicada a la gran cantidad de actores sociales y políticos (organismos estatales, organizaciones no gubernamentales y agencias internacionales) que intervinieron en el proceso de consulta y elaboración, además de la participación de funcionarios del Ministerio del Interior, especialmente de la DNP y la DNM. En el año 2008 se creó una comisión asesora para la reglamentación de la ley de migraciones, la cual estuvo integrada por la Organización Internacional para las Migraciones (OIM), el Alto Comisionado de las Naciones Unidas para los Refugiados (ACNUR), la Fundación Comisión Católica Argentina de Migraciones (FCCAM), el Centro de Estudios Migratorios Latinoamericanos (CEMLA), el Centro de Estudios Legales y Sociales (CELS) y la Asamblea Permanente por los Derechos Humanos (APDH). ${ }^{306}$ En el mes de mayo del 2010, año del Bicentenario de la Argentina, la presidente Cristina Fernández de Kirchner firmó el decreto reglamentario. ${ }^{307}$ En esta ocasión, la presidente describió la reglamentación de la nueva ley de migraciones como la culminación del proceso que permitió sustituir definitivamente la ley Videla, denominándola la "ley de la dictadura en materia migratoria" y contraponiéndola a "la nueva ley de la democracia". Destacó, asimismo, la participación de las organizaciones institucionales y no gubernamentales que estuvieron involucradas en la elaboración del nuevo reglamento, aduciendo que la posición de la Argentina en el terreno de las migraciones está a la vanguardia: "es un decreto absolutamente 
participativo que nos sigue colocando a la Argentina a la vanguardia en materia de políticas migratorias". Se remitió al pasado, ponderando las políticas de fomento de la inmigración que se iniciaron en la Argentina durante el siglo diecinueve y las distintas corrientes de inmigración que constituyen "nuestra realidad histórica". La imagen de la Argentina como país abierto a la inmigración y como sociedad integradora de los inmigrantes -contraponiendo la integración a la discriminación- también resonaron entre sus últimas palabras referidas a la reglamentación de la nueva ley:

Yo me siento muy orgullosa de ser un país que ha acogido a los inmigrantes de distintas oleadas con amor, integrándolos, no discriminándolos, porque eso habla bien de nosotros mismos, habla bien de nosotros como sociedad (Cristina Fernández de Kirchner, Salón Mujeres Argentinas del Bicentenario de la Casa de Gobierno, Buenos Aires, 2010).

Más recientemente, en una de sus intervenciones públicas, el director nacional de Migraciones, Martín Arias Duval, se refirió al proceso de reglamentación de la ley. Su descripción pone de manifiesto algunos mecanismos de construcción de la política que permiten más cabalmente el accionar del Estado y las decisiones cotidianas que están detrás de los grandes enunciados o declaraciones, sean orales o escritas. El decreto reglamentario venía posponiéndose hacía tiempo. Al asumir la nueva gestión de la DNM en el año 2008, una de las prioridades que se fijó fue conseguir la reglamentación de la ley. Para ello, como mencioné más arriba, se conformó una comisión integrada por diversos actores políticos nacionales e internacionales del más amplio espectro ideológico que constituyen los principales grupos de presión en el tema de las migraciones en el contexto argentino. Las instituciones y organizaciones reunidas fueron elegidas de acuerdo a las posibilidades de obtener legitimidad y lograr consensos que permitieran una rápida aprobación de la reglamentación de la ley. Merece ser citada en extenso la descripción que hace el director de la DNM de los comienzos del proceso de reglamentación.

La sanción de un decreto no es un tema fácil, sobre todo un decreto reglamentario de una ley que toca varios aspectos que tienen que ver con acceso a la justicia, seguridad, salud, educación, etcétera, etcétera [...] Por esta complejidad y por esta diversidad de temas que trata la ley 25.871, ese anteproyecto de reglamentación fue circulando por todos los Ministerios [...] Cuando nosotros nos hicimos cargo de la DNM, tomamos como desafío el dictado del reglamento [...] ¿Cómo conformamos la comisión? Primera definición: ¿Cuál es la máxima presión que tenemos para reglamentar 
urgentemente la ley? La demanda internacional de la Comisión Interamericana de Derechos Humanos. ¿Quién estaba patrocinando la demanda internacional? El CELS. Convocamos al CELS y le dijimos “¿ustedes quieren formar parte de la comisión que va a reglamentar el decreto? El CELS aceptó el desafío y dijo "nosotros formamos parte de la comisión". Pensamos también en otros organismos representativos de distintos sectores que de alguna manera le dieran fuerza al proyecto del decreto. Convocamos a la Asamblea Permanente de los Derechos Humanos, convocamos al Centro de Estudios Migratorios Latinoamericanos, el CEMLA, convocamos a organismos internacionales, la OIM, el ACNUR, la Dirección Nacional de Población y pensamos también... si nos quieren correr... y esto también tiene que ver con lo ideológico... si nos quieren correr por izquierda, no nos van a poder correr por izquierda porque está la APDH, está el CELS, que pregona una política de derechos humanos progresista, acá estamos cubiertos... tenemos la solvencia del respaldo de organismos internacionales como la OIM, el ACNUR, tenemos la participación de dos organismos del Estado, la Dirección Nacional de Migraciones y la Dirección Nacional de Población... y pensamos, dijimos bueno, si nos quieren correr por derecha, busquemos algún sector representativo de ideas más conservadoras, entonces convocamos también a la Iglesia... ahí convocamos a la Pastoral para las Migraciones, porque también buscamos convocar a organismos que tengan alguna trayectoria en materia migratoria [...] Y durante dos o tres meses la comisión trabajó este anteproyecto y este anteproyecto se convirtió en un proyecto. Un proyecto que a partir de la fuerza que tenían quienes formaban parte de la comisión, rápidamente logró el consenso del resto de los ministerios que ya habían intervenido con el anteproyecto. (Arias Duval, CineMigrante: Primer Festival Internacional de Cine y Formación en Derechos Humanos, Buenos Aires, 2010)

Ya habiendo conseguido contar con un proyecto de ley consensuado, después había que lograr ubicarlo entre las prioridades de la presidencia para que finalmente fuera aprobado. La firma del decreto reglamentario supuso que uno de los organismos del Estado nacional -en este caso la DNM- recurriera a una instancia internacional para que sus asuntos de interés fueran atendidos en el seno del propio Estado, incorporados como interés del Estado. 
Ahora, ¿cómo logramos colocarlo en la agenda de la presidenta de la Nación? Obviamente había un interés de la presidenta de la Nación, pero en un Estado, en una organización burocrática, a veces es complejo llegar con un instrumento jurídico como es un decreto que tiene que tener dictamen de la asesoría jurídica, de la secretaría legal y técnica, etcétera, etcétera... Viajamos con la Cancillería a Washington a una audiencia pública ante la Comisión Interamericana de Derechos Humanos y asumimos, con el riesgo de que no lográramos el objetivo, asumimos el compromiso expreso de en un plazo que nos fijamos, que fue de un mes si no me equivoco, en nombre de la República Argentina sancionar la reglamentación. Al poquito tiempo viaja a la Argentina la presidenta de la Comisión y se entrevista con el ministro del Interior y la presidenta de la Nación y les recuerda el compromiso de la Argentina y la necesidad de dictar el decreto reglamentario. Bastó eso para que se levantara un teléfono y la presidenta dijera quiero firmar el decreto reglamentario, tráiganmelo, y así logramos la sanción del decreto reglamentario. (Arias Duval, CineMigrante: Primer Festival Internacional de Cine y Formación en Derechos Humanos, Buenos Aires, 2010)

\section{Empezando de nuevo: nueva ley migratoria, nueva política migratoria}

La nueva ley de migraciones se constituyó en un instrumento central de la "nueva política migratoria", confiriéndole la legitimidad necesaria para llevar adelante las medidas gubernamentales que habían empezado a diseñarse en los ámbitos estatales especializados en las migraciones, aún antes de que la aprobación de la nueva ley fuera considerada como una posibilidad concreta. Ella contiene normas de protección de los derechos de los trabajadores migratorios inspirados en instrumentos jurídicos internacionales de Naciones Unidas y elimina parte de las arbitrariedades sustentadas en la ideología de la seguridad nacional contenidas en la ley Videla. Desde sus primeras intervenciones públicas destinadas a explicar y difundir la ley recientemente aprobada y la "nueva política migratoria", los funcionarios de la flamante gestión al frente de la DNM destacarán especialmente estos aspectos reformadores en materia de legislación migratoria. 
Entre las novedades de la norma nacional, la cual se constituye -según palabras del director de la DNM- en el "andamiaje legal" ${ }^{308}$ de la nueva política migratoria, aparecen la afirmación de los derechos humanos de los inmigrantes, reconociendo a la migración como derecho y a los migrantes como sujetos de derecho (Pérez Vichich, 2004), el contexto de integración regional y la figura del ciudadano comunitario, ${ }^{309}$ el "nuevo sujeto de la regionalización" (Giustiniani, 2004), y la inclusión de diversos aspectos relativos a la "integración" de los extranjeros. En efecto, según la letra de la ley, el Estado se compromete a velar por diversos derechos económicos, sociales, políticos y culturales de los migrantes reconocidos en la normativa nacional e internacional, distinguiendo a la migración como derecho. En su articulado establece que "el derecho a la migración es esencial e inalienable de la persona y la República Argentina lo garantiza sobre la base de los principios de igualdad y universalidad". Además, el Estado, en todas sus jurisdicciones, deberá asegurar "las condiciones que garanticen una efectiva igualdad de trato a fin de que los extranjeros puedan gozar de sus derechos y cumplir con sus obligaciones" y "el acceso igualitario a los inmigrantes y sus familias en las mismas condiciones de protección, amparo y derechos de los que gozan los nacionales".

Asimismo, la nueva ley de migraciones estipula la obligación de garantizar el acceso a servicios sociales básicos como salud, educación, justicia, trabajo, empleo y seguridad social, en algunas circunstancias específicas independientemente de la condición de la llamada regularidad migratoria. Precisamente, dedica especial atención a la figura del inmigrante "en situación irregular", buscando atender esta condición mediante la simplificación de los trámites y la flexibilización de los criterios de radicación. En el terreno de la educación, establece específicamente que “(e)n ningún caso la irregularidad migratoria impedirá su admisión como alumno en un establecimiento educativo", ya sea de carácter público o privado; nacional, provincial o municipal; primario, secundario, terciario o universitario. En materia de salud, se indica que "(n)o podrá negársele o restringírsele en ningún caso, el acceso al derecho a la salud, la asistencia social o atención sanitaria a todos los extranjeros que lo requieran, cualquiera sea su situación migratoria". Además, en ambos casos, las autoridades ya no deberán denunciar (como lo exigía la Ley Videla) a aquellos inmigrantes cuya estadía en el territorio nacional no está autorizada por el Estado, sino que “deberán brindar orientación y asesoramiento respecto de los trámites

308 Director de la Dirección Nacional de Migraciones, Encuentro Iberoamericano sobre Migraciones y Desarrollo, Madrid, 2006.

309 En recientes documentos regionales de política migratoria se hace referencia a la "ciudadanía sudamericana". Véase, por ejemplo, la declaración final de la octava y novena ediciones de la Conferencia Sudamericana sobre Migraciones. 
correspondientes a los efectos de subsanar la irregularidad migratoria". En el plano laboral, el empleador deberá cumplir "con las obligaciones emergentes de la legislación laboral respecto del extranjero, cualquiera sea su condición migratoria", a la vez que "en ningún modo se afectarán los derechos adquiridos por los extranjeros, como consecuencia de los trabajos ya realizados, cualquiera sea su condición migratoria”.

Finalmente, otro aspecto que suelen destacar de la nueva ley de migraciones los funcionarios estatales es la atención que reciben algunas cuestiones referidas a la integración de los extranjeros, reunidas bajo el objetivo de "promover" o "favorecer" la inserción social, económica (especialmente laboral) y cultural de los migrantes "en la sociedad argentina". Para ello compromete a los poderes públicos a impulsar "el fortalecimiento del movimiento asociativo entre los inmigrantes" y a apoyar "a los sindicatos, organizaciones empresariales y a las organizaciones no gubernamentales que, sin ánimo de lucro, favorezcan su integración social, prestándoles ayuda en la medida de sus posibilidades". Asimismo, en uno de sus artículos, ya se insinúa el modo en que el Estado operará para hacer efectiva, desde su concepción, la integración de los inmigrantes o los extranjeros - utilizado indistintamente- a la sociedad de destino/recepción: "El Estado proveerá lo conducente a la adopción e implementación de medidas tendientes a regularizar la situación migratoria de los extranjeros". Esta norma es la que servirá a los funcionarios de gobierno no sólo para instrumentar, sino también para legitimar el programa de regularización migratoria, apelando a los derechos humanos de los migrantes reconocidos en ella.

La nueva ley contempla altos estándares de protección de los derechos de las personas migrantes y es la base de la implementación de políticas públicas que buscan integrarlo a la sociedad. (Ricardo Rodríguez, Encuentro Iberoamericano sobre Migraciones y Desarrollo, Madrid, 2006).

Esta nueva ley refleja el compromiso asumido por nuestro país de garantizar el pleno respeto de los derechos humanos de los migrantes y sus familias, al tiempo que establece mecanismos de fácil acceso a la regularidad migratoria, entendiendo que dicha regularidad es indispensable para lograr la plena integración del extranjero a la sociedad de recepción. (MRECIyC, Encuentro Iberoamericano sobre Migraciones y Desarrollo, Madrid, 2006) 


\section{De entradas, permanencias y salidas}

Ahora bien, los principios y derechos declarados, que permiten enmarcar a la nueva ley como lo hacen los funcionarios y muchos estudiosos de la actual política migratoria- en una tradición humanitaria promotora y protectora de los derechos humanos de los inmigrantes, constituyendo su aspecto novedoso, se conjugan con disposiciones preventivas y represivas del régimen de control instituido a lo largo del siglo veinte, matizado con garantías como el debido proceso judicial frente a la cancelación de la residencia y las expulsiones. Precisamente, lo que los funcionarios no suelen dar a conocer o no subrayan en sus intervenciones públicas -en particular, en los foros o reuniones internacionales- son aquellos aspectos de la nueva ley que mantienen importantes continuidades con los principios de control de la normativa anterior y que no rompen con la visión hegemónica instituida en la legislación migratoria argentina y ha sido naturalizada entre funcionarios y empleados gubernamentales, entre otros, en tanto portadores y hacedores del pensamiento de Estado. A juzgar por los criterios de admisión y estadía aplicados a los extranjeros en el territorio nacional, la legislación migratoria argentina ha mantenido hasta nuestros días una perspectiva internacional de corte estatista o estatocéntrica respecto a las migraciones internacionales. Tradicionalmente, esta es la manera en que los Estados nacionales han visto, como señala Bauböck (2004), la inmigración y han interpretado sus intereses y obligaciones, tanto antes como después del ingreso al territorio nacional.

Como en las dos leyes de migración anteriores, la ley Avellaneda y la ley Videla, la DNM es la autoridad de aplicación de la actual ley. ${ }^{310}$ En ella se establece que este órgano estatal tiene competencia en materia de admisión, otorgamiento de residencias y su extensión y, consecuentemente, la facultad de conceder permisos de ingresos, prórrogas de permanencia y cambios de calificación para extranjeros. En el mismo sentido, bajo el mismo artículo, explicita que "controlará el ingreso y egreso de personas al país y ejercerá el control de permanencia y el poder de policía de extranjeros en todo el Territorio de la República", pudiendo delegar el ejercicio de sus funciones y facultades en aquellas instituciones que constituyen la Policía Migratoria Auxiliar 311 o en otras autoridades

310 Así lo dispone el artículo 105 de la ley de migraciones № 25.871.

311 De acuerdo a la nueva ley de migraciones, la Policía Migratoria Auxiliar queda conformada por la Prefectura Naval Argentina, la Gendarmería Nacional, la Policía Aeronáutica Nacional y la Policía Federal. 
nacionales, provinciales o municipales. La propia DNM ha traducido estas disposiciones de la ley referidas a su ámbito de competencia, difundiéndolo de esta manera312:

- Realizar cambios de categoría migratoria

- Tramitar y otorgar residencias: precaria, transitoria, temporaria y permanente

- Regularizar situaciones migratorias

- Controlar el ingreso, egreso y permanencia de extranjeros.

- Ejercer el poder de policía de extranjeros en el territorio nacional

- Requerir a los extranjeros la acreditación de su situación migratoria

- Realizar inspecciones de oficio, a pedido o por denuncia de terceros, en lugares o locales comerciales, industriales, educacionales, hospitalarios, asistenciales y todo aquél en el que pueda existir infracción a la ley migratoria. Para ello, cuenta con la colaboración de la Policía Migratoria Auxiliar.

En otro momento, mediante algunas reformulaciones, sus "funciones y servicios" han sido expresadas del siguiente modo313:

- Controla el ingreso/egreso de personas al territorio en fronteras, aeropuertos y puertos.

- Registra, archiva y procesa el flujo de entrada/salida de todo el país.

- Evalúa y otorga los distintos tipos de residencia de extranjeros y cambios de categorías.

- Promueve la regularización documentaria de los inmigrantes y controla su permanencia.

- Interviene cuando se infringe la Ley de Migraciones $\mathrm{N}^{\circ} 25.871$.

- Proporciona información a todo organismo del estado nacional u organismo no gubernamental que la requiera.

312 Fuente: http://www.gestionmininterior.com.ar/detalle.php?tipo=13\&documento=987683. Acceso: 20 de abril de 2010.

313 Fuente: http://www.migraciones.gov.ar/accesible/?institucional. Acceso: 5 de octubre de 2010. 
- Participa de la Comisión Nacional para Refugiados (Conare), organismo que depende del Ministerio del Interior y que atiende los pedidos de asilo y de refugio de extranjeros.

De ello se desprende que las funciones básicas que asume la DNM y para las cuales según la ley está facultada se relacionan principalmente con la regulación y el control de los ingresos y salidas como de la permanencia de los extranjeros en el territorio nacional, mediante el otorgamiento de diferentes tipos de residencias, con la posibilidad de modificar las categorías asignadas, y la promoción de la regularización migratoria. El control de la permanencia también implicaría, según lo manifestado por la DNM, ejercer el poder de policía en el territorio nacional, requerir a los extranjeros la acreditación de su "situación migratoria" y, realizar "inspecciones de oficio", a pedido o por denuncia de terceros, en diversos espacios públicos y privados, con la asistencia de la Policía Migratoria Auxiliar. Llamativamente, estas acciones del Estado aparecen explicitadas en un momento y omitidas en otro, lo que sugiere que aunque estas funciones se ejerzan, no es conveniente mostrarlas o divulgarlas. Estas funciones quedan condensadas en el mandato de "intervenir cuando se infringe la Ley de Migraciones $\mathrm{N}^{\circ} 25.871$ ", un mandato que, expresado en términos generales, habilita a la DNM a poner en práctica la protección de los derechos de los inmigrantes como las distintas sanciones que dispone para las infracciones en el ingreso y la permanencia. Paradójicamente, las limitaciones para promover y garantizar los derechos enunciados en la ley devienen del nombramiento de la DNM como autoridad de aplicación, un organismo que históricamente se ha especializado en controlar la admisión y la permanencia en el territorio nacional.

En el proyecto de ley original ya se señalaban entre los impedimentos para la admisión y la permanencia algunas cuestiones que habitualmente son tratadas en el marco de asuntos ligados a la seguridad como ilícitos y delitos cometidos que pueden implicar el cruce de una frontera nacional, pero que no podrían abarcar -a excepción del inciso referido a deportados y expulsados- la figura social del inmigrante, en ninguna de sus acepciones, salvo que pretenda ser criminalizada. En esta ocasión la noción de seguridad evita ser nombrada y cuando se lo hace se evade su adjetivación como nacional debido, presumiblemente, a la connotación represiva que ha tenido y tiene el concepto de seguridad nacional en la historia política de la Argentina.

a) Estar cumpliendo condena por delitos cometidos en el exterior que merezcan para la legislación argentina, pena privativa de libertad de tres (3) años o más; 
b) Traficar o haber traficado con estupefacientes;

c) Traficar o haber traficado con personas;

d) Registrar antecedentes que hagan presumir la participación en actividades de lavado de dinero, contrabando de armas o inversiones en actividades ilícitas;

e) Registrar antecedentes que hagan presumir que podría comprometer la seguridad y el sistema democrático;

f) Haber realizado o participado de actos que constituyan genocidio, crímenes de guerra o delitos de lesa humanidad y de todo otro acto susceptible de ser juzgado por el Tribunal Penal Internacional.

g) Haber participado de gobiernos o actos de gobierno acusados de genocidio, crímenes de guerra, delitos de lesa humanidad, y de todo otro acto susceptible de ser juzgado por el Tribunal Penal Internacional.

h) Los deportados o expulsados del país, a menos que la autoridad competente hubiera autorizado su reingreso.

La nueva ley de migraciones, además de contemplar estas materias concernientes a la seguridad, modificando en parte su forma y contenido (por ejemplo, condensa algunos ilícitos y delitos en un solo inciso o incluye la participación en "actos de terrorismo" y las organizaciones involucradas), agrega entre las causas que impiden el ingreso y la permanencia, bajo el mismo artículo, diversos hechos que en la normativa aparecen relacionados con el fenómeno de la llamada migración irregular, con su respectiva sanción en algunos casos, y a partir de los cuales se define -explícita o implícitamente- a un inmigrante o su ingreso o permanencia como ilegal o irregular: ${ }^{314}$

a) La presentación ante la autoridad de documentación nacional o extranjera material o ideológicamente falsa o adulterada. El hecho será sancionado con una prohibición de reingreso por un lapso mínimo de cinco (5) años;

\footnotetext{
314 A diferencia del proyecto original, la nueva ley de migraciones no otorga una definición explícita de lo que se entiende por ingreso o permanencia ilegal/irregular. El proyecto de ley establecía que se consideraba "irregular" aquél "ingreso o permanencia en el territorio nacional del extranjero que se encontrase en algunas de las siguientes situaciones: a) Que hubiere ingresado al país por un lugar no habilitado para tales efectos; b) Que hubiere ingresado sin someterse al control migratorio; c) Que no cumpliere con las disposiciones que regulan el ingreso o la permanencia de extranjeros, según los requisitos impuestos a las categorías de admisión". Un detalle a tener en cuenta: mientras en el proyecto original al título V se lo llama "De la irregularidad e irregularidad de la permanencia", en la nueva ley figura como "De la ilegalidad e ilegalidad de la permanencia".
} 
b) Tener prohibido el ingreso; haber sido objeto de medidas de expulsión o de prohibición de reingreso, hasta tanto las mismas no hayan sido revocadas o se hubiese cumplido el plazo impuesto al efecto;

$[\ldots]$

f) Haber sido condenado, en la Argentina o tener antecedentes por promover o facilitar, con fines de lucro, el ingreso, la permanencia o el egreso ilegales de extranjeros en el Territorio Nacional;

g) Haber sido condenado, en la Argentina o tener antecedentes por haber presentado documentación material o ideológicamente falsa, para obtener para sí o para un tercero un beneficio migratorio;

h) Promover la prostitución; lucrar con ello; haber sido condenado o tener antecedentes, en la Argentina o en el exterior por haber promovido la prostitución; por lucrar con ello o por desarrollar actividades relacionadas con el tráfico o la explotación sexual de personas;

i) Intentar ingresar o haber ingresado al Territorio Nacional eludiendo el control migratorio o por lugar o en horario no habilitados al efecto;

j) Constatarse la existencia de alguno de los impedimentos de radicación establecidos en la presente ley;

k) El incumplimiento de los requisitos exigidos por la presente ley.

Estos impedimentos establecidos para el ingreso y permanencia forman parte de los mecanismos de regulación y control de la migración irregular, los cuales se traducen y habilitan el "rechazo en frontera", una acción corriente del Estado nacional en la regulación de las entradas y salidas del territorio nacional. La ley de migraciones dispone que este procedimiento debe ser aplicado cuando una persona pretenda ingresar al territorio con "un documento extranjero destinado a acreditar su identidad que no cumpliera con las condiciones previstas en la legislación vigente" (salvo que se trate de un reingreso motivado por el rechazo de un tercer país). Un rechazo producido por la presentación de "documentación material o ideológicamente falsa" o que tuviera "atestaciones apócrifas" recibe como sanción la prohibición de reingreso por cinco años. Según la ley, mientras exista "sospecha fundada que la real intención que motiva el ingreso difiere de la manifestada al momento de obtener la visa o presentarse ante el control migratorio", el extranjero debe permanecer en las instalaciones del punto de ingreso hasta que se corroboren las presunciones asumidas inicialmente. Asimismo, el gobierno nacional "se reserva la facultad de denunciar el hecho ante la Justicia Federal cuando se encuentren en juego cuestiones relativas a la seguridad del Estado, a la cooperación internacional, o resulte posible vincular al mismo o a los hechos que se le imputen, con 
otras investigaciones sustanciadas en el territorio nacional". La nueva ley, como veremos enseguida, si bien estipula un conjunto de motivos referidos a la cancelación de la residencia y la expulsión del territorio nacional, subraya la importancia que le atribuye al ingreso irregular (por lugar no habilitado o eludiendo el contralor migratorio) y su correspondiente sanción, dedicándole especialmente un artículo:

Artículo 37.-El extranjero que ingrese a la República por lugar no habilitado a tal efecto, o eludiendo cualquier forma de contralor migratorio, será pasible de expulsión en los términos y condiciones de la presente ley.

Como modo de regular la permanencia, en la nueva ley de migraciones la cancelación de la residencia y la consecuente expulsión es aplicable a cualquiera de las categorías administrativas de ingreso y residencia (permanente, temporaria, transitoria y precaria), que son las mismas de la ley Videla. De acuerdo a lo estipulado en la ley, la cancelación de la residencia supone "la conminación a hacer abandono del país" o "la expulsión del Territorio Nacional", considerando "circunstancias fácticas y personales del interesado". Dicha expulsión, a su vez, "lleva implícita la prohibición de reingreso permanente -salvo las excepciones que disponga la DNM- o por un término que en ningún caso podrá ser inferior a cinco años" y que será regulado "según la importancia de la causa que la motivara". Es decir, al ser definido el estatus de los inmigrantes por su nacionalidad extranjera, el derecho a permanecer en el territorio nacional está siempre condicionado: mientras que sólo los ciudadanos tienen un derecho incondicional de residencia en su país y de (re)admisión después de haber estado viviendo en el extranjero, la presencia de los nacionales extranjeros, o no-nacionales en términos de Sayad, es invariablemente en calidad de invitados y siempre se les puede solicitar que se vayan y que no regresen (Bauböck, 2004).

Una diferencia sustancial entre el proyecto de ley original ${ }^{315} \mathrm{y}$ la norma nacional finalmente sancionada reside en las disposiciones relativas a los nacionales y los extranjeros "residentes permanentes": en el primero hay cierta equiparación de derechos y obligaciones entre unos y otros, mientras que en la segunda la brecha se expande de tal manera que se establece una estricta división entre ambas categorías. Como se puede observar, en la nueva ley de migraciones la cancelación de la residencia no sólo es aplicable a los residentes "temporarios" y "transitorios", sino que también alcanza a los

315 Expediente 769-D-03. Proyecto de ley firmado por los diputados nacionales Rubén Giustiniani, María Barbagelata y Oscar González. 
"residentes permanentes", es decir, a aquellos extranjeros que hayan obtenido la admisión de la DNM "con el propósito de establecerse definitivamente en el país" y cuya "integración en la sociedad argentina" el Estado se compromete a promover, según la letra de la ley. En el proyecto de ley original, en cambio, la cancelación comprendía a los "residentes temporarios", los "no residentes" (así denominados en lugar de "residentes transitorios") y los "precarios", salvando a los "permanentes" de la aplicación de dicha disposición -con excepción de los asuntos tratados anteriormente- $\mathrm{y}$, consecuentemente, no sometiéndolos a la expulsión. Dado que la categoría de "residentes permanentes" también incluye a aquellos "inmigrantes parientes de ciudadanos argentinos, nativos o por opción", la ley prevé exceptuar el cumplimiento de la cancelación cuando "el extranjero fuese padre, hijo o cónyuge de argentino", siempre y cuando no haya "decisión debidamente fundada por parte de la autoridad migratoria" que justifique la cancelación de la residencia. Esta excepción a la regla basada en un vínculo familiar (restringido) con un ciudadano de nacionalidad argentina revela, quizás más que ninguna otra norma, la arbitrariedad que supone la división entre nacionales y extranjeros de acuerdo a criterios basados en la nacionalidad al supeditar una pena o sanción, como la cancelación de la residencia y la expulsión, a la relación de parentesco, equivalente al lazo de sangre, convalidado a través de la nacionalidad. En este punto, paradójicamente, en un Estado que prevalece el ius soli para el otorgamiento de la nacionalidad, esta disposición excepcional opera a modo del ius sanguinis, obviando la posibilidad de que los extranjeros sean impedidos de sanción o adquieran determinados derechos a través de su residencia. Así, lo que se castiga es el hecho de ser extranjero, un extranjero en estado puro, que -como advierte lúcidamente Sayad- pareciera ser el primer delito que han cometido y traen consigo desde su cruce de la frontera.

Por otra parte, la cancelación de la residencia y la efectivización de la expulsión, al igual que se dispusiera a lo largo de todo el siglo veinte, se asume como una sanción a los extranjeros y como una pena a los ilícitos o delitos que hubiera cometido. La nueva ley de migraciones faculta a la DNM a cancelar la residencia y disponer la expulsión en aquellas situaciones en que "se hubiese articulado un hecho o un acto simulado o éste hubiese sido celebrado en fraude a la ley o con vicio del consentimiento o se hubiere presentado documentación material o ideológicamente falsa o adulterada" con el propósito de "obtener un beneficio migratorio o la ciudadanía argentina" o el extranjero residente "hubiese sido condenado judicialmente en la República por delito doloso que merezca pena privativa de libertad mayor de cinco (5) años o registrase una conducta reiterante en la comisión de delitos". También está prevista para aquellos casos en que el extranjero realizare tanto en el país como en el exterior alguna actividad relacionada con "actos de 
gobierno o de otro tipo, que constituyan genocidio, crímenes de guerra, actos de terrorismo o delitos de lesa humanidad y de todo otro acto susceptible de ser juzgado por el Tribunal Penal Internacional" o tuviere antecedentes "por actividades terroristas o por pertenecer a organizaciones nacional o internacionalmente reconocidas como imputadas de acciones de ser juzgadas por el Tribunal Penal Internacional o por la ley $\mathrm{N}^{\circ} 23.077$ de Defensa de la Democracia". Así, la cancelación de la residencia como la expulsión, asumidas como castigo a los ilícitos o delitos cometidos por el extranjero, equiparan bajo una misma figura delictiva situaciones cotidianas en que se pueden involucrar los inmigrantes que no cuentan con una estadía autorizada en su intento desesperado por salvaguardar su presencia en el territorio nacional mediante la obtención de documentación falsificada para obtener la residencia u obtener la nacionalidad, y actos de violencia y violación de derechos humanos como genocidios, crímenes de guerra, actos de terrorismo o delitos de lesa humanidad.

Aún cuando la cancelación de la residencia y la consecuente expulsión no se efectivice, siempre está latente. A diferencia del proyecto de ley, donde la expulsión estaba enunciada como una excepción al manifestar que "los extranjeros no podrán ser expulsados salvo por las razones definidas en la legislación nacional y con sujeción a las salvaguardas establecidas en la presente ley", la nueva ley de migraciones, aunque prevé algunas garantías como el debido proceso, asume la figura de la expulsión como la regla, estableciendo que "la Dirección Nacional de Migraciones, sin perjuicio de las acciones judiciales que correspondieran deducir, cancelará la residencia que hubiese otorgado, con efecto suspensivo, cualquiera fuese su antigüedad, categoría o causa de la admisión y dispondrá la posterior expulsión" determinando los casos que darían lugar a tales procedimientos.

De cualquier manera, esta condición de expulsabilidad es quizás el elemento que mayormente pone de manifiesto el carácter provisorio $^{316}$ de la presencia del inmigrante en

\footnotetext{
316 Para Sayad, una de las características fundamentales del fenómeno de la inmigración es que, más allá de algunas situaciones excepcionales, contribuye a ocultar su propia verdad. Dado que no consigue hacer compatible una situación de derecho y de hecho, la inmigración estaría condenada a engendrar una situación que pareciera estar destinada a una doble contradicción. En este sentido, Sayad señala que todo acontece como si para poder perpetuarse y reproducirse la inmigración necesitase ignorarse (o hacer que se ignora) y ser ignorada en cuanto provisoria y, al mismo tiempo, no admitirse ni admitirla como transplante definitivo. Esta contradicción fundamental, que a su modo de ver sería constitutiva de la propia condición del inmigrante, impondría a todos el mantenimiento de la ilusión colectiva de un estado que no es ni provisorio ni permanente o de un estado que sólo es admitido como provisorio (de derecho) con la condición de que ese provisorio pueda durar indefinidamente, o como definitivo (de hecho) con la condición de que ese definitivo jamás sea enunciado como tal (Sayad, 1998:46).
} 
la sociedad receptora, que instala su provisoriedad, aún más allá de que haya sido admitido formalmente en calidad de "residente permanente". A la vez, la provisoriedad de su presencia, en tanto no-nacional, se confirma frente a su eventual ausencia o la disolución de los motivos que la justificarían: la anulación o suspensión de la residencia y la posibilidad de expulsión está sometida a la ausencia (relativamente) prolongada del territorio nacional en el cual fue autorizado ingresar y permanecer como a la desnaturalización de "las razones que motivaron su concesión". En este sentido, la ley establece en uno de sus artículos que la DNM determinará la expulsión cuando

[...] c) El beneficiario de una radicación permanente hubiese permanecido fuera del Territorio Nacional por un período superior a los dos (2) años o la mitad del plazo acordado, si se tratara de residencia temporaria, excepto que la ausencia obedeciere al ejercicio de una función pública argentina o se hubiese generado en razón de actividades, estudios o investigaciones que a juicio de la Dirección Nacional de Migraciones pudieran ser de interés o beneficiosa para la República Argentina o que mediara autorización expresa de la autoridad migratoria la que podrá ser solicitada por intermedio de las autoridades consulares argentinas; d) Asimismo será cancelada la residencia permanente, temporaria o transitoria concedida cuando se hayan desnaturalizado las razones que motivaron su concesión o cuando la instalación en el país hubiera sido subvencionada total o parcialmente, directa o indirectamente por el Estado Argentino y no se cumplieran o se violaren las condiciones expresamente establecidas para la subvención; [...]

En el proyecto de ley original las causales de cancelación de residencia previstas tanto para aquellos extranjeros con "residencia temporaria" o "no residente" no contemplaban la ausencia del territorio nacional y las excepciones relativas a ella. Sin embargo, en la misma línea de la ley aprobada, en el caso de la categoría "temporaria", la DNM podía disponer, previa sentencia judicial, la "cancelación de la residencia" y la "pérdida de la condición migratoria" - "únicamente” subraya la norma- cuando el extranjero resultara "condenado por delito doloso o por delito culposo que implique una pena privativa de la libertad mayor de tres años", hubiere reingresado al país sin autorización de la DNM después de haber sido expulsado, o hubiere obtenido la residencia "mediante la presentación de documentación falsa, ocultaciones maliciosas o cualquier otro ardid o engaño". Asimismo, para aquellos que hubieran ingresado bajo la categoría de "no residente", la cancelación se aplicaría cuando "se desnaturalizaran los motivos que se tuvieron en cuenta para otorgarla". 
Diversos mecanismos de regulación instituidos históricamente para controlar la inmigración ilegal tampoco han quedado fuera de la nueva ley de migraciones. Se mantienen las restricciones al trabajo y al alojamiento, reguladas a través de prohibiciones o de la intervención de terceros como los dadores de trabajo o alojamiento. Salvo que se les hubiera autorizado una "residencia precaria", los "extranjeros que residan irregularmente en el país" no tienen permitido trabajar o realizar tareas lucrativas, independientemente si es por cuenta propia o en relación de dependencia. También se especifica que ninguna persona puede proporcionarles "alojamiento a título oneroso" ni "trabajo u ocupación remunerada", haciéndose pasibles de sanción si infringieran la norma. En caso de que se contratare o conviniere con ellos alguna acción relativa a bienes inmuebles, derechos o muebles registrables o sociedades civiles o comerciales se "deberá comunicarlo fehacientemente a la autoridad migratoria".

\section{De la integración}

Entre las maneras de regular la inmigración, las propuestas estatales acerca de la integración de los extranjeros también ofrecen un conjunto de elementos que ponen de relieve las tensiones y contradicciones que se desatan cuando el Estado pretende intervenir, material o simbólicamente, sobre la población inmigrante, mostrando sus límites para aceptar su presencia como legítima. De acuerdo a los objetivos explicitados en el texto de la ley317, en tanto ésta regula la inmigración en términos de extranjería, y las categorías de residencia establecidas, la idea de integración queda circunscripta, en primer lugar, a aquellos inmigrantes que sean -jurídicamente- extranjeros (es decir, de nacionalidad extranjera), obviando otras posibles combinaciones entre inmigración y nacionalidad. Se da por sentado que los inmigrantes que necesitan integración son extranjeros, así como los extranjeros que requieren integración son inmigrantes, equiparando inmigración y extranjería, una relación siempre arbitraria (Sayad, 2008; Gil Araujo, 2010). Se trataría de una exterioridad ${ }^{318}$-proveniente del exterior al margen del

\footnotetext{
317 El artículo 3 de la nueva ley de migraciones sostiene: "Promover la integración en la sociedad argentina de las personas que hayan sido admitidas como residentes permanentes" (inc. e); "Promover la inserción e integración laboral de los inmigrantes que residan en forma legal para el mejor aprovechamiento de sus capacidades personales y laborales a fin de contribuir al desarrollo económico y social de país" (inc. h).

318 Sayad (2008:107) plantea que “(1)a inmigración es, por esencia, del orden de la exterioridad: el inmigrante proviene del exterior y, con la inmigración, es la exterioridad que adviene a (o en) la interioridad". Para Sayad esta exterioridad acentúa el carácter construido del inmigrante visto como amenaza o peligro. Entiendo que dicha noción se encuentra en la base de todas aquellos discursos y prácticas que la inmigración como una presencia ilegítima.
} 
tiempo de residencia- que viene a incorporarse a una sociedad preexistente, la "sociedad argentina", y de la cual no formaría parte aún: la ley sostiene que es preciso "promover la integración en la sociedad argentina" ${ }^{319}$ Es a partir de esta combinación entre su condición jurídica como extranjero y su condición social como inmigrante que se lo interpela como objeto de integración. Si se tratara de nacionales en lugar de extranjeros, asumidos socialmente como excluidos o marginales, difícilmente se plantearía su inclusión en clave nacional.

Por otra parte, las disposiciones referidas a la integración tendrían como destinatarios sólo a aquellas "personas que hayan sido admitidas como residentes permanentes". Es decir, no se trata de extranjeros en general, sino de algunos en particular. La definición deja afuera, por ejemplo, a quienes ingresen bajo otras categorías administrativas como la de "residentes temporarios", entre los cuales se incluye una amplia y heterogénea franja de extranjeros clasificados de acuerdo a determinadas subcategorías: trabajador migrante, rentista, pensionado, inversionista, científicos y personal especializado, deportistas y artistas, religiosos de cultos reconocidos oficialmente, pacientes bajo tratamientos médicos, académicos, estudiantes, asilados y refugiados, ciudadanos nativos de Estados Parte del Mercosur, Chile y Bolivia, extranjeros que invoquen razones humanitarias y otros que ingresen al país por razones no contempladas anteriormente y sean consideradas de interés por el Ministerio del Interior y el Ministerio de Relaciones Exteriores, Comercio Internacional y Culto. Más allá de que en la práctica las estrategias de incorporación no sólo tienen lugar a partir de la iniciativa del Estado, es notorio quiénes serían para el Estado los inmigrantes integrables, los contemplados en el proyecto de nación como potenciales sujetos a ser integrados, y la concepción asimilacionista de integración que subyace a esta disposición: los integrables serían sólo aquellos extranjeros que tuvieran interés en establecerse definitivamente en el país, o lo que es lo mismo, aquellos que estén decididos a formar parte del todo nacional. Pero para ello, una condición sine qua non es cumplir con el requisito que requiere el Estado para integrar la nación: estar legal. Como veremos más detenidamente en próximos apartados, al momento de diseñar e implementar una estrategia de intervención, el universo de los pretendidamente permanentes quedará aún más acotado: serán los inmigrantes irregulares, los extranjeros sin documentación respaldatoria de su residencia legal, el objeto específico de las políticas de gobierno. Es decir, no se trata sólo de un extranjero-

319 La idea de integración aparece naturalizada no sólo en el discurso político, sino también en el académico. En relación a la nueva ley de migraciones, los trabajos reunidos en Giustiniani (2004) constituyen una muestra de ello. Véase, en cambio, para una problematización de las políticas de integración, su construcción y sus usos, el ejemplar análisis de Gil Araujo $(2007 ; 2010)$ en el contexto español. 
inmigrante, sino de un extranjero-inmigrante-ilegal/irregular. Bajo esta definición los extranjeros en tanto inmigrantes quedan circunscriptos más específicamente a los inmigrantes de países limítrofes, especialmente a los paraguayos, bolivianos y peruanos, quienes también están comprendidos en la categoría de trabajadores inmigrantes.

Entre los objetivos de la nueva ley, además de procurar la "integración" de los "residentes permanentes", se dedica uno en particular que interpela al inmigrante en su condición de trabajador con residencia legal: allí se expresa la voluntad de “(p)romover la inserción e integración laboral de los inmigrantes que residan en forma legal”. El especial interés del Estado en la dimensión laboral se pone de manifiesto, a su vez, en la intencionalidad que se enuncia al momento de justificar la presencia del trabajador migrante: su "inserción e integración" se sustenta en los beneficios que supondría para el inmigrante, en tanto facilita "el mejor aprovechamiento de sus capacidades personales y laborales", y para la "sociedad argentina", ya que permitiría "contribuir al desarrollo económico y social del país". A la vez, para que dicha integración sea beneficiosa debe estar acompañada por una residencia legal.

Aquí es importante señalar que si bien la nueva ley incluye entre sus objetivos y diferentes apartados aspectos relacionados con la integración de los inmigrantes, como veíamos anteriormente, el proyecto de ley original, preveía también la formación de dos órganos auxiliares con competencias específicas sobre el tema que fueron eliminados de la versión finalmente aprobada. Por un lado, consideraba la creación de un Consejo Nacional de Migraciones como "órgano colegiado de asesoramiento" dependiente del Ministerio del Interior integrado por diversos organismos del Estado. ${ }^{320}$ Entre sus funciones se indica que deberá “(e)stablecer las bases y criterios sobre los que se asentará una política global en materia de integración social y laboral de los inmigrantes, para lo cual recabará información y consulta de los órganos administrativos, tanto [del] ámbito estatal como de los agentes sociales y económicos implicados con la inmigración y la defensa de los derechos de los extranjeros". Por otro lado, disponía la creación del Foro Argentino para la Integración Social de los Inmigrantes en el ámbito del Ministerio del Interior como "órgano de consulta, información y asesoramiento en materia de integración de los inmigrantes", presidido por el Consejo Nacional de Migraciones y compuesto por

320 Entre los organismos considerados se mencionan: Ministerio del Interior (a cargo de la presidencia), Ministerio de Relaciones Exteriores, Comercio Internacional y Culto, Ministerio de Trabajo y Seguridad Social, Ministerio de Desarrollo Social, Ministerio de Salud, Ministerio de Economía, Ministerio de Justicia, Ministerio de Defensa y Ministerio de Educación. 
representantes de organismos de gobierno y de la sociedad civil, entre los cuales están contempladas las asociaciones de inmigrantes.

Por otra parte, el alcance de las medidas referidas a la integración planteadas en la ley está supeditado al contexto de la "comunidad de residencia" de los inmigrantes y acotado a una serie de acciones, pretendidamente multiculturales, que apuntan a favorecer el conocimiento mutuo y el respeto a la diversidad cultural en un marco de convivencia armónico. Así lo manifiesta el artículo 14 de la nueva ley dedicado especialmente a la integración de los extranjeros:

El Estado en todas sus jurisdicciones, ya sea nacional, provincial o municipal, favorecerá las iniciativas tendientes a la integración de los extranjeros en su comunidad de residencia, especialmente las tendientes a: a) La realización de cursos de idioma castellano en las escuelas e instituciones culturales extranjeras legalmente reconocidas; b) La difusión de información útil para la adecuada inserción de los extranjeros en la sociedad argentina, en particular aquella relativa a sus derechos y obligaciones; c) Al conocimiento y la valoración de las expresiones culturales, recreativas, sociales, económicas y religiosas de los inmigrantes; d) La organización de cursos de formación, inspirados en criterios de convivencia en una sociedad multicultural y de prevención de comportamientos discriminatorios, destinados a los funcionarios y empleados públicos y de entes privados.

Estas medidas proponen una interrelación entre nacionales e inmigrantes que se limita al "conocimiento y la valoración de las expresiones culturales, recreativas, sociales, económicas y religiosas de los inmigrantes". También se deposita una excesiva confianza en estrategias de difusión de información y cursos de formación para conseguir la anhelada "integración" de los migrantes. Algunas propuestas de carácter práctico como el ofrecimiento exclusivo de "cursos de idioma castellano en las escuelas e instituciones culturales extranjeras legalmente reconocidas" muestran una marcada impronta monocultural o asimilacionista en el modo de concebir la participación de los inmigrantes en la sociedad receptora.

La incorporación de ciertos elementos del discurso pluralista o multiculturalista ha llevado a algunos autores a sostener que el modelo de sociedad que subyace a esta ley remite a "una sociedad multicultural, integrada en la región e inclusiva, que respeta los 
derechos de los extranjeros y valora su aporte cultural y social" (Novick, 2004:84).321 A mi juicio, estas prácticas se corresponden con las premisas de los modelos de comprensión cultural (McCarthy, 1999).322 Por una parte, suponen una igualdad formal y se apoyan en una visión de reciprocidad y consenso entre los distintos sectores y grupos sociales y étnicos, a la vez que promueven un discurso de aceptación, tolerancia y respeto de las diferencias culturales próximo al multiculturalismo pluralista o, al menos, alejado del multiculturalismo crítico $^{323}$. Por otra parte, a nivel práctico, hay una apuesta por una "mejora en la comunicación" entre los grupos y por un cambio de actitudes para revertir los prejuicios en la sociedad receptora, advirtiendo, en consecuencia, la necesidad de desarrollar programas de sensibilización y formación en relaciones humanas.

$321 \mathrm{El}$ multiculturalismo, como tantos otros conceptos de las ciencias sociales y humanas, no presenta una significación unívoca y es objeto de múltiples desacuerdos. El desconcierto se amplía debido a los difusos límites establecidos entre el "multiculturalismo" y nociones afines, si es que se traza alguna distinción (en la literatura angloamericana predomina el uso exclusivo del término, mientras que en la europea continental se introduce el prefijo inter y el sufijo dad para destacar las discrepancias conceptuales). Una primera diferencia que puede establecerse para despejar ambigüedades es entre el multiculturalismo entendido como descripción y/o como proyecto (Stam, 1997, citado en Santos, 2003). Precisamente, uno de los factores que seguramente favorece la confusión es el uso simultáneo o alternado que puede hacerse del término. Otra de las diferenciaciones que puede realizarse es la que establece Torres (2001): el multiculturalismo puede ser aprehendido como movimiento social, enfoque teórico y educación multicultural. Algunos autores distinguen entre multiculturalidad y multiculturalismo, ya se trate de una situación de hecho o de un programa político o entre multiculturalidad e interculturalidad en función de las formas y contenidos de la comunicación, interrelación e intervención entre las partes. Otros proponen nuevas diferenciaciones: por ejemplo, Enguita (2002) establece que es el "interculturalismo" el que debe guiar la política educativa, Bharucha (2000) distingue entre "intraculturalidad" e "interculturalidad" (citado en Santos, 2003) y Sartori diferencia el multiculturalismo del "pluralismo" (definiendo al primero como la negación misma del segundo).

322 En su análisis sobre la desigualdad racial en Estados Unidos, McCarthy (1999) distingue tres tipos de discursos multiculturales: los modelos de comprensión cultural, los de competencia cultural y los de emancipación cultural.

323 McLaren (1997) propone distinguir diferentes tipos de multiculturalismo según su afiliación ideológica: conservador, liberal, liberal de izquierdas, crítico y de resistencia. Posteriormente, plantea un "multiculturalismo revolucionario" (McLaren, 1998). Es interesante destacar que Bharucha (2000) cuestiona la multiplicación de adjetivaciones del multiculturalismo, ya que considera que el concepto se vacía de un contenido preciso (Santos, 2003:30). Kincheloe y Steinberg (1999), partiendo de la clasificación de McLaren (1997), entienden que desde la posición del multiculturalismo pluralista, "la diversidad reconvierte en algo intrínsicamente valioso y deseable de por sí hasta el punto de que se le da un carácter exótico y fetichista" (Kincheloe y Steinberg, 1999:40). Además, consideran que "(l)os estados de diversidad cultural son traducidos a estados de 'enriquecimiento cultural' susceptibles de ser encomiados sin que por ello se resienta el poder de los grupos dominantes" (Kincheloe y Steinberg, 1999:41). Según McLaren, desde el "multiculturalismo crítico", en cambio, no se entiende la diversidad en si misma como una meta y se indica que "la diversidad debe ser afirmada en una política de criticismo cultural y en un compromiso con la justicia social [...] La diferencia siempre es un producto de la historia, la cultura, el poder y la ideología" (McLaren, 1997:155). 
Frente a los resquemores que produce la presencia de los inmigrantes para los Estados nacionales, algunas proposiciones de la nueva ley evidencian la vigencia que mantienen las ideas asimilacionistas también cuando se imaginan las implicancias o consecuencias de la integración de los inmigrantes para la cohesión social y la unidad cultural. Al mismo tiempo que se declara la importancia que reviste la aceptación de la diferencia cultural, la identidad nacional es definida en términos exclusivistas. Al final del articulado, en un llamado al límite del absurdo, se puntualiza que "(n)inguna de las disposiciones de la presente ley tendrá por efecto eximir a los extranjeros [...] de la obligación de respetar la identidad cultural de los argentinos" (énfasis propio). Esta exigencia es pensada como "contrapartida" -así figura en los fundamentos escritos que acompañan al proyecto original de ley- a los "derechos y libertades de los extranjeros" que el Estado les otorga y garantiza. ${ }^{324}$ Además, según esta visión, las identidades serían fijas o estáticas y supondrían que en la situación previa o posterior al contacto sociocultural la sociedad de destino/recepción sería culturalmente homogénea. ${ }^{325}$ Esta visión de dos grandes grupos culturales homogéneos, definidos en algunas circunstancias a partir de la pertenencia nacional, cuyos contenidos hay que respetar y no modificar voluntariamente, sin que todo ello afecte la subsistencia de la nación argentina, siempre enmarcado en el discurso de respeto a la diversidad cultural, se encuentra esbozada de manera sintética en una de las declaraciones que hizo el director de la DNM durante su primera intervención en la

324 Todo hace suponer que en las primeras formulaciones del proyecto de ley la frase referida a la "obligación de respetar la identidad cultural de los argentinos" estaba colocada al principio, en el Capítulo II del Título I donde se enumeran "las obligaciones de los inmigrantes y atribuciones del Estado".

325 Algunas de las principales críticas que ha recibido el multiculturalismo en términos generales y en sus múltiples versiones han sido sistematizados por autores como McLaren (1997), Kincheloe y Steinberg (1999), Torres (2001) y Santos (2003). Una de las acusaciones, formulada a nivel conceptual, apunta a que el multiculturalismo, como observa Boaventura de Sousa Santos a partir de las consideraciones de Bharucha (2000), forma parte de una imposición que implica la exportación/importación de conceptos o marcos analíticos que sirven como vehículo de una dominación intelectual eurocéntrica: se trata de un concepto creado para describir la diversidad cultural de las naciones norteamericana, canadiense y europea, que busca imponerse a los países menos desarrollados del hemisferio sur como modo de definir su condición histórica y sus identidades (Santos, 2003:30). Por otro lado, intelectuales conservadores y progresistas coinciden en acusar al multiculturalismo directa o indirectamente de "racista". Sartori (2001), por una parte, no fundamenta en absoluto su posición al respecto, solamente señala cierta conveniencia lingüística, pero puede inferirse que su declaración se apoya en el sentido antipluralista que le atribuye al multiculturalismo. Para Žižek, por la otra, el multiculturalismo -reducido a una sola expresión- si bien "no opone al Otro los valores particulares de su propia cultura", lo considera racista porque "el respeto multiculturalista por la especificidad del Otro es precisamente la forma de reafirmar la propia superioridad" (Žižek, 1998:172). En esta misma línea, Fish tilda de "racistas" a los multiculturalistas (conservadores) no por el hecho de que persigan la subyugación de determinados grupos, sino porque reproducen los estereotipos raciales y respaldan a las instituciones que los potencian (McLaren, 1997:151). Para McLaren, el racismo sería una "precondición” para el multiculturalismo de tipo conservador, que convierte a las virtudes occidentales en la base de la estética nacional sobre la civilización y la ciudadanía, no extensible a las demás formas que puede adquirir (McLaren, 1997:152). 
Cámara de Diputados de la Nación, a pocos meses de haber asumido, mientras se refería a las dificultades lingüísticas para comunicarse con algunos inmigrantes de países limítrofes:

Y debemos respetar su cultura y no alterársela, ya que, por el contrario, son parte de nuestra idiosincrasia, como yo, que soy hijo o nieto de gallegos. Si yo pido que respeten mi cultura debo respetar la de ellos. Esto sin perjuicio de la integración e inserción dentro de lo que es la vida nacional. (Ricardo Rodríguez, Cámara de Diputados de la Nación, Buenos Aires, 2004)

Finalmente, otro aspecto de la nueva ley pone de manifiesto las contrariedades que genera a los Estados nacionales el reconocimiento de los extranjeros como sujetos políticos, empezando por el reconocimiento de determinados derechos políticos a los inmigrantes en tanto no-nacionales, a pesar de la progresiva (en algunos casos) extensión de derechos ciudadanos que han obtenido o que se les ha concedido en algunos casos. Aquí, los derechos humanos reconocidos a los extranjeros estarían por debajo de la cobertura que ofrecen los derechos ciudadanos a los nacionales, asegurando más bien derechos mínimos para la sobrevivencia y que podrían terminar siendo los máximos derechos a alcanzar. Del conjunto de derechos reconocidos en la nueva ley de migraciones, a excepción del derecho de reunión y de asociación, los derechos políticos han quedado completamente silenciados, en particular aquellos cuyo ejercicio -como el derecho a elegir y ser elegido en comicios electorales nacionales- desafían el orden nacional. Las elecciones de alcance nacional están reservadas únicamente para los nacionales: aunque hubiera alguna reforma en este sentido, es más probable que por sus implicancias se conceda a los extranjeros residentes el derecho a elegir antes que el derecho a ser elegido, esto es, votante más que representante. Actualmente el derecho al voto de los extranjeros residentes en la Argentina -que no es obligatorio- se encuentra restringido a las elecciones provinciales y/o municipales, según lo que establezca la legislación provincial.326 Para ello deben empadronarse en un registro especial de electores extranjeros, que es administrado por la

326 Actualmente se encuentra con trámite parlamentario un proyecto de ley que pretende se le otorgue "el derecho a voto a los extranjeros que residan en el país" (artículo 1) en elecciones de autoridades nacionales en base al criterio de residencia. Establece como requisitos que: a) sean mayores de 18 años de edad y estén radicados en forma permanente en nuestro país; b) acrediten como mínimo de diez años de residencia, excepto aquellos que hayan contraído nupcias con ciudadanos argentinos y tengas hijos de nacionalidad argentina, a quienes se les reducirá la exigencia de residencia a un mínimo de 5 años; c) cumplan con todas las obligaciones a las que están sometidos los ciudadanos argentinos de acuerdo a las leyes electorales vigentes. 
Justicia Electoral Provincial. Dado que para participar de los comicios electorales es imprescindible contar con un DNI, los extranjeros habilitados para sufragar son los residentes encuadrados en las categorías de "temporarios" y "permanentes".

La falta de reconocimiento del derecho al voto para los extranjeros residentes contrasta fuertemente con su marcado interés en participar de las elecciones políticas. Según una encuesta realizada en los años 2008 y 2009 por encargo de la Dirección Nacional de Población y la DNM a inmigrantes de países sudamericanos (DNP/DNM, 2010), un 87,8\% de los extranjeros nacionales consultados respondió afirmativamente a la pregunta ¿Le gustaría votar en Argentina? ${ }^{327}$ En el caso de países como Bolivia, Paraguay y Perú este porcentaje supera el 90\%. El interés por la participación electoral en la Argentina es más alto a su vez que el declarado respecto al país cuya nacionalidad posee o del cual es ciudadano. En total, el $74,4 \%$ se pronuncia a favor de "votar en su país"328, obteniendo Bolivia el porcentaje más pronunciado: $82,4 \%$ frente al 65,5\% de Paraguay y al 74,5\% de Perú.

Una política "realista, amplia y de regularización": el diagnóstico oficial

Al cabo de algunos años, la "nueva política migratoria", vista retrospectivamente, es definida por algunas voces oficiales como una política "realista, amplia y de regularización". ${ }^{329}$ Tal definición de la política migratoria expresa la respuesta política que desde el Estado se considera oportuna o necesaria de acuerdo a los parámetros de validez que presupone una visión basada en la realidad, en aquella "realidad que queremos

327 De la utilización del potencial en la pregunta, se puede inferir que la consulta se refiere a las elecciones nacionales en las cuales los extranjeros no están habilitados a participar.

328 Así lo destaca la pregunta formulada: ¿Le gustaría votar en su país? Por simple inferencia, consultado el inmigrante primero por su interés en participar en las elecciones en la Argentina y luego en "su país", se le está haciendo saber que la Argentina no es su país, a pesar de que lo haya elegido como lugar para vivir y trabajar. Algo similar ocurre con la pregunta ¿Piensa volver a su país? Como lo señalara Sayad en alguna oportunidad, esta pregunta invita al inmigrante a que regrese al país del cual proviene, cuestionando su presencia en la llamada sociedad de recepción.

329 La política migratoria argentina comenzó a aparecer definida de esta manera recién hacia el año 2008 en algunas intervenciones de funcionarios de la DNM en reuniones internacionales. Esta definición podría ser vista como resultado de la sistematización reflexiva que realizan, circunstancial o deliberadamente, los propios hacedores de las políticas públicas. 
normar", como dice una funcionaria de la DNM. Es decir, como señala Gil Araujo (2010), toda política -sea pública o privada- conlleva siempre una concepción acerca de la realidad sobre la cual se pretende actuar. A continuación veremos que el propio diagnóstico oficial, en tanto instrumento de las estrategias de intervención, ya contiene la visión de la realidad migratoria que se pretende normar, organizar, regular, en definitiva, hacer gobernable.

Las nociones de realismo y objetividad atraviesan los postulados de la "nueva política migratoria". Ambas nociones, junto a eficiencia, constituyen los pilares de una de las dos condiciones básicas que sirven de fundamento a la gobernabilidad migratoria: la eficacia. Según uno de sus mayores propulsores en la región sudamericana, Lelio Mármora, la eficacia estaría basada en la objetividad del análisis del fenómeno migratorio, el realismo con que se plantee la estrategia de acción y la eficiencia en la ejecución (Mármora, 2002:391). Ya a comienzos de la década, como pudimos observar más arriba, los funcionarios de la DNM abogaban por una política migratoria que estuviera asentada en el "conocimiento de la realidad", exigiendo "objetividad" en el análisis que se hiciera de ella. Posteriormente, durante la gestión de Ricardo Rodríguez, diversos documentos oficiales se refieren también a "la aceptación de la realidad" o a "la necesidad de que la política migratoria responda a la realidad y no a preconceptos". En estas declaraciones, al igual que varios años atrás cuando se comenzaba a delinear la "nueva política migratoria", se considera que "(o)bviar este punto puede llevar a fundamentar políticas migratorias partiendo de preconceptos prejuiciosos y carentes de objetividad". ${ }^{330}$

La definición estatal referida a la "nueva política migratoria" como "política realista" también supone una serie de principios que organizan parte del discurso oficial sobre las migraciones internacionales: tratamiento multilateral, solidaridad internacional, cumplimiento de acuerdos internacionales y respeto de los derechos humanos de los migrantes. ${ }^{331}$

330 Ricardo Rodríguez, Encuentro Iberoamericano sobre Migraciones y Desarrollo, Madrid, 2006.

331 Esta definición la retoma el director de la DNM que sustituyó a Ricardo Rodríguez bajo la presidencia de Cristina Fernández de Kirchner: "Hoy Argentina desarrolla una política migratoria realista basada, vale reiterarlo, en el tratamiento multilateral, la solidaridad internacional, el cumplimiento de los instrumentos internacionales suscritos sobre la materia y, fundamentalmente, en el compromiso ético del respeto a los derechos humanos de los migrantes." (Martín Arias Duval, Foro Iberoamericano sobre Migración y Desarrollo, Cuenca, 2008) 
Pasando del marco regional a la situación en la República Argentina, resulta una buena introducción señalar que la política que respecto del tratamiento de los extranjeros, sean estos migrantes o refugiados, que hoy implementa Argentina puede ser definida como una política realista, basada en el tratamiento multilateral, la solidaridad internacional, el cumplimiento de los instrumentos internacionales suscritos sobre la materia y fundamentalmente en el compromiso ético del respeto irrestricto de los derechos humanos. (Adriana Alfonso, Organización de los Estados Americanos, Washington D.C., 2008)

Por otro lado, según el relato de algunos funcionarios de la DNM, el cambio de enfoque en relación a la política migratoria se habría originado en un diagnóstico a partir del pudieron constatar algunos de los principales elementos que compondrían la "realidad migratoria" del país. Así lo sintetiza la funcionaria del área de temas internacionales de la DNM: "Toda esta realidad nos hizo llegar a la conclusión de que era necesario cambiar la óptica con que se estaba manejando la estrategia migratoria". ${ }^{332}$ Entre los elementos que reconoce esta "política realista" como propios aparecen aspectos históricos, geográficos, regionales e internacionales. Sería la respuesta a una de las tres preguntas ${ }^{333}$ que la funcionaria considera necesarias para llevar adelante una medida política: ¿Qué tengo? Este interrogante condensaría tres preguntas que ella misma fórmula: ¿Cuál es la realidad? ¿Qué es lo que tengo? ¿Qué es lo que me condiciona?

Respecto a la "realidad histórica" se pone de relieve tanto la condición de país de inmigración como de país de emigración de la Argentina. En este sentido, el discurso oficial destaca la importancia que tuvo la inmigración en la construcción de la Argentina, sea como país, sociedad o nación, atribuyéndole un "verdadero carácter fundacional”334 o considerándola -equiparando la vida de los países a las de las personas- como un "hecho decisivo". La migración desde países limítrofes, cuya omisión histórica es considerada un

332 Adriana Alfonso, Seminario “Migraciones y Derechos Humanos”, Rosario, 2005.

333 Las tres preguntas son las mismas que la funcionaria planteó en años anteriores: "En el tema de política migratoria, como en otros ámbitos de políticas, también hay que tener en cuenta tres interrogantes para la adopción de las medidas: 1. ¿Qué busco? 2. ¿Qué tengo? 3. ¿Qué puedo hacer entonces con lo que tengo para conseguir aquello que busco?” (Adriana Alfonso, Seminario “Migraciones y Derechos Humanos”, Rosario, 2005).

334 Ricardo Rodríguez, Encuentro Iberoamericano sobre Migraciones y Desarrollo, Madrid, 2006. También la funcinaria de la DNM, Adriana Alfonso, califica como "fundacional” a la migración internacional en la Argentina durante su intervención en el marco del Foro UNESCO en febrero de 2006. 
"injusto error", constituye un aspecto central de la "política realista" que se pretende sostener, recibiendo un particular reconocimiento. Aquí se señala la omisión de la "inmigración limítrofe" que está detrás de la idea de que los "argentinos descendemos de los barcos" y se subraya la contribución, calificada como "silenciosa" y "constante", que ha tenido en la "conformación de la sociedad argentina".

Hablamos de una realidad histórica que nos signa como un país de recepción, y una realidad más reciente que nos signa como un país de emigración, de los argentinos buscando un mejor destino afuera. (Mariana García, Seminario Migraciones y Derechos Humanos, Rosario, 2005) 335

Como en las historias de las personas, en las de los países existen hechos decisivos sin los cuales resulta imposible comprender su presente. Para Argentina uno de esos factores determinante ha sido la inmigración. (Ricardo Rodríguez, Encuentro Iberoamericano sobre Migraciones y Desarrollo, Madrid, 2006)

Haciendo referencia a la numerosa migración europea que Argentina recibió a principios del siglo pasado, solía decirse que los argentinos descendemos de los barcos. Esta afirmación, inducida, llevó a algunos gobernantes y a parte de los sectores, presuntamente intelectuales, al injusto error de obviar a las migraciones que recibimos de Sudamérica, fundamentalmente de países limítrofes; las cuales en forma silenciosa pero constante han contribuido en el pasado y contribuyen en el presente a la conformación de la sociedad Argentina. (Ricardo Rodríguez, Encuentro Iberoamericano sobre Migraciones y Desarrollo, Madrid, 2006)

Esta mirada que se construye desde el Estado sobre la inmigración no implica que ahora la llamada inmigración limítrofe, la cual fue objetada a lo largo de más de un siglo de vida política en el país, se convierta repentinamente en una inmigración deseable -en tanto inmigración fomentada- para el Estado. Más bien pasa a formar parte de la idea de "aceptación de la realidad" del país: la inmigración de países limítrofes es inexorable, en tanto que no es evitable y que, como su origen etimológico lo señala, no se deja vencer con ruegos (por más que se les pida a los inmigrantes que no vengan, igual lo harán). Esto se 
pone de manifiesto en el modo de conceptualizar el origen de las diversas corrientes migratorias: se diferencia una inmigración europea fomentada (no espontánea) y una inmigración limítrofe proveniente (espontánea). Por ende, concebida la migración de países limítrofes como una realidad inevitable y asumidos los resultados obtenidos a través de medios restrictivos para el control de las fronteras como escasos, los objetivos de la política migratoria se erigen alrededor de la regulación de los flujos migratorios, una regulación mediante regularización, que adoptará la nueva ley como marco de orientación.

Este Programa [se refiere al programa de regularización migratoria] es de vital importancia en términos cuantitativos si consideramos el cambio que se ha producido en el patrón de la población migratoria en la Argentina: mientras que históricamente se fomentaba la búsqueda exclusiva de inmigración europea y selectiva -conforme lo establecido en la Constitución Nacionalactualmente la mayoría de los migrantes provienen de países de América del Sur, especialmente de países limítrofes. (MRECIyC, Encuentro Iberoamericano sobre Migraciones y Desarrollo, Madrid, 2006)

Llegando a mitad del siglo pasado las migraciones europeas disminuyeron, por esa circunstancia las provenientes de países limítrofes, si bien continuaban con un volumen constante, cobraron mayor notoriedad y como hecho novedoso comienzan a registrarse flujos de migraciones asiáticas. (Ricardo Rodríguez, Encuentro Iberoamericano sobre Migraciones y Desarrollo, Madrid, 2006; cursivas nuestras)

Respecto a la "realidad geográfica", se hace referencia a la ubicación espacial del territorio nacional en el Cono Sur y las implicancias de su extensa frontera. La Argentina comparte en total 73 pasos fronterizos internacionales con los cinco países vecinos: Chile, Bolivia, Paraguay, Brasil y Uruguay. La DNM tiene 27 delegaciones y 6 oficinas migratorias distribuidas a lo largo del territorio nacional.

Hablamos de realidades de una Argentina geográficamente inserta en América del Sur, donde tenemos una enorme frontera con muchísimos pasos habilitados y muchos otros sin habilitar, pero que permiten el ingreso fácil de ciudadanos de países limítrofes a nuestro territorio. (Adriana Alfonso, Seminario Migraciones y Derechos Humanos, Rosario, 2005) 
La "realidad regional" alude básicamente al proceso de regionalización que supone el Mercosur y la participación de la Argentina en este espacio como miembro pleno. En los documentos oficiales se advierte que "(p)arte importante de la realidad de nuestro país es el MERCOSUR y sus Estados Asociados" 336 y se destaca la decisiva relevancia que tiene la existencia del Mercosur en la definición de la actual política migratoria.

Argentina está desarrollando una política migratoria amplia, de puertas abiertas, y es importante tener en cuenta la incidencia que la realidad del Mercosur ha tenido en la adopción de esta política. (Adriana Alfonso, Seminario Migraciones y Derechos Humanos, Rosario, 2005)

En relación a la "realidad internacional", desde el Estado se reconoce la creciente tendencia a incorporar la perspectiva de los derechos humanos en el tratamiento de la temática migratoria. En este sentido, se señala la voluntad de dar cumplimiento a los compromisos asumidos en el ámbito internacional en materia de protección de los derechos humanos de los inmigrantes, lo cual constituye uno de los requerimientos fundamentales para que las políticas migratorias obtengan legitimidad según las recomendaciones de la perspectiva de la gobernabilidad migratoria (Mármora, 2004). Entre los acuerdos internacionales que suelen citarse se destaca la Convención Internacional sobre la Protección de los Derechos de Todos los Trabajadores Migratorios y de sus Familiares, aprobada por la Asamblea General de las Naciones Unidas en el mes de diciembre de 1990 y en vigor desde el año 2003. A través de un comunicado del Ministerio de Relaciones Exteriores, Comercio Internacional y Culto, al suscribirla en agosto del 2004, la República Argentina sostuvo que la firma de dicha Convención respondía "al incremento en la importancia del tema migratorio, así como a las condiciones de vulnerabilidad de las personas y trabajadores migratorios, que en numerosas ocasiones deben enfrentar abierta hostilidad por parte de la población local y de las autoridades". Señala, asimismo, que "(l) a situación es particularmente grave en el caso de personas indocumentadas, cuya condición las expone a mayores abusos."337 
A su vez, como veíamos anteriormente, la "nueva política migratoria", presentada como respuesta a "la dimensión ética del respeto por los derechos humanos", centrada en el "ser humano", ubica a las migraciones internacionales "como parte de las relaciones internacionales entre los países", concebidas éstas en términos de cooperación antes que de conflicto, y como pieza clave de las políticas de integración regional.

Creemos fervientemente que la nueva lógica de las políticas migratorias debe fundamentar su concepción como parte de las relaciones internacionales entre los países, buscar su inserción en los objetivos de integración, y por sobre todo responder a la dimensión ética del respeto por los derechos humanos. (Ricardo Rodríguez, Encuentro Iberoamericano sobre Migraciones y Desarrollo, Madrid, 2006)

Hoy los funcionarios responsables de la temática migratoria en la República Argentina hemos tomado conciencia que las sociedades aspiran a una democratización creciente de las relaciones humanas, a un cambio de las hipótesis de conflicto por las de cooperación y advierten que la integración de los países en bloque puede resultar una herramienta eficaz para responder a la globalización. (Ricardo Rodríguez, Encuentro Iberoamericano sobre Migraciones y Desarrollo, Madrid, 2006)

¿Cómo estábamos en el plano regional? El MERCOSUR avanzaba desde lo social a pasos agigantados y Argentina se quería insertar en el tema del MERCOSUR. Por esa realidad y por el compromiso ético de reconocer a los migrantes su calidad de seres humanos, y en su calidad de seres humanos, como hombres entonces, entender que tiene derechos propios por su calidad de [humanos] ${ }^{338}$ y no por donde hayan nacido, por su sexo, por su religión, por su creencia, es que Argentina inicia esta etapa de política migratoria amplia, basándose fundamentalmente en la realidad que implica para nosotros el MERCOSUR. (Adriana Alfonso, Seminario Migraciones y Derechos Humanos, Rosario, 2005) 
La actual política migratoria, enmarcada en un proceso de integración regional como el Mercosur, es considerada como una "política amplia" en el sentido de política de puertas abiertas. El discurso oficial afirma el regreso a una política acorde con la "mejor tradición argentina", aquella que establece la Constitución Nacional de 1853 cuando se dirige a "todos los hombres del mundo que quieran habitar el suelo argentino", buscando restaurar la imagen de una Argentina abierta, tolerante y plural en el nuevo contexto de integración regional iniciado en el Cono Sur a principios de los noventa. Este pretendido regreso a la política de puertas abiertas está apoyado en una visión idílica de lo que fue la recepción de la inmigración de ultramar de fines del siglo diecinueve y comienzos del veinte, obviando mencionar los intereses del Estado argentino en el fomento de la inmigración y el hecho de que la política de puertas abiertas también implicó conflictos y contradicciones, además de procesos y mecanismos de inclusión/exclusión de acuerdo al origen o a la composición de los flujos migratorios y a los acontecimientos históricos que marcaron la vida del país en este período, tal como pudimos apreciar en anteriores capítulos. En esta reconstrucción se produce un borramiento de los intereses de clase que motivaron la promoción de la inmigración y los sectores sociales que se beneficiaron a través de ella durante la segunda mitad del siglo diecinueve. ${ }^{339}$

En ese contexto cuando a principios del siglo los migrantes europeos llegaban al Puerto de Buenos Aires, encontraban abiertas las puertas del Hotel del Inmigrante. Ese imponente edificio, hoy monumento histórico, había sido construido por el Gobierno exclusivamente para dar alojamiento, comida y orientación laboral a los migrantes que huían de Europa, corridos por la guerra y la hambruna. Ellos necesitaban de un lugar donde vivir, trabajar y progresar y Argentina estaba dispuesta a cubrir esas expectativas. (Ricardo

\footnotetext{
339 Como sostiene Juliano (1987:88): “Estamos ante un proyecto que no contaba con apoyo popular ni religioso y que sin embargo se llevó a cabo de manera continuada y con todos los recursos de que disponía el nuevo Estado. Es de suponer que era un objetivo del mayor interés para el grupo que detentaba el poder, y en efecto, el sector social latifundista que mantuvo en sus manos el control del país durante toda la época de la gran inmigración se aseguraba por este medio importantes ventajas. Si bien el proyecto se va modificando a medida que se desarrolla, en su conjunto la migración masiva permite afianzarse en el poder económico a los latifundistas, descargando sobre los recién llegados el peso de la reconversión de la producción ganadera a la agrícola y facilitando abundante mano de obra. Al mismo tiempo neutralizaba la demanda por tierra de la población autóctona y la desmovilizaba políticamente, derivando sus quejas a un enfrentamiento interétnico". Esta política de inmigración, definida según los intereses específicos y en provecho de los sectores latifundistas, se impuso a través de un trabajo de legitimación a la cual se abocó la llamada Generación del Ochenta.
} 
Rodríguez, director de la Dirección Nacional de Migraciones, Encuentro Iberoamericano sobre Migraciones y Desarrollo, Madrid, 2006)

Así, en consonancia con el establecimiento de una "política migratoria amplia", la política migratoria es concebida como una política de regularización fundamentada en los beneficios o las ventajas que conllevaría para los extranjeros/inmigrantes y que implicaría para el país. Como veremos en próximos apartados, esta decisión política encuentra su justificación en los escasos resultados obtenidos con la regulación de los flujos migratorios, tanto en la experiencia argentina como en la de otros países, mediante la aplicación de una política migratoria de carácter restrictivo: se señala el fracaso y la inutilidad de las medidas restrictivas y su incompatibilidad con las corrientes migratorias regionales que recibe la Argentina.

La experiencia de Argentina nos indica que las medidas restrictivas no aportan soluciones. No la aportaron en nuestro país y lo que observamos respecto de otros países es que la construcción de muros ya sean de piedras o legales solo generan irregularidad, pérdidas de vidas humanas y hacen más lucrativa la tarea de los traficantes. (Ricardo Rodríguez, Encuentro Iberoamericano sobre Migraciones y Desarrollo, Madrid, 2006)

La dictadura militar, bajo la deleznable excusa de lo que dio en llamarse 'doctrina de seguridad nacional' pretendió imponer una política migratoria restrictiva al amparo de la Ley 22.439 dictada en 1981 en pleno proceso militar. Las medidas implementadas resultaban tan incompatibles con la realidad argentina que terminaron generando un enorme volumen de extranjeros irregulares. (Director de la Dirección Nacional de Migraciones, Encuentro Iberoamericano sobre Migraciones y Desarrollo, Madrid, 2006) 


\section{"El Estado ha confiado en cada uno de nosotros...": los agentes del control (o los guardianes de la nación)}

En el mes de septiembre del año 2006 la DNM, a iniciativa de una de sus delegaciones regionales, organizó el seminario "Migraciones y Ciudadanía” en la ciudad de Rosario. Allí, como parte de la programación de estas jornadas, se ofrecían a los asistentes cuatro talleres organizados especialmente para la ocasión en las aulas de la Facultad de Derecho de la Universidad Nacional de Rosario. Tres de ellos llevaban título y nombre del responsable: el primero sobre "Inteculturalidad y educación" a cargo de una joven investigadora de la UBA, el segundo sobre "Derechos Humanos y Migración" dictado por un representante del CELS, un organismo de derechos humanos con una importante trayectoria en la temática de migraciones, y el tercero referido a "Trabajos de Investigación sobre Migraciones", impartido también por una joven investigadora de la UNLaM. El cuarto taller no tenía asignado ningún título, sólo decía "Inspectores Dirección Nacional de Migraciones" y "Miembros de las Policías Migratorias Auxiliares". Frente a estas opciones, elegí observar el taller que en apariencia organizaba o estaba dirigido a agentes del Estado nacional.

Efectivamente, una vez en la sala pude corroborar que el taller lo organizaba la DNM, coordinado por dos funcionarios acompañados por una asesora jurídica, también representante del Comité de Elegibilidad de ACNUR, y estaba dirigido tanto a agentes de la DNM como de la Policía Migratoria Auxiliar compuesta por la Gendarmería Nacional, la Prefectura Naval Argentina, la Policía Aeronáutica Nacional y la Policía Federal. Como se refirió a sí mismo uno de los agentes de la DNM durante el encuentro, aquí estaban reunidos "todos los que hacemos control". Duró aproximadamente dos horas y hubo alrededor de cuarenta asistentes, casi todos hombres, vestidos en su mayoría con trajes azules y grises o con uniforme militar. Después de presenciar esta reunión pensé que el taller, a falta de título, bien podría haberse denominado Control de la inmigración. Pero en el marco de la "nueva política migratoria" dicho título no hubiera sido aceptado desde las instancias organizativas. Se trataba de un seminario sobre la relación entre migración y ciudadanía, donde el tema de los derechos humanos atravesaba las distintas presentaciones. De alguna manera, este encuentro sintetizaba el estado de la cuestión en materia de política migratoria: mientras las grandes declaraciones de los funcionarios de gobierno hacían hincapié en el respeto de los derechos humanos de los inmigrantes, los agentes estatales que están parados en la frontera o inspeccionan lugares de trabajo o espacios públicos, buscaban respuestas al ejercicio efectivo del control migratorio. Aunque 
sus inquietudes o preocupaciones, siguiendo la temática del seminario, hubieran pasado por el modo de traducir los principios de los derechos humanos y ciudadanos a prácticas o acciones concretas para hacerlos efectivos, la única respuesta posible hubiera sido la que se venía repitiendo y se siguió reiterando en las intervenciones públicas y que también dieron en esta oportunidad quienes organizaban el taller: facilitar la regularización de la situación administrativa de los inmigrantes para que accedan a la legalidad. Lo que no se les dijo en esta oportunidad es que de ellos se espera que sigan haciendo lo que hicieron siempre, pero con distinto trato, con buen trato.

Sin una exposición inicial de parte de los coordinadores, la reunión consistió en un intercambio de preguntas y respuestas, con una abundante mención a casos específicos extraídos de la experiencia cotidiana. Al comienzo, el encuentro transcurrió en torno a la figura del polizón y del refugiado en respuesta a las inquietudes de agentes de Prefectura principalmente. Algunos se mostraron preocupados acerca de qué hacer con el polizón, proveniente de algún país africano, cuando permanece en el territorio nacional. Allí se adjudicaba la llegada de potenciales refugiados a la imagen que ofrece la Argentina hacia el exterior: "La Argentina grita a cuatro vientos que si un refugiado se baja del barco le vamos a dar el mejor trato".

Más adelante, al resurgir la figura del polizón vinculada al proceso de regularización migratoria, algunos asistentes plantearon sus dudas acerca de la suspensión de la certificación médica. Uno de los agentes de la DNM expresó que "no tener la ficha médica para la radicación es una locura" y otro de los participantes planteó que un buque proveniente de África puede constituir un "foco de infección”, a lo cual contestó uno de los compañeros que "es más fácil que una enfermedad venga por avión". Un agente de Gendarmería, ubicado en un puesto fronterizo con Paraguay, llevó espontáneamente el planteo a su terreno, extendiéndolo al transporte terrestre: "Voy a Buenos Aires, voy al médico, tengo tuberculosis...". El caso concreto comentado se resolvió directamente en el paso fronterizo: el gendarme dice que "se le hizo el rechazo". También se marcó la diferencia con Chile, donde directamente se buscaría "sacarse de encima al extranjero". Uno de los coordinadores, sin mayores precisiones, afirmó de manera concluyente: "El Estado ha confiado en cada uno de nosotros que vamos a saber cumplir la función". 
Luego, los coordinadores habilitaron comentarios de agentes de Gendarmería al abrir el diálogo preguntando: ¿Qué experiencia tienen en la frontera? Después de comentar la detención de "nueve chinos" y su aterrizaje en una pista clandestina, uno de ellos declaró: “También tenemos el problema de los indocumentados". Entre las distintas intervenciones uno afirmó que "los tenemos en la guarda hasta que dispone el juez", mientras otros hacían hincapié en las dificultades que encontraban en la relación con ellos: "Se nos hace muy difícil el trato, por el idioma, por la cultura...", explicó un gendarme. "Ellos no quieren hablar con nosotros... son muy cerrados", agregó otro.

En el intercambio emergió también el tema de la seguridad. Uno de los asistentes, contrario a las facilidades para la radicación que supondría el plan de regularización migratoria iniciado pocos meses atrás, se preguntaba si "nuestra sociedad está segura con el ingreso, con esta persona". Destacando que no se requería un análisis de salud, insistió con que si "nuestra sociedad, nuestro país, está seguro con esta persona que puede estar enferma y morirse en el país". Entre los temores que se expresaron en relación al programa de regularización migratoria apareció la idea de nuevos ingresos de inmigrantes con un pasado de ilícitos: "Lo que va a generar el Patria Grande [es que] va a entrar gente, no la que está" y que sea "gente con antecedentes". La asesora jurídica intervino diciendo que "Argentina cumple con la Convención [se refiere a la Convención Internacional sobre la Protección de los Derechos de Todos los Trabajadores Migratorios y de sus Familiares] y le otorga residencia legal”. Un agente preguntó, insistiendo en la peligrosidad de los extranjeros: “¿No podría ser un potencial delincuente?”. Una afirmación posterior reforzó la exterioridad del peligro que podría suponer la presencia de un inmigrante: "Podría serlo, un boliviano, un paraguayo... estamos hablando de una persona que viene de afuera...".

La preocupación acerca de qué hacer con los ilegales atravesó el desarrollo de la reunión. Uno de los agentes lo planteó mediante una inquietante hipótesis formulada a manera de pregunta: “QQué haríamos acá con decenas, cientos de ilegales como en EEUU? ¿Qué haríamos en ese caso?". Las distintas inquietudes expresadas surgieron como un modo de cuestionar lo que los diferentes agentes percibían como debilitamiento del control estatal en materia migratoria a partir de la nueva ley de migraciones y la reciente implementación del programa de regularización migratoria. Por otro lado, la falta de coordinación entre los distintos agentes de control migratorio fue señalada como una tarea pendiente. En este sentido, se indicó que los agentes de Migraciones y de la Policía Migratoria Auxiliar "muchas veces trabajamos separados" y con diferentes criterios. Además de esta 
dificultad, se señaló que "la DNM no llega a algunos puntos de frontera". Un agente de la Policía aeronáutica también planteó la falta de relación entre la información que poseen ellos y la DNM: "Nosotros tenemos una base de datos y Migraciones tiene otra: ¿se puede unificar?". En otro momento, retomando el tema del control fronterizo, uno de los gendarmes preguntó acerca de las acciones que emprende la DNM al respecto: "Con respecto al tema de frontera, [que] es muy amplia en la Argentina, ¿qué hace la institución?". En la respuesta a su inquietud uno de los coordinadores destacó el papel de la DNM en el "control de permanencia". Allí también se precisó una diferencia, que generalmente no es expresada en otros ámbitos, entre migrante "irregular" e "indocumentado": la diferencia consistiría en que el segundo no posee "ningún documento que identifique a la persona".

Otra pregunta de uno de los asistentes parecía sintetizar una preocupación común entre los agentes del control migratorio: “¿Cómo se ataca, combate desde el Estado la migración irregular?". Los encargados del taller ofrecieron una respuesta: "El Estado tiene muchas herramientas", entre ellas el decreto $\mathrm{N}^{\circ} 1.169$ por el cual se implementó la "regularización de la situación migratoria de ciudadanos nativos de países fuera de la órbita del Mercosur" y el programa de regularización migratoria Patria Grande destinado a ciudadanos del Mercosur ampliado que había sido iniciado muy recientemente.

En sus intervenciones la asesora de la DNM subrayó en diversas oportunidades los derechos que poseen los extranjeros en el país, apoyándose en las convenciones internacionales firmadas por el Estado argentino. (Uno de los coordinadores, en cambio, hizo la misma afirmación acompañado de gesto desaprobatorio de "qué se le va a hacer"). Planteó, a su vez, que el reconocimiento de los derechos de los inmigrantes "tiene que ir acompañado de medidas de alcance global”, que no se reduzca a las garantías que pueda brindar el Estado, ilustrando dicha afirmación con la "sanción a dadores de trabajo a migrantes irregulares". También precisó que "no solamente es ratificar la convención, la implementación se complica, tiene que ser una cooperación a nivel de todos los países, a nivel internacional".

La nueva ley de migraciones suscitó una particular atención. Se dijo de ella que es "una ley que facilita el tema de la radicación del migrante". Uno de los asistentes quiso saber: “¿La migración irregular de bolivianos, paraguayos, estaría captada por esta ley de migración?” 
En la misma línea, uno de los coordinadores de la reunión afirmó: "Se está abriendo un poco la puerta sin ningún tipo de restricción". Y otro de los participantes concluyó: "Todos vienen, pero ninguno se va".

Recogiendo las diversas preocupaciones que manifestaron los agentes de la Policía Migratoria Auxiliar, los organizadores del taller, en particular la asesora jurídica, buscaron dejar en claro las directrices de la actual política migratoria: "Lo que quiere combatir el Estado nacional es que no quede gente en situación irregular". El objetivo principal quedó sintetizado en pocas palabras: “¿Adónde apunta? A terminar la irregularidad”. También afirmaron que "desde la normativa vigente no tenemos por qué tener migrantes irregulares" y, explicando el criterio de nacionalidad que rige con el Patria Grande, instruyeron a los agentes del control migratorio acerca del modo de proseguir en la frontera: “Hay que preguntarle, ¿usted quiere radicarse, puede radicarse?”. Precisaron que "el migrante debería expresarlo en la frontera si tiene la intención [de radicarse]". Aclararon, asimismo, que se trata de "facilitar el ingreso, pero no que sean irregulares". Frente a algunas objeciones de los participantes, uno de los coordinadores de la reunión advirtió: "Tampoco podemos ir contra la ley".

También se habló del "rechazo" en la frontera como una respuesta posible contra la "ilegalidad", validado por la propia ley de migraciones: "Se procederá al rechazo... como marca la ley". Uno de los asistentes definió a quién está en esa situación como "el que está en la zona [fronteriza] o en el fragor de la batalla...". Pareciera que allí el dilema es, como planteó uno de ellos, "si lo rechazo, si lo admito". Este dilema se tradujo en cierto desconcierto frente al mandato de control internalizado y transmitido de generación en generación de agentes migratorios: "Les pregunto a los que están afuera de la función, ¿de qué me disfrazo yo?". En este intercambio, uno preguntó a otro: “Tienen muchos bochazos allá en Iguazú?". "Sí, con documentación no habilitante”, le contestó su compañero. También se hizo mención a la prohibición de reingreso. Refiriéndose al control de la permanencia, otro de los asistentes advirtió al resto sobre las consecuencias posibles de los derechos que los extranjeros poseen con la nueva ley: “¿Cuántos extranjeros que delinquen, delinquen más para que el propio sistema judicial permita que permanezcan?".

El reconocimiento y la extensión de derechos humanos a los inmigrantes generó cierto resquemor entre algunos asistentes, quienes cuestionaron indirectamente estos avances 
trayendo a colación la insuficiencia en el cumplimiento efectivo de derechos ciudadanos de los propios nacionales: "Los nacionales no tienen los derechos humanos asegurados". La asesora jurídica respondió que "nuestro país ratificó la Convención” y que "el Estado se tiene que hacer cargo". Y otro asistente insistió en la línea argumental de su compañero: “Tenemos un país que al de afuera se le está dando una mano... tendría que ser también al de adentro, la deuda interna". 



\section{CAPÍTULO 5}

\section{EL ESTADO Y LA “IRREGULARIDAD MIGRATORIA” EN LA ARGENTINA ACTUAL: REGIONALIZACIÓN, LEGALIZACIÓN E INTEGRACIÓN}

En la presente década, el discurso político sobre las migraciones internacionales ha comenzado a manifestar en distintos países sudamericanos algunos cambios significativos. Muchos de ellos han estado o están impulsando una serie de reformas en materia de legislación y política migratoria que han colocado, bajo la cobertura ideológica de la gobernabilidad migratoria, a los derechos humanos de los migrantes como uno de los principales fundamentos de los cambios iniciados o requeridos, otorgándole a la ilegalidad o irregularidad migratoria un lugar destacado en sus lineamientos de política. Esta tendencia observada en algunos países como la Argentina se inscribe en un proceso mucho más abarcativo que traspasa tanto el ámbito nacional como el regional. En este sentido, la experiencia argentina, constituida en un caso paradigmático, no podría comprenderse sin considerar los efectos que ha tenido y tiene la regionalización de la política migratoria como parte de un proceso global de internacionalización de la política de migraciones internacionales, impulsado por agencias multilaterales como la OIM y diversas instituciones de Naciones Unidas, cuyo resultado más visible es la conformación de un régimen global de control migratorio.

Este capítulo analiza la visión que desarrolla el Estado argentino frente a la ilegalidad migratoria en el marco de los desplazamientos de la "nueva política migratoria" acontecidos en el contexto actual de regionalización e internacionalización de las ideas y prácticas destinadas a regular las migraciones internacionales. Para ello realiza una aproximación a la noción de migración ordenada que ha ingresado al ámbito de gobierno de las migraciones con la emergencia del nuevo régimen global de control de las migraciones e inspira y fundamenta en buena medida las medidas de política adoptadas a nivel nacional en el contexto de la "nueva política migratoria". Sistematiza, asimismo, algunos antecedentes del proceso de regionalización de la política migratoria que dan cuenta de la articulación nacional/regional y ayudan a comprender la adopción de determinadas medidas políticas destinadas a la regulación de los flujos migratorios como el programa nacional de regularización migratoria denominado "Patria Grande". Luego examina este programa gubernamental bajo la certeza de que la comprensión de la 
construcción estatal de la ilegalidad no sólo necesita considerar el proceso de ilegalización, sino también el mecanismo que es asumido como su contraparte, la regularización. Más allá de las reformas enunciadas como producto de un cambio de paradigma o modelo, el análisis de este programa muestra el modo en que la división legal/ilegal atraviesa la visión que se construye desde el Estado sobre la inmigración y que hace a la definición de la política migratoria, además de permitir advertir el carácter arbitrario que subyace a la construcción ideológica de la ilegalidad y la definición de sus límites. En tanto asunto de Estado, la migración desde los países vecinos persiste concebida como problema a partir de la ilegalidad o irregularidad que se le adscribe y la solución que se le antepone, la regularización postulada como instrumento de integración, dirimiéndose la legitimidad de la presencia del inmigrante entre los costos y los beneficios de una inmigración ordenada.

\section{La migración ordenada como misión: hacia un régimen global de control de las migraciones internacionales}

La consolidación del nuevo orden mundial, según algunos analistas, estaría determinando un cambio en las lógicas con que tradicionalmente se han definido las políticas migratorias. La región latinoamericana, por su parte, ha empezado a experimentar algunos cambios específicos en el tratamiento de las migraciones internacionales, donde la idea de corresponsabilidad y la búsqueda de consenso entre países de origen y de llegada, constatable en el incremento de las acciones bi y multilaterales frente a la unilateralidad que tradicionalmente asumieron las políticas migratorias, se convirtieron en las principales directrices de las políticas migratorias (Mármora, 2003). Esta tendencia se ha estado desarrollando en el marco de procesos de integración, como la Comunidad Andina de Naciones (CAN) y el Mercado Común del Sur (Mercosur), y de foros consultivos como la Conferencia Regional de Migraciones ${ }^{340}$ (más conocida como Proceso Puebla), y la Conferencia Sudamericana sobre Migraciones ${ }^{341}$ (denominada también en sus inicios Foro

\footnotetext{
340 Los Estados involucrados en la CRM, originada en el año 1996, son Belice, Canadá, Costa Rica, El Salvador, Honduras, Guatemala, México, Nicaragua, Panamá y Estados Unidos. La República Dominicana se incorporó en 1999. Argentina, Colombia, Ecuador, Jamaica y Perú participan como observadores.

341 La Conferencia Sudamericana sobre Migraciones comenzó a funcionar formalmente en el año 2000, después que fuera acordado su inicio en el Encuentro Sudamericano de Migraciones, Integración y Desarrollo de 1999 realizado en Lima. Se ha desarrollado hasta ahora en Buenos Aires (2000), Santiago de Chile (2001), Quito (2002), Montevideo (2003), La Paz (2004), Asunción (2006), Caracas (2007), Montevideo (2008), Quito (2009) y La Paz (2010). Los Estados participantes estables son Argentina, Bolivia, Brasil, Colombia, Chile, Ecuador, Paraguay, Perú, Uruguay y
} 
Sudamericano sobre Migraciones). Estos espacios consultivos de carácter no vinculante, cuya Secretaría Técnica es ejercida por la OIM, como también los foros especializados en migraciones de los procesos regionales de integración económica como el Mercosur y la CAN, tienen entre sus objetivos principales no sólo definir una posición común en el tema migratorio frente al resto de bloques regionales o en conferencias internacionales, sino también fijar lineamientos para la elaboración de políticas nacionales en materia de migraciones internacionales. Esta articulación cada vez mayor entre los espacios nacional, regional e internacional en materia de política de migraciones internacionales ha sido interpretada como un proceso de transnacionalización de facto de la política migratoria (Sassen, 2001; 2003). ${ }^{342}$

Estos espacios regionales son la cristalización de procesos y proyectos de más amplio alcance. Iniciados la mayoría de ellos hacia mediados de la década de los noventa, especialmente a partir de la Conferencia Internacional sobre la Población y el Desarrollo realizada en El Cairo en 1994 y su plan de acción, los procesos consultivos regionales surgieron frente a la constatación de que los Estados no pueden manejar la migración de

Venezuela. En este proceso de consulta regional dedicado específicamente a las migraciones, entre las prioridades del plan de acción adoptado se registra la promoción de los derechos humanos de los migrantes y sus familias, la vinculación entre los nacionales en el exterior y sus países de origen, la inserción de los migrantes en los países de destino, la regularización migratoria, la gobernabilidad de los flujos migratorios, la generación de información y conocimiento acerca de los procesos migratorios intraregionales y extraregionales, la modernización de las administraciones nacionales migratorias y la actualización de las legislaciones migratorias nacionales. En términos más generales, como se desprende de la última reunión de la CSM realizada en Asunción en el mes de mayo de 2006, los grandes ejes temáticos alrededor de los cuales se reafirman los objetivos son: derechos humanos de los migrantes, migración y desarrollo y gobernabilidad migratoria. El hecho de que estas áreas temáticas guarden una estrecha relación con los lineamientos surgidos en eventos organizados por organismos internacionales como la OIM y las Naciones Unidas invitan a indagar más a fondo los condicionamientos que tienen los Estados nacionales cuando proceden a definir la agenda política regional en materia migratoria. Por ejemplo, los grandes ejes temáticos del Seminario sobre Migración Internacional en las Américas fueron: tendencias y patrones migratorios en las Américas; relaciones entre la migración y el desarrollo; gobernabilidad de la migración y diplomacia multilateral; importancia económica y social de la migración; derechos humanos de los migrantes. Más recientemente, el documento la CEPAL titulado "Migración internacional, derechos humanos y desarrollo en América Latina y el Caribe", publicado a comienzos de 2006 antes de la VI Conferencia, presenta sus conclusiones en torno a "migración y derechos humanos de los migrantes", "migración y desarrollo" y "gobernabilidad de la migración internacional”. Para mayores detalles sobre la cuestión migratoria en los procesos de integración subregional y en los foros consultivos regionales mencionados, véanse Mármora (2003), Novick (2005), Martínez Pizarro y Stang (2006) y Stuhldreher (2006), entre otros. Para una aproximación crítica a la relación entre la integración económica, el desarrollo y las migraciones en el marco del Mercosur, véase Romano (2009).

342 La internacionalización o transnacionalización de la política migratoria supone que ella ya no es definida exclusivamente por el Estado en el marco de las fronteras nacionales, sino mediante la actuación de diversos actores sociales y políticos, sean de carácter nacional o transnacional, en espacios locales o supranacionales. 
manera unilateral (Hansen, 2010). ${ }^{343}$ La interrelación entre estos procesos consultivos regionales especializados en migraciones junto a la aparición de otros espacios intergubernamentales como la Iniciativa de Berna y la Global Commission on International Migration (GCIM) a comienzos de la presente década permitió avanzar en la construcción de una serie de consensos acerca de los modos adecuados de administrar, gestionar $o$ gobernar la migración a escala global, dando lugar al proceso que Düvell (2003) ha llamado globalización del control migratorio, bajo el cual se ha ido construyendo la perspectiva del migration management o migration governance, traducidas al castellano generalmente como gestión de las migraciones y gobernabilidad migratoria respectivamente.

Geiger y Pécoud (2010) atribuyen la noción de migration management a Bimal Ghosh, quien durante los años noventa asistió como consultor de Naciones Unidas y de la OIM diversos proyectos referidos a las migraciones internacionales, entre ellos el NIROMP (New International Regime for Orderly Movements of People) que sirvió de base para la estrategia de la OIM. En la constitución de este nuevo régimen internacional, los foros consultivos regionales contribuirían, como se establece en un informe reciente de la OIM, a) construyendo confianza entre los Estados e incrementando el entendimiento sobre los asuntos migratorios; b) derribando divisiones entre Estados y entre diferentes departamentos de gobierno en su interior, creando redes y facilitando la armonización de posiciones a través de las regiones; y c) edificando capacidad y haciendo efectivos los cambios a través de leyes, políticas o prácticas (Hansen, 2010). En las ediciones de la CSM, como señalan Ramírez Gallegos y Alfaro Aramayo (2010), las nociones de gestión y gobernabilidad de las migraciones han cobrado tal entidad que el foro ha llegado a ser definido como "una instancia regional para la concertación de estrategias regionales para la gobernabilidad de las migraciones internacionales" (V CSM, La Paz, 2004). También en las últimas reuniones los Estados acordaron la formación de una Red Sudamericana para la Gobernabilidad Migratoria (VIII CSM, Montevideo, 2008) y la aprobación del denominado Plan Sudamericano de Desarrollo Humano para las Migraciones (X CSM, Cochabamba, 2010), que sería el resultado de "una etapa de consensos donde las acciones específicas promovidas por la Conferencia se encuadran en un cuerpo de principios que los gobiernos asumen como su posición común de gobernabilidad migratoria" (PSDHM, 2010).

343 De acuerdo a Mármora (2003), la CSM, cuya formación responde a los compromisos asumidos por los gobiernos en la Conferencia Mundial de Población de El Cairo (1994), es considerado también como un intento de consolidación, ampliación y programación sistemática de los desarrollos alcanzados en los procesos de integración subregional en América del Sur, tanto en la CAN como en el Mercosur. 
Esta nueva propuesta y el plan de acción adoptado (por mandato de la II Reunión de Presidentes de América del Sur) durante la tercera CSM realizada en Quito en el año 2003 CSM, junto a sus posteriores revisiones, son una muestra concreta de la internalización de los criterios técnico-políticos que propone la perspectiva de la gobernabilidad migratoria. ${ }^{344}$ Como sugieren Andrijavisevic y Walters (2010), el plan de acción debe ser entendido como una técnica clave a través de la cual los gobiernos son construidos como agentes para reformar algunos ámbitos particulares de políticas, estableciendo una nueva relación entre los gobiernos, la comunidad internacional y el control de las fronteras estatales. Dos de los componentes centrales del plan de acción de la CSM, también implícitos en los principios, lineamientos estratégicos y acciones específicas del PSDHM, se relacionan con el desarrollo de programas nacionales y binacionales de regularización migratoria para las personas y familias migrantes y la promoción de la integración e inserción de los migrantes en los países de destino, cuyas metas y actividades apuntan a la implementación, con la participación de la OIM, de "un programa técnico para la identificación y cuantificación de migrantes irregulares en los países con mayor inmigración" y de "acuerdos recíprocos entre gobiernos" para la aplicación de procesos de regularización migratoria, acompañados con acciones que permitan producir "nuevos criterios" relativos a su diseño y puesta en práctica y difundir iniciativas gubernamentales que resalten "los beneficios que implica mantener una condición migratoria regular". Ambos componentes estructuran los discursos y prácticas desarrollados en el marco de la "nueva política migratoria" en la Argentina, especialmente con la implementación del programa de regularización migratoria conocido como "Patria Grande". La estrecha relación y colaboración mantenida durante estos años entre la OIM y el gobierno argentino en materia de políticas migratorias quedó expresamente rubricada en una carta del director William Lacy Swing dirigida a la presidenta de la Nación, Cristina Fernández de Kirchner, en ocasión de su reciente triunfo electoral en el cual fue reelegida: ${ }^{345}$

\footnotetext{
344 Los ejes de acción definidos en el marco de la CSM en el año 2003 fueron: promoción de los derechos humanos de los migrantes y sus familias; fortalecimiento de la gobernabilidad de los flujos migratorios regionales; desarrollo de programas nacionales y binacionales de regularización migratorias para las personas y familias migrantes; vinculación con los nacionales en el exterior y sus países de origen y acompañamiento en la decisión de su retorno; promoción de la integración e inserción de los migrantes en los países de destino; generación de información estratégica permanente para los procesos de toma de decisiones en asuntos migratorios; conocimiento actual y permanente de los procesos migratorios intra y extrarregionales: modernización de las administraciones nacionales migratorias; establecimiento de un sistema de coordinación permanente de las administraciones nacionales migratorias de la región; y actualización coordinada de las legislaciones nacionales.

345 Este acto de reconocimiento fue difundido y destacado por la DNM en su página web el día 27 de octubre de 2011. El título y la bajada decían: "La política migratoria es 'un modelo', expresó la OIM a la Presidenta. La
} 
[...] Aprovecho la oportunidad para reiterarle el compromiso de la Organización Internacional para las Migraciones (OIM) de apoyar las prioridades en materia migratoria que de común acuerdo sean identificadas. Quisiera expresar adicionalmente que las políticas migratorias desarrolladas por el Gobierno de la República Argentina constituyen un modelo que presenta importantes logros que ameritan su difusión a nivel internacional. [...] Confiamos en que podamos potenciar aún más nuestro apoyo al Gobierno Argentino en materia migratoria, a través de nuestra experiencia y de los numerosos programas que desarrollamos en su país y en la región. [...] (Carta del director general de la OIM, William Lacy Swing, a la presidenta de la Nación, Cristina Fernández de Kirchner, Ginebra, Suiza, 27 de octubre de 2011)

Una de las expresiones de este nuevo régimen internacional destinado a regular los flujos migratorios internacionales, como he señalado en anteriores ocasiones (Domenech 2005; 2007; 2008), es la emergencia de una agenda política global promovida y liderada por organismos internacionales ya consolidados en el orden mundial como la OIM y diversas agencias de Naciones Unidas, la cual sería producto del consenso obtenido entre actores del sistema internacional 346. Con una evidente vocación global, los organismos internacionales involucrados en su construcción, han creado o impulsado nuevos programas e instituciones dirigidos a influir sobre las políticas migratorias nacionales y regionales, por tanto, a disputar la definición y el sentido del nuevo orden migratorio internacional. Así surgieron en este comienzo de siglo, por ejemplo, la Iniciativa de Berna promovida por el gobierno de Suiza junto a la OIM y la Global Commission on International Migration (GCIM), la cual recomendó a su vez la conformación del Global Migration Group (GMG), integrado por los directivos de diversas agencias internacionales del sistema de Naciones Unidas y otras instituciones asociadas. ${ }^{347}$ Más recientemente, se formaron otros

Organización Internacional para las Migraciones (OIM) envió una carta a Cristina Fernández de Kirchner donde elogió los avances en materia migratoria, por lo cual refirió la necesidad de su divulgación mundial y reiteró el respaldo del organismo”. Extraído de http://www.migraciones.gov.ar/accesible/?mostrar_novedad=1061.

346 Recientes informes sobre las migraciones internacionales como el de la Global Commission on International Migration (GCIM) de Naciones Unidas pretenden mostrar que son producto del consenso obtenido a través de mecanismos "participativos" como consultas a funcionarios y técnicos de organismos de Estados nacionales, representantes de asociaciones de migrantes, activistas o miembros de organizaciones civiles y eclesiásticas, académicos de centros de investigación, etcétera.

347 El Global Migration Group se conformó a partir del Geneva Migration Group (establecido en 2003) y está integrado actualmente por la Organización Internacional del Trabajo (OIT), la Organización Internacional para las 
espacios multilaterales de carácter intergubernamental como el Foro Global sobre Migración y Desarrollo en el año 2007, después que se recomendara su creación en el Diálogo de Alto Nivel sobre Migraciones convocado por Naciones Unidas un año antes.

Las agencias que lideran esta emergente agenda global, las cuales forman parte de las estructuras hegemónicas del sistema mundial (Guimarães, 2005), disponen de una producción y sistematización de conocimiento y experiencias mundiales y de una extensa red de vínculos con organismos gubernamentales, think tanks, instituciones académicas y centros de investigación, organizaciones de la sociedad civil y del sector privado y medios de comunicación masivos, además de las organizaciones supraestatales regionales o internacionales asociadas, que les permiten llevar adelante su proyecto político y les confieren al menos la base de su legitimación. En este sentido, el régimen global de gestión de la migración, como indica Mezzadra, no refiere a un "gobierno político integrado", sino más bien a "la formación contradictoria y fragmentaria de un cuerpo de conocimientos dentro de comunidades políticas y epistémicas dispares" (Mezzadra, 2012:169). Aquí es importante observar que la constitución de relaciones y redes transnacionales (Mato, 2001; 2004), en correspondencia con la misión institucional que tienen los actores transnacionales y globales, sirve a los intereses de difusión de las representaciones de las ideas clave que dan sentido a sus prácticas (Mato, 2004:72). Cada agencia internacional y regional organiza y financia eventos de distinta índole junto a otros organismos internacionales y/o gobiernos nacionales o convoca y reúne funcionarios políticos, intelectuales del ámbito académico, figuras de la sociedad civil y el gobierno, beneficiarios y diseñadores de programas del tercer sector en congresos y seminarios internacionales, conferencias y talleres, actividades investigación y consultoría, etcétera. En el terreno de las migraciones, la OIM constituye un ejemplo por antonomasia. Este organismo lleva adelante diversas iniciativas en distintos planos con otras instituciones asociadas dentro y fuera del sistema de Naciones Unidas. Así lo explica en uno de sus documentos de difusión ${ }^{348:}$

\footnotetext{
Migraciones (OIM), el Alto Comisionado de Naciones Unidas para los Derechos Humanos (ACNUDH), la Conferencia de Naciones Unidas sobre Comercio y Desarrollo (UNCTAD), el Alto Comisionado de Naciones Unidas para los Refugiados (ACNUR), la Oficina de Naciones Unidas contra la Droga y el Delito (ONUDD), el Departamento de Asuntos Económicos y Sociales (DAES), el Programa de las Naciones Unidas para el Desarrollo (PNUD), el Fondo de Población de las Naciones Unidas (FNUAP), las Comisiones Regionales de las Naciones Unidas, la Organización de las Naciones Unidas para la Ciencia, la Educación y la Cultura (UNESCO), el Fondo de las Naciones Unidas para la Infancia (UNICEF), el Instituto de las Naciones Unidas para la Formación y la Investigación (UNITAR) y el Banco Mundial $(\mathrm{BM})$.

348 Véase el documento "La OIM y el diálogo de alto nivel sobre la migración internacional y el desarrollo", en http://www.un.int/iom/IOM\%20\&\%20the\%20HLD\%20Spanish.doc, acceso 13 de abril de 2008.
} 
En el plano nacional, gracias a su extensa red de oficinas en 118 países del mundo, la OIM se encarga de concienciar a todas las autoridades locales pertinentes sobre el Diálogo de Alto Nivel y ayuda a los países a definir una postura coherente al respecto. Entre esas actividades cabe señalar la organización de eventos nacionales (seminarios, mesas redondas, etc.) para fomentar la deliberación de los temas atinentes al Diálogo antes mencionado. Dichas iniciativas se realizan en cooperación con las autoridades gubernamentales, las Naciones Unidas y otras organizaciones internacionales pertinentes $\mathrm{y}$, donde quiera sea posible, con las $\mathrm{ONG}$, la sociedad civil y el sector privado. En lo que respecta al plano regional y mundial, la OIM está patrocinando varios acontecimientos que se centran en los temas generales y aspectos específicos del Diálogo de Alto Nivel, incluidos la migración laboral, las repercusiones de las remesas en el desarrollo, las diásporas y la feminización de la migración.

La misión institucional de la OIM con la cual se consagra al principio de que "una migración ordenada y en condiciones humanas beneficia a los migrantes y a la sociedad" ha pasado a formar parte de la visión que sostienen todos aquellos actores comprometidos con el nuevo régimen internacional para la migración ordenada de las personas como lo llama uno de sus ideólogos (Ghosh, 2008). Con la paulatina instauración de este régimen ha surgido una nueva manera de organizar, clasificar y controlar los movimientos internacionales de población. Desde esta perspectiva, basada en las nociones de equilibrio y eficacia y en una lógica de costo-beneficio -encarnada en la figura del balance contable aplicado a la inmigración (Sayad, 1998)- pragmática y utilitarista, que advierte la imposibilidad de controlar eficazmente a través de medidas de índole restrictiva a los flujos migratorios, especialmente aquellos de carácter irregular, los migrantes son clasificados sobre la base de una supuesta (in)utilidad, estableciendo una serie de ventajas o beneficios y desventajas o perjuicios (no sólo económicos) de la inmigración. La novedad es que bajo este enfoque las migraciones son consideradas principalmente en términos de oportunidad, quitando del centro la noción de problema asociado a las migraciones durante décadas en la agenda mundial, destacando, por un lado, la vulnerabilidad de los migrantes y acentuando, por el otro, las oportunidades que ofrecen, atribuyéndoles una capacidad de transformación inaudita: el papel de los migrantes en el crecimiento económico, el desarrollo y la reducción de la pobreza. Como lo destaca el conocido lema de la OIM Managing Migration for the Benefit of All, desde esta perspectiva se propone que la migración, administrada adecuadamente, puede beneficiar tanto a las sociedades de 
origen y destino como a los migrantes. Ahora, los flujos migratorios son clasificados en deseables e indeseables de acuerdo a su carácter ordenado/desordenado, voluntario/forzoso y reducido/masivo, desplazando -en tanto enfoque global- los criterios étnico-nacionales que históricamente han distinguido la aplicación de las políticas migratorias selectivas y las definiciones tradicionales sobre el control migratorio. Precisamente, al margen de las distintas apropiaciones que esta perspectiva pueda tener, uno de los aspectos centrales que hace a su propia definición es la noción de frontera que maneja. Andrijasevic y Walters (2010), en su análisis de la OIM y su involucramiento en lo que llaman el gobierno internacional de las fronteras, sostienen que los límites políticos internacionales no son vistos como instrumentos geomilitares que sirvan de contenedores de la población y el territorio, sino como mecanismos privilegiados que permitan regular, en un mundo aún segmentado jurídica y políticamente en espacios nacionales, el modo en que los procesos migratorios globales tengan lugar.

El concepto de migración ordenada como componente constitutivo de la perspectiva de la gobernabilidad migratoria atraviesa desde sus inicios el proceso consultivo regional conocido como Conferencia Sudamericana de Migraciones que integra la Argentina. Desde la primera edición en adelante, los Estados han señalado la conveniencia de promover "una migración ordenada y planificada como solución a la migración irregular y la lucha contra el tráfico de seres humanos". Asimismo, en correspondencia con la mirada que propone la gobernabilidad migratoria sobre las fronteras y el modo de controlar los flujos migratorios internacionales, los Estados han declarado que "la aplicación de medidas restrictivas por los países de destino no constituye una solución realista a la emigración irregular" (VIII CSM, Montevideo, 2008). En diversas oportunidades también han expresado en las declaraciones finales su rechazo a la "criminalización de la irregularidad migratoria" como a la xenofobia y la discriminación. Dado que la perspectiva de la gobernabilidad migratoria parte del supuesto de que una migración ordenada trae consigo innumerables beneficios, las declaraciones suelen resaltar los efectos positivos que tendría la inmigración y el aporte que harían los migrantes en el ámbito económico, social y cultural, omitiendo el político.

Como muestran los catorce procesos consultivos regionales desarrollados a nivel mundial con el apoyo técnico-político de la OIM, no se trata necesariamente de una visión integral ni unívoca. Su desarrollo difiere según los intereses de los actores políticos implicados y las especificidades del contexto sociohistórico: en algunas versiones puede aparecer acentuada, por ejemplo, la regulación de la migración laboral y la migración llamada irregular o la defensa de los derechos humanos, mientras que en otras se puede enfatizar 
la seguridad nacional, suprimiendo cláusulas relativas a los derechos de los migrantes (en las Américas así ocurre, por ejemplo, con la CSM y la CRM respectivamente). Tampoco se trata de lineamientos impuestos de manera unilateral por los organismos internacionales o adoptados mecánicamente por los Estados nacionales: aunque los discursos y políticas de ciertas agencias internacionales ejercen una innegable influencia en la construcción de las agendas políticas nacionales, también es cierto que la agenda global se construye a partir de casos nacionales considerados exitosos que a la vez sirven para mostrar y recomendar a otros Estados las llamadas buenas prácticas. La experiencia argentina reciente, por ejemplo, es presentada en el ámbito regional por representantes de diversas agencias internacionales como modelo a imitar. Además, si bien las iniciativas y medidas estatales pueden responder a recomendaciones $y$ exigencias de organismos internacionales (las cuales son también producto de compromisos estatales asumidos en acuerdos regionales y en reuniones mundiales ${ }^{349}$ ) y el rol de los Estados nacionales se ha visto modificado en la arena política internacional, donde la disputa por la producción de sentido, prácticas y políticas se ha complejizado, aquéllos mantienen su poder de decisión sobre los asuntos migratorios. Más aun, la instauración de este régimen global sobre las migraciones internacionales supone la participación de los Estados nacionales como socios activos de los organismos internacionales que lo impulsan. El Estado sigue siendo un actor clave en la formulación y aplicación de la política migratoria, ya que en virtud de su soberanía nacional aún posee la atribución de permitir, restringir o rechazar la entrada y permanencia de los inmigrantes así como determinar los derechos y obligaciones (diferenciales o no) de los habitantes -a quienes clasifica como nacionales o extranjerosde acuerdo al principio de nacionalidad. 350

\section{Entre la integración regional de los países y la integración social de los extranjeros}

Aunque los procesos consultivos como la CSM no están asociados formalmente a instituciones regionales, interactúan con organismos, asociaciones y procesos de

\footnotetext{
349 En este sentido, también es preciso tener en cuenta que la entrada en vigor de las convenciones internacionales depende de la ratificación de los Estados nacionales.

350 Siempre resulta necesario considerar las diferencias entre aquellas políticas dirigidas a los emigrantes y a los inmigrantes. Respecto a la diferenciación entre las políticas de emigración e inmigración, es preciso destacar la posición ambigua que suelen asumir los Estados nacionales frente al fenómeno migratorio. Mientras que por un lado reclaman igualdad de trato para sus ciudadanos residentes en el exterior, por el otro buscan restringir los derechos de los inmigrantes. El caso de Brasil, entre otros, constituye una muestra clara de esta posición. Agradezco este señalamiento a Bela Feldman-Bianco.
} 
integración regionales de distintas maneras (Hansen, 2010). En el caso argentino, la existencia del Mercosur ha sido crucial en la adopción de la nueva política migratoria. En sus disertaciones públicas, los funcionarios de la DNM suelen descatar aquellas instancias que se han desplegado en el marco del Mercosur, ámbito en el cual el Ministerio del Interior tiene mayor injerencia y el Estado argentino en general ha negociado diversas medidas vinculantes con el resto de los países miembros. ${ }^{351}$ Las explicaciones acerca de la adopción de la nueva política migratoria en la Argentina subrayan la relevancia que ha tenido y tiene este proceso de integración regional, iniciado a principios de los noventa, en la definición de los lineamientos que guían las medidas adoptadas, en particular el programa de regularización migratoria que comenzó a desarrollarse a comienzos del año 2006. Diversas afirmaciones, inclusive el título de algunas de las exposiciones públicas realizadas por funcionarios de la DNM, se refieren a la "influencia del Mercosur en la política migratoria argentina". ${ }^{352}$ En esta línea, uno de los directores de la DNM definió al Mercosur como "una de las piedras angulares de nuestra actual política migratoria". ${ }^{353}$ En diferentes circuntancias, la política migratoria ha sido enunciada como una política de integración y, en particular, como política de integración regional o considerada como uno de los elementos de la política de integración regional: "Argentina apuesta a que esta Política migratoria sea un instrumento más de la Política de Integración Regional que lleva adelante". 354

Acorde con la posición de la DNM en la estructura del Estado, las descripciones del estado actual de la política migratoria privilegian aquellos aspectos resultantes del ámbito de gobierno que atiende el tema de la seguridad (como el Ministerio del Interior), antes que aquellos espacios del proceso de integración regional dedicados a los asuntos sociolaborales en los cuales los movimientos migratorios internacionales son pensados y tratados mayormente -desde la década de los noventa hasta la actualidad- en términos de "libre movilidad de la mano de obra" o "migraciones laborales". 355 Entre los antecedentes

\footnotetext{
351 Véanse Mármora (2003); Novick (2005); Stuhldreher (2006).

352 A modo de ejemplo, la ponencia de la Jefa de la Oficina de Temas Internacionales de la DNM, Adriana Alfonso, en el marco del seminario "Migraciones y Derechos Humanos” realizado en la ciudad de Rosario en el año 2005 se tituló "La política migratoria de Argentina. La influencia del Mercosur".

353 Martín Arias Duval, Foro Iberoamericano sobre Migración y Desarrollo, Cuenca, 2008.

354 MRECIyC, Encuentro Iberoamericano sobre Migraciones y Desarrollo, Madrid, 2006.

355 Durante estos años, fueron tematizadas en el Subgrupo de Trabajo № 2 de Asuntos Aduaneros, pero especialmente en el Subgrupo № 11 sobre Relaciones Laborales, Empleo y Seguridad Social, conformado por sectores gubernamentales, empresariales y sindicales. Con el reemplazo del SGT № 11 por el SGT № 10 de Asuntos Laborales, Empleo y Seguridad Social, la movilidad de trabajadores cambió de enfoque al dejar de ser tratada como "libre circulación de mano de obra" y ser considerada en términos de "migraciones laborales". Posteriormente, hacia
} 
más citados por los funcionarios de la DNM aparecen los distintos avances obtenidos en la Reunión de Ministros de Interior del Mercosur y Estados Asociados, creada en 1996, especialmente el Acuerdo sobre Residencia para Nacionales de los Estados Parte del Mercosur, Bolivia y Chile firmado en el 2002, el cual -como señala Hansen (2010)- está inspirado en las discusiones mantenidas en el marco del proceso consultivo regional sudamericano, la CSM. ${ }^{356}$ A modo de ilustración:

Este acuerdo regional, considerado "un verdadero hito en la historia de la integración del bloque", emana de una propuesta del gobierno argentino referido al acceso a la residencia para los nacionales del bloque regional que, con el tiempo, se convertirá en la plataforma del programa nacional de regularización migratoria "Patria Grande". Fue presentado por los representantes del gobierno argentino en la XII Reunión de Ministros del Interior del Mercosur y suscripto en la Cumbre de Presidentes realizada en Brasilia en diciembre de 2002. Este acuerdo interestatal fija un criterio de radicación basado fundamentalmente en la acreditación de la nacionalidad de uno de los países de la región, estableciendo que "(l)os nacionales de un Estado Parte" que desearan residir "en el territorio de otro Estado Parte" pueden obtener una "residencia legal" mediante "la acreditación de su nacionalidad", entre otros requisitos. ${ }^{357}$ Entre la documentación exigida, los funcionarios de la DNM sólo hacen hincapié en la carencia de antecedentes penales o policiales. La "residencia legal" consiste en "una residencia temporaria de hasta dos años" que luego

mediados de la década, como producto de la redefinición que le imprimió la firma del Protocolo de Ouro Preto al Mercosur, empiezan a adquirir relevancia el Acuerdo Multilateral de Seguridad Social y la Declaración Sociolaboral del Mercosur. Maguid (2006) distingue tres etapas en relación al tratamiento de la cuestión migratoria en el marco del Mercosur. La primera, desde la creación del Mercosur hasta la firma del Protocolo de Ouro Preto, a finales de 1994, el cual da lugar a la segunda etapa que finaliza con la firma del Acuerdo sobre Residencia para Nacionales de los Estados Parte del Mercosur, Bolivia y Chile e inicia la tercera en el año 2002.

356 También el sucesor de Ricardo Rodríguez destaca la importancia que tuvo este evento en la constitución de la "nueva política migratoria": "Para la República Argentina, los compromisos asumidos a partir de la Reunión de Ministros del Interior del MERCOSUR, han tenido una incidencia importantísima en su renovada política migratoria, en línea, nada más y nada menos, con una tradición profundamente enraizada en la conciencia nacional desde los orígenes mismos de nuestra Patria, olvidada por períodos dictatoriales en los que se pretendieron imponer con menor o mayor éxito, medidas restrictivas a la inmigración.” (Arias Duval, Foro Iberoamericano sobre Migración y Desarrollo, Cuenca, 2008)

357 Los requisitos establecidos son: a) pasaporte válido y vigente o cédula de identidad o certificado de nacionalidad expedido por el agente consular del país de origen del peticionante acreditado en el país de recepción; b) partida o certificado de nacimiento y partida o certificado de matrimonio, cuando corresponda; c) certificado que acredite la carencia de antecedentes penales y/o policiales en el país de origen o en los que hubiera residido el peticionante durante los cinco años anteriores a su arribo al país de recepción o a su petición ante el Consulado; d) declaración jurada de carencia de antecedentes internacionales, penales o policiales; f) certificado médico expedido por autoridad médica competente u otra sanitaria oficial del país de origen o recepción; g) pago de tasa retributiva de servicios. 
podrá ser "permanente" mediante el cumplimiento de una serie de requisitos, entre los que se encuentra, además de los establecidos para la temporaria, "la acreditación de medios de vida lícitos que permitan la subsistencia del peticionante y su grupo familiar conviviente".

El Estado argentino es el primero que incorpora el Acuerdo sobre Residencia a la legislación nacional: lo añade a la nueva ley de migraciones, lo aprueba por ley en el año $2004^{358}$ y luego lo aplica mediante la instrumentación del programa de regularización migratoria que distinguirá entre nacionales del Mercosur ampliado y los de fuera del ámbito regional. Un funcionario de la DNM explica que este convenio regional "surge como un mecanismo para avanzar en el fortalecimiento y profundización del proceso de integración mediante la implementación de una política de mecanismos ágiles de acceso a la regularidad migratoria." Este convenio es considerado no sólo como "la base del programa Patria Grande implementado por Argentina", el cual sería "en la práctica la implementación unilateral, por parte de Argentina, del Acuerdo de Residencia del MERCOSUR", sino también "la base de la política migratoria que está desarrollando en este momento Argentina". Es decir, el programa Patria Grande será la traducción del Acuerdo sobre Residencia al ámbito nacional, constituyéndose en el instrumento jurídico-político que condensa el consenso alcanzado en el orden regional para obtener la solución de los problemas nacionales: "la solución a la problemática de la irregularidad" que afecta tanto la integración regional entre los países como la "plena integración" de los inmigrantes. ${ }^{359}$

Este acuerdo fue, como les digo, negociado y suscripto a fines del año 2002. En el caso de Argentina ya ha sido internalizado, ha sido incorporado incluso como criterio de la nueva Ley de Migraciones y a pesar de que todavía no hemos logrado en la región la reciprocidad completa en este tema, Argentina lo va a implementar de manera unilateral, porque está convencida que esa es la solución a la problemática de la irregularidad. (Adriana Alfonso, Seminario Migraciones y Derechos Humanos, Rosario, 2005)

Este Acuerdo, que es la base de la política migratoria que está desarrollando en este momento Argentina, lamentablemente no ha sido internalizado en la

358 Ley № 25.902/04.

359 Véase Grimson (2002) para un análisis de los significados y sentidos de la noción de integración en las ciencias sociales y en el marco de las políticas de vinculación regional que llevan adelante los Estados nacionales como el Mercosur. 
totalidad de los países de la región, esta es la problemática propia de los acuerdos internacionales. [...] Si bien en las negociaciones que hemos sostenido en los últimos meses hemos insistido en los otros países de la región en la conveniencia de aplicarlo de manera conjunta, la falta de éxito y el convencimiento que tiene Argentina de que esta es la solución al problema es lo que nos ha llevado a diagramar una estrategia con la cual en el corto plazo tendríamos ya en aplicación el Acuerdo. (Adriana Alfonso, Seminario Migraciones y Derechos Humanos, Rosario, 2005)

Argentina entiende que ese es el camino. Por ello sin esperar que la norma entrara en vigencia en el bloque y sin exigir reciprocidad ha puesto en marcha el Programa Nacional de Normalización Documentaria Migratoria al cual la sapiencia de nuestro pueblo ha simplificado en un titulo sumamente significativo para el sentir nacional 'Patria Grande'. (Ricardo Rodríguez, Encuentro Iberoamericano sobre Migraciones y Desarrollo, Madrid, 2006)

Cuando Argentina llevó a la mesa de negociación del MERCOSUR el llamado Acuerdo de Residencia lo hizo convencida de que en él se encontraría la solución a la mayor parte de la problemática de la irregularidad migratoria en nuestra región. (Ricardo Rodríguez, Encuentro Iberoamericano sobre Migración y Desarrollo, Madrid, 2006)

La aplicación unilateral que realiza la Argentina de este convenio evidencia el interés estatal en la regulación -concebida como regularización- de los flujos migratorios provenientes de los países vecinos (que por momentos pretende disimular apelando a fundamentos centrados en la "solidaridad") y al mismo tiempo confirma, a través de este acto, su condición de país de inmigración, diferenciándose del resto de países que conforman el bloque subregional que integra. La prioridad conferida a una medida como la regularización migratoria, al confirmar la extranjeridad o exterioridad de la presencia de inmigrantes a través de la ilegalidad que le asigna (aunque no todos los extranjeros son ilegales, los inmigrantes ilegales son siempre extranjeros), no sólo resulta una medida circunscripta al nivel operativo, sino que también funciona como acto simbólico de constatación de aquella condición que históricamente se ha atribuido como país receptor 
de población extranjera, contribuyendo a afianzar aquellos atributos que requiere la constitución de la estatalidad.

Las voces oficiales destacan, a su vez, que el Acuerdo sobre Residencia haya resultado de un ámbito de gobierno donde se define la política de seguridad a escala nacional y regional como la Reunión de Ministros del Interior. La política de puertas abiertas, sostenida por este Acuerdo, se estaría desarrollando a pesar de la tendencia internacional de cierre de las fronteras por motivos de seguridad, especialmente fortalecida desde los acontecimientos del 11/S de 2001, y la asociación entre migración y terrorismo. Aquí la única tendencia internacional reconocida es la llamada securitización de las migraciones, asociada al control restrictivo y represivo de los flujos migratorios internacionales, omitiendo otras formas de control más sutiles y supuestamente más eficaces que han comenzado a vislumbrarse en el orden mundial como las promovidas bajo el enfoque de la gobernabilidad migratoria.

No es un dato menor que este acuerdo se haya suscripto en el ámbito de la reunión de Ministros de Interior del Mercosur si tenemos presente que es precisamente bajo estos ministerios que se desarrolla toda la estrategia de seguridad de nuestros países y de la región. Cuando en otras regiones del mundo se cierran las puertas a los migrantes, basándose en temas de seguridad y de oscurantismo frente al terrorismo, en el Mercosur las puertas se abren. (Adriana Alfonso, Seminario Migraciones y Derechos Humanos, Rosario, 2005)

[...] Volver a la política migratoria de puertas abiertas en la República Argentina no es fácil desde el espacio de gestión porque estamos contradiciendo tendencias internacionales que ligan a la migración con el terrorismo [...] (Mariana García, Seminario Migraciones y Derechos Humanos, Rosario, 2005) ${ }^{360}$ 
No es un dato menor que las afirmaciones vertidas en el párrafo anterior hayan surgido de los Ministros de Interior de la región, quienes también tienen bajo su competencia los temas relacionados con la seguridad. Cuando en otras regiones del mundo las puertas se cierran a las migraciones bajo la excusa de la delincuencia y el terrorismo, en el MERCOSUR hemos demostrado contar con la madurez suficiente para enfrentar el desafío de la seguridad aceptando las falencias internas y sin trasladar las culpas a los migrantes. (Ricardo Rodríguez, Encuentro Iberoamericano sobre Migraciones y Desarrollo, Madrid, 2006)

Otro de los antecedentes mencionados frecuentemente en las intervenciones públicas de los funcionarios de la DNM es la Declaración de Santiago sobre Principios Migratorios, emitida en el año 2004. Este documento contiene muchas de las ideas corporizadas en la "nueva política migratoria" que analicé en el capítulo anterior. Partiendo de la premisa que los migrantes realizan importantes aportes a la conformación de los Estados firmantes y que todos ellos están comprometidos con el respeto de sus derechos humanos, los funcionarios gubernamentales, en representación del Estado argentino, suscriben una serie de principios que reconocen la importancia de tratar la temática migratoria mediante "mecanismos de diálogo multilateral abierto" para "fortalecer el proceso de integración" así como de diseñar una política migratoria acorde a los derechos humanos e inserta en las relaciones internacionales mantenidas entre los distintos países, cuya "eficiencia" dependerá de su "adecuación a la realidad regional e internacional" y de que la "regularidad migratoria" sea asumida como "condición indispensable para lograr la plena inserción del migrante en la sociedad de recepción”. 361

\footnotetext{
361 La Declaración de Santiago sobre Principios Migratorios dice textualmente: “Convencidos: Que se debe abordar la temática migratoria de la región a través de mecanismos de diálogo multilateral abierto como forma de fortalecer el proceso de integración; Que el MERCOSUR debe reafirmar ante el resto del mundo su vocación de trabajar hacia una nueva política migratoria, fundamentada en la dimensión ética del respeto a los derechos humanos y en su inserción en las relaciones internacionales entre los países; Que la eficiencia de la política migratoria dependerá de su adecuación a la realidad regional e internacional y a la aceptación de que la regularidad migratoria es condición indispensable para lograr la plena inserción del migrante en la sociedad de recepción; Que el trato que se dé a los nacionales de los Estados Parte y Asociados del MERCOSUR en terceros países debe ser recíproco al que reciben los nacionales de esos países en nuestro territorio; Que es responsabilidad de los Estados Parte y Asociados del MERCOSUR trabajar en forma coordinada (1) en el combate y prevención del tráfico de personas y de los abusos inherentes a la inmigración clandestina en la región; Que se reconoce que la dimensión cultural de la migración es un valioso aporte en la transculturización de los pueblos; Que se reconoce que el importante rol de los trabajadores migrantes es un valioso capital social que dinamiza y potencia a los diversos sectores económicos y sociales de los
} 

para "la gente que está debajo de la alfombra"

A mitad del año 2004, se inicia mediante decreto presidencial el Programa Nacional de Normalización Documentaria Migratoria dirigido a la "creación del marco de ejecución de nuevas políticas migratorias orientadas a la inserción e integración de la población inmigrante" y a la "regularización de la situación de los inmigrantes". ${ }^{362}$ Como primera medida, se establece un régimen especial de regularización migratoria para los "ciudadanos nativos fuera de la órbita del MERCOSUR". ${ }^{363} \mathrm{Al}$ otro año, se instruye a la DNM a implementar en el marco de este programa nacional "la regularización migratoria de los extranjeros nativos de los Estados Parte del Mercado Común del Sur (MERCOSUR) y sus Estados Asociados", ${ }^{364}$ divulgado más tarde como Patria Grande. ${ }^{365}$ La DNM dispone ejecutar esta medida el 13 de diciembre de 2005.366 Al día siguiente, el presidente Kirchner presentó el programa en el Salón Blanco de la Casa Rosada con la presencia de gobernadores, ministros, diplomáticos y distintos funcionarios nacionales, provinciales y municipales. Durante los años posteriores, se mantuvo vigente el criterio de la nacionalidad Mercosur para las radicaciones, pero oficialmente el Patria Grande finalizó en el año 2009, luego de que se cerrara la segunda etapa del programa destinada a tramitar la residencia temporaria (de dos años de duración) para quienes hubieran obtenido su residencia precaria anteriormente.

países de acogida migratoria; Que es un compromiso para nuestros Estados avanzar en un régimen común de salud y seguridad social para nuestros nacionales en la región.

362 Decreto № 836/04.

363 Decreto № 1.169/04.

364 Decreto № $578 / 05$.

365 Detrás de las decisiones de Estado, grandes o pequeñas, hay funcionarios concretos. Sin embargo, suele ocurrir que las decisiones personales, negociadas en un pequeño círculo de funcionarios, son presentadas como si fueran producto de una voluntad ajena y en ocasiones abstracta. Así sucedió con la denominación "Patria Grande" que recibió el Programa Nacional de Normalización Documentaria Migratoria. En una de sus actuaciones en eventos internacionales, el director de la DNM atribuye su nombre a "la sapiencia de nuestro pueblo [que lo] ha simplificado en un título sumamente significativo para el sentir nacional" (Ricardo Rodríguez, Encuentro Iberoamericano sobre Migraciones y Desarrollo, Madrid, 2006). Pero, como se desprende de una de las anécdotas que narra el Ministro del Interior, Aníbal Fernández, durante una de sus intervenciones, fue el propio director de la DNM quien propuso que se lo llamara de esta manera. El Ministro del Interior al principio se negó "no porque de corazón no lo sintiera, porque esta América morena necesita ser una patria grande en algún momento, sino porque creía que mucha gente nos iba a criticar". Pero el director de la DNM insistió y finalmente se mantuvo. Esto también lo ratifica el ex Jefe de la Delegación Córdoba de la DNM cuando le pregunté por el nombre que se le otorgó al programa de regularización: según él, el propio director de la DNM lo habría propuesto bajo la idea de "unión latinoamericana" (Entrevista con el Jefe de la Delegación Córdoba de la DNM, 2007).

366 Disposición № 53.253/05. 
La efectiva implementación del programa de regularización dependía de la puesta en práctica de la "descentralización operativa"367, la cual requería de la concreción de convenios con las provincias y la adhesión de los respectivos municipios y de la participación de organismos no gubernamentales, denominados "instituciones sociales colaboradoras", cuyo ámbito de aplicación sería "todo el territorio de la República Argentina". Lo que terminó acelerando este proceso fue la muerte de seis personas identificadas como bolivianas, tanto por los funcionarios como por los periodistas, a causa del incendio de un taller textil clandestino, ubicado en el barrio Caballito de la ciudad de Buenos Aires, donde vivían en condiciones de marcada precariedad y trabajaban bajo formas de esclavitud moderna. Como suele ocurrir en los ámbitos de gobierno, un hecho trágico -ocurrido en la madrugada del penúltimo día de marzo- que tomó estado público y que tuvo una enorme repercusión mediática, fue el disparador de las más diversas iniciativas. ${ }^{368}$ Entre ellas, en el mes de abril se comienza a implementar el programa de regularización migratoria, el único plan nacional de política pública destinado a los inmigrantes alrededor del cual giró la gestión de Ricardo Rodríguez al frente de la DNM en el período 2004-2007.

Esta iniciativa gubernamental, si bien tuvo que ser implementada antes de lo que se tenía previsto, se origina a inicios de la presente década cuando en algunos ámbitos específicos -como la Cámara de Diputados de la Nación- se comienza a discutir una "nueva política migratoria" en la Argentina. Ya en aquél entonces la asesora de la DNM, Adriana Alfonso, quien sobrevivió los distintos cambios de directores de la institución, bosquejaba lo que más tarde se convertiría en el planteo central que utilizara para fundamentar las acciones de la gestión actual. Para ello se sirve del esquema, articulado en base a tres preguntas básicas, que ya planteara años atrás para orientar la toma de decisiones políticas: ¿qué tenemos?, ¿qué queremos? y ¿qué podemos lograr? El objetivo político es una "migración ordenada", cuya integración a la sociedad sea "total" o "plena" y se produzca a través de la legalidad, objetivo sólo conseguible mediante la aplicación de medidas que se adecuen a la realidad geográfica e histórica de la Argentina. Así lo expresa en el marco del seminario "Política y Normativa Migratoria en la Argentina", organizado por la Comisión de Población y Recursos Humanos de la Cámara de Diputados de la Nación en el año 2000:

Respecto del qué tenemos, tenemos una realidad geográfica e histórica que nos condiciona respecto de la normativa que podemos llegar a implementar.

367 Decreto № $836 / 04$.

368 Como señalé en el capítulo 2, este hecho también tuvo una importante repercusión en Bolivia, colaborando en el proceso de visibilización de la emigración. 
Respecto del qué queremos, coincidiremos que queremos una migración ordenada y con posibilidades ciertas de integración total a la sociedad, esta integración deberá darse a través de la legalidad. Y ahora sí, viene la conjunción de ambos puntos: qué podemos. Para poder lograr la integración plena a la sociedad a través de la legalidad deberemos implementar medidas que se ajusten a la realidad, debemos tener en cuenta cuál es la realidad que queremos normar. (Adriana Alfonso, Cámara de Diputados de la Nación, Buenos Aires, 2000)

La idea de una migración ordenada, basada fundamentalmente en la legalidad, es una de las premisas del nuevo régimen global de control de las migraciones internacionales, como vimos anteriormente. Una de sus características sobresalientes, como señalan Geiger y Pécoud (2010), es el propósito de convertir a la migración en un proceso más ordenado, predecible y manejable, además de hacerlo provechoso para todos los stakeholders involucrados. De ahí las recomendaciones a los Estados para implementar programas de gobierno que eviten las migraciones irregulares y busquen modos alternativos a las medidas restrictivas para enfrentarlas, entre ellas la promoción de programas de regularización migratoria. Desde la perspectiva de la gobernabilidad migratoria no se propone un esquema de control basado en el aumento de las restricciones (al menos no como principio), sino un modo de regulación que permita conducir, direccionar, canalizar los flujos migratorios. La metáfora que ofrece el ex director de la DNM, Ricardo Rodríguez, expresa de una manera elocuente la concepción sobre las migraciones y su control que subyace a la idea de gobernabilidad de los flujos migratorios como finalidad: las migraciones internacionales son como el agua. ${ }^{369}$

Las corrientes migratorias no se paran con el Ejército, la decisión humana no se puede detener con el Ejército, la única forma es direccionarlas. Siempre

\footnotetext{
369 Esta metáfora también fue utilizada por el director general de Asuntos Consulares del Ministerio de Relaciones Exteriores y Culto, Raúl Martínez Camadro, durante su visita a la Comisión de Población y Recursos Humanos de la Cámara de Diputados de la Nación en el año 2002 en el marco de los intercambios mantenidos acerca de la nueva ley de migraciones. En dicha oportunidad expresó: "Es cierto que históricamente ha existido siempre un flujo y reflujo de corrientes migratorias. Obviamente, el tema de las migraciones es casi como el del agua, en el sentido de que uno puede intentar poner una contención. En efecto, se puede establecer una ley dura, que fije el criterio de la migración cero, como ocurre en los Estados Unidos respecto de los mexicanos; se puede pensar en electrificar la frontera, poner un vallado o utilizar el río. También se puede establecer la idea de la migración selectiva: piden ingenieros, cocineros o gerentes de hotel, como hace Canadá u otros países. Pero lo cierto es que, si bien el derecho legisla, no se puede cubrir toda la realidad, que al igual que el agua, cuando encuentra una piedra da la vuelta por el costado. Es muy difícil estar siempre alerta." (énfasis propio).
} 
comparo las corrientes migratorias con el agua: por más que se construyan diques, por algún lado natural va a buscar el ingreso. Y cuando uno pide requisitos extremos e impide los ingresos, lo único que genera es el negocio de los malos intencionados que viven de las necesidades humanas. Lamentablemente existe esa parte de la naturaleza humana que nos lleva a eso. (Ricardo Rodríguez, Cámara de Diputados de la Nación, Buenos Aires, 2005)

\section{De la ilegalidad como problema y la regularización como solución}

De acuerdo a la premisa de que las migraciones no pueden ser frenadas mediante mecanismos restrictivos y represivos, en el ámbito de gobierno de las migraciones se empieza a consolidar la idea de que es menester direccionar los flujos migratorios de acuerdo a las necesidades económicas del país, decir es, encauzar la mano de obra que proveen los inmigrantes hacia lugares geográficos de la Argentina donde resulte necesaria. De esta manera se evitaría, además, que los servicios públicos como los del sector salud no se saturen. Pero para llevar a cabo dicho proyecto se imponía antes un proceso de legalización que permitiera conocer e identificar este grupo poblacional. Durante su visita a la Cámara de Diputados de la Nación en el año 2004 para explicar los lineamientos de la política migratoria, el flamante director de la DNM expresa algunos conceptos que más tarde reproducirá su sucesor con mayor claridad: potenciar los aspectos considerados positivos de la migración y disminuir los negativos para que con la presencia de los inmigrantes el país obtenga el mayor beneficio.

Evidentemente si estamos queriendo establecer lo que puede llegar a ser una política nacional poblacional, tenemos que contar con todos esos elementos y direccionarlos desde el ingreso, sin abandonarlos. No se trata de hacer un mero conteo sino de saber a dónde va la persona, qué hace y a qué se va a dedicar, como bien lo señalábamos anteriormente. Esto hace a un nuevo concepto de lo que es migración. (Ricardo Rodríguez, Cámara de Diputados de la Nación, Buenos Aires, 2004)

De todos modos, desde nuestro punto de vista no podemos manejar la economía si no tenemos noción de nuestro universo. Todo esto nos lleva a que en el futuro establezcamos una política direccionada y de promoción. ¿Qué es 
lo que necesita el país? Entonces promocionémoslo. ¿Qué es lo que vamos a direccionar? ¿Hacia dónde se va a direccionar la migración? Necesitamos que sea en tal lugar, entonces promocionémoslo, pero tampoco se trata de abrir la puerta y tirarlos para que vayan al tacho de basura del Gran Buenos Aires. Así no se va a solucionar el problema, sino que va a seguir incrementándose, llegándose a que en un momento en el Gran Buenos Aires colapse la salud pública. Esto mismo ocurrirá en Capital y en todos [los] sitios si no direccionamos las corrientes migratorias. Pero esto no podemos hacerlo si primero no otorgamos las facilidades para legalizarlos analizando quiénes y cómo son. (Ricardo Rodríguez, Cámara de Diputados de la Nación, Buenos Aires, 2004)

Un desafío que tenemos a partir de la plena implementación de la política migratoria es buscar la manera de direccionar las migraciones de modo que las migraciones sean positivas y contribuyan también al desarrollo económico de la República Argentina. Entonces en este sentido también esto demuestra que una definición política, una definición en materia de política migratoria tampoco es inocente y lo que busca también es el mayor beneficio para el propio país. (Martín Arias Duval, CineMigrante: Primer Festival Internacional de Cine y Formación en Derechos Humanos, Buenos Aires, 2010)

Así, el principal mecanismo que adoptará el Estado en el marco de la "nueva política migratoria" para regular las migraciones internacionales será un programa de regularización migratoria. Inscripto en la política que el Estado argentino promueve en el marco del Mercosur, el programa Patria Grande, como expresión del cambio de paradigma enunciado en materia migratoria, constituye la respuesta política a lo que el diagnóstico oficial identificara en años anteriores como el mayor y más importante problema que era preciso atacar en el orden de las migraciones: los inmigrantes ilegales, nombrados también como indocumentados. Así lo explicó el director de la DNM durante su intervención en la Cámara de Diputados en el año 2005: “El mayor problema que tenemos respecto a las migraciones es el que hemos atacado primeramente porque creemos que es el más importante: los inmigrantes llamados, entre comillas, ilegales, que nosotros denominamos indocumentados". ${ }^{370} \mathrm{El}$ programa fue presentado también en reuniones internacionales como la solución a la inmigración proveniente de países del Mercosur 
ampliado, los cuales constituyen el mayor volumen de migrantes que recepta la Argentina. Una definición que deja incólume la representación dominante acerca de las migraciones limítrofes en la Argentina: las migraciones regionales, en particular de los países vecinos, establecidas como equivalentes a las migraciones ilegales, se constituyen en el problema que es preciso resolver, la problemática que es necesario atender. Es su construcción como ilegal a manera de una esencia inherente a los inmigrantes lo que históricamente, a pesar de las variaciones que en materia de política ha habido, ha definido y constituido a las migraciones como problema, como un producto que crea problemas. ${ }^{371}$

El Patria Grande es un cambio sustancial, un cambio de fondo en la política migratoria de nuestro país. Es el resultado de un análisis profundo de la realidad tanto nacional, regional como internacional, de los antecedentes existentes sobre la materia en nuestros países y en otras regiones, es también producto del conocimiento de nuestra geografía y de nuestra historia, y fundamentalmente es la solución para el $90 \%$ de los flujos migratorios que recibe Argentina. Efectivamente el 90\% de los migrantes que hoy recibimos provienen de los Países del MERCOSUR y Asociados. (Ricardo Rodríguez, Encuentro Iberoamericano sobre Migración y Desarrollo, Madrid, 2006)

Para los funcionarios la preocupación es entonces "encontrar una solución a esta problemática" definida como "problemática de la irregularidad migratoria". Para ello habrían necesitado conocer "la raíz de la irregularidad, poner los pies en la tierra, plantear entonces, cuál [era] la realidad de nuestros migrantes y cuál era nuestra realidad", una realidad cuya descripción supone en sí misma la identificación del problema. ${ }^{372}$ Mediada la lectura que se realiza de la realidad por el objetivo que se persigue, desde la DNM se establece la "regularidad migratoria" como la máxima expresión de la "gobernabilidad de los flujos migratorios" (como finalidad, no como perspectiva), bajo el fundamento de que "la regularidad migratoria es realmente la base fundamental para conseguir la integración del migrante a la sociedad de recepción". ${ }^{373}$ A través de ella se favorecería al "inmigrante" en tanto posibilitaría su "verdadera inserción" o, como se sostiene en otros pasajes, su

\footnotetext{
371 Según Sayad (1998:15), el discurso sobre el inmigrante y la inmigración establece una relación indefectible con otros objetos o problemas para poder hablar de su objeto: sólo a través de los diferentes problemas a los cuales son asociados es que los inmigrantes pueden ser "nominados, captados y tratados". Aquí los "problemas" son entendidos tanto como "dificultades", "disturbios" o "daños" y como "problemática constituida de forma crítica en relación a un objeto que crea necesariamente un problema" y que debe su existencia a los problemas que representa para la sociedad.
}

372 Adriana Alfonso, Seminario “Migraciones y Derechos Humanos”, Rosario, 2005.

373 Adriana Alfonso, Seminario “Migraciones y Derechos Humanos”, Rosario, 2005. 
"plena integración”, además de los beneficios que supondría la regularización migratoria para la "sociedad de recepción".

¿Qué es lo que busca Argentina? Busca la mayor regularidad posible en las migraciones. Tenemos el convencimiento de que la regularidad migratoria es la única manera de conseguir la verdadera inserción del inmigrante en la sociedad de recepción. (Adriana Alfonso, Seminario Migraciones y Derechos Humanos, Rosario, 2005)

¿Qué se busca desde el punto de vista migratorio? Se busca la gobernabilidad de los flujos migratorios, la integración del migrante a la sociedad, para su beneficio y para beneficio de la sociedad de recepción. (Adriana Alfonso, Foro Internacional sobre el Nexo entre Políticas y Ciencias Sociales UNESCO, Córdoba, 2006)

Esta práctica estatal concebida como programa de legalización migratoria puede comprenderse en los términos de una pedagogía de la conversión (Das y Poole, 2008) mediante la cual, enmarcada en una de las posibles miradas sobre la noción de márgenes del Estado (en este caso, el margen como periferia), el Estado aspira a manejar y disciplinar, sin recurrir necesariamente a la aplicación de la fuerza, un grupo social compuesto por personas consideradas insuficientemente socializadas en los marcos de la ley para transformarlos en sujetos legales del Estado. De este modo, lo que se termina proponiendo básicamente desde el Estado, es "crear mecanismos de fácil acceso a la regularidad migratoria" a través de la "facilitación de acceso a la residencia", es decir, un plan de regularización migratoria para aquellos inmigrantes extranjeros que se mantienen en una situación de "irregularidad migratoria". Sobre ellos se funda el interés estatal en las migraciones. Se trata -como afirma el director de la DNM- de "documentar a los que ya tenemos, que son los que hoy nos interesan". ${ }^{374}$ Para ello resulta posible que "(d)ejemos de lado la ley [de migraciones] porque ésta apunta hacia el futuro, a aquél inmigrante que está ingresando". ${ }^{375}$ Los que ya tenemos son los que ya residen en el territorio nacional, los que ya han ingresado y que permanecen en condición de ilegalidad o irregularidad, son los que interesan o preocupan al Estado -los que representan los desvelos del Estado- en tanto problema y, consecuentemente, a quienes están dirigidos los planes de regularización. Los

374 Ricardo Rodríguez, Comisión de Población y Recursos Humanos, Cámara de Diputados de la Nación, Buenos Aires, 2005.

375 Ricardo Rodríguez, Comisión de Población y Recursos Humanos, Cámara de Diputados de la Nación, Buenos Aires, 2005. 
demás, los que contempla la ley, son aquellos que vendrán, aquellos que todavía no han cruzado la frontera, por tanto, que aún no representan una presencia problemática y no justifican necesariamente una intervención del Estado.

La existencia de la irregularidad migratoria es atribuida a la falta o carencia de política migratoria que habría caracterizado a la Argentina de finales del siglo veinte. Desde la perspectiva de los funcionarios de la DNM, bajo el paraguas de una "política realista", las distintas amnistías dictadas durante las últimas décadas, concebidas ahora como "mecanismos estatocéntricos" que no contemplan la realidad regional e internacional, y los convenios binacionales (complementados mediante protocolos) firmados hacia finales de los noventa con "países de los cuales recibíamos el mayor flujo de migrantes", Bolivia y Perú (no se pudo concretar el acuerdo con Paraguay), no fueron soluciones definitivas, sino "parches coyunturales" o "medidas espasmódicas", que estaban lejos de ser "la solución última a la problemática [de la irregularidad migratoria]". Consideran, a su vez, que "si bien estos acuerdos tuvieron algún tipo de éxito, no tuvieron realmente el éxito que buscábamos". 376

Las últimas décadas del siglo XX encuentran a la República Argentina carente de política migratoria. Pasábamos alternativamente y de forma espasmódica de amplias amnistías a medidas restrictivas. Ni las unas ni las otras traían la solución buscada para la irregularidad migratoria. Las amnistías eran parches coyunturales que solucionaban la situación de quienes estaban en ese momento en el territorio, pero cuando se agotaba la vigencia de la misma se volvía a generar irregularidad. Las medidas restrictivas generaban verdaderos bolsones de extranjeros que encontrándose en nuestro territorio, en la mayoría de los casos trabajando y con hijos concurriendo a la escuela, no podían acceder a un estatus migratorio legal y debían permanecer ocultos sin posibilidad de integración. (Ricardo Rodríguez, Encuentro Iberoamericano sobre Migraciones y Desarrollo, Madrid, 2006)

Es así como las últimas décadas del siglo pasado se caracterizaron por una falta de política migratoria. Lo que nos decía el Senador Giustiniani hace un momento: esta serie de medidas espasmódicas en las cuales pasábamos de situaciones restrictivas a amnistías. Situaciones restrictivas que alejaban por

376 Adriana Alfonso, Seminario “Migraciones y Derechos Humanos”, Rosario, 2005. También expresa esta idea en el Foro UNESCO realizado en Córdoba en febrero de 2006. 
supuesto de la realidad, y que hacían que entonces se generaran mayores bolsones de irregulares en el territorio. Los extranjeros seguían ingresando, no podían regularizar su situación, pero estaban aquí en el territorio. Esto obligaba al gobierno argentino a sacar amnistías, entonces pasábamos espasmódicamente y sin política alguna, de restricción a ampliación, restricción, ampliación. No había ninguna solución al problema que nos aquejaba. (Adriana Alfonso, Foro Internacional sobre el Nexo entre Políticas y Ciencias Sociales UNESCO, Córdoba, 2006)

A diferencia de la década de los noventa, las explicaciones de los funcionarios acerca de la irregularidad migratoria no buscan criminalizar a los inmigrantes que se encuentran en dicha situación. Por el contrario, generalmente son presentados como víctimas de un aparato estatal que no supo solucionar o que fracasó en la tarea de regular la entrada y permanencia de los inmigrantes en el país, produciendo de esta manera ilegalidad o ilegales. Mirando hacia el pasado, desde el Estado se admite ahora su responsabilidad en la producción de lo que las autoridades migratorias suelen llamar "irregularidad migratoria" o, en ocasiones, "bolsones de irregulares". Para dar cuenta de ello el director de la DNM utiliza en sus intervenciones públicas la metáfora del Estado como "fábrica de ilegales".377 Este reconocimiento servirá de sustento para la implementación del programa nacional de regularización migratoria que se propone desde la DNM.

Es importante entender que evidentemente todo el sistema anterior era muy malo porque Migraciones [se refiere a la DNM] solamente era una fábrica de ilegales. Realmente no me gusta usar la palabra 'ilegales', prefiero decir 'indocumentados'. Se generaba un sistema muy perverso, con muchos requisitos prácticamente incumplibles. Esa fue la razón por la cual la gente no los cumplía. (Ricardo Rodríguez, Cámara de Diputados de la Nación, Buenos Aires, 2004)

Esto no ha sido más que el resultado directo de un criterio jurídico político que evidentemente fracasó, porque lo único que significó, como alguna vez lo dijimos, fue una fábrica de ilegales, entre comillas nuevamente, estableciendo resultados nefastos para lo que podría ser el organismo social que es el país. (Ricardo Rodríguez, Cámara de Diputados de la Nación, Buenos Aires, 2005)

377 Esta metáfora es utilizada por el director de la DNM, Ricardo Rodríguez, durante sus dos intervenciones en la Comisión de Población y Recursos Humanos de la Cámara de Diputados de la Nación, una en el 2004 y otra en el 2005. 
Frente a los escasos resultados obtenidos mediante las distintas medidas implementadas en el pasado, se pretende tomar distancia de ellas elevando el programa Patria Grande al rango de "política de Estado". En particular, el interés radica en diferenciarlo de las llamadas amnistías, un mecanismo institucional considerado como estatocéntrico. Precisamente, una de las aclaraciones más frecuentes en las intervenciones públicas de los funcionarios de la DNM es que "el Patria Grande no es una amnistía". El criterio básico que se utiliza para establecer dicha diferenciación es la duración en el tiempo de una y otra medida: el Patria Grande no tendría una "vigencia acotada".

Es así que en un mes, se iniciará el programa de regularización para nativos del MERCOSUR, en el cual esperamos poder acoger aproximadamente entre 500 y 600 mil personas que se encuentran en territorio nacional, pero aspirando a que no sea una situación de coyuntura, sino que sea una política migratoria de Estado, razón por la cual de ahora en más, todo nativo de un país del MERCOSUR podrá residir en la Argentina por su nacionalidad y por carecer de antecedentes, por ser una persona que tiene intenciones de residir en Argentina con una leal y honesta voluntad de arraigo. (Adriana Alfonso, Seminario Migraciones y Derechos Humanos, Rosario, 2005)

Las medidas implementadas resultaban tan incompatibles con la realidad argentina que terminaron generando un enorme volumen de extranjeros irregulares. (Ricardo Rodríguez, Encuentro Iberoamericano sobre Migraciones y Desarrollo, Madrid, 2006)

El Patria Grande no es una amnistía. Amnistías hubo muchas en Argentina y demostraron que no eran la solución última al problema. También hubo medidas restrictivas, que olvidando la realidad de nuestro país, pretendían implementar mecanismos estadocéntricos y buscaban la solución puertas adentro olvidando la realidad regional e internacional. También quedó demostrado que esas no eran la solución. (Martín Arias Duval, Foro Iberoamericano sobre Migración y Desarrollo, Cuenca, 2008) 
En otro plano, la distancia que se pretende tomar de las usualmente llamadas amnistías ${ }^{378}$, puede resultar muy productiva en términos de significación política. La diferenciación establecida entre el actual proceso de regularización migratoria y los anteriores implicó el desuso de la noción de amnistía y la búsqueda de otras denominaciones. La palabra clave incorporada para caracterizar el séptimo proceso de regularización migratoria implementado en la Argentina fue "normalización": formalmente se lo denominó Programa Nacional de Normalización Documentaria Migratoria. El término amnistía relaciona a la migración con la idea de delito, estableciendo su perdón. Etimológicamente, se refiere al olvido de los delitos cometidos (comparte la misma etimología que amnesia en tanto olvido generalizado) por parte de una autoridad, en nuestro caso, una autoridad política, el Estado. El significado de normalización, en cambio, remite a un orden que ha sido alterado y que busca ser restablecido, adaptado a las normas y reglas de las cuales se ha apartado. En esta ocasión, se trata de la restitución del orden establecido a través de la vía legal, entendiendo que el orden jurídico es el orden natural de las cosas. En este sentido, está estrechamente vinculada a la noción de legalización, ya que el Estado convierte mediante un acto administrativo -un acto de magia social- a los ilegales en legales.

Ahora bien, al mismo tiempo que la regularización migratoria es establecida como política de Estado, la política migratoria es reducida a una política de regularización. Así, el éxito de la política migratoria pasa a depender del desarrollo del programa de regularización migratoria, cuyos resultados son medibles. ${ }^{379} \mathrm{El}$ hecho de que la regularización migratoria sea el principio rector de los modos de intervención estatal en materia de migraciones por no decir la única política pública desarrollada de manera sistemática por el Estado en relación a la migración- hace que la compleja problemática migratoria sea simplificada en términos de una problemática de (ir)regularidad migratoria. Igualmente, resulta una

378 Es preciso recordar que si bien "amnistía" es la noción que se popularizó para denominar los procesos de regularización migratoria, dicho término no es utilizado en los decretos que dispusieron tal medida. La única excepción es la primera regularización migratoria de 1949, la cual fue denominada "indulto". De todas maneras, existe una diferencia significativa en relación a la amnistía: por el indulto la persona sigue siendo culpable pero se le perdona total o parcialmente el cumplimiento de la pena o se la conmuta por una más leve.

379 No es casual que en las distintas intervenciones públicas de los funcionarios de la DNM se saquen a relucir las cifras de los inmigrantes regularizados. El Estado publica las cifras de las residencias otorgadas (incluyendo las "residencias precarias", que como lo indica su denominación, aún no se han constituido en residencias "temporales" o "permanentes"), mostradas como logros de eficacia de la gestión gubernamental, pero no de aquellas que fueron denegadas. Existe una excepción: un documento oficial exhibe tanto los números de las residencias aprobadas como las denegadas para el período comprendido entre el 1 de octubre de 2003 y el 20 de julio de 2004. Adriana Alfonso, Comisión de Asuntos Jurídicos y Políticos, Consejo Permanente de la Organización de los Estados Americanos, 2004. 
práctica exitosa de gobierno en tanto contribuye a producir una imagen poderosa del Estado al mismo tiempo que oculta dicha producción (Doty, 1996).

Es sabido que hasta la aprobación de la nueva ley de migraciones, los derechos más fundamentales estuvieron vedados para los inmigrantes sin estadía autorizada, contrariando la normativa internacional sobre derechos humanos que se incorporó con la reforma de la Constitución Nacional de 1994 y que la ley de migraciones actualmente vigente, en cambio, reconoció diversos derechos a los migrantes más allá de su condición administrativa (definida por el Estado como legal/ilegal o regular/irregular). Pero este aspecto transgresor de la nueva ley es neutralizado en la puesta en práctica del programa de regularización, única prioridad y eje de las acciones estatales en materia migratoria, al supeditar el goce de los derechos a la regularidad migratoria, esto es, a la estadía o permanencia autorizada por el Estado. En este sentido, el mensaje de la campaña de difusión del programa Patria Grande es elocuente. Primero pregunta: “¿Usted es inmigrante?"; luego afirma: "Usted tiene derechos"; y finalmente indica: "Para hacerlos valer, regularice su situación". Tal como indica Begala (2006), aunque el objetivo político no sea la restricción, el hecho de que se siga vinculando el ejercicio de los derechos de los migrantes a la regularidad de la residencia no permite romper con la lógica de la restricción.

\section{La delgada línea de la (i)legalidad}

De acuerdo al principio de soberanía, el Estado nacional, en tanto monopoliza el ejercicio de la violencia física y simbólica, no sólo posee la potestad para autorizar o prohibir el ingreso al territorio nacional de los extranjeros, sino que también se adueña de la definición de quién es o será un ilegal y cuándo puede dejar o no de serlo, estableciendo el límite que separa a unos de otros, a los legales de los ilegales, cuando regula las condiciones de su permanencia a través de diversos mecanismos institucionales. En este sentido, el propio acto de regularización, interpretado como rito de institución (Bourdieu, 1999c), instituye "una diferencia constante entre aquellos a quienes concierne el rito y aquellos a quienes no concierne" (Bourdieu, 1999c:78). Se establece así una separación entre quienes se acogen a la regularización migratoria y quienes indefectiblemente no lo harán, más allá de las "facilidades" que el Estado efectivamente pueda brindar, consagrando la diferencia entre los legales y los ilegales o entre los regulares o irregulares. 
Es que, como señala Bourdieu, "cualquier rito tiende a consagrar o a legitimar, es decir a desestimar en tanto que arbitrario o reconocer en tanto que legítimo, natural, un límite arbitrario" (Bourdieu, 1999c:79; énfasis en el original) como lo es la frontera simbólica que instaura el Estado entre aquellos que se convierten en legales y aquellos que permanecerán como ilegales. El Estado, mientras presume -tiene la ilusión- que a través de un programa de regularización migratoria, elevándolo a política de Estado, acabará con la irregularidad migratoria -el problema a resolver- está legitimando aquella división que él mismo crea e impone como un límite natural.

El carácter arbitrario de este límite se pone especialmente de manifiesto cuando se diferencia, mediante un modo determinado de nominación, entre aquellos que permanecen en la ilegalidad/irregularidad a pesar de las posibilidades administrativas que otorgaría el Estado para la radicación: "indocumentados" serían aquellos que en el pasado no pudieron revertir su condición de ilegalidad debido a los obstáculos impuestos por el Estado, bajo administraciones anteriores, e "ilegales" aquellos que no se acogieron voluntariamente a las "generosas" oportunidades que brinda el Estado, bajo la gestión actual, para constituirse en "residentes en situación regular". Una escena transcurrida en la Comisión de Población y Recursos Humanos de la Cámara de Diputados de la Nación en la cual el director de la DNM y una diputada nacional opinan acerca de la manera adecuada (y conveniente) de utilizar la noción de ilegales muestra claramente el carácter arbitrario del límite establecido entre legales e ilegales. Allí define "lo ilegal" como aquello que está "en contra de la ley".

Sr. Rodríguez: Es importante entender que evidentemente todo el sistema anterior era muy malo porque Migraciones [la DNM] solamente era una fábrica de ilegales. Realmente no me gusta usar la palabra "ilegales", prefiero decir "indocumentados". Se generaba un sistema muy perverso, con muchos requisitos prácticamente incumplibles. Esa fue la razón por la cual la gente no los cumplía. Sobre esa base la idea de nuestra gestión fue en primer término trabajar sobre la dignidad del inmigrante. Tenemos que establecer un sistema de control que no sea injurioso para el inmigrante. Desde el centro hasta el norte de la provincia de Buenos Aires la mano de obra es extranjera. Nosotros hicimos un cálculo extrapolando datos -porque no hay ninguna estadística- y tenemos 700 mil ilegales. Reitero que no me gusta la palabra "ilegal", serían "indocumentados". Lo ilegal está en contra de la ley, y aquí en realidad la persona no está contra la ley, sino que lo que hace es un seguimiento de los capitales para tratar de sobrevivir. 
Sra. Foresi: Mi apreciación personal es que no está mal admitir que es una ilegalidad. Creo que tenemos que empezar a llamar las cosas por su nombre, más allá de que usted diga que le da no sé qué la palabra indocumentado. Pero no, está indocumentado porque es ilegal, porque no está dentro de la legalidad. Considero que para lograr esa solución estamos comprometidos todos los presentes. Por ese motivo mencioné el tema de las redes. La gente tiene que asumir que para ordenarnos tenemos que entrar en la legalidad.

Sr. Rodríguez: Cuando hablaba de facilitamiento no significa que en el futuro no ejerzamos una función de control. Ahí podremos hablar de ilegalidad, porque el país ha dado todas las facilidades de ser legal y es un acto voluntario del individuo transformarse en ilegal. Pero hoy no podemos utilizar en contra de esa persona un hecho que hemos generado nosotros. No podemos invocar ese hecho si la persona ha venido a buscar el documento y se lo han negado.

Este intercambio, en particular la respuesta que otorga el director de la DNM a la apreciación de la legisladora (que confunde los términos utilizados por él), revela que son las prácticas del Estado -el ejercicio legítimo de la violencia material y simbólica- las que definen quién es o no ilegal y cuándo puede dejar o no de serlo (aunque sea llamando "las cosas por su nombre"), que la ilegalidad o irregularidad es una construcción material y simbólica del propio Estado, establecida al trazar aquél límite que, arbitrariamente, separa a unos y otros, a los legales y a los ilegales. A partir de allí se puede estar dentro o fuera de la legalidad y es preciso "entrar en la legalidad" para "ordenarnos".

A su vez, es importante observar también cómo en un mismo fragmento el director de la DNM parte de reconocer el papel que juega el Estado en la producción de la ilegalidad -lo denomina "fábrica de ilegales"- para terminar atribuyéndole la responsabilidad de su situación legal al propio inmigrante como si se tratara de una elección individual, o como dice el director de la DNM, un "acto voluntario".380 Esta definición remite al lema bajo el cual se pretendía implementar el programa nacional de regularización migratoria antes de que se lo denominara Patria Grande: "en Argentina será irregular migratorio sólo aquél que elija serlo". ${ }^{381}$ Como explica uno de los funcionarios de la DNM, la idea que motivó

380 Ese mismo año, declaró también a la prensa que "en Argentina será irregular sólo quien elija serlo". (La Voz del Interior, 31 de octubre de 2004).

381 En ocasión de la muerte del ex presidente Néstor Kirchner en octubre de 2010, el director de la DNM Martín Arias Duval, en su carta de despedida escrita a manera de homenaje, le atribuye a él dicha frase. 
dicho lema eran las facilidades administrativas de residencia que pretendía otorgar el Estado a los extranjeros de buena fe: "las posibilidades de regularizar serán totales para los extranjeros de buena fe que quieran residir en nuestro territorio". ${ }^{382}$ Las razones y las formas en que se produce la ilegalidad y las estrategias que despliegan los inmigrantes que viven en dicha situación, las cuales desmienten toda posibilidad de reducir a cero la llamada inmigración ilegal, hacen pensar que las autoridades migratorias proceden con un importante nivel de improvisación, desconocimiento o incomprensión frente a aquellos hechos sociales que pretenden regular o que en aras de atender fundamentalmente el interés estatal a través de una mirada técnica rudimentaria no les queda margen para abarcar la complejidad del fenómeno que pretenden enfrentar.

Por otra parte, el acto de regularización resulta un acto de oficialización. Como dice uno de los directores de la DNM en relación a los "indocumentados": "El problema es que toda esta gente está debajo de la alfombra: están y no están. [...] Siguen estando debajo de la alfombra, sin documentos". Los que están debajo de la alfombra son los inmigrantes llamados ilegales, irregulares o indocumentados, esto es, los que no existen oficialmente debido a la falta de la documentación requerida. Son oficiosos en lugar de oficiales. Desde la perspectiva del Estado, están y a la vez no están de acuerdo a determinados supuestos, porque participan de la vida cotidiana o compiten con la mano de obra local, pero no aparecen en las estadísticas oficiales o porque son difíciles de medir con cierta exactitud; porque son necesarios como mano de obra barata para la reproducción de la economía nacional, pero no se les puede hacer los descuentos de sus salarios por la obra social o la jubilación; porque utilizan los servicios públicos, pero no cumplen con obligaciones fiscales como el pago de impuestos.

También es un hecho que el Estado necesita oficializar a los inmigrantes que están "debajo de la alfombra" para poder regular y controlar esta población diferenciada que, según la visión del Estado, genera costos económicos adicionales, compite con la "mano de obra nacional" y puede vulnerar la "seguridad nacional". Así sucede con la justificación del programa Patria Grande cuando se recurre a evidencias que muestren los beneficios o las ventajas que tiene la regularización migratoria o, su contraparte, los costos o desventajas que implica la irregularidad migratoria para el Estado o la sociedad receptora. Esta visión se corresponde con la figura del balance contable, aplicada a la inmigración, que critica Sayad (1998), la cual muestra la función que se le atribuye a los inmigrantes y el 
significado que se desea reservar a la inmigración: la inmigración y los inmigrantes sólo tienen sentido mientras la contabilización (o comparación) de costos y ventajas deje un saldo positivo. Esta visión, en términos ideales, supone una maximización de las ventajas (principalmente económicas) de la inmigración y a la vez una minimización de los costos (fundamentalmente sociales y culturales) de la presencia de los inmigrantes (Sayad, 1998: 48). Este esquema, contenido expresamente en la perspectiva de la gobernabilidad migratoria, asume implícitamente la rentabilidad como criterio para determinar en qué medida la presencia del inmigrante es o no legítima.

Entre los motivos que se otorgan a favor de la regularización migratoria aparecen las pérdidas o costos económicos que conllevan los "indocumentados" para la economía nacional. En uno de los instrumentos de difusión e información del programa Patria Grande ${ }^{383}$ se sostiene que "sus actividades no generan tributo alguno a la sociedad, sólo genera riqueza para la economía informal"; que "un trabajador regularizado aporta a la economía nacional, a través de los descuentos de sus remuneraciones, sumas mucho más importantes"; que "un indocumentado sólo puede recurrir a la salud pública recargando los costos de la misma cuando, a través de su regularización, podría aliviar los costos estaduales utilizando otras estructuras de atención de la salud, obras sociales, salud privada, etc."384. La pérdida económica que significaría el "migrante irregular" para el sistema fiscal del Estado también es destacado por los funcionarios de la DNM durante sus exposiciones cuando presentan o comentan el programa Patria Grande en eventos nacionales.

Hablábamos de una realidad de tipo fiscal también, en realidad, el migrante irregular no tributa, si estuviéramos pensando en una regularización más amplia, factiblemente nuestras arcas recibirían más dinero. (Adriana Alfonso, Seminario Migraciones y Derechos Humanos, Rosario, 2005)

383 Página web del Programa “Patria Grande” [http://www.patriagrande.gov.ar]. Acceso: 22 de mayo de 2007. 384 Nótese la similitud de estos argumentos con buena parte de las afirmaciones que esgrimía un fiel representante del pensamiento neoconservador y neoliberal en la Argentina, el periodista Daniel Hadad, en la columna editorial del cuarto número de la revista La Primera de la Semana publicada en el año 2000: "Los inmigrantes indocumentados: Sólo consiguen emplearse en la economía informal, deprimiendo los salarios. Utilizan el sistema de salud que pagamos todos. Lo mismo hacen con la educación pública. Según estadísticas oficiales, cometen más delitos que el promedio de la población, y en algunos casos lo hacen para quedarse definitivamente en el país. Todo esto cuesta dinero. Y la Argentina dejó de ser hace mucho tiempo el hermano mayor, rico y poderoso que podía subsidiar a su familia desgraciada..." (Extraído de Jelin, 2006:60). 
Esta visión sobre los costos o pérdidas económicas de la presencia de "inmigrantes indocumentados" para el Estado nacional, esgrimida en esta ocasión para fundamentar la conveniencia de la regularización migratoria, también aparece en ambas intervenciones públicas del director de la DNM en la Cámara de Diputados de la Nación cuando plantea la necesidad de enfrentar la irregularidad migratoria.

Acá pasa lo mismo porque tenemos 700 mil personas -cifra que calculamos, aunque nos podemos llevar una sorpresa- que trabajan y comercian. Ellas alquilan negocios, compran, venden; pasan a integrar una economía subterránea que no paga ningún impuesto. Pero no pagan impuestos porque no quieren; esto lo señalo porque la gran mayoría quiere estar legalmente inscripta. Por ejemplo, cuando se llevaron a cabo algunos mecanismos para ser monotributistas, han ido a anotarse. (Ricardo Rodríguez, Cámara de Diputados de la Nación, Buenos Aires, 2004)

Aún puesto en el peor sentido de egoísmo, que podría ser un criterio economicista, debo indicar que tenemos una gran cantidad de gente en la economía informal que no es sujeto de derecho ni de crédito. Inclusive, en el sentido de sujeto beneficiario de algunas leyes que se han hecho para apoyar la falta de un nivel adecuado de vida. Afortunadamente la ley que se sancionó permitió a los inmigrantes el acceso a la educación y a la salud, cosa por la que nos felicitamos. Se trata de individuos que no tributan; los beneficios de su propia economía no van a la economía en blanco sino a la economía en negro. Además, los ponemos en una situación que los deja al borde del delito. A veces, la sobrevivencia es más importante que el respeto a las leyes. Entonces, inevitablemente están en la fabricación de marcas que todos conocemos, en las ferias paraguayas o bolivianas. (Ricardo Rodríguez, Cámara de Diputados de la Nación, Buenos Aires, 2005)

Del otro lado hablábamos de que tenemos una sobrecarga de gente indocumentada sobre la salud nacional, provincial y municipal. Si esta gente pudiera sindicalizarse, seguramente va a ir a la obra social sindical. (Ricardo Rodríguez, Cámara de Diputados de la Nación, Buenos Aires, 2005)

Otro argumento invocado por el Estado se relaciona con la devaluación del salario de la mano de obra local que producirían los "inmigrantes indocumentados". Aunque fuera un hecho corroborable, como sucede en diversas economías nacionales, en una economía 
precarizada y flexible con un alto porcentaje de empleo informal, adjudicar la presión a la baja de los salarios a los inmigrantes indocumentados, quienes como tales estarían infringiendo la ley, termina responsabilizando a los sujetos que en su búsqueda de subsistencia se atienen a las normas de funcionamiento del mercado de trabajo en lugar de considerar los mecanismos sociales de las economías capitalistas que favorecen la exclusión social para asegurar su propia reproducción. En uno de los documentos de difusión del programa Patria Grande ${ }^{385}$ se indica, por ejemplo, que "un indocumentado provoca inevitablemente una baja salarial”. También el discurso presidencial ofrecido durante la inauguración del Programa Nacional de Normalización Documentaria Migratoria, realizada en diciembre de 2005, señala el riesgo de que los trabajadores extranjeros devalúen el trabajo de los trabajadores nacionales, aunque dicho con eufemismos que no vayan a ofender: el que viene y el que está en el país -ambos bajo la protección igualitaria de leyes inclusoras- son dos figuras sociales que invocan la exterioridad como un elemento que podría vulnerar las condiciones laborales de los establecidos. Al margen de su tiempo de residencia en el país, la condición de extranjería y más aún de ilegalidad/irregularidad mantendría a los trabajadores inmigrantes como recién llegados.

[...] es decir, todo se deba hacer tal cual marca la ley, pero la ley con el sentido de integrar, la ley con el sentido de dar posibilidades, la ley que tenga en el lugar que corresponde al ser humano, la ley que evite el abuso, que valore el trabajo del que viene, la ley que permita garantizar ese trabajo del que viene pero también que no devalúe el trabajo del que está en el país (Néstor Kirchner, Salón Blanco de la Casa Rosada, Buenos Aires, 2005)

Finalmente, otra de las explicaciones utilizadas en determinadas intervenciones públicas de los funcionarios de la DNM para justificar el programa de regularización descansa en aspectos relativos a la seguridad, en particular al control de las fronteras y el territorio nacional, a pesar de la cautela gubernamental dedicada a destacar la importancia de separar la cuestión migratoria del tema securitario. Aquí se revela de manera contundente y por única vez una de las finalidades centrales que persiguen los programas de regularización migratoria: el control de la permanencia de los inmigrantes irregulares. Así lo explica una funcionaria de la DNM: “Documentarlos [a los migrantes] y saber quién está en el territorio pareciera ser lo más lógico desde el punto de vista de la seguridad". En este sentido, asume que "la realidad nos dice que es mucho mejor saber quién reside en 
nuestro territorio, y tenerlo documentado, tenerlo regularizado para poder hacer un seguimiento de los mismos". ${ }^{386}$ En este sentido, se trata de documentarlos para identificarlos.

Y si habláramos desde el punto de vista de la seguridad, ¿no es mejor acaso saber quién reside en nuestro territorio, a seguir con esa postura de esconder la cabeza en la tierra, desconocer la problemática? Documentarlos y saber quién está en el territorio pareciera ser lo más lógico desde el punto de vista de la seguridad. (Adriana Alfonso, Seminario Migraciones y Derechos Humanos, Rosario, 2005)

¿Qué es más seguro para un Estado? ¿Conocer a quiénes tiene dentro de su territorio o mirar para otro lado y hacer como que desconoce quién está? Nosotros sabemos que los migrantes ingresan, nosotros sabemos que hay migrantes en el territorio, ¿no es mejor, entonces, incluso desde el punto de vista de la seguridad, posibilitar su documentación, que tengan ellos su documento? (Adriana Alfonso, Foro Internacional sobre el Nexo entre Políticas y Ciencias Sociales UNESCO, Córdoba, 2006)

Otro dato de la realidad y esta vez relacionado con el tema de la seguridad. Saber que existe en el territorio un número de extranjeros desconociendo su identidad resulta en relación a la inseguridad más preocupante que permitir su regularización migratoria. (Ricardo Rodríguez, Encuentro Iberoamericano sobre Migraciones y Desarrollo, Madrid, 2006)

Efectivamente si se permite regularizar al migrante, mediante un trámite sencillo que exija la presentación de carencia de antecedentes, se trasparentará su presencia en territorio y se los identificará, el individuo recuperará su identidad y en la eventualidad de una posible comisión de delito podrá ser localizado y deportarlo si así correspondiera. (Ricardo Rodríguez, Encuentro Iberoamericano sobre Migraciones y Desarrollo, Madrid, 2006) 
Si lo pensamos también en términos de seguridad, nosotros teníamos en la República Argentina una gran cantidad de migrantes provenientes de países de la región que no sabíamos cuántos eran, que no sabíamos cómo se llamaban y que no sabíamos de qué países venían. Porque la propia ley les impedía salir a la luz. Si se piensa hasta en términos de seguridad que... vuelvo a aclarar que la ley 25.871 separa las cuestiones de seguridad de las cuestiones migratorias. Si se piensa en términos de seguridad, es altamente beneficioso para el país tener identificado su potencial humano y tener identificadas a las personas que viven dentro de su territorio. ¿Por qué? Si la persona que vive dentro del territorio se equivoca, se manda una macana, a quién voy a ir a buscar si no sé cómo se llama, si no sé quién es... (Arias Duval, CineMigrante: Primer Festival Internacional de Cine y Formación en Derechos Humanos, Buenos Aires, 2010)

Muchas de las declaraciones públicas vertidas por los funcionarios políticos al frente de la DNM para explicar la "nueva política migratoria", su origen y desarrollo, aspecto imprescindible en el proceso de legitimación de las medidas que las administraciones gubernamentales llevan adelante, son corroboradas, precisadas, matizadas, profundizadas en la entrevista en profundidad mantenida con un funcionario de planta permanente y mediana jerarquía de la institución. Él mismo, durante una de las entrevistas, explicita que el lugar desde el cual habla, entendido por él mismo como "lugar de observación", remite a una posición específica y particular. En una de las entrevistas aclara: "a mí me parece que desde el Estado, o sea, desde donde yo puedo observar el Estado...". Por un lado, se podría decir que se asume como analista: no reproduce mecánicamente el discurso oficial, sino que adopta una actitud reflexiva sobre su propia práctica o la del Estado; por otra parte, aunque dice tener una postura crítica respecto a la política migratoria argentina, tampoco la cuestiona y si la cuestiona es a nivel técnico. De algún modo allí se pone de manifiesto que la especificidad de su punto de vista se corresponde tanto con su visión en tanto agente del Estado, por un lado, y con su posición en la estructura de poder del Estado, por el otro.

Durante una de las conversaciones mantenidas en su oficina, mientras opina sobre los cambios de la política migratoria, comenta circunstancialmente: "Yo no puedo decir el punto de vista... lo que estoy diciendo son observaciones respecto de la toma de decisiones, yo no participo de la toma de esas decisiones, no podría decir con certeza el punto de vista...". Se refiere al punto de vista de la institución en la cual y para la cual trabaja, la DNM: con ello establece una diferencia entre la "visión institucional" y aquella 
que él tiene en base a su experiencia laboral -efectiva o imaginariamente diferente a la institucional- sobre los acontecimientos que involucran o no medidas de gobierno. La falta de certeza a la cual alude pone en evidencia esta distancia a la vez que permite intuir que los funcionarios experimentan el relato oficial como un relato que no se termina de conocer en profundidad. En este sentido, se trata de un relato por conocer, un relato inconcluso, un relato que interpone dificultades para ser comprendido como totalidad y que los propios funcionarios no pueden aprehender en su integralidad. Por otra parte, sus opiniones no contradicen lo que se proclama desde el discurso oficial, lo cual sugiere que esta diferenciación que establece entre su propia visión y la institucional también podría ser asumida a modo de protección en caso de que algunas de sus declaraciones tomaran estado público. ${ }^{387}$

\section{Trabajando en Migraciones ${ }^{388}$ : la visión de un funcionario de planta permanente}

Alberto Rubio posee casi treinta años de experiencia en el ámbito de gobierno de las migraciones. Lo conocí personalmente en los comienzos de su gestión como Jefe de la Delegación Córdoba durante una pequeña reunión que se realizó, a propuesta de él, en un centro de investigación dependiente de la Universidad Nacional de Córdoba en el año 2002. Luego mantuvimos contactos ocasionales a través del correo electrónico. En el año 2006 coincidimos en una jornada de reflexión y debate sobre las migraciones internacionales en la Argentina, organizada por el Centro Cultural España-Córdoba, a la cual fuimos invitados como disertantes. Durante el año 2007 y parte del 2008, compartimos diversos encuentros de la Mesa de Diálogo por los Derechos de los y las Inmigrantes en Córdoba y el acto de lanzamiento y la entrega de premios del Certamen InmigrARTE que organizara este espacio interinstitucional como una de sus principales acciones.

\footnotetext{
387 En los inicios de la primera entrevista que mantuvimos, el funcionario precisó: "Yo quisiera aclararte en esto que, para no mezclar las cosas, hay algunas cuestiones que te estoy respondiendo desde la experiencia de mi trabajo y otras que son medidas institucionales, entonces me voy a ocupar de decir claramente cuáles son las medidas institucionales y cuales son observaciones o consideraciones que yo pueda hacer, que a mí me parezcan y que esto no implica que sea la visión institucional...” (Entrevista con el Jefe de la Delegación Córdoba de la DNM, 2005) 388 Los funcionarios y empleados de la Dirección Nacional de Migraciones utilizan la fórmula sintética "Migraciones" para denominar su lugar de trabajo.
} 
Fue el Jefe de la Delegación Córdoba de la DNM en el período 2002-2008 y actualmente ocupa el cargo de Director de Control Aéreo de la Dirección General de Movimiento Migratorio en la órbita nacional de la DNM. Llegó a la Delegación Córdoba, la cual salía de una intervención administrativa, con la misión de "producir cambios en esta jurisdicción", trasladado desde la Delegación Bariloche. Allí ingresó como personal administrativo en el año 1980, fue 2do. Jefe de la Delegación y alcanzó el cargo de Jefe de Delegación. Durante estos años desarrolló algunas actividades que, según su relato, resultaron "experiencias formativas". Participó de la creación de la Comisión de Estudios Sociodemográficos de la Municipalidad de Bariloche y junto a una socióloga estudió "la inserción de migrantes chilenos en la construcción y en la gastronomía". Asimismo, estuvo involucrado activamente -a través de los comités de frontera y de los diversos acuerdos de integración- con el "proceso de integración" entre Chile y Argentina a partir de la firma del Tratado de Paz y Amistad en el año 1984. Cuando se modificó la estructura de la DNM en el año 1993, estuvo en Buenos Aires como Director Migratorio organizando la Dirección de Control Migratorio (antes había sido un Departamento). También fue interventor en la Delegación Rosario y coordinador de las delegaciones de la Patagonia.

Durante su carrera de funcionario hubo una serie de acontecimientos que modificaron su visión sobre el sentido y el objeto de su trabajo. Según sus propias palabras, su mirada se volvió "más sociológica" y con ello su actividad administrativa adquirió otra dimensión. Hacia fines de los años ‘80 colaboró con la organización del trabajo de campo en la frontera argentino-chilena que formaba parte de un curso sobre migraciones internacionales dirigido a funcionarios que organizaba la OEA, la OIM y el gobierno argentino. ${ }^{389} \mathrm{Al}$ otro año participó del curso en calidad de becario. Durante los años

389 Se trata del Curso Interamericano sobre Migraciones Internacionales, una iniciativa que "se lleva a cabo desde hace mas de 30 años, dirigida a funcionarios gubernamentales encargados de temas migratorios en los países latinoamericanos. Comenzó a realizarse en España por iniciativa del Gobierno Español y de la Organización de los Estados Americanos (OEA), en el año 1979. En el año 1981, se invitó a la Organización Internacional para las Migraciones (OIM) a que colaborara en la implementación de algunas actividades del programa. En el año 1985, el Gobierno Español decidió dejar de participar y tanto la OIM como la OEA acordaron continuar incrementando su contribución a la realización del Curso. De acuerdo con una propuesta de la OIM, el Gobierno Argentino aceptó desempeñar una función activa en la organización del curso y convertirse en país anfitrión. Entre los años 1985 y 1987 estos cursos de capacitación se organizaron en la Ciudad de Buenos Aires, pero a partir de 1988 se decidió cambiar la sede del mismo a la ciudad de Mar del Plata, lugar donde se sigue desarrollando hasta la fecha y motivo por el cual también se lo conoce como "Curso de Mar del Plata”. A partir del año 1999, la OEA dejó de participar en la organización del Curso. Como resultado, la OIM asumió la responsabilidad total de organizar, administrar y financiar el Curso. Inicialmente el Curso tenía una duración de tres meses. Con el traslado de la sede a la ciudad de Mar del Plata, en el año 1988 y hasta 1996, la duración del Curso se estableció en cinco semanas. Esta modificación respondió 
siguientes estudió Psicología Social en el Centro Regional Universitario de Bariloche. Después de transcurrido cierto tiempo realizó consultorías para la OIM y fue coordinador general y docente del curso sobre migraciones internacionales que suele dictar este organismo. Sumado a su larga experiencia profesional, este recorrido personal le ha permitido incorporar a su discurso una serie de elementos que denotan un nivel de reflexión y autorreflexión que difícilmente pueda compararse con el de muchos funcionarios de alta responsabilidad que ocupan un cargo político por un lapso breve de tiempo.

En el año 88, hice un trabajo... había un curso para funcionarios de migraciones y demografía de países americanos que organizaba la OEA, la OIM y el gobierno argentino y yo hice un trabajo de campo, organicé un trabajo de campo en el 87 para ese curso, que se hacía en Mar del Plata y que siempre tenía un trabajo de campo en frontera. A raíz de ese trabajo de campo, el año siguiente fui becario de ese mismo curso y a raíz de eso, me pasó a interesar más, salí de la cuestión más administrativa y empecé a tener una visión más sociológica del tema, hasta ahí había sido todo muy administrativo, perdón... [interrupción telefónica] Bueno, entonces a raíz de eso mantuve vinculación con la OIM, empecé a estudiar Psicología Social [en el Centro Regional Universitario de Bariloche] también, que era lo único que estando en Bariloche podía estudiar allá, me empezó a entusiasmar la cuestión sociológica [...] y en varias oportunidades fui consultor de la OIM para algunos casos. Hice un trabajo para Paraguay, para Colombia, y también fui después docente del curso de Migraciones Latinoamericanas de la OIM hasta hoy, hasta el día de hoy. Durante 8 años fui coordinador general de ese curso y a partir de eso empecé a entrar en otra dimensión del trabajo, que no era solamente poner el sello o hacer este tipo de tarea, que además hizo que mi trabajo fuera bastante más agradable, en el sentido que aparecía otro aspecto que también me interesaba además del institucional, personalmente, no?

\footnotetext{
a los requerimientos de los países participantes, ya que un Curso de menor duración posibilitaría la participación de funcionarios que desempeñaran cargos con mayor responsabilidad. Posteriormente, en el año 1996, la actividad se limitó a un máximo de cuatro semanas, a fin de lograr un Curso más intensivo y un mayor aprovechamiento de los recursos. En el año 1999, atendiendo también a cuestiones presupuestarias, la duración del curso se redujo aun más, siendo en la actualidad de tres semanas." Extraído de http://www.oimconosur.org/varios/index.php?url=curso_inter (22-05-09).
} 


\section{El país como cuartel militar: la "doctrina del control"}

El funcionario considera que las transformaciones más significativas en términos de política migratoria que él ha podido experimentar a lo largo de su carrera administrativa se produjeron hacia inicios de la presente década y se cristalizaron con la aprobación de la nueva ley de migraciones. Entiende que la etapa anterior estuvo dominada por lo que él llama la "doctrina del control" 390 , bajo la cual la Argentina estaba representada como un cuartel militar: "antes se confundía al país con un cuartel y entonces todos terminaban repitiendo una receta parecida". Esta metáfora que utiliza para ilustrar la concepción del Estado sobre las fronteras políticas y sus implicancias para las migraciones y los migrantes condensa las ideas centrales que guiaron el desarrollo de la política migratoria argentina durante las últimas décadas: la migración internacional comprendida como amenaza a la seguridad nacional. Al igual que otros funcionarios nacionales, como vimos anteriormente, sus objeciones a esta concepción restrictiva de las migraciones internacionales se relacionan principalmente con el demostrado fracaso que tuvo su aplicación según diversas experiencias históricas.

Yo creo que el cambio más importante que he visto a lo largo de estos 25 años es ahora esta ley 25.871, porque todo lo anterior, desde el punto de vista normativo, ha estado muy alineado con la doctrina del control, esta fantasía que supone que un fenómeno tan complejo y tan multicausal como es la migración de las personas le puedo oponer un cuerpo normativo que sea capaz en un lapso de tiempo breve y espacio acotado como lo es la frontera resolver todas las contradicciones y todos los conflictos que conlleva el proceso migratorio, que se puede resolver con un cuerpo normativo y con una persona parada en la frontera o en una oficina de migración. Una fantasía que fracasó a todas luces, porque, digamos, no impidió que la gente, en la órbita socialista, que la gente se fuera de Rusia, que saltara el Muro de Berlín, que se vaya de Cuba y en el ámbito del capitalismo no impidió que grandes grupos de personas sigan entrando aún hoy a Estados Unidos, creo que... el fracaso de la doctrina del control es evidente en todos esos ejemplos ¿no? O los migrantes magrebíes en Alemania o Europa del Norte o los africanos en España e Italia. A pesar de este discurso restrictivo y de todas esas medidas administrativas

390 Aquello que este funcionario denomina como "doctrina del control”, en la literatura especializada se lo conoce como "doctrina de seguridad nacional". 
supuestamente duras, por otro lado las cosas suceden igual, los migrantes llegan, tienen trabajo, hacen su vida... tienen todos los problemas... En realidad, lo que ha generado la doctrina del control es marginación, desintegración y corrupción, nada más.

En referencia a la política migratoria argentina, cuestiona que el carácter restrictivo de la legislación migratoria que habría estado vigente hasta su derogación con la nueva ley de migraciones se corresponda únicamente con el hecho de que fuera instaurada por la última dictadura militar. Señala que los gobiernos constitucionales posteriores, tanto el de Raúl Alfonsín como de Carlos Menem, ratificaron esta visión restrictiva al reglamentar la ley de migraciones establecida en 1981 bajo el gobierno de facto de Videla. Según su opinión, esta concepción restrictiva sobre las migraciones internacionales, compartida tanto por gobiernos autoritarios y democráticos como instituida en distintos contextos nacionales, se relaciona más bien con la "antigua visión geopolítica” del Estado-nación.

En realidad, a mí los aspectos restrictivos de la [ley] 22.439 no me parece que sean exclusivamente por haber sido concebida en un gobierno militar. Porque si uno mira esa ley es bastante parecida, por no decir idéntica, a cualquier otra ley de migraciones... De hecho esa [la Ley Videla] fue reglamentada por Alfonsín en un momento de captación de los derechos humanos y posteriormente por Menem, por dos gobiernos democráticos de distinto signo fue reglamentada, modificado el reglamento y de esa manera confirmada, no? Pero cuando uno mira esa ley y la compara con cualquier ley de los países vecinos, incluso de países europeos, responde más a una visión de la cuestión migratoria que al hecho de pertenecer a un gobierno de facto, autoritario, irrespetuoso de los derechos humanos [...] Podría haber sido cualquier gobierno democrático de cualquier lado... [...] Tiene esa visión, que a mí me parece que... [...] En realidad viene de esa mirada que, a mí me parece, tiene todavía una cosa anterior que es la visión geopolítica, la antigua visión geopolítica del Estado-nación adentro de sus fronteras.

Al mismo tiempo que reconoce la existencia de la "doctrina del control" y su consecuente visión restrictiva sobre las migraciones internacionales, relativiza las medidas represivas llevadas a cabo por el Estado. En dos momentos diferentes de la primera entrevista hizo 
alusión al tema, estableciendo una división entre discurso y acción. ${ }^{391}$ Primero, dejó entender que la restricción no fue llevada necesariamente a la práctica: “...las secuencias históricas han sido trabajar por la restricción, o sea, supuestamente trabajar por la restricción, porque tampoco es...". Luego, en la misma línea, desechó que la vocación de expulsar se haya materializado en acciones estatales concretas: “...tampoco está la vocación de expulsar, no estuvo nunca, estuvo en el discurso, nunca estuvo en la acción...". Siendo la detención y las expulsiones de inmigrantes una práctica cotidiana del Estado, una realidad innegable, la declaración de este funcionario apunta -aparentemente- a señalar que el carácter restrictivo de la política migratoria argentina adoptó más la forma de la ilegalización que de la expulsión del inmigrante. Por otra parte, en referencia al contenido xenófobo y discriminatorio de las declaraciones hechas por los funcionarios de gobierno durante la década de los noventa, opina que la restricción "era más una cuestión de pretender instalar un discurso de forma mediática que estar enfrentando un problema de Estado", descartando que hubiera habido una corriente migratoria que justificara una medida de esta índole.

Según su opinión, durante esta etapa previa, el "tema migratorio" no fue comprendido por los diversos sectores políticos y sociales enfrentados por sus posturas antagónicas en materia de migraciones (esquemáticamente, sectores pro-inmigración y anti-inmigración), aduciéndoles desconocimiento o conocimiento prejuicioso. Tal como se plantea en el marco de la "nueva política migratoria", se trataría de un conocimiento que carece de "objetividad", y por tanto, imposibilitado de dar una "solución al problema". Bajo la gestión actual, asumiendo la concreción de algún tipo de cambio, habría emergido un "discurso más equilibrado".

\footnotetext{
391 En ambos momentos, estas apreciaciones son evocadas mientras comenta las particularidades de la actual política migratoria, comparándola con la anterior. En el primero se refiere a la sustitución de la "restricción" por medio de la "integración", considerando esta relación en términos opuestos: "Porque Argentina tiene que resolver estos temas, en vez de resolverlos por la restricción los está resolviendo por el lado de la integración, me parece que es muy novedoso porque, en general, las secuencias históricas han sido trabajar por la restricción, o sea, supuestamente trabajar por la restricción, porque tampoco es...”. En el segundo momento, su observación se desprende de su opinión respecto a las modificaciones que introduce el proceso de regularización propuesto por la gestión actual: "Para mí, esa visión tiene un reconocimiento de la realidad muy interesante de cómo una persona puede hacerlo y de que si no se hiciera de esta manera lo que va a conseguir es de que esté ilegal, porque tampoco está la vocación de expulsar, no estuvo nunca, estuvo en el discurso, nunca estuvo en la acción...”.
} 
Yo creo que el tema migratorio ha sido un tema desconocido, abordado siempre desde el prejuicio y desde el discurso que llevaban algunos sectores que, paradójicamente, se da que tanto en los sectores favorables a la migración como los que estaban por medidas restrictivas exageraban la cuestión [...] o sea, terminaban confundiendo o terminaban teniendo discursos tan confusos ambos, que ninguno de los dos terminó trayendo solución al problema y a mí me parece que [actualmente] hay un discurso más equilibrado, ha habido un cambio...

El funcionario, quien sólo por momentos se muestra dubitativo respecto a las directrices actuales de política migratoria definidas en instancias superiores a la suya, cree que el rumbo que ha tomado el Estado, visto en términos de factibilidad, es acertado. Habla de "una dosis de realismo" -en contraposición a lo que llama los "mitos" como sinónimo de ficción- mediante la cual se ha demostrado y se demuestra que otras estrategias, principalmente las consideradas como restrictivas, han fracasado tanto en la experiencia argentina como en la de otras latitudes. Señalar que estas medidas fracasaron indica que mediante éstas no se consiguieron los resultados propuestos con este instrumento de control a la vez que se admite la finalidad -el control de la migración- que se persigue. Es decir, cuando desde el Estado se enuncia la idea de fracaso para caracterizar la política migratoria desplegada en el pasado, se establece un cuestionamiento al medio utilizado que deja intacto el fin establecido.

Me parece que hay todo un proceso que, con una dosis de realismo, va mostrando que no hay muchos otros caminos... yo no sé si éste es el mejor camino, pero me parece que ese es posible. Si tengo que opinar, me parece que es el camino posible. Más allá de que a mí me guste, me parece que es el camino posible, que todos los otros que hemos transitado no han funcionado y que estamos viendo que además, las... que los otros tampoco funcionan [...]

\section{Una doctrina por otra: la gobernabilidad migratoria}

Alrededor del año 2002, según los recuerdos y las percepciones del funcionario, las migraciones internacionales habrían empezado a ser vistas de una manera diferente desde 
el Estado. ${ }^{392}$ Aquél "discurso más equilibrado" adoptado en el seno del Estado nacional (o mejor dicho, en determinados ámbitos del Estado nacional) respecto a las migraciones internacionales lo asocia con el paso de la "doctrina del control" a la "doctrina de la gobernabilidad de los procesos migratorios". ${ }^{393}$ Entiende que la perspectiva de la gobernabilidad de las migraciones implica la regulación de los procesos migratorios a través de aquellas "variables" que efectivamente el Estado receptor, en particular el organismo estatal especializado en la materia, puede manejar o conducir, orientada por conceptos como armonía e integración, situadas como contrapuestas a la idea de restricción que asume generalmente la noción de control en el terreno de la política migratoria. En el marco de la perspectiva de la gobernabilidad de las migraciones se asumiría la restricción como necesidad y el control como herramienta, mientras que en la "doctrina del control" se configuraría la restricción como principio y el control como política. Bajo esta visión, los movimientos migratorios son comprendidos como procesos sociales armónicos que pueden ser distorsionados por diversos factores que pueden escapar a las posibilidades de acción estatal. A su vez, dicha distorsión de los flujos migratorios alteraría el funcionamiento de determinados espacios sociales como el mercado laboral o dificultaría los procesos de "integración" de los inmigrantes a la sociedad de recepción.

Este proceso de la gobernabilidad de los flujos migratorios se entiende [como] el manejo de las variables que permitan una integración armónica... la

392 Durante la entrevista, el funcionario establece este año como corte, pero no en respuesta directa a una pregunta, sino mientras yo retomaba su planteo referido a la experiencia de los noventa y la situación de principios de la década en materia migratoria. Al referirme a los “comienzos de esta década”, el funcionario agrega: “Sí, 2002, más o menos" (Entrevista con el Jefe de la Delegación Córdoba de la DNM, 2005). Durante los años posteriores, como hemos visto, la perspectiva de la gobernabilidad migratoria aparece de manera implícita o explícitamente en las exposiciones públicas de los funcionarios estatales, pero rara vez es enunciada en un documento oficial. Recién hacia finales de la década empieza a aparecer publicada en documentos de difusión de la Dirección Nacional de Migraciones del Ministerio del Interior. Un buen ejemplo lo constituye el artículo del director de Asuntos Internacionales y Sociales de la DNM, Federico Agusti, en el cual hace una descripción de los ejes centrales de la política migratoria argentina en la coyuntura actual. Este texto, titulado simplemente "Política migratoria argentina", fue publicado a finales del año 2011 en el libro Migraciones internacionales en el siglo XXI, editado por la DNM, el cual reúne las exposiciones que tuvieron lugar en un encuentro internacional organizado en el mes de septiembre del año 2010 en la localidad de Iguazú, Misiones.

393 He utilizado en esta ocasión la denominación que usó por primera vez para nombrar esta nueva perspectiva que habría adoptado paulatinamente el Estado nacional sobre las migraciones internacionales. De todas maneras, a lo largo de las dos entrevistas realizadas, el funcionario se refiere indistintamente a la "gobernabilidad de las migraciones", la "gobernabilidad de los procesos migratorios" o la "gobernabilidad de los flujos migratorios", caracterizándola como "doctrina" o "corriente". 
gobernabilidad de las migraciones sería eso... la conducción de las variables... porque dentro del proceso migratorio hay variables que la administración migratoria y en algunos casos ni siquiera la administración del Estado puede modificar, no maneja y si las manejara estaría en condiciones de reducir las condiciones de pobreza... esas condiciones estructurales que generan emigración o inmigración. En la medida que, incluso, un Estado no puede actuar sobre las cuestiones estructurales del otro [Estado], lo que se propone es que... dado que este proceso social va a suceder de cualquier manera y va a pasar por encima de las voluntades o de las capacidades que voy a tener de conducirlo en el otro extremo del fenómeno, está la posibilidad... sí está la posibilidad de manejar variables que hagan que esos procesos se desarrollen en un marco de mayor armonía e integración... sería como una anteposición a la restricción, una alternativa a la restricción, no en el sentido de que no sea necesario restringir, sino en el sentido de no restringir como principio, porque en esto que hablábamos de la política migratoria, muchas veces el control migratorio, que es una herramienta, se ha tomado como... se ha confundido lo que es una herramienta con una política migratoria. Se ha hecho del control una política. Y en realidad, el control migratorio, aún en las políticas más abiertas de migraciones, es necesario [...] De hecho, la 25.871, a su manera, de alguna manera lo viabiliza porque plantea el control con sanciones muy fuertes y hasta con figuras penales nuevas y por otro lado el migrante... [interrupción] lo que se está haciendo ahora es intimar a regularizar [interrupción teléfonica] Estábamos... ah, con el tema de la gobernabilidad... La [ley] 25.871 de alguna manera tiende a... porque no se plantea no actuar, sino actuar diferenciando por un lado al inmigrante, a quien se lo intima a regularizar según sus posibilidades y sancionando duramente a los factores que distorsionan los procesos migratorios, el mercado laboral en negro, la utilización de la vulnerabilidad de los inmigrantes para sacar ventajas... todo ese tipo de cosas que violan la armonía no sólo de los flujos migratorios, sino que hacen que el flujo migratorio pueda alterar, en este caso, los mercados laborales o cualquier otra... y consecuentemente también las posibilidades de integración real de las personas de ese grupo... 
El surgimiento de esta concepción sobre las migraciones sería producto de un proceso de "maduración" y "enraizado"394 en la órbita del Estado que comenzó a gestarse algunas décadas atrás mediante la concurrencia de diversos actores sociales y políticos. Para él, hubo "todo un proceso que en algún momento a los tomadores de decisiones políticas les llegó un discurso, o una propuesta o una articulación entre lo operativo, lo normativo y lo político diferente". Fue allí que "empezó a haber el discurso que antes no lo había”. Este "proceso político", según sus palabras, se produjo gracias a la participación de "muchos actores que han influido con su pensamiento" -entre los que menciona organismos internacionales como la OIM y organismos de la sociedad civil involucrados con el "desarrollo de la idea de los derechos humanos"- y al "desarrollo conceptual y teórico del tema que no teníamos". En este sentido, destaca la influencia que tuvieron los cursos de capacitación de la OIM, iniciados a principios de la década del `80, sobre los actuales "tomadores de decisiones". Se trataba de "un discurso diferente de los técnicos de principios de los ‘80, cuando yo empecé a trabajar en Migraciones”. A través de estos cursos, la OIM habría formado un buen número de "los que hoy están en posiciones dirigenciales en los países de la región". ${ }^{395}$ Para él, este espacio de capacitación de funcionarios de gobierno era una "caldera de pensamiento, de discusión" de la cual provinieron ideas que arraigaron en determinados "círculos" sociales y políticos hasta permear los "niveles de toma de decisiones" del Estado. "Muchas de esas ideas han surgido de ahí", dice en referencia a los cambios en la política migratoria argentina. Esta influencia de la OIM sobre la política nacional no se habría ejercido a través de mecanismos de imposición de tipo compulsivo (¿o extorsivo?) como la del Banco Mundial, sino mediante mecanismos que Dale (1999) identifica como diseminación. ${ }^{396}$

No ha sido el organismo [internacional] en el gobierno, sino la generación de conocimiento y opinión en círculos que después fueron llegando a niveles de

\footnotetext{
394 Así lo expresa: “A mí me parece que no es casualidad, que hay un proceso de maduración que cae... que estaba dando vueltas y de golpe hay una instancia histórica, un momento histórico donde esta pieza calza y va para adelante. Y ahora hay un proceso de enraizado... en los funcionarios, en la opinión pública...” (Entrevista con el Jefe de la Delegación Córdoba de la DNM, 2007).

395 Entre ellos nombra a la funcionaria de la DNM, Adriana Alfonso. Opina que fue "el motor de todo este tema en el Mercosur, en la soledad más absoluta, empujando, mostrando y convenciendo" (Entrevista con el Jefe de la Delegación Córdoba de la DNM, 2007).

396 Como muestra Dale (1999) en su análisis sobre los efectos de la globalización en las políticas educativas nacionales, cada agencia internacional desarrolla distintas estrategias y mecanismos de negociación. En su artículo, propone una tipología de estos mecanismos: imposición, instalación de interdependencia, estandarización, diseminación, armonización, aprendizaje y préstamo.
} 
toma de decisiones. Me parece que la influencia ha sido esa, no es una influencia como la del Banco Mundial que se impone [...] Me parece que ha sido un trabajo de mucho tiempo, te contaba el tema del curso [de la OIM] y hoy te encontrás, como te decía, en Ecuador, en Costa Rica, en Uruguay, en Chile con directores de [Migraciones]...

El funcionario destaca especialmente el papel que tuvo un consultor de alto rango de la OIM, Lelio Mármora, en la formación de estos funcionarios ("les lavó la cabeza") y le atribuye "mucha importancia" a su persona ("es un tipo definitivo") y a la labor que desempeñó en el desarrollo de la política migratoria regional. ${ }^{397}$ Es muy ilustrativo el hecho de que durante la VIII Conferencia Sudamericana sobre Migraciones (CSM), realizada en Montevideo en el año 2008, Lelio Mármora fuera presentado por Eugenio Ambrossi, representante regional de la OIM para el Cono Sur, como el padre de la CSM.

El funcionario considera también que el cambio de "enfoque" sobre las migraciones internacionales se relaciona con el proceso de globalización y el modo en que se modificó la "concepción geopolítica de la frontera":

397 Lelio Mármora condensa muy bien la figura del "experto": nacido en Argentina, se formó en sociología, obteniendo su licenciatura en la Universidad de Buenos Aires y su doctorado en la École Practique des Hautes Etudes de la Universidad de Paris; a comienzos de los setenta, fue director de institutos de investigación sociológica y demográfica (1970-1974) y de la DNM (1973-1974); a partir de allí, entre 1975 y 1986, como consultor de diversas organizaciones internacionales y regionales (OIT, ACNUR y OEA) dirigió proyectos de cooperación técnica con todos los gobiernos de América Latina. Posteriormente, fue director de la Oficina Regional para el Cono Sur de América Latina de la OIM hasta comienzos del año 2003. Más recientemente estuvo a cargo del INDEC (2003-2007) y desarrolló consultorías para la Comunidad Andina de Naciones (CAN), entre otras actividades. Además, tuvo siempre una activa participación en la formación de funcionarios mediante el dictado de cursos sobre política migratoria en numerosas dependencias estatales y algunas sedes académicas y la dirección de una maestría en políticas de migraciones internacionales de la UBA. También ha sido conferencista en innumerables eventos políticos y académicos, tanto de carácter nacional como internacional, y ha publicado cuantiosos artículos sobre el tema migratorio y un libro sobre las políticas de migraciones internacionales con una importante acogida en los organismos de administración migratoria de diversos gobiernos latinoamericanos. Así, mediante esta combinación de las figuras de funcionario (nacional primero, internacional después) y académico (más precisamente, de funcionario en los medios académicos y de académico en los ámbitos gubernamentales), se constituyó en el principal impulsor y referente de la perspectiva de la "gobernabilidad migratoria" en América Latina, especialmente en el ámbito sudamericano. En muchas de las palabras y reflexiones del funcionario a cargo de la Delegación Córdoba de DNM resuenan las propuestas técnico-políticas de Lelio Mármora. 
Hoy el concepto de frontera ha variado, el concepto de soberanía ha variado, el tema de la soberanía territorial que era una cosa tan importante... donde la frontera tenía un valor importantísimo como límite, como confín de la soberanía, como contenedor de la soberanía y entonces, de ahí en más, la llegada... todo este asunto de cómo se veía como un peligro la instalación de personas en determinadas zonas del país, la ley de seguridad de fronteras... [...] devenían de toda una visión de los Estados mucho más endocéntrica, mucho más mirando la frontera para adentro que lo que sucede hoy, que en realidad los Estados garantizan su estabilidad vinculándose con el afuera. Su estabilidad, su comercio, digamos, hoy... es todo lo contrario. El fortalecimiento del Estado, del Estado-nación, no del Estado como aparato estatal, está dado por la armonía de sus relaciones con el resto del mundo, no? Y eso me parece también que... [interrupción telefónica] Entonces estas leyes o esas visiones de la cuestión migratoria... el peligro de la instalación de contingentes extranjeros... tenía una coherencia con esa visión de los peligros... de la nación, no? [...]

La frontera era el lugar que nos separaba de los dos lados y era el lugar que se defendía con la bayoneta ¿no? Y de todo eso, aún en el marco del neoliberalismo, empieza a haber un desarrollo diferente, el tipo de al lado es el tipo con el que hago negocios, mi socio, no sé si es mi hermano, pero es mi socio [...] el proceso de globalización, sobre todo a los países periféricos, les generó muchos problemas, que generaron procesos inmigratorios importantes... pero también tiene una cuestión que tiende a hacer desaparecer la barrera que era la frontera, o a concebir a la frontera como un lugar de encuentro, de intercambio, más que como un lugar de separación.

Finalmente, según su visión, un aspecto relevante para comprender los cambios esbozados en materia de política migratoria, lo constituye la llegada al poder del partido justicialista, que califica como una "llegada al poder de decisores con tradición de tomar decisiones", de un "sector político que tiene tradición de producir transformaciones" al cual le atribuye una determinada "posición ideológica": 
Parece que hay una característica histórica, en el sentido de que ha habido más toma de decisiones transformadoras en los gobiernos justicialistas que las que uno puede ver en otros gobiernos, aún en los gobiernos militares... con la suma del poder público. [...] Me parece que, en el proceso histórico, también hay que tener en cuenta... no sé si desde otra posición ideológica se hubiera hecho así con tanta tranquilidad un proceso de cambio tan importante...

Esta capacidad para llevar adelante un "proceso de cambio" que le adjudica al peronismo residiría en la capacidad de gestión que le confiere al equipo de trabajo que tiene a cargo el área de gobierno de las migraciones y en particular a quien lo conduce, el director de la DNM. Para él, esta competencia de los cuadros técnicos se halla en la oferta de respuestas políticas expeditivas a aquellos asuntos administrativos y cuestiones sociales (en este caso, "cuestiones migratorias") que necesitan ser resueltas en el corto plazo. Así, estas soluciones resultarían de conocer de antemano de "qué se trata" y hacia "dónde quiero ir", es decir, del desarrollo de una determinada visión. La particularidad de la gestión de Ricardo Rodríguez radicaría en haberse ocupado no sólo de los asuntos administrativos del Estado, aspecto que siempre resultó prioritario para las gestiones anteriores, sino de haberse propuesto intervenir sobre las "cuestiones migratorias". Ahora, ya superados los aspectos organizativos del organismo, habría llegado "el momento de conducir el proceso, el momento de la gobernabilidad. Porque para tener gobernabilidad tenés que tener gestión, tenés que poder operar, si vos no tenés gente, no tenés presupuesto, no tenés computadoras..."

No sólo él como persona [el director de la DNM], sino que... esos cuadros políticos-técnicos, que son tipos que tienen una definición política y que tienen una instrumentación técnica. Saben cómo trabajar la gestión. Son "gestionadores". Y este equipo es un equipo de gestión. Hablando también de los años que lleva [la DNM], no habíamos visto un tipo que llega a las nueve de la mañana y se va a las nueve de la noche, porque en Migraciones siempre cuando llega el director le lleva año, año y medio enterarse de qué se trata, después le lleva otro tanto para formular la respuesta y cuando la va a dar, ya se está yendo... Este tipo se enteró antes, pero más allá de enterarse antes, tuvieron rápidamente una idea de qué querían hacer. 0 sea dos cosas: por ahí no me enteré de todos los detalles, de cómo, qué, dónde está cada cosa, pero ya sé de qué se trata y sé para dónde quiero ir. Arrancaron antes que cualquier 
otro grupo y arrancaron con más ambiciones que otro grupo. La ambición de las anteriores gestiones era mantener el organismo más o menos bien. Y éstos se propusieron trabajar sobre el campo social, sobre las cuestiones migratorias.

En esta línea, diferencia la gestión de Ricardo Rodríguez a cargo de la DNM de todas las anteriores, sugiriendo un punto de inflexión dado por una voluntad política inexistente en administraciones previas. Con su llegada a la DNM se habría realizado un "diagnóstico" distinto al corriente y se habrían modificado, los objetivos institucionales a alcanzar, además de establecerlos explícitamente: "hacia dónde vamos" y "qué es lo que queremos" o "hacia dónde queremos ir".

Yo lo que veo... volviendo a esta cosa de la historia dentro del organismo... realmente es la primera vez que veo una decisión, digamos, una línea clara de qué es lo que queremos, porque en general antes habíamos hecho variaciones sobre lo mismo, y había algunas cosas que ni siquiera eran políticas, definiciones... sino que era como una idea que esto es así, era como una aceptación... entonces hacemos más/menos algunas cosas, pero siempre en el mismo sentido. En esta oportunidad se ha cambiado el diagnóstico, en primer lugar, y en segundo lugar la visión hacia dónde vamos y hacia dónde queremos ir.

Por otra parte, el funcionario considera que en la actualidad no existen las contradicciones que se dieron durante los años noventa: por un lado, se favorecía la apertura de las fronteras en el marco del proceso de integración regional Mercosur y, por el otro, se implementaban medidas restrictivas dirigidas a los inmigrantes limítrofes. Para él ya no se sostiene este "doble discurso", sino que por el contrario hay lineamientos y prácticas que marchan en un mismo sentido. En su relato contrapone el "doble discurso" -como expresión contradictoria- imperante en los noventa a las "acciones concretas" o "pequeñas medidas", amparadas en "directivas" precisas, del escenario actual destinadas 
voluntariamente a revertir los vestigios heredados del pasado. ${ }^{398}$ En este sentido, la preocupación histórica en torno a la distinción entre el turista y el falso turista, como se denomina a aquél inmigrante que busca ingresar con visa de turista con la intención de establecerse en el país para trabajar, sujeto imaginado que tantas sospechas ha levantado históricamente en los controles fronterizos, habría sido resuelta mediante la aplicación de una medida concreta. La visión contenida en estas prácticas, sugiere el funcionario, supondría una aproximación comprehensiva del desarrollo de las corrientes migratorias antes que una restrictiva.

A mí me parece que desde el Estado, o sea, desde donde yo puedo observar el Estado, yo creo que esta visión no existe [se refiere a lo que denomina como "doble discurso" del Estado durante los noventa], que hay una visión, que en las acciones concretas se manifiesta una visión que se ha generado en el sentido de entender cómo funciona este asunto del flujo migratorio, este fenómeno social de los flujos migratorios y... no existe... yo no veo un doble discurso, desde este lugar de observación, yo no veo que exista el doble discurso... el Mercosur por un lado y ver cómo restringimos por el otro. Por lo menos no está ni en las directivas para ver si... cada día aparece una directiva que elimina alguna de esas... esos resquicios que han quedado. Por ejemplo, todavía en frontera quedaba esta cosa de restringir los días de permanencia que el funcionario le daba cuando ingresa porque es un viejo... una vieja impronta que ha quedado de “¿éste será turista, no será?". Entonces, hoy todos son turistas, excepto que aparezca uno que indique lo contrario, cuando antes era al revés: "Bueno, a ver, le voy a hacer una radiografía para ver si es turista". Entonces, por ejemplo, no hace mucho salió una disposición de la Dirección Nacional: todos los turistas que sean del Mercosur se quedan 90 días. Se acabó la discusión si son 15 o son 20, que si es turista, que si tiene prórroga, que si no tiene. A mí me parece que pequeñas medidas como esas son demostrativas de que hay una voluntad de ir derribando todas estas cuestiones que aparecen, sin descuidar la cuestión administrativa...

Para el funcionario se trata de un cambio rotundo y definitivo, con objetivos claros, que rompe con algunas concepciones muy arraigadas en materia de migraciones y que ha

398 A los fines metodológicos, como señalé en el capítulo 1, resultó de gran interés para este trabajo la idea contenida en las palabras del funcionario al señalar que "en las acciones concretas se manifiesta una visión..." (Entrevista con el Jefe de la Delegación Córdoba de la DNM, 2005). 
supuesto una redefinición ideológica, acompañada de la voluntad política necesaria, en un contexto económico que permitió que dicho cambio tuviera lugar. Entre las condiciones de posibilidad de esta transformación, el funcionario alude, como veíamos, a la penetración que tuvieron determinadas ideas provenientes del ámbito académico o del orden de lo conceptual así como al fracaso de las experiencias de gestiones anteriores.

Creo desde el punto de vista político tiene una posición muy jugada respecto de plantear hacia dónde debemos ir, obliga además a una modificación de toda la región [...] Hay un planteo, me parece un planteo valiente en términos políticos, porque además rompe con ideas-fuerza muy asentadas... A mí me parece un proceso muy interesante, me parece que además está instalado de una manera que es poco probable que tenga marcha atrás, está bien fundamentado, está probando que es mejor... Afortunadamente también... yo creo que en nuestro país había un desarrollo académico, conceptual, había toda la visión de los fracasos que había sido lo anterior, pero lo que faltaba era en primer lugar la visión... la visión ideológica, tener una posición ideológica que permita ver las cosas de otra manera. Y en segundo lugar, tener la valentía de ir a contrapelo de los movimientos populares, porque este asunto va totalmente a contrapelo del mito popular imperante y esta coincidencia se dio en un momento de desarrollo económico. No creo que hubiera sido probable plantearse, en términos políticos, no en términos técnicos, plantear esto en un momento de recesión y de reducción del empleo. Entonces ha coincidido... es un momento histórico en el cual hay una serie de coincidencias que han hecho que las cosas fluyeran y que además se instalen y que demuestren que los años que llevamos ya de esto no ha habido problemas en el terreno laboral, se ha solucionado... la gente regulariza, que no existe esa intención de estar ilegal, supuesta intención de quedarse ilegal... Así que a mí me parece que sí, que el Estado, por lo menos desde el Ministerio del Interior, digamos, la línea que va del Ministerio del Interior a la Presidencia de la Nación es una línea que está convencida y que apostó fuerte. Yo creo que hay convicción. 
Según su testimonio, el "cambio más importante" en materia de normativa migratoria que experimentó durante su carrera como funcionario se relaciona con la aprobación de la ley de migraciones $\mathrm{N}^{\circ}$ 25.871. Ahora, ya derogada la Ley Videla, reconoce sin mayores dificultades los vestigios de la llamada "doctrina del control" en los "modos de hacer" de los funcionarios -él incluido- o empleados estatales, los cuales colaboraron para que la nueva ley de migraciones fuera en mayor o menor medida "resistida". ${ }^{999}$ Explica que "desde ese punto de vista, los que nos formamos en esa forma de trabajar, sentíamos una fuerte presión de combatir la ilegalidad en la cabeza del migrante". A pesar de que aprueba la visión que habría adoptado ahora el Estado sobre las migraciones internacionales, la internalización de estas representaciones y prácticas relacionadas con el férreo control de la frontera, no le permitió, al menos inicialmente, aceptar con facilidad una ley de migraciones que contradecía aquellos postulados y premisas que vertebraron su trabajo diario durante décadas. A la vez, dice haberse asombrado frente al hecho que tanto el Ministerio del Interior como la DNM, organismos centrados históricamente en el control del ingreso y la permanencia de los inmigrantes e identificados con el poder de policía, se acomodaran a la nueva ley, yendo por delante de otras instituciones y sectores sociales.

En realidad, la ley ha tenido mucha resistencia, porque era difícil comprenderla para todos con la croqueta [como sinónimo de "cabeza"] formada en cautelosos, a mí me costó comprenderla... digamos, yo creo en todas las cosas que estamos hablando desde hace bastante tiempo... y $\sin$ embargo, ¿cómo vamos a hacer? A mí me sorprendió que mi organismo la agarrara y le diera para adelante y que fuera mucho más rápido el Ministerio, la Dirección de Migraciones que todo lo demás, porque ahora estamos teniendo, estamos yendo mucho más rápido que el resto, incluso que organizaciones privadas: “¿Cómo lo vamos a inscribir a este alumno? Y sí, pero no tiene...”. “¿Qué problemas tienen? ¿Por qué no lo inscriben?”. Nosotros que somos los que poníamos el problema...

399 Esta observación sobre la actitud contraria a la nueva ley de migraciones aparece en la primera entrevista. Dos años más tarde, durante la segunda entrevista, relativiza esta idea al decir que el creía que la ley iba a tener mayor resistencia. 
En su relato reclama que estos cambios al interior del Estado relacionados con la nueva ley de migraciones no hayan sido advertidos por algunos actores sociales y políticos involucrados con la defensa de los derechos de los inmigrantes. Los reclamos dirigidos históricamente al Estado ya no serían pertinentes ni legítimos, ya que ahora "el Estado está del lado de ellos" y está "diciendo lo mismo" que algunos actores que criticaban a las políticas del Estado argentino en materia migratoria. En ocasión de su participación en una reunión de delegados de las Pastorales Sociales de Migraciones de la Iglesia Católica de todo el país, expresa lo siguiente:

Todavía estaban protestando por algo que ya hacía dos años que no sucedía más. Es como que de golpe se habían quedado en la discusión confrontativa de hace más de dos años, hace tres años y no se habían dado cuenta que en realidad tenían una oportunidad fenomenal ahora... que ya había cambiado la cosa. [...] Los delegados, que son tipos de base, todavía estaban reclamando cosas que ya no suceden, digamos, mejor dicho, cosas que ya no suceden no, cosas que siguen sucediendo pero ya no es que suceden porque el Estado lo imponga, sino que el Estado está del lado de ellos. Como que no se habían dado cuenta de los cambios que han operado y cómo la normativa corre a su favor. La realidad no corre a su favor porque hay que transformarla. Pero en todo caso esta vez no es el Estado el que está impidiendo hacerlo. Entonces era interesante decir: 'bueno, miren muchachos que este asunto es al revés'. Ahora es lo otro lo que tenemos que ir a ver... son los empresarios... digamos, otros sectores de la sociedad porque ahora el Estado dio la vuelta y está diciendo lo mismo que ustedes [se refiere a los investigadores] decían hace cinco años, no cierto?

Entiende que el efecto de la nueva ley es que institucionaliza "toda una visión" sobre las migraciones, es decir, brinda un marco interpretativo diferente del cual el Estado se nutría para llevar a cabo sus políticas. La nueva ley de migraciones habría permitido que el Estado pusiera en práctica aquellas ideas que ya estaban circulando en torno a la temática migratoria y que no contaron con la suficiente legitimidad hasta que fueron validadas con la aprobación de la nueva ley en el Congreso Nacional. Es decir, según su punto de vista, la aprobación de la nueva ley significó la validación de un conjunto de ideas que conformaban una visión sobre las migraciones que resultaba problemática para el propio Estado. 
La ley, en realidad, lo que hizo posible la ley es que el Estado viabilizara estas ideas que andaban dando vuelta, que tuviera visos de comprensión, y al ponerlas en marcha las enraíza, institucionaliza toda una visión que ya queda instrumentada y va para adelante. Éste es el efecto...

Sus observaciones a la nueva ley se relacionan con algunos aspectos técnicos. Como él mismo dice, sería necesario corregir "cuestiones operativas, no de fondo". Es en este sentido que considera que es "imperfecta" y que "en realidad, como instrumento jurídico, hay que agarrarla y hacerla de nuevo". Opina que "(l)e falta como ley consistencia a la norma, en el apuro, quedó en expresión de voluntades, hay un problema de técnica legislativa". A la vez que destaca el derecho a migrar contenido en la ley como algo novedoso, señala que para él tiene "cuestiones muy declamativas" que, aunque son "muy importantes", difícilmente puedan traducirse a la práctica. Entre ellas señala el acceso a la educación y la obligación de orientar a los inmigrantes a que se regularicen. Para él, en caso de que no ocurriera, "(l)a resolución de estas cosas te puede dar vuelta toda la ley". A pesar de estos señalamientos, busca que sus opiniones no queden descontextualizadas y dejar claro que está de acuerdo con la ley, suscribiendo al mismo tiempo la actual política migratoria: "Lo mejor que tiene es que existe".

\section{Resolver el tema migratorio: la regularización migratoria como prioridad}

En concordancia con los lineamientos de política fijados en las altas esferas de gobierno, el funcionario identifica la documentación de los inmigrantes residentes en el territorio nacional -acción denominada "regularización"- como la "prioridad" de la Dirección Nacional de Migraciones desde la aprobación de la nueva ley de migraciones. Unos meses antes que se lanzara oficialmente el programa de regularización migratoria y se diera a conocer como Patria Grande, el funcionario comenta:

Yo creo que esas cuestiones hoy... que la prioridad del trabajo de la Dirección desde la aprobación de la ley es la regularización, la documentación migratoria de las personas que están en el territorio, esa es la prioridad, ahora 
está por salir un programa que se llama... PROAM que es un proyecto, un programa de regularización masiva para ciudadanos del Mercosur...

$\mathrm{Al}$ igual que lo expresado en las intervenciones públicas de los altos funcionarios de la DNM, la regularización, como objetivo estatal, es planteada como la solución a la situación social que atraviesan los "indocumentados" en la Argentina. Como ya lo manifestara el director de la DNM, se trata de los "indocumentados" ya establecidos en el país: "El Patria Grande tiene dos universos: unos son lo que ya estaban en el país y los [otros son los] que vinieron después. Para los que vinieron después está la ley [de migraciones], esos van a seguir blanqueándose siempre". Esta preocupación depositada en la situación de los "indocumentados" es la contracara, no necesariamente contrapuesta, de un interés mayor del Estado. Aunque sin nombrarlo explícitamente, el "tema a resolver" -que también es enunciado por otros funcionarios nacionales como el "problema a resolver"- es la llamada irregularidad migratoria.

El funcionario reconoce que es la Argentina, en tanto "país de destino de todos los flujos migratorios”, el principal Estado interesado en enfrentar este asunto. En la región, aún no implementado el programa de regularización migratoria, el Acuerdo sobre Residencia prefiguraba en aquél momento los objetivos de regularización migratoria que el Estado argentino estaba decidido a poner en práctica. No es casual que dicho acuerdo regional haya sido elaborado -con "letra y música de la Argentina" como expresa resumida y magníficamente el funcionario-y promovido por el Estado argentino.

La visión institucional tiene una preocupación... es que ha habido una preocupación muy clara tanto en el discurso como en las acciones concretas de resolver la situación de las personas... de los extranjeros que se encontraban en la Argentina, y de los indocumentados que se encontraban en la Argentina, esto es claro, es cada vez... se facilita más. Por ejemplo, el acuerdo migratorio Mercosur fue promovido, digamos, todas las normas de facilitación en el Mercosur fueron promovidas por Argentina, que es el país de destino de todos los flujos migratorios... ha sido Argentina, creo que, buscando cuestiones objetivas, donde está la vocación de resolver el tema ¿no? La Argentina propuso el acuerdo migratorio del Mercosur que fue aprobado, letra y música de la Argentina y así como se propuso así quedó...

Ninguno de esos países de la región tenía el apuro que tenía Argentina de resolver el tema, porque Argentina es el más acuciado en resolverlo porque es 
el país de recepción más vasto, tiene todo el cúmulo del intercambio... apareció más preocupada por encontrarle la vuelta al asunto y encontrársela en términos de no generar conflictos también en la región...

Efectivamente, la implementación unilateral que hizo la Argentina del Acuerdo sobre Residencia suscripto con los países del Mercosur ampliado evidencia el particular interés del Estado argentino en el proceso de regularización migratoria para atender aquellos inmigrantes provenientes de Bolivia y Perú. 400

[...] así y todo Argentina unilateralmente está en tratamiento con algunos países del Mercosur, con Bolivia y Perú teníamos un acuerdo bilateral que ya venció pero en la condición o teniendo en cuenta esta intención de Perú y de Bolivia de haber sostenido un acuerdo migratorio, Argentina está dando un tratamiento del Mercosur... Entonces, de hecho, a peruanos y bolivianos que se presenten ahora les seguimos tomando el trámite como si estuviera vigente el convenio y lo resolvemos como el Mercosur, es decir, se sigue manifestando una intención concreta de la opción por regularizar.

Así como lo indicaron los altos funcionarios de la DNM, la regularización migratoria planteada como "solución" respondería a una "necesidad", apoyada en el "reconocimiento de la realidad". Una realidad que no ofrece demasiadas alternativas: muchas otras experiencias habrían mostrado que las medidas restrictivas no aportaron ninguna solución.

[...] Después el reconocimiento de la realidad en cuanto a la necesidad de regularizar. Por eso el acuerdo del Mercosur recoge todas esas cosas y plantea que se puede radicar en cada país, en cada uno de los países miembros una persona de otro de esos países miembros por el simple hecho de ser ciudadano de ese país, no ya porque tenga un contrato de trabajo, [sea] padre, hijo, no: ciudadano del Mercosur. Se puede radicar en la Argentina por el sólo hecho, acreditando que es ciudadano Mercosur... Entonces a esa persona le dan una residencia temporaria por dos años y dentro de estos dos años tiene que demostrar que tiene un modo de vida lícito y ahí pasa a 'permanente'. Esta es la diferencia hasta ahora donde las personas tenían que acreditar todo 
esto antes de entrar en el país... Entonces: “¿Ud. es ciudadano del Mercosur? Venga, tome la residencia provisoria, venga dentro de dos años, dígame lo que hizo, consiguió, tome la residencia". Para mí, esa visión tiene un reconocimiento de la realidad, muy interesante de cómo una persona puede hacerlo y de que si no se hiciera de esta manera lo que va a conseguir es que esté ilegal, porque tampoco está la vocación de expulsar, no estuvo nunca, estuvo en el discurso, nunca estuvo en la acción...

A partir del diagnóstico oficial, el cual incluye el estudio "objetivo" de la realidad migratoria del país, bajo la "nueva política migratoria" se pretende atender los aspectos conflictivos, potenciales o concretos, que pudieran manifestar las diversas corrientes migratorias. Según la visión del funcionario, sólo algunas de ellas justificarían una intervención específica. Mientras desestima la inmigración asiática por su condición coyuntural y relativiza las corrientes migratorias originarias de Chile, Brasil y Uruguay por las características que, aparentemente, asumiría el intercambio poblacional entre la Argentina y estos países en la actualidad, destaca la importancia que tienen los flujos migratorios regionales provenientes de Paraguay, Bolivia y Perú en función de su carácter estable o permanente. Asumiendo como premisa que "los conflictos o las cuestiones a resolver en el ámbito migratorio están vinculadas a la región", son estas "corrientes migratorias establecidas" las identificadas como el problema que necesita solución. Así lo explica:

[...] En realidad, hoy, si los conflictos o las cuestiones a resolver en el ámbito migratorio están vinculadas a la región, digamos no es que hoy... hay un tema que podría ser el tema de los asiáticos, que es un tema que ha sido atendido por cuestiones de corrupción y por documentos falsos, este tipo de cosas, etc. Tampoco son... uno no podría decir que son una corriente migratoria sobre la que tiene que desarrollar una política equis, es más como un fenómeno que parece haber sido circunstancial ¿no? que podría llegar a tomar vigencia, pero lo que llegamos a ver como corrientes migratorias establecidas siguen siendo las del Mercosur, es decir, Paraguay, Bolivia, Perú de alguna manera... Ya no hay migración chilena prácticamente o hay un recambio natural, de flujo y reflujo que tiene que ver también con intereses compartidos, con mercados compartidos, con mercados laborales, tiene cierta armonía el intercambio con Chile, no es unidireccional... Pasa lo mismo con Uruguay y... de Brasil tampoco hay una presión fuerte. Quedan dos fenómenos importantes, dos corrientes 
importantes que son peruanos y bolivianos, paraguayos en la región y en Buenos Aires... [...] las cuestiones que urgen hoy de una respuesta son cuestiones regionales.

A diferencia de las décadas anteriores, bajo la "nueva política migratoria" el modo novedoso de resolver las cuestiones ligadas a la irregularidad migratoria sería a través de la integración, en contraposición a la restricción. Para explicar este cambio de concepción, tal como lo hicieran en reiteradas oportunidades los funcionarios del más alto rango de la DNM en sus intervenciones públicas, el funcionario acude al argumento de la "falta de eficacia" que habría tenido tanto la normativa como las medidas de orientación restrictiva.

Porque Argentina tiene que resolver estos temas, en vez de resolverlos por la restricción los está resolviendo por el lado de la integración. Me parece que es muy novedoso porque en general las secuencias históricas han sido trabajar por la restricción, o sea, supuestamente trabajar por la restricción, porque tampoco es... [...] entonces... leyes restrictivas, con criterios supuestamente restrictivos, hasta que la cantidad o dimensión de la ilegalidad es tal que tenemos que hacer una amnistía. Entonces hay una amnistía en el `64, una en el `74, una en el `84, otra en el '94... el fracaso de... tanto de la normativa restrictiva como de la capacidad de instrumentarla, como de la vocación de instrumentarla, ha sido tal que creo que lo demuestran las sucesivas regularizaciones que hubo que hacer más o menos cada períodos de 10 años para resolver esta gente (sic). Y no se resolvió haciendo expulsiones masivas, se resolvió haciendo medidas de regularización. En eso creo que también hay históricamente como un doble discurso en el sentido en que somos malísimos, restrictivos, y cuando la cosa... "vengan todos pa' dentro". Entonces, el transparentar eso con una política, como una política estable... Es decir, este es un país que acepta todo el mundo, siempre y cuando cumpla con estos requisitos, que ahora son requisitos cumplibles... [...] Hay un discurso que leyó el Director Nacional ante la Comisión de Población de la Cámara de Diputados donde de alguna manera se establecieron las líneas fundamentales de la gestión y coincide con estas observaciones de la falta de eficacia que ha tenido todo el derecho hasta el momento...

Las posibilidades de "resolver el tema migratorio" con éxito, cuyo objetivo o expresión sería una "inmigración equilibrada", estarían limitadas por aquellos factores o variables 
sobre los cuales que el Estado no puede actuar (como los "factores de expulsión" de la sociedad emisora) o que con mayor o menor efectividad puede regular (como los mercados laborales.) Se trata entonces de identificar aquellas variables manejables que permitan mantener "ordenados" ciertos ámbitos de la sociedad, especialmente el mercado laboral. Entre ellas, el funcionario identifica la regularización de los inmigrantes indocumentados y la planificación de los mercados laborales. La convergencia de ambas daría como resultado un "mercado laboral formalizado" que evitaría los "desórdenes migratorios". A decir del funcionario, "no hay mejor medida migratoria que un mercado laboral formalizado". Para ilustrar su explicación, hace referencia a los países escandinavos: allí la noción de orden es el fundamento de la solución a los "problemas migratorios", es decir, un "mercado laboral ordenado" sería la mejor respuesta a los "desórdenes migratorios". Equilibrio y orden, ambos elementos centrales de la definición de gobernabilidad migratoria, estructuran su visión acerca del modo de intervenir sobre la realidad social para restablecer u obtener aquél orden migratorio perdido o aún no encontrado.

Yo te voy a decir qué es para mí es resolver el tema migratorio... para mí resolver el tema migratorio es tener una... una inmigración equilibrada, porque el tema migratorio tiene una generación en la que vos no participás, digamos. Los factores expulsivos de los emisores de migración... no podés operar sobre... o en todo caso, no dependen... son variables que no podés manejar, no podés manejar las variables, cuál va a ser mi equilibrio, digamos, cuál es mi rango de acción en esto. Después, nosotros teníamos una hipótesis de aumento de la migración boliviana bajo la crisis hace tres años... resulta que la asunción de Evo Morales suaviza el flujo migratorio boliviano y el otro día me decía Prieto [el presidente de una asociación de inmigrantes bolivianos] que se está planteando el tema del retorno... Entonces, con esas variables no tenés nada que hacer, ¿qué es lo que podés hacer? Es tener bien claras cómo voy a operar las variables que yo sí manejo [¿Cuáles serían?] Y bueno, que son la regularización, la planificación de los mercados laborales, que no todas son estrictamente migratorias, no hay mejor medida migratoria que un mercado laboral formalizado... uno de los momentos de mayor regularización migratoria fue, me acuerdo, alguna vez que Cavallo fue ministro o secretario de algo... 90, 91... cuando se dio la ley penal tributaria, que asustó a todo el mundo, vos no sabés cómo se regularizaban, era algo ... como medida migratoria fue fenomenal. ¿Pero por qué? Porque uno de los factores determinantes de lo que sucede en el campo migratorio es el mercado laboral. 
Si vos tenés un mercado laboral formalizado, en blanco, ordenado, las cuestiones migratorias sólo pueden... digamos, o funcionan dentro de la formalidad, si vos lo permitís, porque el otro tema es que si yo le voy a pedir al trabajador migrante más requisitos pueden ocurrir dos cosas: o no va a venir o... en este caso si el mercado, si tuviéramos la utopía de que es un mercado... cualquier país escandinavo, Noruega, Suecia ¿por qué no tienen problemas migratorios? Porque la economía es absolutamente blanca y transparente. Y son países de tradicional acogimiento. Pero la gente no va, al menos que tenga un trabajo en blanco. Los países escandinavos son interesantes porque no tienen medidas restrictivas sobre las migraciones, lo que tienen son países ordenados. Entonces no tienen, entre comillas, los desórdenes migratorios de otros países. Pero porque parten de otra base, no porque la ley de migraciones sea mejor o peor, porque es mejor en el orden social... Entonces muchos de los problemas que nosotros tenemos en el ámbito migratorio que hay que solucionar surgen por tener desordenados otros ámbitos de la sociedad como el mercado laboral, por la economía, por la economía en negro. Si vos tenés el ámbito económico, particularmente el laboral, ordenado, entonces qué problema tenés con las migraciones? Ninguno.

Para conseguir dicho equilibrio y orden, la regularización migratoria se convierte en un requisito indispensable. Según su opinión, como también lo expresaran en reiteradas ocasiones las autoridades de la DNM, actualmente el Estado argentino le brinda a los inmigrantes -a los inmigrantes "indocumentados"- todas las facilidades necesarias para regularizar su situación administrativa.

Porque la ley también tiene por ahí un articulito que es interesante, que es que reconoce el derecho a migrar, o sea reconoce la migración como un derecho. Desde el momento que la migración está reconocida como un derecho, el Estado tiene que articularlo como para que trascurra, para que sea posible, de ahí aparece este cambio de visión, en este sentido no de obstaculizarla, en principio de facilitarla para toda persona argentina, en principio tanto lo normativo como la orientación federal prevé facilitar.

A partir de las "facilidades" que brindaría ahora el Estado argentino, las dificultades que pudieran surgir o tener y la consecuente falta de regularización son depositadas en el ámbito de lo personal (¿lo privado?). En esta afirmación resuenan las palabras del director de la DNM cuando sostuvo que en la Argentina "será irregular sólo quien quiera serlo", una 
frase que estuvo a punto de convertirse en el título del programa nacional de regularización migratoria:

Entonces el migrante hoy en la Argentina tiene todo lo necesario para regularizar su situación migratoria... hay problemas de otro tipo, de su... que son de índole personal, de sus posibilidades de hacer las cosas, pero en todo caso el Estado les plantea la posibilidad de regularizar y se lo plantea en términos bastante abiertos.

En suma, la formulación de una política pública dirigida exclusivamente a una fracción de los inmigrantes, población diferenciada producida por el propio Estado, los llamados "inmigrantes ilegales" (también denominados eufemísticamente "irregulares" o "indocumentados"), más allá del marco de legitimidad que pueda proveerle una retórica inclusiva asentada en los derechos humanos, muestra -entre otras cosas- que la inmigración, al margen de la política restrictiva o aperturista que se propugne, es aprehendida necesariamente por el Estado receptor como problema social a la vez que pone de manifiesto que la división legal/ilegal es constitutiva -es decir, fundante, no accesoria- de la visión estatal contemporánea sobre la inmigración. 



\section{CAPÍTULO 6}

\section{EDUCACIÓN, ESCUELA E INMIGRACIÓN: LA PRESENCIA DE LOS BOLIVIANOS EN EL}

ESPACIO ESCOLAR

La visibilidad social y política que adquirió la llamada inmigración limítrofe en la Argentina de los noventa resultante del accionar represivo y persecutorio del Estado, la presencia arrolladora y cómplice de los medios nacionales de comunicación, la actuación denunciante y testimonial de algunos organismos de la sociedad civil y de la creciente formación de organizaciones de inmigrantes de países limítrofes, no tuvo su correlato en el espacio escolar. Salvo algunos episodios en la prensa relacionados con la falta de documentación oficial de los alumnos extranjeros hijos de inmigrantes y su correspondiente denuncia por parte de organismos de derechos humanos o alguna nota aislada sobre la pertinencia o el merecimiento de los alumnos extranjeros para portar la bandera nacional, la denominada cuestión migratoria en las escuelas no participó del debate público ni estuvo contemplada entre los temas de la reforma del sistema educativo que se llevó a cabo durante esos años. A su vez, las posteriores discusiones y cambios de la legislación migratoria estuvieron prácticamente ausentes de los ámbitos de gobierno de la educación, tanto nacionales como provinciales.

En Córdoba, en particular, los organismos oficiales del Estado provincial y municipal tampoco mostraron interés por la situación de los alumnos extranjeros o hijos de inmigrantes hasta mediados de la década actual cuando la Defensoría del Pueblo de la provincia tomó la iniciativa y organizó un espacio interinstitucional para tratar la vulneración de los derechos de los inmigrantes residentes en el ámbito regional. ${ }^{401} \mathrm{El}$ Ministerio de Educación provincial se limitó a organizar un curso de capacitación docente sobre interculturalidad, motivado mayormente por el tema indígena, siguiendo recomendaciones provenientes del orden nacional. El artículo de la nueva ley de migraciones referido al derecho a la educación de los inmigrantes extranjeros en "situación administrativa irregular" pasó desapercibido y las instituciones escolares nunca fueron informadas acerca de estas modificaciones legales. Todo parecía reducirse a una cuestión social que la escuela tenía que encarar por su cuenta y en la medida de sus posibilidades.

401 Véanse Ortiz (2009) y Cappellini et al. (2011) para un análisis sobre la agenda política local (provincial y municipal) en materia de migraciones internacionales. 
En este capítulo se documenta a la vez que se problematiza la presencia de los alumnos identificados como bolivianos en una escuela ubicada en un barrio de la periferia urbana de la capital cordobesa llamado Villa El Libertador, cuya historia y vida cotidiana están atravesadas por el asentamiento temprano de trabajadores inmigrantes provenientes de distintas regiones de Bolivia. A partir de las observaciones hechas en diversas situaciones de la vida escolar y las entrevistas realizadas a las maestras y directivos, junto a algunos documentos oficiales y escolares recogidos, se analiza la constitución de la escuela como escuela del fondo, la regulación jurídica relativa a los llamados indocumentados en el terreno educativo y escolar, la visibilidad que obtuvieron paulatinamente los hijos de inmigrantes bolivianos en la escuela junto con la aparición de la bolivianidad como asunto de interés institucional y los estereotipos y prejuicios construidos acerca de los alumnos bolivianos en la vida cotidiana escolar. A los fines de dar a conocer el contexto y el escenario en el cual tuvieron lugar estos procesos y las escenas en las cuales transcurren los acontecimientos y episodios tratados en el próximo capítulo, se describe, primeramente, la llegada y la presencia de inmigrantes bolivianos en la ciudad de Córdoba, el barrio donde residen las familias y donde está situada la escuela en estudio a la cual asisten sus hijos, así como sus características e historia.

\section{Córdoba como destino: los inmigrantes bolivianos en Villa El Libertador}

Córdoba, sin llegar a ser uno los destinos tradicionales de la migración boliviana a la Argentina como Jujuy, Salta o Buenos Aires, constituye actualmente una de las provincias del interior del país preferidas por los inmigrantes bolivianos, concentrados fundamentalmente en el área metropolitana. ${ }^{402}$ La población nacida en Bolivia, junto a la procedente de Perú, es la más numerosa de las colectividades de inmigrantes latinoamericanos radicadas en la región. ${ }^{403} \mathrm{Si}$ bien la presencia de inmigrantes bolivianos en esta provincia se retrotrae hasta finales del siglo diecinueve, su llegada se intensifica a partir de la década de los cincuenta con el exilio de militantes políticos que produce la revolución de 1952 en Bolivia y, especialmente, desde los años sesenta con el arribo de jóvenes que ingresan a la Universidad Nacional de Córdoba junto a campesinos y obreros

\footnotetext{
402 Según los datos oficiales del Censo Nacional de Población, Hogares y Viviendas realizado en el año 2001, en la provincia de Córdoba reside casi el tres por ciento de la población total nacida en Bolivia radicada en la Argentina. De acuerdo a su peso cuantitativo, se ubica en sexto lugar, después de la provincia de Buenos Aires, la Ciudad Autónoma de Buenos Aires y las provincias de Jujuy, Salta y Mendoza (INDEC, 2001).

403 Para una reciente investigación sobre la inmigración boliviana en Córdoba, véase Pizarro (2011).
} 
que se desempeñan principalmente en el comercio minorista, la carpintería y la albañilería, y la naciente industria automotriz cordobesa.

La gran mayoría de los inmigrantes bolivianos residentes en Córdoba proceden principalmente de áreas urbanas y rurales de los departamentos de Cochabamba, Potosí, Tarija, Oruro, La Paz, Chuquisaca y Santa Cruz. ${ }^{404}$ Del total de personas nacidas en Bolivia residentes en la provincia de Córdoba registradas en el censo del año 2001 se concentran marcadamente en el departamento Capital (casi tres cuartos del total). Los departamentos Colón y Río Primero, al norte y al este de la capital, albergan un 10 por ciento y el resto, que constituye poco más del 15 por ciento, se distribuye principalmente en los departamentos San Javier, General San Martín, Santa María, Río Cuarto y Punilla (Bologna, en prensa). Una alta proporción está concentrada en la zona sur de la ciudad de Córdoba, especialmente en Villa El Libertador, un barrio periférico de la zona sur y el más poblado de la ciudad de Córdoba ${ }^{405}$, situado aproximadamente a ocho kilómetros del centro urbano. Allí están establecidos los residentes más antiguos, predominando los inmigrantes provenientes de los departamentos de Cochabamba y Potosí frente a los de Oruro, La Paz y Chuquisaca. Otros barrios con una significativa proporción de migrantes de origen boliviano son Nuestro Hogar 3, Ciudad Angelelli (llamada anteriormente Villa Angelelli), Villa Esquiú, General Paz, Pueyrredón y Guiñazú (Prieto Terán, 2007). En las zonas periurbanas, muchas de las viviendas, en ocasiones asentadas en tierras fiscales, suelen ser precarias y en algunas zonas carecen de servicios básicos como agua potable, electricidad, gas, cloacas y recolección de la basura. En el área del Gran Córdoba la presencia de inmigrantes bolivianos se destaca en la zona de Monte Cristo. Las localidades de Pilar, Oncativo, Oliva, Villa María, Bell Ville y Río Cuarto, ubicadas hacia el sur de la ciudad de Córdoba, Villa Dolores, Mina Clavero, Cosquín, La Falda y Cruz de Eje, situadas en las sierras occidentales, y Jesús María, localizada al norte de la capital cordobesa, se han constituido en los destinos más elegidos al interior de la provincia.

Las razones laborales aparecen como la principal motivación al momento de migrar, mientras que la existencia de parientes o amigos y el conocimiento de oportunidades laborales son decisivos en la elección del lugar de destino (López Gareri, 1999). En el lugar

404 Según una encuesta realizada en 1996 (Domenach y Celton, 1998), la mayoría radicados en la ciudad de Córdoba provenía del departamento de Cochabamba (34,2\%). Entre los demás departamentos aparecen Potosí (17,5\%), Tarija (13,6\%), Oruro (10,3\%), La Paz (6,5\%), Sucre (5,2\%) y Santa Cruz (4,9\%). En cuanto a los nacidos en Argentina (contemplados dentro de la comunidad boliviana), la gran mayoría era originaria de Córdoba (68,7\%) y el resto prácticamente se repartía entre Jujuy $(15,6 \%)$ y Salta $(10,9 \%)$.

405 Según el Censo Nacional de Población, Hogares y Viviendas del año 2001, la población total del barrio Villa El Libertador es de 39.535 habitantes. 
de origen se han desempeñado como campesinos y mineros; también como artesanos, obreros, comerciantes y empleados informales. Antes de su llegada a Córdoba, muchos tuvieron otras experiencias migratorias "internas" o "externas": se han desplazado al interior de su país (del campo a la ciudad o a zonas de colonización como El Chapare o Santa Cruz de la Sierra) o han vivido en el noroeste de la Argentina (Jujuy y Salta principalmente). Entre otros motivos de la migración también aparecen las mejores condiciones económicas y la facilidad en el acceso a la educación, vinculado al valor que los inmigrantes bolivianos le otorgan a la educación como recurso de movilidad social ascendente, y a la salud pública en la Argentina frente a las dificultades de la vida diaria en Bolivia.

Salvo un reducido número de hombres y mujeres profesionales, la gran mayoría de los trabajadores/as migrantes radicados en Córdoba se desempeña en ocupaciones laborales de baja o mediana calificación, bajo deplorables condiciones de trabajo y con un alto grado de informalidad, lo cual los excluye de la posibilidad de acceder a los beneficios sociales que legalmente aseguran los convenios colectivos de trabajo. En términos generales, los migrantes bolivianos realizan actividades laborales relacionadas con la construcción (como albañiles, en especial yesistas y ceramistas, en pequeñas y grandes obras de construcción), la frutihorticultura ${ }^{406}$, los cortaderos de ladrillos ${ }^{407}$, la industria textil, el comercio minorista (como cuentapropista) y el servicio doméstico. A excepción de algunos trabajos como la albañilería y la limpieza de hogares que son desarrollados exclusivamente por hombres y mujeres respectivamente, el resto de las principales actividades involucran tanto mano de obra masculina como femenina.

En Villa El Libertador, como explica Giorgis (2004), muchos de los hombres trabajan en el sector de la construcción y generalmente no tienen una experiencia previa en esta actividad laboral. Se inician como "ayudante" o "peón de albañil" y con el tiempo suelen alcanzar otras posiciones como "medio oficial" y "oficial”, adquiriendo alguna especialidad (yeseros, ceramistas, encofradores, listoneros, etc.) y desempeñándose como "contratista",

\footnotetext{
406 Se calcula que en Córdoba 300 de las 500 toneladas de frutas y verduras diarias que entran al Mercado de Abasto es producida por residentes bolivianos (La Voz del Interior, 13 de agosto de 2006).

407 Según una nota periodística aparecida en la prensa local, la Unión Obrera de Ladrilleros (UOLRA) estima que hay alrededor de 800 cortaderos en la provincia de Córdoba y que el 30 por ciento del personal está integrado por inmigrantes bolivianos. En la mayoría de los cortaderos no están aseguradas las condiciones mínimas de seguridad, salubridad e higiene. De 300 cortaderos de ladrillos inspeccionados por la delegación Córdoba de la UOLRA, el 98 por ciento no habría cumplido ninguna de estas normas. Tampoco suele respetarse el convenio colectivo que existe con el sindicato de ladrilleros. La UOLRA detectó que la mayoría de estos lugares y personas que trabajan allí no figuran en los registros municipales ni fiscales (La Voz del Interior, 13 de agosto de 2006).
} 
"tantero" o "cuentapropista". Buena parte de las mujeres trabajan en el ámbito del comercio minorista, que en muchos casos es de carácter informal y ambulante. Suelen estar en zonas adyacentes a las ferias y mercados municipales (como el Mercado de Abasto ubicado en una zona céntrica de la ciudad) vendiendo limones, ajos y pimientos. En Villa El Libertador tienen puestos de ropa, juguetes y adornos ubicados en la plaza principal y que funcionan los fines de semana. Otras mujeres bolivianas trabajan como empleadas domésticas. Entre los inmigrantes radicados en otras zonas de la ciudad prevalecen actividades laborales ligadas a la horticultura (en las quintas del cinturón verde de la ciudad), la producción de ladrillos y la industria textil.

Según algunos estudios e informes, las peores condiciones de vida y de trabajo predominan en los cortaderos de ladrillos y en los talleres textiles. En los cortaderos de ladrillos trabajan generalmente más de diez horas diarias (en algunos casos hasta dieciséis horas), siempre a la intemperie, sin ninguna protección contra el alto calor de los hornos. En los talleres textiles, los cuales funcionan en los garajes de las casas o en locales a puerta cerrada y en barrios periféricos como Villa El Libertador, Villa Azalais o Centro América, trabajan a destajo ${ }^{408}$, hacinados en pequeñas e insalubres habitaciones sin ventilación (lo cual hace que se aspire el polvillo de las telas). En ambos casos, los ingresos dependen de la producción diaria y en muchos casos sólo alcanzan para cubrir los gastos mínimos de subsistencia de la familia.

Por otra parte, en la ciudad de Córdoba existen diversas organizaciones creadas por migrantes bolivianos. En la actualidad hay al menos seis organizaciones, la mitad de ellas con personería jurídica (bajo la figura de "asociación sin fines de lucro"). A excepción de la organización de inmigrantes bolivianos más antigua en la ciudad de Córdoba, fundada en la década del ochenta, el resto de las asociaciones fue creado a mediados de los noventa, en pleno auge del asociacionismo inmigrante, o a principios de la presente década. Si bien la gran mayoría de sus miembros son nacidos en Bolivia, es común también que participen los hijos e hijas nacidos en la Argentina. 409

408 En el trabajo a destajo, la remuneración está sujeta a la cantidad de piezas, medidas, trozos, conjuntos o unidades determinadas producidas, lo cual implica una modalidad productiva que lleva a incrementar considerablemente las horas de trabajo para alcanzar niveles mínimos de subsistencia. En el caso de la industria textil, el trabajo a destajo supone que se paga por prenda confeccionada.

409 Producto del asociacionismo inmigrante, durante los noventa también surgieron diversos medios de comunicación de tipo comunitario, producidos y dirigidos a la propia colectividad. En distintas frecuencias de radios locales se pueden sintonizar programas dirigidos a la colectividad boliviana (los sábados y domingos generalmente), conducidos por alguno de sus miembros. En los años ochenta aparece el primer número del boletín de distribución gratuita El Reporter y desde hace algunos años el periódico Renacer, un medio gráfico creado en 1999 en medio de 
El Centro de Residentes Bolivianos fue la primera asociación de inmigrantes bolivianos creada en Córdoba. Formalmente fue fundada en el año 1986, pero sus actividades se iniciaron en la década del cincuenta. ${ }^{410}$ Dos decenios más tarde, comenzó a funcionar la Asociación Deportiva Boliviana, cuya creación fue formalizada en 1996 al obtener la personería jurídica. A mediados de los años noventa se formó la cooperativa ARPEBOCH con miembros de origen nacional argentino, peruano, boliviano y chileno, gentilicios que inspirarían el nombre de esta entidad (ARgentinos, PEruanos, BOlivianos, CHilenos). A inicios de la actual década, se constituyó la Unión Folclórica de Agrupaciones Bolivianas (UFAB) en el 2001, la Federación Boliviana de Fútbol Amateur en el 2004 y más recientemente, motivado por la llegada de Evo Morales a la presidencia de Bolivia en el año 2006, el grupo Bolivia Marka.

Fueron creadas con distinta finalidad, pero comparten su interés por las actividades relacionadas con la organización de eventos sociales y culturales destinados a conmemorar alguna fecha del calendario nacional como el día de la independencia de Bolivia o a celebrar alguna de las festividades regionales como la de la Virgen de Urkupiña. Las fiestas de la colectividad que congregan la mayor cantidad de gente son los carnavales en el mes de febrero y la celebración del día de la independencia (6 de agosto) y de la Virgen de Urkupiña (15 de agosto) durante el mes de agosto. Otra fecha que se ha mantenido en el tiempo es la celebración del día de la "madre boliviana" en el mes de mayo. Las fiestas patronales fueron las primeras que aparecieron en la escena pública y se realizan anualmente en la ciudad de Córdoba desde los años ochenta. La más importante en virtud de su poder de convocatoria es la fiesta de la Virgen de Urkupiña, la cual se celebra en Villa El Libertador desde el año 1982 y en los barrios Villa Azalais y Las Flores; la otra es la de la Virgen de Nuestra Señora de Copacabana en Villa General Bustos (Giorgis, 2004). Desde el año 2003, numerosas agrupaciones folklóricas desfilan por las calles del centro de la ciudad en ocasión de las vísperas del día de la independencia de Bolivia.

los ataques gubernamentales dirigidos a los inmigrantes de países limítrofes que cuenta con una amplia circulación entre los residentes bolivianos en Buenos Aires, posee una corresponsalía en Córdoba. 


\section{La Forestieri, una escuela en la periferia}

La escuela Vicente Forestieri es una institución educativa de nivel primario de carácter estatal ubicada en Villa El Libertador. Según la versión más difundida entre los habitantes de "La Villa", como la denominan los vecinos, el origen del barrio se remonta a la década del treinta. ${ }^{411}$ Fue inaugurado en el año 1932 bajo el nombre de "Villa Forestieri" en alusión a quien fuera el "fundador" del barrio: Vicente Forestieri, un inmigrante italiano propietario de un predio de un centenar de hectáreas que ejercía el oficio de sastre y que a modo de promoción ofrecía a cada comprador de un traje cuyo costo fuere de 49 pesos un terreno de 300 metros cuadrados. El ofrecimiento incluía mil ladrillos para iniciar la construcción de la vivienda y la posibilidad de visitar los terrenos en un ómnibus que el propio Forestieri manejaba. Se distribuyeron 2.000 de los 6.000 lotes que constituían "Villa Forestieri". Desde sus comienzos el barrio contó con un tanque de agua comunitario, un servicio de salud y dos escuelas ${ }^{412}$.

En el año 1950, en ocasión del centenario de la muerte del General San Martín, el barrio fue rebautizado como "Villa El Libertador". Durante esta década y la siguiente tuvo un importante crecimiento poblacional, al cual contribuyó la instalación en 1955 de la fábrica automotriz Kaiser (IKA, Industrias Kaiser Argentina, asociada a fines de los sesenta y adquirida a mediados de los setenta por la empresa Renault), que constituyó el lugar de trabajo de muchos de los habitantes del barrio. En la zona de la plaza principal de "La Villa" se instalaron pequeños negocios, se abrieron lugares de esparcimiento como el Bochín Club Social y Deportivo y se levantó un templo católico, convertido más adelante en la capilla Nuestra Señora del Trabajo (establecida como parroquia desde 1987), alrededor de la cual tendrá lugar a comienzos de los años ochenta la celebración de la fiesta de la

\footnotetext{
411 La información sobre el origen del barrio ha sido reconstruida fundamentalmente a partir de una nota escrita por alumnos y docentes de la escuela primaria Vicente Forestieri publicada en el periódico local "Viento Sur", el artículo del diario la Voz del Interior titulado "Villa El Libertador, un mojón de historia urbana” y el primer número de la revista Historias de Córdoba. Relatos de la ciudad (2005).

412 Producto de un taller de historia oral, en una publicación patrocinada por el CPC de Villa El Libertador de la Municipalidad de Córdoba se relata de esta manera la instalación de las primeras escuelas en el barrio: "Las dos primeras escuelas de Villa Forestieri fueron la Escuela Provincial Blas Parera y la Escuela Provincial № 26. La primera se encontraba en Pasaje 12 y Avenida de Mayo; la segunda, inauguada en 1993, funcionaba en el chalet construido por Vicente Forestieri en la calle Anizacate y Tilcara. La Escuela Blas Parera al tiempo se mudó de la Villa, pero la escuela № 26 comenzó su itinerario por diferentes lugares. Primero se mudó al frente y funcionaba en la casa de los Mercado, luego a la calle Anizacate y Provincias Unidas en lo de Antonia Contreras, luego a Avenida de Mayo y Cosquín en lo de Don Jorge ya como Patricias Mendocinas hasta que por fin en 1958 contó con un edificio propio en la calle Reconquista y Patricios. Desde el 2004 cuenta con un edificio nuevo en el mismo lugar" (Historias de Córdoba. Relatos de la ciudad, Año 1, № 1, 2005).
} 
Virgen de Urkupiña a partir de la iniciativa de un grupo de inmigrantes bolivianos. Con el tiempo los locales de negocios se extendieron a lo largo de sus calles principales y junto a la feria establecida en la plaza central durante los fines de semana se forma un núcleo comercial con capacidad para abastecer a los habitantes del barrio y de zonas aledañas. A mediados de los noventa se inauguró a la "entrada" de Villa El Libertador, sobre la ruta que se dirige a Alta Gracia, el Centro de Participación Comunal (CPC) № 6, que desarrolla ciertas actividades en coordinación con el Centro Vecinal. También el Centro Cultural despliega acciones que convocan a la comunidad. Además de la parroquia Nuestra Señora del Trabajo, la iglesia evangélica MEDEA (que cuenta con una escuela y un club) congrega un importante sector de la población del área sur, entre ellos una significativa cantidad de inmigrantes bolivianos. Entre las organizaciones no gubernamentales, dos desarrollan diversos proyectos en Villa El Libertador desde hace varios años: el SEHAS (Servicio Habitacional y Social) y CECOPAL (Centro de Comunicación Popular y Asesoramiento Legal), organización que cuenta además con la Radio FM Sur, instalada en el barrio.

Cualquier descripción de "La Villa", por más breve que sea, que no haga alguna referencia a la capacidad de organización y resistencia de sus habitantes estaría incompleta. Es que la historia del barrio es en gran medida la historia de "las luchas" de sus habitantes, como ellos mismos las llaman, llevadas a cabo para enfrentar y denunciar la marcada desigualdad y marginación que estructura la vida en el barrio. Desde los años sesenta los vecinos -hombres y mujeres, militantes sociales y políticos, nucleados en organizaciones comunitarias de base como la Multisectorial (la "Multi")- se han movilizado para reclamar ante las autoridades gubernamentales por servicios sociales básicos como agua potable, electricidad y transporte urbano, además de conseguir la creación de servicios públicos de salud y educación y las condiciones materiales indispensables para su desarrollo. La cooperativa ArPeBoCh (formada, como lo indican sus siglas, por argentinos, peruanos, bolivianos y chilenos), por su parte, ha venido peleando desde mediados de los noventa por la escrituración de los terrenos fiscales que obtuvieron en su momento y el acceso al agua potable y la energía eléctrica. Entre los reclamos actuales figuran todavía el alumbrado público, el asfalto en las calles y una mayor presencia de la policía. Este "espíritu de lucha", asumido como una característica distintiva de Villa El Libertador, es destacado también en uno de los informes de la escuela:

La escuela se encuentra en un barrio, que históricamente ha sido injustamente postergado en el reparto de bienes, obras municipales e infraestructura de servicios, pero con aspiraciones, luchas y sueños, para lograr un mejoramiento de su calidad de vida. Villa El Libertador es un barrio de larga y rica historia de 
luchas en la búsqueda por superar la marginación y el olvido al que están sometidas las comunidades más pobres.

La escuela Vicente Forestieri empezó a funcionar en el año 1993 como "anexo" de otra institución educativa de la zona y se inauguró oficialmente el día 30 de mayo del año 1995. Al principio era "la escuela sin nombre", como indica una maestra (Mercedes). No tenía nombre propio, más bien prestado, como una extensión de otra ya existente: era la "Patricias Mendocinas Anexo". El actual nombre de la escuela se definió recién dos o tres años después de su creación a través de una consulta entre padres, alumnos y docentes. Les pareció que Vicente Forestieri era pertinente porque había sido el fundador del barrio: “Con poca información aparte, porque en realidad tampoco teníamos mucha idea de quién era Vicente Forestieri y todo eso... simplemente que vendía trajes y que otorgaba terrenos, nada más...". Este proceso no estuvo exento de tensiones porque al perder el nombre original se perdía también el cobro de la "zona desfavorable" con lo cual algunos docentes se negaban a ponerle o cambiarle el nombre (Mercedes).

El edificio de la escuela, aunque visto desde arriba tiene una distribución rectangular, desde el frente la forma circular de uno de los volúmenes (el SUM o salón de usos múltiples) que se articula con las galerías laterales, junto con el amarillo intenso -pero deteriorado- de las paredes y el verde de los techos inclinados, le otorga un aspecto menos formal del que tienen muchas instituciones educativas de la ciudad. El ingreso de la escuela no tiene puerta, sólo unas rejas deslizantes separan el exterior del interior, dándole una extraña mezcla de transparencia, vulnerabilidad y aspereza. Al lado derecho de la entrada principal se encuentran la sala de dirección, la sala de maestros y la biblioteca y al lado izquierdo el SUM, donde funciona el comedor (años más tarde será subdividido y se trasladará también allí la biblioteca). Las aulas están ubicadas a lo largo de las amplias galerías laterales y en el medio se extiende un gran patio abierto con el mástil (poco tiempo después se lo apartará del centro), donde flamea todos los días la bandera argentina, conectado con el edificio del nivel inicial. Las paredes internas muestran pinturas de los alumnos y alumnas realizadas con la profesora de plástica (en el año 2002 con el ingreso de la nueva directora) que, junto con el rojo furioso de las aberturas, evocan un espacio infantil y alegre. Algunos años después de su creación, en respuesta a los reclamos de la comunidad educativa por la "inseguridad", se agregó un cerco perimetral de alambrado metálico que reforzó el aspecto de prisión que, en alguna medida, ya insinuaban las rejas deslizantes de la entrada principal. La escuela está situada en los márgenes del barrio -en sus comienzos era una zona descampada y posteriormente 
se pobló con la construcción de un "barrio-ciudad", una especie de ghetto ${ }^{413}$ urbano formado por las políticas provinciales de relocalización de asentamientos marginales como las llamadas "villas miseria"- y está rodeada por calles de tierra en malas condiciones (que más adelante serán asfaltadas) y casas uni y multifamiliares, construida la mayoría de material, protegido el frente generalmente con rejas. Atrás de la escuela, donde se extiende la zona conocida como Cooperativa $\mathrm{ArPeBoCh}$, se encuentran viviendas más precarias, algunas construidas con chapa y madera. Así se describe el entorno de la escuela en uno de los informes escolares:

Actualmente la calle sobre la que se sitúa la escuela se encuentra pavimentada (desde mediados del 2004), las calles circundantes son de tierra y a dos cuadras de la escuela se extienden campos sembrados con soja en la mayor parte del año. El barrio es oscuro por las noches, siendo las luces de la escuela las únicas fuentes lumínicas para entrar al ARPEBOCH y muy inseguro en cualquier momento del día. El barrio es muy poblado, con viviendas precarias, con terrenos muy pequeños (menores a las medidas estándar), no hay veredas y se observan muchos terrenos invadidos por yuyos y desperdicios. Si bien se ha finalizado la obra de desagüe de las calles, los días de lluvia continúan siendo una dificultad, ya que las mismas detrás de la escuela están en un nivel más alto, corriendo agua hacia la calle de acceso pavimentada (esto se ve agravado por los sembradíos de soja que impermeabilizan los suelos).

La escuela comenzó funcionando con seis aulas y un comedor. En la actualidad cuenta con seis aulas y veinticuatro secciones, una mitad en el turno mañana y la otra en el turno tarde, una sala de usos múltiples (SUM), donde funciona el comedor (más adelante será subdividido y se incorporará la biblioteca), una sala de dirección, una sala de maestros, una cocina y baños para alumnos y maestros. El turno mañana funciona de 8:00 a 12:00 horas y el turno tarde de 13:30 a 17:30 horas. Al mediodía está abierto el comedor del PAICOR, donde los alumnos reciben su "copa de leche" y el almuerzo (por turnos). La jornada escolar dura cuatro horas y posee dos recreos de quince minutos cada uno, cuyo comienzo y final no es comunicado por el timbre, sino por la propia maestra.

La escuela está vinculada con una serie de instituciones -algunas con las cuales trabaja en red- como el UPAS 23, el Hospital Misericordia, el Centro Cultural de Villa El Libertador, el 
Club de Las Estrellas, la Radio FM SUR y la Multisectorial. La escuela mantiene una estrecha relación con "La Casita" desde su formación, un centro comunitario de formación y capacitación docente que desarrolla diversos talleres y proyectos a partir de las demandas que plantean las maestras o del ofrecimiento que reciben de otras instituciones. Si bien es apoyado económicamente por el gobierno de la provincia de Córdoba, fue conseguido por iniciativa de algunos integrantes de la Multisectorial (entre ellos, la ex directora de la escuela Vicente Forestieri).

En función de la categoría asignada a la escuela por el Ministerio de Educación de la Provincia en base a la cantidad de alumnos y las condiciones socioeconómicas de las familias y del barrio (Grupo C, zona desfavorable), la institución es destinataria de diversos proyectos nacionales y provinciales dirigidos a poblaciones escolares "desfavorecidas". Entre los principales programas gubernamentales de carácter nacional y provincial adoptados en la escuela a lo largo de estos años se encuentran: el Programa Integral para la Inclusión Educativa (PIIE), el Programa Nacional de Inclusión Educativa (PNIE), el Programa Integral para la Equidad Educativa (PIEE), el programa de Asistencia Técnica Escuela y Comunidad (ATEC) y los proyectos Aulas Unidas Argentinas, Autonomía Escolar, Ayudar a Mirar y Rehacer la Escuela en Contextos de Pobreza y Exclusión Social.414

La cantidad total de alumnos varía de año a año, pero generalmente supera los quinientos. Cada sección cuenta con un promedio de veinte alumnos y alumnas. La información estadística oficial sobre matrícula escolar, correspondiente al año 2001, indicaba que era la escuela primaria con la proporción más alta de alumnos extranjeros ${ }^{415}$, básicamente hijos o nietos de inmigrantes bolivianos, nacidos en Bolivia. Si se considera la nacionalidad de los alumnos, la cifra de extranjeros siempre ha sido menor al diez por ciento. Pero si se toma en cuenta el origen nacional de los padres o abuelos de los alumnos, según algunos directivos y docentes la cifra ascendería al veinticinco por ciento aproximadamente; en cada sección habría de cuatro a cinco alumnos o alumnas cuyos familiares son de origen nacional boliviano. De acuerdo a la revisión que realicé de los registros de asistencia del año 2002, donde se puede identificar a los alumnos y alumnas hijos o nietos de bolivianos nacidos en Bolivia o Argentina a partir del apellido (los alumnos bolivianos a diferencia del resto llevan doble apellido, tanto el del padre como el de la madre), su número de DNI y/o

414 Véase Beltramone et al. (2010) para una descripción de estos programas educativos y proyectos escolares.

415 En el caso de la información educativa disponible, como en la mayoría de las fuentes estadísticas secundarias, se utiliza la categoría "extranjero" para diferenciar la población nacida en otro país de la "nativa", adoptando como criterio de clasificación el carácter jurídico de la nacionalidad. 
la nacionalidad de los padres/madres, alrededor del 15\% sería hijo/a de una pareja de bolivianos.

En un documento escolar se precisan algunas cuestiones referidas al desempeño escolar de los alumnos de la escuela. Considera que "en el Primer Ciclo hay un elevado índice de inasistencias, que se revierte en la medida que los niños van adquiriendo autonomía y resuelven por sí mismos asistir a la escuela, observándose en los últimos grados asistencias completas y sostenidas a lo largo del año escolar". La "inasistencia reiterada" es atribuida a la carencia de "elementos necesarios para su vestimenta, zapatillas, abrigos, impermeables, etc.".

Según este informe escolar, el "mayor índice de repitencia" se encuentra en los primeros años, especialmente en primer y segundo grado. Las causas de este fenómeno son asumidas como dificultades que precisan ser resueltas en el orden de lo psicológico: "Muchos niños de estos grados son derivados a psicólogos y psicopedagogos para un diagnóstico, ya que se observa dificultad en la organización del pensamiento, en la formación de hábitos y desconocimiento del nuevo espacio que deben transitar". Considera que la sobreedad existente en la escuela es "heredada". Por ello se entiende que "en su mayoría son niños que no han sido escolarizados a tiempo y no [han sido] aceptados por escuelas de su entorno o bien chicos repitientes de otros establecimientos que no los han contenido". Prácticamente no se registran casos de deserción escolar (sólo dos) y el desgranamiento de la matrícula sería "poco significativo", producido mayormente "por cambio de domicilio" (se aclara que según el seguimiento realizado se ha podido comprobar que "los alumnos asisten a escuelas de sus nuevos barrios"). Como parte del desempeño escolar, el informe también precisa que "en los niños mayores suele persistir la violencia como forma de juego".

El informe subraya, asimismo, la incidencia de la "desnutrición infantil" en el marco del desempeño de los alumnos. Según el relevamiento realizado por personal de Salud Familiar y del UPAS 23 en el Jardín de Infantes y en primer Grado, alrededor del 21\% de la población escolar estaría afectado por la desnutrición. Un dato significativo es la alta proporción de alumnos que realiza alguna comida en la escuela, ya sea a través de la "copa de leche" como del almuerzo. De los 525 niños que asisten, 453 toman "copa de leche" y 456 almuerzan en el comedor escolar.

También se destaca que "la comunidad estudiantil que asiste a la escuela está formada por niños de extrema pobreza en su mayoría" y que "pertenecen a comunidades bolivianas, 
peruanas, chilenas, argentinas". Se precisa, asimismo, que a la escuela asisten "los niños del llamado ARPEBOCH", definido como un "barrio cooperativo integrado por familias de diversas nacionalidades, bolivianos en su mayoría". También destaca que allí se encuentra "la comunidad boliviana más grande de Córdoba y una de las más grandes del país".

De acuerdo al documento, el grupo docente está compuesto por 33 maestros/as de grado, mujeres en su mayoría, de los cuales 22 son titulares, 6 interinos, 3 suplentes y 2 de ramos especiales. El equipo directivo está constituido por una directora y dos vicedirectoras. Hay una alta movilidad de docentes en la escuela, especialmente en el turno tarde (las maestras eligen generalmente el turno mañana al momento de su titularización), lo cual afecta de manera significativa el desarrollo de los proyectos escolares. La dificultad para contar con "personal estable" es destacada por la propia institución y -en uno de sus informes- es atribuido a la gran distancia existente entre la escuela y el hogar y la escasa frecuencia y de líneas de transporte público. Informalmente, algunas maestras, por su parte, también admiten que cuando tienen la posibilidad de elegir, además de buscar escuelas más "cercanas", prefieren escuelas menos "conflictivas", menos "problemáticas", menos "violentas". Estos calificativos, como veremos más adelante, no sólo remiten al modo en que experimentan la vida cotidiana en la escuela, sino también a las características que les atribuyen a los alumnos en general.

La mayoría de las docentes ${ }^{416}$ que estaban presentes en la escuela cuando hice mi ingreso en el año 2002 se había incorporado a la institución entre los años 1997 y 2001. Algunas, incluso, ya estaban desde los inicios de su formación, cuando todavía no tenía edificio propio y dependía de la escuela Patricias Mendocinas. Egresaron de institutos de formación docente de carácter público y al momento de conocerlas la mayoría no tenía más de diez años de antigüedad en la docencia. Es importante destacar que dos maestras de la institución son hijas de inmigrantes bolivianos, una de ellas nacida en Bolivia (la cual tuvo que nacionalizarse para poder ejercer como docente). Varias maestras conocen el barrio y sus habitantes desde pequeñas, ya que han nacido o gran parte de sus vidas ha transcurrido en él. Muchas de las maestras titulares actuales habían trabajado previamente en otras escuelas primarias o asociaciones civiles o religiosas de la zona sur y/o en esta institución como personal ad-honorem, suplente o interino. El acceso a la titularización de buena parte de ellas ocurrió en el año 1999 cuando José Manuel De La Sota asume la gobernación de la provincia de Córdoba. La dirección de la escuela estuvo

416 Es sabido que la docencia primaria es un ámbito donde las mujeres tienen una presencia mayoritaria. A excepción de uno o dos varones, la mayoría de los docentes de la escuela son mujeres. Debido a ello, cuando se hace referencia al conjunto de maestros y maestras de la institución se acude al modo plural femenino. 
ocupada de manera interina hasta el año 2002, cuando ingresó la primera directora concursada.

Los motivos de la elección de la escuela difieren según el momento de la carrera docente. Al inicio, la elección se limita a unas pocas opciones y hasta pueden llegar "reubicadas". La verdadera elección de la institución ocurre al momento de seleccionar una donde hacer efectiva su titularidad. Más allá de estas diferencias, entre los principales motivos para elegir la escuela aparecen la cercanía entre el edificio de la institución y la vivienda y las características del entorno social de la escuela, marcado por la pobreza -en ocasiones, el contexto económico "desfavorable" es visto como un "desafío" para algunas maestras-, la presencia de la llamada "comunidad boliviana" y el "espíritu de lucha" con el que se suele caracterizar y se identifica a los habitantes de "La Villa". En general, esta segunda razón cobra fuerza después de transcurrido un tiempo de trabajo en la institución, sin que haya sido uno de los motivos principales para ingresar a la escuela. En algunos casos, puede aparecer relacionado a experiencias subjetivas e identitarias ligadas a una identificación con aspectos materiales y simbólicos de la "bolivianidad", que son valorados positivamente, como veremos más adelante.

Los recuerdos de la llegada a la escuela y de los primeros días y meses en ella, sobre todo de las maestras más antiguas, se relacionan básicamente con las carencias materiales de la zona y de la institución o con los temores y miedos que produce la inestabilidad docente, más aún con la llegada de un nuevo gobierno provincial.

Llegué el 23, el 23 de febrero [de 1998 o 1999, no recuerda bien], llovía a mares, no podía cruzar la calle, al otro día ya nos compramos botas porque era imposible... nos tuvimos que descalzar, era imposible, era de tierra la calle... (Pilar)

[...] recuerdo que cuando ingresé a esta escuela... yo tuve que debutar dando clases en una casita que había alquilado el gobierno, que queda acá a unos metros sobre la Río Negro, con un cuarto grado con 17 alumnos (Silvana)

Fue una llegada así complicada a la escuela, porque la escuela en ese momento estaba con la gente que prácticamente la había fundado, porque era la gente que estaba desde el principio, que estuvo en toda la historia de la escuela, desde cuando... al principio no tenía mesas, no tenía sillas, había que salir a buscar a las casas y bueno... entonces la comunidad [educativa] estaba muy 
mal, muchas maestras se tenían que ir porque eran interinas... [...] Fue justo cuando se iba Mestre y entraba De La Sota, el primer mandato de De La Sota [1999]. Bueno, en ese momento, llego a la escuela en un segundo grado, en junio, con toda esta problemática de padres muy enojados porque hacía años que habían prácticamente visto o trabajado mucho para que la escuela comenzara a funcionar, se iban con malestar algunas compañeras... [...] Fue todo bastante complicado [...] [Las maestras interinas se fueron a mitad de año porque tenían miedo que después se les negara la titularidad] El colegio contaba... tenía seis aulas, seis secciones, era un colegio con pocos chicos y todo descampado y abierto, pocas casas... me llamó mucho la atención eso, era como que no había nada de seguridad, los chicos podían ir y venir, cualquiera entraba, no había nada... Bueno, me tocó el segundo grado, en el turno de la mañana, veinticuatro, veinticinco chicos, un grupo muy tranquilo, fue una sensación rara, fue como fría por todo esto que estaba pasando... y porque la escuela te daba esa impresión en ese momento, un lugar tan abierto, hacía mucho frío... un lugar descampado... era como irte a otro lado, mirá que vivo acá en la zona, era como irte lejos, te daba esa sensación... esa fue mi llegada a la escuela... (Mercedes)

Para uno de los aniversarios de la escuela, las maestras prepararon un afiche donde se relata su origen. Allí se destacan ciertos aspectos que permiten situar algunos de los procesos y mecanismos sociales estudiados: 1) la creación de la escuela como logro de la comunidad (padres, madres y organizaciones barriales); 2) las precarias condiciones materiales bajo las cuales comenzó a funcionar (y siguió funcionando) la escuela; 3) una enseñanza respetuosa de "la cultura" de los alumnos y alumnas, donde todos aprenden.

Nuestra institución, Vicente Forestieri, se inicia en el año 1995, luego de una larga demanda protagonizada por la comunidad y la multisectorial de Bo Villa El Libertador solicitando a las autoridades provinciales, la apertura de escuelas primarias en este sector. Funcionó primeramente como anexo de la Escuela Patricias Mendocinas. Comienza con sólo seis aulas y un comedor. Las familias de la comunidad sostuvieron solidariamente el inicio de las clases aportando elementos como mesas, sillas y bancos, hasta la entrega del mobiliario por parte del Ministerio. Nuestra escuela tiene un fuerte espíritu comunitario, donde autoridades y maestros enseñan respetando la cultura de los educandos: el alumno aprende y el docente también. (Afiche elaborado por maestras/os, 29/05/2008) 
El traslado de la escuela a la ubicación actual del edificio se produce junto con el establecimiento y posterior crecimiento de un conjunto de viviendas precarias -en los comienzos habitantes del barrio denominaban despectivamente esta zona como "Villa Las Tablitas", debido a que en aquél entonces la mayoría estaba construida con maderas y chapas- que fueron levantadas mayoritariamente por familias de inmigrantes, en especial provenientes de Bolivia. En alusión a los residentes bolivianos, denominados de manera despectiva como "bolitas", también se la llama peyorativamente "Villa Los Rulemanes". Así me lo explicaron: ¿Qué tienen adentro los rulemanes? Bolitas.

Durante los primeros meses la escuela no contaba con los recursos básicos necesarios para que se pudieran desarrollar las clases regularmente. Fue con la participación de la comunidad que se hizo posible.

Fue una llegada así complicada a la escuela, porque la escuela en ese momento estaba con la gente que prácticamente la había fundado, porque era la gente que estaba desde el principio, que estuvo en toda la historia de la escuela, desde cuando... al principio no tenía mesas, no tenía sillas, había que salir a buscar a las casas y bueno... entonces la comunidad [educativa] estaba muy mal, muchas maestras se tenían que ir porque eran interinas... [...] Fue justo cuando se iba Mestre y entraba De La Sota, el primer mandato de De La Sota [año 1999]. Bueno, en ese momento, llego a la escuela en un segundo grado, en junio, con toda esta problemática de padres muy enojados porque hacía años que habían prácticamente visto o trabajado mucho para que la escuela comenzara a funcionar, se iban con malestar algunas compañeras... [...] Fue todo bastante complicado [...] [Las maestras interinas se fueron a mitad de año porque tenían miedo que después se les negara la titularidad] El colegio contaba... tenía seis aulas, seis secciones, era un colegio con pocos chicos y todo descampado y abierto, pocas casas... me llamó mucho la atención eso, era como que no había nada de seguridad, los chicos podían ir y venir, cualquiera entraba, no había nada... Bueno, me tocó el segundo grado, en el turno de la mañana, veinticuatro, veinticinco chicos, un grupo muy tranquilo, fue una sensación rara, fue como fría por todo esto que estaba pasando... y porque la escuela te daba esa impresión en ese momento, un lugar tan abierto, hacía mucho frío... un lugar descampado... era como irte a otro lado, mirá que vivo acá en la zona, era como irte lejos, te daba esa sensación... esa fue mi llegada a la escuela... (Mercedes) 
La participación de la comunidad en la creación de la escuela -desde reclamar un edificio propio hasta conseguir sillas y mesas para que los/as hijos/as pudieran tener clases en las aulas- marcará la vida escolar de manera permanente a lo largo de los años. Con la llegada de la nueva directora en el año 2002, se empezó a promover y facilitar espacios para que la comunidad pudiera participar "desde adentro" y no sólo "desde afuera". Antes, según el testimonio de una maestra, "era solamente venir y dejar los chicos o venir a una reunión, nada más [...] De la manera que se trabaja ahora con la comunidad, nunca, no" (Mercedes). A partir de ese momento, casi todos los años se realizaron diversas protestas, especialmente al comienzo del ciclo lectivo, dirigidas al Ministerio de Educación, adoptando como modalidad de lucha la "toma" de la escuela. ${ }^{417}$ De acuerdo al testimonio de las maestras, este procedimiento de lucha popular se empezó a utilizar con la llegada de la nueva directora, quien favoreció la participación activa de la comunidad del barrio en la escuela y avaló dichos mecanismos de protesta, lo cual le trajo diversas dificultades con las autoridades del Ministerio de Educación. La primera tuvo lugar en el año 1998, al oponerse un grupo de madres y padres (sobre todo madres) a la salida de maestras interinas atemorizadas por su estabilidad laboral con la asunción de José Manuel De La Sota a la gobernación. Posteriormente, las protestas estuvieron motivadas (en su mayoría) por las condiciones materiales del edificio, lo cual constituye todo un símbolo del descuido/desinterés y abandono estatal que sufren diversas escuelas públicas situadas en zonas pobres y periféricas de la ciudad.

Un grupo de madres "combativas" (así se autodenominan y las consideran algunas maestras), preocupadas por el estado del edificio escolar, tomaron la escuela hacia fines del año 2007. Esta vez, su reclamo iba más allá: "un edificio nuevo para nuestros hijos en el mismo lugar". Argumentaban que el deterioro y el tamaño del establecimiento imposibilitaban que los alumnos y alumnas recibieran "la mejor educación" e interpelaban directamente al Ministro de Educación para que le "brinde a nuestros hijos la posibilidad de estudiar como todos los niños de Córdoba". La mayoría de los reclamos pasaron por las condiciones edilicias de la escuela: grietas en las paredes, techos de chapa sueltos, filtraciones de agua, frío y calor en exceso, baños sin funcionar, falta de iluminación en patios internos y externos, entre otros. Al cabo de casi un mes sin clases, lograron que el Ministerio de Educación se comprometiera a construir un edificio nuevo. En el año 2008, después de un arduo proceso de negociación, el organismo público accedió a los reclamos de la comunidad y comenzó a construirlo.

417 Precisamente, mi entrada y salida del campo coincidieron con una toma de la escuela. 


\section{La "escuela del fondo"}

"Nosotros no somos los peores", aclara la directora de la escuela durante la entrevista mantenida con ella. En distintos testimonios, la escuela Vicente Forestieri aparece representada como la "escuela del fondo". Esta denominación estigmatizante sintetiza la marginalidad/marginación espacial y la marginalidad/marginación social que está inscripta como marca en la escuela, grabada en las representaciones que circulan sobre ella tanto adentro como afuera. Se relaciona, por un lado, con su lugar en el espacio geográfico y las carencias de infraestructura, su ubicación en los límites del barrio Villa El Libertador, los confines de lo urbano y, por el otro, con su ubicación en la jerarquía de las instituciones escolares (buenas y malas escuelas) establecida fundamentalmente de acuerdo a la clase social de los alumnos que atiende $y$, consecuentemente, la realidad social que atraviesa sus vidas, en particular las características atribuidas al entorno familiar. Esta institución como tantas otras de la periferia urbana concurridas por alumnos de sectores sociales marginados o excluidos es vista desde afuera como una escuela de negros, expresión que condensa lo que Margulis (1999) llama la racialización de las relaciones de clase. La "escuela del fondo" representa a la vez la escuela en los márgenes y la escuela de los márgenes. Frente a la pregunta por qué la llaman la "escuela del fondo" una de las maestras más antiguas responde:

Porque es la última que está, digo yo, que debe ser... porque no es la escuela del fondo, para eso tiene un nombre... debe ser porque es la última escuela y porque primero está la Juana Manso, está la Patricias [Mendocinas] y después estamos nosotros. Entonces por eso no se les ocurrió nada mejor que decirle la escuela del fondo... [...] No es que se la llame así, alguien... algunos le dicen así... no sé si lo dicen por la ubicación o por la forma despectiva... no tengo idea, pero no es que... ¿Vos adónde vas? Y, yo voy a la Vicente Forestieri, no voy a decir a la escuela del fondo. La escuela del fondo no es un nombre, ¿me entendés? [...] Yo pienso que [le dicen] la escuela del fondo porque es la última escuela y ya estamos lindando con los campos, pero ahora hay otro barrio nuevo cerca de los campos, Ampliación Cabildo, así que ya no es tanto la escuela del fondo, porque si vamos a la escuela del fondo tenemos la [nombre de la escuela], ésa está más al fondo, o no? [...] Te digo que en todas las escuelas se cuecen habas. Partamos de ahí. Yo voy a ciertas escuelas... no voy a dar nombres... la escuela donde yo doy, un secundario, [me preguntan] iy 
adónde das clases? En tal lado... Esa es una escuela de negros, de "negros de m". No te voy a decir nombres... ¿me entendés?" (Pilar)

Sobre todo durante sus primeros diez años de existencia, la ubicación de la escuela en los márgenes del barrio, bajo la imagen de una zona relegada y un lugar "descampado", que ni siquiera aparece (oficialmente) en los planos de la ciudad, le transmitía a las maestras sensaciones de "miedo" o "inseguridad".

Es la escuela del fondo, inclusive si vos te fijás en los planos no hay calles ahí, ahí es todo descampado, es como que ahí terminó... mirá que hemos pedido planos, lo más moderno que venga y en Villa El Libertador no hay... no están en el plano... las calles... es como que ahí lo dejaron... (Gloria)

Es más, a mí me daba en un primer momento... no sé si la palabra es miedo, pero como inseguridad venir y yo no soy una persona que tenga miedo ni nada, te digo, vivo acá y conozco a la gente, pero era como un lugar que no conocía, como que era la escuela del fondo, estaba todo descampado y como que te daba esa sensación fea llegar a la escuela... (Mercedes)

Visto retrospectivamente, la directora que tomó posesión de su cargo en el año 2005, asume que al cabo de quince años de existencia, la escuela, en tanto comunidad educativa, ha dejado de ser la "escuela del fondo", lo cual da cuenta del proceso de construcción social que está detrás de esta operación. Para ello, entendiendo que dicho estigma -así lo denomina- se constituye en torno a la ubicación geográfica del edificio escolar, se apoya en el lugar marginal que deja de ocupar con la aparición de un nuevo complejo habitacional, conocido como "ciudad-barrio", en una zona aledaña. Como veremos enseguida, en su relato también emerge la noción de "fondo" relacionado con "lo peor", noción que connotaría la violencia física que se manifiesta cotidianamente entre los alumnos y el estilo de gestión laissez faire que se inició con la directora que ingresó en el año 2002.

Algunos de los criterios de organización del espacio escolar, alejados de normas instituidas en la vida cotidiana de las instituciones educativas, vividos por esa razón como cambios en la escuela, colaboraron para que dicho estilo de gestión fuera considerado de esta manera: el uso del timbre fue reemplazado por el uso de música para comunicar el inicio y la finalización del recreo; la portación individual de la bandera en los actores escolares fue desplazado por un grupo de abanderados; la formación de filas tanto en el 
aula como en el patio fue sustituida por el "agrupamiento" (como lo denomina la directora).

Paradójicamente, las luchas y demandas, apoyadas por las sucesivas directoras -nada más lejos de la idea de laissez faire- y que llevaron adelante un grupo de madres para conseguir la atención del Ministerio de Educación y resolver los problemas edilicios de la escuela, contribuyeron a que se los considerara como "los peores": "Los que hacen la toma, los que enfrentan al gobierno, porque también estamos vistos como los peores". (Carmen)

¿Qué es la escuela del fondo? / La escuela del fondo era... mirá, te digo `era'... Yo por ahí me pongo que no somos la escuela del fondo porque está el barrio nuevo... [...] Yo creo que la `escuela del fondo’ era geográficamente y [era] la escuela del fondo porque estaba al fondo, en un momento estábamos al fondo, terminaba el barrio y estaba el fondo. Yo también la llamaba [ya antes de ingresar como docente de la institución] la escuela del fondo [...] Y cuando tomé la escuela ¿qué me dijeron? Es la escuela al fondo del barrio. Y así llegué. Y pregunté: ¿dónde está la escuela? Al fondo (risas). Bajé ahí en la esquinita y ¿dónde está la escuela? Al fondo. [...] Todos decíamos la escuela del fondo, te digo decíamos porque ya no es la escuela del fondo, yo creo que logramos salir de ese estigma. / Entonces no es sólo por la ubicación espacial... / Y sí... como que el estigma lo determinaba la cuestión geográfica, pero era la del fondo y hasta en algún momento se decía `está lo peor allá y lo peor era por toda esta sintomatología de violencia, de falta de autoridad, falta de decisión, Carmen es muy blanda, a Estela se le decía que era una directora virtual, [tenía] ideas raras... (Carmen)

La "escuela del fondo" como escuela de los márgenes remite entonces a la marginalidad social que la atraviesa, establecida también a partir del deterioro del edificio escolar, sumado a la escasez de recursos ${ }^{418}$, como de la composición de población escolar, formada en su momento por "lo peorcito".

\footnotetext{
418 Esta escasez de recursos también tiene efectos emocionales sobre las maestras que se proyectan en el trabajo áulico cotidiano. Así lo manifiesta la maestra de plástica: "Hay que tratar de huirle a la desesperanza, porque si no... por ahí me voy de acá me voy re-entusiasmada, bueno, voy a hacer... yo voy a trabajar esto, aquello y después ya llego a mi casa y me entra... o a la vuelta, cuando ya tengo que volver... que faltan cosas o medio complicado concretar..." (Marta).
} 
Había tenido oportunidad de pasar por acá, por la zona y dar una vuelta y era como la escuela del fondo, era... lo peorcito venía a esta escuela, tenía todas las calles de tierra, estábamos en esa época que la pobre estaba bastante como abandonada. (Valeria)

Aquí entran en juego las características que se le imputan a la población escolar a partir de su pertenencia de clase. Ligado a la violencia física que las maestras observan a diario en el medio escolar, los alumnos de la escuela son percibidos como niños con "problemas de conducta", los cuales derivarían de situaciones del hogar que involucrarían ilícitos, cárcel, episodios de maltrato y fragmentación familiar. Una maestra considera que, a diferencia de los alumnos de otras escuelas de la zona, los de esta institución "tienen más problemáticas sociales en las familias" (Valeria). Por otra parte, "lo peorcito" se relaciona con el hecho de que la escuela reciba alumnos repitentes o expulsados de otras instituciones, principalmente por motivos de conducta. Así lo manifiesta una maestra: “Acá lo que tenemos en esta escuela es que vienen de todos lados echados los chicos... [...] Vienen con una conducta... con unos informes de conducta terribles...". Para ilustrar esta afirmación narra una situación en la cual se encuentra con un alumno recién llegado de otra escuela, que a la pregunta de ella “¿porqué venís acá?”, él le responde "por la conducta". Después, al conversarlo con la directora, ella le dice que fue "orden del Ministerio" (Marta).

Así, la "escuela del fondo" es también aquella institución en la cual "entran todos". La falta de aplicación de los mecanismos de selección de otras instituciones contribuye a que persista el estigma que recae sobre la escuela. Como dice la última directora: "Sigue eso que nosotros recibimos a los peores”. Y cuestiona: "Pero vos decís `los chicos necesitan un lugar en la escuela', ¿qué es `entran todos'?”.

Algunas maestras, conscientes de las implicancias que tiene el rótulo de "escuela del fondo", si bien también la identifican como un espacio material y simbólico que encarna la marginalidad geográfica y social, se niegan a asumirlo como una realidad dada e intentan invertir el estigma mediante la idea de "escuela inclusora". Mientras que en las instituciones educativas de la zona (y también entre algunas docentes de la escuela) prevalece la idea de que esta escuela es un reservorio de malos alumnos, sobre todo identificados con "problemas de conducta", que recibe a los repitentes o expulsados de otras instituciones de la zona (las maestras y directoras nombran al menos tres), para otras maestras -sin estar necesariamente exentas de los mismos prejuicios que las demásse trata de una institución que aspira a transformar ciertas condiciones y relaciones 
sociales, guiadas por las nociones de "inclusión" e "igualdad" y recuperando la capacidad de lucha que han demostrado a lo largo de los años las madres de los alumnos.

¿Cuándo llegaste a la escuela ya se la denominaba así? / Sí, la escuela del fondo... Inclusive hay muchas chicas que les llegó el nombramiento a esta escuela y antes de empezar a trabajar querían dar una vuelta para ver cómo era la escuela y hay muchas maestras, comenta la señorita A., comenta que el marido la llevó y el marido le dijo: “acá se terminó la calle", porque antes todo esto era tierra, ahora está asfaltado, pasa el colectivo, se han hecho muchos adelantos, pero antes era todo tierra, barro, pozos, cuando llovía no podías cruzar, muchas veces nosotras hemos tenido que cruzar sacándonos los zapatos y embarrándonos porque no podías cruzar, todo eso era un río de agua... por ejemplo, eso de que un marido la llevaba a una señorita para que conociera la escuela un día anterior y le dijo "no, ahí, no vas a trabajar", porque realmente era una escuela que vos veías que era inaccesible, pero una vez que te metés adentro, que conocés la gente, que ves la fuerza que tienen... pero de a poco, si vos lográs conocer a esas personas que están ahí y que quieren el bienestar de los niños... es un poco como aceptar lo que tenés y mejorarlo, no quedarte con que no, esto no sirve, y no voy a hacer nada por ellos, no, es meterte en esto y tratar de transformarlo, porque eso está en uno mismo, en lo que a vos te hayan enseñado, en luchar... y uno trabaja con personas... yo, que me toca a mí los grados bajos, yo creo en mis... los niños de primer grado, de segundo, son chicos que si vos los hablás, ellos te escuchan, te escuchan... entonces está en vos tratar de llegar a ellos y no que ellos se parezcan a vos, entendés, porque pienso que ahí está el click que tenemos que hacer nosotros... [...] vos podés llegar a ellos cambiando vos [...] te empiezan a contar cosas y ya empezás a conocer la realidad, y ya los empezás a tratar de otra forma y a mirar de otra forma porque a lo mejor el nene es agresivo porque vivió todo ese clima de agresión en la casa... (Gloria)

Porque no queremos que nos digan la escuela del fondo, queremos que nos digan, mirá, una escuela que es inclusora, que es transformadora, porque tenés que cambiarle... la forma de ser de los chicos, que no estén diciendo no, acá no se puede, no, acá no me gusta, es la realidad que les toca, viven en Villa El Libertador y tienen que aprender a decir, no, no soy un villero, soy una persona que vive en La Villa, que trabaja, que me gusta ponerme un par de 
guantes porque he salido a juntar basura, y me lo gané y me lo compré, entendés, y no que digan [que] te lo robaste por ahí... (Gloria)

En esa línea, bajo la idea de una escuela transformadora, algunas maestras, identifican la "escuela del fondo" con un grupo de personas de la institución, diferente del resto, con voluntad de "lucha", que está dispuesta a modificar las relaciones de poder en la comunidad educativa, especialmente entre los docentes y los padres/madres y alumnos, y que no renuncia a obtener resultados concretos con estos alumnos que asisten a la escuela, considerados en su conjunto como "chicos con muchos, muchos problemas".

La escuela del fondo... ¿para mí? Según mi visión, la escuela del fondo es una escuela que se preocupa mucho... por lo menos la esencia de la escuela, te repito, o sea, por ahí las personas que integran el equipo les cuesta entrañarse de esa esencia, pero es fundamentalmente la lucha. Creo que el año pasado se vio reflejado en los padres, es escuchar a los padres, es que los padres puedan intervenir, comprometerse con la escuela y ser parte, es escuchar a los chicos y que los chicos... también puedan opinar y decidir cosas... y es una escuela que tiene chicos con muchos, muchos problemas, pero que, bueno, seguimos intentando que estos chicos... o sea, para nosotros es como un logro muy importante que los chicos puedan hacer cosas... (Mercedes)

La noción de "escuela inclusora" vendría a ser, precisamente, la contracara de aquella institución que expulsa a la vez que se desentiende de determinados alumnos considerados "problemáticos", es decir, una escuela abierta, una escuela que recibe alumnos echados y rechazados en otras instituciones, tanto estatales como privadas, o cuya escolarización -según los parámetros de edad establecidos oficialmente- es tardía.

¿En qué sentido es inclusora la escuela? / Y porque vienen muchos chicos de otras escuelas y la escuela siempre está abierta para esos chicos, chicos que van de una escuela a otra y que les dicen no, acá no, acá, porque tiene muchas faltas, porque nunca viene su papá a registrar la firma, porque su mamá está presa... [¿De escuelas públicas...?] Sí, y también de escuelas privadas... [¿De la zona generalmente?] De la zona, tenemos de distintos... lugares, hay muchos chicos que vienen del interior también, hay muchos chicos que no han ido a primer grado... te estoy hablando del primer ciclo, no? [...] son chicos que a lo mejor no han ido nunca a la escuela y vienen muchos del interior, y en esta escuela, Vicente Forestieri, se los recibe... se les toma una evaluación de 
dirección para ver realmente en qué grado están... una cosa es que el papá y te diga... hasta que, bueno, se consiguen los papeles, la escuela los recibe, no es que les dice, no acá no pueden entrar, vaya busque otra escuela... [...] en esta escuela se los recibe, se les toma una evaluación y de ahí se los asigna, bueno, va a estar en primero, en segundo, en tercero... (Gloria)

En una conversación con una docente sobre la relación entre la escuela y los padres/madres de los alumnos, además de llamarla "escuela del fondo", se refiere también a la "escuela del olvido" (Silvana). Esta imagen de relegación y abandono se corresponde con la mirada que prevalece sobre el propio barrio. Como vimos anteriormente, Villa El Libertador es visto por la comunidad como "un barrio que históricamente ha sido injustamente postergado en el reparto de bienes, obras municipales e infraestructura de servicios", a la vez que se lo caracteriza como "un barrio de larga y rica historia de luchas en la búsqueda por superar la marginación y el olvido al que están sometidas las comunidades más pobres". En este sentido, la escuela Vicente Forestieri condensa, a pequeña escala, lo que representa Villa El Libertador: un lugar desatendido/abandonado por el Estado que sobrevive gracias a la lucha que lleva adelante la comunidad.

Ya construido el nuevo barrio aledaño a la escuela y hecha la mudanza al flamante edificio, durante una reunión del plantel docente, después que la directora volviera de una intensa jornada de capacitación, pregunta: “Qué queremos?”. Algunos plantearon: “Queremos que los chicos viajen, queremos ayuda, queremos capacitación...". No satisfecha con las respuestas, vuelve a preguntar: “QQué queremos como colectivo?”. Un docente le contesta: "Dejar de ser la escuela del fondo, porque ya dejamos de ser la escuela del fondo". Su respuesta muestra la persistencia de la carga valorativa, de la marca del estigma, que aún tiene la escuela como escuela de los márgenes a pesar de haber dejado de ser la escuela en los márgenes.

\section{Acceso restringido: los “indocumentados" y la ley Videla en las escuelas}

Mientras se mantuvo vigente y aún después, la ley Videla sirvió para legitimar numerosas prácticas de exclusión de los inmigrantes de países limítrofes, entre ellas el acceso a determinados servicios públicos como la educación. Apoyado en una visión sobre la inmigración asociada a la "amenaza", el Estado impedía o restringía el acceso a la educación de aquellos inmigrantes o hijos de inmigrantes que fueran extranjeros y se 
encontraran en situación de "indocumentados", violando el derecho a ella establecido en normas de jerarquía superior como la Constitución Nacional. En los años noventa, organismos de derechos humanos como el CELS denunciaron los diversos obstáculos que tenían los inmigrantes o hijos de inmigrantes que carecían de la documentación requerida en las escuelas para acceder a ellas y promocionar y acreditar sus estudios. Aunque en las escuelas primarias se producía una exclusión de hecho, en los centros de educación secundaria se desarrollaba una exclusión de derecho. En uno de sus documentos el CELS destacaba que "(l)os funcionarios de la Dirección de Enseñanza Media de la provincia de Córdoba restringen el ingreso de los chicos extranjeros que no acreditan certificados de residencia de la DNM, tal como lo exige, según señalan, la ley de migraciones" (CELS, 1999). La ley $N^{\circ} 22.439$ establecía que "los institutos de enseñanza media o superior, ya sean públicos o privados, nacionales, provinciales o municipales, solamente podrán admitir como alumnos a aquellos extranjeros que acrediten, para cada curso lectivo su calidad de 'residentes permanentes' o 'residentes temporarios', debidamente habilitados a tales efectos".

Hacia fines de la década, diversos documentos oficiales empezaron a contemplar el derecho a la educación de los alumnos extranjeros considerados "indocumentados". En 1998, los convenios migratorios firmados entre Argentina y dos de los países limítrofes, Bolivia y Perú, incluyeron el principio de igualdad entre nacionales y extranjeros en materia educativa, cubriendo explícitamente el derecho a la educación de aquellos niños cuyos padres estuvieran en una "situación irregular":

Los hijos de los inmigrantes gozarán en el territorio de las Partes, del derecho fundamental de acceso a la educación en condiciones de igualdad con los nacionales del país de recepción. El acceso a las instituciones de enseñanza preescolar o a las escuelas públicas no podrá denegarse o limitarse a causa de la circunstancial situación irregular de la permanencia de los padres.

Asimismo, algunos proyectos de ley de reforma de la ley Videla, algunos de los cuales también sirvieron de base para su derogación, contemplaron este derecho. A pesar de su carácter marcadamente restrictivo y punitivo, los proyectos de ley presentados por el oficialismo en dos ocasiones distintas para modificar la ley Videla contemplaba a los "residentes precarios" como posibles alumnos de las instituciones de nivel medio o superior. ${ }^{419}$

419 Expedientes № 6490-D-96 y № 7952-D-98. 
Los institutos de enseñanza media o superior, ya sean públicos o privados, nacionales, provinciales o municipales, solamente podrán admitir como alumnos a aquellos extranjeros que acrediten, para cada curso lectivo, su calidad de residentes permanentes o residentes temporarios o residentes precarios, debidamente habilitados a tales efectos.

El proyecto firmado por Juan P. Cafiero y otros en el año 1998, el cual promovía una regularización migratoria, iba más allá y proponía sustituir el artículo anterior por este otro:

Los hijos de inmigrantes, sin distinción de su situación migratoria, gozarán en el territorio nacional, del derecho fundamental de acceso a la educación en condiciones de igualdad. El acceso a las instituciones de enseñanza preescolar, media o superior, ya sean públicas o privadas, nacionales, provinciales o municipales, no podrá denegarse o limitarse a causa de la circunstancial situación irregular de la permanencia de los padres.

En el ámbito local y provincial de la región bonaerense, las respectivas legislaturas llevaron adelante, con distinto éxito, modificaciones de sus leyes que tomaban en cuenta la situación de los alumnos extranjeros calificados como "indocumentados". En el mes de junio de 1999, la legislatura de la Ciudad Autónoma de Buenos Aires sancionó una ley que habilitaba la inscripción provisoria de los alumnos/as menores de dieciocho años en establecimientos educativos municipales, "aún cuando no cuenten con el documento de identidad correspondiente". Los alumnos debían ser inscriptos "conforme los datos de la documentación que presente o a los que proporcione", los cuales servían para "todo certificado que se extienda mientras el alumno no haya regularizado su situación documentaria o migratoria". En caso de que hubiera contradicciones entre estos datos y los de "la documentación expedida por la autoridad competente" se considerarían aquellos de la documentación definitiva. Además, el Poder Ejecutivo asumía a través de la Secretaría de Educación la obligación de "establecer los mecanismos de asesoramiento y asistencia a los alumnos/as extranjeros y a sus representantes legales, para la tramitación de la regularización de su situación migratoria permanente o temporaria". Esta ley se reglamentó algunos años más tarde, en el 2002, cuando a nivel nacional se discutía la nueva ley de migraciones. 
Por otra parte, ante diversas situaciones y denuncias de discriminación, organismos representantes de Estados vecinos reclamaron, de manera aislada, ante las autoridades educativas provinciales la revisión de las medidas concernientes al derecho a la educación de alumnos extranjeros. En la provincia de Córdoba, el Estado peruano, a través de su consulado, manifestó en el año 2002, amparándose en el convenio migratorio celebrado en 1999, "su preocupación sobre la problemática que atraviesan diversos niños peruanos respecto a la accesibilidad al Sistema Educativo Provincial y a la obtención de la documentación que certifique sus estudios en nuestro país". En respuesta, el Ministerio de Educación resolvió que "los alumnos de nacionalidad peruana con documentación de origen en regla poseerán pleno derecho de ingresar y egresar del Sistema Educativo Provincial como también de obtener las certificaciones y titulaciones en igualdad de condiciones con sus pares de nacionalidad argentina". 420

Este progresivo reconocimiento en materia educativa, se plasmó en la nueva ley de migraciones, sancionada por el Congreso Nacional a fines del 2003 y promulgada de hecho a inicios del 2004. Ella establece que la "irregularidad migratoria" no puede impedir en ningún caso la admisión a un establecimiento educativo, ya sea de carácter público o privado; nacional, provincial o municipal; primario, secundario, terciario o universitario. Además, las autoridades de las escuelas ya no deberán denunciar a aquellos que se encuentren en dicha situación (como lo exigía la Ley Videla), sino que "deberán brindar orientación y asesoramiento respecto de los trámites correspondientes a los efectos de subsanar la irregularidad migratoria".
Artículo 7.- En ningún caso la irregularidad migratoria de un extranjero impedirá su admisión como alumno en un establecimiento educativo, ya sea este público o privado; nacional, provincial o municipal; primario, secundario, terciario o universitario. Las autoridades de los establecimientos educativos deberán brindar orientación y asesoramiento respecto de los trámites correspondientes a los efectos de subsanar la irregularidad migratoria.

Esta ley, inspirada -como su propio autor lo reconoce- en la Convención Internacional sobre la Protección de los Derechos de Todos los Trabajadores Migratorios y de sus Familiares adoptada en 1990 por la Asamblea General de Naciones Unidas, recupera de ella -a través del proyecto de ley que le diera origen- el derecho de acceso a la educación y la igualdad de trato entre nacionales y extranjeros, independientemente de la situación de 
"irregularidad" que caracterice la permanencia o trabajo de la madre o del padre o la residencia de los hijos:

Todos los hijos de los trabajadores migratorios gozarán del derecho fundamental de acceso a la educación en condiciones de igualdad de trato con los nacionales del Estado de que se trate. El acceso de los hijos de trabajadores migratorios a las instituciones de enseñanza preescolar o las escuelas públicas no podrá denegarse ni limitarse a causa de la situación irregular en lo que respecta a la permanencia o al empleo de cualquiera de los padres, ni del carácter irregular de la permanencia del hijo en el Estado de empleo.

La posterior ley de Educación Nacional, aprobada en el año 2006, recogió en uno de sus últimos artículos -no previsto en el anteproyecto- el derecho a la educación de aquellas "personas migrantes sin $\mathrm{DNI}^{421}$ contemplado en la ley de migraciones promulgada a comienzos de 2004:

Artículo 141.- El Estado nacional, las provincias y la Ciudad Autónoma de Buenos Aires deberán garantizar a las personas migrantes sin Documento Nacional de Identidad (DNI), el acceso y las condiciones para la permanencia y el egreso de todos los niveles del sistema educativo, mediante la presentación de documentos emanados de su país de origen, conforme a lo establecido por el artículo $7^{\circ}$ de la Ley $\mathrm{N}^{\circ} 25.871$.

Ya en vigencia la nueva ley de migraciones, en el mes de noviembre de 2004, la Cámara de Diputados y el Senado de la Provincia de Buenos Aires sancionaron una ley ${ }^{422}$ en la cual se disponía que el Estado provincial, a través de sus organismos especializados en cultura y educación, "establecerá un mecanismo de asesoramiento y asistencia técnica a los alumnos indocumentados o extranjeros, a sus padres, tutores o representantes legales, a fin de facilitar la tramitación de la regularización de su situación" y que los establecimientos educativos provinciales "que inscriban en sus registros alumnos indocumentados o extranjeros, comunicarán en forma inmediata la nómina y situación" al organismo oficial correspondiente a las áreas de cultura y educación. La ley también determinaba que:

421 En la ley de migraciones esta condición es denominada “irregularidad migratoria de un extranjero". 422 Ley № $13.259 / 04$. 
Artículo 3.- Ningún alumno podrá ser dado de baja de un establecimiento educativo por falta de documentación identificatoria o de ciudadanía, ni tampoco se dejarán de extender las certificaciones intermedias o finales de sus estudios, mientras se encuentre cumplimentando los trámites aconsejados para su identificación por el organismo educacional competente.

Artículo 4.- En los casos en que el solicitante regularice su situación migratoria o documentaria y existan contradicciones entre los datos de la documentación expedida por la autoridad competente y los registrados al momento de la inscripción, se tomarán por válidos los datos expedidos por la autoridad competente, actualizando en el registro del establecimiento educativo los datos de filiación establecidos por la misma.

Pero el decreto de promulgación ${ }^{423}$, firmado por el gobernador bonaerense Felipe Solá y el jefe de gabinete Florencio Randazzo ${ }^{424}$, desaprobó lo dispuesto en el artículo 3 en relación al otorgamiento de "las certificaciones intermedias o finales de sus estudios, mientras se encuentre cumplimentando los trámites aconsejados para su identificación por el organismo educacional competente" y suprimió el artículo 4 en su totalidad, alegando inconsistencias procedimentales.

\section{Los "indocumentados" en el espacio escolar}

En los inicios de esta investigación, apenas comenzaba con el trabajo de campo, durante una conversación posterior a las observaciones que realizaba por aquellos días en el aula de una de las secciones de tercer grado, la maestra (nacida en Bolivia e hija de bolivianos) me habló acerca de los "chicos indocumentados" y de las dificultades que tenían para incorporarse a la escuela. ${ }^{425} \mathrm{Al}$ entrar una de las vicedirectoras (Isidora), la maestra la

\footnotetext{
423 Decreto № 2792/04.

424 No puedo dejar de señalar aquí que este funcionario provincial, posteriormente devenido funcionario nacional, que firma el decreto de promulgación mediante el cual se establecen trabas burocráticas a la extensión de certificados de estudios a los alumnos "indocumentados" es el mismo que a finales del año 2007, al comenzar la presidencia de Cristina Fernández de Kirchner, asumió la cartera del Ministerio del Interior del cual depende la Dirección Nacional de Migraciones que se vanagloria de llevar adelante una política de derechos humanos en materia migratoria.

425 En esta ocasión también me comenta que los "chicos bolivianos" no suelen repetir de grado, explicándome que la sobreedad de algunos (esto es, aquellos que superan la edad teórica prevista para el año en curso) se debe a que
} 
participó de la conversación y le preguntó acerca del tema. Ella comentó que generalmente, en el caso de que trajeran "los papeles", se los incorporaba al grado que les correspondía. Si no fuera así, se los sometía a un examen, salvo que el Consulado de Bolivia se hiciera responsable. Según ella, en esta escuela hubo una sola ocasión en la cual se tomó examen a un alumno extranjero. Basándose en su experiencia como profesora en una secundaria, también contó que allí donde ella trabaja, los alumnos "indocumentados" generalmente abandonan, a causa de la falta de DNI, cuando la institución los "presiona" para que lo traigan. Puso como ejemplo el caso de un "muy buen alumno peruano" que tuvo que abandonar en segundo año por la falta de DNI (Notas de campo, jueves 8 de agosto de 2002). Como regla general, hasta el día de hoy, se les toma una evaluación o se hace una entrevista con la familia y los chicos, se trabaja en base a lo que la madre plantea (con muchas dificultades y temores), se lo prueba en un grado de acuerdo a la edad y la maestra evalúa si tiene que ser cambiado de grado.

Luego, mientras caminábamos por el patio le pregunté qué sucedía en la primaria con los "indocumentados", si se les otorgaba alguna certificación. Me respondió que eso dependía fundamentalmente de "la funcionaria", refiriéndose a la supervisora de turno, y que desde hacía dos años estaban aceptando la cédula boliviana. Y recuerda que una supervisora les tenía "terminantemente prohibido" entregarles la certificación por haber concluido la primaria. Por entonces era común que los alumnos llegaran sin ningún tipo de documentación. Ese mismo día, un rato más tarde, conversando con la maestra de tercero en la sala de profesores durante su "hora libre", otra docente comenta indignada la cantidad de problemas que tenía "la gente boliviana" para conseguir el DNI y que sabía de las "trabas" que le ponían también a aquellos bolivianos que estaban casados con un/a argentino/a o tienen hijos argentinos (Notas de campo, jueves 8 de agosto de 2002).426

De acuerdo a la normativa educativa, anterior a la nueva ley de migraciones, los/as directores/as de escuela tienen prohibido "admitir en la escuela alumnos que no estén

iniciaron más tarde a la escuela o a que al momento de llegar desde Bolivia los colocaron en grados inferiores a los que les correspondería por su edad.

426 En el discurso de las maestras suele aparecer una mirada comprensiva sobre las condiciones materiales de vida de los inmigrantes, agravadas en ciertas circunstancias por la falta de documentación. Una maestra reproduce una conversación con una mujer boliviana, madre de alumnos suyos, donde se refleja además la partida a España como salida a la crisis política y económica que se desató en la Argentina a fines del 2001: “Bueno, el papá de Daniela se fue a España, entonces yo le pregunté a la mamá cómo le estaba yendo allá, si se le estaba haciendo muy difícil, le digo... sí, me dijo ella, no más difícil de lo que nos fue acá... [...] Entonces como gente que... muy golpeada, como que vienen con ese temor y siempre tienen tantos problemas con los documentos, Eduardo, gente que los quiere asesorar y les saca plata, les miente para hacer los papeles...” (Valeria). 
matriculados o no reúnan las condiciones ${ }^{427}$ exigidas para el ingreso". Pero desde hace varios años la escuela Vicente Forestieri, consecuente con su autodefinición de "inclusora", no rechaza la admisión de alumnos que no dispongan de los diversos documentos establecidos para la inscripción. ${ }^{428}$ Para este trámite se solicita el Documento Nacional de Identidad, el informe médico de salud psicofísica (el llamado "apto psicofísico"), el carnet de vacunas, la libreta escolar y las respectivas fotocopias. En caso de no tener el DNI, también se recibe la cédula de identidad o la partida de nacimiento en su lugar (en ocasiones los alumnos extranjeros sin DNI se inscriben con la partida de nacimiento donde aparece el número de la cédula de identidad). Según una maestra, desde alrededor del año 2004, la escuela entrega el certificado de estudios primarios aún a aquellos alumnos que no posean el correspondiente documento nacional de identidad: los "argentinos indocumentados" el DNI y los "bolivianos indocumentados" el DNI (argentino) de extranjero. Como documento probatorio de la identidad se acepta la partida de nacimiento, tanto para nacionales argentinos como bolivianos. A los alumnos de nacionalidad boliviana también les reciben la cédula de identidad para entregarles el certificado de estudios. Entre los diversos y complejos mecanismos de exclusión que producen las instituciones educativas, no es precisamente en las instancias de admisión o egreso donde pueden ser observados en la escuela en estudio. Según el testimonio de la directora, las trabas burocráticas suelen aparecer en las sedes de la Supervisión Educativa, con el control de la documentación escolar. Cada fin de año, cuando se llevan los papeles a "Inspección" para hacer los certificados de fin de año, allí se suele confundir el número de la partida de nacimiento (folio) y el de la cédula de identidad, lo que hace que lo rechacen. En ocasiones, directamente no los reciben.

Más allá de las facilidades que obtuvieron los inmigrantes para regularizar su situación administrativa a partir de la implementación del programa Patria Grande, las prácticas estatales no se limitan a poner en regla a los extranjeros. Las dificultades con la documentación, pero más aún las arbitrariedades a las que están expuestos los inmigrantes en el cruce de frontera, se trasladan a la escuela. En algunos casos, no se trata de los obstáculos que interponen las instituciones educativas, sino organismos del Estado encargados del "control migratorio". Como se desprende del relato de una maestra, mientras comenta las reacciones que pueden tener los inmigrantes bolivianos a raíz de los

427 Las condiciones estipuladas en el reglamento son: "haber cumplido la edad escolar"; "no debe padecer enfermedad contagiosa"; "presentar certificados de haber sido vacunados" y "ser presentado al Director, por el padre, encargado o tutor".

428 En su código de convivencia se explicita como compromiso la adopción del principio de no discriminación en el acceso y trayectoria educativa de los alumnos. 
problemas que sufren en su vida cotidiana por la falta de "papeles", un problema en la frontera puede significar que los hijos (en este caso, la hija) pierdan la continuidad de las clases. Esta dimensión del hecho migratorio que aparece, casualmente, en el relato aislado de una maestra, no es registrado ni contemplado por la escuela y menos por un Estado nacional que no puede más que intervenir a través de organismos especializados y parcializados.
A., por ejemplo, estuvo faltando a principios de año... me faltó todicito el mes de marzo y principios de abril porque viajaron a Bolivia, allá en la frontera tuvieron problemas, todo eso por el tema de los documentos, y bueno no es fácil para ellos acá, entonces por ahí hay que sentarse y conocer un poquito qué hay atrás de cada uno para entender a veces ciertas actitudes... si ellos vienen por ahí con ese... al choque o si están a la defensiva es porque también les pasa las mil y una, pero no es para ellos tan fácil, como para todos por supuesto, todos tenemos nuestros problemas y nuestras cosas, pero para ellos... siempre están a la defensiva por eso... (Valeria)

Por otra parte, la división legal/ilegal que establece el Estado también tiene consecuencias insospechadas en el espacio escolar. Frente a determinadas situaciones, que pueden ser algo extremas, la respuesta de la maestra puede cambiar su curso. En otro contexto hubiera procedido mediante una denuncia, pero frente a una familia de inmigrantes, cuyos miembros podrían encontrarse en una situación de irregularidad administrativa, no la hace. No es la veracidad del hecho lo que importa aquí, sino la situación que se produce ante una posible situación de "ilegalidad" y las consecuencias prácticas -detención y expulsión- que pueda tener. Sin mencionarlo explícitamente, el aparato represivo del Estado está contenido en el relato de la maestra, condicionando su accionar.

Entro a la sala de profesores. Jimena me dice que me acerque para "chusmearme" algo: ha podido "confirmar" que a José, un alumno suyo, le quemaron las manos los padres debido a que robó unas monedas (no especifica a quién ni de dónde). Le contó una prima de él, alumna suya. Me comenta también que José tiene muchas dificultades en clase. Hoy le puso un "no satisfactorio", lo cual hizo que ella se sintiera mal y llorara. La prima le dijo que en la casa le pegarían por las malas notas. No sabe cómo manejar esta situación. Piensa ir a hablar personalmente con los padres, pero no quiere hacer ninguna denuncia policial por malos tratos porque cree que pueden estar "ilegales". (Notas de campo, miércoles 5 de noviembre de 2003) 
La categoría que se utiliza para nombrar a los alumnos que no poseen el DNI, indistintamente si son "nacionales" o "extranjeros", es "indocumentados". A diferencia del modo en que el Estado nacional, a través de la normativa migratoria, clasifica a los "extranjeros", en la escuela no se emplean denominaciones como legales/ilegales o su equivalente (aunque con connotaciones diferentes) regulares/irregulares para designar a aquellos alumnos que no cuentan con la documentación exigida para ingresar y permanecer en ella.

La distinción que se realiza en la escuela entre "argentino" y "boliviano", como pudimos observar en el capítulo anterior, no es utilizada para cuestionar el acceso a determinados derechos ciudadanos como la educación. Aquí la comunidad educativa en su conjunto asume el derecho a la educación como un derecho inherente a la condición de la niñez, entendido como una norma superior a cualquier distinción basada en la nacionalidad, la etnia, la religión o el género, entre otros. Es decir, en el caso de la educación, la asignación a una u otra categoría no se traduce necesariamente en una división entre "nacionales" y "extranjeros", la cual supone un acceso diferencial a los derechos ciudadanos.

Según la directora (Carmen), con el paso del tiempo la escuela aprendió qué hacer con el tema de la indocumentación de los alumnos nacionales bolivianos. Hoy en día, al no presentarse algunos alumnos bolivianos al comienzo de clases, la escuela asume que están en Bolivia y que llegarán a finales de marzo, después del carnaval. Se institucionalizó un acuerdo implícito que consiste en esperar que las familias vuelvan de Bolivia. Otros años se hubiera pensado que "perdió el banco", hubiera estado la pregunta si volverá o no. Pero ahora, como dice la directora: "No está el ruido de la pregunta". A diferencia de épocas anteriores, no genera "alarma" ni "ruido". Directamente se les guarda el lugar, sin colocar de antemano "ausente". En algunas oportunidades, las propias familias se han comunicado con la escuela a través de algún familiar o paisano para avisar que están detenidos en la frontera y pedir que se les guarde el banco.

La directora comenta que, en general, nadie confirma la matrícula en la fecha indicada por el Ministerio de Educación. La confirmación de matrícula se establece directamente el primer día de clases cuando los alumnos aparecen "con el guardapolvo". "Ahí sabemos los números", dice la directora. La ex directora comenta que a algunos bolivianos se les entregaba y se les entrega por anticipado la libreta, en el mes de noviembre, frente a la eventualidad del viaje. En la escuela advirtieron que la libreta escolar era mucho más que un certificado de los estudios realizados: les servía para regresar a la Argentina y poder 
cruzar la frontera, es decir, para poder certificar su estadía a manera de certificado de residencia.

\section{Los “bolivianos” en la escuela argentina: ¿una presencia problemática?}

A diferencia de otras instituciones de la zona sur que reciben alumnos identificados como "bolivianos", la escuela ha estado acompañada desde sus comienzos por la presencia de alumnos de familias bolivianas. Según el testimonio de una de las primeras maestras, corroborado por otras, "la comunidad" de inmigrantes bolivianos residentes en la zona nace con la escuela. Aquí la escuela y la comunidad boliviana no sólo se establecieron simultáneamente, sino que se constituyeron mutuamente.

Afuera, en el barrio, porque esta comunidad, que nace acá, detrás de la escuela, en el año 96... en el año 96 ya empieza la escuela, en diciembre del 95 vos te parabas ahí y era una llanura, no veías nada. Cuando nosotros empezamos en febrero estaba todo poblado. Es decir que en los dos meses que nosotros no vinimos a clase se pobló y se hizo un barrio. Se trató primero... sentimos que se trataba de hacer una cooperativa [la Cooperativa ArPeBoCh], donde estaban argentinos, bolivianos... entonces ya tuvieron actividad, la gente de Bolivia tiene tierras, entonces eso les dio más hincapié para poder venir a establecerse acá. Lo que nosotros... pienso que siempre estuvimos con ellos, ellos estuvieron acá desde que la escuela se abrió, porque ya había algunos. En el 96 es como que se hace masivo, tuvimos un montón... que se venían. (María)

Según el relato de una de las maestras más antiguas, la presencia de bolivianos en la escuela aparece representado como algo repentino y masivo debido al modo en que se pobló la zona a partir de su llegada. Una maestra lo compara con la inmigración de ultramar de fines del siglo diecinueve, pero a menor escala.

Se introdujeron masivamente como una inmigración... Viste como cuando en el '80 [se refiere a la década de 1880] se abre la inmigración y tenemos... tuvimos inmigrantes italianos, bueno, distintas colonias europeas? Bueno, lo mismo, esto en chiquito, pero como que hubo muchos... [...] es decir, pudimos ver cómo empezaban a aparecer un montón, entendés, y bueno... vinieron a 
vivir al barrio. [...] Decíme, ¿cómo puede ser que algo crezca...? Si vos, en el mes de diciembre tenés... hasta acá llega el barrio, la escuela está hecha en el límite del barrio, en dos meses se pobló todo. Y cada terrenito es chiquito y tiene una casita y al lado hay otra casita y... creo que tienen cinco metros de ancho, no sé por cuánto, se re-contra pobló... (María)

En otros casos, en cambio, el inicio de la escuela no es recordado con una gran cantidad de alumnos bolivianos y la zona no habría estado demasiada poblada.

Me parece que cuando estaba Mabel [la primera directora] no había tantos chicos [bolivianos], porque me parece que el barrio todavía no estaba muy... con mucha gente, pero después fue más cuando estaba Estela [la segunda directora]... (Mercedes)

Cuando comencé como que no había... comunidad boliviana, peruana, chilena como hay ahora... no había tanta... después como que se hicieron estos barrios nuevos, entonces como que afluyó más... el asentamiento de esos países. (Pilar)

A pesar de esta constitución simultánea y que los hijos de inmigrantes estuvieron presentes desde el comienzo de la escuela y fue constante a lo largo de los años, no siempre fueron percibidos de la misma manera. Durante los primeros años, bajo la gestión de la primera directora, el origen nacional (o étnico-nacional) de los alumnos pasaba desapercibido, los alumnos bolivianos eran "uno más", en el sentido de que no se consideraban las particularidades de la "comunidad boliviana" que más adelante adquirirían mayor visibilidad. De manera categórica, así lo expresó una maestra: "Eran uno más, un alumno más, con otra nacionalidad, punto" (Pilar). En los primeros años de vida de la escuela, el trabajo escolar no involucraba actividades que contemplaran manifestaciones socioculturales o símbolos políticos relacionados con un origen nacional boliviano. Es decir, todo indica que hubo un momento en el cual la diferencia entre argentinos y bolivianos se puso de manifiesto, haciéndose visible a través de "lo cultural" en clave nacional.

[...] Eran uno más... como que pudo haber venido uno de Brasil, como pudo venir uno del sur, como pudo venir uno de Buenos Aires, como pudo venir uno, qué sé yo, de Chile, entendés, uno más... No se trabajaba como se trabaja ahora, así... / No termino de entenderlo... / No se trabajaba como se trabaja 
ahora... de que se festejaba la indepen... [de Bolivia], se nombraba la independencia, sí, siempre, nosotros tenemos fechas para recordar, por supuesto, pero así, específico, de que... la entrada de la bandera de Bolivia, que los caporales, todas esas cosas como que... no, no, no existía, entendés? Tiene el auge desde la época de Estela y de la época de Carmen (Pilar)

Recién transcurridos los primeros tres años de la escuela emergieron algunas experiencias aisladas que fueron llevadas adelante por un pequeño grupo de docentes, guiadas por la idea de "integración", que no fueron asumidas como parte de un proyecto institucional y que no tuvieron mayor continuidad. En aquella época, como recuerda una de las maestras que desde el comienzo fue una de las que más involucradas estuvo con la organización de estas actividades escolares, básicamente se trataba de "incorporar algunas cosas típicas" de la "comunidad boliviana" con la intención de "acercar un poco estas dos comunidades, la argentina y la boliviana, integrarlas, integrarlas, hacer una integración...”, como explica una de las maestras más antiguas (María).

Nosotras fuimos una vez con María Eugenia a la radio... porque estábamos trabajando en ese momento... habíamos hecho un proyecto con María Eugenia, que era incorporar algunas cosas típicas de esto de... de la comunidad boliviana... fuimos a la radio, estuvimos en Radio Universidad hablando acerca de... porque les había interesado el hecho de abrir [la escuela a] la comunidad boliviana, pero después no tuvo un seguimiento... me parece, porque no fue algo a nivel institucional, porque surgió de algunas personas, me entendés? No se prendió toda la institución a hacerlo... [...] No me acuerdo en qué año... en qué grado estaba, pero surgió casi como una idea, como que nosotras al hacer mucho que veníamos viendo eso y bueno nos gustó y nos prendimos y nos fue bien. Pero no se prendió toda la escuela, tampoco por ahí vos podés obligar a todos a que hagan lo que... es decir, lo que a vos te parece criterioso, porque tiene que surgir un poco del montón y de la apertura... [...] Después hubiese sido lindo que se siga trabajando. En la medida en que yo lo pueda hacer, lo hago, pero desde mi postura personal... pero no sé si, si esto estará en el criterio de las demás, habría que preguntarles... qué es lo que piensan las demás, yo no puedo responder por las demás...

\section{No es una preocupación general entonces...}

¿Que no es una preocupación general? No, no es una preocupación, porque sino, eso hubiera tenido eco y hubiera seguido... se hubiera seguido haciendo y no hubiera quedado en dos o tres personas nada más... 


\section{Por lo que me decís, se trabajó bastante la idea ese año...}

Claro, es decir, bien, pero no toda la escuela, vos hacé hincapié en esto, no toda la escuela, algunas personas que... nos parecía bien, que nos prendimos en esto, ¿me entendés? Yo no te puedo hablar... es decir, no surgió como un... un proyecto de... es decir, sí, lo hace toda la institución... se prendía la que le gustaba y la que quería, algo así como por iniciativa propia... porque vos... ¿vos pensabas que... (risas) era distinto? (María)

Como señala esta maestra, se trató acciones impulsadas desde el aula, surgidas a través de iniciativas personales espontáneas, como algo complementario, que no estuvo planificado de antemano. A ello se agrega la falta de formación para trabajar con una población de origen inmigrante, resultando una experiencia "violenta" y un aprendizaje "sobre la marcha".

Siempre surgió como algo anexo: bueno, qué les parece, miren esto o rescatemos este valor... les gusta hacer tal cosa, pero vos viste qué bien, cómo los visten a los chicos -porque se visten re-bien... para las vacaciones de ellos, muy bien para las fiestas típicas de ellos- pero nunca surgió como algo que se trabajó en el colegio... como decir, bueno, lo planteamos como una postura [...] (María)

Ha sido un poco, a lo mejor, muy violento porque de pronto no estábamos tampoco preparados para eso, no, es como que fue... [...] estuvimos trabajando con ellos, es decir, a lo mejor no estuvimos preparados, pero lo hicimos sobre la marcha, fuimos aprendiendo sobre la marcha. (María)

Los recuerdos de aquellos tiempos giran en torno a una feria de platos, música, vestimenta y danzas folclóricas bolivianas que se realizó en el año 1999. Las fotos muestran distintas escenas: en una de ellas se puede observar a la directora, junto a una maestra, frente a la larga mesa de comidas típicas preparadas para la ocasión; en otras dos se muestra a una mujer corpulenta acompañada por niñas también vestidas con trajes tradicionales, paradas en el patio escolar y rodeadas de alumnos/as en una y frente a un automóvil con "cargamentos" en otra; también se puede observar en las fotos a la señora Rosa y a Elizabeth, dos mujeres nacidas en Bolivia, originarias de Cochabamba y Tarija, sosteniendo la bandera de ceremonias boliviana, firmes de pie en el patio de la escuela, al lado de alumnos de guardapolvo blanco; por último, una imagen con varios niños con trajes 
tradicionales encima del techo del automóvil con los "cargamentos". Así recuerda este encuentro la señora Rosa:

Me acuerdo un año hicimos el... ¿Cómo se llama? ¿Tradic...? / ¿El día de la Tradición? / Sí, hicimos... yo había escuchado al grupo, a los de acá, decían "aquí vamos a preparar la humita...” y... a los gauchos y después... [...] Tengo una foto... porque nosotros preparamos, los argentinos, digamos, prepararon todo... cosas, digamos, que han hecho... y nosotros habíamos hecho, las bolivianas, todito hicimos, todas las comidas de toda clase, todo habíamos hecho en el SUM... Traje la Virgen de Urkupiña, traje tejidos, colchas... maíz de toda clase, todo trajimos, comida lo mismo, entonces agarré a todo mi grupo, de mis paisanos, que estaban, de todos estaban en la escuela acá, una familia trae un picante de pollo, bien cocinado, otra familia chicharrón, así... yo he hecho el pique macho, chicharrón, yo traje todos esos platos... entonces todo así, de Tarija también, nos hemos juntado todos, todo lo que era de Tarija, Sucre... los platos favoritos que ellos tenían hemos presentado, todos se admiraban, porque era comida picante (risas), y después empezamos a invitar a todos [...] Porque yo he traído... carrozas vamos a hacer, decíamos... cargamentos, entonces mi compadre tenía su auto, le digo a mi compadre, podemos adornar tu auto como lo hacemos allá, entonces, sí, dice mi compadre, entonces empezamos... trajimos el auto, lo hicimos entrar por allá atrás al patio y los argentinos trajeron a los gauchos con sus caballos... Estaba el grupo de argentinos y el grupo de los bolivianos, nosotros teníamos el cargamento, decimos nosotros, el camión con aguayos hemos adornado, después las cholitas de Cochabamba, Tarija era otra... las ropas de allá las hemos conseguido... ya te voy a mostrar tengo las fotos... después mi nieta de Cochabamba, una cholita la hemos hecho, o sea, mi nieta, todas esas cosas hicimos... (Rosa)

Esta mirada sobre el pasado permite advertir que la incorporación de determinados elementos materiales y simbólicos asociados con Bolivia, o mejor, con la bolivianidad, a la vida cotidiana de la escuela no fue producto de un proyecto institucional ni del seguimiento de lineamientos de política educativa referidos al reconocimiento de la diversidad cultural. Más bien, se produjo a partir de la experiencia próxima con un grupo social concebido como culturalmente diferente a raíz de su pertenencia nacional, la comunidad boliviana. Es decir, una presencia no-nacional -de algún modo una pertenencia impertinente- en un espacio social como la escuela que se define cotidianamente como un 
territorio distintivo de la nación. Las prácticas llevadas a cabo no estaban sustentadas en la interculturalidad u otros principios referidos a la diversidad cultural, sino cruzadas por ideas aprendidas socialmente acerca del modo ideal en que los individuos pertenecientes a diferentes naciones, por ende, a diferentes culturas, deben relacionarse. La idea de integración representa este ideal.

En los años posteriores, habiendo asumido su cargo la nueva directora en el año 2002, la presencia de los bolivianos en la escuela adquirió mayor visibilidad. Con su llegada, la dirección se posiciona explícitamente a favor de una escuela que contemple las particularidades individuales y grupales de los distintos sectores sociales que la conformaban, entre ellos las familias de inmigrantes bolivianos cuyos hijos o nietos asistían a la escuela. ${ }^{429}$ Es en esta línea que una maestra indica que la nueva directora "también trajo toda una nueva forma de trabajar" (Mercedes). En esta etapa, las prácticas desplegadas en torno a la comunidad boliviana se inscribieron en la política de la institución que pretendía estrechar el vínculo entre la escuela y la comunidad del barrio, favoreciendo su presencia en las más diversas instancias escolares. En este sentido, el elevado número de hijos o nietos de inmigrantes bolivianos, vistos como parte de la comunidad boliviana, contribuyó a condicionar y moldear determinados discursos y prácticas escolares, creciendo las referencias a Bolivia en la vida cotidiana de la escuela.

Durante la entrevista con una de las maestras con mayor antigüedad surge la importancia que tiene para la escuela el hecho de que esté próxima al ARPEBOCH, habitado por una importante cantidad de familias bolivianas que envían a sus hijos a esta institución. ${ }^{430}$ En los términos que lo presenta la docente ("nosotros estamos rodeados de gente de nacionalidad boliviana") refuerza la idea de que la escuela está constituida mayormente por bolivianos. El alto número de hijos de inmigrantes bolivianos marcaría la diferencia con otras escuelas de la zona que también reciben sus hijos o nietos, pero en menor cantidad. El hecho de que la escuela tenga esta cantidad alumnos bolivianos haría que no puedan ser "uno más" y, en consecuencia, que se les otorgue "mayor importancia"; en cambio, en la otra sí pueden serlo debido a que la presencia es mucho menor. En las palabras de la docente, "uno más" significa que el origen boliviano pasa inadvertido o al menos que no es tenido en cuenta en términos institucionales.

No, no, porque en la [escuela] Patricias [Mendocinas] también hay bolivianos...

429 La primera muestra de apertura en conocer aspectos relacionados a la presencia de alumnos bolivianos en la escuela fue el interés que la directora explicitó al presentarle el objetivo de mi investigación.

430 Véase Bartolozzi y Koopman (2010) para conocer un estudio sobre la historia y los protagonistas de ARPEBOCH. 


\section{Pero me decía I. que no es tan significativa la presencia...}

Y, bueno, para ellos no, serán uno más, acá sí... por eso te digo, a lo mejor como está rodeándonos el barrio... vos viste, nosotros estamos ro-de-a-dos de... de gente de nacionalidad boliviana, en cambio las Patricias no, entonces es un alumno más, ahí está la diferencia...

\section{No entiendo...}

Y, la diferencia está... nosotros estamos rodeados de alumnos bolivianos, como que existe más comunidad boliviana y la [escuela] Patricias Mendocinas no está rodeada de nacionalidad boliviana. A lo mejor puede ir un chico, suponéte, que vive acá y va a las Patricias... no es que tenga rodeado o cerca los chicos bolivianos, en cambio, nosotros sí, tenemos un barrio, prácticamente hay casi un barrio de gente boliviana, que están atrás, no digo que todos sean bolivianos, pero la mayoría sí, han edificado su casa ahí atrás de la escuela, bueno, entonces, por esa razón es como que le da mayor importancia, porque generalmente esos chicos eligen venir a la escuela nuestra... [...]

\section{¿En qué sentido no son uno más?}

Y porque eran mayoría, me entendés, no era que, bueno, sí, hay uno, hay dos o hay tres, aparte que la Patricias es una escuela grande, y entonces diez bolivianos no le hacen nada, ¿me entendés? En una comunidad de qué sé yo, 800, 900, 700 alumnos... diez no le hacen nada... por eso te digo, es uno más... (Pilar)

El acercamiento de la escuela con la comunidad del barrio, aunque formó parte de aquellos mandatos escolares (no necesariamente escritos) conocidos por toda la comunidad educativa, la mayoría de las acciones específicas que se llevaron a cabo debido a la presencia de alumnos bolivianos -como la celebración de las fiestas bolivianas- siguieron estando libradas a la voluntad individual de cada docente y, consecuentemente, a la visión que cada una de ellas tenía sobre los inmigrantes bolivianos. Básicamente, las referencias continuaron apelando al sentido hegemónico de cultura boliviana: los bolivianos son identificados fundamentalmente -en el doble sentido de ser individualizados y asemejados- con determinadas manifestaciones culturales como fiestas religiosas (la fiesta de la Virgen de Urkupiña), bailes folclóricos (principalmente los caporales), comidas típicas (la salchipapa) y símbolos nacionales (bandera e himno). De todas maneras, se trataba del reconocimiento de la presencia concreta de una comunidad diferente antes que el reconocimiento de la diversidad cultural en términos universales o abstractos. 
Hacia fines del año 2007, en reclamo de un nuevo edificio, se produce la toma de la escuela por parte de un grupo de madres. Bajo este contexto se origina, en palabras de la directora actual, "una ruptura": durante la toma, frente a la postura de suspender las actividades escolares, la "comunidad boliviana" planteaba "tener clases". La directora cuenta que las madres bolivianas iban a la escuela y pedían que se diera clase, aún debajo de un árbol. Esta demanda habría producido "todo un enfrentamiento" con las madres que protagonizaron la toma. La directora resume su planteo de esta manera: "Vos boliviana querés tener clase debajo del árbol y nosotros queremos el edificio". Después de una prolongada lucha, con la promesa del Ministerio de Educación de construir un nuevo edificio, se levanta la toma de la escuela. Durante el año 2008, mientras se llevaba adelante la demolición y se construía uno nuevo, la escuela Vicente Forestieri funcionó, bajo "préstamo", en los espacios desocupados de un establecimiento de un colegio secundario, ubicado en una zona alejada de su lugar original. La directora define este período como "espacio transitorio" y considera que el año siguiente, año de la mudanza al nuevo edificio y de su inauguración, fue de "ambientación" y "acomodamiento". ${ }^{431}$ Según el relato de la directora, este acontecimiento, iniciado con la toma de la escuela y concluido con el regreso al nuevo edificio a comienzos del 2009, marcará un punto de inflexión en torno a la visibilidad y el tratamiento que recibió la presencia de los alumnos hijos de bolivianos durante los primeros años de su gestión.

Mirá, 2005, 2006 era con más fuerza, mayor presencia de la cultura boliviana, desde todo evento, la música, los bailes, las mamás que por ahí se animaban a hacer comidas, nos invitaban... en el 2007, con la toma, esta presencia, cuando las mamás dicen 'nosotros queremos tener clases', ahí hubo ruidos... toda la dinámica, como que la toma del edificio fue... concentrar todas las fuerzas en la toma del edificio... [...] Y el espacio transitorio, donde acomodarnos a un espacio transitorio... y era acomodarnos, era sobrevivir... fue muy fuerte, actos, las cosas que intentábamos rescatar... sobrevivíamos al espacio... y en la Marta Juana, cuando se hace el año aymara, era cuestión de retomar... cuando a mí me habla... Marcela, yo le digo sí, porque estaba ausente, yo lo veía como una estrategia... retomar esa fuerza del año 2005 y 2006, quedó ahí... el año 2009, la ambientación, el espacio, el disfrute, los rituales nuestros estaban... (Carmen) 
La fecha elegida por la escuela como la más representativa para reconocer la presencia de los bolivianos en la institución, el día de la Independencia de Bolivia, si bien continuó incorporada entre los "recordatorios" de las efemérides escolares, dejó de tener la centralidad, significada fundamentalmente como "exclusividad", que tuvo en los años anteriores. Esto también lo constata la investigación de Beltramone et al. (2010), cuyo trabajo de campo se desplegó entre octubre de 2008 y diciembre de 2009. Desde la toma de la escuela, como punto de quiebre, en adelante esta fecha nacional boliviana habría pasado a formar parte de los recordatorios referidos a "lo latinoamericano", visto como el contexto en el cual la Argentina está inserta. En su testimonio, la directora también admite la distancia existente entre aquellas ideas que ella defiende y las prácticas que efectivamente se desarrollan en el aula. Frente a las iniciativas desarrolladas en años anteriores que buscaban incorporar ritmos musicales y bailes del folklore boliviano, como veremos en el próximo capítulo, la actual docente de música sólo transmite algunas expresiones del folklore argentino. Así responde la directora a la pregunta por la continuación de la celebración del día de la Independencia de Bolivia.

No con tanta fuerza, está en la cartelera, se incorpora a la cartelera, a la cartelera... porque hay un acuerdo de incorporar a todos los países latinoamericanos, recordar la fecha de independencia... Yo en su momento pensaba para hacer un todo, o sea, Argentina en un contexto latinoamericano. Y evitar también... ¿cuál sería la palabra? Que solamente se recuerda a Bolivia, porque en la escuela hay chicos argentinos, hay chilenos... un chileno, bolivianos en su mayoría y de nacionalidad peruana... Entonces por ahí también si solamente apuntás al 6 de agosto quedan fuera otras fechas que también son importantes para... yo lo que veo como que, desde mi discurso, de ir dándole más una naturalidad a todos los hechos... y el 6 de agosto es una fecha más... como se recuerda la independencia de Perú, de Uruguay y de Chile... / ¿Eso por la presencia de algún alumno o alumna? / No, porque lo discutimos, en la identidad de la escuela, de tener, de ubicarnos en un contexto latinoamericano, desde la música... presencia, pero esto a nivel discurso, porque en la práctica, A. [la profesora] en música, bueno, ¿qué hay? sigue las chacareras, sigue la música argentina, el folclore argentino, parte del folclore argentino, pero no tan la música latinoamericana. Y desde Bolivia antes era más efusivo, había más presencia, bailes, se bailaba... ya no, no... (Carmen)

A pesar que el hecho y las implicancias de "ser boliviano" persiste como una cuestión no resuelta, lo hace de otro modo, sin salir a la superficie, manteniéndolo la escuela como 
"oculto", lo cual en determinadas circunstancias podría aparecer como un asunto silenciado. La directora reconoce que ella misma busca no darle trascendencia o relevancia para evitar la diferenciación entre alumnos "argentinos" y "bolivianos" o de otras nacionalidades presentes en la escuela.

Porque también dentro de la institución como que ser boliviano es todo... sigue siendo un tema, sigue siendo... Uno trata de... yo ya no le doy la entidad para que se considere, o sea, en la dinámica institucional de no diferenciar el boliviano del que es cordobés, o el peruano, hasta un chileno [...]. Pero que hay... no emerge tanto ya el tema de los bolivianos, no se cuestiona, pero está como oculto, es... se percibe oculto, no? Que esto no se hable... (Carmen)

La presencia de los hijos de inmigrantes bolivianos cobraba una marcada visibilidad en situaciones de abierta hostilidad y agresión que se producían en el espacio escolar, cristalizadas en insultos y peleas. Estos incidentes, interpretados por los docentes como "discriminación" y visualizados -en un contexto más amplio- como expresión de la "violencia" que ejercen entre ellos los alumnos, en su momento inspiraron a la vez que sirvieron de fundamento para llevar adelante y justificar las acciones de "integración" que algunos docentes consideraban como respuesta necesaria. Pero a partir de la toma de la escuela, experimentada como una situación de crisis, estas situaciones, según la visión de la directora, leídas ahora en otra clave, fueron resignificadas y a pesar de su persistencia habrían quedado silenciadas en la vida diaria institucional.

Antes emergía en el 'bolita', en las peleas de los chicos, los chicos venían... `me dijo bolita', eran peleas... ya no está, no se hace presente así de esa forma... y hasta en las docentes, antes lo marcaban mucho, ’esos son bolivianos, son tranquilitos', no está, o sea, quizás dentro de la misma dinámica... institucional lo va ocultando, como que lo va envolviendo, pero no emerge el tema de la comunidad boliviana como un tema específico a hablar. Toda la dinámica institucional... eso a nivel de percepción... porque yo no le doy la entidad... antes me preocupaba mucho por la violencia que había hacia los niños y las niñas bolivianas. [...] [Ahora] No lo registro por violencia, la violencia sale hoy por otro lado, por esto que te digo, el cartonero, la violencia verbal, las chicas entre ellas también... (Carmen)

Porque antes estaba muy fuerte en la institución que los chicos peleaban... venía un niño de nacionalidad... 'me dijo bolita', 'me dijo sucio', y eso 
generaba todo, todo una... y la institución se lo planteó, ¿qué estamos haciendo? ¿cómo miramos a los chicos de nacionalidad boliviana para que entre ellos surjan estas peleas? Pero eso fue fuerte $2005,2006 \ldots$ hasta en los gestos de los chicos, yo los veía con sufrimiento, cansados... (Carmen)

Así, la directora, si bien registra la persistencia de la agresión física y verbal y el modo en que afecta a los alumnos considerados "bolivianos", ahora se lo atribuye a la falta de intervención de la maestra en lugar de focalizarse en el hecho de que sean "bolivianos". 432 Es decir, bajo su (nueva) mirada, el "problema" no radicaría en la presencia de "bolivianos" en la escuela, sino en la ausencia de intervención docente frente a los efectos que produce su presencia. Igualmente, la presencia de los hijos de bolivianos inmigrantes en la escuela, o lo que genéricamente se suele denominar presencia inmigrante, es una presencia problemática, en tanto crea un problema más que un problema en sí mismo.

Yo, ese niño, veo que sufre. Ves que sufre, vos entrás al aula y al niño le pegan. Y no hay un accionar de la docente, si? Y yo no trato a ella de decir, 'mirá, si es boliviano...'. Yo veo que le pegan, pero a la vez se pegan entre ellos porque no hay una intervención docente. Antes, a lo mejor, 2005, el problema era porque era de nacionalidad boliviana. Yo ahora veo que la pelea es ante a la ausencia de intervención docente, no sé si me entendés. 0 quizás yo antes estaba muy pendiente de lo que le pasaba a los chicos de nacionalidad boliviana y en esta etapa estoy viendo que lo que ocurre es porque no está interviniendo el docente. Pero no emerge en la violencia o en las dificultades entre los chicos porque sean de nacionalidad boliviana. (Carmen)

\section{Ser "boliviano" en la escuela argentina}

En la Argentina, históricamente, el éxito de las políticas de asimilación, a diferencia de otras experiencias nacionales, se reflejó -en parte- en la ruptura de aquella generación de hijos de inmigrantes (grupo generacional discutiblemente identificado en la literatura especializada como segunda generación) con la adscripción étnica de sus progenitores. El sentido de pertenencia de los hijos de inmigrantes nacidos en el país se desarrolló bajo un

$432 \mathrm{Si}$ bien en este extracto de entrevista la directora se refiere a los alumnos de "nacionalidad boliviana", el contexto en el cual se enuncia dicha pertenencia permite entrever que en esta ocasión la denominación utilizada no pretende poner de relieve el sentido jurídico de la nacionalidad, sino que sólo evita nombrarlos como "bolivianos". 
proceso de adscripción étnica voluntaria como califica Juliano (1987) aquella forma de adscripción de tipo individual compatible con la concepción de pertenencia producida entre las clases no poseedoras de los medios de producción en la sociedad rioplatense del siglo diecinueve: supone que "un grupo se reproduce no sólo o básicamente por sus descendientes biológicos, sino también por personas nacidas en el seno de otras culturas y que opten por compartir la del grupo receptor". Antes que de "una consecuencia espontánea de la tendencia de cada grupo a su autoconservación", se trata del "resultado de ciertas opciones sociales, es decir una política que a su vez se ha legitimado presentándose como 'amplitud de criterio' o 'tolerancia'” (Juliano, 1987:86). Como veremos específicamente en el próximo capítulo, para la labor ideológica de creación de un patrimonio único o común, en tanto "mecanismo unificador para individuos adscriptos individualmente" (Juliano, 1987:94), la escuela jugó un papel fundamental, hallando en los rituales patrióticos uno de los instrumentos privilegiados en la construcción de la argentinidad.

En la actualidad, diversos estudios locales constatan que la auto y heteroadscripción a categorías remiten al origen étnico o nacional de los propios inmigrantes. Grimson (2006), por ejemplo, indica que la categoría "boliviano", entre otros usos sociales, es utilizada para denominar no sólo a las personas nacidas en Bolivia, sino también a sus hijos: éstos serían argentinos en términos legales, pero bolivianos en términos sociales. También Caggiano (2005) sostiene este planteo para mostrar que en el caso de los inmigrantes bolivianos el modelo de adscripción étnica voluntaria no tiene vigencia. Trpin (2004), asimismo, en su estudio sobre la construcción de la "chilenidad" en una escuela rural de la Patagonia argentina (situada en la zona del Alto Valle de Río Negro), muestra que los hijos o nietos de chilenos son reconocidos y se reconocen como "chilenos" independientemente de la nacionalidad que posean. 433

En general, la escuela asume -como se expresa en distintos documentos escolares- la existencia de "bolivianos" como una característica específica de su realidad institucional y como parte de la conformación social del barrio. En este sentido, la presencia de "bolivianos" en la escuela se vincula con la relación más amplia que mantiene con la llamada comunidad o colectividad boliviana a través de los/as alumnos/as provenientes de "familias bolivianas". Así, más allá de la nacionalidad de los alumnos o del lugar de

433 Trpin (2004) discute que esta categorización responda a procesos de discriminación y estigmatización. Entiende más bien que esta adscripción a la categoría de "chilenos" se produce fundamentalmente en las relaciones sociales que tienen lugar en espacios donde acontece la reproducción del trabajador frutícola (como el trabajo, la familia y el lugar de residencia). 
nacimiento, los alumnos identificados con la "comunidad boliviana" son definidos como "bolivianos" en términos sociales, en tanto grupo nacional con características propias y uniformes. Esto queda expresado claramente cuando algunas maestras utilizan la noción de "los nuestros" para referirse, en sentido amplio, a los alumnos que no son "bolivianos" y distinguirlos de los "argentinos" o "cordobeses". Los "propios" y los "ajenos", los que pertenecen a nuestra nación y los que no.

Diversas representaciones e interacciones cotidianas, como podremos apreciar más en detalle en el próximo capítulo, muestran esta identificación e individualización como "bolivianos" a partir de aspectos sociales y culturales -desde tradiciones folclóricas y costumbres cotidianas, pasando por el uso del lenguaje y el doble apellido hasta determinadas características fenotípicas- comprendidos como rasgos de la "bolivianidad". En otras circunstancias, especialmente a los efectos administrativos o en momentos de reflexión grupal, como las reuniones de personal docente, o individual, como la entrevista en profundidad, las maestras diferencian entre "argentinos" y "bolivianos" de acuerdo al sentido jurídico de la nacionalidad. Es en este sentido que consideran que la mayoría de los alumnos de la "comunidad" o la "colectividad" (dando por sobreentendido que se trata de la comunidad o colectividad boliviana) son "argentinos", ya que han nacido en el país y poseen la correspondiente nacionalidad argentina. En estos casos, una aclaración frecuente entre las maestras es que "no son bolivianos, son argentinos" y que en realidad son "hijos de bolivianos". Complementariamente, identifican como "bolivianos" sólo a aquellos niños que han nacido en Bolivia, asociando país de nacimiento y nacionalidad. Así, en un sentido restringido, "bolivianos" serían aquellos alumnos hijos o nietos de bolivianos que poseen la nacionalidad boliviana, adquirida la mayoría de las veces por su lugar de nacimiento, mientras que en un sentido amplio también estarían incluidos bajo esta categoría aquellos descendientes de bolivianos que poseen la nacionalidad argentina, ya sea por el lugar de nacimiento o haya sido transmitida por la vía paterna o materna (por ejemplo, en el caso de que se hayan "nacionalizado").

Así que es... boliviana [se refiere a la señora Rosa], sus hijos son también traídos de Bolivia, son bolivianos [lo dice rápido y con tono bajo]. [...] Y bueno, al principio teníamos... siempre hemos tenido hijos de gente de Bolivia, nunca hemos tenido bolivianos en sí, sino hijos. (María)

[Son] `hijos de', no tenés ningún boliviano... tenés hijos de bolivianos [...] los bolivianos son los padres [...] no son bolivianos... son hijos de bolivianos... (María) 
¿Y la mayoría de los chicos de familias bolivianas son nacidos en Argentina...?

Sí, la mayoría sí, hay pocos que han venido de Bolivia, que han nacido en Bolivia...

\section{Son hijos o ya nietos algunos...}

Claro...

¿Y siguen manteniendo su doble apellido...?

Sí, la mayoría sí, sigue manteniendo el doble apellido... lo que pasa es que, te repito, no sé si vos alguna vez has venido al festejo de la Virgen [de Urkupiña]... es muy fuerte, es muy fuerte el grupo y sus costumbres las siguen manteniendo, en todo sentido, por ejemplo ellos... [se refiere luego al cumpleaños de quince, al casamiento, a las madrinas] (Mercedes)

La vida cotidiana en la escuela muestra que el sentido social y jurídico de la pertenencia nacional se conjuga de manera compleja. Los alumnos asociados a la "colectividad boliviana" son "bolivianos" en tanto son identificados con determinadas prácticas socioculturales y características fenotípicas a la vez que son considerados como "argentinos", debido a su lugar de nacimiento y su correspondiente nacionalidad. Todo ello se cruza con el uso peyorativo del término boliviano. Así queda expresado durante una entrevista con una de las maestras:

\section{¿Pero los hijos de bolivianos nacidos en Argentina también son bolivianos para mucha...?}

Sí, porque tienen todos los rasgos, porque tienen todos los rasgos, y toda la cultura y por ahí hasta la forma de expresarse y de hablar, sí...

Es decir, sigue siendo denominado "boliviano", haya nacido o no en Argentina...

Sí, es boliviano... por eso te digo...

¿Para los docentes también?

Sí, para todo el mundo... para los docentes, o sea, cuando vos hacés la libreta sabés que es argentino, pero para la gente, para tratarlo... bolivianito, el boliviano, che boliviano, sí, sí...

Para los chicos también, por más que haya nacido en Argentina es boliviano...

Sí, sí, es boliviano...

¿Y qué es lo determinante...? 
El color de la piel, sus características físicas... que por ahí tenés también chicos, profes o maestros que son del norte, de Jujuy, de Salta, y son bolivianos, ¿entendés? (Mercedes)

En el siguiente extracto de diálogo con una maestra se pone de manifiesto que en determinadas circunstancias se los nombra como "bolivianos" independientemente de si nacieron o no en Bolivia, admitiendo el sentido social que se le otorga en situaciones específicas como en el día de celebración de la independencia boliviana, como mostraré en detalle en el siguiente capítulo.

\section{¿Y estos chicos son bolivianos, son argentinos...?}

No, hay muchos que son argentinos, y hay otros que tienen la cédula de identidad [en voz baja], la cédula de identidad boliviana...

\section{Esos son chicos nacidos en Bolivia...}

Claro, claro... los que tiene cédula de identidad son nacidos en Bolivia...

\section{¿Son la minoría o la mayoría?}

La minoría... no, no es la mayoría...

O sea, la mayoría son nacidos acá, son hijos o nietos de bolivianos... Exactamente...

¿Y estos chicos que son nacidos acá, también se los consideran bolivianos en algún sentido?

Y sí... la mayoría de esos chicos te estoy hablando... pero se los considera bolivianos...

Es decir, tienen nacionalidad argentina, pero se los considera bolivianos...

Claro, vendría a ser lo mismo... porque el chico que quiere discriminar le ve la cara nomás, él no sabe si nació en Bolivia o nació acá, ¿me entendés? Partamos de ahí... el que quiere discriminar, no?

¿Necesariamente? Yo...

Le dicen: “¡Calláte, boliviano!”, me entendés? Y él no es boliviano, él nació acá... Pero, por ejemplo, el día del acto de la independencia de Bolivia, el 6 de agosto...

Bueno, hacen pasar esos chicos lo mismo... [...] quienes llevan la bandera son los que tienen... la bandera por lo general la llevan los padres, partamos de ahí, no la llevan los chicos...

¿Los chicos no la pueden llevar? 
Sí, pero siempre se ha elegido... la han querido llevar los padres y a lo mejor pueden estar de escolta los chicos... bolivianos...

\section{¿Sean nacidos o no acá?}

Exactamente...

(Pilar)

Por otro lado, entre los alumnos nombrados como "bolivianos", algunas maestras diferencian los nacidos en Argentina de los nacidos en Bolivia. Igualmente, más allá de esta división, al momento de referirse a "los bolivianos", reúne a todos bajo la misma categoría, diluyéndose la división establecida según el lugar de nacimiento y predominando el sentido social antes que el jurídico.

No, no, yo tengo... los tres que tengo en 5 to. D, los cuatro... son... tengo cinco bolivianos [en el aula]. Pero uno de ellos es nacido... los padres son bolivianos y el nació acá y los otros cuatro son nacidos en Bolivia y vinieron acá de chicos, es más, no tienen documento, no se han... no son nacionalizados... (Nora)

De todas maneras, el criterio de clasificación utilizado para fijar quienes serían "bolivianos" no está claramente establecido, generando confusiones y desacuerdos. A pesar de coincidir en el criterio jurídico para delimitar la pertenencia nacional a uno u otro colectivo (bajo el cual los bolivianos sólo serían aquellos que tienen la nacionalidad boliviana por nacimiento en el país de origen), la maestra hija de bolivianos y nacida en Bolivia reivindica el hecho de ser "boliviano", a pesar de la definición jurídica bajo la cual los hijos de bolivianos nacidos en Argentina son "argentinos". ${ }^{434}$ Es decir, sitúa el sentido social por encima del sentido jurídico. A la vez que reconoce que no son bolivianos, sino "hijos de bolivianos", por el hecho de haber nacido en la Argentina, plantea su pertenencia a la "colectividad boliviana". Así, si bien descarta que sean "bolivianos" en términos legales, la pertenencia al colectivo boliviano vendría dada por la posesión de o con la identificación con una determinada "cultura", la "cultura que ellos tienen", que los

\footnotetext{
434 En el caso de esta maestra nacida en Bolivia e hija de padre y madre bolivianos, hay una doble identificación, la cual se explicita, por ejemplo, para el Día de la Madre, cuyas fechas de celebración por país no coinciden. Igualmente el contexto donde se reside termina definiendo la prevalencia de uno u otro festejo. Así surge de esta conversación: ¿Qué tipo de fechas [bolivianas] son las que se mantienen o se celebran? / El 6 de agosto, el día de la madre boliviana, el día del padre pasa desapercibido (risas)... / Vos, en tu casa... / Yo festejo los dos, el día de la madre boliviana y el día de la madre argentina... Primero porque soy boliviana y segundo porque soy argentina y mi hijo es argentino, y el día del padre... / ¿A tu mamá cuándo la saludás? / En las dos fechas... / ¿En las dos fechas...? / Pero, normalmente, los regalos se los hago en el día de la madre argentina... [si se juntan también es ese día] (Jimena)
} 
diferenciaría de los alumnos considerados "argentinos". Así reconstruye el intercambio que tuvo con otra maestra en la sala de profesores:

\begin{abstract}
Ah, el otro día dijo una maestra... 'Si yo no tengo ningún boliviano' ... [Ella le respondió:] `Pero tenés hijos de bolivianos' ... [...] Y bueno... no sé si estábamos hablando de esto que los chicos bolivianos son más callados, como más respetuosos... y ella dijo, `no, yo no... primero que no tengo bolivianos en mi grado y segundo que...'. Le digo, ‘sí tenés, sí tenés, son hijos de bolivianos, no son bolivianos, pero lo mismo practican la cultura que ellos tienen', le digo, que es distinta. Y ella, `no, no son bolivianos'. 'Pero son hijos de bolivianos'. Y le fui nombrando algunos que yo más o menos diviso... (Jimena)
\end{abstract}

En la escuela estudiada la adscripción a una u otra categoría nacional se produce en términos dicotómicos: las opciones son "ser boliviano" o "ser argentino". Como señala Franzé, esta visión contrastante y dualista de las culturas, que presupone la existencia de diferencias culturales de carácter etno-nacionales, coloca a los alumnos/as entre una "irremediable opción" entre la cultura de origen y la cultura de destino, enajenándolos de "sus experiencias polivalentes donde se conjugan múltiples referentes culturales y múltiples conflictos, en una construcción irreductiblemente personal de la identidad" (Franzé, 2002:326). No son constatables fórmulas que expresen la constitución de identidades "híbridas", "múltiples" o "combinadas" (como podría ser argentino-boliviano o argenbol) o hablen de las "ambivalencias de los vínculos sociales" (Devillard, 2006). Tampoco circulan denominaciones que den cuenta de las pertenencias enunciadas y experimentadas, a partir de identificaciones de distinto tipo, por aquellos individuos niños u adultos- que poseen una nacionalidad distinta a la del lugar de residencia o que pueden ser identificados como ajenos a la comunidad política que, en términos jurídicos, comparten mediante la posesión de una misma nacionalidad. La autoadscripción a una u otra nación discurre entre la identificación con una o más lenguas (en ocasiones, a partir de la lengua de uso familiar, el quechua, y la de uso público u oficial en la sociedad de acogida, el castellano) o determinadas tradiciones culturales, la posesión de la nacionalidad y la duración de la residencia. El siguiente fragmento de la entrevista mantenida con un alumno de quinto grado, nacido en Bolivia e hijo de padres bolivianos, y un compañero suyo nacido en la Argentina y de padres argentinos, pone de manifiesto el modo complejo en que se define la pertenencia a una comunidad política determinada y en que se conjugan la lengua y otras prácticas socioculturales, la nacionalidad y el lugar de residencia, así como el peso específico que obtiene la nacionalidad como pertenencia a un ordenamiento jurídico concreto, en la configuración de las identificaciones nacionales, 
pero sobre todo en la posibilidad de apropiarse legítimamente de una determinada nacionalidad:

César: Yo ya... yo me siento un bilingüe, sé dos idiomas, muchos no lo captan al quechua, pero sé dos, por lo menos. A veces me dicen vos te pareces más a un argentino que a un boliviano, otros me dicen que "vos sos argentino" y "si vos sos boliviano... porque no te vas tratando de nacionalizar". Pero no quise, porque deshonraría a mi país...

\section{¿Deshonrarías a tu país...?}

César: Claro, porque yo dejaría de ser boliviano al nacionalizarme de este país, el dejarlo sería muy malo, por eso entonces (mis padres) no quisieron, sí sigo siendo boliviano, vivo acá en Argentina, mi papá vino por necesidad, porque allá en Bolivia mucho trabajo no había, vino...

Me decís: "sigo siendo boliviano, vivo acá en Argentina"... vos sentís que sos boliviano y argentino entonces...

César: Claro, dos cosas porque, vivo acá, pero nací allá, bueno, otra cosa es que mis padres sean argentinos (pero nací allá), sería hijo argentino...

¿Pero qué hace falta... por qué decís vos, Germán, que te sentís argentino...?

Germán: Bueno, yo me siento argentino, porque vivo en este país, tengo el documento de acá... (...)

César: Acá también el Hugo dice que ser argentino es ser un chico blanco, no negro como nos dice él a nosotros, yo digo que no soy ni tan negro ni tan blanco... pero para Hugo, de la forma que discrimina, es ser blanco... (...)

\section{Entonces... vos te considerás argentino y boliviano...}

César: Las dos cosas, porque vivo en la Argentina, pero soy boliviano...

Y qué notás vos que hace falta para ser boliviano o ser argentino, qué te hace ser de un lugar o de otro....

César: En Bolivia, allá en Bolivia hay muchas tradiciones y diferentes comidas y de cada población hay diferentes bailes, danzas como le llaman... sí, diferentes tradiciones para variar también, saben comer lechón, esas cosas, ve? Son diferentes tradiciones, saben ser las comidas picantes, picante de pollo... y eso el Hugo, llega a ver eso, se va a reír él, esas tradiciones no tienen acá, las tradiciones de ellos son el folclore, la comida, son las empanadas, pastelitos estas cosas, por lo menos es diferente eso...

Germán: Para Hugo ser argentino... qué sé yo, se ríe de cualquier cosa...

César: Que sea igual que él... 
El carácter peyorativo que asume la noción de "boliviano" en el contexto escolar, entre otros espacios sociales, ligado a situaciones descriptas en términos de discriminación en las cuales el gentilicio es usado como calificativo para insultar u ofender a algún compañero, hace que se utilicen algunos eufemismos para nombrar a los alumnos identificados de una u otra manera como "bolivianos". En este sentido, pronunciar la palabra "boliviano" es el equivalente a decir una mala palabra en voz alta. Por ello, suele ser reemplazado por referencias a la "colectividad boliviana", la "nacionalidad boliviana" o la "cultura boliviana". También, en distintas ocasiones, las maestras evitan pronunciar este término (o aunque se lo termine pronunciando, le suele anteceder una pausa) o modifican el tono, en general más bajo. En una de las entrevistas una maestra me quería indicar que una de sus compañeras era "boliviana" (hija de bolivianos nacida en Argentina) después de referirse a los alumnos bolivianos. Nunca alcanzó a pronunciar la palabra "boliviana", sólo hubo un largo silencio: "Ella también es..." (Pilar).

\section{Te confieso que nunca supe bien cómo llamarlos... bolivianos, argentinos, hijos de bolivianos, chicos de nacionalidad boliviana... ¿cómo los llaman?}

Sí, cuando nos referimos a ellos, sí hablamos de los chicos de la colectividad boliviana, de nacionalidad boliviana... lo que pasa es que estamos en este medio donde por ahí decir "boliviano" es como... por ejemplo, vienen las mamás, acá a registrar la firma, y le digo: ¿nacionalidad? Boliviana [en voz baja] o ¡Argentina, seño! [en voz alta] Como diciendo "qué me estás preguntando", entendés, hay una cuestión, en todo sentido, no te voy a decir que no, obvio que uno trabaja y hace cosas pero es algo que está fuerte en la cabeza... y esto de que el boliviano, la palabra boliviano sea un insulto, a mí también me cuesta... (Mercedes)

Entre las familias, frente a la hostilidad con que los hijos de inmigrantes bolivianos experimentan algunas situaciones sociales cotidianas al ser identificados y nombrados como "bolivianos", es común que se apele a la nacionalidad argentina que han adquirido sus hijos (debido al principio ius soli que rige el otorgamiento de la nacionalidad en la Argentina) para cuestionar el trato diferencial que reciben, buscando establecer o reclamando una relación de igualdad basada en la pertenencia a la misma comunidad política, o enfrentar la relación de desigualdad a la que se ven expuestos en tanto "bolivianos". La nacionalidad trasciende el terreno del formalismo jurídico y se vuelve un recurso estratégico. Este uso de la nacionalidad argentina, si bien desplaza en 
determinadas ocasiones la identificación con alguna dimensión que involucre la bolivianidad, no lo sustituye: al mismo tiempo que se recurre al sentido jurídico de la nacionalidad argentina en el espacio escolar, se recupera la identificación con aspectos sociales de la bolivianidad que se busca transmitir en el ámbito familiar. Durante una de las entrevistas mantenidas con las madres bolivianas, una de ellas comenta lo que le aconseja a sus hijos nacidos en la Argentina frente a situaciones experimentadas y nombradas como discriminación. La alusión a estos episodios se deriva de una pregunta inicial simplemente descriptiva: ¿a qué edad viniste a la Argentina?

Me vine más o menos a los dieciséis, diecisiete años. No vivía en este barrio, en ese tiempo vivía por la entrada a la Villa. Al venirme acá, ya había muchos paisanos, mucha mezcla, hay envidia, qué se yo, muchas cosas que pasan. No es lo mismo que cuando vivís tranquila en tu hogar o te conocen. Siempre se da discriminación también con los argentinos, a los bolivianos nos discriminan. Conmigo no pasó muchas veces, pero pasó con muchos paisanos. A veces a mi nena me le decían "boliviana"... ya, o sea, ya con el tiempo fue pasando y se acostumbraron que ellas no eran bolivianas. Te dicen boliviana, decíle con mucho orgullo que no sos tal como ellos, y ya está... (...) Yo les he enseñado de que a ellos les digan "boliviano", todas esas cosas, que no les hagan caso, porque en sí ellos no son bolivianos, son argentinos también. Yo les digo: "Vos no los escuchés, te dicen 'boliviano', bueno, 'vos no les llevés el apunte, vos hacé de cuenta que no escuchaste nada". Hicieron eso hasta que [quienes los molestaban] se cansaron y no los molestaron más a ninguno. Si le dicen ahora "che, boliviana", ella no les lleva el apunte, así que están más tranquilos.

(...)

Me decías que tus hijos habían nacido en Argentina. ¿Es importante para vos que ellos hayan nacido acá por alguna razón?

No, porque yo digo, si es tu hijo que tiene que nacer donde nazca... para mí no, no es importante que... a mí no me beneficia en nada que nazca acá o donde nazca, sea en la China, o donde sea... no, porque yo no tengo documento (y) tampoco hago validez de eso de identidad nacional. No me importa como dicen otros: "pero si tenés tus hijas argentinas, andá, te van hacer el documento más fácil". Es como que las estoy usando también a mis hijas. Así que no, no me importa donde hayan nacido mis hijas, nazcan donde nazcan van a ser siempre mis hijas...

Claro... y cuando a ellas les dicen "bolivianas"... 
Claro, yo les decía que ellas eran argentinas, claro, yo les digo así a ellas, porque les dicen "sos boliviana". "Bueno, vos no sos boliviana, sos argentina y ya está", les digo, qué les molesta a ellos, y nada, es argentina y listo. Y yo les digo a ellas que les contesten, esa es la forma: "Si vos sabés que sos argentina, no sos boliviana". Al menos a mí no me importa que sea boliviana, que sea argentina, que sea lo que sea, así que... a ellas les enseño cosas de Bolivia, o sea, las cosas de comida que hago, que no sé mucho ¿viste? Pero yo les enseño a ellas que esa es comida boliviana. No me la comen por ahí (risas), pero me gusta enseñarles. Por lo menos puse de mi parte a enseñarles algo. Ya si ellas no las quieren aprender, bueno, es cosa de ellas, ya será... o sea, yo intentaba enseñarles cosas de Bolivia y de acá, porque mayormente saben todo de la Argentina que de Bolivia. Por ahí me preguntan cosas de Bolivia y les digo: "yo mucho no te puedo decir", les digo, pero lo que pueda te lo voy a decir", le digo, porque hace cuántos años que estoy aquí, "lo que yo pueda te voy a decir, lo que no pueda, no, y no me preguntes más", le digo. Así que bueno, algunas cosas que yo sé por ahí, ese idioma quechua que hablan, no sé tan bien que se diga, pero bueno, sé, hablo algo, les enseño, pero no pueden hablar bien, por ahí se me hacen burla y dicen "mamá, hablás en chino, en inglés, ¿en qué hablás?". Y, bueno, les digo: “Te estoy enseñando lo que preguntaste, así que yo te estoy contestando lo que vos preguntas", les digo, yo les digo... Pasar por Argentina significa eso. (Isabel)

Otra de las madres entrevistadas transmite la incertidumbre, acompañada de sufrimiento, que les produce a los niños hijos de bolivianos, nacidos en la Argentina, el hecho de ser tratados (despectivamente) como bolivianos. Su comentario trasluce cierta esperanza depositada en los efectos sociales concretos que pueda tener la posesión de la nacionalidad argentina para revertir aquellas situaciones que experimentan como discriminación cuando son llamados "bolivianos" o "bolitas", apelativos que les asignan automáticamente un lugar inferior en la escala social. Un lugar que los niños, a partir de cierta edad, también empiezan a advertir de manera consciente. Así como en un pasaje anterior "ser argentino" era equiparado a "ser blanco", este acto cotidiano de inferiorización envuelve una asociación directa entre "ser boliviano" y "ser negro".

Sí, en la escuela lo mismo, a los hijos le dicen, [a los] hijos de bolivianos: “¡qué negros!". De todo los tratan, a los más chiquitos, chicos así golpeados. Hay otros chicos de bolivianos conocidos: “¡bolivianos! ¡bolitas!”, cómo les gusta eso. Regresan a la casa, llegan llorando. Los bolivianos son discriminados, no 
sólo los nacidos en Bolivia, los nacidos aquí no saben por qué les hacen eso. La más mayorcita ya se dio cuenta, siempre los hijos de bolivianos son de otra clase, no somos como lo que eran, con esa razón se discrimina mucho a los chicos en la escuela, siendo bolivianos... (Sonia)

Estas situaciones a las que se ven expuestos sus hijos "siendo bolivianos" tienen lugar en un contexto social más amplio donde circulan representaciones e imágenes arraigadas en el sentido común acerca de los bolivianos en la Argentina (extensibles también a otros colectivos de inmigrantes y, con sus matices, muy extendidas en distintas sociedades de inmigración) y que con una asombrosa naturalidad son reproducidas por los niños en el ámbito escolar. Una de ellas, como veremos a continuación, es que los bolivianos les roban el trabajo a los argentinos o, directamente, que son ladrones. Esta representación sobre los bolivianos, aunque persistente en el tiempo, encuentra en un contexto de crisis económica, como la vivida en la Argentina a comienzos de la década, ciertas condiciones de posibilidad particulares, pero adquiere una especial connotación entre sectores sociales que conviven a diario con los inmigrante bolivianos, pero que además comparten las vicisitudes del mercado laboral. Entre los alumnos, la identificación de alguno de los compañeros de clase como "boliviano" es independiente de si posee o no la nacionalidad boliviana o si ha nacido o no en Bolivia. Como sucede en el universo docente, la posesión de determinados rasgos fenotípicos, el vocabulario utilizado o el origen étnico/nacional de la familia puede alcanzar para ser considerado "boliviano". De todas maneras, la aparente nitidez del límite divisorio entre argentinos y bolivianos se desdibuja cuando alguien asumido como parte del nosotros nacional no sostiene o pone en cuestión el argumento que, en principio, se corresponde con dicha categoría, es decir, cuando cruza aquella frontera y altera el principio de exclusión que le otorga entidad al nosotros nacional. Esto es lo que ocurre en la siguiente situación de entrevista grupal cuando, entre un grupo de amigas (auto)identificadas todas ellas como "argentinas", una alumna es contradicha por una compañera que a raíz de ello es interpelada, colocándola del lado de los bolivianos, con tono desafiante e irónico al decirle: “qué, sos boliviana?”. Interacciones como éstas se repiten en diversas situaciones de aula o de recreación.

\section{¿Cuál es el problema de que estén acá? Cuéntenme un poco...}

Yamila: Sí, porque ellos vienen y te sacan el trabajo, eh... te quitan la poca plata que tenemos, eh...

\section{¿Cómo te la quitan?}

Yamila: Y sí porque ellos trabajan y nos llevan la poca plata que tenemos, que nosotros podemos agarrarla $\ldots$ 
Jazmín: Ellos tienen más plata en Bolivia...

Yamila: ...ellos tienen más plata en Bolivia, porque el padrino de mi hermana tiene mucha más plata...

Jazmín: ...y es boliviano...

Yamila: ...y es boliviano y él vive acá... y yo le dije el otro día: "Ud. tiene que estar acá tres meses, no más, y si no, tiene que irse a su país". Sí es la verdad, porque nosotros cuando vamos allá ellos nos dejan tres meses y después nos corren...

\section{¿Vos pensás lo mismo?}

Romina: Yamila, dejála hablar a ella...

Maribel: (Risas) Y sí....

Yamila: Sí, porque ellos tienen más plata, más oro, más todo tienen ellos...

Pero porque trabajan...?

Maribel: ¡Trabajan y roban!

Yamila: Y ellos si vienen al país...

\section{¿Cómo?}

Maribel: ¡Trabajan y roban!

Yamila: ...ellos se vienen al país más pobre a sacar plata...

\section{¿Por qué más pobre?}

Porque ellos trabajan y se llevan la poca plata que tenemos nosotros y...

\section{¿Vos también pensás que ellos se tienen que volver a su país?}

A coro: ¡¡Sí!!

Yamila: ii Y vos también te tenés que volver a Mar del Plata si estás estorbando acá!! (risas) No, los marplatenses no, porque son los bolivianos, porque este país es muy pobre...

Jazmín: Sí...

Yamila: Muy pobre, muuuy, muy, muy pobre, entonces ellos son ricos y los ricos se vienen para los pobres y nosotros cuando vamos para allá ellos nos sacan corriendo...

Romina: Pero los bolivianos no tienen la culpa, es el gobierno...

Maribel: Ah, ya metió al gobierno...

Jazmín: El gobierno no tiene la culpa, los bolivianos...

Maribel: Porque ellos nos quitan todo a nosotros y eso qué tiene que ver con el gobierno, acá en la Argentina... es un país...

Romina: Sí, pero los bolivianos trabajan, no roban...

Yamila: Los bolivianos son más ricos que el gobierno, ¿qué hacés? Qué, ¿sos boliviana? 
$(\ldots)$

Romina: El gobierno tiene la culpa...

Maribel: ¿Por qué decís eso Romina?

Romina: ¿Por qué estamos tan pobres en el país, porque ellos tienen la culpa...?

Maribel: Sí, pero los bolivianos son más ricos que el gobierno...

Yamila: Más ricos que todos los ricos...

Romina: Qué sabés si están cagados de hambre...

Así, "ser boliviano" en la escuela, ser nombrado o designado de ese modo, implica lidiar cotidianamente con la carga valorativa que tiene la figura social del inmigrante boliviano. Que los bolivianos sean acusados de robar el trabajo, no sólo presupone el establecimiento de una relación de competencia laboral (un supuesto robo que al final de cuentas no constituye delito), sino también, previamente, la asignación de un lugar ilegítimo en la sociedad de acogida, que le objeta -frente a una posible situación de escasez- el derecho al trabajo a raíz de su condición de no-nacional, que lo acusa de apropiarse de algo que naturalmente no le corresponde. La noción de intruso, utilizada en el siguiente fragmento de entrevista, habla precisamente de la inmigración o los inmigrantes como esa exterioridad que ingresa a un lugar que no le es propio o que ocupa un puesto que no le corresponde por derecho. Frente a dicha construcción, es común que los trabajadores bolivianos busquen distinguirse de "los criollos" -a quienes suelen acusar también de depender excesivamente de la ayuda del Estado- de acuerdo a la predisposición al trabajo de cada parte. ${ }^{435}$ Otra respuesta habitual a los males sociales que se les imputan es la diferenciación entre los buenos y los malos inmigrantes: no todos los inmigrantes "son lo mismo". De este modo, aunque cuestionan ciertas imágenes construidas sobre ellos, ratifican igualmente aquella visión que los propone como ilegítimos apropiadores de diversos bienes obtenidos mediante su trabajo. Así, por ejemplo, un buen inmigrante no debiera enviar dinero a Bolivia o invertir allí el capital económico acumulado a lo largo de varios años residiendo en la Argentina. Es allí donde la Argentina abierta a la inmigración y la esperada gratitud de (o la deuda contraída por) los inmigrantes se cruzan. Cualquier acción que pudiera ser interpretada como contraria a los intereses nacionales (del Estado o sociedad de recepción) pareciera constituir un pequeño acto de deslealtad o ingratitud

$435 \mathrm{El}$ testimonio de uno de los alumnos de quinto grado, hijo de padres bolivianos y nacido en Bolivia, también se apoya en la construcción de los argentinos como gente con falta de predisposición al trabajo y a la espera de la asistencia del Estado. Frente a la pregunta de cómo cree que los argentinos ven a los bolivianos, él responde: "Y hay quienes los ven como ladrones, porque por lo que he visto los argentinos mucho no trabajan y eso que estoy en Argentina, ¿no? Y muchos argentinos se dedican al robo o a quedarse en su casa esperando que vengan a atenderlos a ellos, pero allá en Bolivia no es así, hay gente que trabaja y no tiene qué comer, o sea, todos tienen que trabajar..." (César). 
frente a un país (un Estado, una economía, una sociedad) que le abrió las puertas a la inmigración como si de un gesto de solidaridad se tratara. Como contracara, la exigencia al Estado, frente a una hipotética expulsión, de aquello que se apropió (la fuerza de trabajo) durante sus años de residencia introduce un elemento disruptivo o puede abrir una grieta en aquellas formas o argumentos culpabilizadores. Frente a la pregunta acerca del modo en creen que son vistos los bolivianos por los argentinos, dos madres responden:

La gente, o sea, lo que veo (es que) que nos insultan... "ese boliviano que viene a robarnos el puesto de trabajo", o sea, nos ven como intrusos que venimos a robar los puestos de los otros, o sea, he escuchado por la tele, que dicen que "nos roban el trabajo"... o sea, una no viene a robarles el trabajo, sino quiere salir también de lo que uno estaba viviendo, por ese otro lado que no era su país, de ellos, así que no sé... para mí no vienen para robar el puesto de trabajo, nos ven así, porque dicen que ellos [los bolivianos] guardan su plata o que están llevando a Bolivia montón de plata, o sea, eso es cierto, o sea, algunos paisanos, ni todos son lo mismo, hay paisanos que juntan la plata si se van a Bolivia, algunos que no tienen la casa o viven de alquiler y se van, pero aquellos que tienen su casa la juntan y la quieren tener más como paisanos, no sé si viste [que] la mayoría de los paisanos tiene su auto, su casa, o sea, guardan plata porque les gusta tener a los paisanos, la casa, la plata o sea les gusta tener a ellos, no les gusta vivir siempre de alquiler [...] o sea, guardan la plata, sí, es para comprarse así una casita, un auto o lo que les haga falta a ellos, o sea, no siempre se llevan todo los paisanos, o sea, por uno pagan todos... no todos los paisanos son lo mismo que los otros, o sea, que han hecho mal, o que han robado o se están yendo, o sea, no son lo mismo, todos son distintos, todos son distintos: como el argentino, el boliviano, el peruano, o sea, todos son distintos, todos tienen defectos y... (Isabel)

Como que le sacamos el dinero [con tono risueño], eso piensan, que le venimos a sacar el trabajo, que dicen que nos vendemos más baratos, claro, porque se aprovechan... ellos mismos son los que se aprovechan, que les ofrecen a los bolivianos una transfugueada para hacer, estamos acostumbrados a hacer mitas. Un criollo, él trabaja por... qué sé yo, por las leyes que están marcadas su precio, las horas exactas, nosotros no... quiere buen pago, si no quiere, no va a trabajar, quiere estarse en su casa y de eso nos culpan a nosotros, de que nosotros le sacamos la plata... [...] yo le dije a una amiga que si me quieren botar de este país que me devuelvan el dinero que yo 
me traje de mi patria a este país y me voy, le digo, porque yo, “cómo me voy sin dinero ahora?", le digo... (Adelia)

\section{Los "alumnos bolivianos": estereotipos y prejuicios}

En las conversaciones, formales e informales, mantenidas con las maestras se pueden constatar aquellos estereotipos prejuicios relacionados a la falta de habilidades cognitivas o dificultades de aprendizaje que otros investigadores ya encontraron en sus estudios. ${ }^{436}$ Aunque no es en absoluto extensible a todo el cuerpo docente, en la escuela es identificable la circulación de un conjunto de representaciones emparentadas con lo que Bourdieu (1990) llama el racismo de la inteligencia. En este sentido, se destaca la imagen de alumnos calificados como "lentos", expresión que da por sobreentendido la referencia a las (o a la falta de) habilidades cognitivas o intelectuales, simplificada como "falta de inteligencia", y de ninguna manera -a pesar de lo que la noción de lentitud comúnmente indica en otros espacios sociales- a las (o a la falta de) cualidades físicas de los alumnos. ${ }^{437}$ En el contexto escolar, la noción de "lentitud" es asociada inmediatamente a las facultades mentales de los alumnos. En una oportunidad, durante una de las tantas conversaciones informales que mantuve con las maestras en los recreos, una docente de quinto grado me comenta espontáneamente -con una naturalidad sorprendente- que ella tiene una alumna "boliviana" que es "cero a la izquierda", hermana de otro alumno que tuvo el año pasado. Me dice que ella no sabe si son "lentos" porque no reciben atención en su casa de parte de sus padres, quienes trabajan todo el día en el mercado, o porque tienen problemas de desnutrición...

Esta supuesta "lentitud", adjetivada implícitamente como "mental", está presente, por mención u omisión, en las representaciones de los docentes acerca de sus alumnos considerados "bolivianos": por más que no se haga mención a ello, entre las características que se les atribuye, difícilmente se destaque o se haga referencia a la "rapidez", en tanto sinónimo de "inteligencia". Por el contrario, frente a situaciones de entrevista, algunas

436 Sinisi (1999), por ejemplo, en su análisis sobre la escolarización de hijos de inmigrantes de países limítrofes en escuelas de la ciudad de Buenos Aires, muestra que los estereotipos referidos a los alumnos de nacionalidad boliviana o hijos de bolivianos, construidos a partir de una percepción sobredimensionada de la diversidad, se vinculan con la capacidad intelectual, la limpieza o el aseo personal, los condicionamientos ambientales y la manera de hablar. También señala que los estigmas suelen referirse específicamente a las nociones de raza, nación y cultura. 437 La supuesta "falta de inteligencia" suele aparecer también conceptualizada como carencia de "agilidad mental". 
maestras contraponen a la "lentitud" la actitud responsable o respetuosa del alumno boliviano.

Y bueno, por ejemplo, en el col... la chiquita esta... que está a la defensiva, es muy, muy aplicada, bueno, tiene la carpeta muy aplicada. Le cuesta, le cuesta, en algunas materias como en mi caso, que es matemáticas, pero ella... realiza todas las actividades y una vez que realiza las actividades viene y me trae la carpeta para que le corrija... todo. Parece que le observan muy bien en la casa, entonces ella quiere que le corrija ya, cosa de llevar todo corregido. Pero es así, muy aplicada... que le cuesta, sí... (Soledad)

Destaco, sí, lo respetuoso que es esta otra gente, no? Como también ha habido algunos chicos que... de nacionalidad boliviana que, medio como que... pero muy poco, uno habrá sido... porque trataban siempre de cumplir, me entendés, por más que a lo mejor fueran más lentos, algunos, eh? hay otros... por ejemplo, hace no sé si tres o cuatro años atrás fue nombrado escolta un chiquito boliviano a pesar de tener la nacionalidad boliviana, que no era argentino, por su labor en la escuela, fue yo creo que la primera vez... (Pilar)

Esta "falta de inteligencia" que se les atribuye se fundamenta en las "dificultades de aprendizaje" que son "detectadas" - lo cual constituiría la prueba en mano- por las maestras en clase, especialmente aquellas denominadas como "problemas con lengua", en contraposición a la habilidad particular o preferencia que tendrían para las matemáticas, debido a su temprana relación con el trabajo y el intercambio monetario, sugiriendo en algunas circunstancias que dicha habilidad se relaciona con su predisposición o condición natural para el trabajo. La creencia de que "tienen mucha facilidad para las matemáticas" o para "los números" (Soledad) está bastante difundida entre las maestras. Esta imagen estereotipada, si bien también recae sobre los alumnos bolivianos, aparece como validada para todos los alumnos de la escuela (si bien en el relato no se diferencia entre varones y mujeres, en general, se piensa generalmente en los primeros).438 Aquellos chicos/as que se destacan por su rendimiento escolar son considerados generalmente una excepción.

\footnotetext{
438 Es común que a los alumnos de sectores sociales pobres se los asocie con la carencia de habilidades cognitivas o intelectuales, en especial aquellas relacionadas al aprendizaje de la "lengua", sobre todo del uso "correcto" del castellano. Por otra parte, esta supuesta habilidad natural para las matemáticas fundada en el trato diario que tienen con el dinero los alumnos provenientes de familias de sectores populares y las dificultades de aprendizaje en asignaturas como "lengua", también pude corroborarlo en un estudio anterior sobre cultura escolar y desigualdad social. La descalificación que padecen los alumnos es apenas un esbozo de la violencia simbólica que se ejerce
} 
[...] En general, yo veo que acá en la escuela les gusta más las matemáticas, que la lengua... / ¿A quiénes...? / A todos los chicos, en general, en cada grado vos hablás con cada maestra y te van a decir que les gusta más las matemáticas que la lengua, quizá por que manejen más el tema del dinero, de las compras... entonces, quizá que por eso les guste más las matemáticas. Y tienen muchas dificultades en la lengua... (Nora)

Walter [alumno boliviano] más que para las matemáticas es la plata... como ellos vienen tan... preparados para trabajar y saben que... cuáles son las funciones, que tienen que trabajar... yo los otros días me encontré dos exalumnas mías en la feria, están trabajando en la feria, ellas trabajan a la mañana en la feria y a la tarde vienen a esta escuela. A la tarde están en el colegio, apenas me vieron que me bajé de la bicicleta (risas): "Seño, yo voy a la tarde a la escuela"... porque sabían (risas) que le iba a preguntar a qué hora va a la escuela, ¿viste? (risas) "Voy a la tarde, seño", “Ah, bueno, menos mal” era lo que les iba a preguntar. Y... para las matemáticas, todos los prácticos, pero son... un avionazo, un avionazo... Lo que les cuesta es la producción, ¿viste? (María)

Además de estas prenociones y de las diferentes opiniones que circulan sobre los alumnos y alumnas hijos de inmigrantes bolivianos, prácticamente la totalidad de las maestras entrevistadas destacan lo que a su manera de ver son atributos positivos: los alumnos bolivianos serían fundamentalmente "respetuosos" y "educados". Estas designaciones son utilizadas como equivalentes o intercambiables para caracterizar a aquellos alumnos y alumnas que se comportan de acuerdo a lo que las maestras valoran altamente como las normas de cortesía y el acatamiento de la autoridad docente, o al menos no las cuestionan o quiebran. Es decir, aquellos que -en palabras de una maestra- son "correctos", libres de actitudes contrarias a ciertas conductas sociales esperadas o de aquellos errores o defectos que los apartan de las normas que constituyen el orden escolar y social establecido.

cotidianamente en la escuela: “A estos chicos vos le preguntás y no saben ni contestar, no tienen agilidad mental. Agilidad mental tienen para otras cosas, porque lo practican... ellos viven en un ambiente donde [...] algunos roban por ahí, entonces esas manías se las saben todas, pero bueno, interpretar un texto, ahí ya cambia, interpretar una consigna... manejan muy bien la matemática, por ejemplo, porque ellos manejan la plata, pero en la parte de lengua, les hacés escribir, y bueno, de escribir ni hablemos, no se entiende lo que escriben, un desastre”, decía un maestro (Domenech, 2000:86). 
¿Y entre los docentes qué circula respecto a estos chicos, qué comparaciones se establecen...? / Las comparaciones comunes... o los comentarios que yo escucho en la sala de maestros... que son muy educados, sumamente educados... ah, sí, pero vos viste, Juanito es muy educado... (Valeria)

Claro, lo positivo yo pienso... todos los valores, cómo son ellos de respetuosos, de educados, de interesarse mucho por cosas que hacen... [...] el tema de que son cariñosos, que son... de que están esperando a ver cuál es nuestra actitud frente a ellos, es decir... son miles de... son muy de darse... muy de entregarse... (Mercedes)

Bueno, lo que yo pude observar es que los chicos tanto bolivianos como peruanos ${ }^{439}$ son muy educados, muy correctos... o sea, no se prestan a las malas palabras, por lo menos cuando yo he estado en el grado... cuando se les ha tenido que citar a los padres, los padres han venido, los padres también muy educados en ese aspecto... (Pilar)

La respuesta de una maestra a la pregunta sobre el sentido que le otorga a la noción de "educado" evidencia la connotación moral que posee, reconociendo que la noción de "respetuoso" expresa más adecuadamente lo que se quiere transmitir: que los bolivianos tienen buenos modales, que no son groseros.

\begin{abstract}
¿Cuándo me decías que los chicos bolivianos son educados... educados en qué sentido? Está bien... ¿qué es ser educado? Qué sé yo, viste... saludan, se dirigen a uno de una manera... entre comillas muy educadita... cómo se dirigen, cómo te hablan, a la maestra... Es como que la maestra todavía tiene la ubicación que en algunas familias se ha perdido... no es que eso sea importante, pero... eso me parece que en la casa se lo inculcan, no? Viene de la casa... [...] Son respetuosos, más que educados... respetuosos, esa es la palabra, esa es la palabra... (Marta)
\end{abstract}

\footnotetext{
439 A la escuela asistía un solo alumno de nacionalidad peruana. Sin embargo, la existencia de un único alumno de nacionalidad peruana lleva a la institución en diversas ocasiones a hablar de la presencia de la "comunidad peruana". Resulta un claro ejemplo del sobredimensionamiento de la presencia inmigrante que suele producirse en las escuelas a las cuales asisten hijos de inmigrantes de países limítrofes.
} 
En general, para las madres bolivianas la interacción entre alumnos y entre alumnos y docentes no es la que esperan ni es vista como la adecuada para la vida en una escuela. Las peleas y el vocabulario utilizado entre los compañeros no se condicen con el entorno escolar que ellas pretenden para sus hijos. Consideran que las maestras y los adultos en general no reciben el respeto que deberían tener. Dice una madre que desea cambiar a su hijo de escuela el año próximo:

\section{¿Y qué les cuentan sus hijos de la escuela? ¿Cómo se sienten ellos en la escuela?}

En esta escuela, bueno, mi nene está... sí, se quiere ir de esta escuela, si Dios quiere lo cambio de colegio, porque no le agrada, tienen un vocabulario horrible acá... porque él no está acostumbrado en esta escuela con estos compañeros, palabras que son muy groseras... las peleas constantes que hay, que lo agreden siempre... ya sea verbalmente o le pegan, así de sencillo [...] La agresividad es mucha... no hay respeto para los maestros... son agresivos, no saben lo que es respeto al mayor, ni a los padres, porque los padres, yo pienso que no se hacen cargo de sus hijos, porque si se hicieran cargo no estarían así, hay como mucho... vio? (Adelia)

Esta representación sobre los alumnos bolivianos como "respetuosos" es complementada por o, mejor dicho, se articula en el discurso docente con la idea de que los bolivianos tanto alumnos como padres/madres- son "sumisos". En uno de los testimonios también aparecen nominados como "dóciles". Esta caracterización no llega a advertirse necesariamente entre las maestras como una propiedad negativa (en la mayoría de las entrevistas), al menos no se la cuestiona o contradice, lo cual pone en evidencia la naturalización de la cual ha sido objeto esta representación o la aceptación generalizada que tiene una posición social subordinada; tampoco es reconocida la relación de dominación implicada en la noción de sumisión.

En ocasiones, la construcción de los alumnos bolivianos como sujetos respetuosos o sumisos encierra calificativos como "callados" o "tímidos". Estas imágenes surgen en las entrevistas frente a la pregunta sobre la participación en clase de los alumnos bolivianos. En algunas respuestas se especifica que se trata de una "mayoría", evitando ciertas generalizaciones -todos los bolivianos serían respetuosos, sumisos, callados- comunes en el espacio escolar. De todas maneras, en estas circunstancias, aunque tanto los alumnos bolivianos como el resto de los compañeros sean considerados "callados", no todos 
reciben el rótulo de "sumisos", sino que -en esta escuela 440 - queda reservado para designar a los bolivianos (o algunos bolivianos de acuerdo a determinados testimonios), quienes generalmente no dejan de ser pensados como un grupo mayoritario que contiene excepciones a la regla. Estas imágenes esencializadas acerca de los alumnos bolivianos son construidas alrededor del silencio como un rasgo propio o intrínseco, tanto del orden individual como del grupal, definido por el colectivo al cual se los adscribe, y también ajeno a las circunstancias sociales y educativas más amplias. Estas construcciones en torno al "silencio" atribuido a los alumnos bolivianos, como sugieren Novaro et al. (2008), es un modo de interpretar el hecho de que sus voces, sus palabras, sus saberes no aparezcan directamente expresados en situaciones de clase o que no se expliciten de la misma manera en que lo hacen sus compañeros. Como se desprende de un estudio etnográfico realizado en una institución educativa con una alta proporción de alumnos descendientes de inmigrantes provenientes de Ecuador, Bolivia y Colombia, situada en la ciudad de Madrid, las explicaciones que construyen las maestras sobre el silencio de sus alumnos bolivianos responden a un desajuste interpretativo resultante del encuentro de patrones de interacción/participación del lugar de origen y de destino que son discrepantes entre sí. El silencio como señal de consideración, junto al uso de un tono bajo de voz, la actitud de quietud, el precepto de no contestar y no contraargumentar, forma parte de las disposiciones esperadas tanto por sus familias como por la institución escolar en la sociedad de origen según la jerarquía maestro-alumno socialmente aceptada (Franzé et al., 2011).

\begin{abstract}
¿Son participativos? / La mayoría de los casos son muy callados y muy sumisos. Hay un par que no, para nada son sumisos, para nada callados, por eso te digo que depende, así como hay chicos también... nuestros chicos, cordobeses, argentinos, que también les cuesta participar... puede ser que la mayoría de los casos, si vamos a hacer un porcentaje, sean chicos que les cuesta participar porque... tienen problemas a lo mejor con la pronunciación de algunas palabras o porque viste que a algunas cosas las llaman de otra manera y los demás se les ríen, entendés? Pero... o porque son sumisos y les da vergüenza, son tímidos... (Mercedes)
\end{abstract}

\footnotetext{
440 En un estudio anterior realizado en una de las escuelas denominadas urbano-marginales, los alumnos de sectores populares también eran caracterizados como sujetos pasivos, utilizando para designarlos nociones como "dóciles" o "sometidos". Uno de los directivos declara durante una entrevista: "Son chicos muy humildes, muy dóciles, [...] como en la casa son agresivos, o a lo mejor los castigan, o qué se yo, son sometidos, entonces ellos no se... entonces cuando se los reta o se los... se les hace un llamado de atención es muy difícil que contesten, prácticamente pienso que no ha habido casos, salvo alguno muy esporádico" (Domenech, 2000:86).
} 
Generalmente los chicos de nacionalidad boliviana o de cultura boliviana, no en todos los casos, pero la mayoría, son nenes más bien sumisos, muy respetuosos... que te hablan de una manera rara, pero porque son chicos, porque se expresan de otra manera... te piden las cosas por favor, te dicen gracias... la mayoría de los casos, no en todos... pero la mayoría de los casos, sí... (Mercedes)

¿Son participativos en clase los chicos? Y... sí, algunos sí, otros que más o menos... eso es relativo, porque también el niño boliviano a veces no tiene... es tímido, no quiere participar, entonces ahí interviene el docente y es el que tiene que acercarlo, acercarlo para que el niño pueda acercar sus vivencias, que son muy buenas, muy enriquecedoras, se juntan mucho, hacen mucha convivencia ellos, mucha fiesta, entonces es bueno que ellos también nos cuenten a nosotros... pero eso es como de a poquito, hasta que van entrando en confianza, porque yo noto que son tímidos... (Gloria)

Esta equivalencia que se construye entre silencio, sumisión y timidez también aparece, entremezclada con la lentitud mental que en ocasiones se les atribuye, en la comparación que establece una maestra entre los alumnos bolivianos y un alumno hijo de inmigrantes peruanos que asiste a la escuela.

No era tan tranquilo y sumiso como los bolivianos ese chico. Era más suelto, muy capaz también, o sea, ese chico era muy capaz, muy responsable, entendía, captaba enseguida, pero no era tan sumiso, o sea, participaba en clase. En cambio, a los bolivianos les cuesta participar en clase y si uno les dice... te dicen bajito [disminuye el tono de voz], les da vergüenza, así como hacen los padres también, así vienen los padres y te hablan así como agachando la cabeza y que a veces no les entendés qué quieren decir. (Nora)

Por el contrario, una docente no comparte la idea de que los alumnos bolivianos sean "sumisos" debido a que ellos no se dejarían avasallar. Para fundamentar su opinión establece una diferencia entre "respeto" y "sumisión", nociones que aparecen como equivalentes en otros testimonios. Sin embargo, no descarta que esta noción pueda aplicarse a las alumnas bolivianas. En otra entrevista, una maestra indica que las niñas bolivianas serían aún "más sumisas" que los varones bolivianos, relacionando la idea de sumisión con el silencio (el varón, en cambio, sería algo más "abierto" y "agresivo"). La 
ambivalencia entre el respeto y la sumisión también aparece en las narrativas de las maestras acerca de los familiares de los alumnos bolivianos.

\section{En la escuela hay una apreciación corriente: que los bolivianos son}

sumisos... / Sí, es una apreciación... a lo mejor porque son calladitos... no, pero en la escuela yo no veo que sean sumisos, no se dejan atropellar por el otro... eso es ser sumiso, no? Pero me parece que entre ellos... pero con la maestra es respeto, no es sumisión, creo, no... [...] Ellos son... yo lo veo desde mi lado, ellos son muy respetuosos, no sumisos, pero sí respetuosos, hay excepciones, obviamente... sobre todo las nenas son muy... ellas, quizás... podemos poner la palabra sumisa, a lo mejor... (Marta)

Las nenas bolivianas son más sumisas todavía que los varones. Las nenas son mucho más calladas, mucho más... no te hablan nunca en el aula y a lo mejor son buenas, te muestran interés... vos decís, están en el aula, no participan, parecen que no supieran nada... a lo mejor una evaluación te la hacen de diez... En cambio, el varón, es más abierto, un poquito más abierto que las nenas... más... un poquito más agresivo... (Mercedes)

¿Cómo vemos nosotros a los padres de los chicos bolivianos? Bueno, como te decía anteriormente, muy respetuosos con nosotras, las docentes, muy sumisos también, cuando se les llama la aten... se las habla porque está flojo en esto: "sí, señorita, sí señorita, se va a trabajar, sí". o sea todo muy, muy, muy de... muy sumisos, muy como ya de por demás, ¿viste? [...] Hay padres que se ponen en contra tuyo... [...] Ellos nunca te van a decir nada con respecto a lo que vos le dijiste, nunca... aceptan todo... y si vos los llamás, vienen, siempre vienen. (Nora)

Como se puede observar en el testimonio anterior, a los progenitores de los alumnos bolivianos se les atribuye una predisposición natural a la sumisión. Diversos estudios sobre las representaciones acerca de los inmigrantes bolivianos en distintos espacios sociales, en particular en el ámbito laboral, muestran que la caracterización de los bolivianos como "sumisos" atraviesa el discurso social más amplio. En una entrevista para un medio electrónico local de información al representante de una organización de residentes bolivianos en Córdoba, su testimonio ofrece un punto de vista distinto sobre aquella conducta interpretada (desde la sociedad de acogida) como sumisión. El silencio se vuelve una respuesta estratégica aprendida socialmente bajo diversas circunstancias 
históricas de dominación y violencia vividas en el contexto de origen. Al interpelarlo la periodista diciendo que "la sensación es que los bolivianos son muy sumisos...", él le responde:

Los bolivianos no somos sumisos. Eso que llamas sumisión son tácticas y formas de resistencia. Las rebeldías e insurrecciones que ha habido en el campo fueron respondidas con saña y masacre. Aprendimos que cuando somos débiles debemos mantener el silencio. A la bronca la vamos masticando, teniendo acá dentro y cuando llegamos organizados somos capaces de sacar a patadas a gobiernos apoyados por el imperialismo, la fuerza militar, la oligarquía. Cuando nos discriminan, no pensamos "nos están degradando" sino que el agresor se degrada y lo vemos como un tipo ignorante al que no vale la pena contestar. (Franz Prieto Terán, presidente del Centro de Residentes Bolivianos en Córdoba, 2 de agosto de 2006, en http://www.sosperiodista.com.ar)

Por otra parte, Novaro et al. (2008) encuentran en el discurso docente "una asociación directa entre una posición distante y contenida de los chicos y las referencias culturales con las que estos niños son identificados en la escuela" (Novaro et al., 2008). Esto ocurre, en general, con las explicaciones que otorgan las maestras para sostener las características atribuidas a los alumnos bolivianos. Aquí es habitual que recurran a la cultura a la cual pertenecerían naturalmente, es decir, su cultura. Una idea de cultura esencializada que, en estas circunstancias, desplaza los componentes folclóricos que se les suele atribuir por su membrecía a un colectivo identificado nacionalmente, para añadirle atributos sustentados en valoraciones sociales y morales producidas en relación a sectores sociales afectados por la marginación y la pobreza.

En cuanto a... la diferencia en cuanto a lo que te decía al principio, del respeto, son más tranquilos, más respetuosos, eso es la única diferencia que he notado... yo pienso que [tiene que ver con] la cultura de ellos, porque los padres también tienen esa postura sumisa, no sé, yo... cómo vienen, cómo son ellos allá... debe ser que... cuál es su costumbre, porqué vienen y trasladan eso acá... los nuestros están como más sueltos, más desinhibidos, ellos no... (Nora)

Son más afectivos, más sentimentales, como que les pasa sangre por las venas, en cambio, ellos no, son más tranquilos: nunca un "hola, seño", ni un abrazo, no, y si vos les hacés una caricia es como que se quedan ahí, duros, como que 
les da vergüenza, no sé... por eso nunca supe la... la cultura de ellos... por qué son tan sumisos? Como que hay algo, ¿viste? Como las mujeres que el marido la tiene... que le pega, bueno... que son sumisas o los chicos que son muy golpeados. Bueno, una cosa así... [...] Te digo como que la gran mayoría... que habrá dos o tres que son la excepción, que son un cohete, pero el resto, resumiso... es la característica que yo veo de ellos [...] Por eso es que me gustaría saber por qué esa cultura de ellos, o si es por nosotros o si ellos son así allá, eso no lo sé... [...] ...si ellos ya son así o su cultura y la trasladan acá o bien acá son así y allá son de otra forma, no sé... eso no lo sé... (Nora)

¿Y tienen buen concepto? / Sí, sí, muchos de ellos, sí... por eso te digo, depende mucho de... ellos tienen toda una cultura y toda una formación... y tienen castigos también... las mamás de los chicos, las mamás bolivianas que van a la escuela te hablan de los castigos, de los golpes... lamentablemente hay otras cuestiones como esta cultura de tomar mucho, de las fiestas, cosas feas... (Mercedes)

Wilfredo tenía un problema... pienso yo que tal vez por la forma en que ellos son... ellos son muy estructurados, "usted no tiene que contestar", "usted cállese la boca"... la señora Rosa te lo dice, nadie tiene que contestar, la señorita tenga o no tenga razón baje la cabeza. (Valeria)

Pero de todas maneras cada uno sabe ganarse su lugar... algunos son muy respetados, muy queridos, por las cosas que hacen, sus actitudes, su forma y hay otros que se aíslan... También tiene que ver con su cultura, con su forma, con sus padres... La mayoría de los chicos que son muy sumisos como que se aíslan, sí? (Mercedes)

La maestra que los califica de "tímidos", sin otro atributo, ofrece un punto de vista distinto. En lugar de depositar la explicación en la cultura de origen o el ámbito familiar, la coloca en la interacción con la sociedad receptora, en las implicancias de estar en otro país.

¿Por qué crees que son tímidos? Será porque no le damos mucho la palabra, porque nos ven... ellos nos ven diferentes a nosotros y nosotros los vemos diferentes a ellos... es un poco ponerse en el lugar del otro, saber que están en otro país, que están aprendiendo cosas de otro país... (Gloria) 
Asimismo, el testimonio de la señora Rosa, nacida en Cochabamba y radicada en Córdoba desde muy joven, donde los bolivianos también aparecen calificados como "tímidos", sitúa la explicación acerca de la "timidez" de los bolivianos, una timidez que se revela sólo en el intercambio cotidiano con los argentinos, en el hecho de estar en otro país. De algún modo, bajo estas coordenadas, podría pensarse como una actitud de presunción o sospecha, en tanto anticipación al rechazo social que en ocasiones puntuales de la vida cotidiana se experimenta, acerca de la ilegitimidad que se le confiere a su presencia en una sociedad que le recuerda, mediante pequeños actos cotidianos, que es de otro lugar. Es, quizás, uno de los tantos modos en que la inmigración adquiere materialidad como presencia ilegítima, construida social y políticamente, en las interacciones sociales. Durante la entrevista mantenida con ella explica:

Los bolivianos, como te digo, son tímidos, no... alguna gente que no se defiende para nada... Yo también era muy tímida, ahora ya esa timidez ya se me fue, viste, pero de algunos no, no pueden abrir la boca si quiera con nadie para hablar. [...] Qué se yo, será temor por lo que están en otro país, no sé, algo, esa timidez tenemos, todos, yo he sido peor también, tal vez igual que ellos. Pero nunca, nunca, he molestado a nadie, si tengo, tengo, si no tengo, no tengo, hay así, pero ahora ya... la vida misma a uno le enseña las cosas $y$, entonces, ya me he abierto un poco. [...] Cuando estamos juntos, no, no nos pasa eso, parece que... qué sé yo, que estaríamos más... cómo puedo explicarte... cuando nos juntamos no hay esa timidez como cuando nos juntamos con los argentinos. No hay, no, no lo sentimos entre nosotros, si estamos en ese grupo, pero cuando estamos con otra gente ahí viene la cosa. [...] Es como un rechazo a tu presencia. (Rosa)

Como contraparte, una de las maestras, al referirse a las diferencias de comportamiento entre los alumnos bolivianos y los argentinos, utiliza la metáfora de la escuela como "casa" para explicar la "soltura" corporal de "los nuestros" -los argentinos- frente a los "chicos bolivianos", considerados más "tranquilos" (pero que pueden llegar a "contagiarse" de los primeros). La metáfora remite a la escuela como hogar de los argentinos, territorio material y simbólico de la nación argentina, en la cual "los nuestros" están en su casa, familiarizados con el entorno circundante, mientras que "los chicos bolivianos" estarían convidados, es decir, participados pero extraños al fin.

En general, los notás más callados a los chicos, en tus clases... iy en el patio, por ejemplo, en el recreo...? Se sueltan un poco más en el recreo, es 
como que se contagian también porque ahora con el tema de la "atrapadita" y, bueno, se van contagiando con ellos... y, bueno, y ahí eso, la atrapadita, crea agresión: que se pegan patadas, que se empujan... o sea que... un poco... y hay otros que no, están más tranquilitos, que se aíslan, y otros... y todos los otros que buscan pelear, como este chico que tengo en quinto: está buscando a quién le pega una patada para molestar y seguir... y bueno, ahí vienen los conflictos, pero en general los chicos no, son más tranquilos. Tenemos los nuestros también más tranquilos, pero... Es como que decís: "estás en tu casa, estás más suelto", es una cosa así, yo no sé cómo son los chicos bolivianos en su casa o en la calle, no los he visto. (Nora)

Entre los atributos positivos que se les suele asignar, algunas maestras también enfatizan que son "estudiosos" y "responsables", a diferencia del resto de los alumnos, "los nuestros". Estas características estarían relacionadas con el interés que recibe la educación entre los inmigrantes como recurso de movilidad social ascendente. Las maestras suelen destacar el valor que posee la educación escolar para las familias bolivianas. La profesora de plástica, por ejemplo, comenta que las madres bolivianas siempre se interesan por el rendimiento de sus hijos en su materia "porque forma parte de toda la educación que se les brinda", a diferencia de "los nuestros". También considera que las escasas inasistencias entre los alumnos bolivianos son una muestra del valor que le otorgan a la educación en su búsqueda de "progreso" (Marta). De igual modo, otra maestra sostiene:

[Son] muy respetuosos, tranquilos... estudiosos también, se preocupan más, son más responsables... siempre tratan de cumplir y se ponen mal cuando alguien se olvida, como cuando les llamás la atención, que a lo mejor los nuestros te hacen así [gesto de despreocupación con la mano], o sea, ellos no, jamás te van a hacer un gesto. Son más respetuosos. Y valoran más no sé, el estudio... tienen ganas de estudiar, de progresar, bah... no sé, los veo en eso... en esta actitud. (Nora)

En el espacio familiar, el acceso a la educación escolar de los hijos, aunque no necesariamente sea la motivación principal de la migración a la Argentina, sí resulta un aspecto constitutivo del proyecto migratorio. ${ }^{441}$ Con el tiempo se puede convertir,

441 Como plantean Franzé et al. de acuerdo a los avances de la investigación mencionada, el acceso a la educación formal, apreciado en términos de éxito, ascenso y reconocimiento social, posee una importante valoración entre las 
asimismo, en una de las razones fundamentales para permanecer en el país, aún en tiempos de crisis económica, que puede dilatar el proyecto o el deseo de retorno, o justificar el sufrimiento que produce la distancia con Bolivia, que es, básicamente, la lejanía de la familia. Así hablan dos madres bolivianas en el contexto de crisis social, económica y política que vivió la Argentina hacia inicios de la década:

"Y es por tu futuro más que todo", le digo cuando me hace enojar él. Yo le digo a él: “[Si] yo estoy aquí, es por vos”. “¿Por qué me haces enojar tanto?”, le digo a él [cuando] lo reto. No estaría yo sufriendo, porque estoy lejos de mis afectos, de mis parientes, porque yo tengo muchos hermanos, y soy la única mujer... (Adelia)

Ahorita estoy aguantando yo, con esta situación están aguantando los que tienen casa, los que no tienen casa ya se han mandado a mudar hace mucho... y hay otros que aguantan, porque los hijos están estudiando, por eso...Yo aguanto porque mi esposo no quiere irse, sino me iría... (Sonia)

La reputación de "respetuosos" que los alumnos bolivianos han obtenido entre las maestras sería producto de los aprendizajes que tienen lugar en el entorno familiar. Asociado a ello, algunas docentes también destacan la prolijidad en la vestimenta y el cuidado de su aspecto exterior, en particular de las alumnas: van a la escuela "impecables".

Yo tengo ahora alumnos bolivianos en primer grado y el papá es el primero que está y me pregunta “¿cómo anda mi hijo?” y si... “¿a usted le hace caso...?”. Hace mucho hincapié en eso... que sean muy respetuosos, les enseñan eso a sus hijos, respeto... aparte la prolijidad con la que vienen vestidos... impecables las nenas, sus peinados bien elaborados, se toman el tiempo para hacerse una trenza cosida que a lo mejor te lleva diez o quince minutos, y así vienen las nenas, impecables... / ¿Y los varones, no? / También los varones, pero voy al hecho de que una nena te lleva mucho más tiempo su peinado, su vestimenta, el varón a lo mejor se pone una remera, una campera, un pantalón y ya está listo, pero las nenas bolivianas vienen... se distinguen... (Gloria)

familias inmigrantes y se puede convertir en la justificación del proyecto migratorio familiar. A ello está asociada la idea de "sacrificio familiar" que suele aparecer entre los testimonios de los progenitores (Franzé et al., 2011). 
Estas cualidades personales ligadas al respeto y a la higiene, altamente valoradas entre las maestras y especialmente afines a los parámetros que rigen el orden escolar ligados a la construcción de la idea de nación, como veremos en el próximo capítulo a través del análisis de los rituales patrióticos, son confirmadas o validadas por las madres bolivianas entrevistadas. Al indagar sobre las expectativas que imaginan que la escuela tiene sobre los alumnos y lo que ellas esperan que sus hijos aprendan en la escuela, sus respuestas remiten a un buen comportamiento, circunscripto por las nociones de respeto, responsabilidad e higiene. El respeto a la maestra es un elemento recurrente en las conversaciones informales mantenidas con las madres bolivianas, en particular cuando se refieren a las diferencias que encuentran entre la escuela de allá (Bolivia) y la escuela de acá (Argentina). En estrecha relación al modelo educativo de origen, como sostienen Franzé et al. (2011), la maestra representa, según la relación jerárquica maestro-alumno, una figura de autoridad incuestionable a la que se debe rendir respeto y obediencia. Dado que para ellas constituye uno de los pilares sobre el cual debería descansar la educación escolar, una queja frecuente que expresan entre ellas es, precisamente, la falta de respeto hacia la maestra (además de la indisciplina y la violencia física). Entre las respuestas obtenidas en las entrevistas también se desliza el mandato moral ancestral que en Bolivia se ha transmitido de generación en generación como una de las máximas de la conducta humana y que en la actualidad ha sido adoptado por el discurso político oficial: ama sua, ama llulla, ama quella (que en castellano significa: no seas ladrón, no seas mentiroso, no seas flojo).

\section{¿Cómo crees vos que se quiere que se comporten sus hijos en la escuela?}

Parece que se tienen (que) comportar bien. Siempre les explico eso: respetar a los maestros, respetar a sus compañeros, no agredirlos, siempre les explico eso a ellas, ser solidaria, a prestar todo lo que tiene si el otro nene no tiene, o sea, no ser mezquina, mala, al menos yo veo que hacen eso... (Isabel)

Mientras ellos están en la escuela ¿qué les interesa a uds. que aprendan? El trabajo, el respeto... (Sonia)

\section{¿Cómo esperás que se comporten sus hijos en la escuela...? ¿Qué le decís a tus hijos... cómo deben comportarse?}

Responsables, respetuosos con los compañeros, con la maestra, no pelear, no robar... es un dicho... (risas) [se refiere al precepto ama sua, ama llulla, ama quella] (Adelia) 


\section{A vos, ¿qué te gustaría que la escuela enseñe y que no hace, hay otras cosas que podría hacer, enseñarles...?}

Higiene...

¿Higiene?

Yo he pensado a veces en ofrecerme para revisar la higiene... revisar, por ejemplo, el guardapolvo, que sea blanco, no sé si... con el guardapolvo dicen que limpian los pisos, las uñas las tienen negras... en Bolivia... aquí se debería revisar las orejas y hasta el pañuelo... Porque así ellos están... limpios por ahí, bien limpitos! (risas) (Adelia)

En general, los chicos y chicas identificados como bolivianos no son vistos como alumnos con "problemas de conducta" o "trastornos de conducta", lo cual se relaciona básicamente con los parámetros de comportamiento establecidos por los docentes, un aspecto central de la representación que existe acerca del buen alumno. En cambio, aquellos que podrían llegar a ser considerados como problemáticos debido a su mala conducta son concebidos como excepción.

Yo te puedo señalar dos o tres con problemas de conducta, pero nada más... no hay, no hay... no tenemos los mismos problemas [que] con los nuestros (risas) (María)

Claro... no, no ellos no se involucran en problemas chiquitos, ni grandes... o dejan pasar... yo lo he notado en pocos alumnos, que nunca se han metido en ningún problema... en cambio, acá sí, están viendo a quién pueden molestar y demás... (Soledad)

He estado en 4to., 5to. y 6to., me moví en el segundo ciclo. Y bueno, en general es... son siempre chicos dóciles, hay excepciones. Yo por ejemplo, este año tengo en 5to. D tres chicos que son bolivianos y... cuatro, porque uno de ellos lo pasamos al otro 5to. para probar, que es este chico Leonardo, para probar, para ver si cambiaba la conducta, porque con el grupo se llevaba muy mal. Entonces lo cambiamos de grupo al principio, comenzó bien, tranquilo, trabajaba, conmigo nunca tuvo dificultades, el problema fue con Carola [la otra maestra de quinto grado] en lengua, quizás porque no le guste la lengua. [...] Y, bueno, es como yo te comentaba la otra vez, este chico Leonardo es una palabra... es mala palabra para los bolivianos, porque no es ejemplo, digamos... 
o sea, que en el barrio debe ser que también tiene conductas que no son buenas, no sé cuál específicamente... (Nora)

Entre los compañeros de clase, las características positivas que acercan a los bolivianos al ideal de buen alumno según los parámetros de las maestras, se traducen en atributos negativos como ser "acusetes" o "buchones".

\section{¿Cómo es la relación con ellos?}

Yamila: Con el César bien, con la Nancy... no [hablan todas juntas: no, porque la Nancy: no], y el Jairo tampoco... / ...no podés jugar con la Nancy, porque empieza así... [hace muecas] a hacer caretones... / sí, empieza a pelear con todos / ...pero a la Nancy nadie la quiere en el grado casi... y a la Clara menos... También teníamos una compañera... / Romina: que le echaba la culpa al Hugo, a nosotros... / ...y entonces la sacamos del grupo y la mandamos del otro lado...

\section{Ah, Clara está en 5to. A... ¿Y qué pasó con Clara?}

A coro: Nadie la quería...

Romina: Sí, porque si se perdía algo le echaba la culpa a nosotros y la señorita la cambió porque no se llevaba bien con ninguna... / con ninguna... / ¿Con ninguna del grado? ¿Porque era boliviana? / A coro: No, no, no / ¿Por su forma de ser? [asienten con la cabeza] ¿les molesta su forma de ser...?

Yamila: Sí, que sea egoísta, que sea mala, que sea peleadora... / R: Que no quiera compartir las cosas... / Que sea acuseta... / ¿Y por qué no quieren compartir ellos? / No sé, porque son mezquinos... / ¿Y Juan José? / No, Juan José... / ¿Y Jairo?

(...)

Yamila: Es bueno, pero por ahí...

Yamila: Pero algunos días es acuseta... [imita la tonada] "le voy a acusar a la señorita" (risas), y a nosotros no nos gusta que sea acuseta.

Romina: Cualquier cosa que nosotros estamos haciendo acá sale y nos acusa a nosotras...

Yamila: Los bolivianos son muy acusetos igual que la Mónica, son muy buchones... / ¿Son buchones? ¿Por qué decís que son buchones?

Yamila: Y porque les gusta la lengua...

La respuesta de una de las maestras a la pregunta sobre aquello que se valora a la hora de que un alumno obtenga un buen concepto pone de manifiesto la relevancia que poseen determinados atributos o actitudes en la producción del buen alumno en la escuela. 


\section{¿De qué depende ese buen concepto?}

Y depende... no contestan, no son agresivos, hacen caso cuando vos les llamás la atención, una sola vez, no tenés que estar a cada rato "Rodrigo quedáte quieto, Rodrigo quedáte quieto, Rodrigo calláte, es un ratito que te tenés que.... (Jimena)

Los alumnos también advierten claramente el mensaje que la escuela busca transmitir y los requisitos que deben reunir para ser un buen alumno. Ante la pregunta realizada al grupo de alumnas de quinto grado entrevistado acerca de lo que aprenden en la escuela, una de ellas, con tono irónico y exagerado, responde:

¿Y qué aprenden acá? / A estudiar, a no pelear, a ser respetuosos, solidarios, mucha responsabilidad (risas) / ¿Qué otra cosa aprenden? / Yo quiero ser abanderada o escolta... pregúntele a ella... / ¿Pero para qué vienen acá? / Para estudiar, para ser respetuosos, solidarios (risas) (Yamila)

En la entrevista con la última directora, al hablar sobre el desempeño escolar de los alumnos bolivianos, expresa: "Y los docentes siempre te dicen que son los mejores... pero ¿por qué son los mejores? Porque no hablan... ese es el tema, no hablan...”. Junto a ello, la directora esgrime, sin evitar caer en la generalización, otra de las razones por las cuales no habría o sería excepcional el fracaso escolar entre ellos: "Ellos cumplen fielmente lo que la maestra les dice, son copistas... Está evaluado el desempeño escolar en base a '¿copió bien?, [entonces] está bárbaro..."'.

Los alumnos considerados como problemáticos, en cambio, son los "cordobeses" o "argentinos", denominados también "los nuestros" para diferenciarlos de los bolivianos. Es frecuente que a los alumnos de las escuelas llamadas urbano-marginales sean considerados por los docentes como de este modo, les asignen de manera generalizada atributos relacionados a la "agresividad", la "mala conducta" o la "falta de hábitos". El hecho de que para las maestras los alumnos y alumnas considerados bolivianos se destaquen por su "conducta" los diferencia de "los nuestros".

Me encontré con la gran sorpresa que eran mucho mejor en cuanto a conducta los bolivianos que nuestros argentinos. Eran más tranquilos, más respetuosos, más observadores... los padres, inclusive de estos chicos bolivianos, muy 
respetuosos con nosotros, más colaboradores y... los nuestros, más agresivos. (Nora)

Lo que ellos decían es que nosotros teníamos... que veían que los chicos nuestros eran muy irrespetuosos, porque los chicos... actualmente los chicos bolivianos te dicen "profesora", son más educados, te van a hablar, te van a escuchar cuando vos les quieras decir algo, sos un referente importante. En cambio, los chicos nuestros no, viste, es como que te tratan de igual a igual; ellos no, y la mamá boliviana es igual... es muy madraza, es muy de estar con sus hijos, tipo pollito, de acá para allá, son características que vos vas viendo en cómo eran las actitudes nuestras y las de ellos, totalmente distintas, pero bueno... se fue trabajando, se fueron integrando. (María)

De esta manera, a partir de las diferencias entre alumnos bolivianos y argentinos, se construyen en la escuela, por contraposición, algunos binomios como éstos: respetuosos, educados, correctos y groseros, irrespetuosos; sumisos, dóciles, callados, tímidos y sueltos, desinhibidos, contestadores; impecables, prolijos y sucios, desarreglados; tranquilos y agresivos, conflictivos; responsables, aplicados, estudiosos y vagos, irresponsables. En esta división entre alumnos bolivianos y argentinos, la atribución de características positivas a unos y negativas a otros, respectivamente, hace también que se establezca una marcada preferencia por aquellos identificados como bolivianos. Esta predilección se lleva al límite cuando algunas maestras declaran que ellas desearían que todos los alumnos de la escuela fueran bolivianos. Vale preguntarse qué ocurriría en la escuela y entre los docentes si esta expresión de deseo se tradujera en una presencia real.

Para nosotros, para el grupo de las seños, la gente boliviana... nosotros quisiéramos que la mayoría sea boliviana por el hecho de la educación que tienen, porque los papás siempre están. Tenemos unos que otros que siempre son la excepción como en todos lados, ¿no cierto? Siempre se rompen algunas reglas, pero la mayoría está, Eduardo, no es gente conflictiva, son impecables... les falta siempre, por decirte, la cuestión social que hablamos... [...] Entonces como que nosotros entre las seños vemos que son... al grupo como que a todas nos gustaría tener... más allá de los problemas de lenguaje que encontramos... (Valeria)

Me decías la vez pasada que si todos tus alumnos fueran ... / Ah... si todos mis alumnos fueran de madre o padre boliviano, hijos de bolivianos, sería 
maravilloso... / ¿Por qué? / Qué sé yo, porque son... re-creativos... son muy... te atienden con mucha atención, están como ávidos de hacer cosas... ojo, que hay muchos [otros] chicos que también, no? En general, la mayoría... pero si los sacamos así, si los separamos a ellos... siempre están atentos, te digo, ávidos de trabajar, con ganas de... [...] yo les doy a veces un montón de cosas para trabajar y eligen y se desesperan por trabajar... yo no sé si... porque el nivel económico es igual, algunos pueden tener mayor nivel económico que otros, pero no les falta me parece crayones o pinturas... son responsables... ellos no se olvidan nunca de traer la carpetita el día que la tienen que traer, mirá que son chiquitos, no? [...] son muy entusiastas, todos los chicos son así... más que nada lo digo por el hecho de que son a lo mejor, o sea, uno lo dice y se da cuenta a veces, no, viste, por el hecho de que son chicos que al lado de... comparando, que tampoco es bueno hacer la comparación... no son chicos que tengan conflictos, que sean irrespetuosos, ni que generen conflictos ellos, los conflictos los generan los otros... los cordobeses de madre y padre cordobeses, discriminan porque son discriminados... pero es fuerte la discriminación de algunos, todavía hay... cuando se enojan, les sale de adentro, les sale de adentro... (Marta)

En suma, estas representaciones en torno a los alumnos considerados bolivianos, tanto mujeres como varones, obtienen sus condiciones de posibilidad en un espacio social estigmatizado a raíz de algunas de sus marcas ligadas a la pobreza y la marginalidad social, que es visto desde afuera y también experimentado desde dentro, a pesar de las tensiones y dilemas que genera, como escuela del fondo. Es el contexto escolar específico, configurado por el origen de clase de los alumnos y las características generales atribuidas a ellos como conjunto homogéneo y cerrado, lo que habilita a la vez que explica las connotaciones positivas, referenciadas en la figura del buen alumno como expresión del orden escolar deseado, que se asignan a los alumnos identificados como bolivianos y, en particular, las preferencias que hacia ellos se declaran. 


\section{CAPÍTULO 7}

\section{INMIGRACIÓN BOLIVIANA, NACIONALIZACIÓN Y RECONOCIMIENTO: NACIONALES Y EXTRANJEROS EN LA ESCUELA HOY}

La Argentina, como sociedad nacional, atravesó por momentos históricos que definieron y significaron a su modo la relación con los inmigrantes. La época nombrada y pensada como Argentina aluvial ${ }^{442}$ ha dejado importantes huellas en la relación histórica que se fue construyendo entre el Estado, los nacionales y los extranjeros. ${ }^{443}$ Con la inmigración de ultramar, como vimos en capítulos anteriores, se crearon las instituciones estatales especializadas para regular la población inmigrante, asumiendo el control variadas formas y fundamentos. También otros organismos del Estado como la escuela pública sirvieron a los fines de ejercer el dominio sobre un sector social, que incluyó tanto a nativos como inmigrantes, que parecía reacio a adoptar las normas sociales que las élites dirigentes suponían adecuadas y necesarias para la conformación de la sociedad imaginada. La Dirección Nacional de Migraciones fue el organismo estatal más representativo del control ejercido, con mayor o menor virulencia, a través de la coerción, cuya legitimidad fue buscada de manera incesante en la defensa de los intereses supremos de la nación. La escuela pública, por su parte, fue un poderoso instrumento para llevar adelante, por la vía del consenso, los proyectos estatales de nacionalización de la sociedad, que en el caso de los extranjeros fue concebida en términos de asimilación o argentinización. A través de ella se vehiculizó la idea de una sociedad integrada contenida en la metáfora del $\mathrm{crisol}^{444} \mathrm{de}$ razas. Una metáfora que en muchos casos, como expresión de una noción de sociedad armónica e inclusora, ha escondido la nacionalización compulsiva, como la llama Terán (1986), que también supuso. Un siglo después, con la visibilidad que adquirió en las aulas

\footnotetext{
442 Esta es la expresión que utiliza el historiador José Luis Romero para denominar el período de inmigración de masas. También el sociólogo Gino Germani ha usado la noción de sociedad aluvional para caracterizar al conjunto social de la época. Para un estudio crítico de la idea de Argentina aluvial propuesta por Romero, véase Altamirano (2005).

443 Véase Montesinos (2005) acerca de la construcción del otro como migrante en el campo de la educación durante tres períodos históricos de relevancia en la Argentina (constitución del Estado-nación; sustitución de importaciones; neoliberalismo).

444 Como explica Devoto (2003), la idea de “crisol" remite a dos nociones diferentes: la más antigua se hace alusión al proceso de argentinización, esto es, la incorporación de los inmigrantes a una sociedad o una matriz cultural originaria que los preexistía; la segunda, más reciente, propone el "crisol" como una fusión entre los distintos elementos que daría lugar al surgimiento de una cultura nueva construida con el aporte de los nativos y de los inmigrantes.
} 
la presencia de hijos de inmigrantes de países limítrofes, la construcción hegemónica acerca del otro como objeto de asimilación y argentinización parece adquirir nuevos contornos. La expresión el "crisol de razas" hecho trizas (Neufeld y Thisted, 1999) pone de manifiesto la conflictividad oculta detrás de la metáfora.

El capítulo revisa las respuestas políticas del Estado argentino a la inmigración en el terreno de la educación y el papel de la escuela en el proceso histórico de construcción de la identidad nacional y nacionalización de los extranjeros para luego detenerse en las actuales modalidades específicas que adquieren en el espacio escolar las fórmulas de inclusión y reconocimiento, pensadas como integración, que proponen los docentes, como sujetos que reproducen y resignifican el discurso ideológico oficial, al ser interpelados por la presencia de hijos de inmigrantes de países limítrofes como Bolivia. Para ello se reconstruye la emergencia y desarrollo de los rituales patrióticos, originados en la época de la inmigración de ultramar, a lo largo del siglo veinte en el ámbito educativo. También se analizan, a través de documentos oficiales y escolares, entrevistas con maestras y directivos y notas de campo confeccionadas durante observaciones de situaciones y eventos específicos, las representaciones y prácticas relativas a la construcción del nosotros nacional y la producción de la argentinidad para comprender más cabalmente la visión que se instituye acerca de los otros no-nacionales y el modo en que se propone, así como de la bolivianidad como parte de las respuestas escolares orientadas a reconocer la existencia de hijos de inmigrantes bolivianos, interpelada como una presencia cultural y procesada como una presencia nacional (o no-nacional en tanto presencia nacional extranjera), en un contexto en que el discurso oficial pondera la diversidad cultural como un valor necesario de promoción y protección. Se muestra que la visión de Estado, internalizada en la escuela a través de instrumentos como la normativa jurídica (no necesariamente vigente) destinada a regular la vida en las escuelas $y$, en particular, a asegurar la reproducción del Estado, y prácticas escolares sedimentadas y arraigadas históricamente como los actos escolares, tiene efectos concretos y diversas implicancias en los modos en que la escuela busca, a través de diversas estrategias, otorgar visibilidad y promover el reconocimiento de una presencia que en determinadas circunstancias es vista y vivida como problemática. 
La construcción del Estado argentino y la presencia de los extranjeros: la nacionalización como mandato estatal

Hacia finales del siglo diecinueve, especialmente a partir de la década de 1880, la Argentina experimentó profundas transformaciones en el orden social, económico, político y cultural bajo el signo de la modernidad, acompañadas por cambios sustanciales en el ámbito del Estado. El aparato burocrático alcanzó una relativa consolidación, dejando atrás la precariedad que lo caracterizó durante las décadas anteriores. En esta época tuvo lugar el proceso de adquisición de uno de los atributos fundamentales de la estatalidad: se produjo el surgimiento de "un conjunto funcionalmente diferenciado de instituciones públicas relativamente autónomas respecto de la sociedad civil, con cierto grado de profesionalización de sus funcionarios y de control centralizado sobre sus actividades" (Oszlak, 2004[1997]:157). Entre las primeras instituciones especializadas que permitieron consolidar su poder sobre el territorio y ejercer el control sobre la población estuvieron el Ministerio de Guerra y Marina, el Ministerio del Interior y el Ministerio de Justicia, Culto e Instrucción Pública.

Con la aprobación de la ley de Educación Común ${ }^{45}$ en 1884, mediante la cual la educación quedó establecida como obligatoria, laica y gratuita, el Estado nacional pasó a tener injerencia sobre los establecimientos educativos de la capital, las colonias y los territorios de administración nacional. Así, el Estado nacional extendía su rol a través de la expansión del aparato educativo, una creciente centralización de las funciones reguladoras y un progresivo monopolio de las atribuciones que disputaba, principal pero no exclusivamente, con la iglesia católica (Oszlak, 2004). El Consejo Nacional de Educación (CNE), creado en 1880, fue el principal organismo de gobierno que posibilitó que el Estado nacional tuviera presencia en las instituciones de instrucción pública, tanto fiscales como particulares. Después de su reorganización interna en 1887, el control que ejercía el CNE en el ámbito de la educación formal se amplió a través de la paulatina aplicación de la ley $\mathrm{N}^{\circ} 1.420$ y algunas medidas de alcance nacional. Entre 1888 y 1889, se propició la formación de un cuerpo técnico centralizado de inspectores mediante la reorientación de la vieja inspección (que hasta entonces tenía una existencia casi nominal), se implementó un nuevo reglamento para la inspección nacional y se comenzó a exigir a los maestros con títulos extranjeros que los revalidaran en las Escuelas Normales de la Nación (Bertoni, 2001). Las disposiciones de la ley $N^{\circ} 1.420$, que colocaba a las escuelas particulares bajo la supervisión y control del CNE, también sirvieron para someter a las escuelas de colectividades de extranjeros, cuyas actividades orientadas a mantener lazos con las 
naciones y nacionalidades de origen, inquietaban a las autoridades estatales desde que la escuela había empezado a ser vista como un poderoso instrumento de nacionalización. ${ }^{446}$

La finalidad del sistema educativo argentino en sus comienzos, como explica Lionetti (2005), consistió en disciplinar e integrar consensualmente a los sectores populares bajo el colectivo de ciudadanos y funcionar como instancia de legitimación de las políticas operadas por las élites gobernantes. Es decir, la élite liberal de los ochenta del siglo diecinueve asumió la tarea de "educar al soberano" con un objetivo de socialización política a partir del cual se cimentaría una nueva sociedad civil. En estos tiempos, según Tedesco, la educación cumplió "más que una función económica, una función política": mediante la difusión de la enseñanza se buscaba la estabilidad en la política interna frente a los levantamientos contra el gobierno central provenientes desde el interior del país y formar, en particular en los niveles medio y superior, un tipo de hombre apto para cumplir papeles políticos antes que otros objetivos como la capacitación para el trabajo en actividades productivas (Tedesco, 2009[1986]:61-64). En cierta manera, como señala Oszlak, la educación fue concebida "más como garantía del orden que como condición del progreso" (Oszlak, 2004[1997]:152).

Los políticos e intelectuales de la época, indica Terán (2008), aunque consideraban que la única manera de construir un Estado-nación moderno era activando procesos de modernización, representados por la inmigración, el ferrocarril, el progreso y el crecimiento económico, no dejaban de contemplar sus efectos con cierto escepticismo y malestar. Esto condujo, en parte, a que en la transición entre el siglo diecinueve y el veinte se instale como problemática la cuestión inmigratoria. La preocupación acerca de la incorporación de los extranjeros a la sociedad receptora refractaba en escala ampliada otros aspectos de la época de orden social, político y nacional que resultarían problemáticos. ${ }^{447} \mathrm{Si}$ bien hubo iniciativas desarrolladas por instituciones y asociaciones de la sociedad civil, el papel aglutinador y nacionalizador lo ejerció fundamentalmente el Estado, donde los intelectuales encontraron un espacio privilegiado de intervención. Dado que el proceso de nacionalización suponía la elaboración de una identidad colectiva definida en términos nacionales, tratándose de un proceso fundamentalmente simbólico,

\footnotetext{
446 Sobre las escuelas privadas impulsadas por las colectividades italiana y española, principalmente, en esta época en la Argentina, véase Tedesco (2009 [1986]).

447 Para Terán (2008), la cuestión social se relacionaba con los desafíos que planteaba el mundo del trabajo urbano, la política con el lugar de las masas en la construcción de la democracia y la nacional con el proceso de construcción de una identidad colectiva.
} 
las destrezas y saberes de los intelectuales eran imprescindibles para llevar adelante dicha tarea.

Aunque la inmigración era una realidad antigua, en los años ochenta la imagen positiva del inmigrante, confeccionada desde los orígenes de la organización nacional, empezó a deteriorase y hacia el final de la década los rasgos de la "nueva sociedad aluvional" empezaron a despertar ciertas inquietudes y temores (Bertoni, 2001), que rápidamente se tradujeron en sospechas. La figura de la invasión que circulaba entre la clase dirigente de la época, expresaba, por un lado, el temor al ascenso social de los extranjeros, cuya participación y penetración en las actividades y prácticas de los nativos revelaba una presencia expansiva antes que pasiva, y por el otro, el miedo a la extensión de las ideas anarquistas y socialistas a través del activismo político y sindical que habían comenzado a desplegar algunos grupos de inmigrantes en el mundo del trabajo urbano (Terán, 2008). Los extranjeros fueron pensados como parte de los problemas creados por la inmigración y el Estado buscó resolverlos por medio de la coerción, mediante la aplicación de leyes represivas como vimos en el capítulo 3 , y a través del consenso, centrado éste en la "incorporación plena de los extranjeros y sus hijos a una identidad nacional argentina" (Terán, 2008:120). De este modo, la educación pública se convirtió, junto con el servicio militar obligatorio ${ }^{48}$, en uno de los principales instrumentos de control social que utilizó el Estado para llevar adelante el proceso de nacionalización que se proponía como solución a la amenaza que los inmigrantes supondrían para la formación de una sociedad homogénea así como a la disgregación social que las élites temían frente a la creciente conflictividad social que alcanzaría su punto más álgido en la primera década del siglo veinte en torno a la sanción de las leyes de Residencia (1902) y de Defensa Social (1910).

Durante las dos últimas décadas del siglo diecinueve y la primera del veinte, el interés estatal referido a la identidad nacional y la nacionalización de la sociedad se apoderó de la vida política del país. A partir de la década de 1880, empezó a manifestarse en distintos espacios sociales de la época y en el decenio de 1890, como señala Terán (2008), alcanzó su máxima intensidad y se presentó entre las principales preocupaciones del Estado y de los intelectuales hasta el Centenario, adquiriendo la escuela un importante protagonismo

448 Como señala Oszlak (2004), el servicio militar obligatorio, aprobado por la ley № 4031 en el año 1902, actuó como un "poderoso mecanismo de socialización y adoctrinamiento" de los hijos de extranjeros orientado a la homogeneización étnica. Cumplía fines similares y hasta se complementaba con la ley de educación nacional aprobada unos años antes. 
en el proyecto de construcción de la nación. El nacionalismo culturalista ${ }^{449}$ que finalmente se impuso de manera hegemónica tenía como principal finalidad generar fuertes sentimientos de identificación nacional para incorporar las masas extranjeras de manera homogénea a la nación con el propósito de "promover mejores condiciones de convivencia y gobernabilidad" (Terán, 2008:121). Bertoni (2001) explica que, si bien en los años previos, particularmente en la década de 1870, habían surgido ciertas inquietudes alrededor de la cuestión de la nacionalidad, en la década de 1880 se situó en el centro de las preocupaciones de los grupos dirigentes, adquiriendo una inédita complejidad. El ritmo y las características que asumió la afluencia de la inmigración masiva y el clima de aguda competencia imperialista entre las naciones europeas confluyeron para acelerar su despliegue. Un marcado proceso de construcción de una nacionalidad propia fue la respuesta política: era necesario lograr argentinizar no sólo a los inmigrantes extranjeros mediante las leyes de naturalización, sino también a sus hijos a través de la lengua, las costumbres, la adhesión a la patria, así como cercenar el crecimiento y desarrollo de enclaves de nacionalidades extranjeras, cuya existencia no había sido percibida hasta entonces como problemática. Es en el marco de este proyecto de argentinización, tanto en términos jurídicos como culturales, que emprendimientos de los extranjeros como las asociaciones, los periódicos y las escuelas, que hasta entonces podían pasar desapercibidos, empezaron a recibir una inusitada atención debido a la importancia que empezaron a recibir en la definición de la pertenencia a una nacionalidad. Así, fiestas patrias y espacios públicos, banderas y escudos, escuelas y enseñanzas del pasado se constituyeron en lugares de disputa y conflicto con los inmigrantes extranjeros.

El carácter nacional de la enseñanza no obtuvo mayor atención durante los primeros años de organización del sistema educativo nacional cuando aún se discutía en el Congreso Pedagógico (1882) y en el Congreso Nacional la que más tarde se convertiría en la primera ley de educación común. ${ }^{450}$ Como sugiere el estudio de Bertoni (2001), la orientación nacional(ista) de la educación no fue un asunto problemático hasta que, en tanto institución depositaria de los problemas y las aspiraciones de quienes tenían influencia sobre ella, se comenzó a advertir el papel que podía cumplir la escuela en la construcción de la nacionalidad. Si bien la orientación nacional de la educación quedó expresamente establecida en la ley $\mathrm{N}^{\circ} 1.420$ de 1884 y figuró explícitamente en las conclusiones del Congreso Pedagógico realizado en 1882, no ocupó más que un lugar secundario. Durante

449 Terán (2008) entiende al nacionalismo culturalista como aquél que define la identidad nacional a partir de un conjunto de pautas culturales (lengua, símbolos, usos y costumbres, etc.) a diferencia del nacionalismo constitucionalista guiado por la pertenencia y adscripción a un mismo conjunto de leyes fundamentales.

450 Sobre el Congreso Pedagógico de 1882, véase Recalde (1987). 
estos años, además, las escuelas estaban concentradas en encontrar la manera de desarrollar la enseñanza sin disponer de la cantidad necesaria de maestros bien formados y de edificios adecuados para el número de alumnos que tenían. Fueron funcionarios de mediana jerarquía como inspectores y subinspectores quienes, hacia finales de la década, comenzaron a advertir en sus informes la ausencia del himno nacional y la enseñanza de la historia nacional en las escuelas. Hasta aquél momento, aunque la formación escolar incluía conocimientos de lengua, historia, leyes u organización política, éstos no habían sido considerados instrumentos específicos para la formación de la nacionalidad. La variedad de lenguas y las dificultades en la enseñanza del idioma nacional constituyó una de las principales señales de alerta acerca de las consecuencias culturales de la inmigración en la escuela. Encargada la escuela de la formación de la nacionalidad, se otorgó mayor importancia a la enseñanza de la historia nacional y a la realización de los actos escolares y se procuró que las actividades escolares trascendieran el ámbito escolar en ocasión de las fiestas patrias. Las tensiones y conflictos entre las escuelas del Estado y las de las colectividades de extranjeros, en particular la italiana, también reflejaban la importancia que iría adquiriendo la escuela en la construcción de la nacionalidad. A medida que la idea de nacionalidad fue definiéndose en términos de singularidad cultural, la formación de la sociedad nacional sólo era concebible en términos de homogeneidad, asumiendo al cosmopolitismo como algo antagónico o nocivo para su construcción. 451

\section{Nuevas leyes educativas, viejos mandatos políticos: la ley Federal de Educación y la ley de Educación Nacional}

A medida que se fue consolidando la institucionalización del Estado nacional argentino y la inmigración de ultramar fue declinando, el interés estatal en torno a la incorporación de los extranjeros fue desapareciendo de las directrices políticas en materia educativa, aunque sobreviviendo ciertos mecanismos y estrategias que alguna vez tuvieran como destinatarios a los inmigrantes europeos con el propósito de conseguir su nacionalización (o argentinización) a través de políticas de corte asimilacionista. Recién hacia fines del siglo veinte, con la ola de reformas educativas neoliberales de los años noventa

\footnotetext{
451 Por estos tiempos, la heterogeneidad cultural -o lo que hoy llamaríamos diversidad cultural- era vista como una fuente de conflictos. Así lo muestra de manera elocuente el pensamiento del director del Departamento de Inmigración entre 1890 y 1910, Juan Alsina, en su llamado a la homogeneidad en La inmigración en el primer siglo de la independencia del año 1910: "La diversidad de razas, de tan profunda diferencia, indígena americana, negra, asiática y europea, coexistiendo en una nación crean problemas sociales gravísimos. Conservemos en nuestra república la homogeneidad para disminuir conflictos que no dejarán de presentarse dentro de ella".
} 
implementadas en diversos países de la región latinoamericana, reaparecieron en la Argentina algunas inquietudes acerca de la cuestión migratoria en el marco de las políticas o programas de atención a la diversidad. Sin embargo, la presencia de niños migrantes o hijos de inmigrantes no suscitó demasiada atención, ocupando un lugar periférico o irrelevante tanto en la elaboración y sanción de leyes como en el diseño e implementación de planes y proyectos gubernamentales, tanto nacionales como provinciales, a diferencia del (relativo) protagonismo que adquirió el tema indígena con la emergencia de la llamada educación intercultural.

Las distintas reformas desarrolladas en el ámbito de gobierno de la educación a lo largo del siglo veinte fueron efectuadas sin que fuera derogada la ley de Educación Común de 1884. Con más de cien años de vigencia, su derogación se produjo con la aprobación de la Ley Federal de Educación en 1993, la cual representó la inauguración de la reforma educativa neoliberal de los noventa. Entre sus lineamientos generales se afirmaba que dicha ley indicaba "el inicio y la dirección de su paulatina reconversión para la continua adecuación a las necesidades nacionales dentro de los procesos de integración". Además, establecía que el Estado nacional, contando con la participación de la familia, la comunidad, sus organizaciones y la iniciativa privada, debía asumir "la responsabilidad principal e indelegable de fijar y controlar el cumplimiento de la política educativa" en vistas a constituir "una sociedad argentina justa y autónoma, a la vez que integrada a la región, al continente y al mundo". Esta sociedad que el Estado debía forjar a través de la política educativa presuponía como principio básico de incorporación o cohesión social la construcción de la identidad nacional. La ley expresaba en su articulado un mandato específico que el Estado Nacional, a través de sus diversos organismos especializados (el Ministerio de Educación y el Consejo Federal de Cultura y Educación principalmente), debía llevar a cabo en su construcción: la consolidación, el fortalecimiento o la afirmación de la identidad nacional. Asumiendo que la identidad nacional ya había sido construida, ahora se bregaba por continuar esta tarea performativa reforzándola. ${ }^{452}$

Siguiendo el precepto constitucional, sin mencionar explícitamente a la migración ni nombrar a los extranjeros o a los inmigrantes, se refiere a "todos los habitantes del país", a quienes se les garantizaría "el ejercicio efectivo de su derecho a aprender, mediante la igualdad de oportunidades y posibilidades, sin discriminación alguna". En otros

452 Diversos artículos de la ley se refieren explícitamente a el fortalecimiento de la identidad nacional atendiendo a las idiosincrasias locales, provinciales y regionales (artículo 5), la afirmación de la identidad nacional y regional (artículo 53), la consolidación de la identidad nacional (artículo 55) y a la preservación y desarrollo de la cultura nacional en sus diversas manifestaciones (artículo 56). 
documentos oficiales de la década los migrantes aparecen como parte de una sociedad que es vista por el Estado nacional como multiétnica, pluriétnica y multilingüe, y se explica que dicha "condición de diversidad" no fue reconocida históricamente por las políticas educativas desarrolladas acorde a las estrategias de homogeneización que dominaron el sistema educativo argentino a lo largo de los dos últimos siglos. ${ }^{453}$

La Argentina es un país multicultural, pluriétnico y multilingüe, debido tanto a la presencia de población aborigen como a migrantes hablantes de diversas lenguas y de orígenes culturales distintos. Sin embargo, a lo largo de nuestra historia esta condición de diversidad no ha sido reconocida por el sistema educativo. Las políticas educativas en nuestro país han estado marcadas desde el período de la formación del estado nacional por la tendencia hacia la homogeneización. (Anexo de la resolución № 107/99 del Consejo Federal de Educación del Ministerio de Cultura y Educación)

Este reconocimiento oficial, plasmado tanto en documentos nacionales como provinciales, es asumido como un efecto de las actuales tendencias internacionales y de las recomendaciones de organismos internacionales en materia educativa y se materializaría en la educación intercultural bilingüe. ${ }^{454}$ Esto constituye una muestra elocuente de los efectos que ha tenido la internacionalización de la política educativa (o lo que algunos

453 La resolución № 107/99, a pesar de reconocer la multiculturalidad existente en el país, se centra en los “contactos interculturales" que se producen con los pueblos aborígenes, omitiendo lo relativo a los inmigrantes. Indudablemente, esto es producto de la búsqueda de justicia de las comunidades indígenas a través de sus luchas y reclamos. Es sabido que en América Latina, en términos generales, "el tema indígena tiene más presencia en el debate político, más reconocimiento en la opinión pública, más resonancia en los debates internacionales, y más tradición en la investigación social" (Hopenhayn y Bello, 2001:22). Pero también es probable que, al ser considerados dentro de la sociedad nacional, sus reivindicaciones aparezcan actualmente en el imaginario social con mayor legitimidad que las de los inmigrantes. Es decir, en última instancia se trataría de un reconocimiento hecho a nacionales argentinos, con lo cual, aunque podría llegar a cuestionar la noción de unidad cultural, no vulneraría la idea de unidad nacional. En el caso de los inmigrantes, su condición de extranjeros es lo que parece excluirlos del reconocimiento obtenido por y otorgado a los pueblos originarios.

454 Identificada la diversidad sociocultural como "atributo positivo", en tanto introduce riqueza y variedad a las sociedades, la educación intercultural bilingüe es considerada como la herramienta educativa que permite responder a los procesos de enseñanza y aprendizaje en términos de equidad: "La educación intercultural y bilingüe se constituye como estrategia de equidad educativa porque estriba en el postulado de la plena participación de las lenguas y de las culturas indígenas al proceso de enseñanza y aprendizaje y reconoce la diversidad sociocultural como atributo positivo de una sociedad, promoviendo el desarrollo de tradiciones culturales ricas y variadas" (Anexo de la resolución del Ministerio de Educación y Cultura № 107/99). 
autores del campo de la educación llaman la globalización de la política nacional455) a través de la creciente intervención de los organismos internacionales como la UNESCO ${ }^{456}$ y el Banco Mundial457.

455 Véase Bonal, Tarabini-Castellani y Verger (2007) para conocer diversos aportes en esta línea de trabajo en el campo de la educación.

456 La Organización de las Naciones Unidas para la Educación, la Ciencia y la Cultura (UNESCO) ha cumplido un papel trascendental en la producción y difusión de ideas relativas a la educación y la cultura. En la actualidad, las cuestiones relacionadas con la diversidad cultural y multi/interculturalidad se han vuelto centrales en las acciones que desarrolla. Es una de las organizaciones que con mayor fuerza promueve, a través de sus programas, declaraciones y recomendaciones, una visión armónica y horizontal de las relaciones interculturales. En la Declaración Universal de la UNESCO sobre la Diversidad Cultural, aprobada en el año 2001 se afirma, por ejemplo, que "el respeto de la diversidad de las culturas, la tolerancia, el diálogo y la cooperación, en un clima de confianza y de entendimiento mutuos, están entre los mejores garantes de la paz y la seguridad internacionales", mientras aspira a "una mayor solidaridad fundada en el reconocimiento de la diversidad cultural, en la conciencia de la unidad del género humano y en el desarrollo de los intercambios culturales" y considera que "el proceso de mundialización [...] pese a constituir un reto para la diversidad cultural, crea las condiciones de un diálogo renovado entre las culturas y las civilizaciones". Por otra parte, si bien la trayectoria de trabajo de la UNESCO en materia migratoria es menos conocida que la de otras agencias internacionales como la Organización Internacional para las Migraciones (OIM), la Organización Internacional del Trabajo (OIT) o la Organización para la Cooperación Económica y el Desarrollo (OCDE), su participación en la construcción de la agenda política internacional en el área de las migraciones también es muy relevante. Véase Timur (2000) para una detallada descripción del extenso trabajo institucional de la UNESCO en materia de migraciones desde su creación.

457 La utilización de la educación bilingüe como un instrumento para lograr la equidad forma parte de las recomendaciones del Banco Mundial (BM) (Banco Mundial, 1996), uno de los organismos internacionales que mayor influencia e intervención ha tenido en las políticas educativas nacionales de los países de la región latinoamericana en las últimas dos décadas. En sus documentos de política educativa, el BM establece claramente una asociación entre diversidad, desventaja y equidad: incluye a las "minorías lingüísticas y étnicas" entre los que llama "grupos desaventajados" y, dado que para el BM la falta de acceso a la educación y la baja matrícula de estos grupos responde básicamente a un problema de equidad, sugiere como solución implementar medidas financieras y "medidas especiales" (dirigidas fundamentalmente a los niveles inferiores de la educación), entre las cuales se menciona "proporcionar educación bilingüe en los países con diversidad lingüística” (Banco Mundial, 2004:127). Asimismo, cabe destacar que desde la perspectiva del BM, la educación bilingüe -los documentos del sector de educación no hacen referencia a la "educación intercultural"- es justificada en función de una lógica pragmática sostenida por criterios de eficacia y eficiencia. Se afirma, por ejemplo, que "la educación bilingüe cuenta además con el apoyo de los padres, de manera que aumenta la demanda de educación” o que “(e)n las sociedades multilingües es posible que las escuelas eficaces sean aquellas a las que se permite actuar con flexibilidad en lo que respecta al idioma de instrucción” (Banco Mundial, 2004:132). En función de ello, sugiere que "(l)as autoridades no deberían prescribir la aplicación de normas lingüísticas, al menos a nivel primario" (Banco Mundial, 2004:132). Como vemos, a pesar de que en sus últimas formulaciones de política educativa ya no recomienda centrarse únicamente en la educación primaria, para el BM la educación bilingüe (que no forma parte de una política multi/intercultural en la concepción del Banco) sólo se justifica y debe limitarse a la "educación básica”. Véase Bonal (2002) para un análisis crítico sobre la agenda del Banco Mundial para América Latina. Para una mirada crítica sobre los discursos y políticas del Banco Mundial respecto a la educación y la diversidad cultural en América Latina, véanse Domenech (2007c) y Domenech y Mora-Ninci (2009). 
Con el advenimiento de la democracia en las últimas décadas, la Argentina se adscribe a la tendencia universal de reconocimiento de la diversidad y configura un marco legal que reconoce el derecho de las poblaciones aborígenes a una educación intercultural y bilingüe. (Anexo de la resolución $\mathrm{N}^{\circ} 107 / 99$ del Consejo Federal de Educación del Ministerio de Cultura y Educación)

Nuestro país inicia a partir de la Ley Federal de Educación una profunda transformación educativa. En este sentido, se hace eco de las recomendaciones establecidas por los organismos internacionales que propician cambios desde hace varios años y procura renovar y mejorar todos los niveles y modalidades de su sistema educativo. (Escuela y Diversidad, Capacitación en la escuela, Cuadernillo $\mathrm{N}^{\circ}$ 2, Ministerio de Educación del Gobierno de Córdoba, 2001)

A diferencia de las reconfiguraciones que se produjeron en el ámbito de gobierno de las migraciones, como vimos en los capítulos anteriores, en el área educativa las reformas, con sus sucesivos gobiernos nacionales y diferentes administraciones del Ministerio de Educación de la Nación, no trajeron consigo una nueva mirada sobre aspectos que pudieran concernir a las migraciones y los inmigrantes como la diversidad sociocultural o la identidad nacional: como en un doble movimiento, lo que se pretende abrir por el lado de la diversidad cultural, se cierra por el lado de la identidad nacional, a pesar de la intención de definirla en términos de apertura. Un documento del Ministerio de Educación (2003) titulado La educación en la democracia. Balances y perspectivas explicita la relevancia que se le adjudica desde tiempos inmemoriales a la formación de la identidad nacional en la escuela: "Hoy, como en sus orígenes, la educación es un espacio decisivo para consolidar la identidad nacional y una ruta estratégica para promover el desarrollo personal, social, económico y cultural". En este como en otros documentos posteriores, una de las premisas centrales es que "(l)a escuela fue y debe seguir siendo uno de los pilares de la construcción de la identidad nacional".

Aunque en ocasiones la noción esencialista y exclusivista de identidad nacional suele ser matizada mediante referencias a la importancia que posee el reconocimiento de la diversidad cultural, en particular en relación al contexto latinoamericano, el proyecto de nación permanece sujeto a la idea de "unidad cultural". Así queda sintetizado en el discurso de asunción del presidente Néstor Kirchner en mayo de 2003: 
No hay un factor mayor de cohesión y desarrollo humano que promueva más la inclusión que el aseguramiento de las condiciones para el acceso a la educación, formidable herramienta que construye identidad nacional y unidad cultural, presupuestos básicos de cualquier país que quiera ser Nación.

Posteriormente, en el año 2006, se sometió a discusión un texto elaborado por el Ministerio de Educación de la Nación, titulado Documento para el Debate, que sirviera de base para la confección del proyecto de una nueva ley de educación. El documento oficial, si bien no trata explícita o específicamente la relación entre educación y migración, propone una serie de definiciones en torno a la diversidad cultural y la identidad nacional que permiten extraer algunas implicancias y consideraciones de importancia en torno a ella. Al igual que en los documentos oficiales de los noventa, la Argentina vuelve a ser definida como "un país, multicultural, pluriétnico y multilingüe" a raíz de la existencia de "pueblos originarios" y "migrantes hablantes de diversas lenguas y orígenes culturales". Lo novedoso es el fundamento que se insinúa para el reconocimiento de esta "condición de diversidad" en el sistema educativo argentino: dado que en el pasado, desde los orígenes del Estado nacional hasta la actualidad, las políticas educativas desarrolladas bajo los estrechos parámetros de la homogeneización cultural invisibilizaron la diversidad cultural que históricamente ha caracterizado a la Argentina, ahora sería necesario remediar esta situación a partir de su reconocimiento.

La Argentina es un país multicultural, pluriétnico y multilingüe, debido tanto a la presencia de las pueblos originarios como a migrantes hablantes de diversas lenguas y de orígenes culturales distintos. Sin embargo, a lo largo de nuestra historia, esta condición de diversidad no ha sido reconocida por el sistema educativo, dado que las políticas educativas en nuestro país han estado marcadas desde el período de la formación del Estado Nacional por la tendencia hacia la homogeneización cultural. (Documento para el debate, Ministerio de Educación de la Nación, 2006)

En este sentido, la definición de la Argentina como un país multicultural, pluriétnico y multilingüe podría funcionar como parte de un reconocimiento político inédito si no fuera porque este enunciado, al igual que en los noventa, no supera el orden declamativo ni termina de traducirse en un proyecto político de nación que trascienda las estrechas formas exclusivistas y menos aún en una definición que involucre al propio Estado-nación -es decir, su redefinición- como dan cuenta otras experiencias nacionales de la región 
sudamericana, a pesar de que en el documento se invoque la necesidad de "redefinir las formas sobre las cuales se construye el sentido y la identidad nacional".

El otro aspecto que ofrece el documento como complemento de aquél llamado a reconocer la diversidad sociocultural es su valoración como riqueza o, en tanto proceso social, como enriquecimiento en el marco de llamamientos al reconocimiento y respeto a la diversidad y a las diferencias. Así, de la mano de la educación intercultural bilingüe, cuyos destinatarios naturales parecieran ser las "poblaciones indígenas", se enuncia la importancia de "reconocer la diversidad sociocultural como atributo positivo de una sociedad" y también se indica que " $(\mathrm{t})$ odos los argentinos debemos asumir nuestra diversidad cultural como una riqueza". Estos aspectos se encuentran resumidos en la educación que todos tienen derecho y debieran recibir: se habla de una educación que "valore el pluralismo, la diferencia y la diversidad cultural, sin dar lugar a ningún tipo de discriminación por etnia, religión, origen, género, edad, discapacidad" y que "garantice la posibilidad de acceder a una escolaridad intercultural bilingüe". También se espera que la educación ofrecida "contribuya a construir una identidad nacional".

Precisamente, uno de los planteos centrales del documento es que una sociedad más justa requiere del ejercicio de una "nueva ciudadanía" basada en cuatro pilares que gozarían de un amplio consenso en la sociedad argentina como la identidad nacional, la democracia, la productividad y el crecimiento, y la integración y la justicia social, de los cuales desprende el principio de "Educar para consolidar la identidad nacional", entre otros. Allí se reconoce el papel que jugó la escuela en la construcción de los estados nacionales llevada adelante mediante la "transmisión del patrimonio histórico" y la "definición de un proyecto de futuro", dos dimensiones que estarían en discusión en el presente y permitirían relativizar las tradicionales definiciones estatales acerca de la identidad nacional. Esta superación vendría de la mano de una relación con el patrimonio cultural de la humanidad y la valorización y fortalecimiento de las identidades y culturas regionales, procurando que la educación contribuya a consolidar lo que nos une, lo que nos cohesiona, aquello que nos permite aprender a vivir juntos y perfilar una nación justa e integrada, debiendo aceptar la diversidad cultural como una riqueza y no como un problema.

Consolidar la identidad nacional, conscientes de que nuestro destino está íntimamente vinculado al de América Latina, es fundamental para que podamos integrarnos soberanamente en forma activa y protagónica a un mundo globalizado y crecientemente interdependiente. Desde este punto de vista, fortalecer la identidad nacional no significa negar ni aislarse con 
respecto al patrimonio cultural de la humanidad. Sólo con un alto nivel de seguridad en lo propio es posible vincularse, comprender y enriquecerse con lo diferente. [...] Al mismo tiempo, la identidad nacional no puede apoyarse en la negación de las identidades y culturas regionales sino en su valorización y fortalecimiento. La diversidad cultural es una riqueza y no un problema, razón por la cual la educación debe formar al ciudadano para que comparta el espíritu nacional y se haga responsable solidariamente de la suerte del otro. [...] En este sentido, será preciso que las experiencias de aprendizaje que tienen lugar en la escuela contribuyan al desarrollo de los valores vinculados a fortalecer lo que nos une, lo que nos cohesiona, nos permite aprender a vivir juntos y a diseñar un proyecto de Nación justa e integrada.

Por su parte, la Ley de Educación Nacional458, sancionada y promulgada en diciembre de 2006, también destaca la importancia de la educación para el fortalecimiento y la consolidación de la identidad nacional: "la educación es una prioridad nacional y se constituye en política de Estado para construir una sociedad justa, reafirmar la soberanía e identidad nacional, profundizar el ejercicio de la ciudadanía democrática, respetar los derechos humanos y libertades fundamentales y fortalecer el desarrollo económico-social de la Nación". Aunque pretendidamente matizada por la idea de respeto a la diversidad cultural, también aparece entre "los fines y objetivos de la educación nacional": "Fortalecer la identidad nacional, basada en el respeto a la diversidad cultural y a las particularidades locales, abierta a los valores universales y a la integración regional y latinoamericana”.

Bajo el fundamento de avanzar con la construcción de los procesos regionales en curso, se apela a la noción de identidad nacional abierta: según uno de los artículos, los contenidos curriculares comunes a todas las jurisdicciones deberán contar, entre otros aspectos, con "el fortalecimiento de la perspectiva regional latinoamericana, particularmente de la región del MERCOSUR, en el marco de la construcción de una identidad nacional abierta, respetuosa de la diversidad". Por otra parte, la diversidad cultural es definida como "atributo positivo de nuestra sociedad": se señala que "(e)l Ministerio de Educación, Ciencia y Tecnología, en acuerdo con el Consejo Federal de Educación, definirá contenidos curriculares comunes que promuevan el respeto por la multiculturalidad y el conocimiento de las culturas originarias en todas las escuelas del país, permitiendo a los/as alumnos/as valorar y comprender la diversidad cultural como atributo positivo de 
nuestra sociedad". ${ }^{459} \mathrm{El}$ conocimiento, respeto y valoración de la diversidad, adjetivada generalmente como cultural, constituye uno de los aspectos transversales que emerge de modo recurrente en los documentos oficiales. ${ }^{460}$ En diversos pasajes se hace hincapié en el "respeto a la diversidad cultural", la "valoración y preservación del patrimonio natural y cultural" o la "valoración de la multiculturalidad".461

\section{Reglamentando la rutina escolar: las efemérides y los actos escolares}

Las nociones de orden y autoridad en las escuelas cobran materialidad a través de prácticas concretas que organizan la rutina escolar diaria. Muchas de ellas, como los actos escolares patrióticos, se fueron instituyendo a lo largo de décadas y han sobrevivido hasta la actualidad. Los actos escolares patrióticos no son meramente una puesta en escena de diversos acontecimientos de la historia nacional traducidos a un lenguaje escolar, sino que forman parte de aquellos dispositivos que colaboran en la producción de "una `comunidad imaginaria' para desarrollar su propio modelo de regulación de los conflictos sociales" (Balibar, 2008:50-51). Constituyen un conjunto de rituales cotidianos que organizan las relaciones sociales en el ámbito escolar de acuerdo a una determinada visión del orden social y político. Parte de su eficacia, como señala Enguita (1998[1990]), reside en el hecho de que la autoridad escolar no suele tomar formas ostentosas, sino casi imperceptibles y a pequeña escala, evitando la resistencia que el ejercicio brutal de la autoridad podría suscitar. Aún aquellas que suponen un importante despliegue como algunos de los actos

459 Comparados con el contenido del anteproyecto de ley, estos artículos referidos a la diversidad cultural y la identidad nacional sufrieron sólo leves modificaciones, aunque significativas: en el artículo donde se evoca la importancia de la educación, se sustituyó "identidad cultural” por "identidad nacional” y en el referido a los fines y objetivos de la educación se agrega que el fortalecimiento de la identidad nacional debe estar basada no sólo en las particularidades locales, sino también en "el respeto a la diversidad cultural"; en otro de sus incisos se reemplaza, asimismo, el término "interculturalidad" por "la valoración de la multiculturalidad".

460 Para una sugerente crítica sobre los usos del principio del "respeto a la diversidad" desde su adopción en el contexto educativo argentino, véase Batallán y Campanini (2007).

461 En general, esta aproximación está referida, concretamente, a los "pueblos indígenas". Los documentos oficiales indican que la Educación Intercultural Bilingüe expresa aquella educación que contribuirá a "preservar y fortalecer sus pautas culturales, su lengua, su cosmovisión e identidad étnica; a desempeñarse activamente en un mundo multicultural y a mejorar su calidad de vida". También se reconoce en ella la educación propicia para mantener "un diálogo mutuamente enriquecedor de conocimientos y valores entre los pueblos indígenas y poblaciones étnica, lingüística y culturalmente diferentes" y conseguir "el reconocimiento y el respeto hacia tales diferencias". También establece la necesidad de definir contenidos curriculares comunes que "promuevan el respeto por la multiculturalidad y el conocimiento de las culturas originarias en todas las escuelas del país, permitiendo a los/as alumnos/as valorar y comprender la diversidad cultural como atributo positivo de nuestra sociedad". Se destaca, asimismo, "el conocimiento de la diversidad cultural de los pueblos indígenas y sus derechos". 
escolares que se desarrollan en ocasión de las efemérides patrias, verdaderos actos de ostentación patriótica, cuentan con tal grado de aprobación social que difícilmente pongan en cuestión el orden y la autoridad escolares.

Los actos escolares, en tanto instancia especial de trabajo con las efemérides (Zelmanovich, 1994), se constituyeron a lo largo del siglo veinte en uno de los instrumentos privilegiados del Estado para disponer los comportamientos y los valores que la escuela debía transmitir. El interés estatal por construir la nacionalidad argentina, forjado en una época signada por la necesidad de crear a la nación, además de fortalecer un Estado en plena etapa de constitución, y luego afianzado a partir de las preocupaciones que generó la llegada de numerosos contingentes de inmigrantes de ultramar, llevó a instaurar en el terreno de la educación una serie de prácticas que sirviesen a los fines de formar ciudadanos: tanto sujetos nacionales como nacionales argentinos. Como indica Oszlak, la realización de rituales de pertenencia y lealtad a la patria y la adhesión a los símbolos nacionales -los símbolos patrios-formó parte de los instrumentos de los cuales se sirvió el Estado nacional para "crear en la conciencia ordinaria de los ciudadanos la convicción de que el orden instituido coincidía con un orden legítimo y deseable" (Oszlak, 2004[1997]:157). Para ello, la organización de la rutina escolar a través de disposiciones administrativas nacionales destinadas a regular la celebración de las fechas patrias resultó una herramienta altamente eficaz, que ya desde los orígenes del sistema educativo argentino comenzó a ser utilizada. La creación de un marco de referencia simplificado y el uso diario ritualizado de los símbolos nacionales permitió sustituir las memorias individuales y los relatos recibidos en los hogares por un patrimonio único -es decir, construir una "memoria común" de los argentinos- que aglutinara aquellos sujetos adscritos individualmente (Juliano, 1987). Como muestra Lionetti, la tarea nacionalizadora de "argentinizar" a la sociedad civil a través de ceremonias patrióticas emprendida por la escuela pública fue reforzada mediante la enseñanza moral y cívica, la cual contribuiría a cimentar aquellos valores que la formación del ciudadano y el cumplimiento de los deberes patrióticos requerían: el "buen ciudadano" debía conducirse en su vida pública y privada mediante valores como la honra, la honestidad, la observancia de las obligaciones familiares, el respeto a las leyes y las autoridades y el amor a la patria. En general, las variaciones de los actos escolares como los patrióticos, acordes al momento histórico bajo el cual se desarrollaron, se relaciona, como señala Amuchástegui (2000), con el significado que se les asignó y fueron vividas cada una de estas experiencias, así como su trascendencia para la asignación de sentidos a la reunión, a la fecha, al culto a los emblemas, al trabajo de los docentes organizadores y participantes, a las posibilidades de que la escuela se destaque, entre otros aspectos. 
Es preciso recordar que la celebración de las fiestas patrias empezó a involucrar a la institución escolar hacia fines del siglo diecinueve como parte de un renovado movimiento de construcción de la nacionalidad argentina que impulsaba la élite local frente a un contexto marcado por la presencia de la inmigración masiva de ultramar y, simultáneamente, el inicio de una nueva etapa de formación y expansión de las naciones en Europa. ${ }^{462}$ De acuerdo al estudio de Bertoni (2001), hacia finales de la década de 1880, el espacio escolar aún no estaba particularmente asociado con la simbología patria: la celebración de las fechas patrias, así como el izamiento de la bandera argentina (ritual que más tarde quedará indisolublemente ligado a los actos patrióticos), no constituía una actividad regular en la vida cotidiana de las instituciones escolares y su conmemoración dependía fundamentalmente de la iniciativa de sus maestros y directores. A comienzos de la década, el entusiasmo popular alrededor de las fiestas patrias había decaído y la presencia del Estado se había hecho más notable, adquiriendo las formas de una ceremonia solemne. A partir del año 1887, la preocupación por la nacionalidad en torno a las fiestas patrias desencadenó la organización de grandes celebraciones conmemorativas en las cuales la participación de los escolares -mediante la formación de "batallones" contribuyó en gran medida a reactivar las fiestas públicas oficiales, al punto de convertirse progresivamente en uno de los acontecimientos centrales del programa de festejos. Esta actividad, surgida más o menos espontáneamente en 1887, fue asumida de manera oficial por el CNE en 1888. Es en esta trama de producciones simbólicas, como señala Blázquez (en prensa), que se construyó el carácter de acontecimiento inaugural de la llamada Revolución de Mayo y con él toda una interpretación de la historia que presume la existencia de una conciencia o identidad nacional en quienes protagonizaron los acontecimientos de 1810.

Al mismo tiempo, desde las instancias estatales, se propició que las celebraciones patrias oficiales adquirieran, a través de una serie de disposiciones reglamentarias, mayor relevancia y uniformidad en las escuelas. Hacia finales del siglo diecinueve, como muestra Blázquez (en prensa), el Consejo Nacional de Educación (CNE), inspirado en algunas iniciativas personales desarrolladas en el ámbito escolar, comenzó a emitir circulares, basadas en las resoluciones (llamadas acuerdos) que se adoptaban en su seno, mediante las cuales se imponía la obligación de organizar celebraciones relacionadas con las fiestas

462 A mi modo de ver, uno de los aciertos del trabajo de Bertoni (2001) es que en su explicación sobre la construcción de la nacionalidad en la Argentina de fines del siglo XX considera la influencia que tuvo la competencia que se estableció en el país con los Estados europeos por controlar y conseguir la adhesión nacional de unos y otros ciudadanos. 
patrias, cuyo acatamiento en algunas escuelas supuso la realización de diversas actividades de carácter patriótico. En aquellos años de mediados de la década de 1890 también se empezaron a extender otras formas de conmemoración diferentes a las fiestas íntimas como la Semana de Mayo y la Semana de Julio.

A comienzos del siglo veinte, especialmente con la llegada del médico José María Ramos Mejía como presidente al CNE en el año 1909, la educación patriótica se convirtió en el principal objetivo gubernamental, impulsando para ello la nacionalización de los contenidos de la enseñanza, la multiplicación de los actos escolares patrióticos y la ocupación del espacio público a través de la participación escolar masiva en las festividades patrias (Blázquez, en prensa). La proximidad del Centenario de la Revolución de Mayo constituyó el contexto propicio para cultivar la exaltación patriótica que se anhelaba desde el CNE. El extranjero, visto socialmente como invasor y amenaza, fue considerado por Ramos Mejía como "un aporte conflictivo aunque imprescindible para la construcción de una nación moderna”, cuya incorporación se lograría con la educación pública y con las oportunidades de progreso material que la Argentina ofrecía en aquellos años a los extranjeros recién llegados (Terán, 2008:143). Desde el CNE, Ramos Mejía “apostó a la escuela pública como resorte de nacionalización de las masas que obrara como barrera ante la penetración de ideas subversivas del orden conservador" (Terán, 2008:139). Bajo su gestión, la organización de la rutina escolar se convirtió en objeto de medidas precisas: a partir de instrucciones acerca del mobiliario, el contenido y forma de las ilustraciones, el uso del tiempo, de los programas, la manera en que se debía enseñar, entre otras cuestiones, se dispuso un conjunto de prácticas que se consideraban necesarias para formar y homogeneizar la identidad social (Amuchástegui, 2000). Persuadido de que la producción del sentimiento nacional era el modo de afirmar la pertenencia a la nación, desde su puesto al frente del CNE reglamentó las ceremonias escolares como procedimiento de nacionalización de las masas (Terán, 2008:145), esto es, una educación nacionalizadora capaz de transformar a los hijos de los inmigrantes en verdaderos argentinos.

Las disposiciones estatales orientadas a regular las festividades patrióticas en el ámbito escolar se mantuvieron durante las décadas posteriores y cobraron un nuevo impulso durante la gestión del médico-cirujano Oscar Ivanissevich (1895-1976) al frente del Ministerio de Educación entre 1948 y 1950 en el marco del primer gobierno peronista. Con la enorme relevancia que adquirieron los rituales patrióticos escolares en su mandato se instituyó la publicación del calendario escolar, donde se definieron las características escénicas de los actos y las formas correctas en que debían celebrarse las efemérides que 
permitieron su normalización, rutinización y repetición hasta adquirir una serie de características formales que les aseguraron su eficacia simbólica: se establecieron cuatro modelos escénicos o formas que marcaban la importancia del acontecimiento que se celebraba a partir de la determinación de los ritmos, la duración y las actividades pertinentes para cada modelo (Blázquez, en prensa). Las diversas formas establecidas para conmemorar las fechas establecidas en el calendario escolar, cuya clasificación supone una división jerárquica entre los actos escolares que expresa la importancia otorgada a cada una en la construcción del orden escolar y social, eran las siguientes:

Forma I: Acto solemne en la Escuela, el mismo día, con exclusión de toda otra actividad, o en las dos últimas horas del día hábil anterior según se indique;

Forma II: Acto en la última hora de clase de cada turno;

Forma III: Clase alusiva en cada grado o curso y preparación de la Cartelera de Efemérides;

Forma IV: Preparación de Cartelera de Efemérides.

Las distintas disposiciones estipuladas e innovaciones incorporadas durante la primera mitad del siglo veinte en relación a la celebración de las fechas patrias y el tratamiento y uso de los símbolos nacionales fueron recogidas por la legislación educativa producida durante las décadas posteriores, eliminando, sustituyendo o modificando algunos aspectos puntuales de forma, pero resguardando la finalidad asignada históricamente a la escuela argentina: formar al ciudadano y cultivar el sentimiento cívico-patriótico. Respecto a la regulación de la elección de abanderados y escoltas y de los símbolos patrios, las normas que sirven de referencia y se utilizan actualmente en las escuelas están basadas en un decreto 463 del año 1944 y fueron establecidas durante la última dictadura militar. ${ }^{464}$ Las fiestas escolares y patrióticas, así denominadas en el Reglamento General de Escuelas Primarias ${ }^{465}$ de 1938, pasaron a ser reguladas, después de la gestión de Ivanissevich, por el calendario o anuario 466 escolar establecido por las respectivas administraciones educativas provinciales, las cuales definen los diversos acontecimientos sociales, políticos

\footnotetext{
463 Decreto № $10.302 / 44$.

464 Se trata de las resoluciones ministeriales № 3.482/80, su modificatoria № 6.052 у la № 605/81 respectivamente.

465 En el decreto № 41.009 del 22 de septiembre de 1938, que regía la educación primaria en la provincia de Córdoba, se dedicaba un capítulo entero a las "Fiestas escolares y patrióticas" donde se establecían las fechas, características y objetivos generales de las celebraciones (Blázquez, en prensa).

466 En Córdoba, en el año 1985, la noción de "calendario escolar" fue sustituida por "anuario escolar" (Blázquez, en prensa).
} 
y culturales, de carácter internacional, nacional o local que consideran de especial relevancia, además de incorporar las fechas patrias ya instituidas.

Con el paso del tiempo, en algunos casos, la clasificación de los actos escolares de acuerdo a las formas establecidas durante el primer gobierno peronista se simplificó. En la provincia de Córdoba, por ejemplo, esto actos se dividieron durante los años noventa en actos de celebración especial y celebraciones y actividades relevantes: los primeros son los antiguos actos de tipo I y II (todos los actos del Tipo I están incluidos en las "fechas a recordar el día hábil anterior", aunque esta clase es más extensa dado que incluye algunos actos de tipo II) y los segundos equivalen a los actos de tipo III y IV. La larga permanencia de la clasificación establecida durante el primer peronismo y la estrecha correspondencia entre los criterios clasificatorios antiguos y actuales han contribuido a que la tipología creada por Ivanissevich se mantenga vigente en el ámbito de las prácticas y los discursos institucionales (Blázquez, en prensa). En la actualidad, estas formas establecidas se traducen en la vida cotidiana de las escuelas, según la importancia asignada en el anuario escolar, en dos modos de conmemoración: las que deben ser celebradas mediante un "acto" porque su fecha lo amerita (formas I y II) y aquellas que deben ser evocadas simplemente a través de un "recordatorio" (formas III y IV), pero que a pesar que oficialmente no sean consideradas meritorias de un mayor despliegue, algunas veces suelen tomar una dimensión mayor a la acostumbrada.

Entre un número que fácilmente sobrepasa el medio centenar, no todas las fechas tienen el mismo peso ni reciben el mismo tratamiento. ${ }^{467}$ Las más importantes, cuya recordación es obligatoria, son aquellas que se relacionan con las fechas patrias, las cuales remiten a los orígenes del Estado-nación argentino y rinden culto a los próceres nacionales: el día de la Constitución Nacional (1 de mayo), el día de la Revolución de Mayo (25 de mayo), el día de la Bandera (20 de junio), el día de la Independencia ( 9 de julio), el aniversario de la Muerte del Gral. San Martín (17 de agosto) y el aniversario de la muerte de Domingo Faustino Sarmiento (11 de septiembre). Más específicamente, las fechas patrias privilegiadas en el calendario o anuario escolar se refieren al momento fundacional del Estado-nación argentino y remiten en general al pasado histórico argentino previo a la inmigración de masas. Dicho recorte, como sugiere Devoto (1992a) en su análisis sobre la idea de nación en la historiografía argentina y los textos escolares, refleja una concepción jurídica y territorial de la nación que contribuiría a fijar aquella pedagogía cívica que surgirá como

467 En la provincia de Córdoba, las "las fechas para recordar" establecidas por el Ministerio de Educación a través del anuario escolar son más de sesenta. 
respuesta a la heterogeneidad social y étnica que preocupaba a las élites locales de principios del siglo veinte. Si bien todas ellas ocupan un lugar prominente en el anuario escolar, las cuatro fechas paradigmáticas son el 25 de mayo, el 20 de junio, el 9 de julio y el 17 de agosto, pero especialmente la primera, que rememora la formación de la Primera Junta de Gobierno, la cual se instituyó históricamente como el origen mítico inequívoco de la Argentina, sea como Patria, Nación o Estado. En todas estas celebraciones, "se intenta mantener una imagen de patria donde no hay conflictos y reina la armonía gracias a aquellos héroes que supieron librar importantes batallas" (Olorón, 2000:92).

En la escuela primaria, las efemérides constituyen un componente central en el proceso de organización y transmisión de ideas y creencias acerca de la historia nacional. ${ }^{468} \mathrm{~A}$ través de las efemérides, las fechas patrias son alineadas de tal modo que, gracias a un "azar provechoso" como dice Romero, bosquejan un esquema básico de la historia política argentina: el nacimiento de la patria el 25 de mayo, su independencia el 9 de julio, su consolidación y proyección continental el 17 de agosto (Romero, 2004). Algo así como "los eslabones de la memoria oficial de la nación" (Bertoni, 2001:79). En particular en los grados inferiores, la exposición de los principales acontecimientos del pasado nacional depende de su secuencia en el calendario escolar. Sin embargo este orden cronológico que siguen las efemérides se interrumpe cuando, en el mes de octubre, aparece el "descubrimiento de América", que es rememorado oficialmente como el Día de la Raza. Pero, como sugiere Zelmanovich (1994), el propósito que está detrás de las efemérides patrias no se relaciona tanto con el conocimiento de hechos históricos como de la recuperación de aquellos acontecimientos que en tanto hitos nacionales del pasado dan cuenta de los orígenes de una sociedad nacional que necesitaba ser construida como argentina. 469

\footnotetext{
468 Las efemérides que se desarrollan en las aulas no es la misma que tiene lugar en el patio a través de los actos escolares. Las efemérides que tienen lugar en estos "espacios cerrados" suelen estar referidas casi exclusivamente a la historia argentina, a las fechas que se relacionan mayormente con el origen del Estado y la nación argentinos. La construcción de la bolivianidad, en cambio, se produce y se expresa más bien en los "espacios abiertos" como el patio (donde participa la comunidad educativa en su conjunto): allí tiene lugar la "presencia admitida". Es decir, en el aula se reproduce principalmente aquella efemérides que ocupa un lugar destacado en la jerarquía de las celebraciones de la escuela, los grandes actos establecidos por el Estado, desplazando los pequeños actos que se corresponden con celebraciones secundarias y algunas fijadas por la propia escuela como el Día de la Independencia de Bolivia. 469 Tanto Romero (2004) como Zelmanovich (1994) escriben desde el nosotros nacional. En mis referencias a sus textos, las paráfrasis que realizo de sus palabras intentan situarse desde afuera. Zelmanovich habla por ejemplo, de "nuestros orígenes" y Romero se refiere a "nuestro pasado" mientras se pregunta “¿cómo no llamarlo argentino?".
} 
Según lo pautado en el anuario escolar, otras fechas que suelen recibir cierto tratamiento especial entre los festejos escolares están el día de la Raza (12 de octubre), el día de la Tradición (10 de noviembre) y, en menor medida, el día de las Américas (14 de abril) y algunas fechas locales como el aniversario de la fundación de la ciudad -que en Córdoba se festeja generalmente junto con el día de la Independencia, debido a que ambas suelen coincidir con el período de vacaciones de invierno- y el aniversario de la creación de la escuela. Las fechas locales adoptadas en la escuela Vicente Forestieri son el aniversario de la escuela, que se celebra como acto único en el mes de mayo, y la fecha de fundación del barrio -la "semana de La Villa"- en el mes de agosto. Entre las fechas que se celebran como "recordatorio" -los pequeños actos- hay una gran diversidad de conmemoraciones: por ejemplo, el día del Inmigrante (4 de septiembre), el día de los Derechos del Niño (1 de octubre), la semana de la Integración de personas con capacidades diferentes (4-8 de octubre), el día de la Soberanía (20 de noviembre). Bajo esta opción, las escuelas incluyen también aquellas fechas que consideran importantes o que se relacionan con la comunidad más próxima. De este modo, se incluyó en la escuela Vicente Forestieri el día de la independencia de Bolivia ( 6 de agosto).

La acción nacionalizadora del Estado ha sido tan eficaz que los organismos burocráticos encargados de supervisar las escuelas tampoco se preocupan por controlar su cumplimiento: se sabe de antemano que las fechas patrias serán debidamente recordadas. A pesar de que las directrices estatales nunca son internalizadas en las escuelas de manera mecánica o pasiva, prestándose a diversas negociaciones, el desarrollo de las efemérides escolares en particular suele ser experimentado bajo un intenso sentimiento de imposición. Como dice uno de los directivos: "No pensar, no reflexionar, no preguntarse. Y la efemérides llega así. Te lo establecen. Estas fechas... 9 de julio, 25 de mayo... serán recordadas... acto único... y otras fechas que tienen que ser recordadas el día después" (Carmen). En este sentido, es significativo que la directora, cuando se refiere a las instrucciones que provienen del Ministerio de Educación, hable de "los de arriba". De ahí que la directora distinga entre fechas "impuestas" y "puestas". Con las primeras se refiere a las "fechas que vienen del anuario escolar", en particular las fechas patrias, y con las segundas a las que se definen en la escuela. La celebración de los actos referidos a las fechas patrias -los grandes actos- está establecida como una obligación que las escuelas deben acatar y el margen de elección de las fechas a conmemorar recae sólo sobre aquellas contempladas como "recordatorios". 470

470 Respecto a la selección o delimitación de estas fechas, la directora señala que en general se realiza con el propósito de disminuir su cantidad, por tanto, de ahorrarse el trabajo que supone la organización de un acto escolar: 
Los llamados "actos" se realizan en la última hora del mismo día o en la última hora del día hábil anterior. Su desarrollo debe seguir un orden claramente pautado por la normativa escolar que supone considerar aspectos como la recepción de las autoridades educativas o gubernamentales, en caso que correspondiera; la entrada de la bandera de ceremonias; el izamiento de la bandera de ceremonias; la entonación del himno nacional argentino; las palabras alusivas al hecho social que convoca (autoridades, alumnos, ex-alumnos, etc.); la participación de alumnos; las palabras de la máxima autoridad presente; el retiro de la bandera de ceremonias; y la "desconcentración". Un "recordatorio", en cambio, está pautado -en la escuela Vicente Forestieri como en otras tantas escuelas- de la siguiente manera: a) palabras alusivas a la entrada de cada turno a cargo del/a docente semanero/a y b) preparación de una estera a cargo del docente designado según un listado elaborado por las propias maestras (debe colocarse el mismo día a la entrada si es del turno o el día anterior si es del turno tarde o la fecha cae fin de semana). ${ }^{471}$ En tanto rituales los actos escolares en su conjunto poseen una serie de regularidades: una invocación del pasado (que en el caso de los actos patrióticos se encarna en relatos de los orígenes de la patria) para rememorar y fortalecer el presente; ordenamientos espaciales que distinguen a las autoridades principales del resto de los participantes; un encadenamiento de dramatizaciones (entrada de la bandera de ceremonia, silencios, movimientos corporales, canciones, palabras alusivas, recitados, danzas, vestimenta); y una secuencialidad de la acción, es decir, una serie de pasos diferenciados, con una dirección, que van desde una apertura a un cierre (Visacovski, 1994, citado en Olorón, 2000). Este desarrollo de carácter ritual, esbozado hacia fines del siglo diecinueve y consolidado a lo largo del veinte, ha posibilitado que muchas de las ideas y prácticas que se desplegaron en las escuelas perduren a lo largo del tiempo. Las efemérides y los actos escolares poseen tal arraigo en la vida cotidiana escolar que han pasado a formar parte de la definición que la escuela, en plena acción, otorga de sí misma.

Finalmente, cabe señalar que muchas de estas normas jurídicas que aún hoy en día rigen la organización de la vida cotidiana de la escuela y por las cuales las maestras se guían fueron dispuestas durante la última dictadura militar. Al mismo tiempo que desde el Ministerio de Educación y Cultura se establecía la quema de libros y la prohibición de

\footnotetext{
"El recorte no se hace por el concepto de pensar, el recorte viene para no hacerlo, menos fechas para recordar" (Carmen).

471 De la organización de los actos, sean grandes o pequeños, se suele ocupar aquella docente que resulte elegida o sorteada (en este orden). Para ello cuenta con la colaboración de algunas compañeras. Entre las maestras, la encargada de organizarlo y coordinarlo es denominada "semanera".
} 
obras y autores identificados con el pensamiento marxista o ideas subversivas en defensa de la sociedad, se estimulaban los rituales patrióticos como un medio idóneo para acompañar la tarea de formación nacionalista. Como sucediera en el ámbito de gobierno de las migraciones, en cierta medida se trata de una sistematización y reformulación de disposiciones que fueron elaboradas con anterioridad. Aunque algunas de ellas no se encuentran formalmente vigentes, persisten en las representaciones y prácticas que se despliegan cotidianamente. Estas disposiciones jurídicas destinadas a regular el orden escolar se encuentran reunidas en un solo volumen que en las escuelas se conoce informalmente como el reglamento, un instrumento de consulta permanente. Ante cualquier duda sobre los actos escolares, por ejemplo, la respuesta de los docentes siempre conduce a esta normativa: "Está en el reglamento".

\section{Integrar a los extranjeros cien años después: los actos escolares patrióticos (o la construcción de la argentinidad en la escuela)}

En el año 2002, en ocasión de la conmemoración del 25 de mayo de 1810, en la sala de maestros alguien escribió en el pizarrón de los anuncios una "Receta Patriótica" que condensa bien aquellos símbolos, valores y principios que la escuela como institución del Estado se encarga de transmitir. La metáfora elegida remite a la idea de construcción y a la vez a un modo prescriptivo de hacer las cosas. A través del formato de una receta de cocina, se destacan los tres símbolos patrios con la mayor presencia en la escuela, a los cuales se les debe conferir indefectiblemente respeto: la bandera, la escarapela y el himno. Estos símbolos articulan el pasado, el presente y el futuro, momentos en los cuales se depositan sentimientos como alegría y esperanza. Aparecen como protagonistas de la sociedad nacional las familias y la clase dirigente, actores clave en la formación de la nacionalidad. Entre los valores y principios proclamados, enunciados a manera de ingredientes siguiendo con la metáfora de la receta propuesta, se sugiere agregar algo de paz y dignidad, mucha educación e igualdad "a gusto". Como adornos se proponen hojas de laurel, trabajo y solidaridad y se recomienda presentarlo como acompañamiento de la democracia y la libertad. El llamado final a ayudar a la patria es probable que responda al contexto de crisis política y económica que atravesaba la Argentina en aquél año.

Se necesita una bandera / celeste y blanca con sol, / con escarapela y el himno / bien cantado; / dejarlos remojar en la historia / con un litro de esperanza en el futuro / y la alegría en el presente. / Colocar luego todos los ingredientes / con una multitud de familias / y dirigentes argentinos / en un plato en forma 
de mapa / de Argentina. Aderezar con una cucharada de paz, dos de dignidad, un kilo de educación e igualdad a gusto. / Por último adornar el plato con hojas de laurel, trabajo y solidaridad; este plato sirve muy bien para acompañar / a la DEMOCRACIA y la LIBERTAD. AYUDEMOS A NTRA. PATRIA (Notas de campo, 31 de mayo de 2002)

Esta "receta patriótica" encarna aquellos elementos que se fueron sedimentando y resignificando a lo largo de décadas en el espacio escolar a través de la llamada educación patriótica hasta incorporarse al sentido común de las instituciones educativas formando lo que Elias (2009[1989]) llama habitus nacional. La sola existencia de esta "receta patriótica" en la sala de maestros revela la vigencia que mantiene el cumplimiento del mandato estatal asignado a la escuela en la construcción de la identidad nacional hacia fines del siglo diecinueve. Muestra que aún hoy la idea de formación del "ciudadano de la República" presupone la producción de sujetos leales a la patria como modo de asegurar su subordinación al Estado y mantener la cohesión social que las conflictivas relaciones de clase podrían afectar. La recurrente referencia a los símbolos nacionales expresa, como sostiene (Amuchástegui, 2000), el afán formador de una identidad nacional homogénea, que remite a los objetivos originarios asignados a la escuela pública. Uno de los instrumentos privilegiados para cumplir dicho propósito continúan siendo los actos escolares patrióticos como el 25 de Mayo.

En ocasión de la celebración del 25 de mayo del año 2003 llegué a la escuela por la mañana un rato antes del horario de inicio del acto escolar. Cada turno festejaba por separado. Con alguna demora se dio inicio al acto, conducido por la maestra de una de las dos secciones de primer grado (Silvana): "Sra. Directora, sras. vicedirectoras, docentes, padres, miembros de la cooperadora, alumnos de la Escuela Vicente Forestieri. Hoy como todos los años nos reunimos una vez más para recordar el nacimiento de la patria, el nacimiento de un espíritu de libertad y la formación del primer gobierno patrio conseguida por aquellos patriotas, quienes hicieron posible iniciar los primeros pasos hacia el camino de la independencia".

Después de las palabras introductorias, la maestra se refirió a la bandera, portada por los alumnos abanderados, para dar lugar a su ingreso: "La patria está presente a través de la bandera, que desde el mástil nos mira mientras recordamos los acontecimientos que nos hicieron un país libre, capaz de gobernarse por sí mismo. Con sus hermosos colores, gritando mientras flamea, a todo el que quiera escucharlo, `soy la bandera argentina', hace su entrada a este acto la bandera de ceremonia. Con orgullo la conducen en esta 
oportunidad los alumnos de sexto grado. La portación de la bandera es en forma grupal, teniendo en cuenta su esmero, responsabilidad y logros en su aprendizaje de todo el grupo".

Ya ubicada la bandera de ceremonias, la maestra hizo alusión al himno nacional: "Todos unidos somos un gran pueblo, que ama su tierra y que le canta recordando en las estrofas del Himno, el grito de libertad de los argentinos de hoy y de siempre. A continuación entonemos con entusiasmo nuestra canción patria". Inmediatamente después un grupo de alumnos se dirigió al público destacando el significado de la fecha conmemorada. La maestra hizo la presentación diciendo: "Los aquí presentes y los que participan, en todo el país, de los actos de recordación del 25 de mayo de 1810, sentimos en lo más profundo de nuestro ser, que amamos a la Patria y queremos verla grande. Alumnos de quinto grado nos dirigirán un mensaje de libertad". Finalizada la actuación, la docente expresó unas palabras para despedir a la bandera antes de la finalización del acto, como suele ser habitual: “Orgullosa presenció la evocación del nacimiento de la patria a la cual representa. Ahora debe retirarse hasta que los recuerdos históricos nos convoquen. Con el respeto que se merece despedimos a nuestra Bandera de Ceremonia".

Posteriormente comenzaron las distintas actuaciones de los alumnos, organizadas por sus respectivas maestras durante la jornada escolar en el horario de clases, recordando la maestra la finalidad que persigue el acto: "Ahora los invito a disfrutar de los números que han preparado los alumnos durante la semana pasada cuyo objetivo es la recordación de los acontecimientos que facilita la comprensión de nuestra historia común y contribuye a la formación de la identidad nacional". Como cada año y en cada acto escolar referido al 25 de mayo, los alumnos representaron diversas escenas de la vida colonial: "Viajando en el tiempo, en 1810, por un camino largo, vamos a espiar a esas primeras personas en su vida cotidiana, sus formas de vida, sus costumbres, sus gustos. Los chicos de primer grado realizarán una estampa colonial”. Al final del número, los alumnos de primero, solicitados por la maestra, gritaron “¡Viva la Patria!” a la vez que el resto de los alumnos y familiares también fueron incentivados a hacer lo mismo. Todos los presentes exclamaron al unísono: “¡Viva la Patria!”. A ello le siguió una escena dirigida a actualizar algunos componentes de la vida social de aquella época: "Nuestra historia es lo que sucedió y sucede día a día. A continuación alumnos de tercer grado "A" dramatizarán los vendedores ambulantes de hoy". Entre una y otra actuación hubo por parte de las maestras varios llamados de atención como éste: "Para disfrutar de este acto debemos mantener el orden". 
Siguiendo el motivo central del acto, alumnos de distintos grados evocaron a través de distintos modos la idea de libertad, simbolizada como palomas blancas: "Seguimos espiando y vemos un camino largo rodeado de palomas blancas que surgió del nacimiento de nuestra patria." A continuación alumnos de quinto grado representaron un esquema llamado "Un camino hacia la libertad" y otros de cuarto recitaron una poesía titulada: "Por la libertad". Luego, le siguió el canto, que según la maestra "no puede estar ausente en esta jornada de fiesta”. Así, los alumnos entonaron la canción: ¡Viva la Revolución! Posteriormente, las danzas folclóricas también tuvieron su lugar: "Entre cantos y poesías por supuesto no puede faltar una danza con zapateo y zarandeo". Primero, los alumnos de sexto grado bailaron un "gatito" y para el cierre, agregándole mayor espectacularidad a la celebración, un conjunto de baile folclórico invitado por la escuela hizo su presentación: "La tradición, las costumbres recorren todo un camino desde 1810 hasta hoy; es el conjunto de valores que encadenan el pasado con el presente. Le damos la bienvenida y desde ya un agradecimiento profundo a la academia folclórica "Raíces Criollas" que nos va a deleitar con...". Alrededor de una hora después de iniciado, la maestra da por finalizado el acto, agradeciendo la participación y colaboración de docentes, alumnos y familiares.

Este acto escolar muestra el despliegue que realiza la escuela siguiendo el mandato estatal instituido a lo largo del siglo veinte como instrumento de construcción de la nación argentina y la formación de una identidad nacional homogénea. En este sentido, a pesar de las reconfiguraciones que han tenido los actos escolares patrióticos como el 25 de Mayo, aún hoy expresan aquella concepción cultural esencialista de la nación, defensiva y excluyente, que a partir del Centenario se instauró como sinónimo de lo nacional, desplazando el cosmopolitismo y las demás versiones en pugna (Bertoni, 2001). En estos actos quedan excluidos todos aquellos elementos materiales y simbólicos que no remitan a la visión hegemónica sobre la Argentina o remitan a otras naciones, a pesar de la visibilidad que pudiera haber adquirido la presencia de los alumnos identificados con otras naciones o nacionalidades. No hay allí espacio para la diferencia, aquella que se busca poner de manifiesto en otras conmemoraciones escolares. Así, los alumnos que en determinados contextos y situaciones de la vida son representados e interpelados como bolivianos, en los rituales patrióticos resultan una presencia ausente.

Ahora bien, aunque la finalidad perseguida sea la formación de sujetos como argentinos, en estos actos escolares patrióticos junto a otros rituales cotidianos los alumnos también son interpelados y aprenden a comportarse como sujetos nacionales en tanto súbditos de un Estado. Es decir, con la puesta en práctica de estas ceremonias cívicas los alumnos también son instruidos conforme a los símbolos y principios que constituyen lo nacional. A 
través de ellas, así como una sociedad expresa simbólicamente su subordinación al Estado (la patria, la nación), representando con un mismo comportamiento (silencio, quietud) el sentido del respeto (Amuchástegui, 2000), los alumnos aprenden a cumplir desde temprano el papel de súbditos del Estado nacional al cual como adultos deberán rendirle pleitesía y a cuyas leyes tendrán que someterse, sea como nacionales/ciudadanos o extranjeros/no ciudadanos.

Igualmente relevante es que a través de estos actos patrióticos el Estado nacional cobra existencia material y asegura su reproducción. En términos de Bourdieu (1994) estos actos son el Estado en estado práctico. Es decir, los actos escolares patrióticos no sólo tienen efecto sobre quienes participan -docentes, alumnos, familiares- de ellos, produciendo sujetos argentinos o nacionales, sino que también producen estatalidad Al mismo tiempo, en el despliegue que realiza la escuela en orden a cumplir el mandato estatal de inculcar la identidad nacional se construye y justifica a sí misma, constituyéndose como institución legítima frente a la sociedad mayor y a la comunidad barrial que la frecuenta. En la Argentina de hoy, la idea de escuela es inconcebible e inaceptable sin rituales cívicos que rindan culto a la nación argentina.

Por otra parte, la puesta en escena de la celebración de las fechas patrias, si bien responde a la principal o explícita finalidad de construir y afianzar la identidad nacional para la reproducción de la comunidad nacional, siguiendo un mandato escolar explícito, el mandato oficial, también contribuye a construir un sentido de pertenencia comunitario de otro orden, que ya no responde a las grandes epopeyas nacionales que están detrás de la noción de comunidad imaginada (Anderson, 2000), sino a una idea de comunidad local que pretende ser construida a través de los lazos que se producen diariamente entre la escuela y las familias, habilitando otras posibles identificaciones como las relacionadas mayormente con el barrio. Esto se puso de manifiesto en la escuela Vicente Forestieri cuando en ocasión del día en que se conmemora oficialmente la muerte de uno de los héroes nacionales, el Gral. José de San Martín, a quien se lo denominó también "El Libertador" debido a su protagonismo como militar en la luchas de la independencia de Argentina, Chile y Perú, recupera aquella etiqueta para relacionarla con el nombre que recibió el barrio donde está ubicada la escuela, buscando afianzar la relación escuelacomunidad.

Aquél 17 de agosto de 2003, el acto comenzó cerca de las 9:30 de la mañana. Sonó el timbre y se comenzó con la formación de filas en el patio. La maestra de tercer grado era la encargada del acto escolar que se realizaba en ocasión del aniversario de la muerte de San 
Martín. En el espacio demarcado como escenario, estaba colocada sobre cuatro sillas una estera con imágenes y frases alusivas a San Martín. El afiche, con una imagen de la cordillera de los Andes como fondo, decía: "El 17 de agosto recordamos al Gral. San Martín” y “iQué lindo hubiera sido acompañarte y cruzar los Andes con vos!”. Otro afiche escrito a mano mostraba las llamadas "Máximas de San Martín": "Desde Merceditas a nuestros días: estar formal en la mesa; inspirar sentimientos de respeto hacia todas las religiones; amar la verdad y odiar la mentira; amar el aseo y despreciar los lujos; respetar la propiedad ajena; inspirar amor por la patria y por la libertad; estimular la caridad hacia los pobres; inspirar confianza y amistad, pero unidas de respeto."

Antes de dar inicio formal al acto, se requirió, como en cada encuentro escolar, que los alumnos hicieran silencio: "Bueno, hacemos un poquito de silencio para comenzar con el acto del 17 de agosto". Con relativo silencio, la maestra encargada del acto expresó las palabras inaugurales, seguidas del ingreso de la bandera. Desde el mismo comienzo la maestra asocia el acto conmemorativo con el nombre del barrio: "Hoy queremos recordar... bueno, me escuchan o no, no hay silencio acá.... Hoy queremos recordar a quien le da el nombre al barrio, el Gral. San Martín." Ingresada la bandera de ceremonias y colocada en su lugar, se entona la canción patria por excelencia, seguida de aplausos: "Nuestra máxima canción patria es el himno nacional argentino... entonamos el himno nacional argentino." La versión del himno que se cantó en aquella oportunidad no era la misma que se escucha habitualmente en las escuelas. La maestra que conducía el acto se refirió a la historia del barrio y cerró interpelando a los alumnos: "Se llamó Villa El Libertador. ¿Por qué será?” Una alumna de tercer grado leyó la respuesta y al terminar la maestra aclaró que en el acto se estaba presentando el trabajo realizado en clase donde vieron los tres países que fueron liberados por el Gral. San Martín. Después, la maestra introdujo el siguiente número: "San Martín, además de ser un luchador, fue un hombre, tuvo una hija, Merceditas". Algunos alumnos repitieron de memoria algunas máximas y expresaron su propia interpretación. Uno de ellos dijo: "Respetar a nuestros compañeros peruanos". En el medio, se despidió la bandera, haciendo hincapié en su omnipresencia: "Ahora despedimos con respeto a nuestra enseña patria... Aunque, como se dice por ahí, aunque no la veamos siempre está ahí". Más tarde, un grupo de alumnos de 3ero. B recitó de memoria una poesía acompañada por el sonido de tambores y, luego, algunos alumnos de 2do. grado, acompañados por integrantes del grupo de folclore Raíces Criollas, bailaron, una vez más, un gato "en homenaje a San Martín". Después bailaron los de sexto grado, junto a algunas maestras: "A ellos les toca algo más difícil: una chacarera." Después bailaron varios números los integrantes del grupo Raíces Criollas, ovacionados por alumnos, una y otra vez. Como cierre, aparecieron dos alumnos y una alumna, quienes 
llevaban puesta una banda cruzada con la bandera de Chile, Perú y Argentina, los tres países que liberados por San Martín, el "Libertador de América".

Son dos los guiones coexistentes que la escuela, como indica Díaz (1992) de acuerdo a Zelmanovich (1994), elabora en la puesta en escena de los actos escolares patrióticos: uno explícito, sobre el patriotismo y la identidad nacional, y otro implícito, sobre el quehacer cotidiano de la escuela y los valores de los que se siente depositaria: al mismo tiempo que se teatralizan los acontecimientos históricos para recordarlos y recrearlos, la escuela también transmite los ideales que pretende inculcar y mostrar. En ocasión del aniversario de la muerte de otro de los próceres nacionales, Domingo Faustino Sarmiento, fecha adoptada para celebrar el día del Maestro, entre las referencias al respeto a los símbolos nacionales, el culto al héroe nacional y los bailes preparados por la maestra y sus alumnos, se habló del reconocimiento al otro, apelando a una figura intelectual que ha combatido algunas de las ideas que el propio Sarmiento defendió, y se confrontó la idea del héroe nacional, que supone honores y medallas, con los "héroes anónimos" que "hacen patria" todos los días: un nosotros mucho más amplio, que pretende abarcar la comunidad educativa entera.

En el año 2002, la celebración del día del maestro junto a la conmemoración de la muerte de Domingo Faustino Sarmiento se realizó el día antes, el 10 de septiembre, debido a que al día siguiente era feriado. La maestra encargada de la conducción del acto se dirigió a los alumnos buscando el silencio y la quietud siempre requeridos para comenzar con la conmemoración: "tranquilos, como corresponde... en orden los chicos se ubican en un semicírculo... cada grado con su respectiva maestra". Había pocos familiares presentes. "Vamos a dar inicio al acto... en orden... tranquilos". La maestra recordó primero a los presentes que en esta fecha se celebraba el día del Maestro en conmemoración de la muerte de Sarmiento y luego anunció la entrada de la bandera diciendo: "Nuestra bandera es el símbolo que representa a todos los argentinos". La bandera ingresó con aplausos y acompañada por la correspondiente canción patria. Después que la abanderada y los escoltas ya se habían ubicado en el lugar asignado a la bandera de ceremonias en los actos, se prosiguió con el himno nacional. Antes la maestra había ordenado: "Nos ponemos de pie, parados...”.

Después de cantar el himno nacional, la directora recuperó algunos pensamientos del escritor uruguayo Eduardo Galeano sobre reconocer al otro y de reconocerse en el otro. Ella y luego una madre comentaron una máxima de Sarmiento cada una. Un varón y una nena de tercero leyeron los comentarios escritos por sus compañeros a otras dos máximas del 
prócer argentino (las mismas que se encontraban en la cartelera de la entrada a la escuela). También habló la directora y dirigiéndose a los docentes dijo: "Nosotros hacemos patria todos los días... nosotros somos héroes anónimos". Mientras tanto los chicos volvieron a inquietarse y las maestras volvieron a pedir silencio, orden...

Al cabo de esta introducción, la maestra anunció la despedida de la bandera: "Con el debido respeto que se merece nuestra bandera... todavía escucho murmullo". La falta de silencio llevó a decir a la maestra: "Recuerden que siempre debemos respetar los símbolos patrios". La bandera fue retirada al mismo tiempo que la maestra decía: "Aunque no la veamos siempre está presente". Después los chicos de jardín pasaron a cantar. Continuaron las alumnas de sexto bailando una canción pop de moda y se sortearon los números de rifa de la canasta familiar. Los alumnos hicieron una entrega de regalos a las maestras, organizado por ellas mismas: primero a la directora, después a la vice, a las del jardín después a las de la primaria. La maestra encargada del acto pidió un "feliz día" para ellas y los alumnos respondieron con exclamación. Finalizado el acto, los alumnos pasaron al comedor, mientras los docentes siguieron festejando su día en la sala de maestros.

\section{La bandera idolatrada}

La omnipresencia de la bandera argentina en la escuela la constituye como el símbolo con mayor protagonismo en la construcción de la identidad nacional, un mandato explícito encomendado a la institución educativa y un elemento implícito en la estructuración del orden escolar. La normativa educativa nacional dispone detalladamente su "tratamiento y uso". Allí se afirma que "(e)n todo momento se rendirá el máximo honor y respeto como lección de educación patriótica, dando el ejemplo el personal directivo, docente, especial y de servicio, suspendiendo toda tarea u ocupación al paso de la Bandera para rendirle el homenaje que se le debe". Como señala Amuchástegui (2000), esta conducta reverencial frente a los símbolos patrios como mantenerse de pie y en silencio, así como el sentido de respeto que se le asignó, formó parte del proyecto disciplinador con el que se organizó la formación del ciudadano. Que los niños se formen filas y lo deban hacer en silencio (o con una canción establecida) fue el modo enseñado como correcto y obligatorio para expresar el respeto a la bandera en tanto símbolo de la patria.

Además, la normativa determina que en todos los actos la bandera sea conducida, izada y arriada por los alumnos, debiendo realizarse "por toda la escuela reunida". A su vez, de 
acuerdo al evento que se trate, la bandera siempre es acompañada por una canción patria. Durante el ritual cotidiano de izamiento y arriado de la bandera el canto reglamentario es Aurora o el Saludo a la Bandera. En los actos escolares la canción patria adoptada para asistir a la bandera es el himno nacional. La legislación escolar dispone que sólo se entone "en los actos que presida la Bandera" y que "en todos los actos escolares que corresponda entonar el Himno Nacional lo será por la totalidad de los asistentes, sin exclusión alguna". Mediante el canto o recitado se busca involucrar a los alumnos en estos rituales. Por esa razón, la normativa dispone que su participación en los actos y homenajes a la bandera "no debe omitirse sustituyéndola con música, canto o recitado impresos en discos y transmitidos por altavoces".

Mediante algunas adaptaciones, estos preceptos son incorporados en la organización de la rutina escolar. Todos los días hábiles en todas las escuelas públicas del país, salvo escasísimas excepciones, la jornada escolar se abre por la mañana con el izamiento de la bandera y se termina por la tarde con su arriamiento. Así lo dispone la legislación educativa: "Al iniciarse la actividad diaria se izará la Bandera Nacional, la que concluida la tarea de la jornada, será arriada”. Ambas ceremonias deberán realizarse de acuerdo a lo estipulado oficialmente en relación a tratamiento y uso de los símbolos patrios. ${ }^{472}$ En la escuela Vicente Forestieri, reunidos los alumnos alrededor del mástil, todas las mañanas se iza la bandera, salvo que la directora o quien estuviera a cargo indique lo contrario debido a alguna situación especial. El izamiento de la bandera, a cargo de algún alumno, es acompañado por una canción que se fue popularizando en las escuelas y desplazó a la marcha patriótica "Aurora": se titula "Sube, sube, sube", cantada por Mercedes Sosa, escrita por el cantautor Víctor Heredia. ${ }^{473}$ Allí siempre algún directivo o docente saluda a los alumnos y, si estuviera contemplado en el calendario escolar, se dicen algunas palabras alusivas a la fecha que se conmemora en el día. Por la tarde, diez minutos antes del horario de salida, suena el timbre, los alumnos salen del grado y pasan a formar fila al costado del aula o directamente alrededor de la bandera, siempre en dirección al mástil -nunca se le

472 Resolución ministerial № 1.635/78.

473 A diferencia de las marchas patrióticas como Aurora, esta canción no evoca imágenes y escenas de triunfos militares ni sentimientos nacionalistas: Sube, sube, sube / Bandera del amor / Pequeño corazón / Y brilla como el sol / Y canta como el mar. / Canta como el viento / Peinador de trigo / Canta como el río / Canta pueblo mío. / Si, los pueblos que cantan / Siempre tendrán futuro. / Dame tu esperanza América india / Dame tu sonrisa América negra / Dame tu poema América nueva, / América nueva, América nueva... / Volara tu cóndor y el viento del sur / Soplara las alas de América azul. / Todo el sur, como un corazón, como un pan, / Subirá al cielo de un amanecer sin dolor... / Sube, sube, sube bandera del amor / Pequeño corazón / Y brilla como el sol / Y canta como el mar. / Canta por las voces / De los que soñaron / Canta por las bocas / De los que lloraron. / Canta... / Canta por los bellos / Días que se han ido / Canta por mañana / Canta buen amigo. / Canta ... 
debe dar la espalda a la bandera- junto a la maestra de grado. La directora, la vice o la maestra más antigua es quien preside este pequeño acto cotidiano. El arriamiento de la bandera debe transcurrir en absoluto silencio y quietud, así que generalmente las maestras esperan que los alumnos dejen de hablar y moverse, llamando la atención a algún alumno o alumna más de una vez. "Bien parados", "firmes" y "en absoluto silencio" son consignas habituales. Sin cantar ninguna canción patria, en relativo silencio, la bandera es arriada por uno o dos alumnos y cuando llega abajo todos los presentes aplauden. Si la conducta de los alumnos no fuese la esperada, se los suele reprender con distinto tono y contenido. En momentos como éstos no suele faltar alguna referencia al respeto a los símbolos patrios mientras se les recuerda sus obligaciones como ciudadanos como la defensa de la patria. De esta manera se dirigió una maestra (la más antigua) a los alumnos en una de otras tantas ocasiones: "No es posible que hablen, se rían, se den patadas mientras se baja la bandera... Nos vamos a quedar hasta las seis si no hacen silencio... ¿Así vamos a respetar los símbolos patrios? ¿Así vamos a defender la Argentina?" (Notas de campo, 4 de junio de 2002). Si todo saliera con el silencio esperado y su correspondiente quietud, es muy posible que los alumnos sean felicitados por permanecer "callados". Al final, la despedida habitual: "Hasta mañana, chicos" y "Has-ta ma-ña-na, se-ño-ri-ta...”. Luego se dirigen en fila, la cual se deshace paulatinamente, hacia la salida. Todas las tardes se repite el mismo ritual.

También en los actos escolares, especialmente en los cuales se conmemora alguna fecha patria, la bandera tiene un lugar insustituible y debe recibir un tratamiento específico.474 No hay ritual patriótico sin bandera. Así como nadie puede imaginar una escuela sin la existencia de los actos escolares (sobre todo los "patrióticos"), también resulta impensable un acto escolar sin la presencia de la bandera. En cualquier acto escolar, así lo define el protocolo, el inicio supone el ingreso de la bandera argentina llevada por el abanderado/a y los escoltas, previo anuncio: “con profundo respeto, entra la bandera..." o "con el debido respeto que se merece nuestra bandera...". En ese momento también se pronuncia alguna frase en alusión a ella como "nuestra bandera es el símbolo que representa a todos los argentinos". Siempre entra al escenario, para después ubicarse a un costado o al frente,

\footnotetext{
474 En los actos escolares, según consta en el reglamento utilizado en la escuela, al inicio, "formada la escuela, recibirá a la Bandera de pie y con un aplauso, la que llegará acompañada de dos escoltas y una sección del grado o curso superior de la escuela o del turno"; durante el acto, "el abanderado y los dos escoltas se colocarán en lugar destacado a la derecha [del abanderado] de manera que quienes actúen no den nunca la espalda a la Bandera” y deberá colocarla en la cuja según el caso; al terminar el acto, "si no se hace desfile se procederá a retirar la Bandera antes de salir los alumnos para lo cual el abanderado y ambos acompañantes se colocarán al frente del grado o curso superior de la escuela o del turno, el que la acompañará hasta el lugar donde se guarda” (Decreto $\left.\mathrm{N}^{\circ} 10.302 / 44\right)$. Esta disposición fue luego modificada mínimamente por la Resolución ministerial № 605/81.
} 
acompañada de aplausos y una canción nacional como "Mi bandera". Si no llegara a haber un silencio sepulcral ("todavía escucho murmullo" suelen señalas las maestras en estas ocasiones), la encargada del acto pide silencio y orden, siempre recordando que "debemos respetar los símbolos patrios". Sigue el himno nacional, entonado siempre de pie, presentado con alguna frase que destaque su importancia en la construcción de la nación. Por ejemplo: "El Himno Nacional nos ha acompañado desde el nacimiento de la Patria. Hoy también lo hace para que afirmemos juntos la unidad en el esfuerzo que nos hará seguir siendo argentinos" (Notas de campo, 11 de noviembre de 2002). En algunas ocasiones, no se espera que termine el acto para despedir la bandera y, después de cantar el himno, se acompaña su salida con aplausos. Si así fuera, alguien nos recordará (generalmente la encargada del acto) la omnipresencia de la bandera: "Aunque no la veamos siempre está presente". Esta oración -en su doble sentido, tanto unidad gramatical como rezo- muestra con claridad que el nacionalismo (o una de sus vertientes, el patriotismo) opera a manera de una religión cívica.

\section{Llevar la bandera: el proyecto de abanderados}

Cada año se eligen en todas las escuelas públicas del país aquellos alumnos que al año siguiente tendrán la misión de llevar y acompañar la bandera de ceremonias en los actos escolares, los llamados abanderados y sus escoltas. Es considerada la más alta distinción que puede otorgar la institución escolar a sus alumnos. Formalmente, dado que la bandera siempre debe presidir los actos oficiales, el abanderado es aquél alumno/a que tiene a su cargo portar la bandera en los actos escolares o desfiles públicos en representación de la escuela. Pero tratándose de un objeto altamente preciado como la bandera nacional, a la cual deben rendirse en consecuencia los máximos honores y respeto, quien la porta es investido de un aura especial, convirtiéndose la figura del abanderado/a en el representante, portavoz o defensor de una causa nacional, la nación argentina.

Una distinción tan importante amerita instrucciones precisas. La normativa educativa instruye a las escuelas acerca del procedimiento de "elección de abanderados". ${ }^{475}$ Entre otras cosas, estipula las condiciones que deben reunir los candidatos a la bandera para obtener dicho premio: "Los merecedores de esta distinción serán los que en el curso anterior hayan obtenido las más altas calificaciones; observando muy buena conducta, asistencia y puntualidad y corrección, lo que constituye un ejemplo valioso para sus 
compañeros y personal docente". ${ }^{476}$ También establece el modo en que deben ser elegidos quienes acompañan al abanderado, los escoltas: "en orden descendente, con igual procedimiento, debiendo reunir los mismos requisitos que para ser abanderado". Como toda normativa prevé sanciones a la transgresión a la norma establecida, también existe la posibilidad de que el abanderado o los escoltas pierdan tal condición en caso que infrinjan alguno de los requisitos por los cuales fueron elegidos.

En el año 2002 surgió en la escuela, a iniciativa de la directora, la propuesta de revisar los criterios utilizados para seleccionar a los abanderados, que con el tiempo se instalaría como el "proyecto de abanderados". Se trataba de redefinir quiénes eran los merecedores de la bandera según la visión de la institución y de instaurar un modo alternativo de seleccionarlos. El grupo directivo, al menos parte de él, pretendía con este proyecto democratizar el acceso a la bandera, que no solamente dependiera del rendimiento académico, sino que se reconocieran también ciertas virtudes morales. El proyecto fue visto como una "transgresión" a la normativa escolar.

Algo... que esto lo dejó Estela... la escuela de abanderados... es una ilusión... nosotros tenemos una forma diferente de elegir abanderados, diferente a la legislación y vamos en contra de la ley en ese sentido, pero, bueno, nuestro sueño, es la escuela de abanderados... eso lo dejó ella...

\section{¿Y qué significa?}

Y que... una vez hablando de lo que era antes ser abanderado... que cada uno de nosotros tenía esa ilusión... que era tan inalcanzable para algunos o que algunos estaban tan deseosos de portar la bandera porque era como, entendés, una cosa que tenía que ver con el orgullo, con sentirte protagonista de eso y pensamos en esto de por qué solamente el que tiene buenas notas... hay chicos que trabajan mucho, que se esfuerzan muchísimo y que tienen muy buenos valores, muy buenas actitudes que también la pueden portar, entendés, y nosotros lo que queríamos... el sueño era, alguna vez nos dijo, que toda la escuela pueda portar la bandera...

\footnotetext{
476 La legislación escolar dispone que el abanderado sea elegido considerando como condiciones: a) Ser alumno regular del penúltimo año de la carrera y haberlo cursado totalmente en el establecimiento; b) Tener un promedio general, de todos los estudios cursados, no inferior al establecido para la promoción de la asignatura; c) Registrar buena asistencia y puntualidad. (No haber sido reincorporado, excepto por enfermedad de larga duración. Tener debidamente justificadas las inasistencias en que hubiera incurrido.); d) Haber demostrado en todo momento una correcta presentación y un comportamiento no reñido con la moral y las buenas costumbres (Resolución № 3482/80 modificada por resolución № 6052/80).
} 
De acuerdo a su letra, el proyecto se fundamentaba en el "diálogo intercultural", partiendo de "la necesidad de afirmar la tolerancia, el pluralismo cultural y [de] renunciar a hegemonismos particularistas" así como de "reconocer al 'otro' en tanto distinto e igual al mismo tiempo". Destacaba, asimismo, el enriquecimiento que se produciría en "el encuentro con el otro" y, apoyándose en las situaciones críticas que vivían el país, la provincia, el barrio, la escuela y la comunidad, sostenía que el proyecto aspiraba a "ser un ejercicio de la práctica del diálogo, la valoración de los distintos puntos de vista, el desarrollo de las prácticas de la solidaridad concreta y cotidiana". Ello haría necesario que los docentes se preparasen para "la escucha de las palabras, deseos, necesidades, aspiraciones de los estudiantes y sus familias, valorizando expresamente el medio sociocultural" (énfasis en el original). Entre los objetivos explícitos del proyecto se mencionaba la importancia de "reconocer el valor de nuestros símbolos patrios" como componente de la "formación ciudadana" y como "práctica social" instituida.

Entre otros aspectos relevantes que aparecieron durante el proceso de discusión e implementación del proyecto, se pudieron visualizar aquellas representaciones y sentidos que se ponen en juego y están detrás de la definición de nación argentina que otorga la comunidad educativa y de la apropiación legítima de algunos de los símbolos que la representan. Uno de los asuntos en cuestión era si los alumnos bolivianos -en tanto nonacionales- son portadores legítimos de la bandera argentina. Hasta entonces la escuela no registraba este dilema en su corta historia y sólo había sido considerado en un plano hipotético. En el año 2002, en el marco del proyecto de abanderados, uno de los candidatos a la bandera que resultó seleccionado era un alumno nacido en Bolivia que había llegado de muy pequeño con su familia a la Argentina. La secuencia fue la siguiente.

A finales de noviembre (el día jueves 28) los alumnos de quinto grado de las dos secciones del turno mañana se reunieron con la maestra para tratar el tema de la elección del abanderado. Después que los alumnos de cada sección propusieron algunos nombres de compañeros/as y que los escribieron en el pizarrón, la maestra les pidió que comentaran las razones por las cuales eligieron a uno u otro. Una de las alumnas señaló a una de las elegidas y dijo que "es una buena compañera". La maestra quiso saber qué significaba para ellos ser "buen compañero". Surgieron distintas opiniones: ser "amistoso y solidario con los compañeros", "prestar las cosas y ayudar a los demás", "que te defiendan", "que comparta entre todos". En una segunda ronda los alumnos dieron otros motivos: "es buen compañero y no pelea", "es la más tranqui", "es buena”, "es el más inteligente”. 
En medio de idas y vueltas, la maestra enfatizó la importancia de que tomaran conciencia de los criterios por los cuales se guiaban para elegir al abanderado. Preguntó si se trataba solamente del rendimiento académico logrado por el alumno o de otras características personales en tanto valores puestos en práctica. Un alumno hizo hincapié en la "buena conducta" y algunos de los candidatos a la bandera explicaron sus principales motivaciones. Rosana dijo que su papá la aturdía preguntándole si iba a ser abanderada, debido a que "es un sueño que tiene él porque no terminó la primaria". Cristian, un alumno nacido en Bolivia, expresó por su parte que para sus padres también "sería un orgullo y para mí también", que además "sería una forma de reparar los años perdidos". Después contó que repitió primero y cuarto grado; Rosana también comentó que perdió un año.

A la semana siguiente la maestra organizó una reunión con las madres y padres de los alumnos de quinto grado a la cual asistieron unas veinticinco personas, en su gran mayoría mujeres. Les explicó que se trataba de "ver qué opinan ustedes qué es ser abanderado". Anotó en el pizarrón a medida que se pronunciaban los familiares de los alumnos: que no pelee, estudioso, respetuoso, solidario. Luego preguntó: “¿Qué significa que nuestros hijos lleven la bandera?". Un padre planteó que el criterio que siempre se ha utilizado es la nota más alta y la carpeta. “Ustedes que los tienen acá son los que más saben quienes tienen que llevar la bandera", dijo una madre o abuela de un alumno/a. "Para nosotros la bandera es algo muy grande pero para los chicos...", agregó otra. Un padre también apuntó: “Aparte de haber sido estudioso, tiene que haber tenido respeto a los compañeros y a la maestra". Una madre recordó su paso por la primaria y se refirió a un compañero: "Él se sentía marginado por ser traga... encerrado en su mundo... él estaba sólo". Siguieron varias intervenciones encadenadas sobre el significado de llevar la bandera: "es mucha responsabilidad llevar la bandera"; "hoy como está el país no se la respeta"; "es un honor, más ahora que se ha perdido el respeto a los símbolos patrios"; "yo pienso que no sólo a los símbolos patrios sino también a la escuela". Algunos destacaron que la importancia de llevar la bandera era que "representa a la escuela". Señalando todo lo escrito en el pizarrón, un familiar sintetizó: "La enseñanza no es sólo una nota, sino todo eso".

La maestra planteó que algunos de los alumnos candidatos a la bandera, como Cristian, eran bolivianos o hijos de bolivianos. Les preguntó si tenían alguna objeción y les dijo que le gustaría escuchar sus opiniones al respecto. Los padres reflexionaron: "Él ya adoptó el territorio como propio"; "Si tiene mérito..."; “Cada pueblo lleva su significado [símbolo] patrio adentro". Ninguno de las personas presentes se pronunció en contra de que un alumno de nacionalidad boliviana o descendiente de boliviano lleve la bandera. Alguien preguntó: ¿Por qué no llevarla un boliviano? Las madres bolivianas presentes en la 
reunión, sentadas juntas a un costado, no opinaron. La maestra indicó que la figura del abanderado reforzaba el individualismo y planteó, buscando consensuarlo entre los padres y madres, que la elección del abanderado era una decisión que se tomaría entre el grupo docente, los alumnos y ellos. Algunos sostuvieron que eso está en manos de los maestros casi exclusivamente. Una madre opinó, siguiendo con los criterios para elegir al abanderado, que "el esfuerzo y la continuidad deben reconocerse".

Al igual que en la reunión los alumnos, la maestra preguntó si se debía tener en cuenta solamente el rendimiento académico o también otras características personales. Con la intención de ir instalando la idea del "proyecto de abanderados" indagó también si la bandera debía ser llevada por un solo alumno o debía ser "colectivo". Para la maestra se trataba de un "no al individualismo, esa palabrita que suena feo". Les dijo a los familiares de los alumnos que ella pretendía que se construya "otra mirada sobre la bandera". Una madre comentó que había escuelas que hacían el acto de entrega de la bandera en el CPC. La docente aclaró que en esta escuela se hará en la propia institución. Al final entró una de las maestras que llevaría a los alumnos al cine y les pidió a las madres que sus hijos "lleven puesto el guardapolvo porque representan la escuela".

Al otro día, en uno de los recreos, la maestra me contó que los alumnos volvieron a conversar en el grado sobre los criterios para elegir al abanderado. Entre otros surgieron que debe ser "respetuoso", tener "buenas calificaciones", ser "educado", no faltar a las reglas. Ese mismo día se reunieron en la sala de dirección las maestras de quinto con la directora para tratar el tema. Primero habló una de las maestras de una de las secciones del turno mañana y comentó la reunión con los chicos y los padres, los criterios que sugirieron. Para ella la bandera es vista como "responsabilidad grupal". De acuerdo a su postura, la bandera también significaría un "estímulo" para los chicos. Ahí surgió la propuesta de que los grados superiores (segundo ciclo) acompañen y porten la bandera: "Sería bueno para estimular al resto". Una de ellas comentó que en el jardín la modalidad es rotativa y en la primaria se corta.

En un quinto grado del turno de la tarde una de las candidatas era una alumna de nacionalidad boliviana. Su maestra corroboró este dato mirando el número de documento y aclaró que ella fue elegida por sus alumnos, que nadie se quejó. Es para diferenciarlos, "diferenciarlos en el buen sentido", agregó. Las maestras mencionaron los posibles candidatos a la bandera (tres alumnos, una niña y dos niños). Coincidieron en que se trataba de valorar la solidaridad, el esfuerzo, la responsabilidad, el compañerismo. Se habló de la superioridad que otorga el hecho de ser abanderado. Nora, una de las 
maestras, opinó que "si alguno supera al abanderado [en su rendimiento académico en el transcurso del año] que se cambie". Entre frases típicas en estas situaciones como "mañana que venga bien vestidito porque va a ser abanderado", las maestras dialogaron sobre la legitimidad de los abanderados como representantes: "Los abanderados son de la escuela, no de uno de los turnos"; "Es uno el que representa la escuela"; "Pero todos son dignos de llevar la bandera"; "Que se pase entre todos la bandera para que todos sean dueños de la bandera". Allí otra de las maestras de quinto grado [Carola] utilizó la metáfora del "collar de perlas": "si se opaca una perla [alumno] pierde brillo el collar [escuela]". Se señaló que uno de los alumnos "no tiene trayectoria en la escuela y se incorporó este año", aduciendo otro criterio. Después la discusión giró en buena medida en torno a la conducta. Hubo un claro privilegio de lo actitudinal en la reunión. Se dijo por ejemplo que "son niños con muchos problemas de conducta y personales" o que "es respetuoso, es solidario, es excelente".

Había cuatro candidatos del turno tarde y siete del turno mañana para la bandera. Se habló de "responsabilidad compartida" para llevar la bandera. La directora propuso un "grupo de abanderados": se trataría de "estudiantes destacados para portar la bandera". "Ella es más humilde en sus cosas", se argumentó a favor de una alumna destacada. "Francisco es más aplicado", replicó otra. "Lo que pasa es que Sandra es boliviana y va a traer conflictos", dijo una de las vicedirectoras (Ana) y remarcó: "Va a traer todo un conflicto, lo digo para que estén preparadas". Y concluyó: "Parece que ustedes obvian lo que no hay que obviar". El resto de las maestras no le dio demasiada importancia a su intervención. A pesar de ello se reparó en el tema: "Yo creo que es muy fuerte", dijo una de ellas. "Hay padres que no lo viven naturalmente", agregó una compañera. La directora y la maestra acordaron que asumirían las consecuencias que pudiera haber en caso que un alumno boliviano resultara elegido como abanderado. Hacia el final, la elección de los candidatos parecía que iba a quedar postergado para una próxima reunión, pero ahí mismo se decidió que los nueve alumnos que estaban como candidatos fueran abanderados. Ya no habría más un abanderado con dos escoltas, sino casi una decena, un "grupo de abanderados".

Durante el acto de fin de clases del año 2002 se puso en práctica por primera vez el proyecto de abanderados. En aquella oportunidad todo era más solemne que de costumbre, así correspondía. Como era habitual, primero se recibió con el debido respeto la bandera de ceremonias portada por el abanderado y los escoltas. Para presentarla, la maestra encargada del acto dijo: "La patria siempre nos reúne, también en este día”. Siguió el himno nacional. Después de que la directora y una maestra les hablaran a los egresados, 
se procedió a hacer la entrega de la bandera a los alumnos elegidos como abanderados, quienes fueron recibidos con grandes aplausos. Cada uno fue pasando al frente a medida que se lo nombraba. La directora entregó la bandera de ceremonias al alumno que tenía a su costado y se fue pasando hasta llegar al último. Una de las maestras de quinto se dirigió al público y explicó que se había tomado la decisión de tener varios abanderados y que la modalidad sería rotativa. Se había conformado el "grupo de abanderados". Christian, aquél alumno nacido en Bolivia que nunca se había nacionalizado, era uno de ellos y en esta ocasión era él quien portaba la bandera argentina. Esto no pasó desapercibido para un grupo de madres y padres. Ya finalizado el acto, la maestra que había anunciado la nueva modalidad me contó que hubo cuestionamientos por parte de algunas madres y padres a raíz de que entre los abanderados había alumnos bolivianos.

\section{La nación en disputa: los alumnos bolivianos como abanderados}

Entre las aseveraciones que circulan y se repiten en las escuelas en relación al tratamiento y uso de la bandera es que la normativa escolar establece que los abanderados deben ser de nacionalidad argentina. Esta creencia ampliamente extendida en el ámbito escolar no se corresponde con ninguna de las disposiciones legales nacionales establecidas para acceder a la enseña nacional. Entre los requisitos estipulados para ser abanderado no hay referencia alguna a la nacionalidad del alumno: el criterio que prevalece se basa en algunos indicadores de rendimiento académico y en determinadas pautas de comportamiento. Aunque así fuera, a los efectos formales, un alumno hijo de bolivianos nacido en Argentina (por ende, con nacionalidad argentina), no implicaría ninguna transgresión a la norma y, por tanto, estaría habilitado para portar la bandera argentina. De manera evidente, lo que resulta problemático no es necesariamente la posesión de otra nacionalidad, sino la pertenencia a un colectivo identificado con otra nación, definida en términos estatales. El hecho de que un alumno señalado como boliviano, nacido o no en Bolivia, lleve la bandera argentina de ceremonias no suele pasar inadvertido en la escuela:

[...] Cuando nos toca hacer pasar a la bandera y vos hacés pasar a chicos bolivianos, no sabés cómo los chicos argentinos reniegan: ¿Pero por qué, si son bolivianos...? ¿por qué le ponen la bandera...? Uno de los problemas es el abanderado. ¿Por qué el abanderado? Porque a veces los abanderados son bolivianos. Uh, los padres reniegan... más que los chicos, a veces son los padres los que quieren que estén en la bandera... [...] ¿Por qué chicos 
bolivianos llevan la bandera? Si la tienen que portar los argentinos... según ellos... / ¿A pesar de que muchos de ellos son nacidos en Argentina, no? / Sí, a pesar de que tienen nacionalidad argentina, pero lo mismo... lo mismo se quejan los padres... (Jimena)

Aunque algunas consideran inadecuado que un alumno de una nacionalidad que no sea la argentina porte la bandera nacional, en la escuela se alcanzó un acuerdo bastante generalizado entre las maestras, sobre todo entre las más antiguas, respecto a la irrelevancia que debería tener el criterio de nacionalidad al momento de seleccionar a los abanderados. Una de ellas piensa que la elección de los abanderados debe realizarse de acuerdo a los principios que impulsa y defiende la escuela -una escuela, que como vimos en el capítulo anterior, se define como inclusora- y la población escolar que atiende, lo cual implicaría tomar en cuenta la presencia de alumnos bolivianos.

Lo que pasa es que... mirá... hay una de las normas, lo que establece el estatuto docente, donde para la elección del abanderado uno de los requisitos es ser de nacionalidad argentina... Pero si vos tenés... si vos estás trabajando con un 25, 30 por ciento de hijos de bolivianos, si estás trabajando... no sé ahora... yo te diría con un cinco por ciento, deben ser dos o tres chicos en cada grado a lo sumo de... que son bolivianos, no? Entonces a mí me parece que se debe respetar la igualdad de condiciones, no? Si estamos trabajando con niños, que tenemos que atender a la diversidad, que hablamos de una escuela inclusora, que hablamos del respeto por los demás... [...] entonces me parece que se contradice con lo que dice el estatuto [se refiere a la normativa educativa]. Entonces me parece que la elección de los abanderados se debe hacer desde una buena fundamentación pedagógica y real de la institución, con qué población escolar nos estamos manejando... (Silvana)

Otra docente que también está en desacuerdo con el criterio de nacionalidad para elegir a los abanderados sostiene que "la bandera es un poco de todos y para todos, no es solamente para los argentinos". Argumenta que son las cualidades personales de los alumnos las que los hacen merecedores de tal distinción. Refiriéndose a aquél alumno nacido en Bolivia que suscitó algunos cuestionamientos de parte de algunas madres y padres, ella considera que "era digno de estar en ese grupo de abanderados" debido a que se destacaba por ser "un chico colaborador, respetuoso, participativo". Condesadas aquí en una sola persona, son precisamente aquellas características atribuidas a los alumnos bolivianos como colectivo -como veíamos en el capítulo anterior- las que hacen que sea 
merecedor de la bandera argentina. Una de las maestras considera también que por sus virtudes este alumno "realmente se lo merecía", pero además, resuelve el supuesto incumplimiento de la norma que establece el criterio de nacionalidad como requisito para acceder a la bandera apelando al sentimiento nacional: "Sí, sí, porque él se sentía argentino..." (Pilar).

Dignidad y orgullo, nociones inconmensurables, aparecen como premisas básicas para conferirle a los alumnos el honor de portar o escoltar la enseña nacional. Aunque la bandera sea considerada "un poco de todos y para todos", al estar en juego una de las más altas distinciones escolares, reservada sólo para un grupo acotado de alumnos, quienes asuman la misión de llevar la bandera también "tienen que ser dignos" y "se tienen que sentir orgullosos" (Gloria). A la vez, el orgullo se erige como aquél sentimiento que acompaña a quien ha reunido mediante su esfuerzo los méritos suficientes para ser abanderado, obteniendo como premio o recompensa un símbolo patrio que confirma su pertenencia a la comunidad nacional.

La bandera [es] como un orgullo, nuestro orgullo de ser argentinos o de pertenecer, sí? Creo que portarla, para los chicos, es como... cuando nosotras hacemos encuestas... el año pasado hicimos en quinto grado, hicimos una encuesta a los padres y es algo como que los llena de orgullo, que los motiva a hacer cosas... no te puedo explicar bien por qué, qué les pasará o qué sentirán pero es como ese orgullo, esa cuestión de que... de tener algo que tiene una significación especial, importante... (Mercedes)

Estas maestras encuentran una razón más para no privar a los alumnos bolivianos de portar la bandera argentina en el hecho de que sus familias reciban con orgullo el reconocimiento que hace la institución escolar mediante este acto simbólico. Ellas advierten, acertadamente a mi manera de ver, que el valor que tiene este reconocimiento para las familias migrantes radica en el hecho de que llevan adelante sus vidas en la Argentina, es decir, porque "están acá". Casi excepcionalmente, mediante este acto no son colocados como extranjeros "allá", donde se supone que naturalmente deberían vivir. Por otro lado, en el otorgamiento de la bandera argentina a no-nacionales, se desliza la idea de concesión. La gratitud esperada o el agradecimiento dispensado por poder permanecer en el país y asistir a la escuela, participando de los beneficios materiales y simbólicos que les pudiera traer a las familias inmigrantes, remite a una deuda contraída con la sociedad receptora, por su hospitalidad. Lo agradecen (o deberían siempre hacerlo) porque naturalmente no les correspondería. En la acción de agradecimiento o el sentimiento de 
gratitud se reconoce esa deuda contraída la cual pone de manifiesto que su presencia puede ser legal pero difícilmente legítima.

¿Y para los padres...? / Y para los padres, un orgullo... / Es decir, para los padres de alumnos bolivianos también es importante que lleven la bandera argentina... / Sí, por supuesto... Creo que porque ahí demuestran... primero porque están acá... están agradecidos, viste... digamos, que se les cobija, que se les da lugar en la escuela, que se los tiene presente... (Pilar)

Y la familia nos agradeció... a todo esto se hizo una entrevista con las familias de los alumnos que iban a ser del posible grupo de abanderados, estaban felices porque se los incorporaba en eso, porque les preguntaban qué les parecía... / ¿A las familias bolivianas te referís? / Sí, y a las argentinas... es como que se hizo una entrevista con los padres... y la respuesta que nos devolvieron es que estaban orgullosos de estar en este país y encima... ser los papás de un hijo abanderado... (Gloria)

\section{Honrar la bandera: la "promesa de lealtad a la bandera"}

Entre los importantes cambios sociales acontecidos en la Argentina de finales del siglo diecinueve, la escuela pública fue declarada laica. Desde entonces se eliminó oficialmente la impartición de clases de religión católica y el desarrollo de ceremonias de oración y culto a los símbolos litúrgicos en las escuelas del Estado (lo que no significa que se hayan dejado de practicar o descartado de la vida ritual de las escuelas estatales; el Padre Nuestro es una oración que aún hoy se hace rezar a los alumnos de primaria). Así como otras miles del país, la escuela Vicente Forestieri no promueve ni organiza eventos particulares para destacar alguna fecha religiosa, acogiéndose únicamente a los feriados nacionales establecidos por el Estado. Sin embargo, se da por sentado que todo alumno y alumna que asiste a cuarto grado debe participar de un ritual cívico instituido a comienzos a comienzos del siglo veinte en el marco de los proyectos estatales de nacionalización de la población extranjera: la Promesa de lealtad a la Bandera como se la conoce hoy en día. Esta práctica, llamada en sus inicios Jura a la Bandera, fue introducida por el CNE mediante resolución en el año 1909. La ceremonia, que era realizada el día 9 de julio y organizada por una escuela o por el Consejo Escolar, reunía a todos los alumnos de tercero a sexto grado del distrito en un único espacio físico (Blázquez, en prensa). 
En la actualidad, la Promesa de lealtad a la Bandera se realiza el 20 de junio de junio con motivo del día de la bandera, fecha establecida en homenaje al nacimiento de quien la historia oficial consagró como el creador de la bandera argentina, el Gral. Manuel Belgrano, y está destinado a todos los alumnos y alumnas de cuarto grado. Según la normativa, también están obligados a participar todos aquellos alumnos de los grados posteriores que no hubieran hecho la promesa anteriormente. Formalmente, sólo los estudiantes extranjeros estarían exceptuados. Así está previsto en uno de los decretos sobre los símbolos patrios: "Se excluyen de esta obligación los alumnos de nacionalidad extranjera". Sin embargo, en la vida diaria de las escuelas ningún alumno o familiar de una nacionalidad que no sea la argentina es consultado al momento de organizar esta ceremonia cívica nacional. A través del acto de promesa a la bandera la escuela cumple con el mandato de nacionalización que asumiera como una de sus principales funciones, disolviendo en esta circunstancia la división entre argentinos y bolivianos o, al menos, disimulándola. Además, se da por descontado que todo alumno de nacionalidad argentina desea involucrarse con estos rituales patrióticos. La pertenencia al Estado, como ciudadano, supone la pertenencia a la patria que es asumida como inapelable e irrenunciable.

Este ritual patriótico se organiza de acuerdo a las pautas generales establecidas para los actos escolares, cuidando la solemnidad esperada en las celebraciones de las fechas patrias. La escena central del acto consiste en la lectura por parte de uno de los directivos de alguna fórmula de "promesa de lealtad a la bandera" frente a los alumnos de cuarto grado de ambos turnos, los "protagonistas", acompañados por sus respectivas maestras. Luego de la lectura, los alumnos, estando de pie y extendiendo el brazo derecho hacia la bandera, contestan: "Sí, prometo" o "Sí, prometemos". En la escuela Vicente Forestieri, como en otras instituciones educativas, la fórmula leída no se atiene a la versión original que aún figura en la normativa ni tampoco se sigue estrictamente lo pautado allí. ${ }^{477} \mathrm{El}$

477 La versión original dice así: “Alumnos: la Bandera blanca y celeste -Dios sea loado- no ha sido jamás atada al carro triunfal de ningún vencedor de la tierra. Alumnos: esa bandera gloriosa representa la patria de los argentinos. ¿Prometéis rendirle vuestro más sincero y respetuoso homenaje; quererla con amor intenso y formarle desde la aurora de la vida un culto fervoroso e imborrable en vuestros corazones; preparáros desde la escuela para practicar a su tiempo con toda la pureza y honestidad las nobles virtudes inherentes a la ciudadanía; estudiar con sus huellas luminosas y a fin también de honrar a la Bandera y de que no se amortigüe jamás en vuestras almas el delicado y generoso sentimiento de amor a la Patria? En una palabra, ¿prometéis hacer todo lo que esté en la medida de vuestras fuerzas para que la Bandera argentina flamee por siempre sobre nuestras murallas y fortalezas, a lo alto de los mástiles de nuestras naves y a la cabeza de nuestras legiones y para que el honor sea su aliento, la gloria su aureola, la justicia su empresa?". 
texto de la "promesa de lealtad a la bandera" resulta de la revisión y adaptación que realizan en clase los alumnos junto a sus maestras y algunos familiares de una versión ${ }^{478}$ oficial actualizada. ${ }^{479} \mathrm{En}$ el año 2003 la fórmula leída por una de las vicedirectoras se pronunció así:

Chicos: Ésta que ven es la bandera que creó Manuel Belgrano para acompañar nuestra libertad. Simboliza nuestra tierra, nuestra patria, simboliza la República Argentina. Es el símbolo de los valores que debemos defender con nuestro esfuerzo, nuestro trabajo, nuestra lucha, nuestro sacrificio, más allá de que tengamos triunfos o derrotas. Son valores que tenemos que defender, de libertad, de igualdad, de solidaridad. Es el símbolo de nuestra historia y de los hombres y mujeres que nacieron en nuestra tierra, en nuestra patria, y también de los que vinieron a poblarla, a trabajar en ella y por ella. Representa nuestra tierra, nuestros mares, nuestros ríos, bosques, nuestros llanos y montañas, nuestros sueños, nuestras esperanzas, nuestros logros, realizaciones. Simboliza nuestro presente, pero también nuestro futuro y el futuro de quienes vendrán después de nosotros. Chicos, chicos de cuarto grado: ¿Prometen respetarla, estudiando con mucha voluntad, tratando de ser cada día más libres y justos, aceptando y aceptándonos con todas nuestras diferencias y demostrándolo en cada uno de nuestros actos?

En esta fórmula oficial, traducida por maestras, padres y alumnos, se alcanza a dilucidar la figura de la inmigración de ultramar y, en parte, el papel que se les adjudicó en la historia social de la Argentina cuando se mencionan, además de aquellos "hombres y mujeres que nacieron en nuestra tierra, en nuestra patria", "los que vinieron a poblarla, a trabajar en ella y por ella". La versión original destaca que "los que vinieron a poblarla", lo hicieron "al amparo de nuestra bandera y nuestra Constitución", aspecto eliminado de la versión escolar. Asimismo, en lugar de referirse al futuro de "nuestros hijos y el de las sucesivas generaciones de argentinos" que simboliza la bandera, el texto adaptado en la escuela lo extiende a "quienes vendrán después de nosotros".

478 Esta es la versión que ha adoptado el gobierno de la ciudad de Buenos Aires en su más reciente normativa. 479 A pesar que la innovación, adaptación o actualización de los actos escolares en general forma parte de los modos autorizados de celebrarlos, el hecho de que la escuela no se atenga estrictamente a las formas establecidas según normativa escolar para el acto de "promesa de lealtad a la bandera" -denominado por una maestra entrevistada como el "original”, que en este caso podría adquirir la acepción de "auténtico"- es considerado por algunas maestras como un acto contrario a la norma. 
La directora considera que el modo habitual de realizar el acto de promesa de lealtad a la bandera es un "formato impuesto" que "no tiene sentido". La innovación habría surgido de cierto hastío ${ }^{480}$ frente a la solemnidad que caracteriza estos actos escolares, en particular de los alumnos: "Ante el sufrimiento de los niños y de algunos docentes dijimos, bueno, 'cambiemos el formato'. [...] Todos esperaban solemnidad y, en realidad, a los chicos no les interesa." Aunque a nivel institucional se acordó que el único requisito era traer el guardapolvo, tanto las madres y padres como los docentes esperan que la vestimenta sea acorde a la solemnidad del acto, sin la cual este ritual sería una contravención a lo instituido frente a las características adjudicadas a la imagen de nación: "Se les exige solemnidad y presencia, los padres exigen solemnidad y presencia, van todos [los alumnos] bien vestidos, con el moñito, las chicas con las medias tres cuartos, los zapatos... [...] Después te das cuenta que la exigencia es de los docentes, no?" (Carmen). Esta solemnidad en torno a la promesa de lealtad a la bandera es un requisito intrínseco a los actos patrios en general. Como señala la directora: cuando hay "falta de solemnidad" se considera que "el acto fue un desastre".

A partir de la revisión de algunas de las rutinas escolares, las maestras y directivos prefieren que este ritual sea vivido por los alumnos como un acto de "compromiso" en lugar de "promesa". En su apreciación sobre este acto escolar, sus formas y contenidos, la directora hace hincapié en que se trata de un "compromiso" frente a la bandera con los demás en base a cuestiones del cotidiano escolar y no de "lealtad" hacia ella. El cambio de "formato" que adoptó la escuela acompañaría esta manera de comprender este acto.

La promesa que se hace es un compromiso, que se construye con los niños y los docentes, esto es todo un trabajo... Del compromiso ante la bandera de lo que ellos hacen cotidianamente, no de la lealtad, porque vos tomás el texto legal, por llamarlo de alguna forma... [...] No es de jura de la bandera, es de compromiso ante la bandera de lo cotidiano, de lo que pueden hacer los chicos cotidianamente, y el texto lo elaboran los chicos... de compromiso, no de jura... en un sentido de compromiso, pero de compromiso con otro, no hacia la bandera. La bandera es la presencia, es el día, el día de junio que está ahí... [...] No tiene el sentido, la fuerza inicial... porque era cambiar el formato de esa jura de lealtad a la bandera de unos niños de cuarto grado con la docente

480 La directora considera que la efemérides que se debe desarrollar en la escuela "se sigue viviendo con cierto hastío, porque implica preparar, buscar la información, la termina preparando el docente..." a la vez que "no hay discusión en las aulas" (Carmen). 
solemnemente leyendo un discurso que nadie lo entiende. [...] Y la bandera, todos solemnes y filas... (Carmen)

Este acto de promesa de lealtad a la bandera, aunque es reconocido un acto de subordinación a aquellos elementos que conforman a la nación argentina mediante la exaltación de la importancia que revisten los símbolos patrios como la bandera para la formación de la identidad nacional, es visto preferentemente -aunque, según la maestra entrevistada, no se permita enunciarlo de esta manera- como una instancia en la cual los alumnos se comprometen fundamentalmente con aquellas actitudes que en el presente hacen de los niños un buen alumno y que en el futuro podrán hacer de ellos un buen ciudadano o un buen trabajador.

¿Y cuál es la idea del juramento ${ }^{481}$ a la bandera? / Es... darle a los chicos como una noción de su identidad, de sus símbolos, de... compromiso, de hacer cosas no solamente por la bandera porque la tienen que respetar, sino que nosotros le damos como mucha importancia a que ellos se tienen que comprometer a hacer cosas, más allá de que la bandera es como un símbolo, que tiene que ver con su familia, con ellos mismos, cuando van creciendo, con ideales, con cosas... con aprendizajes que a ellos les va a servir más adelante, que les va a abrir su cabeza, aunque no se lo podemos decir de esa manera, para poder trabajar y poder hacer otras cosas, diferentes... Y creo que el juramento a la bandera, por lo menos los nuestros, prometiendo ellos cosas, concretas, comprometiéndose a estudiar, porque ellos prometen esas cosas, comprometiéndose a no pelear, entendés? El juramento a la bandera tiene que ver con esas cosas, en nuestros chicos, que es diferente al juramento que es el original que hay que hacerlo... (Mercedes)

Sin embargo, además de llevarse a cabo el ritual impuesto por el Estado e incorporado por la escuela a su vida cotidiana consagrando aquello que en estas circunstancias se dice no querer reproducir, el modo en que se enuncia la trascendencia y el significado de la promesa no deja demasiado margen a interpretaciones alternativas: se trata de un compromiso con la patria de carácter obligatorio y eterno, acompañado de sentimientos ya prescriptos como orgullo y patriotismo e inscripto en los sueños de héroes nacionales 
como Manuel Belgrano y cantidades de argentinos. Al comenzar el acto, la maestra encargada de su realización manifestó en nombre de la institución:

Queremos que sea un día muy especial, importante e imborrable. Que nunca se olviden lo que significa esta promesa: un compromiso con la patria que tienen obligación de cumplir con orgullo y patriotismo para que el sueño de Belgrano y de tantos argentinos se haga realidad.

\section{Integrar bolivianos y argentinos: los actos escolares "interculturales" (o la construcción de hermandad latinoamericana y bolivianidad en la escuela)}

A la par de los actos escolares patrióticos, en la vida cotidiana de la escuela se desarrollan otros que por los sentidos que los guían y se les asigna entrarían en la amplia categoría de interculturales. Estos actos son pensados y desplegados bajo una visión dicotómica conformada por el binomio discriminación/integración. Es decir, las situaciones y episodios concretos vividos e interpretados en la escuela como discriminación entre los alumnos identificados como argentinos y bolivianos sirven de fundamento y motivación para construir una respuesta elaborada más o menos espontáneamente que adopta la noción de integración como marco ideal de construcción de las relaciones sociales.

La incorporación a la vida escolar de determinados emblemas culturales y políticos asociados a la nación boliviana -desde comidas y danzas hasta la bandera nacional- a través de las efemérides escolares es el recurso más utilizado para llevar a la práctica la idea de integración. Si bien las representaciones sobre Bolivia -la Bolivia de los argentinos- se elaboran diariamente de manera diversa, los actos -como vehículo de las efemérides- constituyen, al igual que con la producción de la argentinidad, el instrumento privilegiado en la construcción de la bolivianidad en el espacio escolar analizado. Como mostraré en los próximos apartados, estas expresiones socioculturales y políticas aparecen especialmente para la conmemoración de fechas del calendario escolar como el día de la Raza, el día de la Tradición, el día de las Américas o alguna otra celebración particular como el aniversario de la escuela. En el día de la Independencia de Bolivia, el 6 de agosto, tampoco pueden faltar los símbolos nacionales bolivianos, especialmente la bandera. La participación de alumnos en tanto bolivianos en los actos escolares es vista como una expresión del reconocimiento buscado y otorgado, un espacio que supieron y tuvieron que ganarse. 
Yo pienso que ellos tienen su lugar, se lo han ganado y lo tienen acá. Y bueno, hicimos una fiesta muy linda que fue para el día de la Tradición [...] y empezamos a llamar a las academias [de baile] y hemos hecho participar... eso lo empezamos a hacer en el 98, 99... [...] Más allá de la presencia de ellos en un acto, de los chicos que están trabajando acá... otras cosas así, sobresalientes, no, no hemos hecho [...] Empezamos a hacerlos participar ya en los actos, entendés, como dándoles un espacio. (María)

La existencia de estas expresiones de bolivianidad en el espacio escolar, asumidas como componentes estratégicos en la construcción de un modelo de integración ejemplar, suele ser valorado positivamente por quienes son representantes oficiales del Estado boliviano. La vicecónsul de Bolivia en Córdoba, por su parte, en su reconstrucción de la visita a una escuela primaria, ubicada en una zona periférica de la ciudad ${ }^{482}$, a la cual fue invitada para el aniversario de la institución, y a otra que lleva como nombre "República de Bolivia", localizada en la ciudad de Villa María (Villa Nueva) al sur de la provincia de Córdoba, destaca la recreación de determinadas prácticas culturales o el uso de determinados símbolos políticos asociados con Bolivia en la vida escolar: que los alumnos canten el himno nacional boliviano y sepan preparar "comida boliviana", hayan estudiado la historia de símbolos nacionales bolivianos como el escudo y hayan aprendido canciones del folclore nacional boliviano (una cueca, por ejemplo), hayan realizado una feria sobre Bolivia, le hayan escrito una carta al presidente Evo Morales o que el uniforme de gimnasia lleve la bandera nacional de Bolivia. Todos estos aprendizajes son interpretados en términos de integración: para ella se trata de una "linda experiencia de integración" y considera que "es muy interesante ese proceso integrador".

En general, estas prácticas están fundadas en una noción de integración que presupone la existencia de sujetos pertenecientes a culturas diferentes a partir de sus adscripciones nacionales. Mediante la incorporación de expresiones ligadas a la bolivianidad aspiran a promover la integración, entendida por algunos docentes en términos de reconocimiento de la alteridad, a partir de la presencia de un otro diferente que, en tanto iguales conviviendo en un mismo lugar, debe ser respetado y valorado. Dicho reconocimiento, codificado básicamente como respeto al otro diferente en términos étnicos o nacionales, se realizaría empezando por tomar conocimiento de la cultura del otro para poder

482 Se trata de la escuela Florencio Sánchez ubicada en una zona con características rurales conocida como el Gateado. Una nota sobre la experiencia de esta escuela, titulada "Un verdadero respeto por la idiosincracia del otro", se publicó en la revista de divulgación Desafíos Urbanos en el año 2007. La clave de lectura adoptada por la autora para escribir la nota fue la interculturalidad. 
comprenderlo, en particular para que los demás compañeros puedan entenderlos. La frase de una maestra lo sintetiza así: "hemos intentado incorporar esa cultura para que los demás chicos lo entiendan..." (Mercedes). La maestra también destaca la actitud respetuosa que ha tenido la escuela y el trabajo escolar que, aunque sostenido de manera irregular en el tiempo, se ha realizado en este sentido: "la escuela primaria siempre ha sido muy respetuosa de la cultura de los chicos, siempre, por lo menos lo hemos intentado y hemos trabajado... hubo años en los que se lo trabajó más" (Mercedes). Frente a la pregunta por la idea que ha llevado a incluir determinadas manifestaciones culturales y políticas consideradas bolivianas, ella y otra compañera responden:

Con la idea de integración y de conocer, porque a veces uno desprecia o deja de lado o no incluye lo que no conoce. [...] Cuando vos no conocés a veces no podés entender. Yo creo que más que todo para que los demás puedan conocer y puedan ver, porque si son compañeros nuestros y hay muchos que están conviviendo con nosotros, conocerlos, interesarnos por conocerlos, para poder entenderlos, para poder comprenderlos, y creo que todo eso lleva a la tolerancia, lleva a la inclusión... (Mercedes)

El respeto. El respeto... nadie les pide a niños que canten el himno boliviano, pero sí que cuando se entone el himno boliviano no silben, no... miren para atrás, así como el boliviano respeta el himno argentino, nosotros pedimos respeto... [...] Yo voy a la base del respeto, respetar no solamente a los mayores, sino respetarse ellos mismos, el respeto por la palabra del otro, respetar al otro, al que es como ellos, así sea boliviano, argentino, nena o varón, blanco o negro, tienen que aprender a respetar porque estamos conviviendo en un lugar, todos juntos, a lo mejor por un año, por dos, por tres, por seis, tienen que aprender a convivir, a vivir con el otro [...] (Gloria)

La noción de respeto y conocimiento del otro atraviesa el discurso de aquellas maestras -en general, las más antiguas- que apoyan y creen en la necesidad de contemplar la cultura que sus alumnos hijos de inmigrantes bolivianos traerían consigo o a la cual pertenecerían por el hecho de que sus padres sean nacidos en Bolivia. Una maestra, evaluando la sistematicidad con la cual la escuela atiende las particularidades de la comunidad boliviana, considera la importancia y las consecuencias positivas que ello podría tener para sus alumnos bolivianos al poder ver que sus prácticas culturales desarrolladas en el espacio familiar y determinados símbolos referenciales de Bolivia como la Virgen de Urkupiña y la bandera nacional boliviana ingresan al ámbito escolar. 
Bueno, creo que los chicos... una, que ven que lo que se hace en sus casas o pasa en su familia viene a la escuela, creo que para ellos es importante... me parece que sí, o no? Claro que es importante y que los otros vean que... tener respeto, hacer las cosas con respeto, respetar lo que piensa y hace el otro... (Gloria)

A mí me parece... me parece que tiene que estar, son muchos los chicos, pero no, no... [...] Una vez, antes, cuando estaba Estela [la directora], antes que se hiciera [en el barrio] la fiesta de la Virgen [de Urkupiña], vino la Virgen, la trajo la señora Rosa, pasó [por los grados] y después no se volvió a hacer más... si se hubiera repetido, hubiera estado bueno, me parece que hubiera sido positivo... [...] Antes cuando había otra directora, no le gustaba, no sé, no sé... Pero a mí me parece que hubiera sido bueno que se siga haciendo eso... lo de la independencia de Bolivia se tiene que hacer, me parece que sí, como cualquier otra independencia, no sé... (Gloria)

Por parte de las madres bolivianas la idea de respeto o valoración de las costumbres o tradiciones identificadas como bolivianas es asociada a la presencia que tienen algunos símbolos de la bolivianidad en la escuela. Entre ellos, como comenta una madre, la bandera boliviana, no sólo en los actos escolares, sino en actividades áulicas como cuando la maestra le solicitó a su hijo que la dibujara. Iniciativas escolares como la incorporación de comidas o danzas del folklore nacional boliviano en celebraciones para alguna fecha patria como el día de la Tradición también son reconocidas, aunque no sin tensiones, como una forma de respeto a la cultura boliviana:

Ah, sí, sí veo que se hacen, cuando hacen... cómo es que se llama esto... cuando hacen las comidas, todo, o sea, no sé cómo es que se llama este año, donde presentan las comidas de los argentinos, los bolivianos, cada uno que presenta, sí, o sea, lo veo que sí lo hacen... pero los temas [se refiere a las canciones folclóricas bolivianas bailadas en la escuela] no sé si lo respetan o no, pero algunos dicen que les gustan, algunos no, eso no, pero hay siempre cuando hacen algo, o sea, cuando de ponerse a bailar los temas de Bolivia que hacen los chicos y empiezan a decirles: “iMirá lo que bailan, mirá!”. A algunos les gustan y algunos los critican, o sea, no... hay de distintos pasos que critican y de... son de dos cosas... (Adelia) 
Isabel, una madre de 29 años nacida en Bolivia, lleva la mitad de su vida en la Argentina cuando llegó siendo adolescente junto a su hermano mayor. Su testimonio permite advertir que las acciones escolares de reconocimiento de la presencia boliviana en la escuela son experimentadas de manera ambigua por parte, en principio, de los principales destinatarios o beneficiarios de dichos actos. Aunque valoran y aprueban que en la escuela se realicen estas actividades, en particular debido a la importante presencia numérica de hijos de bolivianos (como también lo afirman las maestras), también muestran dudas respecto al sentido que puedan tener debido a la distancia o extrañeza con que ellos las experimentan o al desprecio o burla con que pueden ser recibidas en el contexto escolar. Buena parte de los integrantes de las familias que envían los niños a esta escuela llevan gran parte de su vida en la Argentina, o toda su vida adulta, y el proyecto de vida individual y familiar suele estar arraigado a la Argentina. Aunque el retorno siempre permanece latente, su vida cotidiana transcurre en la Argentina, aquí y ahora. Bolivia es un referente del pasado que se actualiza, aunque no siempre ni en todos los casos, mediante los lazos familiares que mantienen. Aquellas prácticas que se les asigna como propias también pueden haberlo dejado de ser o nunca sido haber parte de sus vidas, es decir, prácticas vividas como algo ajeno. La reconstrucción de lo boliviano ("algo así que se parezca a Bolivia") puede operar como un recordatorio de que no son de este lugar o ser interpretado como una recomendación (siempre moralista) de que no es bueno olvidar que el origen de las raíces culturales (provenientes de otra parte) o que, debido a la equivalencia entre cultura y territorio, ellos son de otra parte.

\section{¿Vos te sentís parte de la comunidad boliviana?}

Sí. Yo soy, yo siempre me siento orgullosa de ser boliviana, así que no... algunos me dicen que no me parezco de Bolivia, pero yo digo, "no, yo soy de Bolivia", siempre les digo a todos... así que me dicen: "ahí viene la boliviana", yo me siento como yo soy, boliviana, porque no me hace más ni menos, yo soy de dónde soy y soy cómo soy... (...) Yo cuando fui [a Bolivia] este año, cuando fui, no me acostumbraba de estar allá, tenía ganas de volverme acá que de estar allá, porque acá ya hice mi vida, ya tengo mis hijas, vienen a la escuela y todo, así que no, o sea, que mi mamá y mi hermana dijeron que me quede allá, pero ya te sentís rara cuando ya hacés tu vida desde chica en un lado y te querés ir a otro lado, o sea, yo sí soy, me siento orgullosa de ser boliviana, pero ya no me llama la atención mucho porque ya estoy acostumbrada acá...

¿Hay algo que a vos te gustaría que la escuela le transmitiera o se ocupara de transmitir a tus hijos en relación a la cultura boliviana...? 
Yo mucho no te puedo decir de transmitir lo de Bolivia, porque no... hace mucho, ya casi, prácticamente, ya me acostumbré a estar... al ambiente de acá de la Argentina y a las cosas que hacen acá y mucho de allá... ya no... ya mucho no me llama la atención, porque ya son años que ya estoy acá y ya hice mi vida y ya, como te digo, no me... no me llama mucho ya la atención y... la mitad les gusta las cosas que hacen de Bolivia y todas esas cosas... pero ya está hecho nomás...

\section{Pero a vos te parece importante que la escuela tenga en cuenta ciertas expresiones culturales...}

Sí, o sea, sí claro... / Sí... / Claro, porque sí hay muchos chicos, muchos paisanos bolivianos, entonces que no queda nada más, o sea, hay que hacer algo por lo menos de Bolivia, pero no, dudo... / ¿Cómo...? / No, dudo que hagan algo así que se parezca a Bolivia... / ¿Por qué? / Porque no les gusta mucho a los chicos así que... / ¿A los chicos en general? ¿A qué chicos? / Claro, no les llama ya la atención, si quieren hacer muy parecido a Bolivia, siempre que tienen que representar en algo a Bolivia, ponen siempre Bolivia y dicen " $\mathrm{a}$ ay, no! ¡ay, todo eso hacen los bolivianos...!"/ Lo dicen los compañeros... / Claro, sí, sí los veo a los chiquitos que dicen "eso hacen los bolivianos, no me gusta" (risas) (Isabel)

La presencia de los hijos de inmigrantes bolivianos, concebida como la materialización de la diferencia, también es vista por las maestras como una presencia de la cual es posible aprender -siempre mientras ellos también aprendan de nosotros- y que, en consecuencia, contribuye al mutuo enriquecimiento. Son las características positivas atribuidas a la comunidad boliviana y sus miembros, en particular ciertas virtudes morales -como veíamos en el capítulo anterior- que no abundarían entre los argentinos, las que a manera de contribución, voluntaria o involuntaria, habilitarían una convivencia basada en la valoración mutua: los bolivianos tendrían algo valioso que aportar.

Enriquece, es casualmente aprender del otro que es diferente... y que somos iguales. Y es un enriquecimiento, porque vos aprendés de ellos y espero que ellos también aprendan de nosotros, pero la comunidad boliviana es realmente... es muy participativa, la madre está siempre presente con el niño, madre y padre, porque esa es una de las cosas que yo a veces veo distinto de nosotros argentinos (Gloria) 
[...] nuestro acto fue abierto, fue recibirlos y bueno tratar de aprender de ellos... y tienen muchas cosas para aprender... muchas cosas... muchas cosas hermosas y valiosas, y te pueden... te dejan con la boca abierta, en las actitudes, en la forma de ser, en el compromiso que ellos tienen con sus hijos, tienen muchos valores que a lo mejor nosotros no... que nos creemos más vivos, más inteligentes... un poquito de... ver que eso es distinto, pero que bueno... (María)

La idea de integración como respuesta a la discriminación está en el fundamento -explícito o implícito- de las diversas acciones de reconocimiento y visibilización del otro diferente, aún en las escasamente desarrolladas en las aulas, que en muchas ocasiones sirven de insumo o complemento a los actos escolares. En correspondencia con la imagen de un otro diferente en términos étnicos, estas actividades han involucrado y han sido elaboradas principalmente en el área de expresión artística. ${ }^{483}$ En el año 2004, gracias a la iniciativa de una de las vicedirectoras (Amalia), dos docentes -la maestra de tercer grado y la profesora de plástica- se involucraron con "un proyecto telemático entre Europa y Latinoamérica para fomentar el conocimiento de la diversidad cultural y una mejor convivencia", llamado el Atlas de la Diversidad.484 De las diferentes propuestas, la que adoptó la escuela consistió en la elaboración de dos "retratos" relativos a la comunidad local en la cual está inserta la escuela. Después de discutir la selección del tema del primer retrato en el grado, se decidió trabajar sobre la fiesta de la Virgen de Urkupiña, una de las celebraciones características del barrio y una de las más representativas de la colectividad

483 Durante el trabajo de campo y en años posteriores, los únicos proyectos áulicos que se desarrollaron o que empezaron a desarrollarse se relacionaron con el área artística. El primero, que sólo llegó a esbozarse, pretendía organizar en el marco de las clases de artes plásticas uno de los bailes tradicionales del folclore boliviano, la diablada; el segundo fue un taller que vinculaba la música y el teatro, cuyo objetivo consistía en "rescatar las raíces"; y finalmente, el tercero, el único de los tres que logró concluirse, fue el proyecto realizado como articulación entre las áreas de lengua y plástica en el marco del Atlas de la Diversidad.

484 En su página web el proyecto se presenta de la siguiente manera: "El ATLAS DE LA DIVERSIDAD es una innovadora herramienta pedagógica. Se compone de una red de escuelas que gracias a la colaboración mutua ha generado una de las bases de datos sobre la diversidad cultural más importantes y extensas del mundo. Un espacio en el que se pretende recoger las particularidades propias de cada lugar a partir del criterio y la visión subjetiva de los participantes. El ATLAS es también un lugar de encuentro, de reflexión y de aprendizaje colaborativo. Una manera de promover, a través de las TIC, la equidad, la tolerancia, el multilingüismo y el pluralismo en todas sus expresiones." Para mayor detalle sobre este proyecto, véase www.atlasdeladiversidad.net 
boliviana en Córdoba que tiene lugar a mediados del mes de agosto. ${ }^{485}$ El retrato recibió un título sumamente significativo: "La fiesta que nos une". 486

Entre las razones que motivaron la elección del tema, las maestras consideraron la relación paradójica, según su interpretación, entre la discriminación a los bolivianos y la trascendencia que tiene una "fiesta boliviana" para la comunidad local. Esta es la idea que dio origen al título del retrato. ${ }^{487}$ Así lo explican en uno de los documentos elaborados: "Nos pareció interesante la paradoja entre la discriminación existente en el barrio y la escuela hacia los migrantes (fundamentalmente bolivianos) y el hecho de que la festividad más importante de la comunidad es una procesión de una virgen que es de origen boliviano, la virgen de Urkupiña (en idioma quechua)". Es decir, buscaron un símbolo que fuera representativo tanto de la colectividad boliviana en Córdoba como de la comunidad local en la cual está inserta la escuela y mantiene sus lazos más estrechos.

La Virgen de Urkupiña es uno de los símbolos con los cuales se identifica la presencia de los bolivianos en Córdoba, especialmente en Villa El Libertador. Como dijo una de las maestras hijas de bolivianos en una oportunidad: la fiesta de la Virgen de Urkupiña, "era la fiesta donde todos nos encontrábamos" (Jimena). La celebración que se realiza en torno a ella en el barrio no sólo remite al pasado vivido en el país de origen, sino que es experimentada en el presente como una extensión de Bolivia, como "Bolivia en la

485 Véanse Giorgis (2004) y Bompadre (2005) para un análisis de esta celebración en la ciudad de Córdoba.

486 La elaboración del segundo retrato apuntaba a "avanzar en ciertas competencias lingüísticas y tecnológicas". Para ello se trabajó con textos narrativos (leyendas) y se promovió el uso de la computadora (transcripción sus textos, visita al cyber). En muchos casos se trataba del primer contacto con la computadora, ya que la gran mayoría no posee ninguna en su casa y la escuela todavía no contaba con PC destinadas a los alumnos. Las leyendas seleccionadas para el segundo "retrato" -eran "leyendas de aparecidos"- fueron aquellas que circulan oralmente en el barrio (algunas locales y otras regionales), recolectadas entre los abuelos y padres de los alumnos, las cuales fueron trabajadas a partir de un intensivo trabajo individual y grupal, articulando la producción escrita con la expresión plástica. El título escogido para el retrato fue "Terrormanía”.

$487 \mathrm{Su}$ desarrollo tuvo diferentes etapas. Primero se comentó la festividad en el aula entre los chicos y las maestras. Luego se buscó y sistematizó información acerca de la fiesta, recurriendo básicamente a las familias de inmigrantes bolivianos de los alumnos y alumnas del grado para las averiguaciones sobre la fecha y el desarrollo de la fiesta, el significado de Urkupiña, la transformación que sufre el barrio durante la celebración, las comidas y los bailes que se despliegan en esta ocasión, y el modo en que participan los alumnos y sus familias del evento. Las preguntas que se utilizaron para sistematizar esta información fueron: ¿Cuándo se celebra esta fiesta? ¿Qué quiere decir Urkupiña? ¿De qué origen es esta fiesta? ¿Cómo cambia el barrio ese día? ¿Cómo participás vos y tu familia? En un segundo momento, a partir de producciones individuales se discutieron y seleccionaron los personajes y escenas para la composición de una historieta grupal: "la procesión”, “el baile” y "los puestos de comidas típicas" fueron las escenas elegidas para la realización de las producciones plásticas, las cuales también fueron digitalizadas para poder colocarlas en la página web disponible. 
Argentina". Durante las diferentes celebraciones, me crucé con algunos inmigrantes bolivianos que lo primero que expresaron fue la emoción que le producían estos festejos. Recuerdo que una mujer nacida en Bolivia que lleva más de tres décadas residiendo en Córdoba y que conocí al comienzo del trabajo de campo manifestó: "me vine a recordar mis pagos"; mientras que el padre de la maestra nacida en Bolivia señaló junto a su hija: "me siento como en mis pagos" (Notas de campo, 17 de agosto de 2002).

Las ideas que guiaron el desarrollo del retrato, desde la elección del tema hasta el propósito perseguido, resumidas de manera elocuente en el título, expresan el modo en que en las instituciones escolares abiertas a la multiculturalidad se suele pensar la relación entre nosotros y los otros, los argentinos y los bolivianos, bajo una mirada que privilegia aquello que supuestamente une a ambos grupos -concebidos en términos de grupos nacionales- antes que aquello que los separa. Condensa un ideal, la integración, entendida como meta, contrapuesto a la discriminación. En este sentido, supone un deseo de unión o una voluntad de encuentro, antes que una constatación de las relaciones sociales que se construyen entre argentinos y bolivianos en este espacio que es considerado en el barrio como "la fiesta de los bolivianos", calificativo que es recuperado en uno de los dibujos realizados por los propios alumnos.

Al concebir este espacio en términos de unión, se ocultan aquellas divisiones que también lo constituyen. Si bien se trata de la "fiesta boliviana" de la ciudad que mayor cantidad de gente convoca, ha sido hasta el momento una "fiesta de los bolivianos para los bolivianos" a la cual algunos vecinos del barrio asisten como espectadores, pero nunca como protagonistas. Muchos ni siquiera se acercan al lugar donde transcurre principalmente la celebración -la plaza central- sino que miran pasar la procesión con sus "cargamentos" o los grupos de baile desde sus casas. Pero tampoco es "la fiesta de los bolivianos para todos los bolivianos": por un lado, la fiesta, si bien atraviesa las distintas clases sociales, la misma celebración supone una división de clase (Giorgis, 2004) que suele pasar desapercibida en el ámbito escolar y convoca mayormente a los sectores de la "colectividad boliviana" más desfavorecidos económicamente; por el otro, aquellos inmigrantes bolivianos que adhieren a congregaciones religiosas que no son católicas como la evangélica tampoco participan de este evento.

Lo expuesto hasta aquí sugiere que, como ha encontrado también Franzé en su estudio llevado a cabo en un contexto social y nacional completamente diferente, la escuela, en tanto percibe a los inmigrantes como pertenecientes a una "comunidad", definida en términos de autenticidad y vista como homogénea y portadora de valores y pautas 
compartidos, no consigue vislumbrar la diversidad de posiciones, experiencias, códigos y hábitos sociales y culturales que se ponen en juego al interior de la "comunidad", a pesar de que sea capaz o se esfuerce en reconocer la diversidad cultural en clave étnica (Franzé, 2002). El relato sobre otras experiencias en escuelas cordobesas con una significativa proporción de alumnos hijos de inmigrantes bolivianos muestra, asimismo, que las prácticas de reconocimiento y visibilización del otro, guiadas por la idea de integración (en algunos casos nombrada como adaptación), se producen a partir de la identificación de determinadas diferencias con lo boliviano. Nuevamente aquí, las diversas expresiones de la bolivianidad, en tanto formas y contenidos culturales y políticos diferenciados interpretados en clave nacional, actuarían como facilitadores de la deseada integración, interpretada como ideal de convivencia armónica. La entrevista con un joven profesor contratado por el Ministerio de Educación para desarrollar un taller de capacitación docente titulado oficialmente como "Educación Intercultural Bilingüe", que él renombró como taller sobre interculturalidad, durante los años 2007 y 2008, permite visualizar que se trata de modos de pensar y hacer ampliamente extendidos entre docentes que buscan respuestas prácticas y se sienten fuertemente interpelados por la presencia de alumnos hijos de inmigrantes de países limítrofes como Bolivia. En los distintos encuentros que tuvo en escuelas esparcidas por toda la provincia, la problematización acerca de la interculturalidad que buscaba llevar adelante a partir de las experiencias escolares cotidianas remitía de modo constante a la incorporación de fechas nacionales como el día de la independencia de Bolivia a las efemérides escolares, la realización de la "semana de Bolivia" y la presencia de comidas típicas para algunos eventos de la escuela.

\section{Los actos escolares "no patrióticos"}

En la escuela Vicente Forestieri, entre los grandes actos escolares, las fechas de las efemérides escolares elegidas para hacer presente a Bolivia son generalmente aquellas que, según las concepciones de las maestras, permiten viabilizar la acepción de integración que maneja la escuela, mostrando y comparando ciertas costumbres y tradiciones argentinas y bolivianas: el día de la Tradición, el día de la Raza (que suele ser nombrado como 12 de Octubre para evitar hablar de raza) o el día de las Américas. En estas fechas la celebración adopta la forma de feria de colectividades: se trata de una exposición de bebidas y platos típicos, danzas y bailes folklóricos, vestimentas tradicionales y símbolos religiosos o lenguas identificados con distintos orígenes nacionales. Es una imagen gráfica 
de lo que en la literatura académica se denomina mosaico multicultural. ${ }^{488}$ En la escuela en estudio, las referencias remiten fundamentalmente al canon folklórico dominante de lo boliviano y lo argentino.

[...] El tema de la integración también se ha trabajado muchísimo... / ¿Y en qué sentido? / De los bolivianos con los argentinos... Eso también se ha integrado... se ha trabajado, también se ha trabajado el tema de la conducta, de la convivencia, siempre se trabaja, todos los años eso... / ¿Y cómo se ha trabajado la integración? / La integración... con los bolivianos. El anteaño pasado se hizo el acto del 12 de Octubre, eso que yo comentaba, con las distintas comidas típicas, vinieron carrozas, todos los bolivianos, o sea, hicimos bien la comparación de nuestras tradiciones con las tradiciones de los bolivianos, con los padres, todo... (Nora)

[...] el 12 de octubre fue, para el día de la Raza, que cada una, que cada grado hizo algo. Uno fue comidas típicas, el otro era... el mapa donde estaba Argentina, otro donde estaba Bolivia... o sea, cada grado se dedicó a una actividad y ese día del acto fue una exposición. Se hizo toda una exposición en el SUM con las comidas típicas de Argentina, de Bolivia, colaboraron mucho las mamas bolivianas para las comidas, para buscar las carrozas, para los bailes, también se bailó, danzas de allá. Los chicos también, en ese entonces eran alumnos míos de 6to. y bailaron con esta vestimenta de todos colores... ¿Cómo se llama? No... no me acuerdo / ¿Caporales? / Caporales, exacto, eso bailaron,

488 Esta expresión del multiculturalismo ha generado diversas críticas en la literatura. Una de las más contundentes, proveniente del marxismo, le atribuye insuficiente capacidad para desafiar el orden social existente, esto es, la organización de la sociedad capitalista, o más aún, formar parte de la ideología del capitalismo global. Obras de la corriente crítica norteamericana como las de McCarthy (1993) y Ladson-Billings y Tate (1995) coinciden en señalar que el multiculturalismo, o mejor dicho algunas de sus facciones, se han visto absorbidas por el "sistema", dirigiendo sus críticas a los fundamentos liberales del multiculturalismo. Además de no ofrecer soluciones radicales a los problemas sociales, económicos y políticos relacionados con la discriminación, la desigualdad y la explotación, reducen la problemática multicultural a la promoción del respeto y la tolerancia, propiciando en todo caso la proliferación de las diferencias en términos de "unidad", entendida toda diferencia en tanto análoga como equivalente, pero reconciliando las tensiones entre ellas (Torres, 2001:252). Jacoby, por su parte, destaca la relación entre la diversidad cultural y la sociedad de consumo y afirma que "esas culturas diversas no ofrecen opción ni al consumismo ni al capitalismo" (Torres, 2001:264). Desde esta perspectiva, la preocupación multiculturalista estaría instalada en la incorporación de los distintos grupos étnicos a la sociedad de consumo en vez de estar focalizada en su superación. Žižek, asimismo, concluye que "la problemática del multiculturalismo que se impone hoy es el modo en que se manifiesta la problemática opuesta: la presencia masiva del capitalismo como sistema mundial universal" (Žižek, 1998:177). 
entonces hubo danzas nuestras, danzas de ellos, comidas nuestras... o sea... fue muy, muy lindo... nunca pensé que fuera a salir tan bien. Porque fue una idea, así... de María Eugenia, que es la coordinadora del acto y, bueno, ha salido entre todos algo muy, muy... Y vino la inspectora, fue realmente... nos felicitó porque había visto bien la integración que había habido con todos y todo lo que habían hecho los chicos, los padres también, se notaba mucho el trabajo de los padres... (Nora)

Claro... en los actos nuestros, que sé yo, en el 29 que hicimos en el día de la Tradición que ellos vinieron, hicieron una exposición acerca de las comidas típicas de Brasil, de Bolivia, de todas las regiones: del altiplano, de la parte de las mesetas, de los valles, trajeron un montón de comidas y se hizo una exposición en el... son preciosas porque trabajaron un montón, trajeron a la Virgen de Urkupiña, trajeron ropa... eh... había eh... había gente que hablaba, porque hablan en quechua, así que había una mamá que había preparado como se decía en quechua algunas cosas -que yo todavía tengo en casa- cómo se decían las cosas nuestras en castellano y cómo se decían en quechua, viste...? Nosotros hicimos una exposición también de la Argentina, entonces estaban las dos naciones: la argentina y la boliviana y participaron las madres con la bandera y el himno nacional. El año pasado también lo hicimos, [ruido ambiente] también hicimos lo mismo, participaron... y ahora para el día de las Américas también lo hicimos... (María)

[...] Una vez, por ejemplo, hicimos lo del... como una feria... [interrupción] ¿Qué estaba diciendo? Que una vez habíamos organizado toda una... que fue creo... que también tenía que ver con la independencia de Bolivia, se hizo toda una muestra de las ropas de ellos, de los bailes, de las costumbres, de las comidas, de las bebidas... que ahí fue mucha gente, se interesaron muchos, fueron muchos... [...] también se hizo este festejo que yo te dije, el día de la Tradición nuestro, en noviembre, y que se incorporó la tradición de los chicos bolivianos también..." (Mercedes)

El día de las Américas, en particular, resulta una ocasión propicia para destacar la hermandad (latino)americana. La celebración de este día, si bien según el calendario oficial corresponde a los grandes actos, puede convertirse de acuerdo a los acontecimientos y urgencias de la vida escolar en un pequeño acto -como ocurrió en el año 2003 en el cual sólo hubo un recordatorio- en el cual se destaca básicamente el origen y la importancia de 
la fecha. Según lo que expresan las maestras, en esta escuela se le otorga un significado especial debido a la presencia de distintas "nacionalidades". Esto se expresa también en los afiches que se preparan para la ocasión:

Hoy se conmemora el Día de las Américas. Llego a la escuela alrededor de las 11:00 de la mañana. A la entrada, en la cartelera, han colgado un afiche amarillo (preparado por S.) que con letras negras y en mayúsculas indica: Tomados de la mano / recordemos: / ¡Somos hermanos americanos! / Para poder de verdad / así, juntos, lograr la paz. Sobre el afiche han pegado una hoja tamaño A4 con banderas de los distintos Estados americanos dibujadas y pintadas a color, un listado de los Estados americanos con su respectiva capital, superficie, población, lengua oficial, religión (mayoría) y año de independencia, fotos (recortes de revistas) de paisajes de Haití (mar y playa), Brasil (selva tropical y río Amazonas) y Bolivia (grupo de cuatro personas con vestimenta típica). Figura, asimismo, un cartel escrito a mano en el cual se hace una descripción (geográfica) breve de la región: "El continente americano es el único caso en el planeta de tierras emergidas que se extienden de polo a polo. La masa continental abarca $14.000 \mathrm{~km}$. de longitud en el sentido nortesur. Su superficie: $42.000 \mathrm{~km} 2$. Presenta una gran diversidad de condiciones naturales. (Notas de campo, 14 de abril de 2003)

También ocurre así para el día de la Raza. En el año 2003, en la estera de la entrada de la escuela colgaba un afiche con una inscripción que aludía, bajo el lema de la hermandad a la unión armónica de las razas como ideal, acompañado de un dibujo que pretende representar la diversidad humana. En el centro un mapamundi y en cada esquina un representante de cada raza: un niño negro, un niño amarillo con ojos rasgados, un niño blanco con pelo colorado y una niña blanca y rubia (Notas de campo, 15 de octubre de 2003). El afiche decía:

DIA DE LA RAZA

Tomados de la mano

Recordemos: jsomos hermanos!

Ojalá que algún día las razas

Se unan en armonía

Para poder de verdad

Así juntos, lograr la paz. 
Estos pequeños actos con formato de recordatorio no duran demasiado tiempo, sólo unos minutos, fusionándose con el saludo general. El recordatorio se convierte en estas circunstancias precisamente en lo que enuncia: cumple la función de recordarles a los alumnos la existencia de los otros que conviven entre nosotros: con los alumnos hijos de inmigrantes como referencia se habla de respetar la cultura y la forma de ser de los otros, nombrados en esta ocasión como "nuestros vecinos" y que en otras oportunidades, en celebraciones como éstas, también son considerados "nuestros hermanos".

Me quedo hasta la tarde para observar el acto del Día de las Américas. Los alumnos forman fila alrededor de la bandera. Inmediatamente después del saludo, una de las vicedirectoras, Amalia, toma la palabra. “ ¿Saben que día es hoy?”, pregunta a los chicos. Un alumno responde: “Lunes!”. Respuesta equivocada. Silencio. Después otro da la respuesta esperada: "El día de las Américas". La vicedirectora aprueba la respuesta y les dice que "hoy debemos acordarnos más que nunca... acordarnos bien de nuestros vecinos, con respeto... a su cultura, a su forma de ser". Después de este breve "recordatorio", que apenas dura unos minutos, hace pasar a los alumnos a las aulas. (Notas de campo, 14 de abril de 2003)

Pero no siempre estas fechas son utilizadas para visibilizar la presencia de los bolivianos o promover la unión entre argentinos y bolivianos. Dado que el acto está a cargo de una maestra, depende de la idea que ella tenga si se incluye o no alguna referencia a la hermandad entre argentinos y bolivianos. Puede resultar que este acto del día de la Tradición asuma o mantenga las mismas características de las celebraciones de una fecha patria en la cual prevalece la noción de argentinidad sobre todas las cosas. A través de representaciones como los bailes folclóricos se esclarece el patrimonio cultural que es seleccionado como distintivo de una nación, permitiendo reconstruir el pasado y la tradición (Olorón, 2000).

Hoy se realiza el acto escolar en conmemoración del Día de la Tradición. Estamos reunidos debajo de la zona de los árboles, a la sombra. Hay alumnos vestidos como gauchos. E. es la encargada de la organización. Abre el acto diciendo: "Pues son mis dichas / desdicha las de todos mis hermanos / ellos guardarán ufanos / en su corazón mi historia. Así escribió Don José Hernández, poeta, soldado, periodista, en cuya memoria se establece el día de su nacimiento, 10 de noviembre de 1834, como día de la Tradición, su famosa obra 'Don Martín Fierro'”. Luego ingresa la bandera: "En este acto en el que 
festejamos nuestra argentinidad, invitamos a nuestra querida bandera a participar del mismo. Recibámosla en manos de abanderada y escoltas...". Como música de fondo suena la canción patria "Mi bandera". Aplausos.

Enseguida se entona el himno nacional: "El Himno Nacional nos ha acompañado desde el nacimiento de la patria. Hoy también lo hace para que afirmemos juntos la unidad en el esfuerzo que nos hará seguir siendo argentinos". Sale la bandera: "Despidamos a nuestra bandera con un respetuoso silencio y le agradezcamos su presencia".

La maestra introduce un número a cargo de los alumnos de tercer grado: “¿Qué es la tradición? Es la vida de nuestros gauchos, de su modo de sentir, de pensar y de hablar. Es el conjunto de costumbres y supersticiones que con el paso de la conquista y civilización fueron perdiéndose por completo. Para conocer algunos de los versos que escribió don José Hernández en su magna obra El Martín Fierro, alumnos de tercer grado nos lo recitarán". Recitado de fragmentos del Martín Fierro por alumnos de tercer grado, un varón y una niña.

Le sigue una escena sobre el "lenguaje del mate" en la cual algunos alumnos de quinto grado cuentan acerca de la manera de cebarlo. Dice la maestra: "Le invito a tomar un mate, acérquese linda moza, soy el mejor cebador, tome mi china hermosa... Su mate está que pela y tiene gusto raro. No sé que pretende usted. ¿No lo habrá engualichao? A la mañana, a la tarde o a la noche, en los hogares hay siempre un compañero infaltable: el mate. Dulce o amargo, o limón, no es sólo una infusión. El mate es un lazo que hermana a la gente de esta nación".

Para el cierre, alumnos de cuarto y sexto grado con vestimentas tradicionales bailan tres danzas del folklore argentino: un chamamé, una chacarera y una zamba. Así los presenta la maestra: "El sauce moja sus ramas en el agua cristalina / mientras el paisano canta con su guitarra argentina / canciones que traen el alma: nuestras danzas argentinas". Los alumnos en el público piden que se repita. La maestra de tercer grado y una pareja de alumnos se suman al baile. Llega el acto a su final. La maestra felicita a los alumnos por su comportamiento y se despide diciendo: "Dado por finalizado el acto, les agradecemos a los papás su presencia y atención y los invitamos a seguir mateando". (Notas de campo, 11 de noviembre de 2002) 
Los actos escolares "bolivianos": la celebración del día de la independencia de Bolivia

El acontecimiento por excelencia que se suele recordar, a manera de celebración, ligado a Bolivia es el día de la independencia del país, el 6 de agosto. Más allá del despliegue que se realice para esta ocasión, que no suele ser más que un pequeño acto, el día de la independencia es la (única) fecha seleccionada e incorporada al calendario propio de la institución para conmemorar oficialmente algún acontecimiento referido a Bolivia. Aunque haya referencias explícitas a Bolivia en otros eventos escolares, es la existencia de esta fecha la que revela la presencia de alumnos identificados como bolivianos. Sin alumnos bolivianos no existiría dicha conmemoración en la escuela; es su presencia, determinada por un número considerado elevado, la que la justifica. A su vez, esta fecha recibe mayor atención -cuando la recibe- que otras incluidas en el calendario oficial, que por asociación directa también podrían tener un lugar relevante como el día del Inmigrante (4 de septiembre).

A diferencia de la centralidad que adquirió la fecha del día de la Independencia de Bolivia entre las celebraciones escolares, el acto del día del Inmigrante ${ }^{489}$ suele pasar completamente desapercibido, más aún si no hay un contexto propicio para festejos o recordatorios. El día del Inmigrante, a pesar de figurar entre las fechas establecidas por el calendario oficial, no recibe ninguna atención especial de parte de la escuela. Aún en aquellas ocasiones que el recordatorio tuvo lugar, con alguna referencia mínima, el referente del acto no es necesariamente la comunidad boliviana, sino la inmigración de ultramar. Igualmente, más que el contenido del acto en sí mismo, lo significativo es la definición que prevalece en la selección y organización de actos escolares dirigidos a reconocer la presencia de los alumnos bolivianos. No es tanto la condición de inmigrante como la de otro nacional o no-nacional la que se recupera en los actos conmemorativos, es decir, la presencia de no-nacionales en el orden escolar en tanto territorio de la nación

\footnotetext{
489 El día del Inmigrante fue establecido durante la primera presidencia de Perón por el decreto № 21.430 en 1949. La elección del 4 de septiembre se corresponde con la fecha del primer decreto del gobierno nacional -en aquella época gobernaba el primer Triunvirato- de 1812 que se expresa a favor del fomento de la inmigración. Este decreto afirmaba que "el gobierno ofrece su inmediata protección a los individuos de todas las naciones y a sus familias que deseen fijar su domicilio en el territorio". Entre los considerandos del decreto que dio lugar a la celebración del día del Inmigrante, se manifiesta: “Que ese primer documento fue, en verdad, el punto de partida de una ininterrumpida serie de actos de gobierno; que a través de leyes, decretos y reglamentaciones estimuló, protegió y encauzó la inmigración". También destaca "la conveniencia de que se rinda un permanente y público homenaje al inmigrante de todas las épocas, que sumó sus esperanzas a la de los argentinos, que regó la tierra con su sudor honrado, que ennobleció las artes, mejoró las industrias".
} 
argentina. Este hecho condensa toda una definición acerca de esos otros culturalmente diferentes: son bolivianos más que inmigrantes.

Hoy es el día del Inmigrante. Entro a la escuela a las 13:30. Aún no ha llegado ninguna maestra. Saludo a la señora Rosa. A los minutos llega la primera maestra. Entramos a la sala de maestros. Allí está una de las profesoras de folclore. Nora le cuenta que hoy hay abandono de tareas entre las 10:00 y las 14:00 horas. La iniciativa surgió de una escuela y recién ayer se adhirió el gremio docente. Espera que se descongele la antigüedad ahora que ha cumplido quince años de servicios. [...] Empiezan a llegar otras maestras. Hablo con Jimena, la maestra nacida en Bolivia. Le pregunto si sabe algo respecto a la conmemoración del día del inmigrante. No se acordaba que fuera hoy, sólo que era el día de la secretaria. Me indica que con los reclamos docentes nadie tiene en cuenta este festejo. Son más de las 14:00 horas. Los directivos aún no han llegado. Hoy no hay formación. Las maestras hacen pasar a los alumnos directamente al grado. Le pregunto a la señora Rosa si sabe algo respecto al recordatorio del día del Inmigrante. Me dice que a lo mejor se dijo algo esta mañana, que no ha podido escuchar. Le recuerdo que el año pasado sólo se hizo alusión a la fecha. Me pregunta si no estuvo a cargo Silvana, que es siempre ella quien organiza algo relacionado a la comunidad. Me retiro alrededor de las 15:00 horas. (Notas de campo, 4 de septiembre de 2003)

La conmemoración de fechas y festividades nacionales de países extranjeros si bien no están reglamentadas, algunas referencias se desprenden de las disposiciones establecidas en relación al tratamiento y uso de los símbolos patrios en aquellas escuelas que llevan el nombre de otros Estados. Una cuestión central es que estas instituciones deben estar "autorizadas para tener la Bandera de ‘ceremonia' de dichas naciones”. Tratándose de un objeto que representa una presencia extranjera, el Estado argentino dispone a través de la normativa escolar que dicha presencia simbólica cuente previamente con el debido permiso para ingresar al ámbito escolar. Así como el Estado autoriza la entrada de los extranjeros al territorio nacional, la bandera de otros Estados nacionales también debe estar autorizada para estar en la escuela. A la vez, según la normativa, la bandera nacional de un país extranjero solamente podrá estar presente cuando se celebren en sus respectivos locales los aniversarios de los respectivos países o en actos relacionados con sus festividades y siempre en compañía de la bandera argentina. Disposiciones como éstas 
relativas al uso de la bandera nacional de países extranjeros son las que contribuyen a definir a la escuela pública como un territorio de la nación argentina.

Así como la bandera es el símbolo político por excelencia con el que se representa y enuncia la presencia de otro Estado, el día de la independencia es el acto político con el cual se identifica su origen y se lo reconoce como nación. La elección de esta fecha nacional boliviana, mediada precisamente por lo establecido en la normativa escolar, como búsqueda de reconocimiento de la presencia de una colectividad de inmigrantes, evidencia la penetración que tiene el pensamiento de Estado en los discursos y prácticas escolares. Pareciera que en determinados contextos los hijos de las familias de inmigrantes bolivianos no pueden ser pensados en otros términos que no sean nacionales, esto es, como una exterioridad nacional. En estas situaciones, aún aquellos hijos de inmigrantes bolivianos de nacionalidad argentina que viven y que quizás pasen su vida entera en la Argentina son extranjerizados. Asimismo, revela que las prácticas de reconocimiento dirigidas a los bolivianos en tanto no-nacionales adopta el mismo formato que aquellas que desarrolla la escuela en su afán por cimentar la idea de nación argentina y cumplir con su mandato de afianzar la construcción de la identidad nacional. Frente a la pregunta por la elección de esta fecha, una maestra responde:

Y para recordar porque es el día... como la independencia nuestra, viste... y si es importante para nosotros, también es importante, pienso, que se la recuerde a la independencia de ellos, que se la tenga presente, por eso siempre se recuerda y se remarca esa fecha... a veces no se consigue la bandera, pero bueno, a la entrada siempre se hace mención, se hace mención... (Plácida)

Al igual que otras fechas que no constituyen las fechas patrias argentinas -los grandes actos del calendario escolar- la conmemoración del día de la independencia de Bolivia generalmente bajo la forma de recordatorio- puede tener lugar o no durante el año (por ejemplo, durante el año 2004 no hubo ninguna celebración), puede adquirir mayor o menor trascendencia, puede tener mayor o menor despliegue. De alguna manera, se trata de una acción contingente. Dependerá de la importancia que le otorgue la maestra, la predisposición de la dirección y la coyuntura en la que se encuentre la escuela en ese momento (desde una reunión de personal hasta un paro docente o una toma de la escuela pueden afectar la realización de estos actos). En general, la organización de algún evento escolar -sea un recordatorio o un acto- relacionado con Bolivia o con cualquier otra conmemoración que no forme parte de las fechas patrias instituidas, dependen en gran 
medida de la decisión personal de alguna docente o directamente del azar. Dado que la organización puede resultar de una elección o sorteo ${ }^{490}$, hay maestras, por muy antiguas que sean, que nunca han participado activamente de la organización de un recordatorio o acto relacionado con alguna de las fechas consideradas como bolivianas.

\section{En la escuela, vos siempre has sido una de las personas que ha promovido recordar las fechas bolivianas...}

Sí, el 6 de agosto, siempre, todos los años lo recordamos con la bandera que nos presta muy gentilmente la señora Rosa, el himno de Bolivia, que escuchamos nosotros con mucho respeto y los que lo saben lo cantan con mucho orgullo, incluso invitamos a los papás a que nos acompañen [...] pero no, no, pero siempre lo recordamos...

\section{¿Se hace todos los años?}

Y mirá, depende de quién está, me parece, depende de quién está... yo siempre trato que se haga... [...] Todos los años se recuerda, puede ser que algunos años se haya recordado con más énfasis, con muchas ganas de trabajar de parte de los maestros y otros años en que solamente se hizo el recordatorio y nada más... este año no lo trabajamos en las aulas, años anteriores se ha trabajado en las aulas... [...]

\section{¿Cuál es la importancia que le otorga el resto de los docentes?}

Lo que pasa, sabés qué... hay mucha movilidad de docentes... entonces el docente hasta que conozca la identidad de la institución, hasta que conozca la comunidad educativa es como que es todo un proceso que se va dando... Quizás a la mañana es un equipo más estable, a la mañana... pero a la tarde es un plantel que ingresó este año, hay más movilidad, entonces es como que el docente que ingresa a la tarde no tiene, no conoce la identidad de la institución, cómo la hemos ido construyendo a lo largo de los años... Depende mucho que el docente conozca la comunidad educativa, la identidad de la institución... (Silvana)

Hay una efemérides, como te decía recién, que se va repartiendo cada maestro, cada maestro se va haciendo cargo... y depende mucho del maestro y depende mucho que en ese momento la dirección de la escuela... tenga... no esté en reuniones o en cosas que tapen esa visión y que se acuerden de ponerla... Por

490 Cuando le pregunté a una de las docentes [Pilar] quién se encarga de organizar estos eventos, me respondió: "las maestras, a la que le toca, la semanera". 
ahí viene la directora y te dice, mirá, ese día tenemos que hacer esto, esto y esto, y otros días que no te dice nada... y también depende de la maestra que te diga "yo quiero hacer algo muy importante" o que no le dé importancia, entendés? (Mercedes)

Llego apurado a la escuela con la intención de observar el recordatorio previsto para el día de la independencia de Bolivia. La maestra encargada de prepararlo, me comentó hace unos días que había hablado con el padre de un alumno suyo de una familia boliviana para que diga algunas palabras alusivas a esta conmemoración. A la entrada, en la esterilla, cuelga un afiche que dice: ¡Último momento! / En un día como hoy, 6 de agosto, / pero de 1825 se proclamó la INDEPENDENCIA / DE BOLIVIA, quien tomó ese nombre en / honor al líder, héroe venezolano y protector de la nueva república / "SIMON BOLIVAR” / ¡Felicidades a nuestros hermanos bolivianos! / Nuestro corazón [gráfico de un corazón] está con ustedes. Pero me encuentro con que, salvo esta referencia a la independencia de Bolivia que cuelga en las paredes en el ingreso a la escuela, no hay nada más. Le pregunto a la maestra por el recordatorio de hoy y me explica que finalmente el padre de su alumno no pudo venir a la escuela. (Notas de campo, 6 de agosto de 2002)

Algunas maestras explicitan que en diversas ocasiones estos actos relativos a Bolivia o a los bolivianos no son organizados de manera espontánea por ellas, sino que surgen en respuesta a las directrices institucionales, a ciertas pautas que se han instituido en la escuela durante estos años, lo cual -según ellas- vaciaría de sentido la realización de estos actos, ya que son vividos como una imposición desde arriba, al igual que las fechas patrias. También serían actos fruto de la improvisación, sin una preparación previa, lo cual sería un indicio de la poca trascendencia o el escaso valor que tienen en la comunidad docente. Por ello, algunas consideran que no se trata de algo "auténtico", utilizando la metáfora del circo para acentuar su carácter de espectáculo ficticio. Algo similar a lo que ocurre con las demás fechas fijadas en el calendario escolar como mostré anteriormente.

Y bueno, y el otro día, que yo lo comenté ni bien entramos al salón de la leche, el día de la celebración del día de la independencia de Bolivia fue espantoso, porque nadie había preparado nada, a las chicas que les tocaba les dijimos "chicas, quieren que hagamos algo, que hablemos a los chiquitos bolivianos... a ellos les da mucha alegría, a los míos por lo menos... cuando estábamos en la formación y entró la bandera de Bolivia a Daniela... se le sonrojaron los 
cachetes... “¡Yo soy de Bolivia, yo soy de Bolivia!”... entonces le dio mucha alegría eso... y no era necesario nada armado por nosotras, sino algo más natural, que saliera de los chicos, brindarles un aplauso, hablar... una improvisación... no sabían dónde estaba la bandera boliviana, iban a hacer entrar la bandera de ceremonias... viste cuando está todo que se arma así en cinco minutos... ¿Por qué? Porque la vieron llegar [a la directora], no porque haya salido de estas chicas, "recuerden que es el día de la independencia de Bolivia, qué vamos a hacer... nuestros alumnos, tenemos muchos alumnos bolivianos...", salir de nosotras no sale. Algunas propusimos... me acoplo, porque yo dije quieren que yo haga... hagamos banderitas? Porque Pilar me dice podemos poner muchas banderas... como tenemos chiquitos bolivianos hagamos banderitas... después quedó todo en que no, que las chicas que eran encargadas de esa fecha lo iban a hacer, todo quedaba... [interrupción] Así que no sé pasó... ese día fue muy triste, porque no salió el himno, más allá que saliera el himno o no, no es el hecho que saliera el himno, sino el hecho de que realmente fuera significativo, nadie lo sintió, para mí nadie lo sintió así, lo sentimos los docentes como algo que había que hacerlo para conformarla [a la directora]... entonces eso no tiene sentido, porque es preferible si uno no lo siente no hacerlo, Eduardo, directamente, que hacer algo así por imposición... [...] Yo no me sentí con ganas de hablar porque me pareció todo un circo y yo para eso no sirvo, Eduardo, si me sale yo hablo, hubiera hecho que le dieran un aplauso a mis alumnos, que recordáramos las familias... nombrar las familias... cuando es un circo para mí no tiene sentido, cuando es algo que realmente vamos a valorar... hasta quizás también pasa por ahí el tema de que los chicos... porque si uno no tiene la convicción de que no son bolivianos sucios o de que no han venido a robarnos nada, ni a desplazarnos de ningún lugar, no se lo podemos transmitir a los otros... yo tal vez vengo hace muchos años trabajando en la comunidad de La Villa, me he topado permanentemente con gente de acá, boliviana... [...] Por eso tal vez uno puede obligar al otro, yo no soy de la idea de obligar a ellas que lo quieran ni nada, pero bueno... estamos en esta comunidad, elegimos esta comunidad, entonces hay que, como tal, tenemos que trabajar sabiendo dónde estamos, pero bueno, como también es una escuela dónde vamos y venimos, se mueven mucho las maestras, no tiene tiempo tal vez de afianzarse, de conocer las familias que hay atrás de cada niño, la vida que llevan, cómo ven las cosas... (Valeria) 
Las maestras más antiguas, en particular aquellas que han elegido la escuela al momento de su titularización, sostienen que a diferencia de ellas, algunas maestras, entre ellas las "nuevas" no le dan mayor importancia, ya sea por falta de compromiso o por desconocimiento. Dado que no conocen aún la "identidad de la escuela", no le darían la trascendencia que tiene para "la institución" (o "nosotros", el grupo de maestras más antiguo).

Las maestras que generalmente son nuevas no saben muy bien la relevancia que tiene para nosotros...

\section{¿Alguien les transmite eso?}

En teoría lo hablamos, lo transmitimos, pero hay veces que se pasa...

¿Y qué dicen las maestras nuevas cuando se encuentran con el festejo de la independencia de Bolivia en una escuela argentina?

Y es como raro, algunas... te repito lo que te dije hoy, algunas no lo entienden... no lo entienden y no lo pueden ver... eso, que no haya timbre, que no se forme... es muy raro y es como un signo de caos...

¿Hay docentes que se niegan o rechacen de alguna forma, por ejemplo, celebrar el día de la independencia de algún país latinoamericano, en este caso Bolivia?

No, no lo hacen explícitamente... por lo menos nunca nadie ha dicho "yo no...", no lo hacen explícitamente, pero por ahí las acciones, esto de no preocuparte demasiado, de no darle importancia...

$[\ldots]$

\section{Entonces las celebraciones referidas a la colectividad boliviana están supeditadas a la voluntad del docente...}

Sí, por un lado sí, por el otro que el equipo tenga suficiente cabeza o se pueda acordar... [...] Pero creo que sí, depende mucho del docente que le toca conmemorar ese día, cómo lo va a hacer, cómo lo va a llevar a cabo y la mirada que tenga sobre eso... Porque yo te digo, si yo hubiera estado en una escuela y no hubiera entendido un montón de cosas, yo tampoco le hubiera dado importancia, no por discriminar ni por nada, nunca fui de esa manera, pero por una cuestión que no me enseñaron, que no lo vi o nunca... entendés? Es otra mirada... [...] Yo por eso no critico tanto a mis compañeras... (Mercedes)

Quienes se ocupan generalmente de la organización del acto o recordatorio del día de la independencia boliviana o de alguna otra fecha propicia para introducir algunos elementos de la bolivianidad son dos maestras hijas de bolivianos, una de ellas nacida en 
Bolivia. Para ello cuentan siempre con la colaboración de la señora encargada del kiosco de la escuela, la señora Rosa, una mujer nacida en Cochabamba que migró a la Argentina en la década de los ochenta, cuyos hijos y nietos han asistido también a esta institución. Es ella quien suele prestarle a la escuela la bandera nacional boliviana. Frente a la falta de interés de buena parte de las maestras, el resto delega la mayoría de las veces en ellas la organización del recordatorio, debido a que son identificadas como las representantes naturales -es decir, oficiales- de la comunidad boliviana en la escuela, y se da por sentado que ellas se ocuparán de su organización, estableciéndose una asociación fija entre ellas y las fechas referidas a Bolivia. Una de ellas lo expresa así:

Por ejemplo, últimamente es como que... "hay que buscar las cosas, hay que buscar" un día antes... y yo también me olvido... claro, como yo soy boliviana me mandan a mí al cajón / ¿Cómo es que te mandan al cajón? / Me dicen: "buscála vos, buscála vos"... este año lo consiguió la Silvana, creo... / ¿Qué? / los papeles, la historia, porque yo no conozco nada de la historia boliviana...". (Jimena)

Son las 13.30 horas. Está por iniciar la jornada escolar del turno tarde. Los alumnos forman fila alrededor del mástil, unos grados en frente de otros. Jimena saluda a los alumnos y ellos responden a coro: "Bue-nas tar-des se-ñori-ta...". Saluda la vicedirectora (Carmen), y les habla a los chicos: "Hay un nuevo deporte...". Se refiere a las cáscaras de naranjas que se tiran entre los alumnos. Les pide a las maestras que se hable en las aulas. Al final pregunta: “¿Podemos tirarnos las naranjas a los cuerpos?”. Los alumnos responden que no. Luego se hace referencia al paro de transporte. “Alguna otra novedad? ¿Podemos pasar...?”. “Pasamos a las aulas...”, dice una de las maestras (Jimena). Los alumnos caminan en fila, algo desordenada, hacia las aulas.

No se ha dicho nada respecto al día de la Independencia de Bolivia. Le pregunto a Jimena, una de las maestras que generalmente se ocupa de organizar algo en estas ocasiones. Me dice que ella le avisó a la directora; le respondió que lo anunciara ella misma. “¿Quién soy yo? ¿La representante de la colectividad?" me dice. Al irme, me detengo frente a un afiche escrito a mano pegado en el vidrio de una de las puertas del comedor que dice con mayúsculas: ¿Qué es la bandera para vos? Es un símbolo patrio. (Notas de campo, 6 de agosto de 2003) 
Salvo algún año en que se organizó como un acto especial, la celebración adopta la forma de recordatorio, que como cualquier otro generalmente dura unos pocos minutos y si no están dadas ciertas condiciones puede quedar recluido a un lugar mínimo, incluido entre los tantos anuncios que tiene la escuela para hacer: así se disuelve el valor que de antemano se le pueda otorgar a este acontecimiento, cuya relevancia es de algún modo rescatada -en tanto reivindicación- a través de los aplausos, los cuales colaboran a diferenciarlo del resto de las novedades anunciadas.

Llego a las 8:00 de la mañana a la escuela. Es esperable que hoy se conmemore el día de la Independencia de Bolivia. En la entrada, ninguna de las esteras hace referencia a esta fecha. Uno días atrás, para el día de la independencia de Perú había una que decía: "28 de julio: Independencia del Perú. Libertador del País: Don José de San Martín, nombrado Protector del Perú." Acompaña un mapa de América del sur donde se resalta Perú.). [...]

Los alumnos comienzan a formar fila, realizando un círculo alrededor del mástil de la bandera (argentina). Las maestras intentan que los alumnos hagan silencio: “Estamos escuchando?”. "Hacemos un poquito de silencio”. Una de las vicedirectoras, Amalia, se encarga de la apertura de hoy. "Vamos a saludarnos: ¡Muy buenos días!”. También saluda a la "señorita directora”. "En posición de firmes, nos sacamos las manos de los bolsillos, nos sacamos las gorras... A los papás también los invitamos a esta postura de respeto." Como es habitual, se entona una canción patria para empezar el día. Aplausos. "En el día de hoy hay varios comunicados...". Una de las maestras (Eli) toma la palabra y se refiere a la organización de los recreos y los patios, a la salud de un profesor, al paro de transporte. Después dice: “Otra notificación: hoy es el día de la independencia boliviana". La maestra pide "un fuerte aplauso... a los integrados, a los hijos de bolivianos y a nosotros". Y continúa preguntando: “¿Alguna información más?”. Silencio. Los alumnos pasan a los grados. (Notas de campo, 6 de agosto de 2003)

Básicamente este pequeño acto dedicado a la independencia de Bolivia consiste en la alusión al acontecimiento histórico que dio origen a la fecha. Para ello las maestras que se ocupan del recordatorio suelen recurrir a la lectura de notas del diario o alguna información extraída de Internet sobre la independencia boliviana. Estos actos escolares como muchos otros parecieran estar suspendidos en el tiempo, es decir, se caracterizan por una atemporalidad que sólo circunstancialmente es interrumpida con alguna intervención no esperada o no planificada. Por otra parte, como símbolo patrio 
representativo de un Estado-nación, la bandera nacional boliviana se constituye en el emblema político imprescindible para que adquiera entidad. Se trata siempre de la bandera nacional tricolor, nunca de la multicolor Whipala, la cual representa las diferentes naciones indígenas que componen Bolivia y que desde la llegada del MAS a la presidencia se convirtió también en bandera oficial. Una de las mayores preocupaciones de las maestras a la hora de organizar el "recordatorio" es precisamente conseguir la bandera nacional boliviana, conseguirla a tiempo. Aún con el mayor o menor despliegue que se realice para la ocasión, siempre se busca que de algún modo la bandera boliviana esté presente. Es a través de ella que la presencia de los alumnos bolivianos pretende ser reconocida, hacerla visible. Son ellos, identificados aquí como miembros de la comunidad boliviana, y cualquier otra persona que pueda ser considerara boliviana de acuerdo a su origen nacional (puede ser algún familiar o la señora del kiosco) quienes son elegidos para portarla como si fueran los representantes oficiales del Estado boliviano. Al mismo tiempo, la bandera toma cuerpo a través de los aplausos y exclamaciones que acompañan su presencia, se torna una experiencia envolvente, lo cual otorga cierta emotividad al acto.

Llego a la escuela a las 8 de la mañana. Hoy se conmemora el día de la Independencia de Bolivia. Me dirijo a la dirección donde encuentro a la directora. Enseguida entra la señora Rosa con la bandera boliviana. Nos saludamos. Le dice a la directora que no pudo conseguir el himno. Salgo al patio.

Los alumnos forman fila en el patio junto a sus maestras alrededor del mástil de la escuela. Algunas han faltado. Saluda la directora a los alumnos y alumnas. Después a las maestras (las "seños") y a los padres. Comenta los destrozos que se han realizado durante el fin de semana en la escuela. Toma la palabra la vicedirectora y saluda a los chicos y chicas: "Bueno... hola, hola, hooola... hola, holala... ¿Cómo están? ¿Hoy no hace tanto frío, verdad? Vamos a... izar la bandera...". La bandera argentina no está colocada en el mástil. Se espera que la traigan. Después ingresa la señora Rosa con la bandera boliviana y la acompañan tres pequeñas alumnas con una banderita cada una y dos alumnos de los grados más altos con una bandera bastante grande de papel; se quedan parados al lado del mástil. Continúa diciendo: "Vamos a recibir con un fuerte aplauso a la insignia nacional de Bolivia [aplausos, algunos alumnos abuchean ("uhhh") en tono bajo], la insignia de la hermana Bolivia, la bandera... ¿Por qué será? A ver alguien... ¿Nadie sabe por qué? A ver... bien, muy bien... hoy es el día de la independencia de Bolivia... ¿en qué año fue la independencia de Bolivia? A ver, ¿se acuerda alguien? Bueno... fue el 6 de agosto de 1825, si? 
Bueno, ahora sigan con... derechitos, sacamos los gorritos de las cabecitas, manitos fuera de los bolsillos...". Se canta la canción "Sube, sube, sube" (escrita por el cantautor Víctor Heredia) dedicada a la bandera. Aplausos. Una maestra toma la palabra: "Bueno, les voy a contar un poquito sobre la independencia de Bolivia para todos aquellos que no conocemos o no conocen... El 6 de agosto de 1825 fue la independencia de Bolivia...." Lee un texto extraído de internet. Luego habla la directora (con tono suave): "Chicos, una pregunta. ¿Quién es el nuevo presidente que tenemos en Bolivia ahora? ¿Quién lo conoce? [una alumna de los grados más bajos dice "Evo"]. ¿Evo...? Evo Morales... bien... ¿Y qué está haciendo Evo Morales por nuestra querida... hermana República de Bolivia? ¿Quién nos puede contar? A ver algunos familiares también que están allá, algunas mamás, si quieren participar... El está peleando también por la independencia del país. Durante muchos años, igual que nuestro país, depende... tenía una economía muy dependiente, donde muchos dirigentes han determinado el nivel de pobreza en que está la República de Bolivia en este momento. Y como dijo la niña, el presidente Evo Morales está intentando revertir lo que ha sido siempre la dependencia del país. El tema que apareció hoy también lo hablemos en cada grado, lo conversemos". Seguidamente, una de las vicedirectoras se refiere a los recreos: "Vamos a ver el tema de los recreos...". Entre alumnos y docentes recuerdan qué patio (interno o externo) le toca a cada ciclo. Al final, una de las vicedirectoras pide un aplauso para la colectividad boliviana: "Pedimos un fuerte aplauso para toda la congregación boliviana". Aplausos. Otra maestra exclama: “Viva Bolivia! (“iViva!”, responden a coro los alumnos) ¡Viva la Argentina!”. “¡Viva!”, responden nuevamente a coro los alumnos.

Vuelvo a la escuela a las 13:15hs. Me encuentro con Silvana en la dirección. Después me dirijo a la sala de maestros para saludar a Jimena. Es la única maestra del turno tarde que conozco y que permanece en la escuela. Le pregunto si se hará algo en ocasión del día de la independencia de Bolivia. Me muestra un recorte del diario que trajo para que se lea antes de entrar al grado. Salgo al patio. Cerca de las $13: 30 \mathrm{hs}$ comienzan a reunirse alumnos y maestros alrededor del mástil. Forman fila en círculo junto a los docentes. Silvana, vicedirectora por concurso, hace algunos anuncios. Los alumnos no prestan demasiada atención. “Están escuchando a la seño Silvana?”, pregunta una maestra a sus alumnos. Se pide silencio. Le da la palabra uno de los maestros de grado. "Eh, no, simplemente vamos a recordar hoy...". Los alumnos siguen hablando entre ellos. Interviene Silvana para hacerlos callar: 
“Tapa, tapita...". "Tapón”, responden los chicos. Se repite y se hace silencio. Continúa el maestro: "Simplemente les voy a leer una... cosita para recordar que hoy es el aniversario del día de la independencia de Bolivia". Comienza a leer el recorte de diario: "Bolivia se independizó en 1825. Antes de la independencia la región que hoy es Bolivia se llamaba Charcas o Alto Perú...”. Termina de leer y Silvana pide un aplauso: "Entonces, un aplauso para todos los hermanos bolivianos...". (Notas de campo, 6 de agosto de 2007)

En general, como veíamos, el día de la independencia de Bolivia es celebrado bajo el formato de "recordatorio", sin mayores preparativos. Pero en una ocasión, en el año 2002, algunas maestras decidieron organizar esta pequeña ceremonia con un despliegue mayor, dedicándole mayor tiempo del habitual a planificarla. ${ }^{491}$ Lo más significativo es el modo en que pensaron y ejecutaron el comienzo del acto: un grupo de alumnos de la escuela ingresó con la bandera argentina y después otro con la boliviana, cada una desplegada por separado, tomada de las puntas y los costados y acompañada por aplausos; posteriormente, se entonaron ambos himnos nacionales, primero la canción patria argentina y luego la boliviana, acompañadas en silencio. Esta disposición de las banderas y los himnos nacionales está pautada en la normativa escolar. Allí se estipula que, cuando el espacio lo permita, la bandera nacional y la extranjera tienen que entrar "en la misma línea", la primera a la derecha y la segunda a la izquierda, acompañada cada una por sus respectivos escoltas. En caso que no hubiera espacio para que las banderas nacionales ingresen simultáneamente, la bandera nacional deberá hacerlo en primer lugar y la extranjera en segundo término. ${ }^{492}$

El episodio, en apariencia insignificante, muestra el modo en que el pensamiento de Estado atraviesa las prácticas escolares destinadas no exclusivamente a reforzar la identidad nacional argentina, sino también aquellas circunstancias en las cuales la escuela se dispone a reconocer la presencia de no-nacionales en ocasión de una fecha nacional del país extranjero. En un contexto escolar marcado por la asistencia de hijos de inmigrantes interpelados en esta ocasión como extranjeros, a través de la presencia de símbolos patrios argentinos en la conmemoración de una fecha nacional de Bolivia -cuestión impensable a la inversa- y la disposición del orden de ingreso de las banderas y de la ejecución del himno nacional de los respectivos Estados, la escuela está indicando -también recordando- quién recibe a quién, y a la vez, qué Estado nacional es depositario de la 
inmigración, validando la imagen de la Argentina como "país de recepción". ${ }^{493}$ Además, aunque ningún alumno hubiera ingresado con la bandera argentina, ella siempre está flameando donde se organiza el acto, alrededor del mástil, revelando que se trata de un territorio nacional argentino. Ese lugar nunca podría ocuparlo la bandera nacional boliviana, sería un acto de subversión, una herejía imperdonable que probablemente sería sancionada por las autoridades del Ministerio de Educación.

Estas imágenes son reforzadas mediante la elección de los alumnos que ingresan con cada bandera: cada grupo de alumnos constituido como grupo nacional -los alumnos investidos como representantes de sociedades nacionales- debe llevar su respectiva bandera; los bolivianos -en esta ocasión, hijos de inmigrantes bolivianos, sean nacidos o no en Argentina- son los encargados de llevar la bandera boliviana y los argentinos la insignia argentina. En este acto es el Estado argentino o los argentinos quienes reciben a los bolivianos, estableciendo un orden ficticio u arbitrario de llegada, en tanto orden inmutable, ya que si al menos fuera pensado en términos cronológicos, sería evidente que las actuales generaciones de bolivianos preexisten a las futuras generaciones de argentinos. Pero más que un orden estrictamente cronológico, lo que pone de manifiesto la supuesta preexistencia de los nacionales frente a los otros no-nacionales es un orden epistémico donde el orden nacional se erige frente a una exterioridad que termina envolviendo a todos los inmigrantes en tanto poseedores de rasgos de extranjeridad socialmente construidos. Estas ideas aparecen también naturalizadas entre las representaciones de los alumnos acerca de los bolivianos. Durante una entrevista grupal con alumnas de quinto grado se produce el siguiente intercambio:

\section{¿Y qué piensan de los bolivianos?}

Yamila: ¡Qué se vayan de nuestro país! ¡Que nos dejen tranquilos!

Jazmín: ¡Qué se vayan a vivir a Bolivia, donde vivieron antes!

Yamila: Porque cuando nosotros los argentinos... cuando antes...

Maribel: Porque primero llegaron los argentinos y después vinieron ellos...

Por otra parte, visto a la inversa, en los actos que se realizan durante el año siguiendo las efemérides escolares dedicadas principalmente a las fechas patrias argentinas como el 25 de Mayo, el 20 de Junio o el 9 de Julio los únicos símbolos nacionales admitidos son aquellos que refieren al Estado nacional argentino. Así lo dispone también la normativa

493 Este mismo orden se reproduce en celebraciones de la propia colectividad boliviana como el festejo del Día de la Madre en el mes de mayo o de la fiesta de la Virgen de Urkupiña en el mes de agosto. 
escolar: “(e)n la celebración de las efemérides argentinas, dichas escuelas presentarán solamente la Bandera nacional". Resulta impensable en estas circunstancias introducir otros colores que no remitan directamente a las insignias nacionales argentinas como el celeste y el blanco. El amarillo, el rojo o el verde, colores representativos de los símbolos nacionales bolivianos, jamás son introducidos en los actos escolares dedicados a celebrar una fecha patria argentina. De igual manera, la bandera boliviana nunca ocupó -ceteris paribus, ni ocupará- el mástil: como decía anteriormente, esto constituiría un acto de subversión que nadie está dispuesto a concretar, en el sentido que subvertiría el orden escolar en tanto orden nacional. Hasta allí llegan los límites del reconocimiento del otro nacional. Tampoco hay ni suele haber referencias a cualquier indicio de interculturalidad (como podría serlo la Whipala bajo la misma lógica que guía los rituales escolares), cuya visibilidad es tan buscada en otros actos o fiestas escolares. Así, las prácticas escolares ratifican que la construcción de la nación argentina sucede remarcando su capacidad para invisibilizar elementos no-nacionales y a través de una fuerte identificación con aquellos componentes considerados exclusivos de la argentinidad. ${ }^{494}$

En suma, en los actos escolares patrióticos, la presencia de los alumnos bolivianos es negada, invisibilizada, es decir, tratada como una presencia ausente que debe ser disimulada, una presencia prescindible, desconociendo todas aquellas expresiones que no hacen a la construcción de la argentinidad. Como bolivianos y en tanto inmigrantes de países limítrofes no ingresan en el relato escolar de la nación argentina. En cambio, en los actos escolares interculturales es una ausencia presente, su presencia es considerada o tratada como permanente o provisoria de acuerdo tenga lugar en los actos no patrióticos o en los actos bolivianos. En los primeros, mientras forme parte de los grandes actos, la presencia es asumida como permanente, aunque rápidamente pueda pasar a ser concebida como provisoria. En los actos bolivianos, en cambio, su presencia es siempre provisoria, determinada por el solo hecho de que su inclusión depende de que la escuela introduzca alguna fecha para que no sea una presencia ausente. Asimismo, el rango de recordatorio que se le otorga refuerza dicha provisoriedad. Hoy podría estar, mañana podría ser olvidada, eliminada o reemplazada. Es aquí donde su presencia es una presencia de no-nacionales, antes que de extranjeros, definida por oposición (no por negación) a los nacionales.

494 Para un análisis sobre la construcción de la identidad nacional en el ámbito escolar a través los textos escolares, véanse Romero (2004) y Novaro (2002, 2005). 
La visión de Estado que se ha ido forjando en la Argentina contemporánea acerca de la inmigración está incontestablemente ligada a la llegada y establecimiento de inmigrantes hacia finales del siglo diecinueve y comienzos del veinte provenientes de ultramar. En esta investigación se ha indagado la formación sociohistórica de aquellas categorías, representaciones y prácticas que hacen a la visión de Estado acerca de la inmigración en la Argentina, la cual define a la vez que supone una determinada relación entre el Estado nacional y los inmigrantes, con el propósito de contribuir a la comprensión de las transformaciones del discurso oficial en sociedades nacionales marcadas por la inmigración. La experiencia argentina, estudiada en esta tesis a partir de una interrogación del presente desde el pasado, muestra la estrecha vinculación existente entre la inmigración europea o de ultramar y la inmigración de países limítrofes o vecinos, genéricamente denominada inmigración limítrofe. Visualizar la relación entre ambas como una relación significativa, desestimada en buena parte de la literatura especializada a raíz de la separación disciplinar establecida (se da por sentado que los historiadores se encargan de estudiar la inmigración de ultramar y los sociólogos y antropólogos, entre otros investigadores sociales, la inmigración de países limítrofes), resulta una tarea ineludible para comprender más cabalmente la configuración actual de los discursos sobre la inmigración en la Argentina, en particular bajo la coyuntura de la llamada "nueva política migratoria". Muchas de las prácticas y creencias que circulan hoy en día acerca de los inmigrantes bolivianos, paraguayos o peruanos se originaron en el período de la llamada inmigración de masas. Sea por la vía de la coerción o del consenso, las políticas de exclusión, especialmente evidente en el terreno del control migratorio, así como las políticas de inclusión, vehiculizadas mayormente por la escuela pública a través del ideal de integración, encuentran en medidas gubernamentales implementadas a principios del siglo veinte sus orígenes y fundamentos. Fue en aquella época que la inmigración empezó a ser pensada, en tanto amenaza al orden público y a la identidad nacional, como problema social. Como vimos, allí se dictaron las primeras leyes destinadas a reprimir y expulsar a los "extranjeros indeseables" y se elaboraron, en el marco de una política más amplia de nacionalización de la sociedad, los instrumentos estatales -como los rituales patrióticospara crear y afianzar la identidad nacional y nacionalizar o argentinizar a los hijos de los extranjeros. Si bien estas disposiciones estatales sufrieron diversas transformaciones a lo largo del siglo de acuerdo a los contextos en que se desplegaron, hay modos de pensar y de 
actuar sobre la inmigración, lógicas y esquemas de legitimación, que muestran ciertas constantes que evidencian la fuerza y el arraigo que posee la internalización del pensamiento de Estado en las prácticas sociales cotidianas.

Es habitual encontrar en el discurso político -también en el científico- una contraposición entre dos modos de concebir la inmigración, cada uno con mayor predominio que otro según el período sociohistórico que se trate: uno fundado en la migración como problema y otro en la migración como oportunidad. Este esquema, tan afín al pensamiento de Estado sobre la migración, está contenido en las visiones que ofrecen diversos actores políticos sobre el hecho migratorio: Estados nacionales, agencias internacionales, organizaciones no gubernamentales, movimientos sociales, etc. La mirada histórica desarrollada en la presente tesis, permite reafirmar, a través del caso argentino, que la inmigración como hecho y relación social es construida indefectiblemente -como señalara Sayad (1998) en su apreciación epistemológica acerca de su constitución en tanto objeto social y sociológicocomo problema o ligada a problemas. En la experiencia nacional argentina este proceso se inició en una etapa de extensión y consolidación del aparato estatal y su incorporación a la economía mundial capitalista en expansión. En dicha definición como problema y sus diversas acepciones según la época, el Estado nacional jugó un rol preponderante frente a otros actores sociales. Hemos visto que, como sucede en el marco de la "nueva política migratoria", aún cuando el discurso oficial toma distancia de aquellas posturas que le atribuyen a la inmigración o a los inmigrantes los males de una sociedad, defendiendo una visión positiva de la migración al rescatar sus supuestos beneficios o ventajas, las prácticas y políticas destinadas a la población inmigrante también pueden hablar acerca de la migración contemplada como problema. Es decir, independientemente de que se pongan de relieve los aportes o contribuciones que la inmigración -en principio- realizaría, no deja de ser concebida como un problema social a pesar de que no sea nombrada como tal. En este sentido, importa lo que el Estado hace y no lo que dice hacer. Lo que dice hacer es más el modo en que pretende que sea visto el Estado y sus representantes antes que la migración.

Dentro de este esquema en el cual se asume la migración como un problema o una oportunidad, que según sea el caso se le asigna atributos o efectos "positivos" o "negativos", la lógica costo-beneficio se ha ido transformando en un principio rector de la visión de Estado sobre la inmigración. Se ha convertido en una de las verdades autoevidentes, pasando a formar parte de la aceptación dóxica -en términos de Bourdieudel mundo de la inmigración. No sólo los Estados nacionales, sino también distintas 
instituciones de las sociedades de inmigración como de emigración, sumados los organismos internacionales, han adoptado esta (falsa) antinomia en su explicación y justificación de las acciones que llevan adelante. Asumiendo que la migración posee en sí misma o intrínsecamente propiedades o consecuencias positivas o negativas, cuando no son más que un recurso de argumentación política, la legitimidad o ilegitimidad de la presencia inmigrante queda sujeta y se termina dirimiendo entre los "beneficios" y los "costos" que la inmigración -siempre según la perspectiva e intereses del Estado nacional como representante de lo universal- traería aparejada. Así, la construcción de la figura social del inmigrante queda signada por una visión dualista que lo concibe en términos negativos o positivos, ya sea atribuyéndole la responsabilidad de los problemas sociales o económicos del país, ya sea rescatando su contribución al crecimiento económico o su aporte al enriquecimiento cultural. Pareciera que los inmigrantes sólo pueden ser aceptados cuando su presencia lo amerita: siempre y cuando constituyan una contribución, un aporte o una ventaja para las sociedades en las cuales decidieron desarrollar sus vidas. Esta visión promueve la idea de que la presencia es legítima en tanto sus efectos sean "positivos" o ilegítima en tanto sean "negativos" para las sociedades de inmigración o emigración. En otras palabras, la presencia del inmigrante sólo es considerada legítima mientras deje un "saldo positivo" para la sociedad receptora. Y para ello, la migración, como sostiene la nueva ortodoxia en la materia, debería ser "ordenada", es decir, libre (o liberada) de migraciones "ilegales" o "irregulares". La llamada “inmigración ilegal”, en particular, no deja margen para interpretaciones abiertas, diversas o inconclusas: su presencia es siempre una presencia anómala, peligrosa, corrosiva, inaceptable, una presencia que no admite mensajes ambiguos para el resto de la sociedad: siempre debe ser "combatida", sea a través de mecanismos represivos, coercitivos, extorsivos o contractuales. La división entre nacionales y extranjeros aún admite la posibilidad de traspasar o difuminar aquellos límites que bajo la división entre legales e ilegales no son franqueables. Mediante mecanismos como la asimilación o la nacionalización (también llamada "naturalización"), los inmigrantes, extranjeros o no (en términos jurídicos), como lo demuestra la historia de distintas sociedades nacionales como la argentina, pueden estar contemplados en un proyecto de nación. Pero para los "ilegales" no hay lugar como tales en la nación, no pueden tener cabida en un proyecto de nación. Colocarlos como sujetos en el lugar de la "ilegalidad" (o su equivalente "irregularidad", término utilizado con aires de neutralidad, extirpándole la idea de "delito", pero que no deja de ubicarlos en el lugar de la falta, el error, la infracción), como transgresores de las leyes del Estado, es el modo más violento de legitimar la desigualdad 
y la exclusión de quienes han sido producidos histórica y socialmente como sujetos indeseables.

Esta visión utilitarista sobre la inmigración y los inmigrantes, implícita en la lógica costobeneficio, aparece concertada en la experiencia argentina reciente con postulados relativos al derecho a migrar. Esta buscada articulación se vuelve problemática en tanto ambos enfoques no responden al mismo discurso de legitimación. Desde una perspectiva que defiende la migración como derecho humano no debería ser relevante si ésta tiene efectos "positivos" o "negativos", si causa "desventajas" o trae "beneficios" a la sociedad receptora. El hecho de que contribuya o no al "crecimiento económico" o aporte al "enriquecimiento cultural" del país resulta innecesaria como argumentación. Es decir, el derecho a migrar trasciende la mirada utilitarista: no se trata de seleccionar a los inmigrantes de acuerdo a los "beneficios" que su presencia habría de tener. Por otro lado, de acuerdo a los planteamientos de Sayad (1998), también es conveniente preguntarse, antes de dar por sentada la buena voluntad o solidaridad de los Estados nacionales, si determinados reconocimientos hechos en el ámbito de los derechos humanos no responden más bien a aquel "mínimo" que se le concede a los migrantes, traducido en políticas públicas, como retribución material y/o simbólica destinada a preservar aquello que el Estado y la sociedad creen que los migrantes les aportan a su reproducción.

En la Argentina, al contrario de lo que suelen sostener algunas revisiones superficiales o apresuradas, la inmigración no empezó a ser pensada ni tratada como problema a partir de la visibilidad que adquirió la inmigración de países limítrofes hacia la década del setenta. Por el contrario, fue una fracción de la población inmigrante de origen europeo la que a lo largo de la primera mitad del siglo veinte motivó sospechas de distinta índole. En aquél entonces la inmigración de países limítrofes ni siquiera era concebida ni definida en términos de inmigración o de extranjería, sino como una mano de obra temporal, cuyo cruce de frontera no importaba al Estado argentino controlar de manera férrea. A diferencia de aquella fracción de "inmigrantes indeseables" a la cual estaban destinados los esfuerzos estatales de control migratorio, los movimientos transfronterizos fueron permitidos y tolerados en tanto significaban una contribución importante a la creciente demanda de trabajadores en los sectores productivos dedicados a la agricultura. Fue el Estado nacional en connivencia con las empresas contratistas el que favoreció aquél reclutamiento laboral que más tarde diera lugar a una inmigración de mayor duración y creciente establecimiento. En este sentido, es importante no desconocer, como sucede con 
varios estudios empíricos, que las redes migratorias formadas posteriormente se originaron en este período de atracción planificada de mano de obra extranjera.

Reinstalada a lo largo de las dictaduras militares de la segunda mitad del siglo veinte como una amenaza al orden público y la seguridad nacional, durante los años noventa, en pleno auge neoliberal, la figura del "inmigrante ilegal" se actualizó como aquella figura social que ponía en riesgo el bienestar de una sociedad pretendidamente opulenta, convirtiéndose en objeto de las más diversas representaciones acusatorias y prácticas persecutorias de la inmigración. Equiparado el "inmigrante ilegal" al "inmigrante limítrofe", sobreentendido éste como "boliviano", "paraguayo" o "peruano", estos nuevos inmigrantes "indeseables", bajo un marcado contexto de criminalización de la pobreza, pasaron a formar parte de un conjunto social más amplio de excluidos y marginados, que no podían ser aceptados en el seno de la sociedad nacional mientras fueran parte de aquellas clases peligrosas con las cuales ya fueron identificados desde inicios del siglo veinte. Así, en tanto ilegales, heredaron el cuerpo de disposiciones estatales creadas y destinadas a aquellos extranjeros europeos considerados durante las primeras décadas del siglo veinte como "indeseables". El "inmigrante ilegal", dada su condición de indeseable, no reúne los atributos necesarios para ser considerado un buen inmigrante y como tal ser aceptado para formar parte de la nación.

Los diversos estudios comparados o de caso realizados acerca de la llamada "inmigración ilegal” y su producción social y política no suelen contemplar la realidad histórica de países tradicionalmente receptores de inmigración como la Argentina. Sin embargo, habiendo sido uno de los destinos más importantes de los flujos migratorios provenientes de ultramar, la Argentina ofrece valiosos elementos para pensar la formación sociohistórica de la llamada "ilegalidad migratoria", constituida en las últimas dos décadas como uno de los principales ejes del discurso global acerca de la inmigración. A lo largo del estudio hemos podido observar que en la Argentina la construcción de la inmigración como problema ha estado siempre acompañada por la figura del "inmigrante ilegal". Como en otras sociedades tradicionales de inmigración, la división legal/ilegal como forma subsidiaria de la división nacional/extranjero ha sido fundante de la visión estatal contemporánea sobre la inmigración. En la Argentina, la separación legal/ilegal -entre otras divisiones posibles- fue adoptada primero para ejercer el control de aquella fracción de inmigrantes europeos de ultramar considerados "indeseables" y luego trasladada a los inmigrantes de países limítrofes, quienes bajo una mayor visibilidad social y política pasaron a ser los nuevos indeseables. A lo largo de décadas han sobrevivido y sedimentado 
formas de pensar y tratar a la inmigración, particularmente evidentes en el terreno de la admisión, la permanencia y la expulsión de los extranjeros, que hicieron a la formación de un régimen de control de la inmigración conformado alrededor de ideas y prácticas de prevención y represión de sujetos migrantes o extranjeros concebidos como ilegales. Las enormes y notables divergencias que han mantenido en el campo de la economía, la política y la cultura los sucesivos gobiernos, las cuales han permitido establecer periodizaciones de distinto tipo, no necesaria ni automáticamente se han registrado o trasladado al terreno de las políticas migratorias. Tanto las constantes y continuidades como las diferencias, variaciones y matices que se pueden advertir en el transcurso de diversos momentos históricos y coyunturas sociales específicas ponen de manifiesto la autonomía relativa que posee el gobierno de los asuntos migratorios respecto a otras esferas estatales. La idea de que la política migratoria estatal es un fiel reflejo del modelo de desarrollo económico y político imperante puede resultar útil como hipótesis de trabajo o punto de partida, pero es problemática cuando se la asume como axioma.

Desde las primeras medidas de carácter punitivo hasta las actuales políticas migratorias pretendidamente "inclusivas", las respuestas políticas desarrolladas frente a la "ilegalidad migratoria", invariablemente vista como uno de los aspectos centrales en el proceso de construcción de la inmigración como problema social, han transitado desde métodos disuasivos y represivos, especialmente durante gobiernos militares, hasta fórmulas de regularización administrativa y garantistas de protección de derechos, únicamente con gobiernos constitucionales. Sin embargo, pareciera no haber modificaciones posibles que afecten el núcleo duro del pensamiento de Estado, el cual no puede desmarcarse de la división legal/ilegal subsumida en la división entre nacionales y no-nacionales, una de las divisiones fundantes del orden social. Mecanismos como la expulsión, aunque su modo de implementación pueda ser disímil, permanecen aferrados a visiones y lógicas estatocéntricas, cuya naturaleza y legitimidad no pueden ser cuestionadas. A tal punto que, como dice Sayad, la expulsabilidad del extranjero es "la marca del pensamiento de Estado, por no decir que es también el pensamiento de Estado en sí mismo" (Sayad, 2010:403). Así como el encierro para los nacionales, el destierro para los no-nacionales actúa como el modo natural y universalmente aceptado para sancionar las conductas humanas que se apartan o trasgreden las reglas sociales devenidas en leyes jurídicas.

A lo largo del siglo veinte se pueden identificar tres figuras paradigmáticas del control migratorio, instituidas históricamente y con una efectiva vigencia que remiten a una visión estatocéntrica en la regulación de la inmigración: la expulsión, la regularización migratoria 
y el retorno voluntario. Todas ellas, subproductos del pensamiento de Estado, fueron creadas exclusivamente para los extranjeros, para regular su presencia, su existencia. Todas ellas interpelan al inmigrante extranjero como una exterioridad, una presencia que sólo puede ser admitida, tanto territorial como socialmente, a condición de que resulte una contribución o un aporte, definidos estatalmente: dicha contribución o aporte siempre contempla el bienestar de la sociedad nacional, cuyo Estado se adjudica la decisión última para determinar qué sujetos son merecedores de habitar el suelo de la nación. Méritos que los nacionales poseerían por sí mismos. Con el tiempo, habiéndose afianzado la "ilegalidad" entre los asuntos migratorios, estas tres figuras paradigmáticas han encontrado en el "inmigrante ilegal" su principal destinatario. El acto de expulsión o la obligación a abandonar el territorio nacional, la conminación a regularizar la situación administrativa del "extranjero ilegal" y la invitación a regresar a la sociedad de origen, eufemísticamente llamado "retorno voluntario", se funda en aquella exterioridad que se le imputa a los extranjeros en un territorio nacional que no se corresponde con el que naturalmente sería suyo. De allí extrae el Estado nacional la legitimidad necesaria para disponer libremente sobre dicha población, así como sobre su relación con el territorio nacional, ya sea a través de mecanismos coercitivos o negociados. Paradójicamente, estos instrumentos estatales son utilizados aún bajo normas legales de corte garantista que disponen sobre la migración como derecho humano. Esta internalización de la frontera política, bajo la forma de esta división, también alcanza diversos espacios sociales como la escuela que, en principio, parecen ser ajenos a los efectos de la división legal/ilegal. Como sugieren algunos de los pasajes descriptos, llegan a trasladarse a la cotidianeidad de la institución escolar, pero sin ser registrado ni contemplado por ella y menos por un Estado nacional que no interviene más que a través de organismos especializados y parcializados. Lo paradójico es que mientras los organismos de control migratorio influyen o condicionan ciertos aspectos y dimensiones de la vida escolar aparentemente ajenas a su accionar, normas legales escritas de alcance nacional, destinadas especialmente a regular el acceso y permanencia de alumnos extranjeros "indocumentados", no son transmitidas a las escuelas a pesar de las vías oficiales abiertas para tal propósito.

En la escuela, siendo un espacio social definido nacionalmente, entre la comunidad educativa la división legal/ilegal, no aparece como sustento o justificación de acciones cotidianas ni opera como principio de diferenciación o como mecanismo de exclusión/inclusión, a pesar del enorme poder de estructuración de los discursos y prácticas sociales que tiene allí el pensamiento de Estado. En el espacio escolar, la división entre nacionales y extranjeros -división sobre la cual el Estado se erige como 
representante de los intereses de una sociedad mediante una operación de universalización de lo particular- se expresa y se traduce a una división concreta definida por los Estados nacionales que estarían representados en dicho espacio social: en el caso estudiado la división se establece entre argentinos y bolivianos, sean de nacionalidad boliviana o no. La mirada diacrónica en un espacio microsocial como la escuela revela que la presencia de los hijos de inmigrantes de países limítrofes en la escuela, o lo que genéricamente se suele denominar presencia inmigrante, es producida como una presencia problemática, en tanto crea problemas más que un problema en sí mismo. Las situaciones de conflicto y violencia que se generan entre los alumnos argentinos y bolivianos inducen a los docentes a experimentar o considerar los efectos de dicha presencia como dificultades concretas que afectan la cohesión social, traducida como "convivencia escolar". Situaciones sociales específicas que suelen ser interpretadas en clave de "discriminación" sirven de fundamento para todas aquellas iniciativas, generalmente de carácter individual, que promueve la escuela a favor de una convivencia esperada como armónica. De ahí que las respuestas escolares se realicen inspiradas en la noción de integración como ideal de convivencia.

A pesar de estar los hijos de bolivianos en la escuela desde su creación, no siempre ni en todo lugar su presencia fue una presencia visible. Hubo un momento en el cual la presencia de los bolivianos en la escuela adquirió una visibilidad inusitada, antes desconocida bajo un patrón de tratamiento de la heterogeneidad sociocultural más afín a las políticas de asimilación. Primero más librada al azar y luego tratada más sistemáticamente mediante su incorporación al calendario escolar, dicha visibilidad se produjo a través del protagonismo que se le otorgó a ciertos símbolos y emblemas político-culturales que remiten tanto a la simbología nacional boliviana como al canon folclórico dominante en Bolivia. Sin lugar a dudas, el elevado número de hijos o nietos de inmigrantes bolivianos, vistos como parte de la "comunidad boliviana", contribuyó a condicionar y moldear determinados discursos y prácticas escolares, creciendo las referencias a Bolivia en la vida cotidiana de la escuela. Como vimos, al principio el trabajo escolar no involucraba actividades que contemplaran manifestaciones socioculturales o símbolos políticos relacionados con la bolivianidad. Fue a través de algunas iniciativas individuales, orientadas por el ideal de "integración", que con el tiempo se plantearía como antagónico a la "discriminación", que emergieron acciones que empezaron a involucrar a la "comunidad boliviana". La incorporación de determinados elementos materiales y simbólicos asociados con Bolivia, o mejor, con la bolivianidad, a la vida cotidiana de la escuela, adoptada como recurso estratégico, no fue producto de un proyecto institucional 
ni del seguimiento de lineamientos de política educativa referidos al reconocimiento de la diversidad cultural. Más bien, se produjo a partir de la experiencia próxima con un grupo social concebido como culturalmente diferente a raíz de su pertenencia nacional, la comunidad boliviana, bajo una política institucional que pretendía estrechar el vínculo entre la escuela y la comunidad del barrio en general. Las prácticas llevadas a cabo no estaban sustentadas en la interculturalidad u otros principios referidos a la diversidad cultural, sino cruzadas por ideas aprendidas socialmente acerca del modo ideal en que los individuos pertenecientes a diferentes naciones, por ende, a diferentes culturas, deben relacionarse. Se trataba de la búsqueda de reconocimiento de la presencia concreta de una comunidad vista como diferente, antes que el reconocimiento de la diversidad o diferencia cultural en términos universales, y tratada como una presencia no-nacional: una presencia de otro orden nacional en un espacio social como la escuela que se define cotidianamente como un territorio distintivo de la nación. Un acontecimiento institucional, que puso en crisis a la escuela, marcó un punto de quiebre: frente a la visibilidad que cobró la presencia de hijos de bolivianos en una determinada coyuntura, la escuela quiso desandar aquél trayecto realizado. Inquietudes acerca de los efectos de dicha visibilización como bolivianos hicieron optar por disimular, ocultar o silenciar, al menos momentáneamente, aquella presencia que la escuela aún no sabe de qué manera procesar.

En el terreno macrosocial, los "inmigrantes ilegales" como aquella fracción de población diferenciada producida por el propio Estado son los que a lo largo de las décadas y de las diversas políticas migratorias permanecen como el problema de la inmigración, el "problema a resolver". Las formas de nombrar y clasificar a los sujetos migrantes sospechados de mantener una relación conflictiva con el cumplimiento de la ley (clandestinos, ilegales, indocumentados, irregulares), sus eufemismos y su recurrencia en el tiempo, han validado y perpetuado el campo de la "ilegalidad migratoria". Las respuestas a la "ilegalidad migratoria" como los programas de regularización migratoria, cualquiera sea su modalidad, muestran la persistencia de fórmulas ancladas en una visión estatocéntrica de la migración. Bajo esta visión no sólo se mantiene naturalizada la división entre nacionales y extranjeros, buscando en el mejor de los casos cierta equiparación entre los derechos y obligaciones establecidos para cada uno en una sociedad democrática, sino que vuelve impensable o impracticable construir relaciones de igualdad entre los nacionales y los extranjeros "ilegales". Esta visión denota la falta de voluntad, imaginación o creatividad política para repensar la división legal/ilegal en un contexto regional políticamente propicio para implementar políticas de libre residencia independientemente de las políticas de libre circulación de trabajadores que han 
prosperado relativamente- que trasciendan la división legal/ilegal a la cual está supeditada cualquier visión de la migración que no pueda desprenderse del pensamiento de Estado. La división legal/ilegal permanece incólume: las figuras de la expulsión y la "expulsabilidad" como un mecanismo de chantaje social que mantiene a los residentes extranjeros en un estado de permanente provisoriedad, la regularización migratoria como respuesta unilateral y unívoca a la llamada "ilegalidad migratoria" y el "retorno voluntario" como un eufemismo para designar aquella invitación a abandonar el país destinada a aquél "excedente" de mano de obra que ha dejado tener utilidad económica son las respuestas estatales a aquella presencia inmigrante que representa los desvelos del Estado. Ofrecida como una solución progresista, la regularización migratoria, como única respuesta política y como medida focalizada en una fracción de la población inmigrante muestra los límites del propio Estado para pensar la migración más allá de la dicotomía legalidad/ilegalidad. Como he mostrado, es toda una manera de definir la cuestión migratoria: identificados los inmigrantes "ilegales" o "irregulares" -según quién los nombre- como el problema, el objetivo político se construye alrededor de la regulación y control de los flujos migratorios mediante la aplicación de una regularización migratoria de carácter permanente. La permanencia del organismo especializado en los asuntos migratorios internacionales, la Dirección Nacional de Migraciones, en el ámbito del Ministerio del Interior a pesar de los cambios acontecidos en materia de política migratoria es expresión de ello. Y aunque sea imperiosa la necesidad de los migrantes de poseer una documentación en regla debido a las trabas y dificultades que sin ella encuentran en una vida social ampliamente regulada por una enorme diversidad de exigencias administrativo-burocráticas, las políticas que se erigen exclusivamente sobre dicha necesidad terminan reduciendo la existencia social y política de los inmigrantes a una condición legal y limitando el ejercicio efectivo de sus derechos de acuerdo a dicho criterio. La disolución de la división legal/ilegal implica una ruptura herética que el Estado-nación y sus agentes no admite debido a que presuponen que dicha operación pone en riesgo el poder y autoridad estatales para regular el fenómeno de la inmigración.

Frente al paroxismo estatal desarrollado hacia a la inmigración de países limítrofes en los años noventa, la conjunción de una serie de discursos y prácticas estatales -entre ellos la nueva ley de migraciones y el plan de regularización migratoria principalmente- han permitido identificar la conformación de una retórica de la inclusión, aferrada a los derechos humanos, la integración regional y la integración de los extranjeros. Fueron las políticas de exclusión de los años noventa las que crearon las condiciones necesarias para que a inicios de la primera década siguiente, bajo un contexto sociohistórico marcado por 
la consolidación política de integración regional y un creciente proceso de trans o internacionalización de la política migratoria, emergiera una retórica de la inclusión en el terreno de las políticas públicas migratorias. El Estado mostraba, mediante un renovado discurso difundido especialmente por funcionarios -entre otros hombres y mujeres oficiales que hablan en nombre del Estado- del organismo especializado en la temática migratoria, su costado más amable y seductor frente a la inmigración. Las modificaciones en la visión de Estado bajo la "nueva política migratoria", asumidas según el discurso oficial como un cambio automático y rotundo en la relación entre el Estado y los inmigrantes, ha llevado a una buena cantidad de estudiosos de las migraciones, especialmente del contexto académico argentino, a atribuir los cambios en la política migratoria a la renovación del proyecto político nacional inaugurado con la llegada de Néstor Kirchner a la presidencia en el año 2003. Se trata, a mi modo de ver, de una explicación reduccionista que establece una linealidad entre Estado, gobierno y cambio social que mediante un análisis empírico sobre el discurso oficial no encuentra sustento suficiente. En esta investigación se describen e interpretan las transformaciones acontecidas en el discurso oficial en materia de migraciones y las diferencias con décadas anteriores, cuidando no perder de vista aquellas continuidades, tensiones o contradicciones que experimenta bajo el "cambio de paradigma" que se enuncia y su vínculo con la perspectiva de la gobernabilidad migratoria, ofrecida como una visión alternativa o de avanzada, afincada en el enfoque de los derechos humanos. Un gobierno (auto)proclamado posneoliberal en tanto protagonista del "giro a la izquierda" latinoamericano de inicios del siglo veintiuno, lleva adelante en materia de migración una política sustentada en la perspectiva tecnocrática de la gobernabilidad migratoria de inspiración neoliberal, como han mostrado recientemente algunos trabajos de carácter crítico como Andrijasevic y Walters (2010) y Geiger y Pécoud (2010), buscando otorgarle un tinte progresista bajo el manto de los derechos humanos. Esta tesis muestra que el discurso de los derechos humanos empieza a aparecer en el ámbito estatal en el período establecido entre la última embestida del menemismo contra la inmigración y el inicio de la llamada "nueva política migratoria" que se instaló con el gobierno de Néstor Kirchner y continuada por Cristina Fernández de Kirchner. Además, pone en cuestión la atribución de dicho cambio de paradigma al proyecto político nacional, mostrando la aparición del discurso de los derechos humanos en el seno del Estado, en particular en aquellos organismos especializados en la materia como la DNM, y su adopción como parte del proceso de transnacionalización de la política migratoria a través de agentes locales específicos. Un buen ejemplo es el reconocimiento que obtuvo paulatinamente en la legislación nacional, tanto del campo migratorio como educativo, el derecho a la educación 
de extranjeros independientemente de su "situación administrativa irregular" es uno de los efectos que ha tenido el proceso la internacionalización del régimen de derechos humanos como parte del proceso de transnacionalización de la política migratoria. La experiencia argentina muestra, asimismo, importantes similitudes y convergencias con la de países periféricos (o, ahora, Sur global) en los cuales la OIM ha tenido una injerencia fundamental en la formulación y ejecución de la política migratoria. Esta investigación evidencia que, más allá de la actuación de las fuerzas sociales locales, los actuales lineamientos de política migratoria se inscriben a su vez en una tendencia internacional y regional -reconocimiento formal de los derechos humanos, diferenciación entre comunitarios y extracomunitarios, introducción de medidas referidas a la integración de los migrantes y adopción del discurso pluralista- que no conllevan una reformulación de las relaciones y poder y dominación entre el Estado y los inmigrantes. En este sentido, entiendo que la Argentina constituye un caso nacional que permite dar cuenta de las conexiones local-regional-global en el proceso de transnacionalización de la política migratoria, generalmente analizada en países del Norte (Sassen, 2001), dado que la experiencia argentina evidencia las ambigüedades, tergiversaciones, tensiones $\mathrm{y}$ contradicciones en las que se sumerge el Estado, sus instituciones y representantes, cuando pretende moverse -estratégicamente- entre un concepto de nacionalidad definido a partir del principio de soberanía y autodeterminación estatales y otro que lo instituye como responsable ante todos sus residentes bajo el estatuto de los derechos humanos, acompañado por la ampliación de la noción de ciudadanía nacional a regional y el deslizamiento de la noción de asimilación a la de pluralismo cultural en la formulación de políticas públicas.

La espectacularidad de las políticas de control desarrolladas en el marco de las migraciones mundiales de orientación Sur-Norte pareciera invisibilizar aquellas que se despliegan en contextos regionales de migración Sur-Sur donde se desenvuelven controles más sutiles y, quizás por ello, menos perceptibles. Una variedad importante de iniciativas gubernamentales impulsadas en materia migratoria en el contexto sudamericano en la actualidad encuentran su sustento ideológico en la perspectiva de la llamada gobernabilidad migratoria, adoptada y resignificada según las particularidades de cada contexto político nacional. En este sentido, he argumentado que la experiencia argentina, constituida en un caso paradigmático, no es posible comprenderla cabalmente sin considerar los efectos que ha tenido y tiene la regionalización de la política migratoria como parte de un proceso global de internacionalización de la política de migraciones internacionales, impulsado por agencias multilaterales como la OIM y diversas 
instituciones de Naciones Unidas, cuyo resultado más visible es la conformación de un régimen global de control migratorio. El análisis realizado muestra que la perspectiva de la gobernabilidad migratoria constituye la visión de Estado que rige los lineamientos de la política migratoria instaurada en la Argentina a partir de la aprobación de una nueva ley de migraciones en el año 2003. He sugerido que su influencia ha sido decisiva en la estructuración de ciertas ideas y prácticas estatales destinadas a regular la inmigración y en particular la llamada "inmigración irregular". Bajo la cobertura ideológica de esta nueva perspectiva técnico-política se lleva adelante lo que se podría llamar un control con rostro humano: amparado en el discurso de los derechos humanos para obtener la legitimidad necesaria para su instrumentación, el control sobre la "inmigración irregular" desplaza (no elimina) formas restrictivas o coercitivas, no con el propósito de hacer efectivos los derechos humanos de los inmigrantes, sino para obtener mayores resultados en la administración eficaz de los flujos migratorios. Como sugiere Mezzadra en relación al régimen global de gestión de la migración, "el poder se está reconfigurando, en un contexto en el que la lógica de la soberanía se entrelaza con la lógica de la gobernabilidad neoliberal, con una gobernanza que se presenta como un sencillo proceso de persuasión sin coerción, según patrones neutros de cálculo y gestión de riesgos" (Mezzadra, 2012:169). El examen de la noción de migración ordenada, ingresada al ámbito de gobierno de las migraciones con la emergencia del nuevo régimen global de control de las migraciones, ha permitido a su vez comprender el origen y fundamento de algunos desplazamientos en las formas de pensar y ejercer el control de las migraciones internacionales en la Argentina actual.

La noción de políticas de control con rostro humano permite dar cuenta del universo de ideas y prácticas que, enmarcadas en el discurso de los derechos humanos como fuente de legitimación, persiguen la misma finalidad que las políticas más abiertamente restrictivas, prometiendo ser más eficaces en la consecución de su objetivo: controlar los flujos migratorios internacionales. El pensamiento tecnocrático parece haber encontrado en el control con rostro humano la fórmula largamente buscada para conciliar la lógica estatocéntrica de la soberanía nacional con el imperativo universalista abstracto de los derechos humanos. En este sentido, la figura del control con rostro humano ayuda a interpretar las transformaciones acontecidas en el ámbito regional sudamericano en materia de política migratoria en la última década por fuera de la dicotomía derechos humanos versus seguridad. Permite comprender determinadas prácticas estatales y no estatales como nuevas formas de control de las migraciones y las fronteras internacionales, inscriptas en el nuevo régimen global de control de las migraciones que 
promueven actualmente organismos supranacionales como la Organización Internacional para las Migraciones (OIM). Esto llevaría también a descartar la idea de que se trata de experiencias nacionales aisladas o inéditas contrapuestas a las tendencias internacionales de fortalecimiento de los controles fronterizos.

Otro de los terrenos en el que el Estado pareciera proponer una nueva relación, siempre conflictiva y contradictoria, respecto a la inmigración y los inmigrantes se relaciona con la integración de los extranjeros y aquellas afirmaciones o medidas que se nutren de elementos del discurso del pluralismo cultural. Aquí, mientras se proclama la aceptación y el respeto a la diferencia cultural, bregando por una nación abierta en un proceso de integración regional y de globalización, las propuestas o lineamientos de políticas están permeados por las viejas ideas asimilacionistas, siendo la identidad nacional construida en términos exclusivistas. La articulación entre pluralismo cultural y asimilación de las políticas culturales propuestas en el campo de migraciones, llevan a sugerir que el pluralismo cultural adoptado operaría a manera de una "nueva ideología de la asimilación". Frente a la pérdida de legitimidad de las políticas de asimilación, las políticas estatales se reconvertirían bajo la forma del pluralismo cultural, aunque con un marcado contenido asimilacionista. Una cuestión clave en este sentido es que en el caso argentino el reconocimiento cultural encuentra sus límites en el propio Estado: el aparato estatal define a la "sociedad argentina" como multicultural y multiétnica, pero no se califica a sí mismo en los mismos términos.

Quizás lo decisivo sea que en muchas de las sociedades contemporáneas los discursos y políticas de exclusión/inclusión se fundan en un modelo orientado al gerenciamiento de las problemáticas sociales, entre ellas las migraciones y la diversidad cultural, más que como una respuesta política a la desigualdad social. La diferencia fundamental radica en que el primero acepta como dado lo que cuestiona la segunda: el orden social establecido. En el marco de esta "nueva ideología de la asimilación" se reconoce la sociedad como multicultural y multiétnica, se valora la contribución de los distintos grupos étnicos y migrantes al crecimiento y desarrollo del país, así como tomar conocimiento de ello, se promueve el respeto y tolerancia a la diversidad cultural para la disminución de la discriminación y los prejuicios, se reconocen derechos de igualdad formal, pero se mantiene inalterada la estructura de poder que (re)produce las condiciones materiales y simbólicas de dominación y exclusión social. En este contexto, es dable que a los inmigrantes se los interpele no sólo ofreciéndoles integrarse en la cultura dominante transformándose en malas copias, o mantener sus particularidades a costa de su 
marginación y exclusión social (Juliano, 1994), sino también invitándolos a conservar algunas de sus particularidades identitarias (en definitiva, aquellas que no amenacen la supuesta "unidad cultural") junto a oportunidades de ascenso social individual a cambio de ignorar o abandonar, parcial o totalmente, reclamos y luchas por proyectos de sociedad que comprometan la estabilidad o reproducción del sistema político, económico y cultural. Por ello, resulta inquietante indagar los límites del reconocimiento estatal.

Encargada de llevar adelante el mandato de formación y consolidación de la identidad nacional, la escuela se instauró como una de las principales instituciones sociales donde se produce y reproduce el pensamiento de Estado. Allí, en tanto territorio privilegiado de producción material y simbólica del Estado-nación, se construyen y circulan representaciones y prácticas concretas que hacen al mantenimiento y a la legitimación de la división principal -la división entre nacionales y extranjeros- que propone el pensamiento de Estado, aprendida y afirmada como una división natural del mundo social. Dicho límite arbitrario habilita diversas superposiciones o equivalencias entre Estado, cultura, territorio, nación e identidad. El pensamiento de Estado es incorporado de modo práctico a través de instrumentos jurídicos de distinto alcance como la normativa educativa destinada tanto a establecer los grandes principios ético-políticos que sirven de fundamento de las políticas educativas nacionales como a regular la vida en las escuelas, los manuales escolares, la enseñanza de las ciencias sociales, en especial la historia y la geografía, y otras prácticas escolares específicas, sedimentadas y arraigadas históricamente, como los actos escolares, en particular los rituales patrióticos, que contribuyen a construir una determinada idea de nación, a formar sujetos nacionales, a ser súbditos del Estado.

Estructuras y prácticas se combinan en el quehacer cotidiano de la escuela mediante la internalización de las normas destinadas a organizar la vida escolar, objetivada en el llamado reglamento, cuya existencia no es un único cuerpo de normas legales, sino un conjunto de disposiciones jurídicas de distinta procedencia, reunidas en un volumen, que buscan reglamentar aquellos aspectos o dimensiones de la vida cotidiana de la escuela que el Estado considera necesario unificar como los actos escolares y el uso y tratamiento de los símbolos patrios. Al igual que con la normativa producida para regular la inmigración, estas disposiciones provienen de la sistematización, reelaboración o adaptación de normas formuladas a lo largo de décadas. Como hemos visto, para la reproducción del pensamiento de Estado no importa tanto su vigencia legal ni el cumplimiento estricto de las normas, sino su persistencia a través de las representaciones y prácticas que, 
sedimentadas a lo largo del tiempo, se despliegan cotidianamente. Prácticas instituidas como los actos escolares no siguen fielmente lo establecido en la normativa escolar ni se desarrollan sin ser cuestionadas. Sin embargo, independientemente de las reapropiaciones o innovaciones de las que suelen ser objeto, difícilmente pongan en cuestión una de las finalidades fundamentales asignadas históricamente a la escuela como formar al ciudadano, al buen ciudadano, mediante la inculcación de valores patrióticos. Pretender modificar el ritual en sus contenidos o formas no hace más que confirmar su existencia como tal. Asimismo, cuestionar la división arbitraria, construida históricamente, entre nacionales y extranjeros, que es el sustento de los rituales patrióticos, significaría ir en contra del principio de exclusión constitutivo de la reproducción del Estado-nación: una ruptura herética no admisible en el territorio de la educación nacional. La relación consustancial construida entre escuela y actos escolares en general y patrióticos en particular hace que la eliminación de los actos escolares patrióticos resulte un cuestionamiento a la acción del Estado, un socavamiento a la autoridad estatal.

En un espacio microsocial como la escuela estudiada la presencia de los hijos de las familias de inmigrantes bolivianos es interpelada en clave nacional, traduciéndose -como señalara anteriormente- la división entre nacionales y extranjeros en una diferenciación entre argentinos y bolivianos. Aún aquellos hijos de inmigrantes bolivianos de nacionalidad argentina que viven y que posiblemente pasen su vida entera en la Argentina, son pensados como no-nacionales, extraños del Estado-nación que les otorgó la nacionalidad, extranjeros en términos sociales, es decir, sujetos extranjerizados, construidos como una exterioridad nacional. En la escuela la existencia de "bolivianos" es asumida como una entidad, una comunidad dada y natural, y al mismo tiempo como una presencia que le imprime un rasgo distintivo frente a otras instituciones educativas del barrio y de la ciudad. Hay alumnos identificados como "bolivianos", tanto en términos sociales como jurídicos, en oposición a quienes son considerados como "argentinos". Aunque en términos de autoidentificación se enuncie o experimente una doble pertenencia, las adscripciones que produce la institución escolar a una u otra categoría nacional se construye en términos dicotómicos, con escaso o ningún margen para las ambigüedades o ambivalencias: las opciones que se ofrecen son "ser boliviano" o "ser argentino". Los argentinos, los "nuestros", los que pertenecen a nuestra nación, y los otros, los bolivianos, los que pertenecen a la comunidad boliviana. La identificación e individualización como "bolivianos" se produce y reproduce en representaciones e interacciones cotidianas ligadas tanto a la producción de la "bolivianidad" (¿para recordarles lo que son?) y la "argentinidad" (¿para mostrarles lo que los "argentinos" son o 
ellos deberían o podrían llegar a ser?). Las conmemoraciones escolares también hablan acerca del modo en que es interpelada aquella presencia construida como diferente. El día de la independencia de Bolivia, la principal fecha elegida por la escuela destinada a reconocer la presencia de la "comunidad boliviana" en la escuela, al mismo tiempo que revela allí la presencia boliviana, es un claro indicio acerca del modo que encuentra la escuela para reconocer la presencia de un colectivo social identificado como nacional y culturalmente diferente. En esta escuela es la condición nacional más que la condición inmigrante la que predomina en la búsqueda de reconocimiento de una alteridad cuya esencialización se construye a partir del referente nacional al cual se supone que los sujetos en cuestión deben responder. Se los identifica como "bolivianos" en tanto individuos de un grupo nacional diferenciado, con características propias, únicas y fijas, a partir de aspectos sociales y culturales que involucran marcas distintivas ligadas a tradiciones folclóricas y costumbres cotidianas, usos del lenguaje y características fenotípicas. Así, en el uso corriente, en un sentido restringido, "bolivianos" serían únicamente aquellos alumnos hijos o nietos de bolivianos que poseen la nacionalidad boliviana, adquirida la mayoría de las veces por su lugar de nacimiento, mientras que en un sentido amplio también estarían incluidos bajo esta categoría aquellos descendientes de bolivianos que poseen la nacionalidad argentina, adquirida ya sea por el lugar de nacimiento o transmitida por la vía paterna o materna (por ejemplo, en el caso de que se hayan "nacionalizado"), pero que reúnen alguno de aquellos atributos que los hacen pertenecer a la "comunidad boliviana". Igualmente, como hemos visto, aunque no se advierte como un límite arbitrario, en la vida cotidiana de la escuela la frontera divisoria entre "argentinos" y "bolivianos" no es nítido y en situaciones sociales específicas los mismos alumnos imaginados como "bolivianos" pasan a ser nominados como "argentinos" o son interpelados como parte del conjunto nacional argentino.

Entre las familias de inmigrantes bolivianos, los hijos, aunque posean la nacionalidad argentina, también son considerados "bolivianos" a partir de determinados atributos asociados a la bolivianidad. Sin embargo, inmersos en un contexto en el cual "lo boliviano" es sinónimo de inferioridad social, la posesión de la nacionalidad argentina es reivindicada como modo de adquisición de aquella igualdad de trato que la pertenencia a la comunidad política formalmente supone y es utilizada como un recurso estratégico mediante el cual se espera poder contrarrestar los efectos sociales que tiene ser identificado como "boliviano" en la vida cotidiana. En ello hay cierta analogía con las expectativas que se generan con el trámite de nacionalización o naturalización de los extranjeros o con el trámite de regularización documentaria migratoria de aquellos que se encuentran "sin 
papeles". Advirtiendo las dificultades que genera la falta de papeles, los extranjeros depositan enormes expectativas en su adquisición, como si un poder mágico de ellos emanara, para modificar las injusticias sociales que experimentan en su vida cotidiana. Suárez Navaz (1999) propone la noción de "fetichismo de los papeles" para discutir el valor que se le asigna a la adquisición de la documentación, sugiriendo que el elemento mágico radicaría en la falsa creencia de que los papeles producen la igualdad y reconocimiento de los derechos de los inmigrantes. La vida social -en algunas sociedades como la argentina mucho más que en otras- está tan regulada y condicionada por la posesión de un documento nacional de identidad, es decir, por la sola demostración de ser titular de una identificación personal, que todo pareciera indicar que allí se encuentra la solución a la desigualdad social.

En la escuela se produce y circula un conjunto de representaciones alrededor de quienes son identificados o pensados como alumnos bolivianos que envuelve atributos valorados socialmente como negativos o positivos. Como han mostrado diversos estudios etnográficos locales, se trata principal pero no exclusivamente de estereotipos y prejuicios relacionados a la falta de habilidades cognitivas o dificultades de aprendizaje: un rasgo que se les suele adjudicar es la "lentitud", sobreentendida como mental o intelectual, en particular para aprendizajes relacionados con la lengua y sus usos. En este sentido, la presente investigación ratifica aquellos hallazgos hechos por otras investigaciones. Pero también explora una dimensión de la vida escolar que permitió advertir otras construcciones en relación a la alteridad signada por la presencia de alumnos bolivianos en la escuela. Una serie diferenciada de atributos que generalmente adquiere una connotación positiva muestra una estrecha relación con la figura del buen alumno que la escuela construye mediante sus grandilocuentes relatos y pequeñas acciones cotidianas: en este sentido, los alumnos bolivianos serían fundamentalmente "respetuosos", "educados", "estudiosos", "responsables" e "impecables". Son estas características positivas, en particular ciertas virtudes morales que escasearían entre el resto de los alumnos, las que a manera de contribución, voluntaria o involuntaria, habilitarían una convivencia basada en la valoración mutua: los bolivianos tendrían algo valioso que aportar. De otra manera, pareciera imposible justificar una presencia construida como extraña o diferente, que si bien resulta problemática en tanto afectaría la cohesión social en el espacio escolar, no puede ser admitida como tal. Pareciera que sólo a condición de que ciertos individuos o grupos reúnan determinadas virtudes morales y sociales pueden ser admitidos o aceptados por aquella "sociedad receptora" en tanto sociedad nacional que se autoinviste con el poder de sancionar quienes son merecedores o no de formar parte de 
ella. Los diversos sentidos y usos del símbolo nacional por excelencia, la bandera, analizados en un espacio escolar marcado por una presencia interpelada como nonacional, condensan a nivel microsocial aquellas tensiones y contradicciones políticoideológicas que desata la convivencia entre nacionales e inmigrantes extranjeros o extranjerizados en el orden macrosocial.

Al mismo tiempo, mediante calificativos como "sumisos" o "dóciles", enunciados como si fueran neutros, son colocados en un lugar de subordinación. Aún con calificativos no necesariamente peyorativos como "callados" o "tímidos" son diferenciados del resto de los compañeros. En general, las representaciones que recaen sobre ellos hablan de aquél comportamiento esperado y valorado en la escuela como son el respeto de aquellas normas cuyo quebrantamiento significaría una alteración del orden escolar establecido. Son calificados como "correctos", son vistos como portadores de un comportamiento correcto, es decir, un comportamiento libre de errores o defectos que no hace necesaria la intervención docente para adecuar su conducta a la que un buen alumno debiera tener. Esta proximidad entre su comportamiento y los parámetros de conducta establecidos por los docentes hace que los alumnos identificados como bolivianos no sean vistos como alumnos "problemáticos". Es decir, aunque como conjunto social son percibidos como una presencia problemática, no son individualizados como alumnos problemáticos. En contraposición, los alumnos considerados de este modo son los "argentinos", asignándoseles atributos "negativos" de diversa índole (relacionados a la "agresividad", la "mala conducta" o la "falta de hábitos"). Esta caracterización del alumnado se corresponde con el estigma que lleva la escuela como escuela del fondo. De esta manera, la división establecida entre alumnos bolivianos y alumnos argentinos habilita la construcción de un conjunto seriado de antinomias basadas en el origen social y nacional de los alumnos.

La asignación de atributos positivos a los alumnos bolivianos descansa en el discurso docente en una serie de explicaciones acerca de las propiedades de la cultura de origen, como si se tratara de un rasgo típico de los bolivianos, ya sea del orden individual como del grupal, y también ajeno a las circunstancias sociales y educativas más amplias. Según los distintos testimonios obtenidos, las cualidades personales asignadas a los alumnos bolivianos son confirmadas o validadas por los progenitores de quienes son depositarios de estas identificaciones: ser un buen alumno implica tener un buen comportamiento que se adquiere mediante respeto, responsabilidad e higiene. Otras explicaciones acerca de las características que diferenciarían a bolivianos y argentinos se sitúan en la interacción con la sociedad receptora, en el intercambio cotidiano con los argentinos, en las implicancias 
de ser extranjero (en el sentido de extraño o ajeno del lugar), en el hecho de estar en otro país. En otro sentido, la metáfora de la escuela como casa u hogar de los argentinos para explicar los diferentes comportamientos entre bolivianos y argentinos, asumiendo la territorialidad material y simbólica de la nación argentina, también denota la diferencia entre anfitriones e invitados, entre nacionales y extranjeros, entre conocidos y extraños. Ilegitimidad consustancial, como la califica Sayad, que se le confiere a su presencia en una sociedad que no deja de recordarles, mediante pequeños actos cotidianos, que ellos, los inmigrantes y sus hijos, nacidos o no en otra parte, nacionales o no-nacionales, son de otro lugar, no pertenecen naturalmente a una sociedad -como si fuera una totalidad completaque se asume espontánea y automáticamente como "receptora". Es a través de estas interacciones sociales cotidianas en diversos espacios sociales como la escuela, que la inmigración, en tanto construcción social y política, se materializa como presencia ilegítima, como una presencia que deber ser permanentemente justificada, porque la sociedad receptora no puede admitirla como una presencia permanente.

Estas características positivas atribuidas a los alumnos bolivianos, como conjunto homogéneo y cerrado, que los acercan a la figura del buen alumno como expresión del orden escolar deseado y con lo cual se ve favorecido su rendimiento académico, no es necesariamente extrapolable a otras instituciones escolares a pesar de las coincidencias que pueda haber en términos de reconocimiento en clave nacional. Además de la presencia numérica, la cual moldea representaciones y prácticas escolares, es el contexto escolar específico, marcado por la pobreza y la marginalidad social, el que hablita estas representaciones positivas acerca de los hijos de inmigrantes bolivianos. Es su presencia en una escuela en los márgenes y de los márgenes, la escuela del fondo, lo que colabora con que los alumnos bolivianos puedan contrarrestar las contrariedades cotidianas a las que están expuestos por el hecho de ser identificados como bolivianos. En otras palabras, es en un contexto de exclusión que su experiencia escolar no queda tan expuesta al fracaso escolar.

En otro plano, las características atribuidas a los alumnos bolivianos se corresponden con aquellos parámetros de conducta y los mismos valores que están detrás del orden escolar que reflejan los actos escolares patrióticos, una conducta que aparece referenciada en los atributos que se espera que el abanderado revista en representación de la escuela, de la escuela de la nación argentina. Los atributos asignados a los alumnos bolivianos como colectivo se corresponden con las condiciones que deben reunir, según la normativa escolar y la comunidad educativa en su conjunto, los alumnos merecedores de la bandera 
nacional, los "abanderados": buen rendimiento académico, buena conducta, además de "asistencia y puntualidad y corrección", según el reglamento escolar, o ser "respetuoso", "educado" y "no faltar a las reglas", según los acuerdos escolares. Sin embargo, a pesar de reunir las características requeridas para ser abanderado, el carácter de no-nacional de los alumnos "bolivianos" despierta un conflicto en torno a la apropiación y representación legítima de los símbolos de la nación argentina. Ni la normativa educativa nacional establece aquella creencia que en la escuela circula como verdad autorrevelada en relación al tratamiento y uso de la bandera: que los abanderados deben ser de nacionalidad argentina. Más que la condición jurídica de extranjero, lo que resulta problemático es la pertenencia a un colectivo identificado con otra nación, definida en términos estatales. Aquí, una vez más, es el sentido social de la nacionalidad más que el jurídico el que actúa en la vida escolar como impedimento y justificativo. Paradójicamente, a pesar de ciertas prácticas pretendidamente inclusivas como el "proyecto de abanderados", una porción importante de los alumnos argentinos que estarían formalmente habilitados para llevar la bandera nacional, tampoco accede a ella debido a que no satisfacen aquellas condiciones establecidas para ser investidos con el honor que confiere la bandera nacional. Al mismo tiempo, aquellos docentes que no reconocen el criterio de nacionalidad para otorgar o negar la bandera argentina a un alumno boliviano, supeditan este acto a sus virtudes personales de acuerdo al ideal de buen alumno, inclusive sentimientos nobles con la nación argentina. De todas formas, se les otorgue o no, la posibilidad cierta de que la reciban en su calidad de no-nacionales hace surgir en las intercambios cotidianos sentimientos y acciones de (in)gratitud, concesión o deuda.

Por otra parte, la internalización de la visión de Estado, como he mostrado, tiene efectos concretos y diversas implicancias en los modos en que la escuela busca, a través de diversas estrategias, otorgar visibilidad y promover el reconocimiento de aquella presencia inmigrante que es asumida e interpelada en clave nacional. Atravesadas por la visión de Estado, representaciones y prácticas escolares cotidianas muestran un importante apego a nominaciones y clasificaciones ancladas en la división de nacionales y no-nacionales: es desde las identificaciones nacionales, a pesar de ser uno entre tantos otros modos posibles de habitar los espacios sociales, que la escuela asume y desempeña su papel histórico de formación del ciudadano. No sólo encuentra allí -entre otros mandatos- su razón de ser, asegurando su propia reproducción, sino también un lugar menos escurridizo, más conocido y seguro, y con amplio consenso social, para afrontar la relación nosotros-otros. A partir de la triangulación entre la normativa educativa nacional y escolar, el discurso de los docentes y otros sujetos de la comunidad educativa y de las 
prácticas escolares cotidianas como los actos escolares, he buscado dar cuenta de las modalidades específicas que adquieren en el espacio escolar las estrategias de reconocimiento de la presencia inmigrante, bajo fórmulas de inclusión/exclusión, que la institución escolar propone frente a una alteridad que, un siglo después, ya no remite a la inmigración europea de ultramar, sino a la de países limítrofes como Bolivia.

Primeramente, importa señalar que la escuela, entre otras instituciones sociales, produce aquella división entre nacionales y extranjeros, cuyos efectos después busca paliar intentando conciliar los opuestos que produce dicha división. Para ello, tanto las políticas educativas como las estrategias puestas en juego en la escuela trabajan básicamente sobre uno de los dos extremos de la relación nosotros-otros: se ocupan de la alteridad, obviando trastocar la mismidad. Corren generalmente en paralelo, con cruces ocasionales o puntuales. Bajo fórmulas como el respeto a la diversidad cultural o el reconocimiento del otro queda en suspenso el nosotros nacional y, por tanto, anulada la posibilidad de revisar la relación de desigualdad y dominación entre el nosotros (nacional) y los otros (nonacionales). Ciertas ideas y acciones analizadas muestran el modo en que el pensamiento de Estado atraviesa las prácticas escolares destinadas a configurar la identidad nacional argentina como también aquellas circunstancias en las cuales la escuela se dispone a reconocer la presencia de no-nacionales. El estudio revela que las prácticas de reconocimiento dirigidas a los bolivianos en tanto no-nacionales adopta el mismo formato ritualizado y el mismo contenido esencialista que aquellas que desarrolla la escuela destinadas a los nacionales en su afán por cimentar la idea de nación argentina y cumplir con su mandato de afianzar la construcción de la identidad nacional. Como he mostrado, en los actos escolares patrióticos la presencia de los alumnos bolivianos en tanto nonacionales en un territorio de la nación argentina es una presencia ausente, mientras que en los interculturales, especialmente en los actos bolivianos, es una ausencia presente que, de manera incierta y provisoria, se debate entre el reconocimiento, la invisibilidad y la indiferencia.

Una de las principales respuestas que desarrolla la escuela frente a la presencia de hijos de inmigrantes toma forma a través de los actos escolares. En el marco de los actos escolares patrióticos los alumnos bolivianos se forman como argentinos, al igual que con sus compañeros aprenden a identificarse con la nación argentina, al mismo tiempo que se forman como sujetos nacionales, es decir, que aprenden a ser súbditos del Estado, lo cual los ubicaría -en caso de un hipotético regreso- en condiciones de reproducir prácticas patrióticas análogas en las escuelas estatales bolivianas. También hemos visto que la 
escuela, además de los llamados actos patrióticos, despliega actos que por los sentidos y finalidades que se les atribuye pueden considerarse interculturales. Éstos constituyen, al igual que con la producción de la argentinidad, el instrumento privilegiado en la construcción de la bolivianidad en el espacio escolar. Guiados por la noción de integración como marco ideal de construcción de las relaciones sociales en tanto convivencia armónica, las prácticas de reconocimiento y visibilización del otro, basadas en la contraposición integración-discriminación, adquieren materialidad a través de expresiones de la bolivianidad, en tanto formas y contenidos culturales y políticos diferenciados interpretados en clave nacional, las actuarían como elementos facilitadores de la deseada integración.

A pesar de las diferencias y variaciones entre los actos interculturales, tienen en común la estrategia de incorporar a la vida escolar determinados emblemas culturales y políticos asociados a la nación boliviana -desde comidas y danzas hasta la bandera nacional- para llevar a la práctica la idea de integración por comparación: costumbres y tradiciones que remiten fundamentalmente al canon folklórico dominante de lo boliviano y lo argentino en términos de bebidas y platos típicos, danzas y bailes folklóricos, y vestimentas tradicionales. Es decir, como sostiene Franzé, la selección y reconstrucción de las otras culturas, sigue los mismos patrones que la escuela tradicionalmente ha privilegiado en la construcción de los conocimientos escolares: de ellas se escogen los saberes o patrimonios consagrados -obviando las reelaboraciones, usos y significados que los sujetos concretos les atribuyen en la vida cotidiana- y se los cosifica y convierte en objetos temáticos de esas culturas (Franzé, 2003). Las prácticas observadas se asientan en una noción de integración que presupone la existencia de sujetos pertenecientes naturalmente a diferentes culturas debido a sus adscripciones nacionales. En tanto expresión de un ideal de convivencia, la coexistencia de estas expresiones relativas a la argentinidad como a la bolivianidad en el espacio escolar es valorado positivamente, salvo situaciones conflictivas específicas, por los diversos actores que intervienen en la vida cotidiana escolar. También cuenta con la aprobación de las más diversas miradas externas (desde funcionarios de gobierno hasta académicos). Sin embargo, las acciones escolares de reconocimiento de la presencia boliviana en la escuela que otorgan existencia a diversas expresiones de bolivianidad también son experimentadas de manera ambigua por parte, en principio, de los principales destinatarios o beneficiarios de dichos actos. Sin desmerecer los esfuerzos que realiza la escuela para que sus hijos obtengan aquél reconocimiento que la sociedad receptora en general les niega, entre las madres bolivianas aparecen sentimientos ambiguos debido a los efectos inmediatos que puedan tener en el contexto escolar. Por 
otra parte, las prácticas escolares orientadas al respeto y reconocimiento del otro implican la construcción de una bolivianidad que coloca a sus hijos en el lugar de extraños: la bolivianidad resignificada como exterioridad. Es decir, extraños de un lugar en el cual llevan o eligieron llevar adelante sus vidas, ya sea de manera provisoria o permanente (sin ninguna certeza al respecto). La ideología asimilacionista que ha sobrevivido en las diversas manifestaciones de argentinidad que construye la escuela día a día, asegurando su propia reproducción como institución social, ofrece, en cambio, como si no hubiera otra opción, formar parte de un conjunto nacional que negará, silenciará, eliminará, subsumirá aquellas visiones y adscripciones identitarias que no se adecuen a aquella configuración nacional que le permita definirse como tal. Sea cual fuere la situación, las prácticas escolares observadas ratifican que la construcción de la nación argentina se desarrolla remarcando su capacidad para obturar elementos no-nacionales y a través de una fuerte identificación con aquellos componentes considerados exclusivos de la argentinidad.

Aunque el límite entre argentinos y bolivianos sea también borroso, resignificado o advertido ocasionalmente como infundado, en la vida cotidiana de la escuela se trazan fronteras que la constituyen en un territorio de la nación argentina, erigiéndose los docentes, no necesariamente de manera voluntaria ni consciente, en sus custodios. Tanto, aunque en un registro diferente, como aquellos funcionarios, técnicos o empleados del Estado que le ponen letra a la visión de Estado, elaboran diagnósticos y explicaciones acerca de la realidad migratoria del país, toman decisiones políticas o tienen a su cargo el control de la frontera y el territorio nacionales. El límite se vuelve nítido cuando el reconocimiento es llevado a sus límites: el reconocimiento de la otredad en tanto presencia extranjera o alteridad no-nacional llega hasta donde lo sagrado se puede volver profano. El mástil de una escuela argentina -probablemente también de cualquier otra sociedad nacional- nunca podría ser ocupado por otra bandera, sea nacional o de cualquier otro signo, que no sea argentina. Entre las distintas innovaciones o transgresiones que practica la comunidad educativa en su conjunto, el límite que no se permite cruzar -aunque sea cruzado- es aquél que, en principio, aseguraría la perpetuación del orden nacional. Actualmente, de las versiones en pugna a finales del siglo diecinueve, aquella concepción cultural esencialista de la nación, defensiva y excluyente, que triunfó sobre relatos más afines al cosmopolitismo, continúa monopolizando la definición de las relaciones sociales establecidas entre "nacionales" y "extranjeros". Desnacionalizar la escuela -un acto hereje que atenta contra el orden nacional incorporado en lo social- se inscribe así en el terreno de lo impensable, lo imposible. 


\section{BIBLIOGRAFÍA}

Abel, Lidia y Sergio Caggiano (2006) "Enfermedades de Estado(s). Los inmigrantes y el acceso a la salud en una provincia de frontera", en Elizabeth Jelin, dir., Salud y Migración Regional. Ciudadanía, discriminación y comunicación intercultural. Buenos Aires: IDES.

Achilli, Elena (1996) Práctica docente y diversidad sociocultural. Los desafíos de la igualdad educativa frente a la desigualdad social. Rosario: UNR / Homo Sapiens.

Albarracín, Julia (2004) Selecting Immigration in Modern Argentina: Economic, Cultural, International and Institutional Factors, Tesis doctoral, Universidad de Florida.

Albarracín, Julia (2005) "Inmigración en la Argentina moderna: ¿un matrimonio en la salud y en la enfermedad con los europeos?", en Eduardo Domenech, comp., Migraciones contemporáneas y diversidad cultural en la Argentina. Córdoba: CEAUNC.

Almandoz, Ma. Gabriela (1997) "Inmigración limítrofe en Tandil: chilenos y bolivianos en los años noventa", en Estudios Migratorios Latinoamericanos, año 12, núm. 37.

Altamirano, Carlos (2004) "Entre el naturalismo y la psicología: el comienzo de la 'ciencia social' en la Argentina, en Federico Neiburg y Mariano Plotkin, comps., Intelectuales y expertos. La constitución del conocimiento social en la Argentina. Buenos Aires: Paidós.

Altamirano, Carlos (2005) Para un programa de historia intelectual y otros ensayos. Buenos Aires: Siglo XXI.

Althusser, Louis (2003[1969]), "Ideología y aparatos ideológicos de Estado" en Slavoj Žižek, comp., Ideología. Un mapa de la cuestión, Buenos Aires, Fondo de Cultura Económica.

Ameigeiras, Aldo y Elisa Jure, comps., (2006) Diversidad cultural e interculturalidad. Buenos Aires: Prometeo.

Amuchástegui, Martha (2000) "El orden escolar y sus rituales", en Silvina Gvirtz, comp., Textos para repensar el día escolar. Sobre cuerpos, vestuarios, espacios, lenguajes, ritos y modos de convivencia en nuestra escuela. Buenos Aires: Santillana.

Andrijasevic, Rutvica y William Walters (2010) "The International Organization for Migration and the international government of borders", en Environment and Planning D: Society and Space, vol. 28, $\mathrm{N}^{\circ} 6$.

Arango, Joaquín (1985) “Las 'Leyes de las Migraciones' de E.G. Ravenstein, cien años después", en Revista Española de Investigaciones Sociológicas, núm. 32.

Arango, Joaquín (2000) "Enfoques conceptuales y teóricos para explicar la migración", en Revista internacional de Ciencias Sociales, núm. 165.

Ardaya Salinas, Gloria (1978) Inserción ocupacional de los migrantes bolivianos en la Argentina. Tesis de maestría, FLACSO-Buenos Aires.

Ardila, Gerardo, ed., (2006) Colombia: migraciones, transnacionalismo y desplazamiento. Bogotá: Universidad Nacional de Colombia. 
Ariza, Marina (2000) Ya no soy la que dejé atrás... Mujeres migrantes en República Dominicana. México D.F.: Instituto de Investigaciones Sociales / UNAM / Plaza Valdés.

Armus, Diego (1986) "Diez años de historiografía sobre la inmigración masiva a la Argentina”, en Estudios Migratorios Latinoamericanos, año 2, núm. 4.

Aruj, Roberto (2004) Por qué se van. Exclusión, frustración y migraciones. Buenos Aires: Prometeo.

Badaró, Máximo (2006) "La conciencia y la ley: la cuestión migratoria en las prácticas de agencias estatales y organismos no gubernamentales en la Ciudad de Buenos Aires", en Alejandro Grimson y Elizabeth Jelin, comps., Migraciones regionales hacia la Argentina. Diferencia, desigualdad y derechos. Buenos Aires: Prometeo.

Badie, Bertrand, Rony Brauman, Emmanuel Decaux, Guillaume Devin y Catherine Wihtol de Wenden (2008). Pour un autre regard sur les migrations: construire la gouvernance mondiale. Paris: La Découverte.

Baeza, Brigida (2006) "Chilenos y bolivianos en Comodoro Rivadavia", en Alejandro Grimson y Elizabeth Jelin, comps., Migraciones regionales hacia la Argentina. Diferencia, desigualdad y derechos. Buenos Aires: Prometeo.

Balán, Jorge (1988) Immigration Policies, Community Networks, and the Development of a Migratory System in the Southern Cone, en Documentos del CEDES, núm. 16.

Balán, Jorge (1990) "La economía doméstica y las diferencias entre los sexos en las migraciones internacionales: un estudio sobre el caso de los bolivianos en Argentina" en Estudios Migratorios Latinoamericanos, año 5, núm. 15-16.

Balibar, Étienne (1991) "La forma nación: historia e ideología", en "Etnicidad ficticia y nación ideal", en Étienne Balibar e Immanuel Wallerstein, Raza, nación, clase. Madrid: IEPALA.

Banco Mundial (1996) Prioridades y estrategias para la educación. Examen del Banco Mundial. Washington D.C.: Banco Mundial.

Banco Mundial (2004). La educación en América Latina y el Caribe. Documento estratégico del Banco Mundial. Washington D.C.: Banco Mundial.

Bartolozzi, Ivana y Ayelén Koopman (2010) "A las flores se las llevaron otros" Una etnografía sobre los sentidos de lo "barrial" y las prácticas políticas en Cooperativa ARPEBOCH a través de la imagen fotográfica. Tesis de licenciatura, Universidad Nacional de Córdoba.

Basch, Linda, Nina Glick-Schiller y Cristina Szanton-Blanc (1994) Nations unbound: transnational projects, postcolonial predicaments and deterritorialized nation-states. Amsterdam: Gordon and Breach.

Batallán, Graciela y Silvana Campanini (2007) “El 'respeto a la diversidad' en la escuela: atolladeros del relativismo cultural como principio moral", en Revista de Antropología Social, núm. 16.

Bauböck, Rainer (2004) “Cómo transforma la inmigración a la ciudadanía: pespectivas internacionales, multinacionales y transnacionales" en Gemma Aubarell y Ricard Zapata, eds., Inmigración y procesos de cambio. Barcelona: Icaria/IEMed.

Baumann, Gerd (2001) El enigma multicultural. Un replanteamiento de las identidades nacionales, étnicas y religiosas. Buenos Aires: Paidós.

Begala, Silvana (2006) "No condicionar los derechos de los inmigrantes a la situación de residencia”, en Desafíos Urbanos, año 12, núm 54. 
Begala, Silvana (2007) "El concepto de habitante en el artículo 14 de la CN: una medida a los derechos de los migrantes", en Anuario del Centro de Investigaciones Jurídicas y Sociales de la Universidad Nacional de Córdoba, núm. 10.

Beheran, Mariana (2007) El tratamiento de la diversidad cultural en las escuelas públicas primarias de la ciudad de Buenos Aires. Tesis de maestría, Universidad de Buenos Aires.

Bellati, Corina (1973) Los migrantes de países limítrofes: Bolivianos en las fincas y viñedos de la Provincia de Mendoza. Oficina Sectorial de Desarrollo de Recursos Humanos del Ministerio del Interior, Buenos Aires.

Beltramone, Ana Clara, Eugenia Nava y Verónica Villada Medina (2010) Diálogo cultural en la escuela: visibilización de las diferencias. Trabajo final de licenciatura, Universidad Nacional de Córdoba.

Benencia, Roberto (1992) "El mercado de trabajo rural: posibles cambios en un futuro próximo", en Realidad Económica, núm. 109.

Benencia, Roberto (1997) "De peones a patrones quinteros. Movilidad social de familias bolivianas en la periferia bonaerense", en Estudios Migratorios Latinoamericanos, año 12 , núm. 35.

Benencia, Roberto (1999) "El fenómeno de la migración limítrofe en la Argentina: interrogantes y propuestas para seguir avanzando", en Estudios Migratorios Latinoamericanos, año 13/14, núm. 40/41.

Benencia, Roberto (2000): "Colectividades de extranjeros en Neuquén: génesis y trayectorias de sus organizaciones", en Estudios Migratorios Latinoamericanos, año 15, núm. 45.

Benencia, Roberto (2003) “Apéndice: La inmigración limítrofe", en Fernando Devoto, Historia de la inmigración en la Argentina. Buenos Aires: Sudamericana.

Benencia, Roberto (2004) "La existencia de modelos históricos contrapuestos en la integración de los migrantes en la sociedad argentina", Les Cahiers ALHIM, núm. 9 [En línea: <http://alhim.revues.org/index430.html >].

Benencia, Roberto (2006) "Bolivianización de la horticultura en Argentina", en Alejandro Grimson y Elizabeth Jelin, comps., Migraciones regionales hacia la Argentina. Diferencia, desigualdad y derechos. Buenos Aires: Prometeo.

Benencia, Roberto y Gabriela Karasik (1995) Inmigración limítrofe: los bolivianos en Buenos Aires. Buenos Aires: Centro Editor de América Latina.

Benencia, Roberto y Gazzotti, Alejandro (1995) “Migración limítrofe y empleo: precisiones e interrogantes", en Estudios Migratorios Latinomericanos, año 10, núm. 31.

Benencia, Roberto y Geymonat, Marcela (2005) "Migración transnacional y redes sociales en la creación de territorios productivos en la Argentina. Río Cuarto, Córdoba", en Cuadernos de Desarrollo Rural, núm. 55.

Benencia, Roberto y Karasik, Gabriela (1994) "Bolivianos en Buenos Aires: aspectos de su integración laboral y cultural", en Estudios Migratorios Latinoamericanos, año 9, núm. 27.

Bertely Busquets, María (2000) Conociendo nuestras escuelas: un acercamiento etnográfico a la cultura escolar. México D.F.: Paidós.

Bertoni, Lilia Ana (2001) Patriotas, cosmopolitas y nacionalistas. La construcción de la nacionalidad argentina a fines del siglo XIX. Buenos Aires: Fondo de Cultura Económica. 
Betrisey Nadali, Débora (2005) “La producción social del conocimiento sobre los procesos migratorios contemporáneos”, en Anthropologica, vol.23, núm. 23.

Betts, Alexander (2011) "Introduction: Global Migration Governance”, en Alexander Betts, ed., Global Migration Governance. Oxford: Oxford University Press.

Bialogorski, Mirta (2002) La presencia coreana en la Argentina: la construcción simbólica de una experiencia inmigratoria. Tesis doctoral, Universidad de Buenos Aires.

Biernat, Carolina (2007) ¿Buenos o útiles? La política inmigratoria del peronismo. Buenos Aires: Biblos.

Blanco, Alejandro (2004) "La sociología: una profesión en disputa”, en Federico Neiburg y Mariano Plotkin, comps., Intelectuales y expertos. La constitución del conocimiento social en la Argentina. Buenos Aires: Paidós.

Blanco, Alejandro (2006) Razón y modernidad. Gino Germani y la sociología en la Argentina. Buenos Aires: Siglo XXI.

Blanco, Alejandro (2009) José Luis Romero y Gino Germani: la inmigración masiva y el proyecto de una comprensión histórico-sociológica de la Argentina moderna". Ponencia presentada en las Jornadas Internacionales "José Luis Romero", Universidad Nacional de General San Martín y Biblioteca Nacional (Buenos Aires, Argentina).

Blanes, José (1986) “Movilidad espacial en Bolivia. Reflexiones sobre su carácter temporal” en ...Se fue a volver. Seminario sobre migraciones temporales en América Latina. México D.F.: PISPAL/CIUDAD/CENEP.

Blázquez, Gustavo (1996) ¡Viva la Patria! Una etnografía de los actos escolares. Tesis de maestría, Universidad Nacional de Córdoba, Córdoba.

Blumer, Herbert (1971) "Social problems as collective behaviour", en Social Problems, vol. 18, núm. 3.

Bologna, Eduardo (2007) La Reversibilidad en los Estadios Avanzados de los Sistemas Migratorios, el caso de Argentina y Bolivia. Córdoba: CEA-UNC/CONICET, Institut de Recherche pour le Développement.

Bompadre, José María (2005) "La fiesta como espacio de discurso y prácticas sociales: el caso de la Virgen de Urkupiña", en Eduardo Domenech, comp., Migraciones contemporáneas y diversidad cultural en la Argentina. Córdoba: CEA-UNC.

Bompadre, José María (2007) “Boliviano... i¿y qué?!” Etnicidades e identidades. Barrios, familias y fiestas: Hacia la construcción de espacios de migración en la Córdoba de principios del siglo XXI. Tesis de maestría, Universidad Nacional de Córdoba.

Bonal, Xavier (2002) "Globalización y política educativa: un análisis crítico de la agenda del Banco Mundial para América Latina", en Revista Mexicana de Sociología, vol. 64, núm. 3.

Bonal, Xavier, Aina Tarabini y Antoni Verger, comps., (2007), Globalización y Educación: Textos Fundamentales. Miño y Dávila: Buenos Aires.

Boudieu, Pierre (1990) “El racismo de la inteligencia”, en Sociología y Cultura. México D.F.: Grijalbo / CONACULTA.

Bourdieu, Pierre (1996) Cosas dichas. Barcelona: Gedisa.

Bourdieu, Pierre (1997) Razones prácticas. Sobre la teoría de la acción. Barcelona: Anagrama. 
Bourdieu, Pierre (1999a) "El espacio de los puntos de vista", en Pierre Bourdieu, dir., La Miseria del Mundo. Buenos Aires: Fondo de Cultura Económica.

Bourdieu, Pierre (1999b) "Comprender" en Pierre Bourdieu, dir., La Miseria del Mundo. Buenos Aires: Fondo de Cultura Económica.

Bourdieu, Pierre (1999c) ¿Qué significa hablar? Economía de los intercambios lingüísticos. Madrid: Akal.

Caggiano, Sergio (2005) Lo que no entra en el crisol: Inmigración boliviana, comunicación intercultural y procesos identitarios. Buenos Aires: Prometeo.

Caggiano, Sergio (2006) "Fronteras de la ciudadanía. Inmigración y conflictos por derechos en Jujuy", en Alejandro Grimson y Elizabeth Jelin, comps., Migraciones regionales hacia la Argentina. Diferencia, desigualdad y derechos. Buenos Aires: Prometeo.

Caggiano, Sergio (2009) "Enfermedades, aeropuertos y fronteras", en E-misférica, núm. 61 [En línea: <http://hemi.nyu.edu/hemi/es/e-misferica-61>].

Calderón Chelius, Leticia (2006) "El estudio de la dimensión política dentro del proceso migratorio", en Sociológica, año 21, núm. 60.

Camas Baena, Victoriano (2001) "Vigencia y olvido de El campesino polaco en Europa y América”, en Empiria. Revista de Metodología de Ciencias Sociales, núm. 4.

Canales, Alejandro (2006) "Presentación", en Alejandro Canales, ed., Panorama actual de las migraciones en América Latina. Rio de Janeiro: ALAP.

Canelo, Brenda, Leonardo Angelo, Carla Gallinati, Natalia Gavazzo, Lucía Groisman y Lucila Nejamkis (2010) "Todos con Evo: El voto boliviano en el exterior. Notas acerca de la primera experiencia en Buenos Aires". Ponencia presentada a las VI Jornadas de Investigación en Antropología Social (Buenos Aires, Argentina).

Cappellini, Natalí, Cesia Carballo, Milton Escobar, Alejandra Ruiz y Gisella Viale (2011) "Conformación de la agenda gubernamental y alcance de las prácticas políticas: el caso de los inmigrantes bolivianos en Córdoba", en Cynthia Pizarro, ed., Ser "boliviano" en la Región Metropolitana de la Ciudad de Córdoba. Localización socioespacial, mercado de trabajo y relaciones interculturales. Córdoba: Universidad Católica de Córdoba.

Carretero, Mario (2007) Documentos de Identidad. La Construcción de la memoria histórica en un Mundo Global. Buenos Aires: Paidós.

Casaravilla, Diego (1999) Los laberintos de la exclusión: relatos de inmigrantes ilegales en Argentina. Buenos Aires: Lumen-Humanitas.

Casaravilla, Diego (2000) Ángeles, demonios o chivos expiatorios? El futuro de los inmigrantes latinoamericanos en Argentina. Informe final, Programa Regional de Becas CLACSO [En línea: < http://bibliotecavirtual.clacso.org.ar/ar/libros/becas/1999/casara.pdf>].

Castiglione, Celeste y Daniela Cura (2007) "Las migraciones en los medios de comunicación escrita (2000-2005)", en Susana Novick, dir., Sur-Norte. Estudios sobre la emigración reciente de argentinos. Buenos Aires: Catálogos.

Castles, Stephen y Mark J. Miller (2004) La era de la migración Movimientos internacionales de población en el mundo moderno. México D.F.: Miguel Ángel Porrua / UAZ / Cámara de Diputados LIX Legislatura / Fundación Colosio / Secretaría de Gobernación, Instituto Nacional de Migración. 
CELS (1997) "Inmigrantes", en Informe sobre la situación de los derechos humanos en Argentina 1997. Buenos Aires: Eudeba.

CELS (1999) Inmigración, política estatal y vigencia de los derechos económicos, sociales y culturales de los inmigrantes y trabajadores migratorios peruanos y bolivianos en Argentina. Buenos Aires: CELS.

CELS (2000) Inmigración, política estatal y vigencia de los Derechos Económicos Sociales y Culturales de los inmigrantes y trabajadores migratorios peruanos y bolivianos en Argentina. Informe presentado a la Plataforma Sudamericana de Derechos Humanos, Democracia y Desarrollo, en Los Derechos Humanos de los Migrantes. La Paz: CEDLA / CEDAL / CELS [En línea: $<$ http://www.cels.org.ar/common/documentos/inmigrantes peruanos bolivianos.p $\underline{\mathrm{df}}>]$.

CELS (2001) "Inmigrantes: señales de alarma e inacción", en Informe Anual sobre la Situación de los Derechos Humanos en Argentina 2001. Buenos Aires: Siglo XXI.

CELS (2005) "A dos años de la nueva Ley de Migraciones: avances, cuestiones pendientes y casos preocupantes", en Derechos Humanos en la Argentina: Informe 2005. Buenos Aires: Siglo XXI.

CELS (2007) "Derechos de las personas migrantes luego de la sanción de la nueva Ley de Migraciones 25.871: sin cambios efectivos", en Derechos Humanos en la Argentina: Informe 2007. Buenos Aires: Siglo XXI.

CEPAL (2006) Migración internacional, América Latina y el Caribe Observatorio Demográfico, Santiago de Chile, CEPAL, año 1, núm. 1.

Ceriani Cernadas, Pablo (2004) "Nueva Ley: un paso hacia una concepción distinta de la migración", en Rubén Giustiniani, comp., Migración: un derecho humano. Buenos Aires: Prometeo.

Ceriani Cernadas, Pablo (2011) "Luces y sombras en la legislación migratoria latinoamericana”, en Nueva Sociedad, núm. 233.

Cerrutti, Marcela y Emilio Parrado (2002) “Migración laboral de trabajadores paraguayos a la Argentina: entrada a los mercados trabajo y trayectorias ocupacionales", en Estudios Migratorios Latinoamericanos, año 16, núm. 48.

Ceva, Mariela (2006) “La migración limítrofe en la larga duración”, en Alejandro Grimson y Elizabeth Jelin, comps., Migraciones regionales hacia la Argentina. Diferencia, desigualdad y derechos. Buenos Aires: Prometeo.

Charbit, Yves (2006) "Marx y la población: a propósito de la lectura althusseriana”, en Estudios, núm. 19.

Cherñavsky, Moisés (1993) La seguridad nacional y el fundamentalismo democrático. Buenos Aires: Centro Editor de América Latina.

Clavijo, Janneth (2011) La política migratoria colombiana en el período 2002-2006: el programa Colombia Nos Une (CNU). Tesis de maestría, Universidad Nacional de Córdoba.

Clavijo, Janneth y Silvana Santi (2009) "Estado argentino y emigración: la cooperación, gobernabilidad y reciprocidad en el discurso estatal actual", en Eduardo Domenech, comp., Migración y política: el Estado interrogado. Procesos actuales en Argentina y Sudamérica. Córdoba: Universidad Nacional de Córdoba.

Cohen, Néstor (1998/99) "Cuando la visión del otro se basa en la visión de las diferencias", en Estudios Migratorios Latinoamericanos, año 13/14, núm. 40-41. 
Constantino, Santiago, Alejandro Giampieri y María de los Ángeles Lasa (2008) La sofisticación de la [exclusión] en los barrios-ciudades de Córdoba, los nuevos ghettos del siglo XXI. Ponencia presentada a las VI Jornadas Interdisciplinarias: acerca del reconocimiento del otro en la cultura contemporánea (Córdoba, Argentina).

Cook-Martín, David (2006) "Soldiers and Wayward Women: Gendered Citizenship, and Migration Policy in Argentina, Italy, and Spain since 1850", en Citizenship Studies, vol. 10, núm. 5.

Cook-Martín, David (2008) "Rules, Red Tape, and Paperwork: The Archeology of State Control over Migrants, 1850-1930", en Journal of Historical Sociology, vol. 21, núm. 1.

Cortes, Geneviève (2004a) "Una ruralidad de la ausencia. Dinámicas migratorias internacionales en los valles interandinos de Bolivia en un contexto de crisis", en Alfonso Hinojosa Gordonava, comp., Migraciones transnacionales. Visiones de Norte y Sudamérica. La Paz: CEF/Plural.

Cortes, Geneviève (2004b) Partir para quedarse. Supervivencia y cambio en las sociedades campesinas andinas de Bolivia. La Paz: IRD/IFEA/Plural.

Courtis, Corina (2000) Construcciones de alteridad: discursos cotidianos sobre la inmigración coreana en Buenos Aires. Buenos Aires: Eudeba.

Courtis, Corina (2006) "Hacia la derogación de la Ley Videla: la migración como tema de labor parlamentaria en la Argentina de la década de 1990" en Alejandro Grimson y Elizabeth Jelin, comps., Migraciones regionales hacia la Argentina. Diferencia, desigualdad y derechos. Buenos Aires: Prometeo.

Courtis, Corina y Laura Santillán (1999) "Discursos de exclusión: migrantes en la prensa", en María Rosa Neufeld y Ariel Thisted, comps., De eso no se habla... los usos de la diversidad sociocultural en la escuela. Buenos Aires: Eudeba.

Courtis, Corina y María Inés Pacecca (2007) "Migración y derechos humanos: una aproximación crítica al 'nuevo paradigma' para el tratamiento de la cuestión migratoria en Argentina", en Revista Jurídica de Buenos Aires.

Cozzani de Palmada, María Rosa (2000) "Inmigrantes limítrofes en Argentina. ¿Tolerancia o rechazo?", en Les Cahiers ALHIM, núm. 1 [En línea: $<$ http://alhim.revues.org/index37.html >].

Dale, Roger (1999) "Specifying globalization effects on national policy: a focus on the mechanisms", en Education Policy, vol. 14, núm. 1.

Dandler, Jorge y Carmen Medeiros (1991) "Migración temporaria de Cochabamba, Bolivia, a la Argentina: Patrones e impacto en las áreas de envío" en Patricia Pessar, comp., Fronteras permeables. Buenos Aires: Planeta.

Das, Veena y Deborah Poole (2008) "El estado y sus márgenes. Etnografías comparadas", en Cuadernos de Antropología Social, núm. 27.

De Genova, Nicholas (2002) "Migrant 'Illegality' and Deportability in Everyday Life”, en Annual Review of Anthropology, núm. 31.

De Genova, Nicholas (2003) "La producción legal de la 'ilegalidad' migrante mexicana”, en Estudios Migratorios Latinoamericanos, año 17, núm. 52.

De la Torre Ávila, Leonardo (2006) No llores, prenda, pronto volveré. Migración, movilidad social, herida familiar y desarrollo. La Paz: PIEB/IFEA/UCB.

De la Torre Ávila, Leonardo (2011) Migración y competencias estatales. Documento de Trabajo, Dirección General de Asuntos Consulares del Ministerio de Relaciones 
Exteriores de la República de Bolivia / Organización Internacional para las Migraciones / Programa Aeneas (UE).

De la Torre Ávila, Leonardo y Yolanda Alfaro Aramayo (2007) La cheqanchada. Caminos y sendas de desarrollo en los municipios migrantes de Arbieto y Toco. La Paz: CESU/DICYT-UMSS/PIEB.

De Marco, Graciela (1986) "Extranjeros en la Argentina: Cuantía y continuidad de los flujos inmigratorios limítrofes 1970-1985”, en Estudios Migratorios Latinoamericanos, núm. 3.

De Marco, Graciela; Raúl Rey Balmaceda y Susana Sassone (1994) "Extranjeros en la Argentina. Pasado, presente y futuro", en Geodemos, núm. 2.

Devés Valdés, Eduardo (2003) El pensamiento latinoamericano en el siglo XX. Desde la CEPAL al neoliberalismo (Tomo II). Buenos Aires: Biblos.

Devin, Guillaume (2005) “Norbert Elias y el análisis de las relaciones internacionales”, en Colombia Internacional, núm. 62 [En línea: $<$ http://redalyc.uaemex.mx/redalyc/src/inicio/ArtPdfRed.jsp?iCve=81206212>].

Devoto, Fernando (1989) "Políticas migratorias argentinas y flujo de población europea”, en Estudios Migratorios Latinoamericanos, año 4, núm. 14.

Devoto, Fernando (1992a), "Idea de nación, inmigración y cuestión social en la historiografía académica y en los libros de texto de Argentina (1912-1974)", en Estudios Sociales, núm. 3.

Devoto, Fernando (1992b) Movimientos migratorios: historiografía y problemas. Buenos Aires: Centro Editor de América Latina.

Devoto, Fernando (2001) "El revés de la trama: Políticas migratorias y prácticas administrativas en la Argentina (1919-1949)", en Desarrollo Económico, vol. 41, núm. 162.

Devoto, Fernando (2003) Historia de la inmigración en la Argentina. Buenos Aires: Sudamericana.

Devoto, Fernando (2004) "Las políticas migratorias de Francia y Argentina en el largo plazo" en Estudios Migratorios Latinoamericanos, año 18, núm. 53.

Devoto, Fernando y Otero, Hernán (2003) "Veinte años después. Una lectura sobre el crisol de razas, el pluralismo cultural y la historia nacional en la historiografía argentina", en Estudios Migratorios Latinoamericanos, año 17, núm. 50.

Di Liscia, María Silvia y Melisa Fernández Marrón (2009) "Sin puerto para el sueño americano. Políticas de exclusión, inmigración y tracoma en Argentina (19081930)", en Nuevo Mundo Nuevos Mundos [En línea: < http://nuevomundo.revues.org/57786>].

Díaz, Raúl y Cristina Valdez y Valdez (2009) "Derribando estereotipos Los actos escolares desde una mirada crítica intercultural", en Decisio. Saberes para la Acción en Educación de Adultos, núm. [En línea: $<$ http://atzimba.crefal.edu.mx/decisio/images/pdf/decisio 24/decisio24_saber3.pd $\underline{\mathrm{f}}>$ ].

Díaz, Raúl (2001) Trabajo docente y diferencia cultural. Buenos Aires: Miño y Dávila.

Díaz, Raúl y Graciela Alonso (2004) Construcción de espacios interculturales. Buenos Aires: Miño y Dávila.

Domenach, Hervé y Dora Celton, comps., (1998) La comunidad boliviana en Córdoba. Caracterización y proceso migratorio. Córdoba: CEA-UNC / UP / ORSTOM. 
Domenech, Eduardo (2000) La cultura escolar entre la reproducción y el cambio. Tesis de maestría, Universidad Autónoma de Barcelona.

Domenech, Eduardo, comp., (2005) "Introducción", en Eduardo Domenech, comp., Migraciones contemporáneas y diversidad cultural en la Argentina. Córdoba: CEAUNC.

Domenech, Eduardo (2007a) "La agenda política sobre migraciones en América del Sur: el caso de la Argentina", en Revue Européenne des Migrations Internationales, vol. 23, núm. 1.

Domenech, Eduardo (2007b) "Migraciones contemporáneas y pluralismo cultural en la Argentina: el discurso oficial y las prácticas escolares", en Denise Jardim (org.), Cartografias da Imigração: Interculturalidade e Políticas Públicas. Porto Alegre: UFRGS.

Domenech, Eduardo (2007c) "El Banco Mundial en el país de la desigualdad: políticas y discursos neoliberales sobre diversidad cultural y educación en América Latina”, en Alejandro Grimson, comp., Cultura y neoliberalismo. Buenos Aires: CLACSO.

Domenech, Eduardo (2008) "La ciudadanización de la política migratoria en la región sudamericana: vicisitudes de la agenda global", en Susana Novick, comp., Las migraciones en América Latina. Políticas, culturas y estrategias. Buenos Aires: Catálogos / CLACSO.

Domenech, Eduardo (2009) "La visión estatal sobre las migraciones en la Argentina reciente. De la retórica de la exclusión a la retórica de la inclusión", en Eduardo Domenech, comp., Migración y política: el Estado interrogado. Procesos actuales en Argentina y Sudamérica. Córdoba: Universidad Nacional de Córdoba.

Domenech, Eduardo y Alfonso Hinojosa Gordonava (2009) “Emigración, Estado y sociedad en Bolivia: la reivindicación del 'voto en el exterior"', en M. Roosta (coord.) Población y Desarrollo. Bolivia y los fenómenos de la migración internacional. La Paz: CIDES-UMSA/OMS.

Domenech, Eduardo y Carlos Mora-Ninci (2009) "World Bank Discourse and Policy on Education and Cultural Diversity for Latin America", en David Hill y Ravi Kumar (eds.) Global Neoliberalism and Education and its Consequences. Nueva York: Routledge.

Doty, Roxanne Lynn (1996): "Immigration and national Identity: constructing the nation", en Review of International Studies, vol. 22, núm. 3.

Durand, Jorge y Douglas Massey (2003) Clandestinos: Migración México-Estados Unidos en los albores del siglo XXI, México D.F.: Miguel Ángel Porrua / UAZ.

Düvell, Franck (2003) "The globalisation of migration control", en OpenDemocracy [En línea: $<$ http://www.opendemocracy.net/peoplemigrationeurope/article 1274.jsp>].

Düvell, Franck (2008) "Clandestine migration in Europe", en Social Science Information, vol. 47, núm. 4.

Eagleton, Terry (1997) Ideología. Una introducción. Barcelona: Paidós

Eguiguren, María Mercedes (2011) Sujeto migrante, crisis y tutela estatal. Quito: FLACSOEcuador.

Eguiguren; María Mercedes y Lorena Araujo 2009 La gestión de la migración en los países andinos: entre la securitización y los vínculos diaspóricos, en AndinaMigrante, núm. 3 . 
Elias, Norbert (1990) Compromiso y distanciamiento. Barcelona: Península.

Elias, Norbert (2009[1989]) Los Alemanes. Buenos Aires: Nueva Trilce.

Emmerich, Gustavo y Ludger Pries (2011) La transnacionalización : enfoques teóricos y empíricos. México, D.F.: UAM / Miguel Ángel Porrúa.

Enguita, Mariano (1986) “Texto y contexto en la educación para una recuperación sociológica de la teoría materialista de la ideología", en Mariano Enguita (ed.) Marxismo y sociología de la educación. Madrid: Akal.

Enguita, Mariano (1988) "Entre la esperanza del cambio y el estigma de la reproducción", en Revista de Educación, núm. 286.

Enguita, Mariano (1995) "Escuela y etnicidad: el caso de los gitanos", en AA.VV., Volver a pensar la educación: política, educación y sociedad, vol. I. Madrid: Paideia/Morata.

Enguita, Mariano (1998[1990]). La escuela a examen, 3a edición ampliada. Madrid: Eudema.

Enguita, Mariano (2002) “Iguales, libres y responsables”, en Praxis, núm. 1 [En línea: $<$ http://www.revistapraxis.cl/>].

Eróstegui, Cecilia (1997) “Ser boliviano en Jujuy”, en Yachay, vol. 14, núm. 26.

Etcheverry, Daniel (2007) Identidade não é documento: narrativas de ruptura e continuidade nas migrações contemporáneas. Tesis de maestría, Universidade Federal do Rio Grande do Sul.

Farah, Ivonne (2005) "Migraciones en Bolivia: estudios y tendencias”, en Umbrales, núm. 13.

Favell Adrian (2001a) "Integration policy and integration research in Europe: a review and critique", en Alexander Aleinikoff and Doug Klusmeyer, eds., Citizenship Today: Global Perspectives and Practices. Washington, DC: Brookings Institute / Carnegie Endowment for International Peace.

Favell, Adrian (2001b) Philosophies of Integration: Immigration and the Idea of Citizenship in France and Britain. London: Palgrave.

Feldman-Bianco Bela, ed., (2001) "Brazilians in Portugal, Portuguese in Brazil: cultural constructions of sameness and difference" en Identities: Global Studies in Culture and Power, vol. 8, núm. 4.

Feldman-Bianco, Bela (2007) "Empires, postcoloniality and diasporas" en Hispanic Research Journal, vol. 8, núm. 3.

Feldman-Bianco, Bela (2011) “Caminos de ciudadanía: emigración, movilizaciones sociales y políticas del Estado brasilero", en Bela Feldman-Bianco, Liliana Rivera Sánchez, Carolina Stefoni y Marta Inés Villa Martínez, comps., La construcción social del sujeto migrante en América Latina: prácticas, representaciones y categorías. Quito: CLACSO / FLACSO-Ecuador / UAH.

Feldman-Bianco, Bela y Nina Glick-Schiller (2011) "Una conversación sobre transformaciones de la sociedad, migración transnacional y trayectorias de vida", en Crítica y Emancipación, núm. 5.

Fernández Terán, Roberto (2004) FMI, Banco Mundial y Estado neocolonial: poder supranacional en Bolivia. La Paz: UMSS/Plural.

Ferrufino Quiroga, Celia, Magda Ferrufino Quiroga y Carlos Pereira Bustos (2007) Los costos humanos de la emigración. Cochabamba: PIEB / CESU-UMSS / DICYT-UMSS.

FIO (2003) I Informe sobre Derechos Humanos: Migraciones. Madrid: CICODE / Dykinson. 
Fontana, Silvia (2006) "La importancia del don en la sociedad occidental contemporánea", en Studia Politicae, núm. 9.

Franco, Marina (2009) “La 'seguridad nacional' como política estatal en la Argentina de los años setenta”, en Antíteses, vol. 2, núm. 4.

Franzé Mudanó, Adela (2002) Lo que sabía no valía: escuela, diversidad e inmigración. Madrid: Consejo Económico y Social de la Comunidad de Madrid.

Franzé Mudanó, Adela (2003) “¿De qué hablamos cuando hablamos de integración educativa? Imágenes, discursos y prácticas interculturales en la escuela", en S. Gil y M. Dahiri (coords.), Movimientos de población en el Mediterráneo Occidental. ¿Un fenómeno o un problema? Córdoba: Ayuntamiento de Córdoba.

Franzé Mudanó, Adela, María Fernanda Moscoso y Albano Calvo Sánchez (2011) “'Donde nunca hemos llegado'. Alumnado de origen latinoamericano: entre la escuela y el mundo laboral", en Ángeles Arjona Garrido, Francisco Checa y Olmos, Teresa Belmonte García, eds., Biculturalismo y segundas generaciones. Integración social, escuela y bilingüismo. Barcelona: Icaria.

Galante, Miguel (2008a) “La construcción de políticas migratorias en tiempos de transición y consolidación del primer peronismo: del nacionalismo racista a la planificación económico-social y la promoción de la inmigración" [En línea: $<$ http://www.serviciosesenciales.com.ar/articulos/001-galante.pdf $>$ ].

Galante, Miguel (2008b) "La promoción de la inmigración en el primer peronismo y una política específica: las herramientas jurídicas de inclusión para los trabajadores de origen limítrofe", en Actas del Primer Congreso de Estudios sobre el Peronismo: La Primera Década, Universidad Nacional de Mar del Plata, Mar del Plata, noviembre [En línea: <http://redesperonismo.com.ar/archivos/CD1/EPP/galante.pdf>].

García Borrego, Iñaki (2006) "Generaciones sociales y sociológicas: un recorrido histórico por la literatura sociológica estadounidense sobre los hijos de inmigrantes", en Migraciones internacionales, vol. 4, núm. 1.

García Linera, Álvaro (2005) "La lucha por el poder en Bolivia”, en Álvaro García Linera et al., Horizontes y límites del Estado y el poder. La Paz: Muela del Diablo.

García Linera, Álvaro (2007) "Estado plurinacional”, en Álvaro García Linera et al., La transformación pluralista del Estado. La Paz: Muela del Diablo / Comuna.

Gavazzo, Natalia (2004) "Identidad Boliviana en Buenos Aires: las políticas de integración cultural”, en Theomai, núm. 9. [En línea: <http://www.theomai.unq.edu.ar>].

Geiger, Martin y Antoine Pécoud (2010) The Politics of International Migration Management. Houndmills / Basingstoke: Palgrave Macmillan.

Ghosh, Bimal (2008) “Derechos humanos y migración: el eslabón perdido”, en Migración y Desarrollo, núm. 10.

Gil Araujo, Sandra (2004) ¿De qué hablan cuando hablan de integración? Propuesta para el análisis comparado de las políticas autonómicas de integración de inmigrantes. Los casos de Cataluña y Madrid. Ponencia presentada al VIII Congreso Español de Sociología (Alicante, España).

Gil Araujo, Sandra (2007) Las argucias de la integración. Construcción nacional y gobierno de lo social a través de las políticas de integración de inmigrantes. Los casos de Cataluña y Madrid. Tesis doctoral, Universidad Complutense de Madrid.

Gil Araujo, Sandra (2010) Las argucias de la integración. Políticas migratorias, construcción nacional y cuestión social. Madrid: IEPALA. 
Giorgis, Marta (1998) "Y hasta los santos se trajeron". La Fiesta de la Virgen de Urkupiña en el boliviano Gran Córdoba. Tesis de Maestría, Universidad Nacional de Misiones.

Giorgis, Marta (2000) "Urkupiña, La virgen migrante. Fiesta, trabajo y reciprocidad”, en Cuadernos de la Facultad de Humanidades y Ciencias Sociales de la Universidad Nacional de Jujuy, núm. 13.

Giorgis, Marta (2004) La virgen prestamista: la fiesta de la Virgen de Urkupiña en el boliviano Gran Córdoba. Buenos Aires: Antropofagia.

Giusti, Alejandro (2005) Trayectorias migratorias, redes de intercambio y circulación en la comunidad chilena en Argentina. Ponencia presentada en la XXV Conferencia Internacional de Población ( Tours, Francia).

Giustiniani, Rubén (2004) "Fundamentos de la Ley" en Rubén Giustiniani, comp., Migración: un derecho humano. Buenos Aires: Prometeo.

Giustiniani, Rubén (2004) Migración: un derecho humano. Buenos Aires, Prometeo.

Glick-Schiller, Nina, Linda Basch y Cristina Szanton-Blanc, eds., (1992) "Towards a Transnational Perspective on Migration: Race, Class, Ethnicity and Nationalism Reconsidered", en Annals of the New York Academy of Sciences, vol. 645.

Goetz, Judith y Margaret Le Compte (1988) Etnografía y diseño cualitativo en investigación educativa. Madrid: Morata.

González Cámara, Noelia (2010) De indeseables a ilegales: una aproximación a la irregularidad migratoria, en Arbor, vol. 186, núm. 744.

Gramsci, Antonio (1984) Notas sobre Maquiavelo, sobre la política y sobre el Estado. Buenos Aires: Nueva Visión.

Gramsci, Antonio (1985) La alternativa pedagógica. Madrid / Barcelona: Istmo / Hogar del libro.

Grimson, Alejandro (1999) Relatos de la diferencia y la igualdad. Los bolivianos en Buenos Aires. Buenos Aires: Eudeba.

Grimson, Alejandro (2002) El otro lado del río. Periodistas, Nación y Mercosur en la frontera. Buenos Aires: Eudeba.

Grimson, Alejandro (2003) "La vida política de la etnicidad migrante: hipótesis en transformación”, en Estudios Migratorios Latinoamericanos, año 17, núm. 50.

Grimson, Alejandro (2006) "Nuevas xenofobias, nuevas políticas étnicas en Argentina", en Alejandro Grimson y Elizabeth Jelin, comps., Migraciones regionales hacia la Argentina. Diferencia, desigualdad y derechos. Buenos Aires: Prometeo.

Grimson, Alejandro y Marcial Godoy-Anativia (2003) "Introducción", en Estudios Migratorios Latinoamericanos, año 17, núm. 52.

Grimson, Alejandro, comp., (2000) Fronteras, naciones e identidades. La periferia como centro. Buenos Aires: Ciccus / La Crujía.

Guarnizo, Luis Eduardo (2006) "El estado y la migración global colombiana”, en Migración y Desarrollo, núm. 6.

Guaygua, Germán, Beatriz Castillo, Patricia Prieto y Pamela Ergueta (2010) La familia transnacional. Cambios en las relaciones sociales y familiares de migrantes de El Alto y La Paz a España. La Paz: PIEB.

Guaygua, Germán, coord., (2008) El rol del parentesco andino en la constitución de trayectorias y redes migratorias hacia España en las familias de las ciudades de La Paz y El Alto. Informe de avance. La Paz: PIEB. 
Guber, Rosana (2001) La Etnografía. Método, campo y reflexividad. Buenos Aires: Norma.

Guber, Rosana (2004) El salvaje metropolitano. Reconstrucción del conocimiento social en el trabajo de campo. Buenos Aires: Paidós.

Guibourdenche de Cabezas, Marta (1976) Migración boliviana en Mendoza. Mendoza: Universidad Nacional de Cuyo.

Guillén, Cristina Irma (2008) "Los rituales escolares en la escuela pública polimodal argentina", en Avá, núm. 12.

Guimarães, Samuel (2005) Cinco siglos de periferia. Una contribución al estudio de la política internacional. Buenos Aires: Prometeo.

Halperín Donghi, Tulio (1987) “¿Para qué la inmigración? Ideología y política inmigratoria y aceleración del proceso modernizador: el caso argentino, (1810-1914)”, en Tulio Halperín Donghi, comp., El espejo de la historia. Problemas argentinos y perspectivas latinoamericanas. Buenos Aires: Sudamericana.

Halpern, Gerardo (2005) "Neoliberalismo y migración: paraguayos en Argentina en los noventa”, en Política y Cultura, núm. 23.

Hammer, Tomas (1990) Democracy and the Nation State: Aliens, Denizens, and Citizens in a World of International Migration. Aldershot: Avebury.

Hammersley, Martyn y Paul Atkinson (1983). Ethnography: Principles in Practice. London: Tavistock.

Hansen, Randall (2010) An Assessment of Principal Regional Consultative Processes on Migration, IOM Migration Research Series, núm. 38. Ginebra: OIM.

Hecht, Ana Carolina (2007) "Educación intercultural Bilingüe: de las políticas homogeneizadoras a las políticas focalizadas en educación indígena argentina", en Revista Interamericana de Educación de Adultos, año 29, núm. 1.

Heras, Ana Inés y Holstein, Adriana (2003) "Herramientas para comprender la diversidad en la escuela y la comunidad", en Cuadernos de la Facultad de Humanidades y Ciencias Sociales de la Universidad Nacional de Jujuy, núm. 22.

Heras, Ana Inés (2002) "Acerca de las relaciones interculturales: un presente-ausente tenso", en Scripta Ethnologica, vol. 24.

Heras, Ana Inés (2005) "Marcadores de valor y disvalor en situaciones de contacto sociocultural: percepción y expresión de la diferencia a través del discurso", en Eduardo Domenech, comp., Migraciones contemporáneas y diversidad cultural en la Argentina. Córdoba: CEA-UNC.

Heras, Eduardo, Daniel Guillot y Rodolfo Galvez (1978) Migración tradicional y migración de crisis, una década de afluencias bolivianas y chilenas a Argentina y la región cuyana, 1965-1975. Documento final presentado al Programa de Investigaciones Sociales sobre Problemas de Población relevantes para Políticas de Población en América Latina (PISPAL).

Herrera Carassou, Roberto (2006) La perspectiva teórica en el estudio de las migraciones. México D.F.: Siglo XXI.

Herrera Lima, Fernando (2000) "Las migraciones y la sociología del trabajo en América Latina", en Enrique de la Garza Toledo, coord., Tratado Latinoamericano de Sociología del Trabajo. México D.F.: Fondo de Cultura Económica.

Herrera, Gioconda (2011) "La familia migrante en las políticas públicas en Ecuador: de símbolo de la tragedia a objeto de intervención”, en Bela Feldman-Bianco, Liliana Rivera Sánchez, Carolina Stefoni y Marta Inés Villa Martínez (comps.) La 
construcción social del sujeto migrante en América Latina: prácticas, representaciones y categorías. Quito: CLACSO / FLACSO-Ecuador / UAH.

Hinojosa Gordonava, Alfonso, Liz Pérez Cautin y Guido Cortéz Franco (2000) Idas y vueltas. Campesinos tarijeños en el norte argentino. La Paz: PIEB.

Hinojosa Gordonava, Alfonso (2006) La diáspora boliviana: Estado de situación de los procesos migratorios transnacionales en Bolivia. Ponencia presentada en el Foro Internacional sobre el Nexo entre Políticas y Ciencias Sociales (Córdoba, Argentina).

Hinojosa Gordonava, Alfonso (2008) "España en el itinerario de Bolivia. Migración transnacional, género y familia en Cochabamba", en Susana Novick (comp.) Las migraciones en América Latina. Políticas, culturas y estrategias. Buenos Aires, Catálogos / CLACSO.

Hinojosa Gordonava, Alfonso (2009) Buscando la vida. Familias bolivianas transnacionales en España. La Paz: CLACSO / PIEB.

Hinojosa Gordonava, Alfonso; Guido Cortéz Franco y Liz Pérez Cautin (1998-99) "Estrategias migratorias: entre la subsistencia y la búsqueda de oportunidades en el valle tarijeño", en Estudios Migratorios Latinoamericanos, vol. 13/14, núm. 40-41.

Hirsch, Silvia (1999) "Mbaporenda: El lugar donde hay trabajo. Migraciones guaraníes al noroeste argentino", en Etnohistoria (CD-Rom). Buenos Aires: Noticias de Antropología $y \quad$ Arqueología. [En línea: <http://www.etnohistoria.com.ar/htm/04 articulo.htm>].

Hirsch, Silvia (2000) "Tirando el mal del otro lado de la frontera: brujería e identidad cultural entre los guaraníes de Bolivia y Argentina", en Revista de Investigaciones Folclóricas, vol. 15.

Hollifield, James (1992) "Migration and International Relations: Cooperation and Control in the European Community", en International Migration Review, vol. 26, núm. 2.

Hollifield, James (2004) "The Emerging Migration State", en International Migration Review, vol. 38, núm. 3.

Hopenhayn, Martín y Álvaro Bello (2001) Discriminación étnico-racial y xenofobia en América Latina y el Caribe. Santiago de Chile: CEPAL.

INDEC (1996) La población no nativa de la Argentina 1869-1991. Buenos Aires: INDEC.

INDEC (1997) La migración internacional en la Argentina: sus características e impacto. Buenos Aires: INDEC.

Izaguirre, Inés (2004) "La ideología de la seguridad nacional. Ayer y hoy", en Daniel Feierstein y Guillermo Levi (eds.), Hasta que la muerte nos separe. La Plata: Al Margen.

Izaguirre, Inés (2006) "Nuevas consideraciones sobre la ideología de la Seguridad Nacional", en Irma Antognazzi y Luis A. Lobato, comps., Historia y memoria colectiva. Dos polos de una unidad. Rosario: UNR.

Jelin, Elizabeth (2006) "Migraciones y derechos: instituciones y prácticas sociales en la construcción de la igualdad y la diferencia", en Alejandro Grimson y Elizabeth Jelin, comps., Migraciones regionales hacia la Argentina. Diferencia, desigualdad y derechos. Buenos Aires: Prometeo.

Jelin, Elizabeth, Alejandro Grimson y Nina Zamberlin (2006a) “Servicio? ¿Derecho? ¿Amenaza? La llegada de inmigrantes de países limítrofes a los servicios públicos de salud", en Elizabeth Jelin, dir., Salud y migración regional: Ciudadanía, discriminación y comunicación intercultural. Buenos Aires: IDES. 
Jelin, Elizabeth, Alejandro Grimson y Nina Zamberlin (2006b) "Los pacientes extranjeros en la mira", en Elizabeth Jelin, dir., Salud y migración regional: Ciudadanía, discriminación y comunicación intercultural. Buenos Aires: IDES.

Jensen Solivellas, María Florencia (2009) "Inmigrantes en Chile: la exclusión vista desde la política migratoria chilena”, en Eduardo Bologna, org., Temáticas migratorias actuales en América Latina: remesas, políticas y emigración. Rio de Janeiro: ALAP.

Juliano, Dolores (1987) "El discreto encanto de la adscripción étnica voluntaria", en Roberto Ringuelet, comp., Procesos de contacto interétnico. Buenos Aires: Búsqueda.

Juliano, Dolores, (1994) "La construcción de la diferencia: los latinoamericanos", en Papers, núm. 43.

Karasik, Gabriela (1992) "Plaza Grande y Plaza Chica: Etnicidad y poder en la Quebrada de Humahuaca", en Cultura e identidad en el Noroeste argentino. Buenos Aires: Centro Editor de América Latina.

Karasik, Gabriela (2000) "Tras la genealogía del diablo. Discusiones sobre la nación y el Estado en la frontera argentino-boliviana", en Alejandro Grimson, comp., Fronteras, naciones e identidades. La periferia como centro. Buenos Aires: CICCUS/La Crujía.

Karasik, Gabriela y Roberto Benencia (1999) "Apuntes sobre la migración fronteriza. Trabajadores bolivianos en Jujuy", en Estudios Migratorios Latinoamericanos, año 13/14, núm. 40.

Kearney, Michael (1986) "From the invisible hand to visible feet: Anthropological studies of migration and development", en Annual Review of Anthropology, vol. 15.

Kincheloe, Joe y Shirley Steinberg (1999) Repensar el multiculturalismo. Barcelona: Octaedro.

Klein, Herbert (2002[1982]) Historia de Bolivia, tercera edición aumentada y corregida. La Paz: Librería Editorial G.U.M.

Kymlicka, Will (1996): Ciudadanía multicultural. Una teoría liberal de las minorías. Barcelona: Paidós.

Lattes, Alfredo y Rodolfo Bertoncello (1997) “Dinámica demográfica, migración limítrofe y actividad económica en Buenos Aires", en Estudios Migratorios Latinoamericanos, vol. 12, núm. 35.

Lattes, Alfredo, Pablo Comelatto y Cecilia Levit (2003) “Migración internacional y dinámica demográfica en la Argentina, durante la segunda mitad del siglo XX", en Estudios Migratorios Latinoamericanos, año 17, núm. 50.

Lazzari, Axel (2004) “Antropología en el Estado: el Instituto Étnico Nacional (1946-1955)”, en Federico Neiburg y Mariano Plotkin, comps., Intelectuales y expertos. La constitución del conocimiento social en la Argentina. Buenos Aires: Paidós.

Leal Buitrago, Francisco (2003) "La Doctrina de Seguridad Nacional: materialización de la Guerra Fría en América del Sur", en Estudios Sociales, núm. 15.

Levitt, Peggy y Nina Glick-Schiller (2004) "Conceptualizing simultaneity: a transnational social field perspective on society", en International Migration Review, vol. 38, núm. 3.

Lionetti, Lucía (2005) "La función republicana de la escuela pública. La formación del ciudadano en Argentina a fines del siglo XIX", en Revista Mexicana de Investigación Educativa, año vol.10, núm. 27.

López Sala, Ana (2005a) Inmigrantes y Estados: la respuesta política ante la cuestión migratoria. Barcelona: Anthropos. 
López Sala, Ana (2005b) El control de la inmigración: política fronteriza, selección del acceso e inmigración irregular, en Arbor, vol. 181, núm. 713.

Machado, Igor José de Renó (2004) "Estado-nação, identidade-para-o-mercado e representações de nação", en Revista de Antropologia, vol.47, núm. 1.

Magliano, María José (2009) El rol de la mujer boliviana en el proceso migratorio hacia Córdoba, 1947-2001. Tesis doctoral, Universidad Nacional de Córdoba.

Maguid, Alicia (1995) "Migrantes limítrofes en la Argentina: su inserción e impacto en el mercado de trabajo", en Estudios del Trabajo, núm. 10.

Maguid, Alicia (1997) "Migrantes limítrofes en el mercado de trabajo del Área Metropolitana de Buenos Aires, 1980-1996", en Estudios Migratorios Latinoamericanos, año 12, núm. 35.

Maguid, Alicia (2006) "Migración internacional: factores socioeconómicos y políticas migratorias en el Cono Sur de América Latina", en Carlos Gonzalez Gutiérrez, Relaciones Estado-diáspora: la perspectiva de América Latina y el Caribe, tomo II. México D.F.: SRE-IME / Universidad Autónoma de Zacatecas / ANUIES / Miguel Ángel Porrúa.

Mallimaci, Ana Inés (2010) Construyendo comunidades. Géneros, tiempos, espacios y memorias de los/as bolivianos/as en Ushuaia. Tesis doctoral, Universidad de Buenos Aires.

Mansilla, H.C.F. (1997) "La identidad colectiva boliviana. Tradiciones y coerciones universalistas", en Nueva Sociedad, núm. 152.

Margheritis, Ana (2011) “Todos somos migrantes (We are all migrants). The Paradoxes of Innovative State-Led Transnationalism in Ecuador", en International Political Sociology, vol. 5, núm. 2.

Margulis, Mario; Urresti, Marcelo y otros (1998) La segregación negada. Cultura y discriminación social. Buenos Aires, Biblos.

Mármora, Lelio (1988) "La fundamentación de las políticas migratorias internacionales en América latina", en Estudios Migratorios Latinoamericanos, año 3, núm. 10.

Mármora, Lelio (1994) "Migraciones en América Latina: lógicas políticas e integración regional", en Dora Celton, comp., Problemas de población en América Latina. Córdoba: CEA-UNC.

Mármora, Lelio (1996) "El desafío de las políticas migratorias: su gobernabilidad”, en Dora Celton, coord., Migración, integración regional y transformación productiva. Córdoba, CEA-UNC.

Mármora, Lelio (2002) Las políticas de migraciones internacionales. Buenos Aires: Paidós / OIM.

Mármora, Lelio (2003) "Políticas migratorias consensuadas en América Latina” en Estudios Migratorios Latinoamericanos, año 17, núm. 50.

Mármora, Lelio (2004) "Las leyes de migraciones como contexto normativo (De la "Ley Videla" a la Ley de Migraciones 25.871)" en Rubén Giustiniani, comp., Migración: un derecho humano. Buenos Aires: Prometeo.

Marquiegui, Dedier (2005) "Pluralismo social y cultural, crisol de razas y multiculturalismo en el estudio de las migraciones masivas a la Argentina: una mirada histórica retrospectiva", en Astrolabio, núm. 2. Disponible en: 
Marshall, Adriana y Dora Orlansky (1981) "Las condiciones de expulsión en la determinación del proceso emigratorio desde países limítrofes hacia la Argentina", en Desarrollo Económico, vol. 20, núm. 80.

Marshall, Adriana y Dora Orlansky (1983) "Inmigración de países limítrofes y demanda de mano de obra en la Argentina, 1940-1980", en Desarrollo Económico, vol. 23, núm. 89.

Martine, George, Ralph Hakkert y José Miguel Guzmán (2001) "Aspectos sociales de la migración internacional: consideraciones preliminares", en La migración internacional y el desarrollo en las Américas: Simposio sobre migración internacional en las Américas: San José de Costa Rica: CEPAL-CELADE/BID/OIM/FNUAP.

Martínez Pizarro, Jorge (2001) "Reflexiones sobre la gobernabilidad de la migración internacional en América Latina”, en Migraciones Internacionales, vol. I, núm. 1.

Martínez Pizarro, Jorge y Fernanda Stang (2006) "El tratamiento migratorio en los espacios de integración subregional sudamericana”, en Papeles de Población, núm. 48.

Martínez Pizarro, Jorge (2005) "Reseña de 'La era de la migración. Movimientos internacionales de población en el mundo moderno' de Stephen Castles y Mark J. Miller", en Migraciones Internacionales, vol.3, núm. 2.

Masseroni, Susana y Natalia Ponisio (2005) "Europeos del Este en la Argentina. Experiencia migratoria, nostalgia y memoria", en Néstor Cohen y Carolina Mera., comps., Relaciones interculturales: experiencias y representación social de los migrantes. Buenos Aires: Antropofagia.

Massey, Douglas (1990) "The Social and Economic Origins of Immigration", en The Annals of the American Academy of Political and Social Science, vol. 510, núm. 1.

Mato, Daniel (2001) "Producción transnacional de representaciones sociales y transformaciones sociales en tiempos de globalización" en Daniel Mato, comp., Estudios latinoamericanos sobre cultura y transformaciones sociales en tiempos de globalización. Buenos Aires: CLACSO.

Mato, Daniel (2004) "Redes transnacionales de actores globales y locales en la producción de representaciones de ideas de sociedad civil" en Daniel Mato, coord., Políticas de ciudadanía y sociedad civil en tiempos de globalización. Caracas: FACES, Universidad Central de Venezuela.

Mayorga, René (1999) "La democracia o el desafío de la modernización política”, en Fernando Campero, dir., Bolivia en el siglo XX. La formación de la Bolivia contemporánea. La Paz: Harvard Club de Bolivia.

McCarthy, Cameron (1999) "Enfoques multiculturales de la desigualdad racial en Estados Unidos” en Mariano Enguita, ed., Sociología de la Educación. Barcelona: Ariel.

McLaren, Peter (1997) Pedagogía crítica y cultura depredadora. Políticas de oposición en la era posmoderna. Barcelona: Paidós.

Meichtry, Norma y Hugo Beck (1999) Caracterización Demográfica de la Inmigración Limítrofe en el Nordeste de Argentina. Resistencia: Instituto de Investigaciones Geohistóricas, CONICET / UNNE.

Mera, Carolina (1998) La inmigración coreana en Buenos Aires. Multiculturalismo en el espacio urbano. Buenos Aires. Eudeba.

Mera, Carolina, Liliana Palacios de Cosiansi y Carmen González (2005) Coreanos en Argentina: 40 años de historia. La Plata: Al Margen. 
Meyers, Eytan (2000) "Theories of International Immigration policy-A Comparative analysis", en International Migration Review, vol. 34, núm. 4.

Mezzadra, Sandro (2005) Derecho de fuga. Migraciones, ciudadanía y globalización. Madrid: Tinta limón / Traficantes de sueños.

Mezzadra, Sandro (2012) "Capitalismo, migraciones y luchas sociales. La mirada de la autonomía", en Nueva Sociedad, núm. 237.

Montesinos, María Paula (2005) "En torno a la diversidad sociocultural. Algunas relaciones posibles entre migraciones, Estado, sociedad y educación en Argentina”, en Eduardo Domenech, comp., Migraciones contemporáneas y diversidad cultural en la Argentina. Córdoba: CEA-UNC.

Mugarza, Susana (1985) "Presencia y ausencia boliviana en la ciudad de Buenos Aires" en Estudios Migratorios Latinoamericanos, año 1, núm. 1.

Muñoz, Humberto y Orlandina de Oliveira (1972) "Notas acerca de la teoría de las migraciones internas: aspectos sociológicos" en Humberto Muñoz, Orlandina de Oliveira, Paul Singer y Claudio Stern, Migración y Desarrollo. Consideraciones teóricas. Buenos Aires: CLACSO.

Neufeld, María Rosa y Jens Ariel Thisted, comps., (1999) De eso no se habla... Los usos de la diversidad sociocultural en la escuela. Buenos Aires, Eudeba.

Nicolao, Julieta (2010) "El Estado argentino ante el reto de las migraciones internacionales: reflexiones del reciente cambio de rumbo en la política migratoria argentina", en Convergencia. Revista de Ciencias Sociales, núm. 53.

Nina, Andrés (1979) "La doctrina de seguridad nacional y la integración latinoamericana", en Nueva Sociedad, núm. 27.

Novaro, Gabriela (1999) "El tratamiento de la migración en los contenidos escolares. Nacionalismo, integración y marginación", en María Rosa Neufeld y Jens Ariel Thisted, comps., De eso no se habla... Los usos de la diversidad sociocultural en la escuela. Buenos Aires: Eudeba.

Novaro, Gabriela (2002) Nacionalismo y diversidad cultural en educación. Un análisis antropológico de los contenidos escolares. Tesis doctoral, Universidad de Buenos Aires.

Novaro, Gabriela (2005) "Nacionalismo escolar y migraciones en educación: de las 'hordas cosmopolitas' a los 'trabajadores competentes', en Eduardo Domenech, comp., Migraciones contemporáneas y diversidad cultural en la Argentina. Córdoba: CEAUNC.

Novaro, Gabriela, Laureano Borton, María Laura Diez, Ana Carolina Hecht (2008) "Sonidos del silencio, voces silenciadas. Niños indígenas y migrantes en escuelas de Buenos Aires", en Revista Mexicana de Investigación Educativa, vol. 13, núm. 36.

Novick, Susana (1986) "Las políticas inmigratorias argentinas en su expresión jurídica. Una perspectiva secular”, en Estudios Migratorios Latinoamericanos, año 2, núm. 2.

Novick, Susana (1992) Política y población. Argentina 1870-1989. Buenos Aires: Centro Editor de América Latina.

Novick, Susana (1997) "Políticas migratorias en la Argentina", en Enrique Oteiza, Susana Novick y Roberto Aruj, Inmigración y discriminación. Políticas y discursos. Buenos Aires: Grupo Editor Universitario.

Novick, Susana (2001) Democracia y Población: Argentina 1983-1999. Documentos de Trabajo del IIGG, Universidad de Buenos Aires, núm. 28. 
Novick, Susana (2004) "Una nueva ley para un nuevo modelo de desarrollo en un contexto de crisis y consenso" en Rubén Giustiniani, comp., Migración: un derecho humano. Buenos Aires: Prometeo.

Novick, Susana (2005) "La reciente política migratoria en el contexto del Mercosur" en Novick, Susana; Hener, Alejandro y Pablo Dalle, en El proceso de integración Mercosur: de las políticas migratorias y de seguridad a las trayectorias de los inmigrantes. Documentos de Trabajo del IIGG, Universidad de Buenos Aires, núm. 46.

Novick, Susana (2008) "Migración y políticas en Argentina: Tres leyes para un país extenso (1876-2004)", en Susana Novick, comp., Las migraciones en América Latina. Políticas, culturas y estrategias. Buenos Aires: Catálogos / CLACSO.

Novick, Susana, Alejandro Hener y Pablo Dalle (2005) El proceso de integración Mercosur: de las políticas migratorias y de seguridad a las trayectorias de los inmigrantes. Documentos de Trabajo del IIGG, Universidad de Buenos Aires, núm. 46.

Novick, Susana, dir., (2007) Sur-Norte. Estudios sobre la emigración reciente de argentinos. Buenos Aires: Catálogos.

Olorón, Cecilia (2000) "Imágenes de unos rituales escolares", en Silvina Gvirtz, comp., Textos para repensar el día escolar. Sobre cuerpos, vestuarios, espacios, lenguajes, ritos y modos de convivencia en nuestra escuela. Buenos Aires: Santillana.

Olrog, Claudia y Carmela Vives (1999). "La normativa migratoria. Su papel en la producción de discursos y representaciones sobre los inmigrantes", en María Rosa Neufeld y Ariel Thisted, comps., De eso no se habla... los usos de la diversidad sociocultural en la escuela. Buenos Aires: Eudeba.

Ortiz, Claudia (2005) "Proyectos político-culturales de las organizaciones de inmigrados: estrategias para la reterritorialización del desarraigo", en Eduardo Domenech, comp., Migraciones contemporáneas y diversidad cultural en la Argentina. Córdoba: CEA-UNC.

Ortiz, Claudia (2006) El Centro de Residentes Bolivianos: un espacio de construcción identitaria. Un estudio de caso en la ciudad de Córdoba (1990-2000). Tesis de maestría, Universidad Nacional de Córdoba.

Ortiz, Claudia (2009) "Agendas Institucionales locales en torno a la nueva Ley de Migraciones: aspectos preliminares de su constitución. El caso de la ciudad de Córdoba" en Eduardo Domenech, comp., Migración y política: el Estado interrogado. Procesos actuales en Argentina y Sudamérica. Córdoba: Universidad Nacional de Córdoba.

Oszlak, Oscar (2004[1997]) La formación del Estado argentino: orden, progreso y organización nacional. Buenos Aires: Planeta.

Oteiza, Enrique (2004) "Hacia una nueva política migratoria argentina: inmigración, integración y derechos humanos", en Rubén Giustiniani, comp., Migración: un derecho humano. Buenos Aires: Prometeo.

Oteiza, Enrique y Roberto Aruj (1997) "Inmigración real, inmigración imaginaria y discriminación en la Argentina" en Enrique Oteiza, Susana Novick y Roberto Aruj, Inmigración y discriminación. Políticas y discursos. Buenos Aires: Grupo Editor Universitario.

Oteiza, Enrique y Novick, Susana (2000) Inmigración y derechos humanos. Política y discurso en el tramo final del menemismo. Documentos de Trabajo del IIGG, Universidad de Buenos Aires, núm. 14. 
Pacecca, María Inés (2000) "Legislación, migración limítrofe y vulnerabilidad social", en Realidad Económica, núm. 171.

Pacecca, María Inés (2001) Migrantes de ultramar, migrantes limítrofes. Políticas migratorias y procesos clasificatorios. Argentina, 1945-1970. Informe final, Programa Regional de Becas CLACSO [En línea: $<\underline{\text { http://bibliotecavirtual.clacso.org.ar/ar/libros/becas/2000/pacecca.pdf }>\text { ]. }}$.

Pacecca, María Inés (2003) "El fantasma en la máquina: la praxis política de los extranjeros y la ley de Residencia", en Susana Villavicencio, ed., Los contornos de la ciudadanía. Nacionales y extranjeros en la Argentina del Centenario. Buenos Aires: Eudeba.

Pacecca, María Inés y Corina Courtis (2008) Inmigración contemporánea en Argentina: dinámicas y políticas. Santiago de Chile: CEPAL.

Pallma, Sara y Liliana Sinisi (2004) "Tras las huellas de la etnografía educativa. Aportes para una reflexión teórico-metodológica”, en Cuadernos de Antropología Social, núm 19.

Paz Soldán, Edmundo (2000) “Obsesivas señas de identidad: los bolivianos en los Estados Unidos” en Alejandro Grimson y Edmundo Paz Soldán, Migrantes bolivianos en la Argentina y Estados Unidos, PNUD, Cuaderno de Futuro, núm. 7.

Penchaszadeh, Ana Paula (2008) "La cuestión del extranjero. Una mirada desde la teoría de Simmel”, en Revista Colombiana de Sociología, núm. 31.

Peñaloza Chej, María Teresa, Soledad Guzmán Villarroel, Luis Rojas Vaca (2008) Dinámicas socioculturales en construcción. El caso de los/as migrantes transnacionales de Cochabamba. Informe de investigación, PIEB, La Paz.

Pérez Vichich, Nora (1988) "Las políticas migratorias en la legislación argentina" en Estudios Migratorios Latinoamericanos, año 3, núm. 10.

Pérez Vichich, Nora (2004) "Los trabajadores migrantes en la nueva ley de migraciones: de objeto de normas a sujetos de derecho" en Rubén Giustiniani, comp., Migración: un derecho humano. Buenos Aires: Prometeo.

Petracci, Mónica, Luis Quevedo y Ariana Vacchieri (1998) "Las políticas comunicacionales del SIDA y del cólera 1991-1993", en ZER Revista de Estudios de Comunicación, núm. 4.

Phizacklea, Annie (1984) “A sociology of migration or 'race relations'? A view from Britain”, en Current Sociology, vol. 32, núm. 3.

Pizarro, Cynthia (2009) "La vulnerabilidad de los inmigrantes bolivianos como sujetos de derechos humanos: experimentando la exclusión y la discriminación en la región metropolitana de la ciudad de Córdoba". Informe del Concurso de Proyectos de Investigación sobre Discriminación 2008, Instituto Nacional contra la Discriminación, la Xenofobia y el Racismo, Ministerio de Justicia, Seguridad y Derechos Humanos, Gobierno de la República Argentina. [En línea: $<$ http://www.inadi.gov.ar/inadiweb/index.php?option=com content\&view=article \&id=1410\&Itemid $=22>$ ].

Pizarro, Cynthia, ed., (2011) Ser "boliviano" en la Región Metropolitana de la Ciudad de Córdoba. Localización socio-espacial, mercado de trabajo y relaciones interculturales. Córdoba: Universidad Católica de Córdoba.

Portes, Alejandro (1997) "Immigration Theory for a New Century: Some Problems and Opportunities”, en International Migration Review, vol. 31, núm. 4.

Portes, Alejandro (2001) "Debates y significación del transnacionalismo de los inmigrantes", en Estudios Migratorios Latinoamericanos, año 16, núm. 49. 
Portes, Alejandro (2003) "Conclusion: Theoretical Convergencies and Empirical Evidence in the Study of Immigrant Transnationalism", en International Migration Review, vol. 37, núm. 3.

Portes, Alejandro (2004) "La sociología en el continente: convergencias pretéritas y una nueva agenda de alcance medio", en Revista Mexicana de Sociología, año 66, núm.3.

Portes, Alejandro y John Walton (1981) Labor, Class, and the International System. Nueva York: Academic Press.

Portes, Alejandro y Josh DeWind, coord., (2006) Repensando las migraciones Nuevas perspectivas teóricas y empíricas. México D.F.: Miguel Ángel Porrua, UAZ, Secretaría de Gobernación Instituto Nacional de Migración.

Pousadela, Inés (2011) "Introducción" en AA.VV. Las izquierdas latinoamericanas: de la oposición al poder. Buenos Aires: CLACSO.

Quinteros, Marcela (2008) Os Olhos da Nação. As imagens construídas sobre o estrangeiro nas políticas imigratórias argentinas (1930-1955). Curitiba: Instituto Memória.

Ramírez Gallegos, Jacques y Yolanda Alfaro Aramayo (2010) "Espacios multilaterales de diálogo migratorio: el proceso Puebla y la Conferencia Sudamericana de Migración", en AndinaMigrante, núm. 9.

Rea, Andrea y Maryse Tripier (2003) Sociologie de l'immigration. Paris: La Découverte.

Recalde, Héctor (1987) El Primer Congreso Pedagógico (1882). Buenos Aires: Centro Editor de América Latina.

Ribeiro, Gustavo (1996) "Globalización y transnacionalización. Perspectivas antropológicas y latinoamericanas” en Série Antropologia, núm. 199.

Rivera Sánchez, Liliana y Fernando Lozano Ascencio, coords., (2009) Encuentros disciplinarios y debates metodológicos. La práctica de la investigación sobre migraciones y movilidades. México D.F.: UNAM-CRIM / Miguel Ángel Porrúa.

Rockwell, Elsie (2009) La experiencia etnográfica. Historia y cultura en los procesos educativos. Buenos Aires: Paidós.

Román Arnez, Olivia (2008) Mientras no estamos. Estudio de caso sobre la migración de mujeres-madres de Cochabamba (Bolivia) a España. Tesis de Maestría, Universidad Andina Simón Bolívar (Sede Quito).

Romano, Silvina (2009) "Integración económica, desarrollo y migraciones en el MERCOSUR. Una aproximación crítica”, en Eduardo Domenech, comp., Migración y política: el Estado interrogado. Procesos actuales en Argentina y Sudamérica. Córdoba: Universidad Nacional de Córdoba.

Romero, Luis Alberto, coord., (2004) La Argentina en la escuela: La idea de nación en los textos escolares. Buenos Aires: Siglo XXI.

Ruibal, Beatriz (1993) Ideología del control social, Buenos Aires 1880-1920. Buenos Aires: Centro Editor de América Latina.

Sabarots, Horacio (2002) La construcción de estereotipos en base a inmigrantes 'legales' e 'ilegales' en la Argentina, en Intersecciones en Antropología, núm. 3.

Sagastizábal, María de los Ángeles y otros (2000) Diversidad cultural y fracaso escolar. Educación intercultural: de la teoría a la práctica. Rosario: IRICE.

Sala, Gabriela (2000) "Mano de obra boliviana en el tabaco y la caña de azúcar en Jujuy, Argentina", en Estudios Migratorios Latinoamericanos, año 15, núm. 45. 
Sala, Gabriela (2002) Entre el temor y la exclusión: acciones de salud dirigidas a migrantes bolivianos y acciones sanitarias en la frontera norte de Argentina. Ponencia presentada en el XIII Encontro da Associação Brasileira de Estudos Populacionais (Ouro Preto, Minas Gerais, Brasil).

Sánchez Alonso, Blanca (2004) "Algunas reflexiones sobre las políticas de inmigración en América Latina en la época de las migraciones de masas", en Estudios Migratorios Latinoamericanos, año 18, núm. 53.

Santamaría, Enrique (1994) “Extranjero', nada menos que una palabra mayor”, en Papers, núm. 43.

Santamaría, Enrique (2002) “La incógnita del extraño: una aproximación a la significación sociológica de la 'inmigración no Comunitaria'”. Rubí, Barcelona: Anthropos.

Santos Boaventura de Sousa (2010) Refundación del Estado en América Latina: Perspectivas desde una epistemología del sur. La Paz: Plural.

Santos, Boaventura de Sousa, org., (2003) Reconhecer para libertar. Os caminhos do cosmopolitismo multicultural. Rio de Janeiro, RJ: Civilizaçao Brasileira.

Sartori, Giovanni (2001) La sociedad multiétnica. Pluralismo, multiculturalismo y extranjeros. Madrid: Taurus.

Sassen, Saskia (2001) ¿Perdiendo el control? La soberanía en la era de la globalización. Barcelona: Bellaterra.

Sassen, Saskia (2003) Los espectros de la globalización. Buenos Aires: Fondo de Cultura Económica.

Sassen-Koob, Saskia (1988) The Mobility of Labor and Capital. A Study in International Investment and Labor Flow. Cambridge: Cambridge University Press.

Sassone, Susana (1987) "Migraciones ilegales y amnistías en la Argentina", en Estudios Migratorios Latinoamericanos, año 2, núm. 6-7.

Sassone, Susana (1988) "Migraciones laborales y cambio tecnológico. El caso de los bolivianos en el Ramal jujeño", en Cuadernos de Antropología Social, vol. 1, núm. 1.

Sassone, Susana (2002) Geografías de la Exclusión. La inmigración limítrofe indocumentada en la Argentina. Del Sistema-Mundo al Lugar. Tesis doctoral, Universidad Nacional de Cuyo.

Sayad, Abdelmalek (1979) “Qu'est-ce qu'un immigré?”, en Peuples Méditerranéens, núm. 7.

Sayad, Abdelmalek (1984a) "État, nation et immigration: l'ordre national à l'épreuve de l'immigration", en Peuples méditerranéens, núm. 27-28 [Traducción al castellano: "Estado, nación e inmigración. El orden nacional ante el desafío de la inmigración", Apuntes de Investigación del CECYP, núm. 13, 2008].

Sayad, Abdelmalek (1984b) "Tendances et courants des publications en sciences sociales sur l'immigration en France depuis 1960", en Current Sociology, vol. 32, núm. 3, tomo 2.

Sayad, Abdelmalek (1989) "Elements pour une sociologie de l'immigration", en Cahiers internationaux de psychologie sociale, núm. 2-3 [Traducción al castellano en Empiria. Revista de Metodología de Ciencias Sociales, núm. 19, 2010].

Sayad, Abdelmalek (1996) "Entrevista. Colonialismo e migracoès", en Mana. Estudios em antropologia social, vol. 2, núm. 1 [Traducción al castellano en Empiria. Revista de Metodología de Ciencias Sociales, núm. 19, 2010]. 
Sayad, Abdelmalek (1998) "Le retour, élément constitutif de la condition de l'immigré", Migrations sociétés, vol. 10, núm. 57 [Traducción al castellano en Empiria. Revista de Metodología de Ciencias Sociales, núm. 19, 2010].

Sayad, Abdelmalek (1998) A imigracão ou os paradoxos da alteridade. San Pablo: EDUSP.

Sayad, Abdelmalek (1999) La double absence. Des illusions de l'émigré aux souffrances de l'immigré. Paris: Seuil. [Traducción al castellano: La doble ausencia. De las ilusiones del emigrado a los padecimientos del inmigrado, Anthropos, Barcelona, 2011].

Sayad, Abdelmalek (2000) "O retorno. Elemento constitutivo da condiçao do imigrante", en Travessia. Revista do Migrante, año 13, número especial.

Sayad, Abdelmalek (2008) “Estado, nación e inmigración. El orden nacional ante el desafío de la inmigración", Apuntes de Investigación del CECYP, núm. 13.

Schmitter-Heisler, Barbara (2008[2000]) "The Sociology of Immigration: From Assimilation to Segmented; Assimilation, from the American Experience to the Global Arena", en Caroline B. Brettell y James F. Hollifield, Migration Theory: Talking Across Disciplines (segunda edición). Nueva York: Routledge.

Seeghers Vargas, Patricia y José Téllez Flores (2007) Reflexiones sobre una política migratoria en Bolivia. La Paz: Fondo Editorial de los Diputados.

Senkman, Leonardo (1985) "Política internacional e inmigración europea en la Argentina de post-guerra (1945-1948). El caso de los refugiados", en Estudios Migratorios Latinoamericanos, año 1, núm. 1.

Shore, Cris y Susan Wright (1997) "Policy: A New Field of Anthropology", en Cris Shore and Susan Wright, eds., Anthropology of Policy. London: Routledge.

Silva, Sidney da (1997) Costurando sonhos. Trajetória de um grupo de imigrantes bolivianos en São Paulo. Sn Pablo: Paulinas.

Silva, Sidney da (2005) Bolivianos. A presença da cultura andina. San Pablo: Lazuli.

Silva, Sidney da (2006) "Bolivianos em São Paulo: entre o sonho e a realidade", en Estudos Avançados, vol. 20, núm. 57.

Simmons, Alan (1991) "Explicando la migración: la teoría en la encrucijada" en Estudios Demográficos y Urbanos, vol. 6, núm. 1.

Sinisi, Liliana (1999) "La relación nosotros-otros en espacios escolares 'multiculturales': estigma, estereotipo y racialización”, en María Rosa Neufeld y Ariel Thisted, comps., De eso no se habla... Los usos de la diversidad sociocultural en la escuela. Buenos Aires: Eudeba.

Slipak, Daniela (2011) "Entre límites y fronteras: articulaciones y desplazamientos del discurso político en la Argentina pos-crisis (2002-2004)", en AA.VV. Las izquierdas latinoamericanas: de la oposición al poder. Buenos Aires: CLACSO.

Soria, Sofía (2011) Sistema educativo argentino y pueblos indígenas. Alcances de una política educativa Multi/Intercultural. Tesis doctoral, Nacional de Córdoba, Argentina.

Stang, María Fernanda "El migrante unidimensional. El dispositivo jurídico migratorio en la Comunidad Andina de Naciones", en Eduardo Domenech, comp., Migración y política: el Estado interrogado. Procesos actuales en Argentina y Sudamérica. Córdoba: Universidad Nacional de Córdoba.

Stefoni, Carolina (2011) "Ley y Política Migratoria en Chile. La ambivalencia en la comprensión del migrante", en Bela Feldman-Bianco, Liliana Rivera Sánchez, Carolina Stefoni y Marta Inés Villa Martínez, comps., La construcción social del sujeto 
migrante en América Latina: prácticas, representaciones y categorías. Quito: CLACSO / FLACSO-Ecuador / UAH.

Stolcke, Verena (1999) “La nueva retórica de la exclusión en Europa”, Revista Internacional de Ciencias Sociales, núm. 159.

Stuhldreher, Amalia (2006) "La problemática de la migración en América Latina: ¿De enfoques intergubernamentales hacia la transnacionalización de la política migratoria?" en Ingrid Wehr, ed., Un continente en movimiento: Migraciones en América Latina. Madrid / Frankfurt: Iberoamericana / Vervuert.

Suárez Navaz, Liliana (1999) "La construcción social del 'fetichismo de los papeles'. Ley e identidad en la frontera sur de Europa", en Actas del VIII Congreso de Antropología, vol. 4 (Santiago de Compostela).

Svampa, Maristella (2007) "Las fronteras del gobierno de Kirchner: entre la consolidación de lo viejo y las aspiraciones de lo nuevo", en Cuadernos del Cendes, año 24, núm. 65.

Taks, Javier (2006) "Migraciones internacionales en Uruguay: de pueblo trasplantado a diáspora vinculada", en Theomai, núm. 14.

Taks, Javier (2010) “Antecedentes y desafíos de las políticas de migración en Uruguay”, en Cristina Zurbriggen y Lenin Mondol, Estado actual y perspectivas de las políticas migratorias en el MERCOSUR. Montevideo: FLACSO-Uruguay / UNESCO.

Tapia Valdés, Jorge (1980) El terrorismo de Estado. La doctrina de Seguridad Nacional en el Cono Sur. México D.F.: Nueva Imagen.

Tapinos, Georges y Daniel Delaunay (2001) “'Se puede hablar realmente de la globalización de los flujos migratorios?" en Notas de Población, núm. 73.

Taylor, Charles (1993) El multiculturalismo y "la política del reconocimiento". México D.F.: Fondo de Cultura Económica.

Tedesco, Juan Carlos (2009[1986]) “Educación y Sociedad en la Argentina (1880-1945)”. Buenos Aires: Siglo XXI.

Terán, Oscar (2008) Historia de las ideas en la Argentina. Diez lecciones iniciales, 18101980. Buenos Aires: Siglo XXI.

Timur, Serim (2000) "Cambios en las tendencias y problemas fundamentales de la migración internacional: una perspectiva general de los programas de la UNESCO”, en Revista Internacional de Ciencias Sociales, núm. 165.

Torales, Ponciano; González, Estela y Pérez Vichich, Nora (2003) Migraciones laborales en Sudamérica: la Comunidad Andina, Oficina Internacional del Trabajo, Estudios sobre Migraciones Internacionales, núm. 60.

Torpey, John (2000) The Invention of the Passport. Survillance, Citizenship and the State. Cambridge: Cambridge University Press.

Torres, Carlos (1996) Las secretas aventuras del orden: Estado y educación. Buenos Aires: Miño y Dávila.

Torres, Carlos (2001) Educación, democracia y multiculturalismo. México D.F.: Siglo XXI.

Trpin, Verónica (2004) Aprender a ser chilenos. Identidad, trabajo y residencia de migrantes en el Alto Valle de Río Negro. Buenos Aires: Antropofagia.

Vacaflores, Víctor (2003) "Migración interna e intrarregional en Bolivia. Una de las caras del neoliberalismo" en Aportes Andinos, núm. 7. 
Vainer, Carlos (1995) Estado e migração internacional: da imigração à emigracão, en Neide Lopes Patarra, coord., Emigração e imigração internacionais no Brasil contemporâneo. San Pablo: FNUAP.

Valcarce, Federico Lorenc (2005) "La sociología de los problemas públicos. Una perspectiva crítica para el estudio de las relaciones entre la sociedad y la política", en Nómadas. Revista Crítica de Ciencias Sociales y Jurídicas, núm. 12.

Vargas, Patricia (2005) Bolivianos, paraguayos y argentinos en la obra: identidades étniconacionales entre los trabajadores de la construcción. Buenos Aires: Antropofagia.

Velásquez Rivera, Édgar de Jesús (2002) Historia de la Doctrina de Seguridad Nacional, en Convergencia, año 9, núm. 27.

Vertovec, Steven (1999) "Conceiving and Researching Transnationalism" en Ethnic and Racial Studies, vol. 22, núm. 2.

Villar, Juan (1972) Historia y significación de la migración boliviana en la Argentina. Tesis de licenciatura, Universidad Católica, Buenos Aires.

Villar, Juan Manuel (1975) Los migrantes de países limítrofes bolivianos en los ingenios azucareros de Salta y Jujuy. Oficina Sectorial de Desarrollo de Recursos Humanos del Ministerio del Interior, Buenos Aires.

Villar, Juan Manuel (1984) "Argentine Experience in the Field of Illegal Immigration”, en International Migration Review, vol. 18, núm. 3.

Vior, Eduardo (2008) "Tareas pendientes del estado argentino para ajustarse a la nueva política de inmigración", en Dora Celton, Mónica Ghirardi y Enrique Peláez, eds., El nexo entre ciencias sociales y políticas: migración, familia y envejecimiento. Córdoba: UNESCO / UNC.

Whiteford, Scott (1975) Urbanization of Rural Proletarians: Bolivian Migrant Workers in Northwest Argentina. Tesis doctoral, University of Texas.

Wimmer, Andreas (2003) "Methodological nationalism and the study of migration: beyond nation-state building", en International Migration Review, vol. 37, núm. 3.

Wimmer, Andreas y Nina Glick-Schiller (2002) "Methodological Nationalism and Beyond. Nation-state Building, Migration and the Social Sciences", en Global Networks, vol. 2, núm. 4.

Woods, Peter (1987) La escuela por dentro. La etnografía de la investigación educativa. Barcelona: Paidós.

Zalles Cueto, Alberto (2002) "El enjambramiento cultural de los bolivianos en la Argentina", en Nueva Sociedad, núm. 178.

Zelmanovich, Perla (1994) Efemérides, entre el mito y la historia. Buenos Aires: Paidós.

Zimmermann, Eduardo (1995) Los liberales reformistas. La cuestión social en la Argentina, 1890-1916. Buenos Aires: Sudamericana / Universidad de San Andrés.

Žižek, Slavoj (1998): "Multiculturalismo o la lógica del capitalismo multinacional”, en Fredic Jameson y Slavoj Žižek, Estudios Culturales. Reflexiones sobre el multiculturalismo. Buenos Aires: Paidós.

Zolberg, Aristide (1978) "International Migration Policies in a Changing World System" en William H. McNeill y Ruth S. Adams, eds., Human Migration: Patterns and policies. Bloomington: Indiana University Press.

Zolberg, Aristide (1981) "International Migrations in Political Perspective", en Mary Kritz, Charles Keely y Silvano Tomasi, eds., Global Trends in Migration: Theory and 
Research on International Population Movements. Nueva York: Center for Migration Studies.

Zolberg, Aristide (1989) “The Next Waves: Migration Theory for a Changing World”, en International Migration Review, vol. 23, núm. 3. 


\begin{tabular}{|c|c|c|c|}
\hline Nombre y/o apellido * & Rol o cargo & Fecha & Lugar \\
\hline Adelia & Madre de alumno/a & $25 / 09 / 02$ & $\begin{array}{c}\text { Sala de depósito de la } \\
\text { escuela }\end{array}$ \\
\hline Sonia & Madre de alumno/a & $25 / 09 / 02$ & $\begin{array}{c}\text { Sala de depósito de la } \\
\text { escuela }\end{array}$ \\
\hline Isabel & Madre de alumno/a & $26 / 09 / 02$ & $\begin{array}{c}\text { Sala de depósito de la } \\
\text { escuela }\end{array}$ \\
\hline César y Germán & $\begin{array}{l}\text { Alumnos de quinto } \\
\text { grado del turno mañana }\end{array}$ & $15 / 12 / 02$ & Aula de la escuela \\
\hline $\begin{array}{c}\text { Yamila, Jazmín, Maribel } \\
\text { y Romina }\end{array}$ & $\begin{array}{l}\text { Alumnas de quinto } \\
\text { grado del turno mañana }\end{array}$ & $15 / 12 / 02$ & Aula de la escuela \\
\hline María & Maestra de grado & $10 / 06 / 02$ & $\begin{array}{c}\text { Sala de maestros de la } \\
\text { escuela }\end{array}$ \\
\hline Soledad & Maestra de grado & $10 / 06 / 02$ & $\begin{array}{c}\text { Sala de maestros de la } \\
\text { escuela }\end{array}$ \\
\hline Nora & Maestra de grado & $12 / 06 / 02$ & $\begin{array}{c}\text { Sala de maestros de la } \\
\text { escuela }\end{array}$ \\
\hline Gabriela & $\begin{array}{c}\text { Integrante del equipo } \\
\text { de Atención a la } \\
\text { Diversidad del } \\
\text { Ministerio de Educación }\end{array}$ & $13 / 05 / 05$ & $\begin{array}{c}\text { Oficinas del Ministerio de } \\
\text { Educación de la Provincia } \\
\text { de Córdoba en el colegio } \\
\text { Carbó }\end{array}$ \\
\hline Mariela & $\begin{array}{l}\text { Integrante del equipo } \\
\text { de Atención a la } \\
\text { Diversidad del } \\
\text { Ministerio de Educación }\end{array}$ & $13 / 05 / 05$ & $\begin{array}{c}\text { Oficinas del Ministerio de } \\
\text { Educación de la Provincia } \\
\text { de Córdoba en el colegio } \\
\text { Carbó }\end{array}$ \\
\hline Alberto Rubio & $\begin{array}{c}\text { Jefe de la Delegación } \\
\text { Córdoba de la DNM }\end{array}$ & 05/07/05 & $\begin{array}{l}\text { Despacho de la delegación } \\
\text { regional de la Dirección } \\
\text { Nacional de Migraciones }\end{array}$ \\
\hline Adrián Agüero & $\begin{array}{l}\text { Director de Derechos } \\
\text { Humanos de la } \\
\text { Provincia de Córdoba }\end{array}$ & $23 / 05 / 07$ & $\begin{array}{l}\text { Despacho de la Dirección } \\
\text { de Derechos Humanos de } \\
\text { la Provincia de Córdoba }\end{array}$ \\
\hline Amalia Basualdo & $\begin{array}{c}\text { Defensoría del Pueblo } \\
\text { de la Provincia de } \\
\text { Córdoba }\end{array}$ & $23 / 05 / 07$ & $\begin{array}{c}\text { Despacho de la Defensoría } \\
\text { del Pueblo de la Provincia } \\
\text { de Córdoba }\end{array}$ \\
\hline Amalia Basualdo & Defensoría del Pueblo & $30 / 07 / 07$ & Despacho de la Defensoría \\
\hline
\end{tabular}




\begin{tabular}{|c|c|c|c|}
\hline Nombre y/o apellido * & Rol o cargo & Fecha & Lugar \\
\hline & $\begin{array}{l}\text { de la Provincia de } \\
\text { Córdoba }\end{array}$ & & $\begin{array}{c}\text { del Pueblo de la Provincia } \\
\text { de Córdoba }\end{array}$ \\
\hline Ulises Rojas & $\begin{array}{c}\text { Ministerio de Educación } \\
\text { de la Provincia de } \\
\text { Córdoba }\end{array}$ & $31 / 07 / 07$ & $\begin{array}{c}\text { Oficina del Ministerio de } \\
\text { Educación de la Provincia } \\
\text { de Córdoba }\end{array}$ \\
\hline Alberto Rubio & $\begin{array}{l}\text { Jefe de la Delegación } \\
\text { Córdoba de la DNM }\end{array}$ & $17 / 08 / 07$ & $\begin{array}{c}\text { Despacho de la delegación } \\
\text { regional de la Dirección } \\
\text { Nacional de Migraciones }\end{array}$ \\
\hline Doña Rosa & $\begin{array}{c}\text { Dueña del kiosco de la } \\
\text { escuela }\end{array}$ & $10 / 08 / 07$ & Aula de la escuela \\
\hline Marta & Profesora de plástica & $24 / 08 / 07$ & $\begin{array}{c}\text { Sala de maestros de la } \\
\text { escuela }\end{array}$ \\
\hline Valeria & Maestra de grado & $24 / 08 / 07$ & Biblioteca de la escuela \\
\hline Jimena & Maestra de grado & $25 / 08 / 07$ & Domicilio particular \\
\hline Frank Prieto Terán & $\begin{array}{l}\text { Presidente del Centro } \\
\text { de Residentes } \\
\text { Bolivianos en Córdoba }\end{array}$ & $28 / 09 / 07$ & $\begin{array}{c}\text { Sede del Centro de } \\
\text { Residentes Bolivianos en } \\
\text { Córdoba }\end{array}$ \\
\hline Ximena Guzmán & $\begin{array}{c}\text { Vicecónsul de Bolivia en } \\
\text { Córdoba }\end{array}$ & 02/10/07 & Bar-restaurante céntrico \\
\hline Silvana & $\begin{array}{c}\text { Maestra de grado, } \\
\text { vicedirectora } \\
\text { concursada }\end{array}$ & $30 / 11 / 07$ & Sala de dirección \\
\hline Mercedes & $\begin{array}{c}\text { Maestra de grado, } \\
\text { vicedirectora interina }\end{array}$ & $30 / 05 / 08$ & Biblioteca de la escuela \\
\hline Gloria & Maestra de grado & 02/06/08 & $\begin{array}{l}\text { Sala de maestros de la } \\
\text { escuela }\end{array}$ \\
\hline Pilar & $\begin{array}{c}\text { Maestra de grado, } \\
\text { vicedirectora interina }\end{array}$ & $04 / 06 / 08$ & Sala de dirección \\
\hline Estela & $\begin{array}{c}\text { Directora concursada } \\
(2002-2004)\end{array}$ & 06/06/08 & Domicilio particular \\
\hline Matías Delprato & $\begin{array}{c}\text { Profesional contratado } \\
\text { por el Ministerio de } \\
\text { Educación }\end{array}$ & 08/08/08 & Domicilio particular \\
\hline María Angélica & Supervisora de zona & $06 / 10 / 08$ & $\begin{array}{l}\text { Sede de la inspección de } \\
\text { zona }\end{array}$ \\
\hline
\end{tabular}




\begin{tabular}{|cccc|}
\hline Nombre y/o apellido * & Rol o cargo & Fecha & Lugar \\
\hline Carmen & $\begin{array}{c}\text { Maestra de grado, } \\
\text { vicedirectora } \\
\text { concursada (2003- } \\
\text { 2004) y directora } \\
\text { (2005- ) }\end{array}$ & & \\
& & & \\
\hline
\end{tabular}

* El nombre de docentes, directivos, madres y alumnos entrevistados ha sido reemplazado por nombres ficticios para asegurar el anonimato. 



\section{LEGISLACIÓN}

\section{Argentina: Migraciones}

Declaración del 4 de septiembre de 1812.

Ley N 817, Ley de Inmigración y Colonización, 19 de octubre de 1876.

Ley $\mathrm{N}^{\circ}$ 4.144, Ley de Residencia, 1902.

Ley Nº 7.029, Ley de Defensa Social, 1910.

Decreto, Reglamentación de la ley N 817, 31 de diciembre de 1923.

Decreto, Detención de indeseables que entran al país, 8 de noviembre de 1932.

Decreto, Restricción de la entrada de inmigrantes al país, 26 de noviembre de 1932.

Decreto, Entrada de pasajeros al país, 19 de enero de 1934.

Decreto, Contralor de ingreso de pasajeros al país, 17 de octubre de 1936.

Decreto $\mathrm{N}^{\circ} 142.845$, Establece que los capitanes de buques que arriben a puertos de la República Argentina deberán presentar ante la Dirección de Inmigración una copia del rol de tripulación debidamente legalizada, 16 de febrero de 1943.

Decreto $\mathrm{N}^{\circ} 1.162$, Dicta normas reglamentando obligaciones de las personas a las que como turistas o en cualquier otro carácter se les ha acordado permanencia temporaria en el país, 20 de enero de 1949.

Decreto $\mathrm{N}^{\circ}$ 15.972, Concede indulto general a extranjeros que ingresaron al país con violación de disposiciones legales o reglamentarias, 8 de julio de 1949.

Decreto $\mathrm{N}^{\circ}$ 24.666, Dispone se consideren radicados de hecho los extranjeros que acrediten residencia y arraigo en el país anterior al 8 de julio de 1949, 4 de octubre de 1949.

Decreto $\mathrm{N}^{\circ} 3.364$, Radicación legal de extranjeros ingresados de hecho al país antes del $1^{\circ}$ de mayo de 1958, 4 de agosto de 1958.

Decreto-ley $\mathrm{N}^{\circ}$ 4.805, Extranjeros; régimen de admisión, permanencia y expulsión del territorio de la República, 17 de junio de 1963.

Decreto $\mathrm{N}^{\circ} 49$, Radicación definitiva de extranjeros nativos de países limítrofes, 3 de enero de 1964.

Decreto $N^{\circ}$ 4.418, Reglamento de Migración, 4 de junio de 1965. 
Decreto $\mathrm{N}^{\circ}$ 5.144, Estudiará una Comisión Interministerial los problemas emergentes de la afluencia al país y permanencia en él de personas provenientes de países limítrofes, 20 de junio de 1965.

Decreto-ley $\mathrm{N}^{\circ}$ 17.294, Inmigración clandestina; prohibición de emplear o dar alojamiento en hoteles, casas de hospedaje, etc. a quienes no acrediten su residencia legal, 23 de mayo de 1967.

Decreto-ley $\mathrm{N}^{\circ}$ 17.489, Transporte ilegal de extranjeros al país; modificación del monto de las multas establecidas por el dec.-ley 4805/63, 23 de octubre de 1967.

Decreto-ley N¹8.235, Extranjeros; Expulsión de indeseables, 30 de mayo de 1969.

Decreto $\mathrm{N}^{\circ}$ 46, Políticas nacionales, 17 de junio de 1970.

Decreto N³.206, Reglamento de Migración; Modificación del art. 87, 20 de agosto de 1971.

Ley $N^{\circ}$ 19.349, Ley de Gendarmería Nacional, 25 de noviembre de 1971.

Decreto $\mathrm{N}^{\circ}$ 87, Migración; radicación definitiva de extranjeros nativos de países limítrofes que hayan ingresado en forma irregular; requisitos, 11 de enero de 1974.

Decreto $\mathrm{N}^{\circ} 1.483$, Migración; obligación de los extranjeros que se encuentren ilegalmente en el país de presentarse ante las autoridades migratorias; plazo, 26 de julio de 1976.

Decreto $\mathrm{N}^{\circ}$ 464, Migración; programas especiales de radicación e instalación de extranjeros en el país; organismo competente para su evaluación, 21 de febrero de 1977.

Decreto $\mathrm{N}^{\circ}$ 1.835, Migración; requisitos para obtener la radicación definitiva en el país, 24 de junio de 1977.

Decreto $\mathrm{N}^{\circ}$ 1.966, Migración; plazo para que los extranjeros que residen ilegalmente en el país se presenten ante las autoridades migratorias, 8 de julio de 1977.

Decreto $\mathrm{N}^{\circ}$ 3.938, Objetivos y políticas nacionales de Población, 29 de diciembre de 1977.

Ley $\mathrm{N}^{\circ} 22.439$, Ley General de Migraciones y de Fomento de la Inmigración, 23 de marzo de 1981.

Decreto $\mathrm{N}^{\circ}$ 1.434, Reglamentación de la Ley general de migraciones y fomento de la inmigración, 31 de agosto de 1987.

Decreto $\mathrm{N}^{\circ} 780$, Radicación definitiva de extranjeros, 12 de marzo de 1984.

Decreto $N^{\circ} 3.213$, Reglamentación de la Ley N²3.059, 28 de septiembre de 1984.

Decreto $\mathrm{N}^{\circ} 1.033$, Política migratoria para extranjeros nativos de países limítrofes residentes en territorio nacional, 24 de junio de 1992.

Decreto $\mathrm{N}^{\circ} 2.771$, Migración; Control de la situación legal de inmigrantes, 30 de diciembre de 1993. 
Resolución del Ministerio del Interior $\mathrm{N}^{\circ} 4.632$, Declárense inmigrantes procedentes de Europa Central y Oriental comprendidos en el artículo 15, inciso 11) del Decreto $\mathrm{N}^{\circ}$ 1434/87, 19 de febrero de 1994.

Decreto $N^{\circ}$ 1.023, Reglamento de Migración, 29 de junio de 1994.

Ley $N^{\circ} 24.393$, Modificación de la Ley N²2.439 Ley General de Migraciones y de Fomento de la Inmigración, 18 de noviembre de 1994.

Ley provincial $\mathrm{N}^{\circ} 5.043$, De censo migratorio y de análisis de la incidencia económica de la inmigración en la provincia de Jujuy, 12 de marzo de 1998.

Decreto ํㅜㄴ.117, Modifícanse los Decretos № 1434/87 y 1023/94 en relación a trámites migratorios que deben sujetarse al pago de tasas retributivas de servicios, 23 de septiembre de 1998.

Ley $N^{\circ} 25.098$, Apruébase un Convenio de Migración, suscripto con la República de Bolivia, 5 de mayo de 1999.

Ley $N^{\circ} 25.871$, Ley sobre Política Migratoria Argentina, 20 enero de 2004.

Disposición $\mathrm{N}^{\circ} 2.079$, Suspéndense las medidas de extrañamiento de los nacionales de los países limítrofes, con excepción de aquellas expulsiones que estuvieren fundadas en la existencia de antecedentes penales de los ciudadanos a los cuales se dirijan tales medidas, 28 de enero de 2004.

Decreto $\mathrm{N}^{\circ}$ 836, Declárase la emergencia administrativa del citado organismo descentralizado de la órbita del Ministerio del Interior. Facúltese a la mencionada Dirección Nacional a crear el Registro Nacional Único de Empleadores y Requirentes de Extranjeros y el Registro Nacional Único de Apoderados de Inmigrantes. Funcionamiento del Área de Asistencia e Información. Elaboración de un plan de acción para la regularización de los trámites pendientes, 7 de julio de 2004 .

Decreto $\mathrm{N}^{\circ} 1.169$, Regularización de la situación migratoria de ciudadanos nativos de países fuera de la órbita del MERCOSUR, que al 30 de junio de 2004 residan de hecho en el territorio nacional, 6 de septiembre de 2004.

Disposición $\mathrm{N}^{\circ} 29.929$, Suspéndense medidas de conminación a salir del país y expulsiones dispuestas respecto de ciudadanos nativos de la República del Perú, excepto aquellas que hubieren estado fundadas en la existencia de antecedentes penales o en situaciones encuadrables en los incisos a) a h) del artículo 29 de la Ley $\mathrm{N}^{\circ} 25.871,17$ de septiembre de 2004.

Disposición $\mathrm{N}^{\circ} 33.349$, Régimen especial de regularización migratoria dispuesto por el Decreto $N^{\circ} 1169 / 2004,8$ de octubre de 2004.

Disposición $\mathrm{N}^{\circ}$ 15.440, Créase el Registro Nacional de Admisión de Extranjeros, 27 de abril de 2005.

Disposición $N^{\circ}$ 15.441, Créase el Registro Nacional de Aptitud Migratoria, 27 de abril de 2005. 
Disposición $\mathrm{N}^{\circ}$ 15.442, Créase el Registro Nacional de Ingreso y Egreso de personas al territorio nacional, que contendrá la base de datos generales de almacenamiento electrónico y automatizado o manual respecto del ingreso y egreso de personas, $27 \mathrm{de}$ abril de 2005.

Decreto $\mathrm{N}^{\circ}$ 578, Dase por prorrogada la emergencia administrativa de la citada Dirección Nacional, organismo descentralizado actuante en la órbita del Ministerio del Interior, 2 de junio de 2005.

Disposición $\mathrm{N}^{\circ}$ 53.253, Programa Nacional de Normalización Documentaria Migratoria para extranjeros nativos de los estados parte del Mercado Común del Sur y sus Estados Asociados, 13 de diciembre de 2005.

Disposición $\mathrm{N}^{\circ}$ 6.726, Establécense subcategorías de admisión al Territorio Nacional, 14 de febrero de 2006.

Disposición $\mathrm{N}^{\circ}$ 14.954, Impleméntase un procedimiento especial de regularización que comprenderá a los ciudadanos nacionales de la República de Bolivia que hayan sido víctimas de explotación laboral en talleres clandestinos de costura o establecimientos similares, 11 de abril de 2006.

Disposición $\mathrm{N}^{\circ}$ 4.871, Apruébase el Instructivo para la Emisión de un Permiso de Ingreso y Visación Consular para personas nativas de los Estados Parte del Mercado Común del Sur y sus Estados Asociados, 8 de febrero de 2007.

Decreto $\mathrm{N}^{\circ} 616$, Reglamentación de la Ley de Migraciones $\mathrm{N}^{\circ} 25.871$ y sus modificatorias, 3 de mayo de 2010 .

\section{Argentina: Educación}

Ley N¹420, Ley de Educación Común, 1884.

Ley Nº 24.195, Ley Federal de Educación, 1993.

Resolución $\mathrm{N}^{\circ}$ 72, Consejo Federal de Cultura y Educación, Ministerio de Cultura y Educación, 1998.

Resolución $\mathrm{N}^{\circ}$ 107, Consejo Federal de Cultura y Educación, Ministerio de Cultura y Educación, 1999.

Resolución N 107, Anexo I, Consejo Federal de Cultura y Educación, Ministerio de Cultura y Educación, 1999.

Resolución N 107, Anexo II, Consejo Federal de Cultura y Educación, Ministerio de Cultura y Educación, 1999.

Ley $\mathrm{N}^{\circ}$ 26.206, Ley de Educación Nacional, 2006. 


\section{Bolivia: Migraciones}

Ley de Residencia, 18 de enero de 1911.

Ley, Requisitos que debe llenar todo extranjero que desee ingresar al país, 12 de enero de 1924.

Decreto Supremo, Reglamento de permisos de ingreso a Bolivia, 28 de enero de 1937.

Decreto Supremo, Clasificación oficial de extranjeros en Bolivia, 2 de agosto de 1937.

Decreto Supremo, Creación de la Dirección General de Extranjería y Turismo, 30 de septiembre de 1937.

Decreto Supremo, Control de la emigración de braceros nacionales al exterior, 5 de octubre de 1937.

Decreto Supremo, Reglamento de Emigración, 30 de julio de 1938.

Decreto Supremo, Normas para la aplicación de la Ley de Residencia a extranjeros indeseables, 15 de febrero de 1939.

Decreto Supremo, Reglamento para el ingreso de agricultores extranjeros, 28 de junio de 1939.

Decreto Supremo, Requisitos para autorizar el ingreso al país de familiares de los extranjeros residentes, 17 de abril de 1942.

Ley, De la concesión de tierras a colonizadores, 4 de enero de 1950.

Decreto Supremo, Procedimiento que deben seguir los inmigrantes que desean radicarse en el país, 13 de febrero de 1951.

Decreto Supremo, Penalidades a empresas que contraten el servicio de turistas, 25 de marzo de 1954.

Decreto Supremo, Plazo mínimo de permanencia obligada en el país para extranjeros que han obtenido su naturalización, 12 de junio de 1958.

Decreto-ley $\mathrm{N}^{\circ}$ 10.460, Ley de Organización Administrativa del Poder Ejecutivo, 12 de septiembre de 1972.

Decreto-ley $N^{\circ}$ 13.344, Ley de Inmigración, 30 de enero de 1976.

Decreto Supremo № 21.945, Pasaportes oficiales y diplomáticos, 13 de mayo de 1988.

Decreto Supremo N²4.423, Régimen Legal de Migración, 29 de noviembre de 1996.

Decreto Supremo № 25.150, Servicio Nacional de Migración, 4 de septiembre de 1998.

Decreto Supremo $N^{\circ} 27.698$, Reglamento sobre doble nacionalidad y recuperación de la nacionalidad boliviana, 24 de agosto de 2004 . 
Ley N ${ }^{\circ} 3.057$, Ratifica el segundo Protocolo Adicional al Convenio de Migración entre la República de Bolivia y la República Argentina, 13 de mayo de 2005.

Ley $N^{\circ} 3.240$, Acuerdo Migratorio entre la República de Bolivia y la República Argentina, 22 de noviembre de 2005.

Decreto Supremo N² 28.709, Situación migratoria de los bolivianos en la Argentina, 10 de mayo de 2006.

Proyecto de ley $\mathrm{N}^{\circ} 443$, Ley de voto de ciudadanos bolivianos residentes en el extranjero, 2008.

\section{INTERVENCIONES PÚBLICAS DE FUNCIONARIOS DE GOBIERNO}

\section{Argentina}

Exposición del Director Nacional de Migraciones, Ángel Roig, Comisión de Población y Recursos Humanos de la Cámara de Diputados de la Nación, Buenos Aires, 1 de diciembre de 2000 .

Exposición del Director Nacional de Investigación, Política y Desarrollo Demográfico del Ministerio del Interior, Noel Breard, Comisión de Población y Recursos Humanos de la Cámara de Diputados de la Nación, Buenos Aires, 1 de diciembre de 2000.

Exposición de la asesora de la DNM, Adriana Alfonso, Comisión de Población y Recursos Humanos de la Cámara de Diputados de la Nación, Buenos Aires, 1 de diciembre de 2000.

Exposición del Director Nacional de Migraciones, Juan Manuel Llavar, Comisión de Población y Recursos Humanos de la Cámara de Diputados de la Nación, Buenos Aires, 10 de abril de 2002.

Exposición del Director general de Asuntos Consulares del Ministerio de Relaciones Exteriores y Culto, Raúl Martínez Camadro, Comisión de Población y Recursos Humanos de la Cámara de Diputados de la Nación, Buenos Aires, 21 de mayo de 2002.

Discurso de asunción del presidente Néstor Kirchner, Buenos Aires, 25 de mayo de 2003.

Exposición del Director Nacional de Migraciones, Jorge Rampoldi, Comisión de Población y Recursos Humanos de la Cámara de Diputados de la Nación, Buenos Aires, 2 de julio de 2003.

Exposición del Director Nacional de Migraciones, Ricardo Rodríguez, Comisión de Población y Recursos Humanos de la Cámara de Diputados de la Nación, Buenos Aires, 24 de marzo de 2004. 
Exposición del Director Nacional de Migraciones, Ricardo Rodríguez, Comisión de Población y Recursos Humanos de la Cámara de Diputados de la Nación, Buenos Aires, 30 de marzo de 2005.

Exposición de la Jefa de la Oficina de Temas Internacionales de la DNM, Adriana Alfonso, Seminario Migraciones y Derechos Humanos, Rosario, 8 y 9 de septiembre de 2005.

Exposición de la Jefa de la Delegación Rosario de la DNM, Mariana García, Seminario Migraciones y Derechos Humanos, Rosario, 8 y 9 de septiembre de 2005.

Discurso del Presidente Néstor Kirchner en el acto de presentación del Plan Nacional de Normalización Migratoria, Buenos Aires, 14 de diciembre de 2005.

Exposición de Jefa de la Oficina de Temas Internacionales de la DNM, Adriana Alfonso, Foro Internacional sobre el Nexo entre Políticas y Ciencias Sociales UNESCO, Córdoba, 2123 de febrero de 2006.

Exposición del MRECIyC, "Un cambio de paradigma: el tratamiento de la cuestión migratoria bajo la perspectiva de los derechos humanos", Encuentro Iberoamericano sobre Migraciones y Desarrollo, Madrid, 18 y 19 de julio de 2006.

Exposición del Director Nacional de Migraciones, Ricardo Rodríguez, "Una experiencia argentina para América del Sur. Plan Patria Grande", Encuentro Iberoamericano sobre Migraciones y Desarrollo, Madrid, 18 y 19 de julio de 2006.

Discurso del Ministro del Interior Aníbal Fernández durante la firma del convenio de cooperación institucional con la FATERyH, Buenos Aires, 7 de septiembre de 2006.

Exposición de Jefa de la Oficina de Temas Internacionales de la DNM, Adriana Alfonso, Sesión especial sobre temas de actualidad del derecho internacional de los refugiados, Organización de Estados Americanos (OEA), Washington D.C., 29 de enero de 2008.

Exposición del Director Nacional de Migraciones, Martín Arias Duval, Foro Iberoamericano sobre Migración y Desarrollo, Cuenca, Ecuador, 10 y 11 de abril de 2008.

Discurso de la presidenta Cristina Fernández de Kirchner en ocasión de la reglamentación de la Ley de Migraciones, Salón Mujeres Argentinas del Bicentenario de la Casa de Gobierno, Buenos Aires, 3 de mayo de 2010.

Exposición del Director Nacional de Migraciones, Martín Arias Duval, CineMigrante: Primer Festival Internacional de Cine y Formación en Derechos Humanos, Buenos Aires, 22-29 de septiembre de 2010.

\section{Bolivia}

Discurso de apertura del Ministro de Relaciones Exteriores y Culto de Bolivia en la V Conferencia Sudamericana sobre Migraciones, La Paz, 2004. 
Discurso de apertura del presidente constitucional de la República de Bolivia, Evo Morales Ayma, en la Octava Conferencia Internacional de Instituciones Nacionales para la Promoción y Protección de los Derechos Humanos Santa Cruz, Santa Cruz, 2006.

Intervención y reporte de la República de Bolivia en su carácter de Presidencia ProTémpore saliente en la VI Conferencia Sudamericana sobre Migraciones, Asunción, mayo de 2006.

Exposición del Viceministro de Relaciones Exteriores y Cultos de Bolivia en la VI Conferencia Sudamericana sobre Migraciones, Asunción, mayo de 2006.

Discurso del presidente Evo Morales Ayma en la XVI Cumbre Iberoamericana de Jefes de Estado y de Gobierno, Montevideo, noviembre de 2006.

Mensaje del presidente Evo Morales Ayma en ocasión del $182^{\circ}$ aniversario de la Independencia de Bolivia, La Paz, agosto de 2007.

Carta abierta del presidente Evo Morales Ayma a propósito de la Directiva de Retorno de la Unión Europea, La Paz, junio de 2008.

Exposición de la representante del Estado boliviano en la VIII Conferencia Sudamericana sobre Migraciones, Montevideo, septiembre de 2008.

Mensaje del presidente Evo Morales Ayma en ocasión del $184^{\circ}$ aniversario de la Independencia de Bolivia, La Paz, agosto de 2009.

Exposición del Director de Asuntos Internacionales y Sociales de la DNM, Federico Agusti, el Congreso Internacional: "Migraciones Internacionales en el Siglo XXI", Iguazú, 3 y 4 de septiembre de 2010 .

\section{OTROS DOCUMENTOS OFICIALES}

Constitución Nacional, República Argentina, 1853.

Constitución Nacional, República Argentina, 1949.

Decreto Supremo Nº 21.060, República de Bolivia, 29 de agosto de 1985.

Convención Internacional sobre la Protección de los Derechos de Todos los Trabajadores Migratorios y de sus Familiares de Naciones Unidas, Asamblea General de las Naciones Unidas, diciembre de 1990.

Constitución Nacional, República Argentina, 1994.

Convenio Migratorio Argentina-Bolivia, 1998.

Declaración de la I Conferencia Sudamericana sobre Migraciones, Buenos Aires, 2000. 
Declaración de la II Conferencia Sudamericana sobre Migraciones, Santiago de Chile, 2001.

Declaración de la III Conferencia Sudamericana sobre Migraciones, Quito, 2002.

Acuerdo sobre Residencia para Nacionales de los Estados Partes del Mercosur, Bolivia y Chile, 2002.

Declaración de la IV Conferencia Sudamericana sobre Migraciones, Montevideo, 2003.

Declaración de la V Conferencia Sudamericana sobre Migraciones, La Paz, 2004.

Declaración de Santiago sobre Principios Migratorios, Santiago de Chile, 2004.

Declaración de la VI Conferencia Sudamericana sobre Migraciones, Asunción, 2006.

Declaración de la Octava Conferencia Internacional de Instituciones Nacionales para la Promoción y Protección de los Derechos Humanos, Santa Cruz, Bolivia, 2006.

Plan Nacional de Desarrollo: Bolivia digna, soberana, productiva y democrática para Vivir Bien (2006-2010), Ministerio de Planificación del Desarrollo, República de Bolivia, 2006.

Ley de Educación Nacional: Hacia una educación de calidad para una sociedad más justa. Documento para el debate, Ministerio de Educación, Ciencia y Tecnología, Buenos Aires, 2006.

Consideraciones respecto del anteproyecto Ley de Educación Nacional efectuadas por el INADI, Buenos Aires, 2006.

Declaración de Montevideo, XVI Cumbre Iberoamericana de Jefes de Estado y de Gobierno, Montevideo, noviembre de 2006.

Declaración de la VII Conferencia Sudamericana sobre Migraciones, Caracas, 2007.

Nueva Constitución Política del Estado Plurinacional de Bolivia, aprobada por la Asamblea Constituyente, 2007, y compatibilizada en el Honorable Congreso Nacional, 2008.

Declaración de la VIII Conferencia Sudamericana sobre Migraciones, Montevideo, 2008.

Declaración de la IX Conferencia Sudamericana sobre Migraciones, Quito, 2009.

Plan Sudamericano de Desarrollo Humano para las Migraciones, X Conferencia

Sudamericana sobre Migraciones, Cochabamba, 2010.

Declaración de la X Conferencia Sudamericana sobre Migraciones, Tiquipaya

(Cochabamba), 2010. 